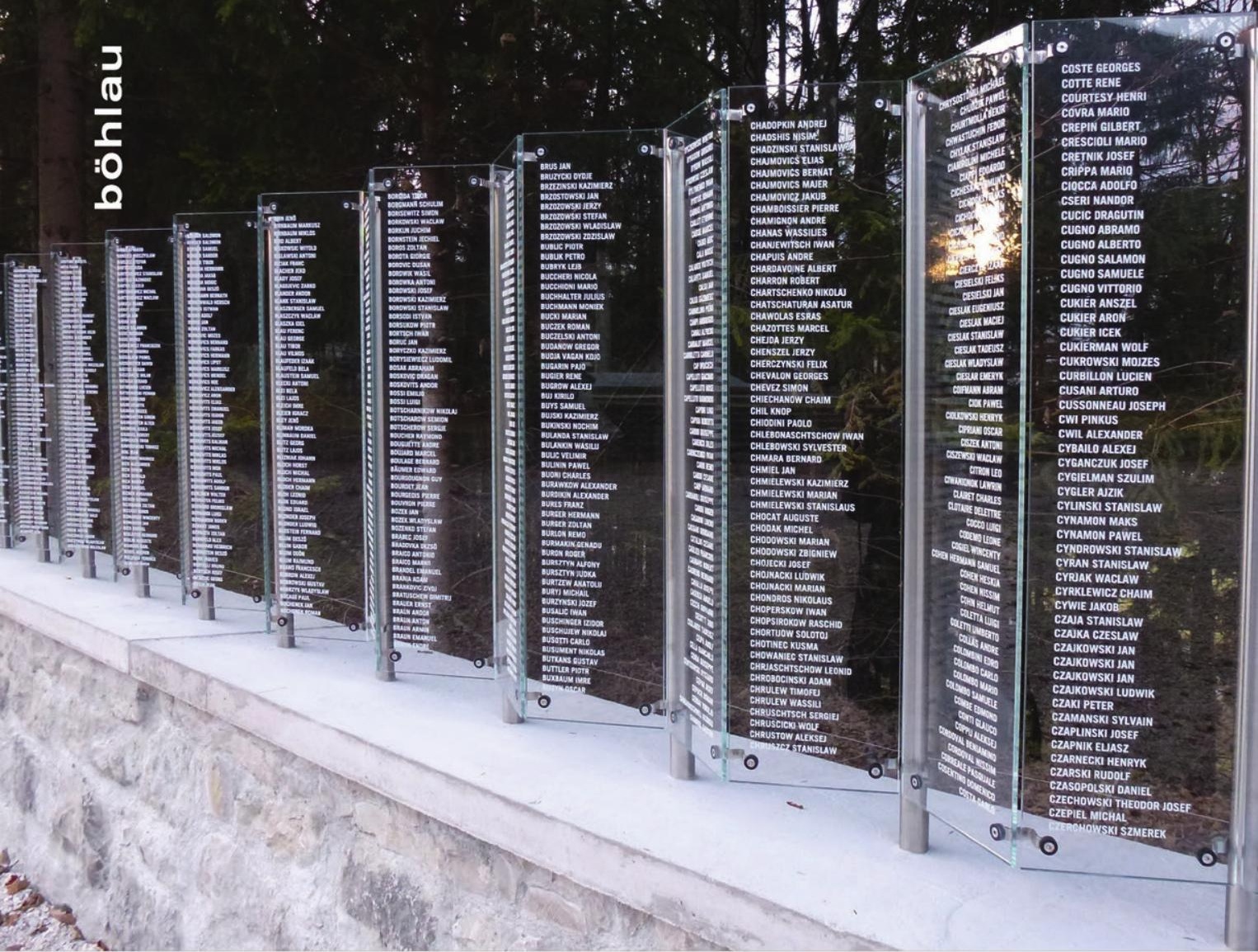

\title{
Der Opfermythos \\ bei Elfriede Jelinek
}

\section{EINE HISTORIOGRAFISCHE UNTERSUCHUNG}

Sylvia Paulischin-Hovdar 
böhlau 


\section{Literatur und Leben. Neue Folge}

\section{Band 88}


Sylvia Paulischin-Hovdar

\section{DER OPFERMYTHOS BEI ELFRIEDE JELINEK}

Eine historiografische Untersuchung

2017

BÖHLAU VERLAG WIEN KÖLN WEIMAR 


\section{Veröffentlicht mit Unterstützung des Austrian Science Fund (FWF): PUB 391-G28}

Open Access: Wo nicht anders festgehalten, ist diese Publikation lizenziert unter der CreativeCommons-Lizenz Namensnennung 4.0; siehe http://creativecommons.org/licenses/by/4.0/

(C) 2017 by Böhlau Verlag Ges.m.b.H \& Co. KG, Wien Köln Weimar Wiesingerstraße 1, A-1010 Wien, www.boehlau-verlag.com

Umschlagabbildung: Namenstafeln der Opfer des Konzentrationslagers Ebensee.

Foto: Archiv KZ-Gedenkstätte Ebensee

Alle Rechte vorbehalten. Dieses Werk ist urheberrechtlich geschützt.

Jede Verwertung außerhalb der engen Grenzen des Urheberrechtsgesetzes ist unzulässig.

Korrektorat: Ulrike Weingärtner, Gründau

Einbandgestaltung: Michael Haderer, Wien

Satz: Michael Rauscher, Wien

Druck und Bindung: Generaldruckerei, Szeged

Gedruckt auf chlor- und säurefrei gebleichtem Papier

Printed in the EU

ISBN 978-3-205-20325-4 


\section{Inhalt}

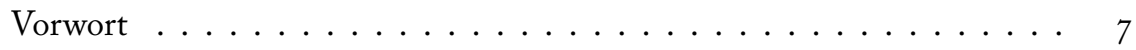

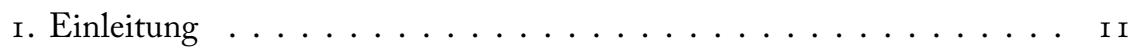

I. I Inhalte und Ziele . . . . . . . . . . . . . . I 2

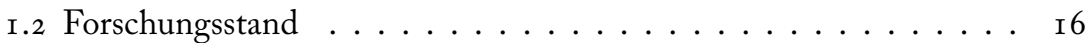

I.3 Darstellung der Gliederung . . . . . . . . . . . . . . . 20

I.4 Diskussion der zentralen Begriffe . . . . . . . . . . . . . 22

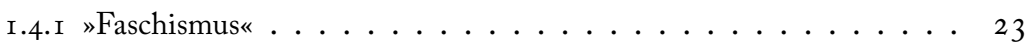

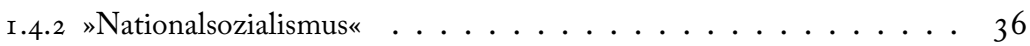

I.4.3 »Mythos« nach Roland Barthes . . . . . . . . . . . . . . . . . . . . . .

I.4.4 Der Begriff»Opfermythos« . . . . . . . . . . . . . . . . 43

I.5 Elfriede Jelinek: Annäherung an eine »synthetische

Künstlerbiografie« . . . . . . . . . . . . . . . . . . 55

г.6 Poetologische Einführung . . . . . . . . . . . . . . . . . . . . 67

r.6. I Jelineks ästhetische Position:»Tradition des Sezierens« . . . . . . . . 67

r.6.2 Destruktion des Opfermythos: »Das ist mein Angelpunkt« . . . . . 79

2. Methodische Reflexion . . . . . . . . . . . . . . . . . . . . . 99

2.r Zur Intertextualität . . . . . . . . . . . . . . . . . I 0 o

2.2 Darstellung der angewandten Methodik . . . . . . . . . . . I05

3. Lektüre- und Deutungsvorschläge . . . . . . . . . . . . . . . . . . . . . . . . . . I08

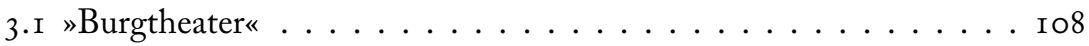

3.I.I Zur verwendeten Sekundärliteratur . . . . . . . . . . . . . . . . . . I

3.I.2 Formales, Setting und Plot . . . . . . . . . . . . I I 2

3.I.3 Die Figuren:»Sprachschablonen« . . . . . . . . . . . I I 5

3.r.4 Die Sprache: ein Mythos . . . . . . . . . . . . . . . . I 43

3.I.5 Die Rezeption: ein Skandal. . . . . . . . . . . . . . . I 55

3.I.6 Die Wessely/Hörbigers: eine Potenzierung des Opfermythos . . . . I 58

3.2 "Die Kinder der Toten" . . . . . . . . . . . . . . . . . . . . . . . . . . . . . . .

3.2.I Zur verwendeten Sekundärliteratur . . . . . . . . . . . . . I73

3.2 .2 Formales, Setting und Plot . . . . . . . . . . . I 8 I

3.2 .3 Referenzen und Intertexte . . . . . . . . . . . . . I 86

3.2.4 Die Erzählinstanz als multiperspektivische Kunst- und Kippfigur . 203

3.2.5 Der Opfermythos als perfides Geflecht nationaler Mythen . . . . . . 2 I 3

3.2.6 $»$ Die Kinder der Toten«: Die große Anklage . . . . . . . . . . 245 
$3.3 »$ Das Lebewohl« . . . . . . . . . . . . . . . . . . . . . . . . . . . . . . . 247

3.3. I Zur verwendeten Sekundärliteratur . . . . . . . . . . . . . . . . . . . . . . . . . . . . . . . .

$3 \cdot 3.2$ Formales, Setting und Plot . . . . . . . . . . 250

3.3.3 Der sprecher: Destruktion eines vermenschlichten Mythos . . . 252

3.3.4 Entstehungskontext und Rezeption . . . . . . . . . . 274

4. Resümee ... . . . . . . . . . . . . . . . . . 279

4.I Zusammenfassung der Ergebnisse ............. 280

4.2 Interdisziplinäre Zusammenschau: Zum »Mehrwert« von Literatur 29I

5. Epilog-Wir waren's nicht? . . . . . . . . . . . . . 296

6. Anhang . . . . . . . . . . . . . . . . . . . . . 299

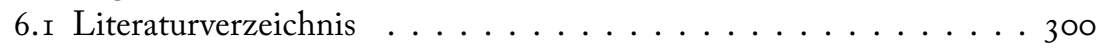

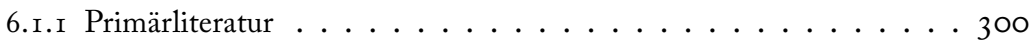

6.I.2 Sekundär- und Referenzliteratur . . . . . . . . . . . 30 I

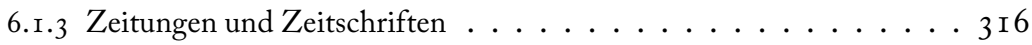

6.r.4 Filme und TV-Beiträge . . . . . . . . . . . . . . . 3 I 7

6.1 .5 Internet-Seiten . . . . . . . . . . . . . . 3 I 7

6.2 Abbildungsverzeichnis ...................... 3 I 8

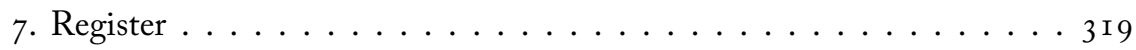

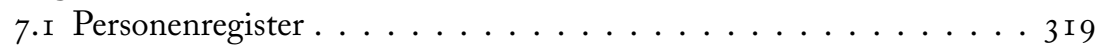

7.2 Sachregister ....................... 32 I 


\section{Vorwort}

Bei der vorliegenden Studie handelt es sich um die überarbeitete und aktualisierte Fassung meiner Dissertation mit dem Titel »Wir waren's nicht! Zur Destruktion des Opfermythos bei Elfriede Jelinek«, eingereicht und approbiert an den Fachbereichen Germanistik und Geschichte der Paris Lodron-Universität Salzburg im Herbst 2013.

Im Sinne der sprachlichen Ökonomie und zugunsten der Lesbarkeit wurde in diesem Buch auf eine "gegenderte" Sprachverwendung verzichtet. Generisch unmarkierte Pluralwörter umfassen sowohl maskuline als auch feminine Formen; im Falle einer Bedeutungsunterscheidung wurde das jeweilige Genus markiert.

An dieser Stelle danke ich der Universität Salzburg für die Auszeichnung meines Dissertationsprojekts mit dem Forschungsstipendium 2010/I I und dem österreichischen Wissenschaftsfonds FWF für die gewährten Publikationsmittel.

Für stets konstruktive Kritik und empathische Begleitung meiner Recherchen möchte ich außerdem den beiden Gutachtern meiner Arbeit, Karl Müller und Ingrid Bauer, aufrichtigen Dank aussprechen. Meiner Mutter, Maria Hovdar, danke ich für die Grundsteinlegung meiner Begeisterung für Literatur und die geisteswissenschaftliche Forschung. Weiters gebührt Helmut Sagmeister Dank für wertvollen Input in prägenden Jahren. Insbesondere aber möchte ich mich bei meinem Mann Rafael Paulischin-Hovdar für seine große Liebe und Unterstützung bedanken sowie bei unseren beiden Töchtern für größtmögliches Verständnis, wenn die Mama stundenlang in Büchern vergraben war oder am »Kompüter« arbeiten musste.

Gewidmet ist dieses Buch meinem 2007 verstorbenen Vater, Terje Hovdar, von dem ich gelernt habe, Hindernisse als Herausforderung zu sehen und für gesteckte Ziele zu kämpfen, solange man sich dabei nicht selbst verliert. Du fehlst.

Salzburg, im Dezember 2016

Sylvia Paulischin-Hovdar 
»Tell all the truth but tell it slant Success in Circuit lies

Too bright for our infirm Delight

The Truth's superb surprise

As Lightning to the Children eased

With explanation kind

The Truth must dazzle gradually

Or every man be blind $-«^{1}$

I Dickinson, Gedichte, S. 4 I o f. Dt. Übersetzung von Gunhild Kübler: „Sag Wahrheit ganz, doch sag sie schräg -/ Erfolg liegt im Umkreisen/ Zu strahlend tagt der Wahrheit Schock/ Unserem Begreifen/ Wie Blitz durch freundliche Erklärung/ Gelindert wird dem Kind/ Muß Wahrheit sachte blenden/ Sonst würde jeder blind - « (I 872 ). 


\section{Einleitung}

»Das politische Engagement ist Teil meiner Literatur.

Das eine gehört zum anderen. ${ }^{1}$

I Jelinek, zitiert nach: profil, Nr. 42, 2004, S. I 24. 


\subsection{Inhalte und Ziele}

»Wie immer man zu Jelineks politischer

Situierung stehen mag: ohne sie zur Kenntnis zu nehmen ... ist ihr Werk mißverstanden. ${ }^{2}$

Das Sekundärwerk zu Elfriede Jelineks CEuvre ist umfassend - jedoch mangelt es auch Jahre nach der Verleihung des Nobelpreises immer noch an schlüssigen Lektüre- und Interpretationsansätzen. Es gilt daher, neue interdisziplinäre Herangehensweisen zu entwickeln, die plausible Zusammenhänge erschließen und damit die intertextuellen, semantisch heterogenen Texte Jelineks für eine gewillte Leserschaft zugänglich machen.

Innerhalb des Feuilletons ist Jelineks Werk - dem Nobelpreis zum Trotz immer noch umstritten. ${ }^{3}$ Die durch den Preis erreichte Aufmerksamkeit bewirkte zwar eine außerordentliche Differenzierung und Internationalisierung des Forschungsdiskurses. Bemerkenswert daran ist aber, dass Jelineks intensive Auseinandersetzung mit dem österreichischen Opfermythos, einem wirkungsmächtigen Geschichtsbild der Zweiten Republik, in diesem umfangreichen und avancierten Sekundärwerk immer noch sehr häufig entweder unpräzise unter den Begriff »Faschismuskritik« subsumiert oder die Opferthese per se mit »Vergangenheitsverdrängung « verwechselt wird, was auf mangelnde historische Sensibilität hinweist.

Mitunter wird sogar zwischen der Person und der Autorin Jelinek unterschieden: Gerade dass sie eine politisch engagierte Frau sei, habe sie davor bewahrt, »eine politische Schriftstellerin sein zu müssen«, schreiben etwa die Verfasser des bislang einzigen deutschsprachigen Autorinnenporträts:

"Als Schriftstellerin nimmt sie sich das Recht auf Kunst, als öffentliche Person das Recht auf entschiedene Auffassungen. ${ }^{4}$

Das Porträt stellt en bloc eine unbedingt empfehlenswerte Lektüre dar, wenn auch die genannte Behauptung von Verena Mayer und Roland Koberg als unzutreffend bezeichnet werden muss, denn der ideologische Standpunkt Jelineks, der vom Geist der I 968er-Bewegung und der marxistischen Gesellschaftskritik durchdrungen ist, hat in entscheidendem Maße deren literarisches Werk

\footnotetext{
2 Janz, Elfriede Jelinek, S. VIII.

3 Vgl. Lücke, Elfriede Jelinek, S. 7.

4 Mayer/Koberg, Ein Porträt, S. 9.
} 
geprägt. »Das politische Engagement ist Teil meiner Literatur«, so die Autorin selbst: „Das eine gehört zum anderen. ${ }^{5}$

Ihre (links-)politische Agitation hatte Jelinek von Seiten der (Rechts-)Konservativen, die seit Anbeginn der Zweiten Republik die österreichische Tagespolitik mitbestimmt hatten, vorwiegend Unverständnis und Häme eingebracht. Mit Bekanntgabe der Nobelpreisentscheidung wendete sich das Blatt jedoch schlagartig. So kam nicht nur aus dem sozialdemokratischen Lager Lob und Beifall der Wiener SPÖ-Bürgermeister Michael Häupl bezeichnete die Ausgezeichnete als »Blume im Knopfloch Österreichs ${ }^{6}{ }^{-}$, sondern machte auch der damalige ÖVP-Nationalratspräsident und spätere Bundespräsidentschaftskandidat Andreas Khol seine heimliche Leidenschaft für Jelineks Literatur öffentlich. ${ }^{7}$ Einzig der inzwischen tödlich verunglückte Rechtspopulist Jörg Haider erkannte nach wie vor »keine literarische Wertigkeit ${ }^{8}$ in Jelineks Schaffen und witterte eine Verschwörung des Schwedischen Nobelpreiskomitees gegen Österreich. Jelinek selbst wehrte sich so gut wie möglich gegen jedwede politische Vereinnahmung.

»Es lässt sich wahrscheinlich nicht vermeiden, dass das jetzt zur snationalen Sacheく hochstilisiert wird. Ich versuche mich möglichst fern zu halten von dem ganzen Getriebe, denn in dem Augenblick, in dem man zu viel Beifall von offizieller Seite bekommt, verliert man den Biss, die Mächtigen auch zu kritisieren, und das ist immer ein wesentliches Movens meiner Literatur gewesen. Deswegen halte ich mich auch bewusst von linken Positionseliten fern. "9

Dazu ist anzumerken, dass Jelinek I 7 Jahre lang Mitglied der Kommunistischen Partei gewesen war. Enttäuscht und wütend hatte sie der Partei jedoch I99I den Rücken gekehrt: Sie und andere Kollegen mit bekanntem Namen seien lediglich als »nützliche Idioten « missbraucht worden, ärgerte sie sich am Ende. ${ }^{10}$

Dem Zerwürfnis mit der KPÖ zum Trotz bezeichnete sich Jelinek selbst immer wieder als "Marxistin «"11, warnte aber gleichzeitig vor ideologischer Blind-

5 Jelinek, zitiert nach: profil, Nr. 42, 2004, S. I 24. Vgl. auch Gürtler, Gegen den schönen Schein, S. 7 .

6 Häupl nach Bekanntgabe der Entscheidung des Nobelpreiskomitees am 7.10.2004 im ORF-Radio.

7 So las Khol in der TV-Dokumentation »Wer hat Angst vor Elfriede J.?« einzelne Passagen aus Jelinek-Texten für die Kamera vor und amüsierte sich demonstrativ über deren Sprachwitz.

8 Jörg Haider in derselben TV-Dokumentation.

9 Jelinek in einem ÖI-Radiogespräch mit Günter Kaindlstorfer, 7. I0.2004.

Io Dies., zitiert nach: Janke, Die Nestbeschmutzerin, S. 27.

I I Dies., zitiert nach: Kerschbaumer, Für mich hat Lesen etwas mit Fließen zu tun, S. I46. Vg1. auch Janke, Die Nestbeschmutzerin, S. 27. 
heit und beschrieb die Grundidee des Kommunismus, wonach es keine Ausbeuter und Ausgebeutete geben sollte, sondern Kommunikation unter Gleichen angestrebt werde, als »utopisches Ideal ${ }^{12}$. Sie selbst praktiziere einen »idealistischen prächristlichen Vulgärmarxismus«:

»Wenn alles nach rechts rennt, möchte man, daß wenigstens einige Leute nach links rennen. Aber Sozialist kann man nur dort sein, wo Sozialismus keine Staatsform ist. « ${ }^{13}$

Fern jedweder politischen Positionierung soll nun in der vorliegenden Studie auf systematische, detaillierte und textnahe Weise und unter Rückgriff auf fundiertes zeithistorisches Wissen der Nachweis erbracht werden, dass die Kritik am österreichischen Opfermythos eines der zentralen Themen in Jelineks literarischem Werk darstellt, das die Autorin über die explizite Thematisierung hinaus vor allem implizit, auf einer intertextuellen, metasprachlichen Ebene realisiert. Zwar mag dieses Vorhaben angesichts der überwältigenden Fülle an Sekundärtexten als obsolet erscheinen, tatsächlich fehlt aber bei den bisher geleisteten Analysen zu diesem Themenkomplex, ob sie nun aus dem deutschsprachigen Raum (Marlies Janz, Christa Gürtler, Pia Janke u.a.) oder aus dem nicht-deutschsprachigen Raum (Allyson Fiddler, Monika Szczepaniak u.a.) kommen, die systematische Engführung mit gegenwärtigen zeithistorischen Theorien zu Faschismus und Nationalsozialismus, aber auch zu innerösterreichischen Gedächtnisdiskursen, die ungeahnte Möglichkeiten zum besseren Textverständnis von Jelineks stark ästhetisierter Literatur über die Grenzen geisteswissenschaftlicher Fachkreise hinweg auch für eine interessierte Leserschaft bereithält. In diesem Sinne wird in dem vorliegenden Buch nach einigen notwendigen Diskussionen um die Termini Operandi zunächst zu Jelineks biografischen und künstlerischen Anfängen zurückgeblättert, um sowohl die methodische Entwicklung des fokussierten Themas als auch dessen zentrale Bedeutung im Gesamtwerk besser demonstrieren $\mathrm{zu}$ können.

Mit ihrem speziellen ästhetischen (Selbst-)Verständnis und ihren innovativen Methoden steht Jelinek in der Tradition avantgardistischer und experimenteller Literaturtraditionen des 20. Jahrhunderts. Vor allem die Nähe zu den Techniken des Wiener Aktionismus und der Wiener Gruppe ist deutlich erkennbar. Ihr favorisiertes Textherstellungsverfahren ist die Destruktion, die als "Zerschlagung" und "Zerstörung« das Gegenstück zum erfinderischen, kreativen Akt (gemeinhin die erwartete Leistung von Literatur) darstellt: Dabei collagiert und montiert sie Sprachmaterial aus unterschiedlichsten Bereichen (etwa aus politischen

I 2 Dies., zitiert nach: Kerschbaumer, Für mich hat Lesen etwas mit Fließen zu tun, S. I46.

I 3 Dies., zitiert nach: Venckute, Lust, unpaginiert. 
und publizistischen Diskursen, der hohen und trivialen Literatur ebenso wie aus der Fernsehwerbung, aus Boulevard-Magazinen oder aus Comic-Heften), entfremdet daraus einzelne Elemente orthografisch, syntaktisch, semantisch und/oder phonetisch, um deren konventionelle Bedeutungen in Frage zu stellen und damit den scheinbar natürlichen Zusammenhang von Zeichen und Bezeichnetem zu durchbrechen. Auf diese Weise soll der Konstruktionscharakter gesellschaftspolitischer und medialer Diskurse entlarvt werden. Die Auswahl bestimmter Sprachgebrauchsformen ist in Jelinek-Texten demnach bereits als Inhalt zu lesen, deren destruktive Verzerrung als Ausdruck der ironischen Kontrafraktur.

In diesem Sinne geht Jelinek nicht nur destruierend (zerstörend), sondern auch dekonstruierend (zerlegend, aufösend) vor -, aber eben nicht immer. Tatsächlich schwankt ihr Umgang mit Mythen zwischen destruierenden und dekonstruktierenden Verfahren; dementsprechend finden sich in der Literatur auch beide Begriffe in inkohärenter Verwendung wieder. ${ }^{14}$ Der Dekonstruktionsbegriff impliziert dabei eine weitaus analytischere Vorgehensweise als der Destruktionsbegriff, denn bei der Dekonstruktion werden sprachlich und symbolisch konstituierte Mythen Schicht für Schicht abgetragen und auf diese Weise die dahinter steckenden Intentionen offengelegt. In Jelineks Texten sind die Übergänge zwischen dem destruierenden und dem dekonstruierenden Schreiben fließend. Da jedoch auch das Dekonstruieren die Zerschlagung und Zerstörung von Mythen bezweckt (»Ich schlage sozusagen mit der Axt drein, damit kein Gras mehr wächst, wo meine Figuren hingetreten sind $\aleph^{15}$ ), wird die terminologische Treffsicherheit des Destruktionsbegriffs hier als etwas umfassender begriffen, weshalb in der vorliegenden Untersuchung in erster Linie mit diesem Begriff hantiert wird.

Zur exemplarischen Interpretation ausgewählt wurden das Skandalstück "Burgtheater« aus dem Jahr I 984, welches das Politikum vorgeblich unpolitischen Künstlertums thematisiert und Jelineks Ruf als »Nestbeschmutzerin« begründete; weiters der große Gespensterroman »Die Kinder der Toten« aus dem Jahr 1995, den die Autorin zwar als ihr "wichtigstes Werk « ${ }^{16}$ bezeichnet hatte, der aufgrund seines Umfangs und seiner Komplexität bisher aber kaum interpretiert, wahrscheinlich auch wenig gelesen wurde; und schließlich eine kleine, aber wortgewaltige Theatersatire aus dem österreichischen »Wendejahr« 2000 mit dem Titel »Das Lebewohl« - einer der Höhepunkte der jahrelangen öffentlichen Auseinandersetzung zwischen Elfriede Jelinek und Österreichs bekanntestem Rechtspopulisten Jörg Haider.

I 4 Vgl. Degner, Mythendekonstruktion, S. 45.

I 5 Jelinek, Ich schlage sozusagen mit der Axt drein, S. I 4.

I6 Jelinek, zitiert nach: profil, Nr. 42, 2004, S. I 25. 
Diese Auswahl wurde getroffen, weil es für die genannten Texte zum einen bis dato nur wenige schlüssige Interpretationsansätze gibt, zum anderen weil sie auf unterschiedliche Art und Weise die Destruktion des Opfermythos in ihr Zentrum stellen, sowohl ex- als auch implizit.

Das Innovative an diesem Projekt ist die Einbeziehung zeitgeschichtlicher Theorien: Faschismus- und Opfermythostheorien werden in die Textinterpretation integriert, um auf diese Weise zu neuen Deutungsmöglichkeiten zu gelangen. Darüber hinaus soll über die interdisziplinäre Beschäftigung mit den Beispieltexten eine Brücke zur geschichtswissenschaftlichen Forschungspraxis geschlagen werden, denn die Annäherung an historisch-politische Themen kann, wie im Folgenden gezeigt werden soll, auch über die Literatur führen.

\subsection{Forschungsstand}

»... diese eingrenzende und verdinglichte Form des Umgangs mit dem Faschismus ... ist genau das, was Jelineks Schreibweise zu kritisieren und zu destruieren versucht. ${ }^{17}$

Offensichtlich war eine Intervention aus Schweden notwendig, um die deutschsprachige Jelinek-Forschung aus ihrem Dornröschen-Schlaf aufzuschrecken. Zwar herrschte schon in den I 99oer Jahren an Bildmaterial, Feuilletonkommentaren und Interviews kein Mangel: Der Stand der Publikationen füllte nicht nur "Karteikästchen fleißiger Dissertantinnen ${ }^{18}$, sondern auch bereits drei Sammelbände. Wer allerdings nach wissenschaftlichen Analysen oder gar plausiblen Interpretationsvorschlägen suchte, der fand einen recht überschaubaren Bestand vor. $\mathrm{Zu}$ Recht beklagte Marlies Janz I995, dass von einer Jelinek-Forschung "noch keine Rede« sein könne und kritisierte das bestehende Sekundärwerk als einseitig und tendenziös: Jelineks Werk werde bedenkenlos vereinnahmt für »unverbindliche kulturkritische Räsonnements, für einen vermeintlich postmodernen Budenzauber sowie für pseudo-feministische Positionen, die auf das >Frausein als vermeintlich privilegierten Status des >Unterdrücktseins` rekurrieren zu können glauben«. Seinen Grund habe das vermutlich in der »anhaltenden Verkennung Jelineks als politischer Autorin«. Jelineks Faschismuskritik werde von der Forschung noch nachhaltiger verdrängt als deren marxistische Analysen. ${ }^{19}$

I 7 Janz, "Die Geschichte hat sich nach 45 entschlossen«, S. 238.

I 8 Doll, Mythos, Natur und Geschichte bei Elfriede Jelinek, S. 9.

I 9 Vgl. Janz, Elfriede Jelinek, S. VII ff. 
Neben Janz, die einen kompakten Überblick über die literarische Produktion Jelineks (von den Anfängen bis zur Mitte der r 99oer Jahre) und kurze, exemplarische Interpretationen einiger Theaterstücke und Prosatexte verfasst hatte, waren es in den r 99oer Jahren vor allem zwei wichtige Sammelbände, die eine Annäherung zwischen Jelineks sprachkritischen Verfahren und ihren favorisierten Themen leisteten: zum einen der von Christa Gürtler herausgegebene Band »Gegen den schönen Schein«, der aus den verschiedenen Blickwinkeln der teilnehmenden Autoren (darunter Dagmar von Hoff und Marlies Janz, aber auch der streitbare österreichische Philosoph Rudolf Burger) Jelineks Verfahren der Mythendestruktion beleuchtet und sowohl Jelineks Prosa- als auch Dramenästhetik untersucht; und zum anderen das Elfriede Jelinek gewidmete "Dossier" von Kurt Bartsch und Günther Höfler, in dem neun kurze Aufsätze und - bezeichnend für die Jelinek-Rezeption - wiederum wesentlich mehr Rezensionen untergebracht sind.

Eine systematische und luzide Einführung liegt in englischer Sprache vor: Allyson Fiddlers Monografie "Rewriting Reality: an introduction to Elfriede Jelinek« aus dem Jahr I 994. Die englische Literaturwissenschafterin bietet in diesem Buch (eine Überarbeitung ihrer Doktorarbeit) neben einigen allgemeinen Kapiteln zu biografischem und künstlerischem Hintergrund Jelineks pointierte Analysen zu ausgewählten Prosa- und Theatertexten der österreichischen Skandalautorin, die - der Chronologie folgend - von »wir sind lockvögel baby!« bis »Lust« reichen. Vor allem Klarheit und Präzision der Sprache zeichnen diese Einführung aus. Leider gibt es bislang keine aktualisierte Neuauflage, auch keine Übersetzung ins Deutsche. (Der von Fiddler treffend gewählte englische Begriff des »Rewritings« wäre auch nicht adäquat in die deutsche Sprache übersetzbar.) Fiddler arbeitet aber nach wie vor zu Jelinek und veröffentlicht unter anderem einschlägige Aufsätze in dem vierteljährlich erscheinenden »Journal of Austrian Studies«.

Daneben sind einige engagierte Abschlussarbeiten zu nennen, deren Verfasserinnen (tatsächlich nur Frauen) versuchten, Jelineks Werk oder einzelne Texte unter neuen Perspektivierungen zu betrachten und der Bedeutung von Jelineks sprachkritischer Methodik in Hinblick auf die Thematisierung von Nationalsozialismus und Faschismus Rechnung zu tragen, so etwa die Magisterarbeiten von Evelyn Annuß, Sylvia Mindlberger, Heike Ehlers oder Sabine Edith Braun. Annette Doll konnte mit ihrer 1994 publizierten Dissertation zu »Mythos, Natur und Geschichte bei Elfriede Jelinek« die immanente Bedeutung des Mythosbegriffs nach Roland Barthes für Jelineks Schreiben schlüssig herausarbeiten, ebenso wie die polnische Literaturwissenschafterin Monika Szczepaniak in ihrer Dissertation "Dekonstruktion des Mythos in ausgewählten Prosawerken von Elfriede 
Jelinek« aus dem Jahr I $998 .^{20}$ Margarete Sander legte mit ihrer Dissertation aus dem Jahr I 996 eine differenzierte Studie über Jelineks Textherstellungsverfahren vor, die sie am Beispiel des Theaterstücks »Totenauberg« untersucht hatte.

Die Verleihung des Nobelpreises im Jahr 2004 schließlich brachte immens große Steine ins Rollen. Jelinek, die für ihr Gesamtwerk ausgezeichnet wurde, findet heute weitestgehende Anerkennung als Autorin politisch engagierter Literatur - auch im Feuilleton, das mit polemischer Kritik zurückhaltender wurde. Die Literaturwissenschaft erweiterte ihr Instrumentarium zur Textanalyse und erschloss neue Forschungsschwerpunkte. Vor allem das von Pia Janke geleitete Forschungszentrum in Wien leistet mit seinen Publikationen und Veranstaltungen einen wichtigen Beitrag zur Differenzierung des Forschungsdiskurses, außerdem dokumentiert es in einem umfangreichen, zweibändigen »Werkverzeichnis« penibel Primär- und Sekundärwerk. In einer Reihe des Zentrums mit dem Titel »Diskurse.Kontexte.Impulse sind bereits zwölf Bände erschienen. ${ }^{21}$ Es handelt sich dabei vor allem um Symposiums- und Tagungsdokumentationen. Außerdem gibt das Forschungszentrum seit 20 Io ein "JELINEK[JAHR] BUCH « heraus, in welchem sich Autoren verschiedener Provenienz (Wissenschafter, aber auch Weggefährten der Autorin, Schriftsteller- oder Theaterkollegen) zu neuen Texten, zum aktuellen Diskurs und zu Veranstaltungen des Forschungszentrums äußern (erscheint jährlich im Praesens Verlag).

In enger Kooperation mit dem Zentrum wurde zudem 2013 die »Forschungsplattform Elfriede Jelinek« konstituiert, die einen international vernetzten, interdisziplinären Jelinek-Diskurs erleichtern und koordinieren soll. Auch der wissenschaftliche Nachwuchs hat hier die Möglichkeit, abgeschlossene oder laufende Projekte zur Diskussion zu stellen, was der weiteren Entwicklung des Diskurses nur zuträglich sein kann. ${ }^{22}$

Besonders hingewiesen sei im Zusammenhang mit dem Fokus der vorliegenden Arbeit auf den vom Forschungszentrum 2010 herausgegebenen Band »Die endlose Unschuldigkeit«: Das Buch befasst sich mit Jelineks Theatertext »Rechnitz« (2006), in welchem sich die Autorin auf ein im März I 945 verübtes Massaker an bis zu 200 jüdischen Zwangsarbeitern bezieht, das im Rahmen eines von Margit Batthyány (geb. Thyssen-Bornemisza) veranstalteten Festes stattgefunden hat. Das Buch basiert auf einer 2009 vom Forschungszentrum organisierten Veranstaltungsreihe, der Titel referiert auf einen frühen Essay Jelineks.

20 Szczepaniak publiziert nach wie vor Arbeiten zu Jelinek und organisierte unter anderem im März 2015 eine Konferenz zu »Jelineks Räumen« in Warschau.

2 I Stand: Juni 2016.

22 Homepage der Plattform: https://fpjelinek.univie.ac.at 
Zudem sei im Besonderen auf das von der »Forschungsplattform» herausgegebene "Jelinek-Handbuch« verwiesen - eine erste umfassende Gesamtdarstellung von Jelineks Leben, Werk und Rezeption, die in der Reihe »Personenhandbücher « des Metzler Verlags erschienen ist: Neben Beiträgen, die sich mit biografischen und künstlerischen Aspekten auseinandersetzen, bietet das Handbuch lexikonartige Artikel zu einzelnen Werken, deren formale und inhaltliche Aspekte jeweils kurz verhandelt werden. Darüber hinaus wird ein sehr kompakter Überblick über die Forschungslage vermittelt. ${ }^{23}$

Das Handbuch stellt eine gut strukturierte und literaturwissenschaftlich fundierte Übersicht über die Erkenntnisse, Entwicklungen und Modifizierungen der Jelinek-Forschung der vergangenen Jahrzehnte dar. Allerdings wird auch hier mitunter mangelndes historisches Bewusstsein deutlich, etwa wenn Sabine Treudes Beitrag zu Jelineks großem Roman »Die Kinder der Toten« jeglichen Hinweis auf die österreichische Opferthese vermissen lässt: So schreibt Treude zwar von der Verdrängung des Holocaust und fehlender Trauerarbeit in der Zweiten Republik Österreich ${ }^{24}$, die aber in Bezug auf alle drei Nachfolgestaaten des nationalsozialistischen Deutschen Reichs konstatierbar sind, wenn auch in unterschiedlichem Ausmaß. Doch der Opfermythosbegriff ist mit dem Phänomen der Verdrängung nicht gleichzusetzen, denn er meint nicht nur die Aussperrung gewisser Sachverhalte aus der Erinnerung, sondern auch deren Umschreibung. Die Opferthese exkludiert jegliches Bekenntnis zur Mitschuld. Obwohl also mit dem Handbuch tatsächlich Großartiges geleistet wurde, bleibt das Desiderat einer fundierten zeitgeschichtlichen Perspektivierung innerhalb des Sekundärwerks vorerst bestehen.

Neben den Veröffentlichungen des Forschungszentrums und der Forschungsplattform müssen im Besonderen die Arbeiten von Bärbel Lücke hervorgehoben werden, etwa »Gespenster« aus dem Jahr 2007, die erste größere Publikation $\mathrm{zu}$ Jelineks Internet-Privatroman »Neid« mit dem Titel »www.todsuende.com Lesarten zu Elfriede Jelineks `Neid«« (als fünfter Band des Forschungszentrums 2009 erschienen) oder »Elfriede Jelinek. Eine Einführung« aus dem Jahr 2008, in welchem Lücke Jelineks Textherstellungensverfahren im Sinne Jacques Derridas als Ästhetik des "Zugleich und des Zwischen ${ }^{25}$ beschreibt und im Anschluss eine Werkschau mit exemplarischem Charakter anbietet (darunter auch eine etwa zehnseitige und daher sehr komprimierte Auseinandersetzung mit Jelineks Opus Magnum »Die Kinder der Toten«.)

23 Zusammenfassend dazu Gürtler, Forschung, S. 356-366.

24 Vgl. Treude, Die Kinder der Toten, S. I I 3. Ähnliche Formulierungen finden sich auch in dem Beitrag von Monika Meister: Vgl. Meister, Bezüge zur Theatertradition, S. 69. 
Und schließlich haben Verena Mayer und Roland Koberg 2006 das erste deutschsprachige Autorinnenporträt in Buchform vorgelegt. ${ }^{26}$ Innerhalb der Jelinek-Forschung konnte damit eine längst fällige Leistung erbracht werden. Das Buch ist gewissenhaft recherchiert und wird vorerst eine der Hauptreferenzen für biografische Darstellungen zu Elfriede Jelinek bleiben. Wie verlässlich die darin zusammengetragenen biografischen Informationen, die zum Teil aus Interviews und Gesprächen mit der Autorin selbst stammen, tatsächlich sind, kann zum jetzigen Zeitpunkt mangels alternativer Biografien nicht festgestellt werden. Die Subjektivität der Darstellung muss daher im Falle einer Beschäftigung mit dem Porträt immer mitberücksichtigt werden. ${ }^{27}$

Dem Umfang und dem Engagement des bisherigen Sekundärwerks zum Trotz fehlt bislang eine mit den historischen Disziplinen verschränkte Analyse des Opfermythos in Jelineks Werk; zum einen vermutlich deshalb, weil dieser eine spezifisch österreichische Problematik darstellt und von literaturwissenschaftlicher Seite her (sehr unpräzise) vielfach unter den Begriff der »Faschismuskritik« subsumiert wird. Zum anderen scheinen Bedeutung und Einfluss geschichtswissenschaftlicher Diskurse für Jelineks Werk nach wie vor unterschätzt zu werden.

\subsection{Darstellung der Gliederung}

»Ordnung ist die Tochter der Überlegung. ${ }^{28}$

Um eine Interpretation der ausgewählten Beispieltexte leisten zu können, ist es zunächst notwendig, die zentralen Begriffe, mit denen in dieser Studie operiert werden wird, zu definieren und deren Besonderheiten sowie Bezüge zu Jelineks Schreiben kurz darzustellen.

Daher werden in der Einleitung die Begriffe "Faschismus«, "Nationalsozialismus« und »Opfermythos« anhand von Exkursen in die zeithistorische Forschung theoretisch erläutert. Zudem wird im Rahmen dieses Kapitels in die Trivialmythentheorien Roland Barthes' eingeführt, da die Schriften des französischen Philosophen und Semiotikers Jelineks eigene ästethische Position maßgeblich geprägt und die Entwicklung ihres Destruktionsverfahrens vermutlich initialisiert haben.

262005 hatte Yasmin Hoffmann unter dem Titel "Elfriede Jelinek. Une biographie« das erste Porträt in französischer Sprache veröffentlicht.

27 Vgl. Kapitel I.5 dieser Studie.

28 Lichtenberg, zitiert nach: http://www.aphorismen.de (Zugriff am Io.4.2010). 
In einem weiteren Schritt soll eine Annäherung an die umstrittene Biografie der Autorin geleistet werden, die sich unter anderem an dem Jelinek-Porträt von Verena Mayer und Roland Koberg orientiert, gleichzeitig aber die Frage nach der Authentizität der dargestellten biografischen Fakten aufwirft.

Im Rahmen einer »Poetologischen Einführung" werden danach Jelineks wichtigste Textherstellungsmethoden untersucht, die neben den Bezügen zu Barthes von Einflüssen der (jüdisch-)österreichischen Literatur des I 9. und frühen 20. Jahrhunderts, vom Geist der i 968er-Bewegung, den Sprachexperimenten der Wiener Gruppe, der Kultur- und Medienkritik der Frankfurter Schule sowie der marxistischen Gesellschaftstheorie geprägt sind.

Das theoretische Kapitel abschließend wird die Destruktion des Opfermythos anhand exemplarischer Textausschnitte aus verschiedenen Werken Jelineks sichtbar gemacht: Es wird gezeigt, mit welchen Mitteln und in welch unterschiedlichen Ausprägungsformen die Autorin den Opfermythos von Anfang an sowohl thematisch als auch sprachlich in den Mittelpunkt ihres Schreibens stellte.

Auf die Einleitung folgt eine »Methodische Reflexion«, in welcher der für die Jelinek-Rezeption so wichtige Intertextualitätsbegriff zunächst skizziert und in Folge seine Praktikabilität in Hinblick auf die Interpretation von Jelinek-Texten hinterfragt wird. Des Weiteren wird in diesem Kapitel die im empirischen Teil der Arbeit angewendete Methodik kurz dargelegt, deren wichtigster Baustein neben einer modifizierten Variante der Intertextualität vor allem die Einbeziehung der in der Einleitung diskutierten zeitgeschichtlichen Theorien ist.

Im Anschluss an dieses Kapitel folgt im empirischen Teil eine Interpretation der drei Beispieltexte »Burgtheater«, »Die Kinder der Toten« und »Das Lebewohl«, die an dem im methodischen Kapitel beschriebenen Verfahren orientiert ist und auf diese Weise einen plausiblen Lektüre- und Deutungsvorschlag der drei Texte anbieten will. Durch die Verknüpfung germanistischer Verfahren mit historischem Wissen soll die Ausgangsthese der Arbeit bestätigt werden.

Zuletzt werden die wichtigsten Ergebnisse aus dem theoretischen und dem empirischen Teil der Arbeit noch einmal zusammengefasst. In einem interdisziplinären Resümee wird außerdem ein Fazit über die Möglichkeiten und Grenzen philologisch-historischer Zusammenarbeit gezogen. 


\subsection{Diskussion der zentralen Begriffe}

»Allgemeine Begriffe und großer Dünkel sind immer auf dem Wege entsetzliches Unglück anzurichten. ${ }^{29}$

Zunächst müssen einige Modelle zu Faschismus und Nationalsozialismus verhandelt werden, die den aktuellen geschichtswissenschaftlichen Diskurs widerspiegeln und eine Einordnung von Jelineks »Faschismuskritik « ${ }^{30}$ ermöglichen sollen. Interessanterweise ist von dieser in Sekundärtexten gerne die Rede, ohne dass jedoch auseinandergesetzt würde, was jeweils unter dem sehr sensiblen Faschismusbegriff zu verstehen ist. Verständlicherweise fokussiert das bisherige Sekundärwerk auf sprach- und literaturwissenschaftliche Analysen, lässt dabei aber zum Teil den reflektierten Umgang mit historischen Begriffen vermissen ein Umstand, der gerade bei der Beschäftigung mit politisch engagierter Literatur als Manko gesehen werden muss.

Tatsächlich existiert ein starker Konnex zwischen den hier präsentierten wissenschaftlichen Theorien und Jelineks artifiziellen Texten, wie sowohl im theoretischen als auch empirischen Teil der vorliegenden Studie deutlich werden wird, denn die Werke der österreichischen Nobelpreisträgerin spiegeln immer bis zu einem gewissen Grad den wissenschaftlichen Diskurs wider, greifen diesem in manchen Punkten voraus oder arbeiten sich an überholten Theorien ab, auf die im öffentlichen Diskurs oder der Publizistik nach wie vor zurückgegriffen wird, um das faschistische Phänomen erklären zu wollen.

Jelineks eigener, spezieller Faschismusbegriff wurzelt in ihrer Sozialisation als Autorin in der sprachkritischen Literaturszene der österreichischen I 968er-Bewegung. ${ }^{31}$ Auch wenn die Aufarbeitung der nationalsozialistischen Verbrechen bis heute eines der zentralen Themen im Jelinek'schen Euvre darstellt, so muss doch festgestellt werden, dass die Autorin den Nationalsozialismus nicht als singuläres historisches Ereignis begreift, sondern - aus dem Blickwinkel einer deklarierten Marxistin - als gewaltsame Eskalation einer allgemeinen, überzeitlichen Tendenz zur Herstellung ungleicher Besitz- und Gewaltverhältnisse innerhalb der Gesellschaft, die mit der nationalsozialistischen »Rassenlehre« biologistisch begründet wurde und mit zahlreichen Strategien der »Verdummung«

29 Stapf, Goethes Werke, S. I I 24.

30 Zur unreflektierten Verwendung des Faschismusbegriffs vgl. Janz, Elfriede Jelinek, S. VIII, dies., Falsche Spiegel, S. 85, Ehlers, Die Faschismuskritik der Elfriede Jelinek; Arnold, Faschismuskritik bei Elfriede Jelinek; Mertens, Die Ästhetik der Untoten, etwa auf S. 4.

3 I Vgl. Kapitel r.6. I dieser Studie. 
und Manipulation im Alltagsleben der deutschen und österreichischen Bevölkerung ihren Niederschlag fand. Dabei umschreibt Jelinek diesen ubiquitären Faschismus in all seinen Facetten und schreibt ihn in ihre literarischen Texte ein (»Success in Circuit lies« ${ }^{32}$ ).

Auf diese Weise wird der Faschismus in seinen historischen, aber auch aktuellen Ausprägungsformen zum zentralen Gegenstand in ihrem Werk, und zwar nicht nur als Thema, sondern auch als Fixpunkt ihrer literarischen Verfahrensweisen. ${ }^{33}$ Dass diese eng mit Jelineks früher Rezeption von Roland Barthes' Mythentheorien zusammenhängen und welche österreichspezifischen Problematiken in der weiteren Auseinandersetzung besondere Beachtung finden müssen, wird im Anschluss in den Kapiteln über »Mythos« und »Opfermythos« erläutert.

\subsection{1 »Faschismus«}

»Yes, everything does depend on definition, but this should not be a reason for abandoning the concept. ${ }^{34}$

Das originäre Problem an dem viel diskutierten »Faschismus«-Begriff ist, dass er von Anfang an mehrdeutige und vereinnahmende Verwendung fand. So wurde sowohl im öffentlichen wie auch im wissenschaftlichen Diskurs »keineswegs immer und keineswegs eindeutig genug ${ }^{35}$ zwischen »Faschismus als linkem Kampfbegriff, als Spezifikum italienischer Geschichte und als epochaler Erscheinung unterschieden. ${ }^{36}$ Der Begriff »Faschist « wurde mitunter »so lax gebraucht, dass mancher dafür plädierte, ihn für die wissenschaftliche Forschung überhaupt aufzugeben « ${ }^{37}$.

$\mathrm{Zu}$ berücksichtigen ist daher stets, dass die historischen wie auch aktuellen Definitionen und Theorien immer bis zu einem gewissen Grad die unterschiedlichen wissenschaftlichen, aber auch politischen Standpunkte ihrer Verfasser widerspiegeln, wenngleich neuere Theorien differenzierter und weniger vereinnahmend zu sein scheinen als jene vorangegangener Konjunkturen der Faschismusforschung in den I 920 r bis I 94 oer und den I $960 e r$ bis I $970 e r$ Jahren. ${ }^{38}$

32 Dickinson, Gedichte, S. 4 Io. Vgl. das lyrische Motto dieser Studie.

33 Vgl. Janz, »Die Geschichte hat sich nach 45 entschlossen«, S. 225.

34 Passmore, Fascism, S. 2.

35 Wippermann, Faschismustheorien, S. 4.

36 Vgl. ebd.

37 Paxton, Die fünf Stadien des Faschismus, S. 64.

38 Zur Periodisierung vgl. Reichardt, Neue Wege, S. 9. 
Heutige Definitionen richten sich zumeist nicht an einem statischen Merkmalskatalog aus, sondern vergleichen die verschiedenen, zum Teil ambivalenten realhistorischen Wege des Faschismus. ${ }^{39}$ Sie lenken den Blick auf die sozialen und kulturellen Praktiken: die Organisationsformen, Rituale und Feiern sowie Ästhetiken, vom Führerkult bis hin zu den in Szene gesetzten Massenversammlungen. Der Faschismusbegriff ist damit ein ganzes Stück flexibler geworden - er ist prozessual ausgerichtet und will das Entwicklungspotential und die Wandelbarkeit des faschistischen Phänomens erfassen. ${ }^{40}$ Nicht zuletzt haben die Ereignisse der I 990er Jahre mit dem Ende der Sowjetunion und der kommunistischen Regime in Europa den Blick zurück auf die Geschichte des 20. Jahrhunderts verändert. ${ }^{41}$

Doch zurück zum Anfang: Faschismustheorien gibt es ebenso lange, wie es den Faschismus selbst gibt: Mit dem Akt der Angelobung Mussolinis als Chef einer von der »Nationalen Faschistischen Partei« (ital. »Partito Nazionale Fascista «) geführten Minderheitsregierung in Italien am 28. Oktober 1922 gelangte der Faschismus erstmals zu staatlicher Macht. ${ }^{42}$ Parallel zum Aufstieg des »Fascismo setzte in den I 92 oer Jahren eine von Italien ausgehende Publikationswelle theoretischer Auseinandersetzungen mit dem faschistischen Phänomen ein, die im deutschsprachigen Raum mit einiger Verspätung rezipiert wurde. ${ }^{43}$ Die Weltanschauung und die politische Ausrichtung der national-faschistischen Partei Mussolinis wurden in diesen frühen Definitionsversuchen als charakteristisch auch für andere faschistische Bewegungen in Europa betrachtet. ${ }^{44}$

In Anlehnung an das Gros der herangezogenen Autoren, auch neuester Studien, wird der deutsch-österreichische Nationalsozialismus (1933/38 bis

39 Vgl. Reichardt, Neue Wege, S. 25.

40 Vgl. ebd., S. i $8 \mathrm{f}$.

4I Vgl. Gentile, Eine Definition zur Orientierung, S. 8I. - Interessant ist, dass Gentile hier vom "weltweiten« Niedergang des Kommunismus schreibt und damit Staaten wie China, Nordkorea oder Kuba außen vor lässt.

42 Vgl. Wippermann, Faschismustheorien, S. I. Bemerkenswert ist nach Wippermann vor allem der Umstand, dass »Mussolinis Partei nur über ganze 35 von 500 Sitzen im italienischen Parlament verfügte«.

43 Vgl. Wippermann, Faschismustheorien, S. 7.

44 Dazu werden üblicherweise folgende gezählt: die »British Union of Fascists« (1932 bis I 940) in Großbritannien, die von José Antonio Primo de Rivera in Spanien geführte »Falange Española de las Juntas de Ofensiva Nacional-Sindicalista« (I933 bis 1937), die »Ustascha« (»Die Aufständischen«) in Kroatien (I 929 bis I 945), die »Garda de Fier» (»Eiserne Garde«) in Rumänien ( 927 bis I944) und die "Nemzeti Akarat Partja (»Pfeilkreuzler«) in Ungarn (1935 bis I945). Vgl. Payne, Geschichte des Faschismus, S. 356-435. Ergänzt werden könnte diese Aufzählung noch mit der »Action Française«, die aber bereits I 898 gegründet worden war. 
I $945^{45}$ ) im Rahmen der vorliegenden Untersuchung als eine spezifische Form genauer: als nationale Variante - des Faschismus betrachtet (»... I join those, who believe that Nazis were fascists and that fascism can be treated as a more general phenomenon ${ }^{46}$ ), wobei nachdrücklich auf die historische Singularität des Holocaust hingewiesen sei. Die antisemitische Rassenpolitik, die das nationalsozialistische Deutsche Reich nicht nur theoretisch plante, sondern auch tatsächlich verwirklichte, war für den italienischen »Fascismo « jedenfalls nicht kennzeichnend. Renommierte Forscher wie Renzo di Felice oder Karl-Dietrich Bracher haben sich dagegen ausgesprochen, den Nationalsozialismus unter den Faschismusbegriff zu subsumieren. ${ }^{47}$ Umgekehrt wird unter vielen Opfern der NS-Diktatur der Ausdruck »nationalsozialistisch« gemieden, da er als euphemistisch empfunden wird. Theodor Adorno etwa, der als Sohn eines jüdischen Vaters 1938 in die USA emigriert war, benutzte stets den Ausdruck »faschistisch«, wenn er auf das NS-Regime Bezug nahm. ${ }^{48}$ Diese Frage ist also nicht ganz eindeutig zu beantworten.

Eine zweite Konjunktur der internationalen Faschismusforschung wurde mit Ernst Noltes Habilitationsschrift »Der Faschismus in seiner Epoche« von I 963 eingeläutet. Nolte vergleicht darin Tradition, Geschichte, Praxis und Doktrin der »Action Française«, des »Fascismo« und des Nationalsozialismus. Er stellt die Behauptung auf, dass der Faschismus ein Phänomen der Weltkriegsepoche gewesen sei (»Epochencharakter ${ }^{49}$ des Faschismus) und benennt die seiner Meinung nach grundlegenden Charakteristika des Faschismus mit dessen drei oppositionellen Prinzipien »Anti-Marxismus«, »Anti-Liberalismus« und »Anti-Konservativismus«. Weiters seien Führerprinzip und (paramilitärische) Bewaffnung kennzeichnend gewesen. Stanley Payne fügte dieser Aufzählung in seiner Überblicksdarstellung »Geschichte des Faschismus« noch weitere Merkmale wie Nationalismus, Imperialismus, Militarismus und Gewalt, aber auch Mystizismus, Romantik und Freiwilligkeit hinzu, was der US-amerikanische Soziologe Michael Mann mit augenzwinkernder Kritik vermerkte (»Quite a list $\left.\aleph^{50}\right)$. Die additive Aneinanderreihung bestimmter Charakteristika ist zwar hilfreich bei der Erstorientierung, macht den Faschismusbegriff aber unflexibel und trägt nicht unbedingt zum besseren Verständnis von dessen differenzierten Mechanismen bei. ${ }^{51}$

45 Deutschland: 1933 bis I 945 , Österreich: 1938 bis 1945.

46 Mann, Fascists, S. 9.

47 Vgl. dazu Paxton, Die fünf Stadien des Faschismus, S. 56.

48 Vgl. Geml, Zum Begriff des Faschismus bei Adorno, S. I 8.

49 Nolte, Der Faschismus in seiner Epoche, S. 25.

50 Mann, Fascists, S. Iо.

5 I Vgl. ebd. 
Dennoch dürfen die Leistungen vorangegangener Generationen von Faschismusforschern nicht unterschätzt werden. Ernst Nolte etwa, der sich in den I 98 oer Jahren im Rahmen des von ihm ausgelösten "Historikerstreits « ${ }^{52}$ erhebliche Kritik zuzog, war in den r 96oer Jahren immerhin der erste deutschsprachige Historiker ohne marxistischen Hintergrund gewesen, der den Faschismusbegriff genutzt hatte. Mit seinen Studien hatte er wesentlich zur Legitimität eines allgemeinen Faschismusbegriffs beigetragen. ${ }^{53}$ Auch wenn die von ihm vorgenommene Epochisierung von späteren Forschungen verworfen wurde und auch seine "phänomenologische Methode ${ }^{54}$, die den Faschismus auf Basis seiner Selbstäußerungen zu definieren sucht, heute als eindimensional gilt, so muss doch festgehalten werden, dass namhafte Studien der letzten beiden Dekaden Noltes Ansätze in neuere, differenziertere Modelle integrieren: So schließen einige nicht nur an sein generisches Modell an, das die ideologischen Gemeinsamkeiten faschistischer Bewegungen betont ${ }^{55}$, sondern beziehen auch die Selbstbeschreibungen und -repräsentationen der Faschisten mit ein. ${ }^{56}$

Zu Noltes Verdiensten zählt außerdem, dass er einer der Ersten war, die auf die Ambivalenzen des Faschismus hinwiesen - Ambivalenzen, die sich in der paradoxen Ausbildung einer Ideologie äußerten, die dem Kommunismus ebenso radikal entgegengesetzt wurde, wie sie auch zu ihm benachbart war, zudem in der Anwendung nahezu identischer wie auch charakteristisch umgeprägter $\mathrm{Me}$ thoden. ${ }^{57}$

Die Gemeinsamkeiten faschistischer und realsozialistischer Regime sollten in den USA und Westeuropa nach I 945 anhand von "Totalitarismustheorien ${ }^{58}$ erklärt werden, welche die Wesensähnlichkeiten von Faschismus und Kommunismus zu beschreiben versuchten, deren grundsätzliche ideologische Differen-

52 Nolte hatte die nationalsozialistischen "Rassenmorde« mit den »Klassenmorden« in den bolschewistischen Gulags verglichen. Er hatte damit die historische Singularität des Holocaust in Frage gestellt, was ihm u. a Jürgen Habermas als »Revisionismus« ankreidete. Vgl. dazu Geiss, Die Habermas-Kontroverse; Herbert, Der Historikerstreit; Wippermann, Umstrittene Vergangenheit; Diner, Ist der Nationalsozialismus Geschichte?; Kühnl, Vergangenheit, die nicht vergeht; Nolte, Das Vergehen der Vergangenheit usw.

53 Vgl. Kühnl, Faschismustheorien, S. I60.

54 Nolte, Der Faschismus in seiner Epoche, S. 53.

55 Vertreter der generischen Theorie sind u. a Ernst Nolte, Stanley Payne, George Mosse, Roger Griffin, Roger Eatwell und Richard Thurlow.

56 Zum Beispiel bei Griffin, The Nature of Fascism.

57 Vgl. Nolte, Epoche des Faschismus, S. 49-58. Vgl. dazu auch Reichardt, Neue Wege, S. I 8.

58 Vgl. dazu den Pioniertext von Hannah Arendt: Elemente und Ursprünge totaler Herrschaft. Arendt vergleicht darin Stalinismus und Nationalsozialismus und bezeichnet sie sogar als »Variationen des gleichen Modells« (vgl. ebd., S. 640). 
zen $^{59}$ aber zum Teil ausblendeten: So postuliert der Kommunismus die klassenlose, auf Solidarität beruhende Gesellschaftsordnung, während der Faschismus die Naturnotwendigkeit von Herrschaft und Unterordnung propagiert sowie den ewigen Kampf der Völker bzw. der »Rassen« ums Dasein und das Recht des Stärkeren als Lebensprinzip. Die »Totalitarismustheorien« zählten daher in den I $980 e r$ Jahren zum »Gerümpel des Kalten Kriegs « ${ }^{60}$ und wurden in dieser Phase aus der historischen Forschung fast zur Gänze verbannt. In der heutigen Historiografie sind Totalitarismusmodelle wieder möglich, sofern sie vergleichend und nicht gleichsetzend vorgehen. Sie sind unter anderem in den theoretischen Ansätzen zur »Politischen Religion ${ }^{61}$ des »Fascismo«-Experten Emilio Gentile zu finden. ${ }^{62}$

In Fortführung der Thesen Noltes beschrieb der deutsche Historiker Wolfgang Wippermann ${ }^{63}$, der auf zahlreiche einschlägige Publikationen zurückblicken kann, den »Fascismo« in Italien als "faschistischen Realtypus « ${ }^{64}$ : Jene Parteien und Bewegungen, die im Hinblick auf Erscheinungsbild, politischen Stil, ideologische Ausrichtung, soziale Funktion, Art und Weise der Machtergreifung sowie die Struktur ihrer Regime bedeutende Ähnlichkeiten mit dem italienischen Faschismus aufweisen, seien demnach als "faschistisch " zu bezeichnen. ${ }^{65}$

»Diese Parteien waren hierarchisch nach dem Führerprinzip gegliedert, verfügten über uniformierte und bewaffnete Abteilungen und wandten einen damals neuartigen spezifischen politischen Stil an, den man auf Massenkundgebungen und auf Massenaufmärschen zelebrierte, wobei der jugendliche und vor allem männliche Charakter der einzelnen ,faschistischen Parteien betont wurde. Hinzu kam eine ausgesprochene pseudoreligiöse Ausrichtung. ... Doch im Mittelpunkt sowohl der Propaganda wie der Politik stand die Gewalt. Sie wurde in offener und ritualisierter Form gegen >Feinde und >Fremde< gleichermaßen eingesetzt, was Außenstehende sowohl abschreckte wie anzog und im Innern den Zusammenhalt der Parteimitglieder festigte. ${ }^{66}$

Erstaunlich ähnlich und in Verklammerung mit anderen Modellen finden sich Wippermanns theoretische Charakterisierungen in literarisierter Form in di-

59 Vgl. Kühnl, Faschismustheorien, S. I 37.

6o Gentile, Eine Definition zur Orientierung, S. 8I.

6I Siehe dazu Gentile, Le religioni della politica. Liegt auch in englischer Übersetzung vor: Gentile, Politics as Religion.

62 Vgl. Gentile, Eine Definition zur Orientierung, S. 8 I.

63 Wippermann hatte in den I 970er Jahren bei Nolte promoviert.

64 Vgl. Wippermann, Hat es Faschismus überhaupt gegeben, S. 56.

65 Vgl. ebd., S. 64.

66 Vgl. ebd. 
versen Jelinek-Texten wieder, wie etwa in dem empirischen Kapitel über den Bühnentext »Das Lebewohl« ausgeführt werden wird. Auf geschichtswissenschaftlicher Ebene muss Wippermanns Beschreibung eines realtypischen Faschismusbegriffs jedoch als überholt gesehen werden. Wippermann selbst ergänzte sein Modell in einer jüngeren Veröffentlichung mit dem Hinweis auf "multikausale Faschismustheorien mittlerer Reichweite « ${ }^{67}$ : Demnach können mit Modernisierungstheorien die Voraussetzungen, mit sozialen/sozialpsychologischen Thesen die Anziehungskraft auf bestimmte gesellschaftliche Gruppen und mit Bonapartismustheorien die Machtergreifung und -festigung erklärt werden. ${ }^{68}$ Wippermanns theoretischer Ansatz erscheint damit auf den ersten Blick relativ umfassend; doch lässt er auch erahnen, dass der prozessuale und ambivalente Charakter faschistischer Bewegungen und Regime auf diese Weise schwer zu fassen ist. Kollegen bemängelten die methodischen Schwächen des Wippermannschen Faschismusbegriffs, der die Erkenntnisse der letzten beiden Dekaden historischer Forschung ignoriere. ${ }^{69}$

Auch der Konstanzer Historiker und Faschismusexperte Sven Reichardt kritisierte in seinem Editorial der Zeitschrift »Mittelweg 36 « $^{70}$ vom Jänner 2007, dass renommierte Forscher wie Wolfgang Wippermann, George Mosse, Stanley Payne oder Wolfgang Schieder zwar bis in die r 99oer Jahre hinein wichtige und viel beachtete Beiträge publizierten ${ }^{71}$, die Probleme der tradierten Faschismusforschung der I 97oer Jahre dabei aber nicht überwinden konnten. Reichardt beklagt gar den "Niedergang der vergleichenden Faschismusforschung ${ }^{72}$ seit den I98oer Jahren. Den »Scherbenhaufen ${ }^{73}$ vergleichender und theoriegeleiteter Faschismusforschung gesteht auch Wippermann rückblickend ein und macht nicht zuletzt den von Ernst Nolte I986 in Gang gesetzten »Historikerstreit» dafür verantwortlich. ${ }^{74}$

Reichardts Lamento fokussiert in erster Linie auf den deutschsprachigen Raum: Die häufig ökonomistisch verengten und vergleichsarmen Interpretationen deutschsprachiger Wissenschafter, welche die Faschismustheorie fast ausschließlich am Beispiel des Nationalsozialismus zu exemplifizieren suchten,

67 Wippermann, Hat es Faschismus überhaupt gegeben, S. 64.

68 Vgl. ebd., S. 64 f.

69 Vgl. etwa die Beiträge von Friedrich Pohlmann, Karin Priester und Achim Siegel in demselben Band.

70 Zeitschrift des Hamburger Instituts für Sozialforschung; erscheint zweimonatlich.

7I Es handelt sich um Beiträge, die, mit einigen Ergänzungen und Kommentaren versehen, zum Teil auch nach der Jahrtausendwende noch neu aufgelegt wurden.

72 Reichardt, Neue Wege, S. 9.

73 Wippermann, Faschismustheorien, S. 9.

74 Vgl. ebd., S. 8 f. 
haben die Durchsetzung eines modernen, auf dem Stand der empirischen Einzelforschung beruhenden, innovativen Faschismusbegriffes verhindert. ${ }^{75}$

Tatsächlich erscheint es befremdlich, dass etwa Wolfgang Schieder zu Beginn der I 99oer Jahre im Rahmen einer Bestimmung historischer Grundbegriffe die Behauptung formulierte, dass der Faschismus seit I 945 keine Zukunft mehr habe, da die beiden führenden Faschismen in Italien und Deutschland nach ihrem »selbstverschuldeten Untergang ${ }^{76}$ an politischer Attraktivität verloren haben. Ohne den Bezug auf Mussolini oder Hitler könne es keinen Faschismus mehr geben - eine Behauptung, die schon per se angezweifelt werden muss, aber auch in ihrer Argumentation, denn mit seiner Konklusio knüpfte Schieder an die in den Jahren nach I 945 vor allem von bundesdeutschen Historikern vertretene "Führertheorie« an, wonach die Person des »Führers« als nahezu ausschließliche Ursache für die Entstehung faschistischer Bewegungen und deren Etablierung als Herrschaftssysteme begriffen wird. Die Führertheorie flammte in den I 97oer Jahren durch eine Welle von Hitler-Publikationen, zum Beispiel Joachim Fests bekannter Hitler-Biografie, neu auf. Auch Elfriede Jelinek findet die Theorie unglaubwürdig: Hitler hätte als Einzelperson den Nationalsozialismus nicht an die Macht bringen können, »das wäre nicht gelungen ${ }^{77}$, meint sie. Auch in ihren literarischen Texten befasst sich die Autorin wiederholt mit Stehsätzen aus dem Volksmund und der Publizistik, die das nationalsozialistische Phänomen auf die rigiden Führungseigenschaften Adolf Hitlers reduzieren, und führt die Führertheorie ad absurdum, wie in dem empirischen Kapitel zu ihrem großen Roman »Die Kinder der Toten« erläutert wird.

Nicht nur die eindimensionale Führertheorie erlebt (vor allem im deutschsprachigen Raum) immer wieder Renaissancen; auch lebte in der zweiten Hälfte der r99oer Jahre mit der "Goldhagen-Debatte«, die um die Ursachen des Holocaust geführt wurde, die Idee einer anderen, eigentlich längst ad acta gelegten Theorie wieder neu auf: die ursprünglich von Karl Dietrich Bracher formulierte »These vom deutschen Nationalcharakter«, wonach Faschismus jeweils ein Produkt nationaler Besonderheiten wäre und sich der Nationalsozialismus in Deutschland aufgrund eines unterstellten deutschen Nationalcharakters habe entwickeln können ${ }^{78}$ (wobei Bracher österreichische Spezifika immerhin ansatzweise miteinbezog). ${ }^{79}$

75 Vgl. Reichardt, Neue Wege, S. 9 ff.

76 Ebd., S. 178.

77 Jelinek, zitiert nach Janke/Kovacs/Schenkermayr, Die endlose Unschuldigkeit, S. 2 I.

78 Bracher, Die deutsche Diktatur. Die These vom Nationalcharakter findet auch in Bezug auf andere Völker Anwendung, etwa auf die Spanier und ihr südländisches Temperament, das zum Ausbruch des Spanischen Bürgerkriegs geführt habe usw.

79 Vgl. ebd.: Ausführungen zu Österreich vor allem in dem Kapitel „Österreichische Vorläufer«, S. 53-6o, zum Teil auch in dem nachfolgenden Kapitel über Adolf Hitler, S. 60-72. 
Diese - biologistisch anmutende - These, die auch Jelinek mit Bestimmtheit ablehnt (wie unter anderem in dem Kapitel über "Burgtheater" auseinandergesetzt wird), war vor allem in der amerikanischen Publizistik lange populär. Der erwähnte US-amerikanische Soziologe und Politikwissenschafter Daniel Goldhagen, Sohn eines Holocaust-Überlebenden, provozierte in seinem 1996 veröffentlichten Buch $»$ Hitlers willige Vollstrecker ${ }^{80}$ mit der Behauptung, dass die nationalsozialistische Judenvernichtung aufgrund eines in der christlich geprägten Bevölkerung des Deutschen Reichs tief verankerten »eliminatorischen Antisemitismus « ${ }^{81}$ heraus habe durchgeführt werden können, was (vor allem in Deutschland aber auch international) heftige Reaktionen in Wissenschaft und Publizistik auslöste. Auch die Kirche wehrte sich gegen Goldhagens Vorwürfe, der radikale europäische Antisemitismus sei eine »Begleiterscheinung des Christentums « ${ }^{82}$ gewesen.

Abseits der streitbaren Studie von Daniel Goldhagen kommen die neuen, entscheidenden Impulse der vergleichenden Faschismusforschung seit Beginn der I99oer Jahre tatsächlich nicht aus dem deutschsprachigen Raum oder Italien, sondern vor allem aus den USA und England. Tragende Namen dieser neuen (dritten) Konjunktur sind etwa Roger Griffin, Roger Eatwell, Kevin Passmore, Robert O. Paxton, Richard Thurlow oder Michael Mann. ${ }^{83}$

Deren Publikationen stellen in der Regel Verknüpfungen, Differenzierungen und Weiterentwicklungen älterer Modelle dar. Die Leistungen früherer Forschungsarbeiten sind daher trotz aller Kritik nicht von der Hand zu weisen. Doch die »Untersuchung einer Extremität mag in Hinblick auf das ganze Tier vielleicht zu falschen Schlüssen führen ${ }^{84}$. Stellen sich ältere Theorien also vor allem als Fokussierungen auf spezifische Einzelaspekte des Faschismus dar, versuchen neuere Ansätze zumeist das Phänomen als Ganzes zu erfassen.

So etwa die Arbeiten des in Oxford lehrenden Zeithistorikers Roger Griffin, der mit seiner 1991 publizierten Monografie "The Nature of Fascism ${ }^{85}$ viel Aufsehen erregt hatte: Griffin plädiert darin für die Beibehaltung des generischen, ideologiezentrierten Faschismuskonzepts. Er greift mit seiner Theorie auf Vorarbeiten von George Mosse ${ }^{86}$ zurück und versucht in »The Nature of Fascism« einen vergleichenden, idealtypischen Faschismusbegriff zu schaffen,

8o Goldhagen, Hitler's willing executors. Liegt auch in dt. Übersetzung vor: Goldhagen, Hitlers willige Vollstrecker.

8I Ebd., S. 7I-Io5 sowie ro7-I6r.

82 Ebd., S. 7 I.

83 Vgl. Reichardt, Neue Wege, S. Io sowie Fußnote 7 desselben Texts.

84 Paxton, Die fünf Stadien des Faschismus, S. 67.

85 Griffin, The Nature of Fascism.

86 Vgl. Mosse, International Fascism. Vgl. auch: Ders.: The Fascist Revolution. 
den er »Fascist Minimum « ${ }^{87}$ nennt. Auch wenn neue Ansätze versuchen, den prozessualen Charakter des Faschismus besser zu erfassen, muss doch eingeräumt werden, dass es eine Notwendigkeit der wissenschaftlichen Praxis bleibt, den Kern des Untersuchungsobjekts idealtypisch benennen zu können. ${ }^{88}$ Was Reichardt zufolge in Griffins Modell zu kurz kommt, sind die institutionellen Strukturen, der organisatorische Aufbau, die soziale Basis und die sozioökonomischen Funktionen des Faschismus. ${ }^{89}$ Nach Griffin ist Faschismus »a genus of political ideology whose mythic core in its various permutation is a palingenetic form of populist ultra nationalism ${ }^{90}$.

Diese Definition greift insgesamt zu kurz, resümiert Sven Reichardt, denn sie »schließt wichtige Merkmale wie den Massenappeal, die charismatische Führerschaft, den Korporativismus oder ökonomische Triebkräfte aus « ${ }^{91}$. Auch der US-amerikanische Historiker Robert O. Paxton bemängelt die Statik des »faschistischen Minimums «. ${ }^{92}$

Eine auf die ideologischen Aspekte fokussierte Verortung des Begriffs erscheint schon alleine deshalb problematisch, weil sich die nationalen Ausprägungen europäischer Faschismen jeweils sehr unterschiedlich darstellten und deren Ideen tatsächlich »flexibel genug« waren, um »je nach machtpolitischer Opportunität ... aktualisiert und verändert werden zu können « ${ }^{93}$. Auch der amerikanische Soziologe Michael Mann wendet sich gegen die generische Theorie, denn es sei schließlich einer der wesentlichen Aspekte des Faschismus, dass er kein einheitliches ideologisches Konzept war und hatte:

»... unlinke socialism (which has Marxism), fascism contains no systematic theory. « ${ }^{94}$

Mann hält in Bezug auf faschistische Systeme den Begriff »Weltanschauung« für passender und zutreffender als »Ideologie ${ }^{95}{ }^{95}$ Selbst Emilio Gentile - Ver-

87 Griffin, The Nature of Fascism, S. 38 .

88 Vgl. Reichardt, Neue Wege, S. i 8 f.

89 Vgl. Reichardt, Neue Wege, S. I 2.

90 Griffin, The Nature of Fascism, S. 44. Der Begriff der »Palingenese" geht auf Emilio Gentile zurück: Er bezeichnet die (konter-)revolutionäre Idee einer »nationalen Wiedergeburt«, die ein zentrales Element der generischen Theorie darstellt. Vgl. Gentile, Le Origini dell'Ideologia Fascista. Gentile selbst beschrieb den italienischen Faschismus sowohl als "politische Religion", die den Glauben an die Nation, den Duce und die Partei einforderte, als auch als militärischen und revolutionären Totalitarismus. Vgl. Gentile, Fascismo, S. 63-68.

9 I Reichardt, Neue Wege, S. I3.

92 Vgl. Paxton, Die fünf Stadien des Faschismus, S. 65.

93 Reichardt, Neue Wege, S. I 5.

94 Mann, Fascists, S. ı.

95 Vgl. ebd. 
treter der frühen generischen Theorie - warnt inzwischen vor dem »inflationäre[n] Gebrauch ${ }^{96}{ }^{9}$ dieser Kategorie, da die organisatorische und institutionelle Dimension des Faschismus dabei nachrangig behandelt werden: Nur zusammen mit der ideologischen Dimension sei es möglich, die historischen Wirklichkeiten des Faschismus zu beschreiben, so der italienische Faschismusexperte. Griffins Ansatz wirkt im Lichte dieser kollegialen Kritik vereinfachend und altmodisch. Nichtdestotrotz hält Gentile die Erkenntnis, dass der Faschismus eine eigene Ideologie und Kultur gehabt habe, für eine der wichtigsten Errungenschaften der jüngeren Geschichtswissenschaft. ${ }^{97}$

Um das Problem der inkohärenten ideologischen Ausrichtung und politischen Praxis in den Griff zu bekommen, erweiterte der an der Universität Bath lehrende Politologe Roger Eatwell den Begriff des "faschistischen Minimums« um den der »faschistischen Matrix«: Demnach sei es gerade die Stellung zwischen klassischer Linker und klassischer Rechter gewesen, die den Faschismus charakterisiert habe, etwa "seine Mischung aus rechtem Vitalismus und Willenskult einerseits und einer eher linken Bindung an Wissenschaftlichkeit, zwischen dem rechten Einstehen für private Eigentumsrechte und den eher linken Formen von öffentlicher Wohlfahrt ${ }^{98}$. Die neue politische Elite habe es sich zum Ziel gesetzt, einen synkretistischen »Dritten Weg« zu kreieren, der die Massen mobilisieren sollte:

"Fascist ideology is ... a form of thought which preaches the need for social rebirth in order to forge a holistic-national radical Third Way. «" ${ }^{99}$

Tatsächlich strömten Menschen aus verschiedenen soziokulturellen Zusammenhängen und aus verschiedenen Motiven heraus faschistischen Bewegungen zu. ${ }^{100}$

Eine Weiterentwicklung dieser - immer noch ideologiezentrierten - Interpretation leistete der in Cardiff lehrende Historiker Kevin Passmore. Ihm zufolge werde der Faschismus gerade durch die ihm inhärenten paradoxen Strukturen charakterisiert:

»Yet how can we make sense of an ideology that appeals to skinheads and intellectuals; denounces the bourgeoisie while forming alliances with conservatives; adopts a macho style yet attracts many women; calls for a return to tradition and is fascinated

96 Gentile, Eine Definition zur Orientierung, S. 85.

97 Vgl. Gentile, Eine Definition zur Orientierung, S. 86 f.

98 Reichardt, Neue Wege, S. I 7.

99 Eatwell, Fascism, S. I I.

ıoo Vgl. Reichardt, Neue Wege, S. I7. 
by technology; idealizes the people and is contemptuous of mass society; and preaches violence in the name of order? «101

Passmore beantwortet diese Frage mit den Möglichkeiten, die dieses ambivalente Gebahren für den Faschismus offenhielt, denn nur so konnte dieser gleichermaßen Intellektuelle wie auch Schläger in seinen Bann ziehen. ${ }^{102}$ Das erklärt auch den Sachverhalt, warum der Faschismus antibürgerliche Kritik an den etablierten konservativen Eliten erlaubte, mit denen er gleichzeitig Allianzen schloss - ein in sich widersprüchliches Verhalten, das frühere »Bündnistheorien«, die Faschismus als Ergebnis eines Abkommens zwischen Politik und traditionellen Eliten in Wirtschaft, Staatsapparat und Militär zu beschreiben suchten, weitestgehend ausgeblendet ließen. ${ }^{103}$

Um die Statik des »faschistischen Minimums « ${ }^{104} \mathrm{zu}$ überwinden, schlug Robert O. Paxton Ende der I 99oer Jahre einen prozessualen und handlungstheoretisch orientierten Faschismusbegriff vor, der fünf Stadien des Faschismus beschreibt:

I. die Initiierung faschistischer Bewegungen,

2. deren Etablierung im politischen System als Parteien,

3. die Übernahme der Macht,

4. die Ausübung der Macht,

5. die Radikalisierung. ${ }^{105}$

Paxton griff damit auf Vorarbeiten Wolfgang Schieders zurück, der in einem dreistufigen Modell zunächst Bewegungs-, Durchsetzungs- und Regimephase des italienischen »Fascismo« definiert hatte. ${ }^{106}$ Mit seinem Fünf-Stufen-Modell konnte er die Idee eines praxeologischen Faschismusbegriffs bislang am weitesten entwickeln. ${ }^{107}$

Eine neue sozialgeschichtlich orientierte Definition des Begriffs nahm schließlich Michael Mann zu Anfang des neuen Jahrtausends vor. In seiner 2004 publizierten Arbeit »Fascists « ${ }^{108}$ führte der an der UCLA lehrende Soziologe

I I Passmore, Fascism, S. I I.

IO2 Vgl. dazu auch Reichardt, Neue Wege, S. I7.

I03 Siehe dazu die wohlwollende Einschätzung von Kühnl, Faschismustheorien, S. I 83-228.

I04 Griffin, The Nature of Fascism, S. 38.

I05 Vgl. Paxton, Die fünf Stadien des Faschismus, S. $66 \mathrm{f}$.

ro6 Vgl. Schieder, Faschismus, S. I 84 sowie S. I 94.

I07 Vgl. Reichardt, Neue Wege, S. i 9.

ro8 Mann, Fascists. Siehe dazu auch die übersetzte und gekürzte Fassung der Einleitung: Mann, Der Faschismus und die Faschisten (In: Mittelweg 36, Nr. I, 2007, S. 26-54). 
zunächst eine (allgemein gehaltene) Bestimmung der sozialen Basis faschistischer Bewegungen durch, die er in einem nächsten Schritt an sechs Beispielen exemplifizierte: Italien, Deutschland, Österreich, Ungarn, Rumänien und Spanien. Mann entwickelte damit frühere Mittelstandstheorien weiter: So hatte etwa der marxistisch geprägte Psychoanalytiker Wilhelm Reich schon in den I 93oer Jahren Studien zu Beamten und Angestellten vorgelegt ${ }^{109}$, um das große Votum der Mittelschichten für die NSDA P zu erklären, an die Erich Fromm I 94I mit seinem Buch »Die Furcht vor der Freiheit« anschloss. Fromm definierte darin bestimmte Wesenszüge des sozialen Charakters, die bereits als Konzept für den Begriff des »autoritären Charakters« gesehen werden können: Autoritarismus, Destruktivität, Rückzug, Selbstinflation und Konformismus. Dieser Typus ist nach Fromm sadomasochistisch veranlagt: So bewundert er gleichermaßen die Autorität, wie er danach strebt, sich ihr zu unterwerfen (ein Verhalten, das nach Fromm vor allem bei Beamten und Angestellten konstatierbar ist). ${ }^{110}$ Theodor Adorno vertiefte die »Studien zum autoritären Charakter« im Rahmen eines groß angelegten Forschungsprojekts im US-amerikanischen Exil und veröffentlichte I950 seine Ergebnisse erstmals in englischer Sprache. ${ }^{111}$

Manns Studie bleibt nicht - wie frühere Arbeiten - auf die Kategorie der sozialen Klasse beschränkt, sondern integriert Parameter wie Jugend, Bildung, Religion oder militärische Erfahrungen. ${ }^{112}$ Seine Herangehensweise wirkt dabei differenziert, diskursanalytisch und durchaus empathisch: Individuelle Schicksale werden nachvollziehbar und ihre Übertragbarkeit in andere Settings anschaulich gemacht, etwa wenn Mann den großen Zustrom junger Menschen zu faschistischen Bewegungen zu erklären sucht, die seiner Ansicht nach in deren angebotenen Aktivitäten vor allem Möglichkeiten der Sozialisierung zu finden glaubten:

»Fascists were not fully formed at the moment they entered the movement. People may formally sign up for a movement and yet possess only a rudimentary knowledge of it - sympathy for a few slogans, respect for a charismatic Führer or Duce, or simply following friends who have joined. Most recruits joined the movement young, unmarried, unformed, with little adult civilian experience. On them, fascist parties and paramilitaries were especially powerful socialization agencies. ${ }^{113}$

I09 Reich, Die Massenpsychologie des Faschismus (zuerst 1933 in Kopenhagen erschienen).

i io Vgl. Fromm, Die Furcht vor der Freiheit..

I I I Adorno, Theodor W./Frenkel-Brunswik, Else/Levinson, Daniel J./Sanford, R. Nevitt: The Authoritarian Personality. New York: 1950 . In deutscher Übersetzung posthum erschienen unter dem Titel: Adorno, Studien zum autoritären Charakter.

I 2 Vgl. Reichardt, Neue Wege, S. 2 I.

II 3 Mann, Fascists, S. 28. 
Die sozialhistorische Grundierung wird mit der expliziten Betonung der Gewaltkomponente verbunden. So hebt Mann die tatsächlich rassistische Politik (und eben nicht nur Ideologie) des Faschismus hervor. Krieg und Gewalt haben demnach den Faschismus geprägt. »Inklusion« und »Exklusion« stellen dessen grundlegende Prinzipien dar: Erst der Ausschluss und die Ausbeutung gemeinschaftsfremder Gruppen und Personen habe dieses Herrschaftssystem möglich gemacht, denn durch die Exklusion Gemeinschaftsfremder sei eine breite $\mathrm{Zu}$ stimmung zu Gewalt und Krieg erreicht worden, wie im Nationalsozialismus auf schaurige Art und Weise vorgeführt wurde. ${ }^{114}$

Das 20. Jahrhundert mag ein "monströses Jahrhundert " gewesen sein, jedenfalls ein Jahrhundert mit objektiv zu konstatierendem »Ausnahmecharakter«:

»Es war die großartigste Epoche, was die Leistungen auf dem Gebiet der Wissenschaft und Technik, der Verbesserung der materiellen Lebensumstände, der Ausweitung individueller und kollektiver Emanzipation, des Fortschritts der Vernunft, der Toleranz, der Freiheit und der Menschenwürde anlangt. Gleichzeitig war es die fürchterlichste Epoche - angesichts des Ausmaßes und der Grausamkeit ihrer Kriege und Vernichtungsaktionen, der Entfesselung eines eher unmenschlichen denn übermenschlichen Willens zur Macht, der Erfindung neuer, maßloser Herrschaftstechniken und der Vernichtung der Freiheit und Würde so vieler Menschen, die den Angriffen des Irrationalismus, des Integralismus und des Fanatismus ausgeliefert waren.« ${ }^{115}$

Die verschiedenen Wege, das faschistische Phänomen erklären zu wollen, haben erhellende, differenzierte und empirisch gut belegte Erkenntnisse mit sich gebracht. Dennoch wird die Geschichte des 20. Jahrhunderts im Rahmen der internationalen, vergleichenden Faschismusforschung immer wieder neu geschrieben werden müssen - ans 2 I. Jahrhundert wollen wir dabei noch gar nicht denken.

Das Bemühen um die Erforschung des Faschismus in seinen verschiedenen Kontexten und Dimensionen, seinen ambivalenten Ausprägungsformen und seiner Wandelbarkeit wird auch in den kommenden Dekaden die wichtigste Aufgabe und größte Herausforderung der vergleichenden Faschismusforschung darstellen.

I I 4 Vgl. Reichardt, Neue Wege, S. 22 f. Vgl. dazu auch die Vorarbeiten von Arendt, Macht und Gewalt.

I 5 Gentile, Eine Definition zur Orientierung, S. 82. 
1.4.2 »Nationalsozialismus«

»[Die NS-Herrschaft] war keine bloße Diktatur von oben nach unten, sondern eine soziale Praxis, an der die deutsche Gesellschaft in vielfältiger Weise beteiligt war. ${ }^{116}$

Die Abkehr von besagtem Merkmalskatalog kennzeichnet auch die neuere $\mathrm{Na}$ tionalsozialismusforschung. Diese fokussiert auf anthropologisch determinierte Ansätze ${ }^{117}$, welche die Wandelbarkeit und Dynamik des deutsch-österreichischen Faschismus nachvollziehbar machen und damit zur Differenzierung und Weiterentwicklung früherer Modelle beitragen, die den Nationalsozialismus vor allem als "Mobilisierungs- und Manipulationsprojekt ${ }^{118}$ der politischen Eliten zu beschreiben suchten. Die Änderung des Blickwinkels widerspiegelt dabei die politischen Entwicklungen seit I 945 : Nach dem Ende des Zweiten Weltkriegs war zunächst vor allem der Eroberungskrieg als Hauptmerkmal des NS-Regimes in den Blick genommen worden; in den Interpretationen der r96oer und I970er Jahre hatten die Zerschlagung von Demokratie und Sozialismus sowie der Widerstand gegen das Regime im Vordergrund gestanden. ${ }^{119}$ Seit den I98oer Jahren differenzierte sich das Nachdenken über den Nationalsozialismus, im wissenschaftlichen wie auch im gesellschaftlichen Diskurs. ${ }^{120}$ In den Geschichtswissenschaften gilt der Holocaust zunehmend als präzedenzloses, zentrales Kernereignis des Nationalsozialismus:

»Die `Chiffre Auschwitz bezeichnet am Beginn des 2 I. Jahrhunderts einen >globalen

Referenzpunkt‘, der nicht mehr allein als Kernereignis des Nationalsozialismus interpretiert wird, sondern als `Signatur eines ganzen Zeitalters« ${ }^{121}$

I 6 Bajohr, Zustimmungsdiktatur, S. I 2 I.

I 7 So z.B. die "Alltagsgeschichte«: Diese untersucht die konkreten historischen Lebenssituationen der Menschen und zielt dabei auf eine Rekonstruktion der Wahrnehmungs- und Deutungsweisen der Menschen ab. Vg1. Jordan, Theorien und Methoden, S. I 56. Auch die "Mikrohistorie« rückt das Individuum stärker in ihren Blick: Sie will über die Betrachtung des Kleinen Aufschlüsse über die Gestalt des Großen gewinnen. Vgl. ebd., S. I 55 .

I 8 Kritisch dazu Bauer, Mobilisierung, S. 288.

I 9 Vgl. Uhl, Zivilisationsbruch und Gedächtniskultur, S. 8 f.

I 20 Vgl. Bauer, Mobilisierung, S. 294.

I 2 I Uhl, Zivilisationsbruch und Gedächtniskultur, S. 8. Uhl beruft sich in ihrer Ausdrucksweise auf: Habermas, Geschichtsbewußtsein, S. г6 I-I79. 
Der Holocaust, die Shoah, wird als Fluchtpunkt der europäischen und nicht mehr nur der deutsch-österreichischen Geschichte betrachtet. ${ }^{122}$

Die Beschäftigung mit dem Angriffskrieg und der rassistisch begründeten Menschenvernichtung der Nationalsozialisten führt unwillkürlich immer zu der großen Frage nach dem Warum, die der Historiker Dan Diner, der in den späten I 98oer Jahren den Begriff des "Zivilisationsbruchs « ${ }^{123}$ geprägt hatte, zu der anthropologisch angeleiteten Frage nach dem Wie weiterspinnt (»Wie konnten Menschen anderen Menschen derartiges Leid zufügen ...? « ${ }^{124}$ ). Um mögliche Antworten auf diese Frage zu finden, ist es sinnvoll und notwendig, sich einzelne Fallbeispiele zu vergegenwärtigen, konkrete »Lebenswelten ${ }^{125} \mathrm{zu}$ rekonstruieren und deren Vielfältigkeit und Dynamik zu akzeptieren. Möglich wird dies etwa anhand der Analyse so genannter »Ego-Dokumente ${ }^{126}$ oder auch Oral History-Interviews:

"Lebensgeschichtliche Interviews machen ganz allgemein sichtbar, wie die national-sozialistischen Angebote in die privaten, persönlichen Bedürfnis- und Gefühlslagen eingebaut wurden... Ihre Brisanz bekommen sie, weil es in einem totalitären System, das alles bis aufs letzte politisierte, keine sozusagen sauberen, unschuldigen Handlungsfelder gibt. ${ }^{127}$

Bei der Beschäftigung mit lebensgeschichtlichen Quellen, aber auch im Rahmen von alltags- oder mikrohistorischen Studien wird deutlich, dass die scheinbar eindeutigen Kategorien von »Opfer-« und »Täterschaft« innerhalb individueller Biografien wechseln oder sich überlagern konnten: „Mitmachen, Hinnehmen und gelegentliches Widerstehen lagen ... im Gemenge. « ${ }^{128}$ Die Zurkenntnisnahme und Beschreibung dieser (partiellen)»Teilnahme der Vielen ${ }^{129}$, die in der historischen Literatur auch als »(Selbst-)Mobilisierung 'von unten « ${ }^{130}$ oder als »Selbst-Dynamisierung der Vielen ${ }^{131}$ bezeichnet wird, stellt einen wichtigen Perspektivenwechsel in der Nationalsozialismusforschung dar,

I 22 Vgl. ebd., S. 8 f.

I 23 Diner, Dan (Hg.): Zivilisationsbruch. Denken nach Auschwitz. Frankfurt am Main: Fischer I 988 .

I 24 Ders., Den Zivilisationsbruch erinnern, S. I 8 .

I $25 \mathrm{Zu}$ dem historischen Begriff der »Lebenswelt(en)« vgl. Welz, Kritik der Lebenswelt. Etwas komprimierter bei: Gabriel, Lebenswelt und Handeln, S. 37-56.

I $26 \mathrm{Zu}$ »Ego-Dokumenten« vgl. die Erläuterungen von: Lüdtke, Macht der Emotionen, S. 49-5 2.

I 27 Bauer, Mobilisierung, S. 29 I.

I 8 Langthaler, Die tägliche Mobilisierung, S. I 95 .

I 29 Lüdtke, Macht der Emotionen, S. 54.

I30 Langthaler, Die tägliche Mobilisierung, S. I 90.

I 3 I Lüdtke, Macht der Emotionen, S. 54. 
die zunehmend die Verschränkungen zwischen Herrschaftssystem und Gesellschaft in den Blick nimmt, genauer: die »Interaktion zwischen den Strategien der Machteliten und dem sozialen Handeln der seinfachen`VolksgenossInnen, das Wechselverhältnis von Anreizen und Zustimmung, von Repression und Anpassung, aber auch Zurückweisungen der NS-Herrschaft durch oppositionelle Handlungen « ${ }^{132}$. Dabei geht es darum, die gewöhnlichen Bürger nicht als willenlos geführte Marionetten oder als Teil eines stummen Kollektivs zu sehen, was sie ungerechtfertigterweise automatisch in die Opferposition rücken würde, sondern als historische Akteure - in ihrem jeweiligen Handlungsspielraum - zu begreifen. Die Reichweite dieses Spielraums indes ist nachrangig, denn Mikrohistorie meint nicht, kleine Dinge anzuschauen, sondern vielmehr »im Kleinen ${ }^{133} \mathrm{zu}$ schauen, um den Blick für Vielfältigkeiten und Ambivalenzen zu schärfen und damit die Makrohistorie besser verstehen zu können. ${ }^{134}$

Im Rahmen dieser Sichtweise wird außerdem die integrative Wirkung von Feindbildern hinterfragt, was im Weiteren dazu führt, menschliche Emotionen als Gegenstand der geschichtswissenschaftlichen Forschung zuzulassen ${ }^{135}$, womit (wenigstens zum Teil) die »Intensität der Verzweiflung « ${ }^{136}$ erklärt werden kann, die es möglich machte, dass die Ausgegrenzten, Verfolgten und zum Tode Verurteilten das Versagen und die Auslöschung jedes Gefühls erfuhren ${ }^{137}$ - die unbarmherzige Folgerichtigkeit der als »Inklusion« und »Exklusion « ${ }^{138}$ bezeichneten Systematik, welche die tödliche Trennlinie "zwischen dem >Wir der so genannnten >Volksgemeinschaft und den snicht-arischen Anderen « ${ }^{139}$ ausmachte, die im Nationalsozialismus dazu führte, dass zuvor unbescholtene Bürger den Gashahn aufdrehten.

Die Geschichte der Gefühle ist ein Bereich, der in den letzten Jahren auch in der historiografischen Forschung verstärkte Beachtung findet. ${ }^{140}$ Emotionen haben einen kulturgeschichtlichen, performativen, aber auch handlungsrelevanten Charakter. ${ }^{141}$ In letzter Instanz müssen auch Gefühle bis zu einem gewissen

I32 Bauer, Mobilisierung, S. 289.

I33 Kolportiertes Zitat von Giovanni Levi, zitiert nach: Jordan, Theorien und Methoden, S. 158.

I34 Vgl. Langthaler, Die tägliche Mobilisierung, S. I 83. Vgl. dazu auch Jordan, Theorien und Methoden, S. I 52 fff.

I35 Vgl. Lüdtke, Macht der Emotionen, S. 45. Zur Geschichtlichkeit und Geschichtsmächtigkeit von Gefühlen vgl. jenen sehr interessanten Sammelband, in dem sich Lüdtkes Aufsatz befindet: Klimó/Rolf, Rausch und Diktatur.

I36 Lüdtke, Macht der Emotionen, S. 55.

I37 Vgl. ebd.

I 8 Vgl. dazu Mann, Fascists. Vgl. auch Bajohr, Meister der Zerstörung, S. 689.

I 39 Bauer, Mobilisierung, S. 290.

I40 Klimó/Rolf, Rausch und Diktatur, S. I3.

I4 I Ebd., S. I4. 
Grad als »erlernte Kompetenzen« betrachtet werden; insofern erscheint die historische Auseinandersetzung mit menschlichen Gefühlen auch für die Nationalsozialismusforschung als überaus lohnend, da sie als »Interpretationstor für gesellschaftliche Grundkonfigurationen « ${ }^{142}$ erkannt wurden.

Die Verlagerung des Erkenntnisinteresses innerhalb der Geschichtswissenschaften, die zunehmend »im Kleinen« schaut, brachte neue terminologische Bestimmungen mit sich. So werden Begriffe wie »NS-Diktatur« oder »Führerstaat» mehr und mehr durch Begriffe ergänzt und/oder ersetzt, welche bereits im Wort selbst auf die beschriebenen Verschränkungen zwischen Machteliten und gewöhnlichen Bürgern verweisen: so zum Beispiel der von Frank Bajohr vorgeschlagene Begriff der »Zustimmungsdiktatur ${ }^{143}$, das Begriffspaar »Gleichschaltung/Selbstgleichschaltung ${ }^{144}$ von Axel Schildt oder die von Götz Aly in die Diskussion eingebrachte Bezeichnung des nationalsozialistischen Deutschen Reichs als »Hitlers Volksstaat ${ }^{145}$. In seiner gleichnamigen, durchaus heftig umstrittenen Publikation versucht Aly der seiner Meinung nach »immer noch unbeantwortete[n] " ${ }^{146}$ Frage nach dem Warum auf die Spur zu kommen, indem er die NS-Herrschaft aus einem Blickwinkel betrachtet, der diese als "Gefälligkeitsdiktatur « ${ }^{147}$ beschreibt. Der Nationalsozialismus habe das Gewissen, das Wissenwollen und das Erinnern der übervorteilten »Volksgenossen« nachhaltig narkotisiert - und dies auf Basis materieller Zuwendungen (Lebensmittelkarten, Rentenerhöhungen, Ehestandsdarlehen, Kinderbeihilfen, Steuerfreiheit für Zuschläge auf Nacht- und Wochenendarbeit usw.), die mithilfe einer progressiven Arisierungs- und Vernichtungspolitik sowie der Ausraubung der okkupierten Territorien finanziert wurden. ${ }^{148}$ Wiederum wird hier nach jenen Handlungsspielräumen gefragt, innerhalb derer die »nicht diskriminierte, nicht oppositionelle Mehrheitsbevölkerung « ${ }^{149}$ vor dem Hintergrund der jeweiligen »Lebenswelten « ${ }^{150}$ auf Angebote und Zumutungen der Nationalsozialisten eingingen oder eben nicht. ${ }^{151}$

Im Rahmen der Faschismusdiskussion wurde bereits festgehalten, dass der Faschismus kein einheitliches Konzept war und hatte, was dem nationalsozialistischen System große Flexibilität einräumte, Angebote an die Mehrheitsbevölkerung je nach

I42 Ebd., S. I 5 (beide Zitate).

I 43 Bajohr, Die Zustimmungsdiktatur.

I 44 Schildt, Jenseits der Politik, S. 249.

I 45 Aly, Hitlers Volksstaat.

I 46 Ebd., S. 35 .

I 47 Ebd., S. 49-90.

I 48 Ebd., S. 368. Vgl. dazu auch Bajohr, Meister der Zerstörung, S. 687.

I 49 Bauer, Mobilisierung, S. 290.

I $50 \mathrm{Zu}$ dem historischen Begriff der »Lebenswelt(en)« vgl. Kapitel I.4.2 dieser Studie.

I 5 I Ähnlich auch bei: Langthaler, Die tägliche Mobilisierung, S. I 82. 
machtpolitischer Opportunität zu gestalten. Dies mag das starke Ausmaß an aktivem Konsens und passiver Teilnahme der »Vielen ${ }^{152}$ zu einem gewissen Teil erklären. ${ }^{153}$

Demgegenüber stand der Widerstand der »Wenigen « ${ }^{154}$, der politisch motiviert sein konnte (so zählten Kommunisten und Sozialdemokraten zu Widerständigen der ersten Stunde) oder auch religiös (neben Juden waren auch Angehörige verschiedener christlicher Religionsgemeinschaften von Verfolgungsmaßnahmen betroffen) oder der sich aus mitmenschlichen und weltanschaulichen Gründen heraus bei Menschen mit verschiedensten sozialen Hintergründen manifestierte (sogar in bürgerlichen Kreisen regte sich mitunter Widerstand, man denke nur an die Geschwister Scholl). ${ }^{155}$

Sowohl die ideologischen »Hardliner« als auch die Widerständigen machten prozentuell gesehen jedoch nur einen kleinen Anteil der Bevölkerung aus. Tatsächlich wird die Position der »schweigenden Mehrheit « ${ }^{156}$ irgendwo zwischen den beiden Polen der vollständigen Ablehnung oder Zustimmung zu verorten sein. ${ }^{157}$

Wichtig ist in diesem Zusammenhang die Feststellung, dass das individuelle Verhalten im täglichen Leben durchaus von Ambivalenzen geprägt war (so wie es das heute noch ist). So waren etwa »Nicht-PGs « unter Umständen loyal und umgekehrt. ${ }^{158}$ Zudem war es möglich, im alltäglichen Leben abweichendes Verhalten an den Tag zu legen, ohne dabei den grundsätzlichen Konsens in Frage zu stellen. Dieses Verhalten äußerte sich etwa »in der Teilnahme an kirchlichen Prozessionen, im >Nörgeln $<$ hinter vorgehaltener Hand, im Verwenden von >Grüß Gott ‘ anstatt `Heil Hitler « ${ }^{159}$.

Die Differenzierungsbestrebungen der neueren historischen Forschung erreichten auch deren Analysen zum Widerstand, die ihren Blick nunmehr verstärkt auf individuelle Nonkonformitäten und Dissens im Alltag, auf partielle Distanzierungen von Vereinnahmungen und Zumutungen durch das Regime richten. ${ }^{160}$

Zusammenfassend lässt sich festhalten, dass sich der Nationalsozialismus nicht allein als Diktatur mit einer ausschließlichen Wirkung »von oben nach unten « ${ }^{161}$ interpretieren lässt. Nicht nur die "aktiven Nazis« oder die Widerstandskämpfer, sondern auch die »Vielen« sind als historische Akteure zu begreifen.

I 52 Ebd., S. I97. Auch bei: Bauer, Mobilisierung, S. 288.

I53 Vgl. Langthaler, Die tägliche Mobilisierung, S. I 83.

I 54 Garbe, Institutionen des Terrors, S. 5 I 9.

I 55 Vgl. ebd., S. 555 fff.

I 56 Wippermann, Autobahn zum Mutterkreuz (Begriff wird bereits im Untertitel des Buchs eingeführt: "Historikerstreit der schweigenden Mehrheit«).

I 57 Vgl. Schildt, Jenseits der Politik, S. 254.

I 58 » $\mathrm{PG}$ « = Abk. für »Parteigenosse«. Vgl. ebd., S. 25 I f.

I59 Langthaler, Die tägliche Mobilisierung, S. I97.

I60 Vgl. Bauer, Mobilisierung, S. 289.

I6 I Vgl. ebd., S. 3 I 8. Ähnlich bei Bajohr, Zustimmungsdiktatur, S. I 2 I. 
Die »Vielen«, die einmal wegschauen und einmal mitmachen, die »Vielen«, die von sich behaupten, unpolitisch zu sein, und dabei verkennen, welche Reichweite ihr alltägliches Handeln hat und welche Konsequenzen dieses in Summe nach sich zu ziehen vermag - sie sind die Protagonisten der Jelinek'schen Prosa- und Dramentexte. Insofern leistet die Autorin seit Jahren einen wichtigen Beitrag zum differenzierten Verständnis historischer Ereignisse und deren Verankerung im individuellen wie auch kollektiven Gedächtnis. Nur eines gesteht die Autorin mit dem »bösen Blick « ${ }^{162}$ ihren Figuren - im Gegensatz zu neueren wissenschaftlichen Publikationen (etwa Michael Manns »Fascists«) - nicht zu: Entwicklungs- und Veränderungspotential. Die Jelinek'schen Hauptfiguren rennen stets ins vorhersehbare Verderben oder verharren, allen Emanzipationsbestrebungen zum Trotz, in ihren von Abhängigkeiten geprägten Schicksalen. Warum das so ist und was die Autorin mit ihrem nicht-psychologisierenden, unempathischen Figurenverständnis erreichen will, wird im Rahmen der poetologischen Einführung eingehend erläutert und in der Empirie an praktischen Beispielen demonstriert werden.

Dass die Systematik der »schweigenden Mehrheit« unter gewissen Voraussetzungen über Jahre hinweg und größtmöglichen menschlichen Einbußen zum Trotz funktioniert, hat das nationalsozialistische Regime auf denkbar tragischste Weise gezeigt. Nur auf Basis der stillen Akzeptanz der »Vielen« konnte der deutsch-österreichische Faschismus funktionieren, bis er unter der Übermacht seiner äußeren Feinde im Mai I 945 schließlich zusammenbrach. ${ }^{163}$

\subsection{3 »Mythos« nach Roland Barthes}

»In der Tat verblüfft es immer wieder, wie präzise Jelinek sich in beinahe jedem ihrer Werke sowohl auf die Thesen als auch auf einzelne Formulierungen von Roland Barthes bezieht und welche Dimensionen für das poetische Verfahren sie dem Text von Barthes abzugewinnen vermocht hat. ${ }^{164}$

In Hinblick auf den sensiblen Mythosbegriff muss zunächst festgestellt werden, dass keine einheitliche Definition möglich ist, denn »endgültig faßbar, eindeutig interpretierbar, exakt definierbar ist der Mythos nicht « ${ }^{165}$. Nur Annäherun-

I62 Burger, Der böse Blick der Elfriede Jelinek, S. I 7.

I63 Vgl. Bajohr, Meister der Zerstörung, S. 687.

I64 Janz, Elfriede Jelinek, S. 9 f.

I65 Szczepaniak, Dekonstruktion des Mythos, S. I3. 
gen an plausible Begriffsbestimmungen sind in diesem Fall leistbar. Das Wort "Mythos « ist eine Entlehnung aus dem Griechischen und allgemein mit »Wort, Rede, Erzählung, Fabel, Sage ${ }^{166}$ zu übersetzen, was allerdings noch nicht sehr aussagekräftig ist. Im Rahmen der vorliegenden Studie orientiert sich die Begriffsdefinition an den Mythostheorien des französischen Philosophen und Semiotikers Roland Barthes (»Mythen des Alltags ${ }^{167}$ ), da diese als zentrale Leseerfahrung $^{168}$ Jelineks gehandelt werden und deren Schreiben merklich beeinflussten, mehr noch: Es ist vermutlich nicht möglich, Jelinek-Texte sinnvoll zu rezipieren, ohne Roland Barthes gelesen zu haben. Jelineks Auseinandersetzung mit Barthes' Trivialmythen-Konzept Ende der I96oer Jahre war schließlich »die Initialzündung für die Entwicklung ihrer eigenen ästhetischen Position « ${ }^{169}$. So hatte Jelinek in ihrem Essay »Die endlose Unschuldigkeit« von I970 Barthes' Theorien explizit übernommen und einzelne Textpassagen sogar wörtlich zitiert.

Nach Barthes werden mythische Aussagen stets von Menschenhand geschaffen und bewusst mit bestimmten Bedeutungen und Intentionen versehen. Aus der »Natur« der Dinge vermöge der Mythos nicht hervorzugehen, auch wenn ihm dies immer unterstellt werde. Zudem sei er kein statisches, sondern ein dynamisches, veränderbares Phänomen und werde von der Gesellschaft immer wieder in neue Zusammenhänge gebettet und neu interpretiert. ${ }^{170}$

Träger der mythischen Aussage können die unterschiedlichsten Medien sein: der geschriebene Diskurs, der Sport, die Fotografie, der Film, die Reportage, das Schauspiel, die Reklame. Die Objekte selbst »können Aussagen werden, wenn sie etwas bedeuten ${ }^{171}$, denn der Mythos werde als ${ }^{1}$ reiches, spontanes, gelebtes, unschuldiges, unbestreitbares Bild « ${ }^{172}$ wahrgenommen. Dieses werde ausgeborgt, um zum Helfershelfer eines Begriffes gemacht zu werden. Dabei wird weder etwas verborgen noch gelogen; der Mythos verwandle Geschichte in scheinbare Natur. Deshalb sei eine Verschleierung der Intention eines Begriffs nicht notwendig - der Mythos lasse ihn in den Augen des Rezipienten ohnehin »natürlich« erscheinen. ${ }^{173}$

I66 Duden, Herkunftswörterbuch, S. 547 .

I67 Das Buch war als Artikelfolge in den Jahren davor entstanden. I 957 wurde diese erstmals als Monografie unter dem Titel »Mythologies« auf Frz. veröffentlicht, I 964 als »Mythen des Alltags« in dt. Übersetzung.

I68 Vgl. Mayer/Koberg, Elfriede Jelinek, S. I 48.

I69 Janz, Elfriede Jelinek, S. VII

I 70 Vgl. ebd., S. 85 ff.

I7 I Ebd., S. 87 .

I 72 Ebd., S. 98.

I73 Vgl. ebd., S. i 2 f. 
In diesem Sinne sei der Mythos als ent-historisierte und ent-politisierte Aussage zu definieren, wobei der Vorsilbe »ent-« ein aktiver Wert zugesprochen werden müsse. ${ }^{174}$

Finaler Zweck des von Barthes definierten Mythos ist es nach Jelinek »eine unbewegliche Welt ${ }^{175} \mathrm{zu}$ erzeugen und diese »in ihrer unbeweglichkeit (sic) zu halten ${ }^{176}$. Bei Barthes wie auch bei Jelinek wird der Mythos als Instrument der Manipulation und Kontrolle begriffen, das zu unlauteren poltischen Zwecken missbraucht wird:

»Diese wunderbare Verflüchtigung der Geschichte ist eine andere Form eines Begriffs, der den meisten bürgerlichen Mythen gemeinsam ist: der Unverantwortlichkeit des [einzelnen] Menschen. ${ }^{177}$

Die von Barthes angeregte Entschleierung von Mythen sollte zu Jelineks zentralem Schreibziel avancieren, für das die Autorin ein spezifisches Verfahren entwickelte und über Jahre hinweg modifzierte, welches die germanistische Forschung mit dem Begriff der »Mythendestruktion« (auch: »-dekonstruktion«) zu umschreiben weiß. Dieses Verfahren wird im Rahmen der poetologischen Einführung eingehend erläutert werden.

\subsubsection{Der Begriff »0pfermythos«}

"Die österreichische Staatsdoktrin, eine Lüge, lautet: Wir sind das erste von den Nazis besetzte Land gewesen, und daher können wir es nicht gewesen sein, die auf dem Heldenplatz gejubelt haben, und diejenigen, die zu Opfern gemacht wurden, sie zählen nicht. Es war alles ein Missverständnis. ${ }^{178}$

Der aus der Zeithistorie entlehnte Begriff »Opfermythos « ${ }^{179}$ bezeichnet ein wirkungsmächtiges Geschichtsbild der Zweiten Republik, das Österreich als

I74 Vgl. ebd., S. I3 I ff. Wie Barthes definiert auch Jelinek den Mythos als Aussage, die Geschichtliches mit »Natur« zu begründen versucht und damit politische Veränderungen und soziale Emanzipation niederhält.

I75 Ebd., S. I 44 .

I 76 Jelinek, Die endlose Unschuldigkeit, S. 82.

I77 Barthes, Mythen des Alltags, S. I4I.

I78 Jelinek, Die Österreicher als Herren der Toten, S. 6r.

I79 Synonym werden in der Literatur auch die Ausdrücke »Opferthese« oder »Opfertheorie« verwendet, so auch in dieser Studie. 
das erste Opfer nationalsozialistischer Aggressionspolitik beschreibt: Demnach wäre Österreich im März I 938 von deutschen Truppen gewaltsam besetzt und während des Zweiten Weltkriegs zur Pflichterfüllung in der Deutschen Wehrmacht gezwungen worden. Seit dem "Anschluss « ${ }^{180}$ hätte es keinen Staat und keine österreichische Regierung mehr gegeben, daher bestünde auch keine Mitschuld für die Verbrechen des Nationalsozialismus. Die Jahre zwischen 1938 und I 945 werden im Rahmen dieser Sichtweise aus der spezifisch österreichischen Historie ausgeklammert, indem die Verantwortung für das Terrorregime und den Offensivkrieg an Deutschland verwiesen wird. Voraussetzungen, Inhalt und Konsequenzen des Nationalsozialismus hätten demnach für Österreich nur »sekundäre Relevanz « ${ }^{181}$, denn sie gehören - so die These - in die Geschichte Deutschlands. Die österreichische Position wird, wenn, dann nur unter dem Aspekt von Widerstand und Freiheitskampf gegen die vermeintliche Fremdherrschaft behandelt. ${ }^{182}$

Als ein identitätsstiftendes Moment der Zweiten Republik hatte der Opfermythos über Jahrzehnte hinweg die Möglichkeit geschaffen, die Konfrontation mit Schuld und Verantwortung aus der kollektiven österreichischen Erinnerung zu verdrängen. Darüber herrscht in der Zeitgeschichtsforschung weitgehender Konsens. Im Rahmen der vorliegenden Studie wird daher der Opfermythos per se nicht in Frage gestellt. Er stellt eine weithin akzeptierte zeitgeschichtliche These dar, die als Ausgangspunkt für die Auseinandersetzung mit Jelineks Schreiben begriffen wird, weil klar ist, dass die Autorin von deren Plausibilität überzeugt ist:

»Wir wollten doch nur ein bißchen in deutschen Betten liegen, wer hätte uns das nicht gönnen wollen? Aber wir sind es nicht gewesen, und daher hat man uns - im Jahre I 955 selbstverständlich oder wann dachten Sie denn? - auch ordnungsgemäß befreit! Wir sind überhaupt die Unschuldigsten und sind es daher auch immer gewesen. ${ }^{183}$

I80 Der Begriff »Anschluss« bezeichnet »den Einmarsch der deutschen Truppen in Österreich am I2. März I938 und das >Bundesverfassungsgesetz über die Wiedervereinigung Österreichs mit dem Deutschen Reich sowie ein entsprechendes deutsches Reichsgesetz vom I 3. März I 938, ferner die >Machtergreifungく der österreichischen Nationalsozialisten am i r./I 2. März I 938 ; weiters die Vorbereitung und Durchführung der Volksabstimmung vom ıo. April I 938 (...) sowie die verwaltungsmäßige `Eingliederung Österreichs in das Deutsche Reich«. Siehe Haas, Der Anschluss, S. 26.

I 8 I Lepsius, Das Erbe des Nationalsozialismus, S. 250.

I 82 Vgl. Uhl, Das »erste Opfer«, S. 19. Vgl. auch Lepsius, Das Erbe des Nationalsozialismus, S. $250 \mathrm{f}$.

I 83 Jelinek, In den Waldheimen und auf den Haidern, S. 43. 
Die Zerschlagung des Regimes, die Niederlage im Krieg und die Konfrontation mit den Gräueln in den Konzentrationslagern hatten nach 1945 zur Freisetzung ambivalenter Gefühle in weiten Teilen der Bevölkerung geführt. Zur Abwehr von Scham- und Schuldgefühlen traten an die Stelle von Trauerarbeit Mechanismen wie Gegenidentifikation, Verleugnung und Aufrechnung. ${ }^{184}$ Die Gesellschaft bildete »einen mehr oder weniger verbindlichen Modus « ${ }^{185}$ darüber heraus, mit welcher Erinnerung sie glaubte, leben zu können: „Man kann durchaus etwas wissen, ohne es denkend verarbeiten zu müssen. « ${ }^{186}$

Warum das Ausland Österreichs Selbstdefinition als Opfer zuließ, kann zum Teil damit erklärt werden, dass die Siegermächte des Weltkriegs danach strebten, das Wiedererstarken einer deutschen Großmacht zu verhindern, und daher Österreichs Tendenzen zur Eigenstaatlichkeit, auch in der Frage der nationalen Selbstdefinition, unterstützten. ${ }^{187}$ Zudem dürfte sich die Zuspitzung des Kalten Kriegs in dem ersten Jahrzehnt nach 1945 für Österreich integrativ ausgewirkt haben - zum einen, weil es im Interesse der Westmächte war, Österreich in ihren Block aufzunehmen, zum anderen, weil sich auch ehemalige Nationalsozialisten mit deren plakativem Antikommunismus identifizieren konnten. ${ }^{188}$

Schon in der "Moskauer Deklaration« von r 943 hatten die Außenminister Großbritanniens, der USA und der Sowjetunion Österreich als das »erste freie Land« bezeichnet, das der »Hitlerschen Aggression zum Opfer gefallen« sei und »befreit werden « ${ }^{189}$ müsse. In der so genannten »Mitschuldklausel « wurde Österreich allerdings unmissverständlich auf seine Beteiligung am Krieg hingewiesen. Zudem war die Erklärung von den Alliierten ursprünglich mit dem Ziel verfasst worden, den innerösterreichischen Widerstand zu beflügeln - nicht als Konzept für ein österreichisches Nachkriegsszenario. ${ }^{190}$ Dennoch wurde sie zum fixen Bezugspunkt für Österreichs Opferthese. Mit der Zweckentfremdung der in der Moskauer Deklaration festgehaltenen Fremdcharakterisierung konnte ein Geschichtsbild geschaffen werden, das in der Unabhängigkeitserklärung vom 27. April I 945 seinen Ausdruck fand: Darin wurde die »völlige politische, wirtschaftliche und kulturelle Annexion des Landes « ${ }^{191}$ durch die

I 84 Vgl. Ziegler/Kannonier-Finster, Österreichisches Gedächtnis, S. 76 f.

I 85 Ebd., S. 77 .

I 86 So der Psychoanalytiker Mario Erdheim (Universität Zürich), zitiert nach: ebd., S. 77.

I 87 Vgl. Bergmann/Erb/Lichtblau, Schwieriges Erbe, S. 2 I.

I 88 Vgl. Uhl, Das »erste Opfer«, S. 23.

I 89 Formulierungen der "Moskauer Deklaration«, zitiert nach: Blänsdorf, Die Einordnung der NS-Zeit, S. 20.

I 90 Vgl. Uhl, Das »erste Opfer«, S. 2 I.

I 9 I Vgl. die Proklamation über die Selbständigkeit Österreichs vom 27. April I 945 ; StGB1 I/ I 945 . On- 
Reichsregierung Adolf Hitlers dafür verantwortlich gemacht, dass das »machtund willenlos gemachte Volk Österreichs in einen sinn- und aussichtslosen Eroberungskrieg geführt « worden sei, den »kein Österreicher jemals gewollt « ${ }^{192}$ habe. In einer Rede am I 9. August 1945 erklärte der spätere Bundeskanzler Leopold Figl:

»Sieben Jahre schmachtete das österreichische Volk unter dem Hitlerbarbarismus. Sieben Jahre wurde das österreichische Volk unterjocht und unterdrückt, kein freies Wort der Meinung, der Bekenntnis zu einer Idee war möglich, brutaler Terror und Gewalt zwangen die Menschen zu blindem Untertanentum. ${ }^{193}$

Figls Rede kann als repräsentatives Beispiel für die Selbstdarstellung Österreichs im Rahmen der Opfertheorie festgehalten werden. ${ }^{194}$ Der Holocaust fand in der Unabhängigkeitserklärung keine Erwähnung. Die jüdischen Opfer des Nationalsozialismus wurden nach I 945 aus der kollektiv-österreichischen Erinnerung verdrängt, ebenso wie andere Minderheiten (Roma und Sinti, Angehörige der slowenischen oder anderer nationaler Minderheiten, Zwangsarbeiter, Homosexuelle, Behinderte, Deserteure u.a.), die von der nationalsozialistischen Verfolgungs- und Vernichtungspolitik betroffen gewesen waren, aber jahrzehntelang um Anerkennung kämpfen mussten. ${ }^{195}$

Österreichs Bemühen, selbst als Opfer anerkannt zu werden, fand seinen offiziellen Abschluss in den Verhandlungen zum Staatsvertrag I 955, denn die österreichische Delegation konnte immerhin erreichen, dass auf einen in der Präambel vorgesehenen Passus über Österreichs Mitschuld am Krieg verzichtet wurde und nur die Bewertung als Opfer blieb. ${ }^{196}$

Aufgrund dieser und anderer Besonderheiten im Kriegs- und unmittelbaren Nachkriegsgeschehen war es für Österreich - im Gegensatz etwa zur BRD möglich, bis zur Waldheim-Debatte in den r $980 e r$ Jahren ein »weitgehend unhinterfragtes, positives Image ${ }^{197}$ im Ausland aufrechtzuerhalten, denn die Weltöffentlichkeit hatte sich darauf festgelegt, Österreich zu den Opferstaaten einer nationalsozialistischen »deutschen« Expansionspolitik zu zählen.

line als pdf abrufbar unter: http://www.ris.bka.gv.at/Dokumente/BgblPdf/I945_I_o/I945_I_o. pdf (Zugriff am o6.09.2016).

192 Ebd.

I 93 Leopold Figl, zitiert nach: Uhl, Das »erste Opfer«, S. 2 .

I 94 Vgl. ebd., S. 20 f.

I95 Vgl. Botz, Nachhall und Modifikationen, S. 6o2.

I96 Vgl. Bergmann/Erb/Lichtblau, Schwieriges Erbe, S. 2 I.

I 97 Vgl. Uhl, Das »erste Opfer«, S. 22. 
Mit der Rückbesinnung auf die österreichische Eigenstaatlichkeit sollte nach I 945 die Ursache für die Etablierung des Nationalsozialismus ex post korrigiert werden. ${ }^{198}$ Die politische Symbolik der Nachkriegszeit sowie die Art der Darstellung der NS-Zeit unmittelbar nach Kriegsende waren von diesem Bestreben durchdrungen. So wurde es zum Beispiel im Staatswappen der Zweiten Republik zum Ausdruck gebracht, das den Adler aus der Ersten Republik übernommen hatte, ihn aber nun mit gesprengten Ketten zeigte, was die Befreiung vom "nationalsozialistischen Joch« symbolisieren sollte. ${ }^{199}$

Nicht nur Österreich, sondern alle drei Nachfolgestaaten des »Dritten Reichs«, auch die beiden deutschen Staaten, versuchten, ihre politische Neuordnung über die jeweilige Interpretation der Ursachen für den Nationalsozialismus zu legitimieren. ${ }^{200}$ Die Schwierigkeit bestand jeweils darin, dass der politische Neubeginn einerseits unter dem Lichte der Distanzierung vom Nationalsozialismus und in Anerkennung seiner Verbrechen erfolgen musste, andererseits aber Deutungsmuster favorisiert wurden, welche die rasche Reintegration der früheren Parteimitglieder in Politik und Alltag als gerechtfertigt erscheinen ließen. ${ }^{201}$

Da die »Schuldfrage« in Bezug auf die Bundesrepublik Deutschland von Seiten der Alliierten und der Weltöffentlichkeit als eindeutig erkannt worden war, sah sich die BRD dazu gezwungen, die Überwindung des Nationalsozialismus durch institutionelle und demokratiepolitische Reformen nach außen hin zu demonstrieren. ${ }^{202}$ Auf diese Weise konnte im Rahmen der bundesdeutschen Erinnerung zumindest erreicht werden, dass der Nationalsozialismus als negativer Gründungsmythos normativ »internalisiert ${ }^{203}$ wurde. »In Deutschland herrscht ein ganz anderes politisches Bewusstsein«, so Jelinek, »denn Deutschland war ja viel länger ein von den Alliierten besetztes Land und musste seine Lektion in Antifaschismus und Demokratie lernen, sehr zu seinem Vorteil.« ${ }^{204}$

I98 Vgl. Bergmann/Erb/Lichtblau, Schwieriges Erbe, S. I 5 .

I99 Vgl. Spann, Zur Geschichte von Flagge und Wappen der Republik Österreich, S. 59.

200 Vgl. Bergmann/Erb/Lichtblau, Schwieriges Erbe, S. I I-I 5 .

201 Vgl. Blänsdorf, Die Einordnung der NS-Zeit, S. I 9.

202 Vgl. Bergmann/Erb/Lichtblau, Schwieriges Erbe, S. I 5; vgl. auch Weidinger, Konsens. In: Der Standard, S. 28.

203 Die DDR wählte die fehlgeschlagene Revolution von I9r8/r9 als positives Bezugsereignis, das den Nationalsozialismus hätte verhindern können und nun unter der Führung der Arbeiterklasse in Gestalt der Sozialistischen Einheitspartei (SED) nachgeholt werden sollte. Durch die Verknüpfung von Faschismus und Kapitalismus verlor der Nationalsozialismus jede Beziehung zur nunmehr sozialistisch geführten DDR und wurde zur kritischen Verurteilung der kapitalistisch gebliebenen Bundesrepublik benutzt (»Universalisierung«). Vgl. Lepsius, Das Erbe des Nationalsozialismus, S. 25 I. Jelinek, zitiert nach: Janke/Kovacs/Schenkermayr, »Die endlose Unschuldigkeit«, S. 2 I. 
In Österreich hingegen wurde der Nationalsozialismus als eine »Intervention in die österreichische Geschichte durch das nationalsozialistische Deutsche Reich ${ }^{205}$ interpretiert, was eine Externalisierung ${ }^{206}$ zur Folge hatte: Verantwortung und Schuld wurden an Deutschland verwiesen. ${ }^{207}$

Hierzulande wurde über Jahrzehnte hinweg, etwa in Schul- und Geschichtsbüchern, aber auch in anderen offiziösen Publikationen, das Argumentationsmuster der Opfertheorie vertreten (und ist dort bisweilen heute noch vorzufinden). Schon in der »Geschichte Österreichs« von Ernst Joseph Görlich und Felix Romanik, einem historischen Standardwerk, war zu lesen, dass der Zweite Weltkrieg "nicht zur eigentlich österreichischen Überlieferung« gehöre, weil Österreich »als Staat ${ }^{208}$ nicht an ihm teilgenommen habe. Auch das von der Regierung I 946 herausgegebene »Rot-Weiß-Rot-Buch« dokumentiert diese Auffassung eindrücklich: »Die Einstellung der österreichischen Bevölkerung zum 〉Hitlerkriege` war von allem Anfang ablehnend «, heißt es darin, »sofern sie nicht von seinem Ausgang die einzige Möglichkeit einer Befreiung vom Nazijoche erhoffte. ${ }^{209}$ Das vermeintlich »wehrlose ${ }^{210}$ Österreich habe sogar als erster und einziger freier Staat der Aggressionspolitik Hitlers fünf Jahre lang "praktischen Widerstand geleistet “211. In eine ähnliche Kerbe schlägt das I948 im Auftrag des österreichischen Pressedienstes herausgegebene "Österreich-Buch ${ }^{212}$. Das nach I 945 konstituierte Selbstverständnis der Österreicher unterliege einer darin klar nachverfolgbaren »Effeminierung « ${ }^{213}$, meint der Geschichtswissenschafter Siegfried Mattl: der Zuschreibung vermeintlich weiblicher Eigenschaften wie Sinnlichkeit, Weichheit, Anpassungsfähigkeit, Hingabe. Es gebe schließlich kein geeigneteres Objekt zur Dokumentation dieser Auffassung:

»Das `Österreich-Buch` war ein Geschichtsbuch, aber es erzählte eine Geschichte ganz eigener Art, nämlich einen Mythos. Und es erzählte diesen Mythos durch die Verteilung des geschichtlichen Stoffes nach kulturellen Mustern, die die Weltpolitik nach männlichen und weiblichen Völkern und Attributen strukturierte.« ${ }^{214}$

205 Vgl. Lepsius, Das Erbe des Nationalsozialismus, S. 25 O.

206 Ebd.

207 Ebd., S. 250 f. Vgl. auch: Bergmann/Erb/Lichtblau, Schwieriges Erbe, S. I 5.

208 Görlich/Romanik, Geschichte Österreichs, S. 55 I.

209 Rot-Weiß-Rot-Buch, Erster Teil, S. 94.

2 Iо Ebd., S. 5.

2 I I Ebd., S. 7.

2 I 2 Marboe (damals Leiter des Bundespressedienstes), Österreich-Buch.

2 I 3 Mattl, Geschlecht und Volkscharakter, S. 500.

2 I 4 Ebd., S. 504 . 
Dieser unmittelbar nach Kriegsende gefestigte Mythos, der nicht nur der innerösterreichischen Selbstvergewisserung, sondern auch der neuen, außenpolitischen Positionierung Österreichs diente, blieb über Jahrzehnte hinweg mehr oder minder unangetastet als Teil eines nationalen Konsens bestehen.

Der tatsächlich existierende Widerspruch zwischen dieser Auffassung und der historischen Realität brauche "nicht näher erläutert ${ }^{215} \mathrm{zu}$ werden, befindet Zeithistorikerin Heidemarie Uhl, weist aber trotzdem auf die breite Zustimmung der Österreicher zum so genannten "Anschluss«, die starke Identifikation mit der Deutschen Wehrmacht und die Virulenz eines aggressiven Antisemitismus hin. ${ }^{216}$

Parallel und zum Teil im Widerspruch zum Opfermythos konnte sich seit I 949/50 im innerösterreichischen Gedächtnis ein Narrationsstrang festsetzen, der den Kriegsdienst von Österreichern in der Deutschen Wehrmacht neu zu bewerten suchte. Weil die »Minderbelasteten« zu den Wahlen I 949 wieder zugelassen waren, setzten sich Politiker aller Parteien in dieser Phase öffentlich für die volle Ehrenrettung ehemaliger Wehrmachtssoldaten ein. Während Denkmäler für die Opfer des Nationalsozialismus nur wenige Jahre nach dem Krieg als »Instrumente kommunistischer Propaganda ${ }^{217}$ verpönt waren, setzte eine breite Bewegung für die Errichtung von Gefallenendenkmälern ein. ${ }^{218}$ In einem Zeitungskommentar aus dem Jahr I 949 hieß es, dass die Gefallenen des Zweiten Weltkriegs von nun an einen Ehrenplatz im »Gedächtnis unseres Volkes« einnehmen müssten und ihrer als »Helden der Pflichterfüllung und Tapferkeit« gedacht werden sollte. ${ }^{219}$ Erst die deutsche Wehrmachtsausstellung, die Ende der I990er Jahre erstmals auch in Österreich gezeigt wurde, brach mit dem Bild von der "sauberen Wehrmacht" und löste eine heftige und emotional geführte Debatte um die Rolle von Österreichern in der Wehrmacht aus. ${ }^{20}$ Gerade in dem Nebeneinander widersprüchlicher Narrationen bestehe aber das eigentliche Charakteristikum österreichischer Geschichtspolitik, befindet Uhl. ${ }^{221}$

In den ig6oer Jahren, angeregt durch den Generationenwechsel und die damit verbundene gesellschaftliche Aufbruchssituation, wurden die Grenzen zwischen den politischen Lagern durchlässiger. Die Schlagworte »Modernisierung«

2 I 5 Uhl, Das »erste Opfer«, S. 2 I.

2 I 6 Vgl. ebd.

2 I 7 Gustav Canaval in einem Zeitungskommentar I954, zitiert nach: Ebd., S. 24.

2 I 8 Vgl. ebd., S. 23 f.

2 I 9 Zeitungskommentar aus der »Murtaler Zeitung«, zitiert nach: Ebd., S. 24.

220 Vgl. Hamburger Institut für Sozialforschung: Dimensionen des Vernichtungskrieges I94II944; vgl. auch Manoschek, Die Wehrmacht im Rassenkrieg; Hartmann, Verbrechen der Wehrmacht; Embacher, Umkämpfte Erinnerung.

22 I Vgl. Uhl, Das »erste Opfer«, S. 20 sowie S. 23-26. 
und »Demokratisierung « prägten eine politische Reformphase, in deren Kontext auch eine "partielle Transformation des Geschichtsbewusstseins « ${ }^{222}$ stattfand. Die Politisierung der studentischen Jugend (die sich etwa in der Borodajkewycz-Affäre $^{223}$ äußerte) und das Entstehen eines neuen Typs von kritischem Journalismus trugen dazu bei, die Rahmenbedingungen des österreichischen Geschichtsbewusstseins langfristig zu verändern. In den innerösterreichischen Gedächtnisdiskursen begannen sich Wandlungsprozesse abzuzeichnen. ${ }^{224}$

Seit der Debatte um die Kriegsvergangenheit Kurt Waldheims 1986/8 $7^{225}$ wird schließlich der geschichtswissenschaftliche Diskurs von Neubewertungen der Jahre I 938 und I 945 bestimmt, welche die Opfertheorie als nationalen Mythos definieren und den Umgang der Zweiten Republik mit dem »Zivilisationsbruch Auschwitz «226 als mangelhaft beschreiben. Als Gradmesser dafür werden das Ausmaß der Umsetzung von Entnazifizierung und Elitenaustausch, die materielle und finanzielle Entschädigung der Opfer, aber auch die Gestaltung der Erinnerungskultur herangezogen. ${ }^{227}$

Der Paradigmenwechsel im geschichtswissenschaftlichen Diskurs widerspiegelt aber auch eine Trendwende in der öffentlichen Debatte. In den Jahren I 986 bis I 988 seien »konträre politische, generationsspezifische und geschichtspolitische Sichtweisen und Milieus ${ }^{228}$ so offen und heftig aufeinandergeprallt wie niemals zuvor oder danach in der Zweiten Republik, schreibt Gerhard Botz. Auch Michael Gehler meint, dass die Waldheim-Affäre vermutlich »die schwerste Krise für das staatliche Selbstverständnis Österreichs seit I $955^{229}$ dargestellt habe.

Diese Krise sollte nicht ohne Folgen bleiben, sondern führte schließlich zu einer (teilweisen) Neuinterpretation der »Selbst- und Fremdbilder Österreichs im Spiegel seiner NS-Vergangenheit « ${ }^{230}$. Zum einen hatte die Waldheim-Affäre die Legitimität des Opfermythos erstmals entscheidend in Frage gestellt, zum

222 Ebd., S. 25.

223 Deutschnationale und antisemitische Äußerungen des Universitäts-Professors Taras Borodajkewycz hatten Demonstrationen von Anhängern und Gegnern ausgelöst, bei denen im April I 965 ein Demonstrant getötet wurde. Vgl. ebd., S. 25 f.

224 Vgl. ebd.

225 Zur Waldheim-Debatte vgl. Heindl, Wir Österreicher sind ein anständiges Volk. Vgl. auch Göllner, Die politischen Diskurse zu »Entnazifizierung«, »Causa Waldheim«, und »EU-Sanktionen«, S. 247-400.

226 Uhl, Das »erste Opfer«, S. I 9 sowie S. 30. Mit dieser Ausdrucksweise lehnt sich Uhl ihrerseits an Dan Diner an: Diner, Zivilisationsbruch. Vgl. auch Diner, Den Zivilisationsbruch erinnern.

227 Vgl. Bergmann/Erb/Lichtblau, Schwieriges Erbe, S. I 2.

228 Botz, Nachhall und Modifikationen, S. 583.

229 Gehler, Politische Affären, S. 664.

230 Botz, Nachhall und Modifikationen, S. 584. 
anderen führte das öffentliche Interesse, das durch die Debatte geweckt worden war, zu einer verstärkten Vermittlung von neuen, differenzierteren Forschungsergebnissen.

Durch das Gedenkjahr I 988 wurde dieser Trend noch weiter verstärkt. Die öffentliche und mediale Aufmerksamkeit, die diesem Thema nunmehr zuteil wurde, führte $\mathrm{zu}$ einer langsamen Erosion $^{231}$ der Opferthese, welche eine breite Akzeptanz in der Bevölkerung fand und eine neue Sensibilität im Umgang mit der Sprache über die NS-Vergangenheit mit sich brachte.

Schriftsteller, Architekten und andere Künstler spielten eine tragende Rolle bei der Vermittlung und Verbreitung einer veränderten Geschichtskultur. ${ }^{232}$ »Auch wenn es auf diesem Feld noch erratische Blöcke von altem künstlerischen Antifaschismus gab«, so Botz, "gibt es auch den >Heldenplatz Thomas Bernhards, das Euvre Elfriede Jelineks, Gerhard Roths oder Josef Haslingers und viele andere Werke, welche die NS-Involvierung der Österreicher, oft schon vor der Waldheim-Affäre, zu einem zentralen Thema ihrer Kunst gemacht haben. ${ }^{233}$

Das Umschreiben der österreichischen NS-Geschichte mündete nicht nur in einem symbolschwangeren Bekenntnis des offiziellen Österreich zu Mitverantwortung und Schuld, sondern auch in der Anerkennung bisher marginalisierter Opfergruppen und der (sehr spät, aber doch erfolgten) Einrichtung entsprechender Restitutionsfonds.

Die späten I980er Jahre stellen demnach die größte geschichtspolitische Zäsur der Zweiten Republik dar. Kurt Waldheim selbst hatte bereits im März I 988, dem »Anschluss«-Gedenkjahr, in einer Fernsehansprache an die Nation einen geschichtspolitischen Gesinnungswandel angedeutet. ${ }^{234}$ Zwar hielt er an der Opferthese fest, indem er erklärte, dass Österreich als Staat »das erste Opfer Hitlers« ${ }^{235}$ gewesen sei, zugleich entschuldigte er sich aber für »von Österreichern begangene Verbrechen ${ }^{236}$. Drei Jahre später hielt Bundeskanzler Franz Vranitzky eine viel beachtete Rede vor dem Nationalrat, in welcher er erklärte:

»Viele Österreicher waren an den Unterdrückungsmaßnahmen und [der] Verfolgung des Dritten Reichs beteiligt, zum Teil an prominenter Stelle. (...) Wir bekennen uns

23 I Uhl, Das »erste Opfer«, S. 26-30. Zur Erosion des Opfermythos vgl. auch Botz, Nachhall und Modifikationen, S. 588-596.

232 Vgl. Botz, Nachhall und Modifikationen, S. 587.

233 Ebd.

234 Ebd., S. 589 .

235 Kurt Waldheim in einer Fernsehansprache am Io. März I 988, zitiert nach: Botz/Sprengnagel, Kontroversen um Österreichs Zeitgeschichte, S. 642.

236 Ebd. 
zu allen Daten unserer Geschichte und zu den Taten aller Teile unseres Volkes, zu den guten wie zu den bösen... Dieses Bekenntnis haben österreichische Politiker immer wieder abgelegt. Ich möchte das heute ausdrücklich auch im Namen der österreichischen Bundesregierung tun..." ${ }^{237}$

Das sich wandelnde geschichtspolitische Selbstverständnis Österreichs, das in der zeithistorischen und politologischen Literatur mit dem Begriff der »Mitverantwortungsthese« bezeichnet wird, sollte sich im Laufe der I 99oer Jahre bis zum Ende der Großen Koalition im Jahr 2000 als neuer politischer Grundkonsens herauskristallisieren. ${ }^{238}$ Auch in weiten Teilen der österreichischen Bevölkerung scheint die Mitverantwortungsthese inzwischen angekommen zu sein. ${ }^{239}$

In Antithese dazu stehen nach wie vor die Geschichtspolitik der traditionell deutschnationalen, fremden- und EU-feindlichen FPÖ sowie deren Wahlerfolge unter den Obmännern Jörg Haider und Heinz-Christian Strache. ${ }^{240}$ Auch der Bundespräsidentschaftswahlkampf des FPÖ-Kandidaten Norbert (Gerwald) Hofer von 2016 spiegelt diese Antithese wider.

Kritisch festgehalten werden muss weiters, dass die ÖVP unter der Führung von Wolfgang Schüssel - der neuen geschichtspolitischen Sensibilität zum Trotz - im Jahr 2000 eben diese FPÖ unter Jörg Haider mit in die Regierung geholt hatte, was zu einem Wiederaufflammen der Diskussionen um die unzureichende NS-Vergangenheitsbewältigung, auf nationaler wie auf internationaler Ebene, führte. Trotz heftiger Kritik aus dem Ausland und Sanktionen der anderen EU-Staaten ließ sich der damalige ÖVP-Bundeskanzler Wolfgang Schüssel sogar dazu hinreißen, die Opferthese im Zuge eines Zeitungsinterviews im Jahr 2000 sowie in einem Gespräch mit einem Redakteur der »Neuen Zürcher Zeitung« 2005 öffentlich zu bekräftigen - »Ich werde nie zulassen, dass man Österreich nicht als Opfer sieht. Das Land war in seiner Identität das erste militärische Opfer der Nazis ... $\ll^{241}$-, was er vermutlich aus Gründen der außenpolitischen Selbstdarstellung tat (etwa als Reaktion auf die EU-Sanktionen). ${ }^{242}$

237 Franz Vranitzky in seiner Erklärung vor dem Österreichischen Nationalrat am 8. Juli I99 I, zitiert nach: Ebd.

238 Vgl. Uhl, Das »erste Opfer«, S. 27.

239 I 947 hatten noch über zwei Drittel der Bevölkerung jede Mitverantwortung am Holocaust abgelehnt, im Jahr 2000 glaubten nur noch I 3 Prozent an eine Alleinschuld Deutschlands. Vgl. Fröhlich-Steffen, Identität im Wandel, S. 156.

240 Vgl. Uhl, Das »erste Opfer«, S. 27.

24I Wolfgang Schüssel in einem Interview im Jahr 2005, zitiert nach: Botz, Nachhall und Modifikationen, S. 592.

242 In einem Interview mit Jeff Barak, dem Chefredakteur der Jerusalem Post sagte Schüssel, dass nicht nur »der souveräne österreichische Staat (...) das erste Opfer des Nazi-Regimes« ge- 
Der öffentliche Aufschrei blieb aus. Jelinek hingegen kritisierte Schüssel, dem wegen seiner Teilnahmslosigkeit gegenüber den verbalen Entgleisungen seines Regierungspartners FPÖ und dessen offener Verharmlosung der österreichischen NS-Vergangenheit der Beiname "Schweigekanzler« anhaftete, in ihrer Rede zur Verleihung des Heine-Preises 2002, »... durch das Schweigen entzieht man sich allem ganz leicht ${ }^{243}$ und noch einmal expliziter, $» . .$. sprechen kann er nicht, er ist eher still, der Herr Kanzler, der zu allem geschwiegen hat, denn Schweigen macht mächtig « ${ }^{244}$. Schüssels Zeitungsinterview und andere ähnliche Wortmeldungen politischer Repräsentanten lassen darauf schließen, dass sich die offizielle Haltung zur Opferthese seit der Jahrtausendwende hin zu einem erinnerungsgeschichtlichen Kompromiss entwickelt hat, der bei Botz als »Opfer-Täter-Gedächtnis « ${ }^{245}$ bezeichnet wird und sowohl das Eingeständnis der Mitverantwortung als auch das Beharren auf dem Opfermythos beinhaltet. So ließ etwa der ÖVP-Bundespräsidentschaftskandidat Andreas Khol April 2016 mit der Aussage aufhorchen, dass das Land Österreich ein Opfer des Nationalsozialismus gewesen wäre, viele Österreicher aber auch Täter gewesen seien - und gab damit tiefe Einblicke in sein Geschichtsverständnis. ${ }^{246}$ "Der heutige Umgang mit dem Nationalsozialismus ist auch wieder paradox«, so Jelinek:

»... eine Mischung aus Ständig-Darüber-Sprechen, also einem ritualisierten gebetsmühlenhaften Sprechen, mit dem die Taten der Vergangenheit beurteilt werden und man sich von ihnen distanziert (mit dem alle Politiker bei Gedenkveranstaltungen die Verbrechen öffentlich routiniert verabscheuen. Aber was sollten sie sonst tun?), und der totalen Verleugnung bei der extremen Rechten. ${ }^{247}$

Im Bereich der österreichischen Restitutionspolitik sind seit Mitte der I990er Jahre Maßnahmen erfolgt, die zumindest als "Gesten der Entschuldigung « ${ }^{248}$

wesen wäre, sondern auch »die Österreicher die ersten Opfer« gewesen wären. In: Die Presse, Iо. I .2000, S. 7. Auch in: Der Standard, го. I .2000, S. го. Ähnliches erklärte er in einem Gespräch mit Charles Ritterband von der »Neuen Zürcher Zeitung« im Februar 2005. Vgl. Botz, Der Kanzler als Schulmeister der Nation, S. I 2.

243 Jelinek, Österreich. Ein deutsches Märchen, unpaginiert.

244 Ebd.

245 Botz, Nachhall und Modifikationen, S. 6or.

246 Kann etwa in folgendem Online-Artikel nachgelesen werden: http://derstandard. at/2000034653467/Khol-sieht-Oesterreich-als-Opfer-des-Nationalsozialismus (Zugriff am 30.06.2016).

247 Jelinek, zitiert nach: Janke/Kovacs/Schenkermayr, »Die endlose Unschuldigkeit«, S. I 9.

248 Heinz Fischer, damals Nationalratspräsident, zitiert nach: Uhl, Das »erste Opfer«, S. 28. 
interpretiert werden können, denn Wiedergutmachung können sie allenfalls in materieller Hinsicht leisten. So wurden drei große Fonds zur Entschädigung der Opfer des Nationalsozialismus eingerichtet und I 998 eine Historikerkommission berufen, die den Vermögensentzug im Rahmen der Arisierungen erforschen sollte, um dementsprechende Entschädigungszahlungen anregen zu können. ${ }^{249}$ Neben Versuchen der materiellen Entschädigung fand die veränderte Sichtweise aber auch in der symbolischen Repräsentation ihren Niederschlag, etwa in der Einrichtung des NS-Opfer-Gedenktages am 5. Mai oder Denkmalinitiativen für die Opfer. ${ }^{250}$

Auf Basis einer neuen politischen Selbstdefinition der Zweiten Republik und begünstigt durch das Nachwachsen unbelasteter Generationen könnte es heute zu einer systematischen öffentlichen Auseinandersetzung mit der NS-Geschichte kommen. ${ }^{251}$ Jüngste innenpolitische Entwicklungen geben allerdings zu befürchten, dass diese Leistung in den kommenden Jahren nicht in dem wünschenswerten Ausmaß erbracht werden wird, weil eine - durch die seit 20 I 5 vermehrt nach Europa kommenden Kriegs- und Krisenflüchtlinge aus (vor allem) Syrien, Irak und Afghanistan begünstigte - rechtspopulistische Welle das Interesse sowie die erforderliche Sensibilität im Umgang mit diesem Thema hinwegzuspülen scheint.

Die Rekonstruktion der österreichischen Zeitgeschichte im Sinne einer Entlarvung des Opfermythos ist eines der zentralen Anliegen, das Elfriede Jelinek mit ihrem literarischen Werk verfolgt. In Hinblick auf die Interpretation ihrer Texte soll an dieser Stelle noch einmal die Erkenntnis herausgestrichen werden, dass das individuelle Gedächtnis nicht unabhängig vom Kollektivgedächtnis arbeitet und dass es keine unabhängige, neutrale Geschichtsschreibung gibt. Vielmehr ist diese immer in Abhängigkeit von interessegebundenen Interpretationen zu lesen:

»Die Vergangenheit spricht nicht aus sich selbst heraus. Sie lehrt nichts, was wir, die wir aus der Gegenwart auf sie zurückblicken, aus ihr nicht lernen wollen. Die historischen Ereignisse haben als solche keine Bedeutung. Sinn erhalten sie von den Interessen, Wertigkeiten, Zielsetzungen derer, die ihre Rekonstruktion betreiben. ${ }^{252}$

249 Vgl. Botz, Nachhall und Modifikationen, S. 602-608 (zu den Entschädigungsfonds) sowie S. 6o8-6 I 2 (zu den Historikerkommissionen).

250 Als Beispiel sei hier die Wiedererrichtung der Grazer Synagoge genannt. Vgl. Uhl, Das »erste Opfer«, S. 28.

25 I Vgl. Bergmann/Erb/Lichtblau, Schwieriges Erbe, S. I I.

252 Ziegler/Kannonier-Finster, Österreichisches Gedächtnis, S. 73. 


\subsection{Elfriede Jelinek: Annäherung an eine "synthetische Künstlerbiografie"}

»Alle, die glauben, sie wüßten etwas über mich, wissen nichts $(\ldots) . \ll^{253}$

I 983 erschien Elfriede Jelineks autobiografisch gefärbter Roman »Die Klavierspielerin«, bis heute das bekannteste Buch der Autorin, wenngleich diese behauptet, es "nie so besonders geschätzt zu haben ${ }^{254}$. Dennoch sei es ein Buch gewesen, »das geschrieben werden musste, es musste einfach aus mir heraus. Formal bin ich heute aber, nach so vielen Jahren der Arbeit, schon weiter ${ }^{255}$. »Die Klavierspielerin« wurde in dutzendfacher Auflage gedruckt, in zahllose Sprachen übersetzt und von Michael Haneke verfilmt. Es ist eines der wenigen Bücher von Elfriede Jelinek, die fast einhellig positiv kritisiert wurden. Zudem ist es bis heute das am besten erforschte Buch der Nobelpreisträgerin. ${ }^{256}$

In dem Roman wird die Beziehung der neurotischen Klavierlehrerin ERIK A конит zu deren autoritären Mutter geschildert. Die sich anbahnende Affäre mit einem ihrer Klavierschüler könnte für ERIK A eine Gelegenheit darstellen, aus dem mütterlichen Ordnungssystem auszubrechen. Doch sie erstickt ihr Aufbegehren letztlich selbst im Keim, denn mit der sexuellen Leidenschaft des jungen WALter KLEMMER weiß ERIKA, die Enddreißigerin, die bislang an gegenseitige Abhängigkeitsverhältnisse gewöhnt ist, nichts anzufangen; am Ende bleibt ihr nur die Rückkehr in die kranke Zweisamkeit mit der alles kontrollierenden Mutter: »Erika weiß die Richtung, in die sie gehen muß. Sie geht nach Hause. Sie geht und beschleunigt langsam ihren Schritt. « ${ }^{257}$

Parallelen zu der Autorinnenbiografie sind nicht von der Hand zu weisen und wurden von Jelinek auch nie abgestritten. Obwohl sie I974 den Informatiker Gottfried Hüngsberg geheiratet hatte, lebte sie mit ihrer Mutter im Familienhaus in Wien-Hütteldorf, bis diese 97-jährig verstarb. Heute lebt sie alleine dort. Der Erfolg des Romans machte ihr Privatleben über Nacht zu einem öffentlich diskutierten Thema. Die Analyse ihres Persönlichkeitsprofils fand nunmehr Eingang ins Feuilleton aber auch in die Sekundärliteratur wie zuvor bei keiner anderen deutschsprachigen Autorin: «In fact, so much has been written about Jelinek's personality and beliefs that, rather like one of the figures in her novels,

253 Jelinek, zitiert nach: Winter, Gespräch mit Elfriede Jelinek, S. I I.

254 Dies., zitiert nach: profil, Nr. 42, 2004, S. I 25.

255 Ebd.

256 Vgl. Mayer/Koberg, Ein Porträt, S. i 6 f.

257 Jelinek, Die Klavierspielerin, S. 285. 
she has been reduced to a cliché of herself ${ }^{258}$, bemerkt dazu Allyson Fiddler. Die Geschichte von eriка конит wurde zu Jelineks eigener Geschichte. Seit dem Erfolg des Romans wird sie in der öffentlichen Wahrnehmung mit ihrer Mutter in Zusammenhang gebracht. ${ }^{259}$

Tatsächlich erzählte Jelinek selbst in Interviews und Gesprächen immer wieder freimütig von den Gemeinsamkeiten ihrer Hauptfigur mit sich selbst, bezeichnete den Roman sogar als ihre »eingeschränkte Biografie ${ }^{260}$.

Auch in anderen Zusammenhängen erscheint es immer wieder erstaunlich, mitunter befremdlich, wie viele Details sie aus ihrem Privatleben verriet. »Selten hat eine Schriftstellerin so tatkräftig die eigene Legende mitgestaltet, indem sie die Medien bereitwillig mit stereotypen Bildern zu ihrem Leben und ihrem Werk bediente ${ }^{261}$, kritisiert Annette Doll. Jelinek habe in entscheidendem Maße daran mitgewirkt, das Bild einer neurotischen und obsessiven Schreiberin zu erzeugen und aufrechtzuerhalten. Aus einer Montage mit nur wenigen Teilen entstehe eine »synthetische Künstlerbiografie«, die Teil einer "geschickten Vermarktungsstrategie» sei - nur selten erreiche experimentelle Sprachkunst schließlich derart hohe Auflagen. ${ }^{262}$

Auch Margarete Sander zeigt sich davon überzeugt, dass Jelinek die Auswahl der Informationen, die über sie weitergegeben wurden, von Anfang an gesteuert und deren Position, Funktion und Bewertung selbst inszeniert habe, glaubt aber nicht, dass Jelinek dies aus Gründen der Vermarktung getan habe, sondern um sich auf diese Weise ihren eigenen Mythos zu schaffen, der ihr den Zufluchtsort der extremen Künstlichkeit gewähre. ${ }^{263}$

Verena Mayer und Roland Koberg, die das erste deutschsprachige Autorinnenporträt verfasst und 2006 publiziert haben, berufen sich über weite Strecken hinweg auf Aussagen, die Jelinek selbst über ihre Kindheit, ihre Eltern, ihre ideologische Positionierung oder ihren Standpunkt als Autorin getroffen hat. Das ist natürlich insofern problematisch, als dass die zum Teil ironischen, sprachlich stilisierten Rückblenden der Autorin mit biografischen Tatsachen verwechselt werden. Die »Subjektivität und die Zeitbezogenheit « ${ }^{264}$ ihrer Darstellung gestehen die Autoren des Porträts im Vorwort ein und können damit sich anbahnender Kritik Wind aus den Segeln nehmen. Dennoch bleibt der

258 Fiddler, Rewriting Reality, S. I.

259 Vgl. Mayer/Koberg, Ein Porträt, S. I I 7.

260 Jelinek, zitiert nach: Ebd., S. I 4.

26 I Doll, Mythos, Natur und Geschichte, S. 9 f.

262 Vgl. ebd., S. Io f.

263 Vgl. Sander, Textherstellungsverfahren, S. I 8

264 Mayer/Koberg, Ein Porträt, S. 8. 
Verdacht der Mythisierung bestehen. Jelinek, die sich schreibend am »mütos « ${ }^{265}$ abarbeitet, ist selbst zum Mythos geworden. Dass dies passiert ist, bestreitet die Autorin auch gar nicht, lehnt jedoch die Einschätzung ab, dass dies mit Vorsatz passiert wäre. Gerade sie habe doch immer die Wahrheit hinter dem Schein hervorholen wollen. ${ }^{266}$

Das von Mayer und Koberg mit zahlreichen Details ausgestattete Porträt entspricht in weiten Teilen der seit dem Erfolg von »Die Klavierspielerin« tradierten Legende. In dieser gibt es »einen mit Goethe-Gedichten genährten Säugling namens Elfriede, eine kalte und grausame >Kunsteislaufmutter , einen geisteskranken Vater, einen frühen Nervenzusammenbruch der Autorin und schließlich eine aufgeklärte Ehe mit Gottfried, dem Informatiker « ${ }^{267}$.

In dieser Legende wird die Geschichte eines Mädchens namens Elfriede erzählt, das 1946 als Tochter von Ilona ${ }^{268}$ und Friedrich Jelinek in Mürzzuschlag geboren wird und in Wien aufwächst. Von frühester Kindheit an ist es der mütterlichen Dressur unterworfen und wird schon als kleines Kind zum Ballett-, Musik- und Fremdsprachenunterricht geschickt. Der Vater, ein atheistischer Jude, hat der nationalsozialistischen Vernichtung entkommen können, weil er als Chemiker kriegswichtigen Dienst bei Semperit in Traiskirchen geleistet hatte. ${ }^{269}$ Sprachlich ist der Vater »äußerst eloquent«, gibt »Ironie und Sarkasmus « ${ }^{270}$, mit welchen er sich seiner dominanten Frau gegenüber behauptet, an die Tochter weiter, die sich an die Sprache wie an einen Lebensretter klammert:

»Ich glaube, daß mir die Sprache das Leben gerettet hat gegen eine drückende und auch geistig verwirrte mütterliche Autorität. Es gab einen Vater, der mich nicht gerettet hat vor dieser Mutter, aber er hat mir wenigstens die Sprache gegeben, so daß ich subversiv, mit Sprache, in einer Weise untendurch tauchte, wo mir die Autorität nicht folgen konnte. ${ }^{271}$

Angetrieben von seiner Frau arbeitet der Vater als über 50-Jähriger, neben seinem Beruf als Oberstadtbaurat, mit größtem Unwillen an einer Dissertation in organischer Chemie. Die Arbeit fällt ihm schwer, die Eltern streiten viel. Mit-

265 Jelinek, Die endlose Unschuldigkeit, S. 49.

266 Vgl. Winter, Gespräch mit Elfriede Jelinek, S. ro f.

267 Doll, Mythos, Natur und Geschichte, S. ro

268 Die Mutter hieß eigentlich Olga Ilona Jelinek, wurde aber stets mit dem zweiten Vornamen angesprochen.

269 Die »Semperit Gummiwerke« hatten während des Kriegs Laufrollen für Panzerfahrzeuge und Flugzeugreifen produziert. Vgl. Mayer/Koberg, Ein Porträt, S. I 2 I.

270 Ebd., S. I 24.

27 I Jelinek, zitiert nach: Ebd. 
unter passiert es, dass der Vater tagelang nicht spricht - aus Trotz und zur Bestrafung. ${ }^{272}$ Zudem scheint er von der Erfahrung traumatisiert zu sein, dass er als Kunststoffexperte im Krieg jenem Regime zuarbeiten musste, das sich die physische Vernichtung der Juden auf die Banner geschrieben hatte. Viele der jüdischen Familienmitglieder waren während der NS-Zeit ermordet worden. ${ }^{273}$ Schon als Kind muss die Tochter den Vater in die Filme der Alliierten begleiten, in denen die Leichenberge aus den Konzentrationslagern gezeigt werden. Die Bilder verstören das Kind und prägen sich ihm ein. ${ }^{274}$

Als Dreizehnjährige wird Elfriede als jüngste Studentin für das Orgelstudium am Wiener Konservatorium aufgenommen. Nur ein Jahr später bewirbt sie sich außerdem für das Klavierstudium. Nebenbei lernt sie noch Bratsche, Gitarre, Blockflöte und Geige. Der Vater ist inzwischen schwer erkrankt, verliert seine sprachliche Eloquenz, ist verwirrt, orientierungslos, leidet möglicherweise an einer Form der Alzheimer-Krankheit. ${ }^{275}$ Die Unmöglichkeit, sich mit dem Vater austauschen zu können, drückt Elfriede noch mehr nieder. Für sie ist der Vater "von einem unglaublich klugen Menschen zum völligen Idioten geworden. Das verzeiht eine Tochter dem Vater nicht ${ }^{276}$. Den Sprachverlust ihres Vaters habe sie als gleichbedeutend mit Existenzverlust erlebt, so Mayer/Koberg:

»Vielleicht ist ihr Werk, vor allem in seiner späten Phase, auch deshalb ein so gewaltiger Sprechakt. Nur solange man spricht, lebt man. ${ }^{277}$

Bereits in der Pubertät beginnt das Mädchen, unter schweren Angstzuständen zu leiden. Die Mutter schickt sie, anstatt in die Gesellschaft von Gleichaltrigen, zur Therapie - in die Gesellschaft von »schwergestörten Neurotikern und Psychopathen « ${ }^{278}$, wie die Tochter der Mutter später vorhält. Ungeachtet all der psychischen und familiären Belastungen ist das Mädchen als Gymnasiastin

272 Vgl. ebd., S. I 23 f. Vgl. auch Meyer, Sturm und Zwang, S. 50.

27349 Verwandte aus der väterlichen Linie seien in der NS-Zeit ums Leben gekommen, erzählte Jelinek in einem Interview - verwies aber darauf, selbst nur von einer Cousine davon erfahren zu haben. Vgl. profil, Nr. 49, 2004, S. I 33. Gesichert ist, dass zwei Schwestern des Großvaters I 942 Opfer des Holocaust geworden seien, berichten Mayer/Koberg, vgl. Ein Porträt, S. 98.

274 Vgl. Mayer/Koberg, Ein Porträt, S. I $24 \mathrm{f}$.

275 Vgl. ebd. S. 39. In einem Interview relativierte Jelinek diese Einschätzung, indem sie meinte, man habe eigentlich nicht genau gewusst, woran der Vater erkrankt war, es sei möglicherweise Alzheimer gewesen, möglicherweise aber auch eine Art Berufskrankheit, da er als Chemiker viele toxische Substanzen eingeatmet habe. Vgl. Meyer, Sturm und Zwang, S. $34 \mathrm{f}$.

276 Jelinek in einem Interview, zitiert nach: Müller, Elfriede Jelinek, S. 200.

277 Mayer/Koberg, Ein Porträt, S. 220.

278 Meyer, Sturm und Zwang, S. 7 . 
bereits auf dem besten Wege, eine ausgezeichnete Berufsmusikerin zu werden. Gleichzeitig sucht es nach anderen Möglichkeiten, sich auszudrücken, kleidet und schminkt sich extravagant, beginnt Gedichte zu schreiben, komponiert ein wenig. In der Klosterschule lernt es, »die fromme Miene heraus- und hineinzuschrauben, je nachdem, wo die Miene explodieren sollte « ${ }^{279}$. Jedes Reden über Sexualität ist selbstverständlich ein Tabu, in der Schule wie auch zu Hause.

Im Sommer I 964 kulminiert das psychische Leiden: Kurz nachdem Elfriede die Schule erfolgreich abgeschlossen hat, erleidet sie einen Nervenzusammenbruch und wird ins Krankenhaus eingeliefert: "Angstneurose ${ }^{280}$, so die Diagnose. Die Anfälle wiederholen und häufen sich. Als sie im Herbst mit dem Studium (Theaterwissenschaft und Kunstgeschichte) in Wien beginnen will, kann sie kaum das Haus verlassen, hat Angst davor, mit der Straßenbahn zu fahren oder an Vorlesungen teilzunehmen. Nach kurzer Zeit bricht sie das Studium ab und verlässt - so die Legende - für ein Jahr das Elternhaus nicht, in welchem der schwer kranke Vater bis kurz vor seinem Tod lebt und die Mutter alle Türen abschließt, weil der todkranke Vater unter dem für die Alzheimer-Krankheit typischen Wandertrieb leidet. Die Familie wird damit vollends zum Schauplatz einer "psychischen Ausnahmesituation ${ }^{281}$. Um dieser zu entkommen, liest das Mädchen alles, was ihm in die Hände fällt, sieht sich alles an, was die beiden österreichischen TV-Programme damals zeigen. ${ }^{282}$ In diesem Isolationsjahr zu Hause schreibt Elfriede ihren ersten Roman, »bukolit ${ }^{283}$ und beginnt sofort nach dessen Fertigstellung mit einem neuen Projekt, einem »Illustriertenroman«.

Im Mai I 969 wird sie zur Jugendkulturwoche nach Innsbruck eingeladen und mit zwei Preisen der Jury, in den Sparten Prosa und Lyrik, ausgezeichnet. ${ }^{284}$ Die Anerkennung ihres Schreibens hilft ihr dabei, die Angstzustände zu überwinden, das Haus zu verlassen und wieder am sozialen Leben teilzunehmen. ${ }^{285}$ Sie ist jedoch keine, die unbemerkt in der Menge verschwinden kann. Geht die junge Frau unter Menschen, dann »wirkt sie in der grauen, leicht verfetteten Wiener Kaffeehausatmosphäre wie ein fremder Vogel ${ }^{286}$. Ihr extravagantes Äußeres fällt auf.

279 Jelinek, zitiert nach: Mayer/Koberg, Ein Porträt, S. 3 I.

280 Dies., zitiert nach: Kerschbaumer, Porträt einer jungen österreichischen Autorin, S. I 45.

28 I Mayer/Koberg, Ein Porträt, S. 40.

282 Vgl. ebd., S. 40 f. Auch heute noch sei sie fernsehsüchtig, erklärte Jelinek in Interviews wiederholt. Sie sei unter anderem deswegen abhängig vom Fernsehen, weil sie ja aufgrund ihrer agoraphobischen Ängste nicht ins Kino gehen könne. Vgl. profil, Nr. 49, 2004. S. I 34 .

283 Der Roman wurde allerdings erst I 979 veröffentlicht.

284 Vgl. Mayer/Koberg, Ein Porträt, S. 44.

285 Vgl. ebd., S. 50

286 Kerschbaumer, Porträt einer jungen österreichischen Autorin, S. I 44. 
Zwei Wochen nach dem Treffen in Innsbruck stirbt der Vater im Krankenhaus Baumgartner Höhe, ausgerechnet jenem Krankenhaus, das - "grausame Ironie des Schicksals« ${ }^{287}$ - während des Kriegs Schauplatz nationalsozialistischer »Euthanasie» gewesen ist und immer noch von Heinrich Gross ${ }^{288}$ geleitet wird. Elfriede und Mutter Ilona bleiben alleine in dem Familienhaus in Wien-Hütteldorf. Mit großer Produktivität arbeitet Elfriede indes an weiteren Texten. Ihr zweites Buch »wir sind lockvögel baby!« wird I 970 von dem etablierten Rowohlt-Verlag veröffentlicht. Das Musikkonservatorium schließt sie zwar ein Jahr später mit Auszeichnung ab, den Weg als Berufsmusikerin schlägt sie aber trotzdem nicht ein. Das Schreiben habe sich als »der bessere Weg ${ }^{289}$ erwiesen.

Mit dem Text »der fall des leander kaiser« tritt Elfriede, inzwischen eine junge Frau, erstmals schreibend gegen die staatliche Autorität in Aktion. ${ }^{290}$ Die Parteinahme für Kaiser stellt die erste von unzähligen Stellungnahmen dar, die sie in den folgenden Jahren in Form von Essays, Reden oder Kommentaren verfassen oder über Interviews ausrichten lassen wird, um für Freunde oder Gleichgesinnte einzutreten. $^{291}$

I 974 heiratet sie den Informatiker Gottfried Hüngsberg, zieht aber nicht mit ihm zusammen, sondern lebt mit ihm in einer Fernbeziehung zwischen München und Wien. »ich hab geheiratet, sonst gehts mir auch gut", schreibt die Frischvermählte in einem Brief an ihren Mentor Otto Breicha, »gottseidank

287 Mayer/Koberg, Ein Porträt, S. I 26.

288 Gross war I944 als Stationsarzt im Krankenhaus »Am Spiegelgrund (heute: »Baumgartner Höhe«) tätig gewesen. Er soll sich dort im Rahmen der so genannten »Euthanasie-Programme« an der Ermordung zahlloser behinderter Kinder beteiligt haben, wurde strafrechtlich jedoch nie belangt (ein Urteil wegen Totschlags von I 950 wurde wieder aufgehoben). Er blieb von der Entnazifizierung weitgehend unbehelligt und konnte in der Zweiten Republik Karriere als Neurologe und Psychiater machen. Für seine Forschungen an teils aus der NSZeit stammenden Kinderhirnen wurde er sogar I 959 mit dem Theodor-Körner-Preis ausgezeichnet. Als im Jahr 2000 das Verfahren gegen ihn wiederaufgenommen werden sollte, galt er wegen Demenz bereits als verhandlungsunfähig. Vgl. Wiener Zeitung, Donnerstag, 2 2.I 2.2005. Vgl. auch Häupl, Die ermordeten Kinder vom Spiegelgrund.

289 Mayer/Koberg, Ein Porträt, S. 26

290 Kaiser wurde wegen eines Artikels (»Über die Kirche und die Sexualität«) zu drei Monaten Haft verurteilt. Es wurde ihm der Verstoß gegen das Pornografie-Gesetz angelastet, weil dem Artikel ein Bildausschnitt aus einem Aufklärungsfilm Oswald Kolles beigefügt gewesen war. Der Richter verlangte zudem ein psychiatrisches Gutachten, welches ausgerechnet von Heinrich Gross erstellt wurde. Jelinek schrieb über den Prozess gegen ihren Freund und machte den ihrer Meinung nach totalitären Staat für das Urteil verantwortlich. Das Urteil wurde letzten Endes in eine Bewährungsstrafe umgewandelt. Vgl. ebd., S. 56-59.

29 I Vgl. ebd., S. 58. 
keinen künstler..., sondern einen naturwissenschafter... das ist sehr angenehm. einen münchner, daher teil ich jetzt meine zeit zwischen wien und münchen, ist ja nicht weit. « ${ }^{292}$ Kinder haben die beiden keine. Elfriede möchte keine; offiziell, weil sie nicht wolle, dass ein unschuldiges Wesen ihre Neurosen ausbaden müsse. ${ }^{293}$ Die Beziehung mit Gottfried Hüngsberg sei »keine normale Ehe ${ }^{294}$, ihr Mann sei ebenso ein Einzelgänger wie sie. ${ }^{295}$ In demselben Jahr, in dem Elfriede heiratet, geht sie außerdem noch eine weitere Verbindung ein: Sie tritt (aus marxistischer Überzeugung) der Kommunistischen Partei bei, wird diese aber I 99 I im Streit wieder verlassen.

1975 erscheint der Roman, der Elfriede zum »literarischen Durchbruch ${ }^{296}$ verhilft: »Die Liebhaberinnen«. Ihr erstes Theaterstück, »Was geschah, nachdem Nora ihren Mann verlassen hatte«, I 977 erschienen, wird I 979 in Graz uraufgeführt, weitere Theatertexte folgen, die meisten werden jedoch zunächst vor allem an deutschen Bühnen gezeigt. I 980 erscheint der Roman »Die Ausgesperrten«, dem eine aufsehenerregende Familientragödie aus dem Wien der I 95oer Jahre zugrunde liegt. Das Buch wird von Franz Novotny verfilmt.

I983 schließlich kommt »Die Klavierspielerin« heraus, jener Roman, in welchem Elfriede unverhohlen autobiografisch mit der überpräsenten, autoritären Mutter abrechnet. Der Vater wird in diesem Buch nur an einer einzigen Stelle erwähnt. ${ }^{297}$ Die Erinnerung an den Vater wird erst viel später, dafür aber mit »umso größerer Intensität « ${ }^{298}$ wiederkehren: Gegen Ende der I 99oer Jahre wird Elfriede beginnen, sich mit dem fehlenden Vater in ihren Texten zu konfrontieren, etwa im »Sportstück (I998), in dem eine Figur namens ELFi ELEKTRA ihren toten Vater beklagt. Das Stück kulminiert in der Anrufung des Vaters durch die Figur der AUTORIn, die sich laut Regieanweisung von ELFi ELEKTRA »vertreten lassen ${ }^{299}$ kann - ein Monolog, der von Wut, Trauer und Schuldgefühlen getragen ist:

292 Jelinek, zitiert nach: Ebd., S. 75.

293 Vgl. Die Zeit, Nr. 3, 2006, S. 6o. Außerdem: Müller, Ich bin die Liebesmüllabfuhr, S. 28.

294 profil, Nr. 49, 2004, S. I36.

295 Gottfried Hüngsberg, der jede Öffentlichkeit meidet, zeichnet für die Gestaltung von Elfriede Jelineks Homepage verantwortlich, die laufend aktualisiert wird: http://www.elfriedejelinek. com.

296 Janz, Elfriede Jelinek, S. 2 I.

297 Gleich zu Beginn wird darauf verwiesen, dass der Vater nicht (mehr) da ist: „Nach vielen harten Ehejahren erst kam Erika damals auf die Welt. Sofort gab der Vater den Stab an seine Tochter weiter und trat ab.«Jelinek, Die Klavierspielerin, S. 7.

298 Vgl. Die Zeit, Nr. 3, I 2. I. 2006, S. 6o.

299 Jelinek, Sportstück, S. I 84. 
»... Papi. Wo ist das Wort, das ich vorhin gefunden und jetzt wieder verlegt habe? Du hast manchmal geredet wie ein Jud. Keine Angst vor dir, das heißt, meine Angst vor dir nicht absolut, sondern daß du nicht daß du nicht daß du nicht geredet hast. Manchmal wochenlang. (...) Papi. Du sollst jetzt bitte auftreten und mir einen Vorwurf machen. Aber du kannst dich mir ja schließlich nicht nachtragen! Da warst du und ich hab dich nicht gesehen. (...) Ich bin ein Beispiel dafür, daß die Schuldigen am Leben bleiben, hier in meiner Nähe passiert ihnen nichts. Ich bin allerdings die einzige in meiner Nähe.» ${ }^{300}$

Mutter Ilona hingegen nimmt bis zuletzt lebhaften Anteil am Leben der Tochter, kocht, putzt, nimmt Anrufe entgegen, kopiert Manuskripte und bewirtet Elfriedes Gäste. ${ }^{301}$ Die Beziehung zur Mutter ist - so die Legende - eine »Hassliebe ${ }^{302}$, die von gegenseitiger Abhängigkeit geprägt ist. Nichtsdestotrotz veröffentlicht Elfriede ein Buch ums andere. ${ }^{303}$

Die Uraufführung des »Burgtheater«-Stücks I984 in Bonn ruft einen österreichweiten Theaterskandal hervor und begründet ihren Ruf als »Nestbeschmutzerin «, da sie in dem Stück an dem bis dahin tradierten Opfermythos rührt. ${ }^{304}$

In Deutschland reagiert man anders. I 986 erhält Elfriede als erste Frau den Heinrich-Böll-Preis der Stadt Köln. Mit ihrer Dankesrede »In den Waldheimen und auf den Haidern« leistet sie einen kritischen Beitrag zur Waldheim-Debatte, was ihr in vielen Medien eine pauschale Verurteilung als Autorin einbringt: Jelineks Literatur sei »Gespeibsel ${ }^{305}$, schreibt etwa ein Redakteur im »Kurier«, und die Preisrede in Köln nur als »infame Österreichbeschimpfung ${ }^{306}$ zu bezeichnen.

Trotz ihrer starken Angstzustände macht Elfriede immer wieder den Schritt in die Öffentlichkeit, scheut sich nicht davor, offen auf Konfrontation mit Politik und Medien zu gehen. Im Juni I987 stellt sie sich im Rahmen einer Mahnwache vor das $\mathrm{O}_{5}-\mathrm{Zeichen}^{307}$ am Wiener Stephansdom und verteilt Flugzettel mit der Aufschrift:

300 Vgl. ebd., S. I 84 ff. Der ganze Monolog geht bis S. I 88.

30 I Vgl. Mayer/Koberg, Ein Porträt, S. I I I.

302 Ebd., S. I29.

303 Etwa die Romane »Lust« ( I 989), »Gier« (2000) und »Neid« (2008), den großen Roman »Die Kinder der Toten« (1995), aber auch Theaterstücke (z.B. „Clara S.«, I98 I, »Krankheit oder Moderne Frauen«, I987, »Raststätte«, I994, »Ein Sportstück«, I 998, »In den Alpen«, 2002, "Das Werk«, 2003) und etliche Essays.

304 Vgl. Kapitel 3.I dieser Studie.

305 Leitner in seiner Kolumne »Menschlich gesehen«. In: »Kurier«, I 2.I 2.I 986. Faksimile abgedruckt in: Janke, Nestbeschmutzerin, S. 56.

306 Ders.in: »Kurier«, 23.I 2.r 986. Faksimile abgedruckt in: Janke, Nestbeschmutzerin, S. 59.

$307 \mathrm{O}_{5}=$ Kürzel für die wichtigste österreichische Widerstandsgruppe gegen den Nationalsozialismus. 
»Wir können nicht wissen, wie wir uns damals verhalten hätten, aber wir wissen, wie wir uns verhalten hätten sollen. Wir ehren die Helden des österreichischen Widerstandes, wir gedenken der Opfer. ${ }^{308}$

Auch hält sie r 99I eine öffentliche Rede bei einer großen Demonstration gegen Fremdenhass in Wien. Schreibend reagiert sie mit zwei Essays auf das »Ausländervolksbegehren« der Haider-FPÖ. In sämtlichen Theatertexten und vielen Essays der I 99oer Jahre verarbeitet sie fremdenfeindliche und rechtsideologische Tendenzen in Österreich. ${ }^{309}$ Auch ihr Opus Magnum, der Roman "Die Kinder der Toten« (I995), ist unter diesem Lichte zu lesen. Als I995 das Theaterstück »Raststätte«, von Claus Peymann im Akademietheater inszeniert, vom Feuilleton als »Porno-Schwank ${ }^{310}$ zerrissen und Elfriede auf Wahlplakaten der Wiener FPÖ persönlich angegriffen wird, gibt sie ihren Rückzug aus der Öffentlichkeit bekannt und erlässt ein österreichweites Aufführungsverbot für ihre Theaterstücke.

Bereits I 998 kehrt sie aber mit dem »Sportstück» ans Burgtheater zurück, weil Einar Schleef, ihr favorisierter dramaturgischer Widerpart ${ }^{311}$, sich zu dessen Inszenierung bereit erklärt hat. Das Stück wird in einer sechsstündigen Marathon-Inszenierung gezeigt. Trotz der Länge wird es zu einem »Triumph « ${ }^{312} \mathrm{am}$ Burgtheater, die Inszenierung wird zum Berliner Theatertreffen eingeladen und mehrfach ausgezeichnet. ${ }^{313}$ Als Schleef im Sommer 200 I an der Inszenierung von »Macht nichts«, Elfriedes nächstem Stück, arbeitet, verstirbt er plötzlich an den Folgen eines Herzinfarkts, worüber sich Elfriede tief getroffen zeigt. Sie hatte bereits weitere Stücke für ihn in Arbeit gehabt. ${ }^{314}$ Schleefs Inszenierung von »Macht nichts« kommt nicht mehr heraus, die Uraufführung muss verschoben werden. Dennoch gewinnt das nunmehr unter der Regie von Jossi Wieler uraufgeführte Stück 2002 den Mülheimer Dramatikerpreis. ${ }^{315}$

Die öffentlichen Auseinandersetzungen mit der FPÖ vertiefen sich indes weiter. Im Jahr 2000 marschiert Elfriede Jelinek mit Trillerpfeife bei den wöchentlichen »Donnerstagsdemos« gegen die neue, schwarz-blaue Koalition (ein Bündnis der konservativen Volkspartei und der rechtspopulistischen Freiheit-

308 Jelinek, zitiert nach: Janke, Nestbeschmutzerin, S. 5 I.

309 Zum Beispiel »Totenauberg« (1992), »Stecken, Stab und Stangl« (I 996), und »Die Österreicher als Herren der Toten« (I99I).

3 ro Janz, Nestbeschmutzerin, S. I 86.

3 I I Vgl. Mayer/Koberg, Ein Porträt, S. 224 f.

3I 2 Ebd., S. 224.

3I3 Vgl. ebd., S. 2 I 9-224.

3 4 "In den Alpen« ist bereits fertiggestellt, »Das Werk« gerade im Entstehen.

3I5 Vgl. ebd., S. 228-23I. 
lichen) mit, der in Österreich aufgrund der offen fremdenfeindlichen und antisemitischen Positionierung des kleinen Koalitionspartners massive Proteste entgegenschlagen. ${ }^{316}$ Der Theatermonolog "Das Lebewohl« wird im Rahmen einer dieser Demonstrationen öffentlich gezeigt - er ist dem freiheitlichen Parteiobmann, Jörg Haider, offenkundig auf den Leib geschrieben. Um ihren Unwillen gegenüber der neuen Regierungskoalition kundzutun, verhängt Elfriede außerdem zum zweiten Mal ein Aufführungsverbot für ihre Theaterstücke, das zwei Jahre lang aufrecht bleibt. Im selben Jahr stirbt die Mutter. Die Tochter sagt, sie sei »jeden Tag froh ${ }^{317}$ darüber.

2003 wird "Das Werk" in der Inszenierung von Nicolas Stemann am Wiener Akademietheater gespielt. Auch dieses Stück, in dem die Errichtung des Wasserkraftwerks Kaprun und die dabei zu Tode gekommenen Zwangsarbeiter thematisiert werden, gewinnt den Mülheimer Dramatikerpreis. Noch im selben Jahr wird »Bambiland (2003) unter der Leitung von Christoph Schlingensief am Burgtheater aufgeführt, 2005 folgt »Babel«, das am Akademietheater gespielt wird.

Im Oktober 2004 passiert es schließlich: Elfriede Jelinek erhält - und sie hat nach eigener Aussage dafür gebetet, dass es nicht passieren möge ${ }^{318}$ - den Literaturnobelpreis.

Die Reaktionen auf die Auszeichnung sind ambivalent und entsprechen den polarisierenden Meinungen, die Jelinek seit ihren Anfängen begleiten. ${ }^{319}$ "Mit Sprachgewalt und Österreich-Hass zum Literaturnobelpreis « ${ }^{320}$ titelt das Wochenmagazin "profil«, bringt aber dennoch einen umfangreichen, wohlwollenden Beitrag. Das Boulevardblatt »Die Kronen Zeitung« weigert sich, die Nachricht wie alle anderen österreichischen Zeitungen auf Seite eins zu setzen. Auch FPÖ-Parteiobmann Jörg Haider nimmt die Wahl unwillig zur Kenntnis: Er erkennt nach wie vor »keine literarische Wertigkeit « ${ }^{321}$ in Jelineks Schaffen, wettert er öffentlich. Ansonsten wird der Preisträgerin von offizieller Seite her »durchaus höflich gratuliert ${ }^{322}$. Neu hingegen ist die Feindseligkeit in der deutschen Presse: So wird Jelinek etwa in der »Welt« als »Vollnullität« bezeichnet. ${ }^{323}$

3 6 Zu dem umstrittenen schwarz-blauen Koalitionsabkommen von I999/2000 und den »Donnerstags-Demos« vgl. Kapitel 3.3.4 dieser Studie. Zu dem Beleg über Jelineks Partizipation vgl. profil, Nr. 49,2004 , S. I 32 f.

3 I 7 Jelinek, zitiert nach: profil, Nr. 49, 2004, S. I 32.

3 8 Vgl. Müller, Ich bin die Liebesmüllabfuhr, S. 2 I f.

3 9 Vgl. Mayer/Koberg, Ein Porträt, S. 253.

320 profil, Nr. 42, 2004.

32 I Jörg Haider in der TV-Dokumentation "Wer hat Angst vor Elfriede J.?«.

322 Mayer/Koberg, Ein Porträt, S. 255.

323 Vgl. ebd. 
Die Ausgezeichnete nimmt den Preis an, bleibt der Verleihung jedoch fern und lässt stattdessen ein Video übertragen, in welchem sie einen Essay mit dem Titel "Im Abseits« verliest. ${ }^{324}$ Nach dem Nobelpreis zieht sie sich mehr denn je zurück und agiert in erster Linie über ihre Homepage, auf der Kommentare und Essays $\mathrm{zu}$ aktuellen Themen zu lesen sind und auf welcher auch der bislang letzte Roman, "Neid" (2008), in Fortsetzungen veröffentlicht wird. Außerdem schreibt sie laufend neue Theaterstücke, darunter »Rechnitz (Der Würgeengel)«, das ihr 2009 zum dritten Mal den Mülheimer Dramatikerpreis einbringt. 20 I I wird sie für »Winterreise« schließlich zum vierten $\mathrm{Mal}$ mit diesem wichtigen Theaterpreis geehrt.

Elfriede Jelinek, die Hauptfigur dieser unglaublichen Geschichte, die nach eigener Aussage von der Mutter emotional geknebelt und vom kranken Vater früh verlassen wurde, ist zur umstrittensten und wahrscheinlich bekanntesten zeitgenössischen Autorin im deutschsprachigen Raum avanciert.

»Wäre sie nicht bereits vorhanden, man müsste die Biographie dieser Autorin erfinden. ${ }^{325}$

Dass die vorhandene Autorinnenbiografie erfunden wäre, ist nicht gesagt - dass sie nicht erfunden wäre, allerdings auch nicht. Die spannendste aller Geschichten Elfriede Jelineks ist schließlich ihre eigene. In dem Bemühen um Authentizität konfrontieren Mayer/Koberg in ihrem Porträt die autobiografischen Erzählungen der Autorin mit Archivquellen sowie mit Aussagen von künstlerischen Wegbegleitern, aber auch Kritikern und stellen die einzelnen lebensgeschichtlichen Kapitel jeweils in Zusammenhang mit Jelineks literarischem Werk. Insofern haben die Autoren ein Porträt vorgelegt, das zwar nicht unbedingt sachlich-distanziert, aber in jedem Fall äußerst gewissenhaft recherchiert ist. Es wird vorerst eine der Hauptreferenzen für biografische Darstellungen über Elfriede Jelinek bleiben.

Jelinek selbst betont, dass keine geplante Medienstrategie hinter ihren Aussagen in Interviews stecke. Ursprünglich habe sie den Leuten "was erklären« wollen, damit diese ihre Texte besser verstehen, dann habe sie jedoch gemerkt, dass das nicht funktioniere, weil »die Leute nicht glauben, daß man ihnen etwas sagen möchte, sondern irgendeine List dahinter vermuten « ${ }^{326}$. Gerne würde sie die Dinge, die sie über sich preisgegeben hat, wieder zurücknehmen:

324 Jelinek hatte im Vorfeld der Preisverleihung ein TV-Team zu sich bestellt, ließ die Lesung des Texts aufzeichnen und bei der Preisverleihung abspielen, da sie sich außerstande sah, selbst nach Stockholm zu reisen und den Preis entgegenzunehmen.

325 Spanlang, Anmerkungen zu einer ungewöhnlichen Biographie, S. 247.

326 Fuchs/Jelinek, »Man steigt vorne hinein...«, S. 9. 
„Da ich inzwischen weiß, daß alles, was man sagt, gegen einen verwendet wird, wünsche ich, ich hätte nie etwas gesagt. ${ }^{327}$

Die für sie logische Konsequenz habe darin bestanden, keine Interviews mehr zu geben. Außerdem sei es ihr inzwischen »unerträglich, wie primitiv Aussagen über die eigenen Texte im Vergleich zur Vielschichtigkeit der Texte selber sind ${ }^{328}$.

Ebenso wie die literarischen Texte sind auch Jelineks autobiografische Schilderungen einer starken Stilisierung unterworfen. Auch die mündlich oder schriftlich (etwa per E-Mail) geführten Interviews sind von Übertreibung, Ironie und Sarkasmus geprägt. »Ich bin eine Autorin, die nicht einfach eins zu eins etwas herauskotzt, sondern die das ganze einer sprachlich so starken Stilisierung unterwirft, daß die Autorin am Ende in ihrem Text verschwindet", glaubt Jelinek selbst; sie sei zwar »überall drin«, aber so verschlüsselt, dass man sie nicht finden könne. ${ }^{329} \mathrm{Da}$ irrt sie jedoch - oder stilisiert sich wieder, denn in den meisten ihrer Texte findet man sie ohne große Mühe schnell wieder. Der »offensive Umgang mit den eigenen Neurosen ${ }^{330}$ kann nur als ironische Selbststilisierung und -distanzierung begriffen werden:

»Sicher versuche ich mich gegen Anwürfe schon im Vorhinein zu schützen, indem ich sie auf die Werfer zurückschmeiße, noch bevor ich den Schneeball auffangen konnte.«31

In diesem Sinne sind auch ihre autobiografischen Aussagen zu verstehen. Wie verlässlich oder »synthetisch" die in dem Autorinnenporträt dargelegten Informationen sind, kann zum jetzigen Zeitpunkt mangels alternativer Darstellungen nicht geklärt werden. Diese bleiben ein Desiderat für weitere lebensgeschichtliche Forschungen über Elfriede Jelinek.

Bei Berücksichtigung der genannten Problematiken stellt das Porträt von Mayer/Koberg eine geeignete Orientierungshilfe bei der ersten Annäherung an die Autorin dar, die sich selbst und ihre Innenwelt immer sehr stark in ihre Textproduktion einbringt. »Ich sage kaum jemals Ich, wenn ich mich in meinen Texten meine. ${ }^{332}$ Dennoch ist das Naheverhältnis einer ERIKA KOHUT oder ELFI ELEKTRA zu deren Schöpferin erahnbar. Es empfiehlt sich, auf die zahlreich vorhandenen Interviews zurückzugreifen, um sich selbst ein Bild darüber machen zu

327 Jelinek, zitiert nach: Winter, Gespräch mit Elfriede Jelinek, S. I I.

328 Fuchs/Jelinek, »Man steigt vorne hinein...«, S. го

329 Jelinek, zitiert nach: Winter, Gespräch mit Elfriede Jelinek, S. ıо.

330 profil, Nr. 42,2004 , S. I 24.

33 I Jelinek, zitiert nach: Janke/Kovacs/Schenkermayr, »Die endlose Unschuldigkeit«, S. 20.

332 Jelinek, oh mein Papa, unpaginiert. 
können, wie authentisch oder »synthetisch« die Lebensgeschichte der Nobelpreisträgerin ist oder nicht ist. ${ }^{333}$ Ironie und Witz, die Jelinek sich selbst zuschreibt, müssen auch im Falle der Autorinnenbiografie stets mitgedacht werden.

\subsection{Poetologische Einführung}

»Ihre ideologische wie ästhetische Position ist geprägt vom Geist der sechziger Jahre, vom Marxismus, von der Kritischen Theorie der Frankfurter Schule, insbesondere Th. W. Adornos, und vom frühen Roland Barthes. «334

Spätestens seit der Auszeichnung mit dem Nobelpreis ist Elfriede Jelinek zu einer "postmodernen Klassikerin ${ }^{335}$ geworden. Der Schreibstil der Nobelpreisträgerin zeichnet sich vor allem durch seinen innovativen Charakter aus, der sowohl in der Tradition der Moderne steht als auch Theorien der Postmoderne integriert. Von Anfang an hat Jelinek mit neuen Formen und mit Sprache experimentiert, »im Sinne einer Avantgarde der Avantgarde «36. Die Einflüsse, die auf die Entwicklung ihrer spezifischen Sprachästhetik und deren im Laufe der Jahre vorgenommene Modifikation eingewirkt haben, sind dabei vielfältig. Einige besonders prägende lassen sich dennoch konkret festmachen und sollen im Folgenden kurz dargestellt werden.

\subsubsection{Jelineks ästhetische Position: »Tradition des Sezierens«}

"Jelineks Werk steht im Zeichen der Abwendung von einer narrativen Tradition, die stark inhaltszentriert ist ... und die Literatur als srealistische< Abbildung der $>$ Wirklichkeit< versteht ...« $\ll^{337}$

Als Elfriede Jelinek in den I96oer Jahren ihre ersten Texte verfasste, tat sie dies unter dem Eindruck des Aufbegehrens einer jungen Generation, welche sich

333 Vgl. etwa Meyer, Sturm und Zwang; vgl. Fuchs, »Man steigt vorne hinein...«; vgl. Müller, Ich bin die Liebesmüllabfuhr; vgl. Friedl, Die Tiefe der Tinte; vgl. Winter, Gespräch mit Elfriede Jelinek; u.a.

334 Gürtler, Gegen den schönen Schein, S. 7.

335 Steinkellner, Traditionen der Moderne, S. 3.

336 Lücke, Elfriede Jelinek, S. 9 f.

337 Ebd., S. 8. 
mit den Werten und Traditionen der Eltern in Konflikt sah (jener Generation, die in den Nationalsozialismus und den Zweiten Weltkrieg involviert gewesen war). In Österreich fiel die Rebellion - verglichen mit den turbulenten, aufsehenerregenden und tragischen Ereignissen in den USA, in Frankreich oder in Deutschland - gemäßigt aus. ${ }^{338}$ So wird die österreichische r968er-Bewegung in Historie und Medien gerne als "Mailüfterl ${ }^{339}$, als »heiße Viertelstunde ${ }^{340}$ oder als "zahme Revolution « ${ }^{341}$ bezeichnet. Dennoch haben die Ereignisse der ausgehenden I 96oer Jahre die österreichische Gesellschaft stärker und schneller verändert als zu anderen Zeiten. ${ }^{342}$

Hierzulande war es vor allem eine Revolte der Künstler, die (in homöopatischen Dosen ${ }^{343}$ ) zu nachhaltigen Veränderungen in den alltäglichen »Lebenswelten « ${ }^{344}$ führte. Aktionskünstler wie Hermann Nitsch, Günter Brus oder Otto Muehl veranstalteten provokative »Happenings«, in denen sie den Körper selbst zum Ausdrucksmittel einer radikalen Gesellschaftskritik machten. ${ }^{345}$ Es wurden »Exzesse inszeniert und Ekelschranken durchbrochen, wurde mit Blut, Kot, Urin am nackten Körper experimentiert, öffentlich onaniert, enttabuisiert, provoziert ${ }^{346}$ - und nicht selten dafür Geld- und Freiheitsstrafen in Kauf genommen. Das von Künstlern und dem VSSTÖ ${ }^{347}$ gemeinsam organisierte Teach-in »Kunst und Revolution«, das medial zur »Uni-Ferkelei« hochstilisiert wurde, gilt heute vielen noch als Sinnbild eines österreichischen » 1968 « ${ }^{348} \mathrm{Im}$ Bereich der Literatur sorgten vor allem die Autoren der Wiener und der Grazer Gruppe, in deren Umfeld sich in späteren Jahren auch Elfriede Jelinek bewegte, für neue Impulse. ${ }^{349}$

338 Vgl. Hiebl, Lebenswelt(en) der 68er in Salzburg, S. 299.

339 Zitiert nach Bauer, Das 68er-Gedächtnis in Österreich, S. I3 I sowie S. I36.

340 Vgl. Keller, Mai 68, S. 74-79.

34I Vgl. Ebner/Vocelka, Die zahme Revolution, S. I I 8-r 44.

342 Vgl. Hiebl, Lebenswelt(en) der 68er in Salzburg, S. 299.

343 Vgl. ebd.: Hiebl zitiert eine Aussage Günther Nennings: „Das Jahr 1968 hat ein Jahr gedauert, aber in einem bestimmten Sinn dauert es immer noch fort, unterirdisch, homöopathisch. Nichts ist mehr so, wie es im Jahr 1967 war.«

$344 \mathrm{Zu}$ dem historischen Begriff der »Lebenswelt(en)«vgl. Kapitel I.4.2 dieser Studie.

345 Vgl. Bauer, Das 68er-Gedächtnis in Österreich, S. I 32. Vgl. dazu auch Hiebl, Sit-In, Teach-In, Go-In, S. I4.

346 Bauer, Das 68er-Gedächtnis in Österreich, S. I 32.

347 Abkürzung für den »Verband sozialistischer Student_innen Österreichs«.

348 Vgl. Bauer, Das 68er-Gedächtnis in Österreich, S. I 32.

349 Zur Wiener Gruppe gehörten H. C. Artmann, Konrad Bayer, Oswald Wiener, Gerhard Rühm und Friedrich Achleitner, im weiteren Umkreis auch Ernst Jandl und Friederike Mayröcker. Zur ursprünglichen Formation der Grazer Gruppe, die sich rund um das »Forum Stadtpark» gebildet hatte und die Zeitschrift »manuskripte« herausgab, gehörten unter anderem Peter 
Auch hier galt es, althergebrachte Traditionen zu überwinden und neue Formen zu finden. Die Wiener Gruppe hatte schon seit den r 95 oer Jahren versucht, an die von den Nationalsozialisten verfemten Avantgarden des frühen 20. Jahrhunderts anzuknüpfen und sich gleichzeitig von der völkischen Idiomatik vorangegangener Dekaden abzugrenzen. Dieses »antifaschistische Programm « ${ }^{350}$ sollte über eine neue Sprache zum Ausdruck gebracht werden, die sich allgemein über bisherige Konventionen hinwegsetzte und den »Materialaspekt « ${ }^{351}$ von Sprache in ihren Mittelpunkt stellte: Sprache sei demnach als optisches und akustisches Material zu verstehen, mit dem gearbeitet werden könne. Die Techniken der Wiener Gruppe umfassten das Montieren vorgefundener Sprachteile, das Variieren eines Wortstocks nach seriellen Prinzipien oder auch die Verwendung des Dialekts als Mittel der klangästhetischen Verfremdung. ${ }^{352}$ Dieser neue, experimentelle Umgang mit Sprache spiegelte sich etwa in H. C. Artmanns Dialektgedichten oder Ernst Jandls visueller Lyrik wider. In Berufung auf die Ideen Ludwig Wittgensteins sollten die Wechselwirkungen von Sprachgebrauch und Denkformen einer Gesellschaft deutlich werden. ${ }^{353}$

In diesem Milieu der von Künstlern inszenierten Provokation, der durch Literatur vermittelten Sprachskepsis und des gesellschaftlichen Aufbruchs sozialisierte sich Elfriede Jelinek als Autorin und verfasste ihre frühen Texte, die in methodischer Hinsicht bereits als richtungsweisend für ihr späteres Werk gelten können. Zu ihrer literarischen Selbstvergewisserung, aus der heraus sich ihre spezifische Schreibweise habe entwickeln können, sei Jelinek mit ihrem I 970 erschienenen Essay »Die endlose Unschuldigkeit« gelangt, so Janz. Der Essay rekurriert vorwiegend auf zeitgenössische (mediale) Bezüge:

»fernsehen ist heute so etwas wie das massenkommunikatorische über ich. es hat die vergesellschaftung übernommen als das technisch fortgeschrittenste medium... die werbung in zeitschrift und massenmedien sowie die sogenannten familienserien... und kurzfilme dieser sparte haben den karakter von kontrollinstanzen. von harter lenkung durch einsicht ...« ${ }^{354}$

Handke, Klaus Hoffer, Barbara Frischmuth und Wolfgang Bauer; in späteren Jahren kamen Gert Jonke, Gerhard Roth, Michael Scharang und eben Elfriede Jelinek dazu.

$35^{\circ}$ Vgl. Janz, Elfriede Jelinek, S. I.

35 I Doll, Mythos, Natur und Geschichte, S. I3.

352 Vgl. ebd., S. I3.

353 Vgl. Wittgenstein, »Philosophische Untersuchungen«.

354 Jelinek, Die endlose Unschuldigkeit, S. 52 f. 
Außerdem nennt Jelinek darin einige ihrer prägenden Vorbilder beim Namen: Roland Barthes, Hans Barth ${ }^{355}$, aber auch Theodor Adorno, der die Verantwortung der »Kulturindustrie « ${ }^{356}$ für die Etablierung des deutsch-österreichischen Faschismus hinterfragt hatte. Die Bedeutung der frühen Prosatexte (»bukolit«, "wir sind lockvögel baby!«, »Michael«) besteht vor allem darin, dass sich Jelinek hier ein nicht unwesentliches Repertoire an Bildern und Methoden zurechtgelegt hatte, auf das sie bei der Arbeit an späteren Texten zurückgreifen konnte und das grundlegend bleiben sollte für ihren charakteristischen Schreibstil. ${ }^{357}$ Besonders die Kritik an einer vom Faschismus vereinnahmten Sprache, aber auch die Nähe zu den Techniken der Wiener Gruppe sind bis heute kennzeichnend für ihr Schreiben geblieben. ${ }^{358}$

Neben der Orientierung an den »literarischen Kapazitäten ${ }^{359}$ rund um die Wiener Gruppe bezieht sich Jelinek auch immer wieder ausdrücklich auf die jüdisch-österreichische Literaturtradition, die aus der Bevölkerungskonstellation des Habsburger-Reichs erwachsen war, denn der hohe jüdische Bevölkerungsanteil hatte eine nicht unwesentliche Rolle für die Entwicklung einer spezifisch österreichischen Literatur gespielt, die sich von der deutschen in einigen Punkten wesentlich unterscheidet: Durch den Einfluss des Jüdischen wurde vor allem die Satire mit in die österreichische Literatur getragen, die in diesem Maße in Deutschland nie Fuß fassen konnte. ${ }^{360}$ Sie selbst sehe sich in der »Tradition des Sezierens von Karl Kraus und Elias Canetti, die vom Faschismus vernichtet worden ist oder die eben ausstirbt « ${ }^{361}$, bekennt Jelinek und verweist auf ihre familiär bedingte Verwurzelung in der jüdischen Kultur:

»Ich meine, dass ich sehr stark meine Wurzeln in der jüdischen Kultur habe, weil mein Vater Jude war, ein Ostjude aus der Tschechoslowakei. Und das sind meine persönlichen kulturellen Wurzeln. Und das spüre ich auch. Also Traditionen von Canetti, Kraus oder Joseph Roth. Das ist wirklich eine sterbende Kultur... Ich bin wahrscheinlich eh die letzte Dichterin dieser Richtung ...« ${ }^{362}$

Tatsächlich sind die Eigenheiten der österreichischen Varietät der beste Nährboden für das satirische Schreiben, denn auch in seiner schriftlichen Form bleibt

355 Auch Hans Barth befasste sich mit Mythentheorien. Vgl. Barth, Masse und Mythos.

356 Horkheimer/Adorno, Dialektik der Aufklärung, S. I4 I-I 9 I.

357 Vgl. Janz, Elfriede Jelinek, S. 7; vgl. auch Doll, Mythos, Natur und Geschichte, S. I 3 f.

$35^{8}$ Vgl. Doll, Mythos, Natur und Geschichte, S. I3.

359 Mayer/Koberg, Ein Porträt, S. 42.

$360 \mathrm{Vgl}$. Sander, Textherstellungsverfahren, S. 2 I.

36 I Jelinek, zitiert nach: Hoffmeister, Interviews, S. Io9.

362 Jelinek, zitiert nach: Sander, Textherstellungsverfahren, S. 2 I. 
das Österreichische gerne mündlich, was sich zum Beispiel in der übermäßigen Verwendung des Perfekts als Erzählzeit äußert. ${ }^{363}$ Sie fühle sich, so Jelinek, »leidenschaftlich und patriotisch und geradezu fanatisch « als österreichische und nicht als deutsche Autorin:

„Das Österreichische ist eine ganz andere Sprache... Jedenfalls haben die österreichischen Autoren - Gruppierungen wie die Wiener Gruppe zum Beispiel belegen das ja der Sprache selbst immer mehr vertraut als die Deutschen, die die Sprache eigentlich immer nur als Vehikel für irgendwelche Inhalte genommen haben. ${ }^{364}$

Auch die »beißende Kritik « ${ }^{365}$ der Wiener Volkstheaterdichter Johann Nestroy und Ferdinand Raimund, die sich im 20. Jahrhundert in der Literatur von Karl Kraus und Ödön von Horváth fortsetzte, sind als prägende Einflüsse für Jelineks Schreiben zu nennen: So finden sich Grotesken des Wiener Volkstheaters wie auch der nachgeahmte Bildungsjargon, mit dem Horváth seine Spießbürger ausstattete, als typische Gestaltungselemente in Jelineks Texten wieder. ${ }^{366}$

Auf diesen spezifisch österreichischen Traditionen baut der »böse Blick « ${ }^{367}$ der Elfriede Jelinek auf. Bei der (österreichischen) Autorin Jelinek werde nichts »normal« gesagt, bemerken die (deutschen) Jelinek-Biografen Mayer/Koberg:

»... bei Elfriede Jelinek geht es oft zu wie bei Nestroy: Nichts wird ınormak gesagt. Jeder Satz platzt auf, jede gewundene Formulierung hat mindestens eine Windung zu viel, an verräterischer Stelle, als Zeichen dafür, dass etwas nicht stimmt. «368

Jelinek betont zwar, dass sie sich immer bewusst darum bemüht habe, ihre Literatur in den Dienst einer "politischen Aussage zu stellen « ${ }^{369}$. Allerdings realisiert sie dieses Vorhaben nicht, indem sie versucht, die Wirklichkeit möglichst realistisch abzubilden, im Gegenteil: Mit ihrer Literatur wendet sie sich gegen eine Erzähltradition, die in sich geschlossene Geschichten mit Anfang, Mitte und Ende und mit psychologisch fundierten Charakteren erzählt, die sich zur

363 Vgl. Mayer/Koberg, Ein Porträt, S. 258. Zur österreichischen Varietät der deutschen Sprache vgl. Muhr/Schrodt/Wiesinger, Österreichisches Deutsch. Vgl. auch Ammon, Die deutsche Sprache in Deutschland, Österreich und der Schweiz, S. I I 7-22 7 .

364 Jelinek, zitiert nach: Sander, Textherstellungsverfahren, S. i $9 \mathrm{f}$.

365 Ebd., S. 22.

366 Vgl. ebd., S. 22 f.

367 Burger, Der böse Blick der Elfriede Jelinek, S. I 7 .

368 Mayer/Koberg, Ein Porträt, S. 259.

369 Fuchs/Jelinek, "Man steigt vorne hinein...«, S. 20. 
Identifikation anbieten. ${ }^{370}$ Es stimmt zwar, dass »... >reality< and its inscription in the ideology of our times is at the centre of Elfriede Jelinek's literary investigations", wie Allyson Fiddler schreibt, aber: «Jelineks form of realism ... is a concentrated or ssuper-reality«. 371

Ja, sie sei »eine Triebtäterin beim Schreiben « ${ }^{372}$, bekennt Jelinek. Sie verschlinge einen Gegenstand und mache »Sprachmarmelade « daraus, die man den Leuten "aufs Brot schmiert ${ }^{373}$. Die darzustellenden Wirklichkeiten werden in ihren Texten im jeweiligen Sprachgebrauch einer Gesellschaft oder einer gesellschaftlichen Gruppe reflektiert, den die Autorin bis ins Aberwitzige verzerrt und im Brecht'schen Sinne verfremdet, um die darin enthaltenen "manipulativen Strukturen « ${ }^{374}$ satirisch zu entlarven. Durch Versetzung der vorgefundenen Sprache mit ihrer Individualsprache wolle sie Bewusstmachung erreichen, so Jelinek. $^{375}$ „Die Sprache selbst will jetzt sprechen gehen! ${ }^{376}$, heißt es in dem Skandalroman »Lust« aus dem Jahr I 989. Auf diese Weise erscheint die Sprache als missbrauchter Ideologieträger, der die Künstlichkeit und Mythenhaftigkeit medialer und gesellschaftspolitischer Bezüge verschleiert. Nach Adorno manifestiert sich in der Sprache der »autoritäre Charakter» einer Gesellschaft, der diese auf den Faschismus vorbereite. ${ }^{377}$ Bei Jelinek aber wird das Instrument der Verführung mit allen Mitteln der Satire entblößt. Das Wort steht in ihren Texten daher stets über dem Inhalt. Es ist - in der jeweiligen Art und Weise seiner Verwendung - bereits als Inhalt zu lesen. Logos und Mythos stehen in einem ewigen Wechselspiel zueinander, das es $\mathrm{zu}$ hinterfragen und in weiterer Folge zu destruieren gilt. Die Wirklichkeit müsse immer falsch beschrieben werden, »aber so falsch, daß jeder, der sie liest oder hört, ihre Falschheit sofort bemerkt ${ }^{378}$.

Dementsprechend greift Jelinek bei der Textherstellung stets auf bestehende Prätexte zurück, die sie in den unterschiedlichsten Bereichen, der hohen wie auch der trivialen Kultur, der Wissenschaft, dem Boulevardjournalismus, in Werbeslogans oder in Liedtexten vorfindet. Diese »extreme ${ }^{379}$ Intertextualität ist charakteristisch für ihr gesamtes Werk:

370 Vgl. Lücke, Elfriede Jelinek, S. 7.

37 I Fiddler, Rewriting Reality, S. 3 I.

372 Jelinek, zitiert nach: Meyer, Sturm und Zwang, S. 74

373 Dies., zitiert nach: Urbach, Die Sprache unter dem Skalpell, S. I 5.

374 Dies., zitiert nach: Mayer/Koberg, Ein Porträt, S. 82.

375 Dies., zitiert nach: Kerschbaumer, Porträt einer jungen österreichischen Autorin, S. I 46.

376 Dies., Lust, S. 28

377 Bezüge zu Adornos »Studien zum autoritären Charakter«.

378 Jelinek, Im Abseits, unpaginiert.

379 Janz, Elfriede Jelinek, S. IX. 
»Fremdtexte waren und sind das Ausgangsmaterial ihres Schreibens. Nicht immer sind es literarische Texte, es können auch naturwissenschaftliche, philosophische oder triviale Lektüren sein, eine Zeitungsmeldung oder historisches Material.... Sie braucht die verschiedenen Jargons, als Unterlage, als Gegengewicht oder als Klangfarbe.« ${ }^{380}$

Dabei betreibt Jelinek ein ständiges, detailverliebtes Spiel mit dem Veränderungspotential aller Sprachelemente, die aus ihren vorgefertigten Sinnzusammenhängen herausgerissen und deren durch Konventionen festgelegte Bedeutungen dadurch in Frage gestellt oder verworfen werden. Sabine Braun bezeichnet diesen Prozess als »semantische Umcodierung « ${ }^{381}$. Diese wendet die Autorin auf verschiedenen Ebenen der Sprache an. Auf der Wortebene kann sie als Veränderung oder Verschiebung einzelner Buchstaben, als Alliteration, Wiederholung, Kalauer (»Ich liebe Kalauer! ${ }^{382}$ ), als Aneinanderreihung gleich oder ähnlich klingender Wörter und/oder als bewusster Verstoß gegen die Orthografie daherkommen. ${ }^{383}$ Auch auf Ebene der Phrasen und Idiome realisiert Jelinek dieses Verfahren, indem sie gängige Phrasen aufgreift, deren herkömmliche Bedeutungen jedoch ad absurdum führt, etwa durch die übermäßige Verwendung von Metaphern und Vergleichen, durch die Integration von Zitaten und Aphorismen, das Wörtlichnehmen idiomatischer Wendungen oder die Verwendung verschiedenster Jargons und Dialekte. Auch auf der Textebene greift sie bereits bekannte Texte oder Diskurse auf und verarbeitet sie weiter, indem sie diese aus ihren herkömmlichen Sinnzusammenhängen herausreißt und dadurch fragwürdig erscheinen lässt. ${ }^{384}$ Das methodische Prinzip ist immer dasselbe: Jelinek arbeitet »mit vorgefertigten und vorgestanzten Mustern« der trivialen, aber auch der hohen Kultur, um sie »in Verfahren der Collage und Montage zu verformen und ideologiekritisch zu brechen ${ }^{385}$. Die genannten Ebenen der Textherstellungsmethodik können dabei nicht unabhängig voneinander betrachtet wer-

$380 \quad$ Mayer, Elfriede Jelinek, S. 77.

38 I Braun, Sprache und Ironie bei Elfriede Jelinek, S. 28

382 Jelinek, zitiert nach: Mayer/Koberg, Ein Porträt, S. 258

383 Jelineks Verweigerung der Neuen Rechtschreibung wird hier nicht zu den Stilmitteln gerechnet - sie ist vermutlich als Ausdruck ihres Protests gegen die jüngste Rechtschreibreform zu verstehen. In jungen Jahren wendete Jelinek, so wie viele ihrer sprachkritischen Vorbilder, kategorische Kleinschreibung an und schrieb ohne Interpunktion, manchmal über die Zeilenränder hinausgehend, in einem durch. Das normative Regelwerk der Sprache wurde damals und wird heute von ihr bewusst durchbrochen. Dieses Durchbrechen ist Teil ihres destruktiven Programms.

384 Vgl. Braun, Sprache und Ironie bei Elfriede Jelinek, S. $27 \mathrm{f}$.

385 Janz, Elfriede Jelinek, S. VII f. 
den - sie stehen in einem "symbiotischen Verhältnis « ${ }^{386}$ zueinander. Gemein ist ihnen die Tatsache, dass es sich in den meisten Fällen um bewusste (syntaktische, semantische oder orthografische) Regelverstöße handelt. ${ }^{387}$ "Ich schlage sozusagen mit der Axt drein, damit kein Gras mehr wächst, wo meine Figuren hingetreten sind $\aleph^{388}$, beschreibt die Autorin ihre Theaterästhetik und rekurriert damit auf Franz Kafkas Ansicht, dass Literatur, die uns glücklich mache, obsolet sei. ${ }^{389}$ Auch Elfriede Jelinek hat sich diesen Anspruch zur Aufgabe gemacht, weshalb ihr von Seiten der Literaturkritik oft vorgeworfen wird, dass sie sich einer Literatur der totalen Negativität verschrieben habe. ${ }^{390}$

Die Negativität steckt freilich im Kern des Destruierens, denn dem Destruieren ist der »Wille zur Zerstörung « ${ }^{391}$ eigen - zur Verfremdung und Auflösung der »Trivialmuster unserer Welt « ${ }^{392}$. Allerdings setzt die verkehrte Welt stets eine bessere als Maßstab und Ziel der Kritik voraus, weil das satirische Schreiben, zu welchem sich Jelinek bekennt, ohne eine theoretisch vorhandene bessere Welt nicht funktionieren würde. ${ }^{393}$ Insofern ist das Eingeständnis der Negativität als relativ zu betrachten.

Das Aneinanderreihen und Ineinandermontieren verschiedenster Textelemente geschieht bei Jelinek zwar, wie Braun feststellt, ohne erkennbare Rangordnung ${ }^{394}$, jedoch wohl nur scheinbar zufällig, denn in Bezug auf die Frage der Textherstellung sollte Jelineks klassische Musikausbildung nicht außer Acht gelassen werden. Tatsächlich gehorchen die Texte der diplomierten Organistin - so sehr sie auch darauf abzielen mögen, mit sprachlichen Konventionen zu brechen - einer (klang-)ästhetischen Logik, welche die Schwedische Akademie als "musikalischen Fluss ${ }^{395}$ bezeichnet hat. Doch nicht nur das vom Nobelpreiskomitee prämierte Spiel von Stimmen und Gegenstimmen erzeugt den Eindruck eines musikalischen Schreibstils, sondern auch die starke Ästhetik der lautlichen Verfremdung (die auch die Laut- und Dialektgedichte der Wiener Gruppe kennzeichnete).

386 Braun, Sprache und Ironie bei Elfriede Jelinek, S. 28.

387 Vgl. ebd.

388 Jelinek, Ich schlage sozusagen mit der Axt drein, S. I4.

389 Ein Buch müsse »die Axt sein für das gefrorene Meer in uns«, hatte Kafka in einem Brief an Oskar Polack vom 27. Januar 1904 geschrieben. Zitiert aus: Kafka, Gesammelte Werke, S. 27 f. Vgl. Gürtler, Gegen den schönen Schein, S. 9 f.

39 I Hoff, Stücke für das Theater, S. I I 4.

392 Alms, Triviale Muster, S. 3 I.

393 Vgl. Claßen, Satirisches Erzählen, S. 8.

394 Vgl. Braun, Sprache und Ironie bei Elfriede Jelinek, S. 28.

395 Aus der Pressemitteilung der Schwedischen Akademie vom 7.IO.2004, zitiert nach: Janke, Literaturnobelpreis Elfriede Jelinek, S. I 9. 
In einem kompositorischen Akt entstehen ineinander verwobene monologisierende, selten narrative Texteinheiten (inzwischen vor allem: »Textflächen«), die durch ihren formalen, lautlichen und/oder inhaltlichen Gehalt Assoziationen bzw. Assoziationsketten hervorrufen. Die Grenzen zwischen Gattungen und Formen sind kaum mehr erkennbar, auch die auftretenden Figuren sind nicht als psychologisch-einheitliche Charaktere aufzufassen, sondern als »Vermischungs-, Verschränkungs-, Kunst- und Kippfiguren ${ }^{396}$, aus denen Stimmen des Bewussten wie auch des Unbewussten sprechen. ${ }^{397}$

Jelineks Sprache "tummelt sich selbst im Wahnsinn ${ }^{398}$, befindet Barbara Alms. Für die Rezeption bedeutet dies, dass sich viele Texte dem unmittelbaren, spontanen Verstehen entziehen. Vor allem in jüngeren Texten ist der inhaltliche »rote Faden« nur schwer erkennbar; er ist jedoch vorhanden, in die Textflächen eingenäht; durch die semantische Verkettung der genannten Texteinheiten muss er aus der Tiefe erst hervorgeholt werden, immer in direkter Abhängigkeit vom Rezeptionsprozess. Viele Jelinek-Texte zielen auf ein assoziatives Rezeptionsverständnis ab. Die Autorin selbst glaubt, unter einem krankhaften Assoziierungszwang zu stehen:

»Irgendwie sind meine Ganglien offenbar so lose verdrahtet, daß ich einen ständigen Assoziierungszwang habe. Wenn ich ein Wort höre, auch im Alltag, muß ich zwanghaft sofort Alliterationen, Paraphrasen, Metathesen herstellen, Silben vertauschen. ${ }^{399}$

Nun pflegt Elfriede Jelinek die Angewohnheit, zwar sehr schnell und viel zu schreiben, ihre Texte aber immer wieder zu überarbeiten, bis diese in einer Form sind, mit der sie zufrieden ist ${ }^{400}$, was wiederum als Hinweis dafür gelten kann, dass sie die Elemente ihrer Texte nicht zufällig aneinanderreiht, sondern tatsächlich einen kompositorischen und klangästhetischen Plan verfolgt. Außerdem gilt sie als "Fanatikerin der sauberen Seite « ${ }^{401}$, die im Zeitalter der Schreibmaschine ganze Manuskriptseiten neu abgetippt hatte, wenn sie fehlerhaft gewesen waren. ${ }^{402}$ Was Jelineks Neigung zum wiederholten Überarbeiten zweifelsohne entgegenkommt und darüber hinaus ihren "anarchischen « ${ }^{403}$ Schreibstil befördert, ist die Tatsache, dass sie schon sehr früh den Computer

396 Lücke, Elfriede Jelinek, S. 9.

397 Vgl. ebd., S. 8 f.

398 Alms, Triviale Muster, S. 3 I.

399 Jelinek, zitiert nach: Meyer, Sturm und Zwang, S. 72.

400 Vgl. Mayer/Koberg, Ein Porträt, S. 78.

$40 \mathrm{I}$ Ebd., S. I 46.

402 Vgl. ebd.

403 Fuchs/Jelinek, »Man steigt vorne hinein...«, S. 2 O. 
als Arbeitsinstrument adaptiert hat. ${ }^{404}$ Texte oder Textteile können mit dem Computer ungleich schneller verändert, kopiert, gelöscht oder erweitert werden als mit der Schreibmaschine. Der Computer, so Jelinek, fordere sie regelrecht dazu heraus, die Wörter wie LEGo ${ }^{\oplus}$-Bausteine hin- und herzuschieben. ${ }^{405} \mathrm{Die}$ Arbeit mit dem PC erleichtert der Autorin demnach nicht nur den formalen Schreibprozess, sondern begünstigt darüber hinaus ihren Hang, spielerisch mit allen Komponenten der Sprache zu hantieren. Ihren letzten Roman, den sie als "Privatroman« bezeichnet, hat Jelinek sogar ausschließlich (in Fortsetzungen) auf ihrer Homepage veröffentlicht und nicht als Buch von einem Verlag herausgeben lassen. „Dieser Text mit Namen `Neid gehört nicht in ein Buch«, soll sie Freunden ausgerichtet haben, die nach einer Printversion des Texts verlangt hatten, »er gehört nicht auf Papier, er gehört in den Computer hinein, dort habe ich ihn hineingestellt ... und bin dann einfach weggegangen. ${ }^{406}$

Prinzipiell gilt, dass Jelinek schreibend nichts Neues schafft, sondern Bestehendes aufgreift, in seine Einzelbestandteile zerlegt, in veränderte Zusammenhänge stellt oder mit etwas Neuem zusammenführt. Auf diese Weise destruiert sie bestehende Sprachgebrauchsformen, anstatt schreibend zu konstruieren, und zeichnet sich durch die Konsequenz dieser methodischen Umsetzung aus.

\begin{abstract}
»Niemals wird einer sunwirklichen « Welt eine >wirkliche`, wird der Fiktion die >Realität entgegengesetzt. Vielmehr wird die Entlarvung des Falschen und Entfremdeten vorgenommen durch seine abermalige Entstellung, die nichts Neues und Anderes schafft, sondern selber gebunden bleibt an die trivialen Muster und ihre wie immer auch deformierende Reproduktion. ${ }^{407}$
\end{abstract}

Durch diese Techniken ergeben sich allerdings auch Einschränkungen für die Rezeption, denn die Autorin legt sich nicht nur durch die Auswahl ihrer Themen, die sehr stark auf aktuelle gesellschaftspolitische und mediale Bezüge rekurrieren, sondern auch durch ihren intertextuellen Schreibstil bewusst auf den (süd-)deutschen/österreichischen Sprachraum fest. Eine internationale Rezeption erscheint daher nur eingeschränkt möglich. Die Übersetzung ihrer Texte bedeutet in jedem Fall die Herausforderung, in der jeweiligen Zielsprache einen neuen Schreibstil entwickeln zu müssen, der Jelineks Methoden adaptiert. Selbst

404 Auf Anregung ihres Mannes, Gottfried Hüngsberg, hin, begann Jelinek bereits Mitte der I $980 e r$ Jahre den Computer zum Schreiben zu benützen. Mayer/Koberg, Ein Porträt, S. 76 sowie S. $145 \mathrm{f}$.

405 Vgl. Leiprecht, Die elektronische Schriftstellerin, S. 3.

406 Vgl.»Ein paar Anmerkungen zu Neid«, online abrufbar unter: http://www.elfriedejelinek.com.

407 Janz, Elfriede Jelinek, S. 7 . 
wenn diese Herausforderung geschafft ist, sind die gesellschaftlichen Rahmenbedingungen der jeweiligen Sprachgemeinschaft trotzdem immer noch gänzlich andere. Daher wurden bisher vorrangig die narrativen Texte (»Die Liebhaberinnen«, »Die Klavierspielerin«, »Die Ausgesperrten«) in Fremdsprachen übersetzt sowie die frühen Theaterstücke (mit Ausnahme des »Burgtheater«-Stücks, das eine hochartifizielle Sprache aufweist). Durch die Verleihung des Nobelpreises wurden jedoch auch in dieser Hinsicht neue Anstrengungen unternommen: So liegen etwa inzwischen Übersetzungen neuerer Theaterstücke ins Englische und Französische vor sowie Übersetzungen ihres großen Romans »Die Kinder der Toten« ins Niederländische, Russische, Polnische und Japanische, die französische Ausgabe (»Enfants des Morts Seuil«) wurde 2006 mit dem André-GidePreis ausgezeichnet.

Als für die Rezeption weiters einschränkende Komponente muss hier ebenfalls auf die Zeitbezogenheit vieler Jelinek-Texte verwiesen werden: Das vielfache Rekurrieren auf zeitgenössische Diskurse ermöglicht der Schriftstellerin zwar den Kommentar und die Kritik an aktuellen Geschehnissen und Rahmenbedingungen, macht aber ein Verständnis aus der nachträglichen Perspektive nur bedingt möglich - was der Autorin jedoch sehr wohl bewusst ist. Schließlich sei es ihr wichtig, ihre Literatur in den Dienst »der politischen Aussage zu stellen ${ }^{408}$, was eine Bindung an gegenwärtige Verhältnisse zwangsweise mit sich bringt. Vor allem die Sprache der Medien ist einem ständigen Wandel unterworfen; Anspielungen auf aktuelle Fernsehserien, Kinofilme, Werbespots oder Zeitungsmeldungen sind daher für nachgeborene Generationen nur eingeschränkt nachvollziehbar.

Selbsteinschränkungen nahm Jelinek wiederholt in Interviews vor, aber vor allem auch in ihrer Nobel Lecture, deren Niederschrift mit dem Titel »Im Abseits « als ihr "poetologisches Manifest ${ }^{409}$ gehandelt wird. Nun, es wäre nicht Elfriede Jelinek, wenn sie nicht auch die eigene Sprache, das eigene Schreiben ihrem zentralen Verfahren, der Mythendestruktion, unterziehen würde. Ihr Verhältnis zur Sprache sei durch gegenseitige Abhängigkeiten und wechselnde, stets ungleiche Machtverhältnisse charakterisiert: Einmal sei es die Schriftstellerin, die sich der Sprache als "Wirkungsmaschine ${ }^{410}$ bedient, einmal die Sprache, die an der Schriftstellerin zerrt und zieht wie ein Hund, der seinen Besitzer »an der Leine hinter sich her zerrt ${ }^{411}$ und die Richtung, in der es weitergeht, vorgibt. »Wenn ich schreibe, dann führen mich bei irgendeinem Wort

408 Ebd., S. 20.

409 Mayer/Koberg, Ein Porträt, S. 257.

4IO Ebd.

4I I Jelinek, zitiert nach: Ebd. 
die Assoziationen plötzlich in eine ganz unerwartete Richtung, dann gibt es in einem Satz plötzlich drei Doppelaxel ${ }^{412}$, so Jelinek. Der Dichter stehe immer im »Abseits«, außerhalb der Wirklichkeit, die er versuche abzubilden, erklärte sie in ihrer Rede zum Nobelpreis. Von dort aus sehe er die Wirklichkeit zwar besser, könne selbst aber nicht dort bleiben, weil es in der Wirklichkeit keinen Platz für ihn gebe. ${ }^{413}$ Und nun scheine es so, als ob die Sprache in die Wirklichkeit verschwinde und die Dichterin im Abseits allein lasse:

»Weil ich im Schreiben Schutz gesucht habe, kehrt sich dieses Unterwegssein, die Sprache, die in der Bewegung, im Sprechen, mir ein sicherer Unterstand zu sein schien, gegen mich. (...) Was immer geschieht, nur die Sprache geht von mir weg, ich selbst, ich bleibe weg. Die Sprache geht. Ich bleibe, aber weg. Nicht auf dem Weg. Und mir bleibt die Sprache weg. ${ }^{414}$

Dass Elfriede Jelinek tatsächlich die Sprache wegbliebe, steht nicht zu befürchten. »Im Abseits« widerspiegelt zum einen den vorläufigen Endpunkt einer jahrelangen ästhetischen Entwicklung und ist zum anderen wie sämtliche Jelinek-Texte als Satire zu lesen. Und so bereitet der Autorin, die souverän wie kaum eine andere mit Sprache hantiert, die scheinbare Unterordnung unter ihr "Hündchen« keinerlei Probleme. Die Dankesreden, die Jelinek im Laufe der Jahre aus Anlass verschiedenster Ehrungen gehalten hat, dokumentieren einen »schleichenden Rückzug « ${ }^{415}$, meinen die Biografen Mayer/Koberg. Am Ende dieses Rückzugs stehe die vielleicht bittere, aber jedenfalls befreiende Erkenntnis, für niemanden mehr Verantwortung tragen zu müssen: weder für die Mutter, noch für die Gesellschaft, noch für das eigene Schreiben.

Jelineks zentrales Schreibverfahren ist die Destruktion, ihr bevorzugtes Genre die Satire. Am Höhepunkt ihres literarischen Schaffens destruiert sie die eigene Sprache, das eigene Schreiben, den eigenen Mythos. Aus dem Abseits kann sie, die Nobelpreisträgerin, die alles erreicht hat, was man im Beruf des Schriftstellers erreichen kann, entspannt beobachten, wie bemühte Germanisten versuchen, das zusammenzubasteln, was sie längst in die Freiheit entlassen hat. Wer hier wen Gassi führt, ist demnach schon längst entschieden.

4I 2 Dies., zitiert nach Leiprecht, Die elektronische Schriftstellerin, S. 3.

4I3 Vgl. ebd.

4I4 Ebd.

4I 5 Mayer/Koberg, Ein Porträt, S. 257. 


\subsubsection{Destruktion des Opfermythos: »Das ist mein Angelpunkt« ${ }^{416}$}

»Diese falsche und verlogene Unschuldigkeit

Österreichs ist wirklich immer mein Thema gewesen, eigentlich in allen meinen Sachen. Ja, ich würde sagen, das ist mein Angelpunkt.«" ${ }^{417}$

Wenn die germanistische »Quasi-These ${ }^{418}$ stimmt, dass jeder Dichter nur ein großes Thema hat, das er in seinem gesamten Werk immer neu variiert und in immer neuen Verfahren durchspielt, dann ist schnell klar, welches Thema Elfriede Jelinek immer wieder aufs Neue an den Schreibtisch treibt. Das Schicksal der Vater-Familie mag die beständige Konfrontation mit Faschismus und Opfermythos bedingt haben. Bereits in ihrer frühesten Kindheit habe sie die jüdische Familie des Vaters auf das »Nie wieder!« eingeschworen, so Jelinek in einem Interview, was bei ihr in "rasende Rache- und Wutfantasien ${ }^{419}$ umgeschlagen sei.

Dabei begreift Jelinek den Nationalsozialismus nicht als singuläres historisches Ereignis, sondern sieht ihn vielmehr - aus dem Blickwinkel einer deklarierten Marxistin - als gewaltsame Eskalation einer allgemeinen, überzeitlichen Tendenz zur Herstellung ungleicher Besitz- und Gewaltverhältnisse innerhalb der Gesellschaft (etwa zwischen den sozialen Klassen, den Geschlechtern, den In- und Ausländern, den Generationen, in der NS-Zeit zwischen »Ariern« und »Nicht-Ariern«), die in der nationalsozialistischen »Rassenlehre« biologistische Begründung und mit zahlreichen Strategien der »Verdummung« und Manipulation im Alltagsleben der deutschen und österreichischen Bevölkerung ihren Niederschlag fanden. Unaufhörlich hebt sie die historische Singularität des Holocaust hervor; doch mit ständigen Verweisen auf die Kontinuitäten des faschistischen Phänomens wendet sich Jelinek eindeutig gegen Ernst Noltes Charakterisierung vom »Epochencharakter ${ }^{420}$ des Faschismus, die auch von der Zeithistorie längst verworfen wurde. Sie wolle, so Jelinek, in ihren Texten einen Faschismus beschreiben, der in der Familie, in der Beziehung zwischen Mann und Frau beginne, und Faschismus als »allgemeinen Gemütszustand « ${ }^{421}$ aufdecken. Dabei charakterisiert dieser »allgemeine Gemütszustand« die Haltung

\footnotetext{
4 6 Jelinek, zitiert nach: Janke/Kovacs/Schenkermayr, »Die endlose Unschuldigkeit«, S. 2 I f.

$4 \mathrm{I} 7$ Ebd.

4I 8 Lücke, Elfriede Jelinek, S. 7 .

4I 9 Jelinek, zitiert nach: Nüchtern, »Ich bin ein Racheengerl«, Falter I 4/o3.

420 Nolte, Der Faschismus in seiner Epoche, S. 25. Vgl. auch Kapitel I.4.I dieser Studie.

42 I Jelinek, zitiert nach: Sander, Textherstellungsverfahren bei Elfriede Jelinek, S. 3 I.
} 
der Vielen $^{422}$ (die ent-individualisierte, ent-politisierte und ent-historisierte Mehrheitsbevölkerung), ohne deren stille Duldung die Eskalation von Gewalt und Krieg im Nationalsozialismus nicht möglich gewesen wäre. ${ }^{423}$

Auch ihre scheinbar rein feministischen Texte, der Roman »Die Liebhaberinnen« oder das Theaterstück »Was geschah, nachdem Nora ihren Mann verlassen hatte ihre Situierung im Kontext von Poststrukturalismus und Postmoderne werden jedoch »zumeist falsch eingeschätzt, weil ihre marxistischen Orientierungen ausgeblendet werden ${ }^{424}$, so Marlies Janz. Jelineks Mythendestruktionen verstehen sich als "aufklärerische Ideologiekritik ${ }^{425}$. In dieser werden die ungleichen Machtverhältnisse von der jeweils herrschenden Klasse, gesellschaftlichen Gruppe oder dem dominierenden Geschlecht künstlich hergestellt und als gesellschaftliche Mythen weitergegeben. Als Vehikel für deren Propagierung dient eine manipulierbare und ideologisch vereinnahmbare Sprache, welche über die modernen Massenmedien als scheinbare Norm transportiert wird.

Mit ihrer Sprach- und Medienkritik steht Jelinek in der Tradition Theodor Adornos, der Faschismus als ein Phänomen der manipulierten, verdummten und ent-politisierten Masse dargestellt sowie den Zusammenhang von Sprache und Faschismus beschrieben hat. ${ }^{426}$ Für Adorno bestand die größte Gefahr des Nationalsozialismus in dem »Fortbestand jener Strukturen, welche ihn seiner Meinung nach einst befördert und gestützt hatten ${ }^{427}$.

Eben jenen Fortbestand will Jelinek mit ihrem Destruktionsverfahren aufzeigen, das keine Lösungen anbietet, sondern Sprachgebrauchsformen widerspiegelt und parodiert, denn anhand der Sprachverwendung einer Gesellschaft können Mythen reflektiert werden. Auf diese Weise wird »das Wiedergängertum des Faschismus ${ }^{428}$ zum zentralen Gegenstand in ihrem Euvre, und zwar nicht nur als Thema, sondern auch als Fixpunkt ihrer literarischen Verfahrensweisen. ${ }^{429}$

Der Opfermythos als spezifisch österreichisches Phänomen stellt sich dabei für Jelinek als Folge der Verschleierung und Manipulation einer politisch ver-

422 Lüdtke, Macht der Emotionen, S. 54.

423 Vgl. Kapitel r.4.2 dieser Studie.

424 Janz, Elfriede Jelinek, S. VII.

425 Ebd.

426 Vgl. Adorno/Horkheimer, Dialektik der Aufklärung, vor allem das Kapitel »Kulturindustrie. Aufklärung als Massenbetrug«, S. I4I-I9I. Vgl. auch Geml, Zum Begriff des Faschismus bei Adorno, S. $67 \mathrm{ff}$.

427 Geml, Zum Begriff des Faschismus bei Adorno, S. 69.

428 Lücke, Elfriede Jelinek, S. 7 .

429 Vgl. Janz, »Die Geschichte hat sich nach 45 entschlossen«, S. 225. 
einnahmten Sprache dar. Offenbar wird er durch die Widerspiegelung und Verfremdung bestimmter Sprachgebrauchsformen, die einen Mythos manifestieren, der in Bartheschem Sinne nur als Entscheidung bewusst handelnder Menschen zu einer ihnen dienlichen Interpretation der Geschichte verstanden werden kann - als nationaler Konsens, der in der Sprache der Medien, der Politik und der österreichischen Soziolekte seit I 945 festgeschrieben ist. ${ }^{430}$

Schon in »bukolit", ihrem ersten Roman, thematisierte Jelinek das Fortleben einer deutschen »Volksempfängerkultur ${ }^{431}$ und beschäftigte sich auch in »wir sind lockvögel baby!« mit dem medialen Nebeneinander von amerikanischer Popkultur und faschistoider Heimat- und Volkstümelei. ${ }^{432}$ Sprachlich orientiert sich das »lockvögel«-Buch an den experimentellen Mitteln der Wiener Gruppe: Das Schriftbild ist von Kleinschreibung, dem Verzicht auf Interpunktion und der Eindeutschung von Fremdwörtern geprägt. Auch die Verwendung des Dialekts als Mittel der phonetischen Verfremdung ist dem methodischen Repertoire der Wiener Gruppe entlehnt. ${ }^{433}$ Einen Inhalt wiederzugeben, ist schwierig: In »thrillerartigen Plots ${ }^{434}$ tauchen die Beatles, diverse Comicfiguren und Filmhelden auf, daneben der osterhase und der White giant aus der Waschmittelwerbung. Das Buch »invertiert die heile manichäische Welt der Comics, um deren implizite Ideologie offenzulegen ${ }^{435}$.

So versuchte Jelinek mit starkem Bezug zu Barthes und der sinngemäßen, mitunter sogar wörtlichen Wiedergabe seiner Thesen in ihren frühen Texten vorrangig die zeitgenössische Trivialkultur auf die in ihr virulente Gewalt durchsichtig zu machen. ${ }^{436}$ Was die Rezeption ihrer frühen Prosa aus heutiger Sicht allerdings erschwert, sind die darin zahllos enthaltenen Anspielungen auf damals aktuelle TV-Serien, Filme, Trivialromane, Comics, Musikidole und Werbeslogans, die von nachgeborenen Generationen nicht dementsprechend decouvriert werden können. Der Zusammenhang zwischen Medien- und Faschismuskritik blieb (vermutlich auch deswegen) in der Jelinek-Rezeption lange unbemerkt. ${ }^{437}$

\footnotetext{
430 Vgl. Kapitel I.4.4 dieser Studie.

43 I Janz, »Die Geschichte hat sich nach 45 entschlossen«, S. 228.

432 Vgl. ebd.

433 Vgl. Scheidl, Ein Land auf dem rechten Weg, S. I45. Vgl. auch Doll, Mythos, Natur und Geschichte, S. I3.

434 Scheidl, Ein Land auf dem rechten Weg, S. I 45.

435 Ebd.

436 Vgl. Janz, »Die Geschichte hat sich nach 45 entschlossen«, S. 229.

437 Eine Neubewertung des Frühwerks leistete erstmals Evelyn Annuß in ihrer Magisterarbeit von 1994: Annuß, Wa/h/re Intertextualität. Vgl. Janz, »Die Geschichte hat sich nach 45 entschlossen«, S. $227 \mathrm{f}$.
} 
Der 1972 erschienene Prosatext »Michael. Ein Jugendbuch für die Infantilgesellschaft « markiert eine Hinwendung Jelineks zu realistischeren Inhalten. ${ }^{438}$ Sie habe »sehr experimentell begonnen «, so Jelinek, und dann versucht, realistische Inhalte mit formal und ästhetisch avancierten Methoden zu verbinden. ${ }^{439}$ Von der Schreibweise der experimentellen Literatur blieben in »Michael« nur die Kleinschreibung und die fehlende Interpunktion übrig, das Wortmaterial per se hingegen blieb intakt. Die Mythendestruktion erreichte die Autorin in diesem wie auch in dem nachfolgenden Roman (»Die Liebhaberinnen«) über konstruktivistische Prinzipien wie Wiederholung, Parallelismus und Anapher. ${ }^{440}$ Wiederum stehen die Trivialmedien als Träger ideologisch aufgeladener Inhalte im Mittelpunkt: "Michaek ist die Sprache der elektronischen Medien, die den Menschen im Spätkapitalismus immer mehr verdummen und auf den Status von unmündigen Kindern fixieren. Das geschieht natürlich im Interesse der herrschenden Klasse, der selbstdenkende Individuen gefährlich werden können « ${ }^{441}$, so Jelinek. Die Lehrlinge ING RID und GERDA repräsentieren das Zielpublikum von Illustrierten und Fernsehserien. Vor allem Themen und Ausdrucksweisen aus damals beliebten Familienserien wie »Flipper«, »Lieber Onkel Bill» oder »Ida Rogalski« werden aufgegriffen und parodiert. ${ }^{442}$ Die Sprache des Fernsehens wird dabei als Instrument der sozialen Beschwichtigung vorgeführt: Das Fernsehen - als das neue große Massenmedium der i 96oer/7oer Jahre - soll die Trivialmythen im Bewusstsein der Menschen verankern und damit die Welt in ihrer »unbeweglichkeit ${ }^{443}$ halten. ${ }^{444}$ Ihren Traum vom sozialen Aufstieg wollen INGRID und GERDA durch Heirat herbeiführen (wobei der Mann selbst oder gar romantische Gefühle wie Liebe oder Verliebtheit dabei sekundär sind). Sie lassen nichts unversucht, den Firmenchef jeweils für sich zu gewinnen. Ihr Traum von einem besseren Leben kann sich auf diese Weise natürlich nicht erfüllen. Stattdessen müssen INGRID und GERDA wahre Gewaltorgien über sich ergehen lassen. ${ }^{445}$

»Jelinek transformiert so genannte >strukturelle Gewalt ‘ in Bilder physischer Gewaltanwendung - eine Konstante in ihrem Werk. «"46

438 Vgl. Scheidl, Ein Land auf dem rechten Weg, S. I45.

439 Jelinek, zitiert nach: Winter, Gespräch mit Elfriede Jelinek, S. I 2.

440 Vgl. Janz, Elfriede Jelinek, S. I 5 f.

44I Kerschbaumer, Poträt einer jungen österreichischen Autorin, S. I 46.

442 Vgl. Janz, Elfriede Jelinek, S. I6.

443 Jelinek, Die endlose Unschuldigkeit, S. 82.

444 Vgl. Janz, Elfriede Jelinek, S. I 7.

445 Vgl. Scheidl, Ein Land auf dem rechten Weg, S. I $45 \mathrm{f}$.

446 Ebd., S. 146. 
Der Titel des Romans verweist nicht nur auf einen in den r96oer Jahren beliebten Taufnamen, sondern zugleich auch auf einen 1929 erschienenen, autobiografisch gefärbten Roman des späteren NS-Propagandaministers Joseph Goebbels - »Michael. Ein deutsches Schicksal in Tagebuchblättern«, der mit seinem im Titel geäußerten Repräsentationsanspruch in der NS-Zeit als »Bildungsroman« weite Verbreitung fand. Die Referenz auf Goebbels' Roman kann nach Janz als Hinweis auf die starke Politisierung Jelineks in dieser frühen Phase ihres literarischen Schaffens gewertet werden, die für ihr weiteres Schreiben charakteristisch blieb. ${ }^{447}$

In dem wenige Jahre später erschienenen »Liebhaberinnen«-Roman griff Jelinek Motive auf, welche vor allem in trivialen Liebesromanen (»Groschenromanen«) als Rechtfertigungsmuster für ideologisierte Gewalt zwischen den Geschlechtern, aber auch zwischen den sozialen Klassen angeboten wurden. ${ }^{448}$ Der gesamte Text arbeitet mit bipolaren Mustern, die auf beständige Konfrontation von Trivialmythen und Realität abzielen (Entgegensetzung der beiden Protagonistinnen paula und brigitte, Entgegensetzung von Stadt und Land usw.). Die in Heimat- und Liebesromanen beschworenen Mythen von romantischer Liebe, Freude an der Arbeit und idyllischem Landleben werden anhand der eigentümlich steril wirkenden Nachahmung der Bauprinzipien von Trivialromanen destruiert. Die Protagonistinnen paula und BRigitTe werden $\mathrm{zu}$ »Gegenständen« degradiert, was die Aussichtslosigkeit ihrer Situation verdeutlicht: Frauen aus der Arbeiterklasse sind demnach einer zweifachen Diskriminierung ausgesetzt, einmal aufgrund ihrer Zugehörigkeit zur Arbeiterklasse und einmal als Frauen - wobei die Klassenhierarchie die Geschlechterhierarchie prioritiert. ${ }^{449}$ An dem klar durchkomponierten, eher narrativen Roman kann Jelineks Vorstellung von der Verwobenheit der gesellschaftlichen Macht- und Gewaltstrukturen auf verschiedenen Ebenen, die ihren spezifischen Faschismusbegriff prägen, abgelesen werden. Wichtig ist auch hier wiederum die Feststellung, dass anhand der angesprochenen Themen die Kritik an einer ent-politisierten und -historisierten Sprache dargebracht wird, welche die modernen Massenmedien transportieren. Ohne diese wäre eine Verbreitung der Trivialmythen in der Gesellschaft nicht möglich und in weiterer Konsequenz auch nicht die Verteidigung des Opfermythos.

Den »Liebhaberinnen«-Text ergänzend griff Jelinek wenige Jahre später in ihrem »Nora«-Stück (»Was geschah, nachdem Nora ihren Mann verlassen hatte oder Stützen der Gesellschaften«) bürgerliche Mythen von Emanzipation

447 Vgl. Janz, Elfriede Jelinek, S. I6.

448 Vgl. Janz, »Die Geschichte hat sich nach 45 entschlossen«, S. $228 \mathrm{f}$.

449 Vgl. Janz, Elfriede Jelinek, S. 22 f. 
und Selbstverwirklichung auf: Vor allem die Weiblichkeitsvorstellungen der bürgerlichen Protagonistin werden »unmittelbar enggeführt mit Nazi-Ideologie ${ }^{450}$. Zugleich ist »Nora das einzige Stück Jelineks, das eine positive Heldin in der Figur der Arbeiterin Eva kennt. Diese vertritt aufgeklärte Positionen und erkennt den von Jelinek propagierten Zusammenhang von Ökonomie und Emanzipation. ${ }^{451}$ Der Feminismus der Hauptfigur nor a hingegen wird als unpolitisch und trivialmythisch destruiert. ${ }^{452}$ Jelinek selbst bezeichnete ihre Protagonistin als »sehr negative Frauenfigur ${ }^{453}$, die an ihrem emanzipatorischen Vorhaben scheitert, weil sie sich letzten Endes - obwohl ihr als Frau aus dem Bürgertum durchaus Alternativen offengestanden wären - selbst zur Komplizin ihres Mannes degradiert. ${ }^{454}$ Anklänge an das Brechtsche Lehrstück lassen einen didaktischen Auftrag erkennen, den spätere Jelinek-Stücke (jedenfalls in dieser offenkundigen Form) nicht mehr kennen. ${ }^{455}$ NOR A steht vor der Entscheidung zwischen zwei möglichen Schicksalen: dem selbstbestimmten und dem fremdbestimmten, (vom Mann) abhängigen Leben. Wahre Emanzipation mit gleichzeitiger Bindung an einen Partner kann aber nach Jelinek nicht glücken, da diese immer eine Form von »Komplizenschaft « nach sich zieht:

"Ich habe die Frauen sehr kritisch als Opfer dieser patriarchalen Gesellschaft gezeigt, die sich aber nicht als Opfer sehen, sondern glauben, sie könnten Komplizinnen sein.... sobald die Frauen sich zu Komplizinnen der Männer machen, um sich dadurch einen besseren sozialen Status zu verschaffen, muß das schiefgehen.» ${ }^{456}$

In Jelineks »Nora«-Stück ist bereits die (später noch radikalisierte) Theaterästhetik der Autorin erkennbar, in der sie ihre Figuren »entmenschlicht«, indem sie ihnen jede Individualität und jede Fähigkeit zur freien Meinung abspricht: Keine Figuren, keine Körper stehen hier auf der Bühne, sondern hohle »Kadaver ${ }^{457}$, die Sprachklischees wiedergeben und schablonenhaft von scheinbaren Wirklichkeiten erzählen - auch dies zweifelsohne eine didaktischen Maßnahme, jedoch auf Umwegen (»The Truth must dazzle gradually ...« ${ }^{458}$ ).

$45^{\circ}$ Janz, »Die Geschichte hat sich nach 45 entschlossen«, S. 229.

45 I Vgl. Janz, Elfriede Jelinek, S. 32 f.

452 Vgl. ebd., S. 36 .

453 Jelinek, zitiert nach: Meyer, Sturm und Zwang, S. 59.

454 Vgl. ebd.

455 Vgl. Janz, Elfriede Jelinek, S. 38.

456 Jelinek, zitiert nach: Winter, Gespräch mit Elfriede Jelinek, S. I3.

457 Vgl. Janz, Elfriede Jelinek, S. 37 f. Vgl. Jelinek, Ich schlage sozusagen mit der Axt drein, S. I 4 ff. Vgl. auch dies.: Ich möchte seicht sein, S. I57-16r.

458 Dickinson, Gedichte, S. 4Io f. Vgl. das lyrische Motto dieser Studie. 
Für die Hauptfigur NORA gerinnt der Feminismus zu einer Aussage über die angebliche "Natur" von Mann und Frau, die unhistorisch und unpolitisch bleibt und daher im Barthes'schen Sinne nur als "Mythos" klassifiziert werden kann. ${ }^{459}$ Das Stück endet mit einer Anspielung auf den Reichstagsbrand. An die Stelle gesellschaftlicher Reflexion tritt jedoch der Mythos vom Juden als Brandstifter. ${ }^{460}$ Dieser Ausblick auf den Nationalsozialismus sei ihr "sehr wichtig ${ }^{461}$ gewesen, so Jelinek. Zugleich arbeitet sie sich in diesem Stück an der Totalitarismustheorie ${ }^{462} \mathrm{ab}$, indem sie die sozialdemokratischen Positionen der dargestellten Arbeiterinnen mit deren faschistoider Mutterschaftsideologie verbindet, womit vermutlich aufgezeigt werden soll, dass weder im bürgerlichen noch im proletarischen Lager wirkliche politische Reflexion stattfindet, »sondern >linkes` wie >rechtes` Gedankengut jeweils trivialmythisch rezipiert wird ${ }^{463}$.

Der Roman »Die Ausgesperrten« (I 980), der aus einem Drehbuchprojekt hervorgegangen ist ${ }^{464}$ und I 982 auch unter der Regie von Franz Novotny verfilmt wurde, stellt Jelineks ersten wirklich narrativen Text dar, der eine linear erzählte Handlung und individualisierte Figuren enthält. Auch in puncto Orthografie verabschiedete sich Jelinek mit diesem Roman von den experimentellen Mustern der Wiener Gruppe und passte sie der gängigen Praxis an. ${ }^{465}$ Der Inhalt orientiert sich an der wahren Geschichte eines tragischen Familienmords im Wien der I 95oer Jahre. Gleich zu Beginn wird der Opfermythos - und hier so explizit wie selten - als eines der Hauptthemen eingeführt:

\begin{abstract}
»Zu dieser Zeit [1955] gibt es ... immer noch zahlreiche unschuldige Täter. Sie blicken voller Kriegsandenken von blumengeschmückten Fensterbänken aus freundlich ins $\mathrm{Pu}-$ blikum, winken oder bekleiden hohe Ämter. Dazwischen Geranien. Alles sollte endlich vergeben und vergessen sein, damit man ganz neu anfangen kann. ${ }^{466}$
\end{abstract}

Die Figur des Vaters w тт кош к г personifiziert den Opfermythos nahezu: Als ehemaliger SS-Offizier, der in den Konzentrationslagern Auschwitz und Treblinka Dienst getan und an der Ostfront an Kriegsverbrechen teilgenommen hat, nimmt er die Haltung des offiziellen Österreich zum Anlass, I 945 auch zu seiner persönlichen »Stunde Null« zu machen:

459 Vgl. Kapitel I.4.3.

460 Vgl. Janz, "Die Geschichte hat sich nach 45 entschlossen«, S. 228 f.

46 I Jelinek, zitiert nach: Meyer, Sturm und Zwang, S. 59.

462 Vgl. Kapitel I.4.I.

463 Janz, Elfriede Jelinek, S. 36.

464 Vgl. ebd., S. 47.

465 Vgl. Scheidl, Ein Land auf dem rechten Weg, S. I 46.

466 Jelinek, Die Ausgesperrten, S. 7. 
"Die Geschichte hat sich nach 45 entschlossen, noch einmal ganz von vorne zu beginnen, zu demselben Entschluß hat sich auch die Unschuld durchgerungen. Witkowski fängt in ihr wieder ganz von unten an, wo sonst nur junge Menschen anfangen, die alles vor sich haben... « ${ }^{467}$

Die faschistische Gewalt, die wiт Kow sк I während des Kriegs in den Konzentrationslagern praktizierte, hat er jedoch nicht überwunden, sondern übt sie an den nun verfügbaren Opfern aus: an der alles erduldenden Ehefrau und den bereits jugendlichen Kindern, den Zwillingen RAIner und ANnA. Diese sind psychische »Krüppel der kleinbürgerlichen Familie ${ }^{468}$, welche die von Wilhelm Reich diagnostizierte Anfälligkeit des Kleinbürgertums für den Faschismus, den sie durch den Vater erleiden, bloß reproduzieren. ${ }^{469}$ Zusammen mit zwei anderen Jugendlichen, sopHiE, einer Tochter aus reichem Hause, und dem jungen Arbeiter HANs, überfallen sie nachts Passanten, berauben und quälen sie. Die Kinder des Kriegs revoltieren gegen die Eltern - jene Generation, die in den Nationalsozialismus involviert war und am Krieg aktiv oder passiv teilgenommen hat. ${ }^{470}$ Auf der intertextuellen Ebene sind Bezüge zu Jean Paul Sartre, vor allem zu dessen Roman "Zeit der Reife«, dominant. ${ }^{471}$

In der Darstellung des Kleinbürgertums folgt der Roman weitestgehend den Theoremen des frühen Wilhelm Reich. ${ }^{472}$ In der Figur des wіткоwsк I setzte Jelinek dessen "Analyse der kleinbürgerlich-patriarchalen Familie und ihrer Sexualverdrängung « ${ }^{473}$ literarisch um. Diese schlägt um in Sadismus und willkürliche Gewaltanwendung, der von Jelinek vermutete Zusammenhang der kleinbürgerlich-patriarchalen Familienform mit dem Nationalsozialismus wird deutlich: W гткош к Is nunmehr gepflegter Alltagsfaschismus soll ihm die Sensation von Leichenbergen aus den Konzentrationslagern ersetzen. ${ }^{474}$

Hinter den Gewaltakten der jugendlichen Protagonisten, die als Kinder von Tätern und als Kinder von Opfern in unterschiedlicher Weise vom NS-Faschismus gezeichnet sind, steht der Wunsch nach gesellschaftlichem Aufstieg. Diesen wollen sie über Bildung erreichen: »In dieser neuen Zeit macht Wissen frei

467 Ebd., S. 98.

468 Janz, Elfriede Jelinek, S. 42.

469 Vgl. ebd.

470 Vgl. Scheidl, Ein Land auf dem rechten Weg, S. I 46.

47 I Vgl. Janz, Elfriede Jelinek, S. 49.

472 Vor allem dem 1933 zuerst erschienenen Werk »Die Massenpsychologie des Faschismus«. Vg1. Kapitel I.4.I dieser Studie. Zu dem Vergleich mit Reich siehe Janz, Elfriede Jelinek, S. 45 f.

473

474 Janz, Elfriede Jelinek, S. 45. Vgl. ebd. 
und nicht die Arbeit « ${ }^{475}$ - eine Anspielung auf den euphemistischen Schriftzug »Arbeit macht frei«, der über den Eingangstoren verschiedener nationalsozialistischer Konzentrationslager prangte (darunter Auschwitz, Groß-Rosen, Theresienstadt). Da es ihnen jedoch rein um den sozialen Aufstieg, nicht wirklich um Bildung geht, ist diese Vorstellung zum Scheitern verurteilt. ${ }^{476}$ Jelineks Figuren sind - im Gegensatz zu den Figuren des bürgerlichen Entwicklungsromans, der hier karikiert wird - nicht entwicklungsfähig. ${ }^{477}$ Durch die unnahbare bürgerliche Tochter SOPHIE, die RAINer und Hans bloß benutzt und am Ende die Überlegene bleibt, während RAINER im dramatischen Finale des Buchs seine Familie »hinmetzelt ${ }^{478}$, bleiben sie aus der Klasse, die sie erreichen wollen, »ausgesperrt« - wiederum ein Verweis auf Sartre: Dessen Theaterstück »Die Eingeschlossenen« von 1959 spielt wie Jelineks Roman in den I95oer Jahren. Beide Texte handeln von der Verstrickung zweier Generationen in den Faschismus, und in beiden sind die Figurenkonstellationen Vater/Sohn sowie Bruder/ Schwester zentral. ${ }^{479}$

Das ganze Setting von Jelineks »Ausgesperrten« ist überflutet von dem überwunden geglaubten Nazismus, der trotz Besatzung und Entnazifizierung nicht von der Bildfläche verschwunden ist: Nach dem Abzug der Besatzungstruppen treten »die neuen Nazis sowie die guten alten ... wieder zutage ... wie die Blümelein in ihren grauen Nistkästen ${ }^{480}$. Die Opfer der Vernichtung, die »Erschlagenen, Gehenkten, Vergasten, Erschossenen, Goldzahnausgebrochenen « ${ }^{481}$, begleiten das Plot des Romans von Anfang bis Ende. Wiederum stellt sich der Faschismus als gesellschaftliches Kontinuum dar, der Nationalsozialismus hingegen als eine seiner möglichen Äußerungsformen, nicht als singuläres Ereignis, wenn auch der Holocaust als einzigartig gelten muss.

$\mathrm{Zu}$ Beginn der I $980 e r$ Jahre begann Jelinek verstärkt am Wortmaterial direkt zu arbeiten und Wörter, Phrasen und idiomatische Wendungen zu deformieren, um die Gewalt an der Sprache, also deren Manipulation und ideologische Vereinnahmung, noch deutlicher vorzuführen und damit deren Mythenhaftigkeit zu entlarven. Ihr Destruktionsverfahren gewann damit einen neuen Charakter.

»Ich folge halt einem kompositorischen Verfahren, das mit Lautverschiebungen und -vertauschungen arbeitet... Eine Kollegin hat seinerzeit aus Aussprüchen von Kurt

475 Jelinek, Die Ausgesperrten, S. 35 .

476 Vgl. Janz, Elfriede Jelinek, S. 40 fff.

477 Vgl. ebd., S. 44 f.

478 Scheidl, Ein Land auf dem rechten Weg, S. I 46.

479 Vgl. Janz, Elfriede Jelinek, S. $46 \mathrm{f}$.

480 Jelinek, Die Ausgesperrten, S. ro9.

48 I Ebd., S. 3 O. 
Waldheim Anagramme gemacht, und egal, wie sie die Wörter geschüttelt hat, es blieben immer die Buchstaben SA und SS über. Das ist für mich der Beweis, dass die Sprache selber sprechen kann. ${ }^{482}$

Das Verfahren der "sprechenden Sprache« setzte sie in späteren Texten fort, zum Beispiel in dem Theaterstück »Totenauberg", in welchem sie sich mit der komplizierten Beziehung zwischen dem Philosophen Martin Heidegger, der mit den Nationalsozialisten sympathisierte, und der jüdischen Publizistin und Philosophin Hannah Arendt befasste, oder auch in »Wolken.Heim«. Sie modifizierte dieses Verfahren jedoch stetig weiter. ${ }^{483}$

Das »Burgtheater«-Stück von I982/84 beklagt den Zusammenhang von NS-Ideologie und Künstlermythen: Es zeigt opportunistische Theater- und Filmschauspieler, die ihr fehlendes Unrechtsbewusstsein mit ihrer angeblichen Hingabe zur Kunst rechtfertigen. In Wahrheit sind sie ideologisch ebenso vereinnahmbar wie die Sprache, derer sie sich bedienen. Wegen der offenkundigen Ähnlichkeit der Hauptfiguren mit Paula Wessely sowie dem Brüderpaar Paul und Attila Hörbiger, Ikonen des Burgtheaters und des Heimatfilms, löste die Uraufführung des Stücks in Bonn einen österreichweiten Theater- und Medienskandal aus. ${ }^{484}$

I 986 - dem Jahr, in dem Österreichs Bevölkerung den ehemaligen Offizier einer SA-Reiterstandarte und Mitglied des nationalsozialistischen Studentenbunds NSDStB, Kurt Waldheim, nach einer aufgeregten Wahlkampfauseinandersetzung zum Bundespräsidenten wählte und der Rechtspopulist Jörg Haider den eher liberalen FPÖ-Parteivorsitzenden Norbert Steger vom Obmannsessel stieß $^{485}$ - wurde Jelinek mit dem Heinrich-Böll-Preis der Stadt Köln ausgezeichnet. In ihrer Dankesrede mit dem vielsagenden Titel »In den Waldheimen und auf den Haidern« nutzte sie die Gelegenheit, zur politischen Situation in Österreich Stellung zu beziehen, indem sie Österreichs »Arroganz« kritisierte, sich vor allem wegducken und dafür »auch noch geliebt werden zu wollen ${ }^{486}$ :

"In den Waldheimen und auf den Haidern dieses schönen Landes brennen die kleinen Lichter und geben einen schönen Schein ab, und der schönste Schein sind wir.

482 Jelinek, »Ich bin ein Racheengerl«. Mit der »Kollegin« ist die Lyrikerin und Essayistin Heidi Pataki gemeint, worauf Jelinek in einem anderen Interview verwiesen hat: Vgl. Fuchs/Jelinek, "Man steigt vorne hinein...«, S. 20.

483 Vgl. Janz, »Die Geschichte hat sich nach 45 entschlossen«, S. 230.

$484 \mathrm{Zu}$ »Burgtheater" vgl. Kapitel 3.I dieser Studie.

$485 \mathrm{Zu}$ Jörg Haiders Machtergreifung in der FPÖ 1986 vgl. Zöchling, Haider, S. I I 5-I 44, außerdem Kapitel 3.3.3 dieser Studie.

486 Mayer/Koberg, Ein Porträt, S. I42. 
Wir sind nichts, wir sind nur, was wir scheinen: Land der Musik und der weißen Pferde. ${ }^{487}$

In ihrer Heimat habe sich Jelinek mit dieser Rede jedenfalls »nicht gerade beliebter gemacht«, stellt die Literaturwissenschafterin Christa Gürtler trocken fest, denn »mit Künstlern, die sich ideologiekritisch mit dem schönen Schein dieses Landes auseinandersetzen, will dieses Land... nichts zu tun haben ${ }^{488}$.

Aus Anlass der Waldheim-Affäre verfasste Jelinek außerdem das Dramolett »Präsident Abendwind « - eine Paraphrase auf Johann Nestroys »Häuptling Abendwind«, in welcher Bundespräsident Kurt Waldheim als Kannibalenhäuptling einer Südseeinsel dargestellt ist. ${ }^{489}$

Die von Gürtler angesprochene ideologiekritische Auseinandersetzung erfolgt in Jelineks essayistischen Texten und Reden erstaunlich offen, sehr explizit und sehr deutlich: So bezeichnete sie etwa Österreichs Selbststilisierung als Opfer eines vermeintlich deutschen Faschismus in einem Essay aus dem Jahr I 99 I als "Staatsdoktrin ${ }^{490}$, also als staatlich verordneten Verdrängungsprozess, oder schreibt an anderer Stelle vom »Judenschlachten« - eine »liebe alte Gewohnheit hierzulande von altersher ${ }^{491}$.

Die Prosa- und Theatertexte sind naturgemäß weitaus artifizieller, die Ideologie- und Sprachkritik wird hier mit anderen Mitteln dargebracht. So steigt das gesellschaftlich Verdrängte in Jelineks Romanen und Theaterstücken (spätestens seit den I $980 e r$ Jahren) immer wieder als untotes Relikt an die Oberfläche, was sich durch das wiederholte Auftreten von Geistern, Zombies oder Vampiren niederschlägt, etwa in den Theaterstücken »Krankheit oder Moderne Frauen« oder »Ulrike Maria Stuart«. In dem Untoten-Topos findet die »Entmenschlichung" der Figuren, die in Jelineks Texten immer schon hohl, tot, nur scheinbare Individuen waren, ihren gesteigerten Ausdruck.

In ihrem Opus Magnum, dem Roman »Die Kinder der Toten« aus dem Jahr 1995, geistern sowohl Opfer als auch Täter des Nationalsozialismus als verwesende Zombies durch ein Österreich mit einschlägiger Vergangenheit. ${ }^{492} \mathrm{Wie}-$ derum dürfte nicht zuletzt die eigene Familiengeschichte das Wiederholen und Variieren dieses Toposı motiviert haben:

487 Jelinek, In den Waldheimen und auf den Haidern, S. 42.

488 Gürtler, Gegen den schönen Schein, S. 7 .

489 Vgl. Janke, Nestbeschmutzerin, S. 50-53.

490 Jelinek, Die Österreicher als Herren der Toten, S. 6r.

49 I Jelinek, Ein deutsches Märchen, unpaginiert.

$492 \mathrm{Zu}$ »Die Kinder der Toten« vgl. Kapitel 3.2 dieser Studie. 
»Ich grabe also meine toten Voreltern aus dem Grab heraus ... ich sage: Schlaf nicht ein, Großväterchen, bleib wach, ich brauch dich noch, um mit dir was zu beweisen! Alle sollen es hören! Heraus aus dem Grab, mach schon!«"493

Ein ebenso wiederkehrendes Motiv ist die Metapher einer Decke des Vergessens, die sich über das Land zieht: Jelinek bezeichnet sie einmal als "natürlichkeitsschleim ${ }^{494}$ oder als »Schleim von Aliens ${ }^{495}$, einmal als »Gras ${ }^{496}$, als wachsendes »Eis ${ }^{497}$ oder als »braunen Schleim», der »aus den Mündern quillt ${ }^{498}$. In dem Theaterstück »Stecken, Stab und Stangl« ist es eine rosarote Häkeldecke, an der die auftretenden Figuren gemeinsam arbeiten und die nach und nach die ganze Bühne überzieht. ${ }^{499}$

Für Jelinek, selbst eine bekennende TV-Süchtige, waren die Medien, vor allem die Unterhaltungsindustrie und die Werbung, von Beginn an wichtige Themen, da diese die manipulierte Sprache unters Volk bringen und so die öffentliche Meinung in die jeweils gewünschte Richtung lenken. In »Die endlose Unschuldigkeit « bezeichnete sie die modernen Massenmedien als »Kontrollins$\operatorname{tanzen}{ }^{500}$ der Gesellschaft. Charakteristisch für diesen Standpunkt ist ihre jahrelange öffentliche Auseinandersetzung mit der »Kronen Zeitung«: »Bei uns daheim passt die halbe Bevölkerung in eine einzige Organisationsform «, befindet die Autorin, "und das ist die Kronenzeitung. " ${ }^{501}$ Als meistgelesene österreichische Tageszeitung übernehme die "Krone« das Sagen und Fühlen der Mehrheit der Österreicher und suggeriere gleichzeitig, dass sie bloß das formuliere, was dem gesunden Volksempfinden nach ohnehin jeder denke:

»Die Kronenzeitung sagt, Politik verdirbt die Menschen, sie brauchen sich jetzt aber gar nicht mehr um diese Politik zu kümmern, das übernimmt diese liebe gute Zeitung ja für sie, sie nimmt ihnen das Politische ab. ${ }^{502}$

493 Jelinek, Ein deutsches Märchen, unpaginiert.

494 Dies., Die endlose Unschuldigkeit, S. 56.

495 Dies., Dem Faß die Krone aufsetzen, unpaginiert.

496 Dies., Ein deutsches Märchen, unpaginiert.

497 Dies., oh mein Papa, unpaginiert.

498 Dieselbe, zitiert aus einer Rede mit dem Titel »Rotz«, die sie am I6. März 20or auf der Antirassismus-Kundgebung der »Demokratischen Offensive« am Wiener Stephansplatz gehalten hat (nachzulesen auf ihrer Homepage unter » 6.3.200I « oder auch bei Janke, Nestbeschmutzerin, S. 154).

499 Vgl. Ehlers, Die Faschismuskritik der Elfriede Jelinek, S. I 5.

$500 \quad$ Jelinek, Die endlose Unschuldigkeit, S. 53.

5 or Dies., Dem Faß die Krone aufsetzen, unpaginiert.

502 Ebd. 
Zur Verbreitung von faschistoiden Inhalten trage die »Kronen Zeitung«, die stets gegen die "Ausländerbagage ${ }^{503}$ hetze, wesentlich bei. Als einer der schlimmsten Hetzer gegen "Ausländer, Intellektuelle und linke Künstler « ${ }^{504}$ tritt etwa der langjährige Krone-Kolumnist »Staberl« in »Stecken, Stab und Stangl« als FLEISCHER in rosa Häkelkleidung mit einem übergestülpten, gehäkelten Schweinskopf auf. ${ }^{505}$ Dieses Theaterstück verfasste Jelinek, nachdem vier Roma im burgenländischen Oberwart I 995 von einer Rohrbombe getötet worden waren. Das Attentat führte schlimmerweise nicht nur zu Reaktionen wie Entsetzen und Mitgefühl, sondern riefen auch den damaligen FPÖ-Obmann und umstrittenen Rechtspopulisten Jörg Haider auf den Plan, der öffentlich die Ansicht vertrat, die Roma hätten an ihrer Ermordung möglicherweise selbst Schuld gehabt: So stellte er die Meinung in den Raum, dass ein Konflikt bei einem Waffengeschäft, einem Autoschieberdeal oder um Drogen hinter dem Anschlag stecken könnte - eine Aussage, die Jelinek offensichtlich so schauderhaft fand, dass sie diese als Zitat ihrem Theaterstück voranstellte. ${ }^{506}$ Auch sollen die ermittelnden Polizeibeamten den Hinterbliebenen eines Opfers dazu aufgefordert haben, er möge doch endlich zugeben, dass sein getöteter Stiefbruder selbst den Sprengstoff besorgt habe. ${ }^{507}$ So wird in »Stecken, Stab und Stangl« nicht das Geschehene selber, also das Rohrbomben-Attentat, sondern vielmehr das Sprechen darüber in den Mittelpunkt gestellt, wobei die ermordeten Roma eine Art roten Faden für das Stück bilden, das - wie sämtliche neuere Theaterstücke Jelineks - keine lineare Handlung verfolgt, sondern als Aneinanderreihung von monologisierenden Textflächen gestaltet ist und stark auf der assoziativen Ebene arbeitet. Mit dem Titel bezieht sich die Autorin auf die Psalmen Davids: In Psalm 23 heißt es: "Dein Stecken und Stab trösten mich«, wobei »Stab« eine offenkundige Anspielung auf den Kolumnisten »Staberl« darstellt. Mit »Stangl« ist Franz Stangl, der Kommandant des Konzentrationslagers Treblinka, gemeint, worauf Jelinek in einem Interview selbst hingewiesen hat. ${ }^{508}$

503 Ebd.

504 Ehlers, Die Faschismuskritik der Elfriede Jelinek, S. 4.

505 Vgl. Jelinek, Stecken, Stab und Stangl, Beschreibung des Fleischers in der Regieanweisung auf S. 22.

506 Vgl. Jelinek, Stecken, Stab und Stangl, S. I 5.

507 Vgl. Ehlers, Die Faschismuskritik der Elfriede Jelinek, S. 3. Ehlers zitiert aus diversen profil-Artikeln zu dem Attentat und dessen Reaktionen: profil Nr. 07, I995 und profil Nr. 34, I 995 .

508 Das Interview »Ich bin im Grunde ständig tobsüchtig über die Verharmlosung«, das Stefanie Carp mit Jelinek geführt hat, kann unter dem Link "Zum Theater« auf Jelineks Homepage nachgelesen werden. Vgl. auch Ehlers, Die Faschismuskritik der Elfriede Jelinek, S. 4 f. (Sie bezieht sich vermutlich auf Jelineks Erläuterungen in diesem Interview.) 
Die FPÖ war immer schon ein Problem für Jelinek gewesen und umgekehrt: Tatsächlich ließ die Partei keine Gelegenheit aus, der linken Künstlerin eins auszuwischen. Bereits I 969 hatte die FPÖ als Reaktion auf Jelineks zweifache Auszeichnung bei den Innsbrucker Jugendkulturwochen eine parlamentarische Anfrage gestellt, ob denn auch "pornografische Texte« prämiert würden. Die Innsbrucker Jugendkulturwochen fanden in Folge der Aufregung nicht mehr statt. Jelineks Retourkutsche folgte mit dem Roman »Oh Wildnis, oh Schutz vor ihr« (1 985), in welchem sie die FPÖ, damals Unterstützerin der SPÖ-Minderheitsregierung, als direkte Nachfolgepartei der NSDAP darstellte: ${ }^{509}$

»Die Roten haben neuerdings nur einen Ehrgeiz unter ihrem neuen Anführer: für das Nationallager in Braun keine Fehlinvestition sein! Die sind jetzt in unserer ureigensten Regierung, tobt das Volk nicht, denn es ist ortskundig. « ${ }^{510}$

Zugleich kritisierte sie damit die SPÖ unter Bruno Kreisky für den Pakt mit der FPÖ, weil die Sozialdemokraten sich aus rechnerischen (also eigennützigen) Gründen darauf eingelassen hatten, die »Wiederkunft ${ }^{511}$ der Braunen zu begünstigen. Das Volk tobt eben nicht, obwohl es dies aus moralischen Gründen sollte, weil es »ortskundig“ ist und man hier schon immer mit den Braunen sympathisiert hatte.

Der Text setzt sich weitestgehend aus Anspielungen, Dialektismen und anderen Wortspielen zusammen, welche die Mythen Natur und Vergangenheit umkreisen. Das Plot ist wiederum schnell erzählt: Der frisch geschiedene Holzknecht ERICH ${ }^{512}$ beliefert die Bergbewohnerin AICHHOLz gegen Bezahlung mit Lebensmitteln. Die Natur hat den Waldarbeiter für die Vergehen seiner Vergangenheit, etwa das Verprügeln seiner Kinder, mit schweren Arbeitsunfällen gestraft, die ihn körperlich zeichnen. Anders als die Touristen sieht ERICH in der Natur keine Idylle, nur Gewalt und Schmerzen. Die Aichноцz hingegen, die Frau auf dem Berg, versucht sich als Dichterin und produziert unablässig lyrischen Naturkitsch - eine »Verhöhnung literarischer Naturverherrlichung « ${ }^{513}$, so Janz, auch zeitgenössische Autoren wie Peter Handke seien damit adressiert. ${ }^{514}$ Die AICHHOLZ will ERICH verführen, was ihr allerdings nicht gelingt. Der Holzknecht interessiert sich vielmehr für eine deutsche Managerin, von der er sich

509 Vgl. Scheidl, Ein Land auf dem rechten Weg, S. 2 I 4 f.

5 Io Jelinek, Oh Wildnis, S. I 66.

5 I I Ebd., S. I66.

5 I2 ERICH ist möglicherweise eine Reproduktion des ERICH aus Jelineks "Liebhaberinnen«-Roman.

5 I3 Janz, Elfriede Jelinek, S. Ioo.

5 I 4 Vgl. ebd. 
verspricht, dass sie ihm zu Geld und sozialem Aufstieg verhelfen könnte. Diese sieht in ERICH aber nur ein Nutzobjekt ihrer sexuellen Lust, die Natur begreift die Geschäftsfrau als bloßes Mittel, um Geld zu machen. Über die drei Figuren wird der Mythos Natur auf mehrfache Weise destruiert: »Die Natur ... taugt ... nur als Ware für den Wintersport, und ist im übrigen so marode, dass sie als sunecht ' gegenüber ihrer Medienreproduktion erscheint. « ${ }^{515}$ Das Fernsehen liefert schönere, scheinbar »echtere« Bilder von der Natur. Als ERICH aus dem Schlafzimmer der Managerin flieht, wird er von »den Beherrschern der Wildnis « ${ }^{516}$ erschossen. Durch eine weitere Figur, den Ex-Geliebten der AICHHolz, kommt die Opferthese explizit ins Spiel: H Aus B E Rg L ist ein Philosoph, dessen Ideen von der nationalsozialistischen Ideologie durchtränkt sind; immer wieder verweist der Text damit auf Heidegger und Nietzsche. Dennoch genießt H Au s be rgl höchstes Ansehen. Die Figur kann als exemplarisch begriffen werden; jedoch gibt es ein konkret rückverfolgbares Vorbild für sie: Franz Hausberger, in den I $970 e r$ Jahren ÖVP-Bürgermeister der Tiroler Stadt Mayrhofen, der mit seiner Vergangenheit in der Ersten SS-Infanteriebrigade geprahlt hatte, die im Zweiten Weltkrieg an Massenmorden beteiligt gewesen war. Hausberger selbst soll in Holland ein Kind erschossen haben, das sich nicht von seinem Hund trennen wollte. ${ }^{517}$ Eine nationalsozialistisch belastete Vergangenheit stellte aber nicht unbedingt ein Hindernis für eine politische Karriere im Nachkriegsösterreich dar.

»Die [Braunen] wollen schon wieder ... Minister und Landeshauptschutzleute werden. ${ }^{518}$

Die politische Anerkennung durch einflussreiche Konservative und eine schwache Kreisky-SPÖ ermögliche ihnen dies, so der implizite Vorwurf der Autorin. ${ }^{519}$

Tatsächlich gewann die FPÖ als offen »rechte« Partei seit den I $980 e r$ Jahren stark an politischem Einfluss. Mit dem Obmann Jörg Haider wurde der Rechtspopulismus salonfähig gemacht, was auch auf die Sprache und den Politstil der Großparteien abfärbte, vor allem in Zeiten des Wahlkampfs.

Die Aussagen freiheitlicher Politiker, die aus ihrer deutschnationalen, ausländerfeindlichen Gesinnung keinen Hehl machen, werden in Jelineks Thea-

5I5 Ebd.

5 I 6 Jelinek, Oh Wildnis, S. 282.

5 I 7 So Recherchen des Wochenmagazins profil, vgl. profil online, Zeitgeschichte, abrufbar unter: http://www.profil.at/articles/0503/560/ro3307/zeitgeschichte-die-schwarzen-braunen (Zugriff am 4.9.2013). Zu dem Rückschluss auf das historische Vorbild vgl. Scheidl, Ein Land auf dem rechten Weg, S. I47 f.

5 I 8 Jelinek, Oh Wildnis, S. I 57.

5 I 9 Vgl. Scheidl, Ein Land auf dem rechten Weg, S. I 48. 
ter- und Prosatexten, aber vor allem auch in zahlreichen ihrer Essays zitiert, parodiert und destruiert. In den I 93oer Jahren sei es der schlichte Oberösterreicher Adolf Schicklgruber (Hitler) gewesen, der sich das Volk gekrallt habe, in den I $990 e r$ Jahren ein »einziger, schlichter Kärntner « ${ }^{520}$ : Jörg Haider, der zwar gebürtiger Oberösterreicher war, in Kärnten aber seine Wahlheimat gefunden hatte. In ihrem Opus Magnum »Die Kinder der Toten« stellte Jelinek die Figur des Parteiführers (Haider) als Doppelgänger des »Führers« (Hitler) vor:

»Dieser junge Führer... das Gebiß wird gebleckt, die Zähne sind Flammen, sie verbergen zum Teil das etwas schief geratene Gesichtsfabrikat, das uns trotzdem mit seinem Stempel sein Muster aufdrücken will. ... Der Führer. Man würde ihn mit einer Lampe suchen gehen, verschwände so einer in Österr. einmal von der Bild-Fläche. So einen Mann hat dieses Land bereits einmal erbaut (die Pläne hat es sich sicherheitshalber aufgehoben), und da der große Aufruhr, den dieses Bauen hervorgerufen hat, gestillt war, reichte man sie wieder ein, die Pläne, für eine heftige Volksbewegung, für eine dritte Republik, aus der Tiefe geholt, aber doch etwas von oben herab. ${ }^{521}$

Die Wiener FPÖ reagierte daraufhin mit einem Wahlplakat zur Wiener Gemeinderatswahl, das die »Freiheit der Kunst« einforderte und interessanterweise Elfriede Jelinek und Claus Peymann im selben Atemzug mit den SPÖ-Politikern Rudolf Scholten, Michael Häupl und Ursula Pasterk nannte, was der damalige FPÖ-Bundesgeschäftsführer mit der Bemerkung kommentierte: »Wir haben schon immer die witzigsten Plakate gemacht. « ${ }^{522}$

Die Aufschrift implizierte den Vorwurf, dass die Schriftstellerin und der Burgtheater-Intendant der SPÖ nahestünden. Sinn der Kampagne war es, gegen FPÖ-kritische Kulturschaffende (Peymann, Roth, Turrini, Jelinek) Stimmung zu machen, da diese "Österreichbeschimpfer ${ }^{523}$ seien und als solche kein Anrecht auf staatliche Förderung hätten. ${ }^{524}$ Die Partei appellierte damit an »die antiintellektuellen Emotionen jener Menschen, die mit (moderner) Kunst nichts anzufangen wissen und nicht verstehen, wieso ihr hart verdientes Geld in die Subventionierung von Theatern, Künstlern oder anderen Kulturprojekten gesteckt wird « ${ }^{525}$.

Einige österreichische Intellektuelle und Journalisten reagierten kritisch auf die Diffamierungen Jelineks durch die Wiener FPÖ, größere Proteste, etwa von

520 Jelinek, Ein deutsches Märchen, unpaginiert.

52 I Dies., Die Kinder der Toten, S. 46 f.

522 Gernot Rumpold, zitiert nach: Mayer/Koberg, Ein Porträt, S. 197 f.

523 So die FPÖ in ihrem Wahlkampffolder, Faksimile abgedruckt in: Janke, Die Nestbeschmutzerin, S. 88.

524 Vgl. Scheidl, Ein Land auf dem rechten Weg, S. 215.

525 Scheidl, Ein Land auf dem rechten Weg, S. 2 I 5. 
Seiten der Schriftsteller-Vereinigungen, blieben aber aus. ${ }^{526}$ Jelinek selbst zeigte sich von der Aktion tief getroffen. In einem Kommentar nannte sie diese Strategie der FPÖ eine "schleichende Faschisierung der Öffentlichkeit in Österreich «. ${ }^{527}$ In der Heine-Preisrede 2002 ergänzte sie, dass die selbsternannten "Saubermänner« der extremen Rechten, denen nichts lieber sei als die Wörter »Ordnung« und »Sauberkeit«, immer Ordnung machen wollen, indem sie andere fertigmachen, aber:

"Es kann im Schreiben keine Ordnung sein, deshalb werden die Schreibenden von den Saubermännern auch so gehaßt. ${ }^{528}$.

Man sieht, dass das literarische Schaffen und die politische Agitation Jelineks entgegen anders lautenden Behauptungen - nicht voneinander zu trennen sind. ${ }^{529}$

In der bereits zitierten Heine-Preisrede prophezeite Jelinek die Wiederkehr des Faschismus: Die Freiheitliche Partei und die schlagenden Burschenschaften seien »Geschichtslügner und -leugner « ${ }^{530}$. Der Volkssturm bleibe zwar noch ein wenig aus, aber: "Wir warten derzeit ... auf ihn. ${ }^{531}$

Auch vor großem Publikum scheute sich Jelinek nicht davor, deutliche Worte über die Haider-Partei zu finden: Die FPÖ »kotzt uns ihre antisemitischen und menschenfeindlichen Sprüche vor die Füße « ${ }^{532}$, ärgerte sie sich nach der schwarz-blauen Regierungsbildung bei einer Kundgebung auf dem Wiener Stephansplatz im Jahr 2000. Und: Sie habe allmählich keine Lust mehr, dauernd mit einem Fetzen »hinter ihnen herzurennen « ${ }^{533}$.

Mit dem Theatermonolog »Das Lebewohl ${ }^{534}$ verabschiedete sie Jörg Haider satirisch aus der Bundespolitik - ein vorläufiger Höhepunkt der jahrelangen Auseinandersetzungen. Haider zog sich als Landeshauptmann offiziell nach Kärnten zurück, übte als »einfaches Parteimitglied« (vielbemühte Eigendefinition Haiders) aber weiterhin großen Einfluss auf die Entscheidungen der Bundes-FPÖ aus, bis es bei einer Delegiertenversammlung in Knittelfeld 2005 zur Spaltung der Partei kam.

526 Vgl. Janke, Die Nestbeschmutzerin, S. 88.

527 Vgl. Scheidl, Ein Land auf dem rechten Weg, S. 2 I 5 . Jelineks Kommentar ist abgedruckt in: profil, Nr. 34, I998, S. 81.

528 Jelinek, Ein deutsches Märchen, unpaginiert.

529 Vgl. Kapitel I.I sowie I.2 dieser Studie.

530 Jelinek, Ein deutsches Märchen, unpaginiert.

53 I Ebd. Vgl. auch das Wortspiel in demselben Text: „Volk - Volkstum - Volkstrumm«.

532 Jelinek, Rotz, abgedruckt in: Janke, Nestbeschmutzerin, S. I 54.

533 Ebd.

534 Vgl. Kapitel 3.3 dieser Studie. 
Im Oktober 2008 verunglückte Haider tödlich. Doch der »Erlöser ist unsterblich ${ }^{535}$, schrieb Jelinek in einem sarkastischen Nachruf auf den Verunglückten. Haiders »Gesinnungskameraden ${ }^{536}$ tragen sein politisches Erbe weiter, das mit der Beschönigung der österreichischen NS-Vergangenheit spielt, gegen Ausländer hetzt und gegen linke Künstler agitiert.

Auch Antisemitismus und Anti-Israelismus tauchen in der politischen Debatte da auf, wo sie hineinzupassen vorgeben. Ein Beispiel dafür lieferte die FPÖ unter der Führung von Heinz-Christian Strache im Europa-Wahlkampf 2009, als sie in der "Kronen Zeitung" ein Inserat schalten ließ, in welchem sie nicht nur gegen den EU-Beitritt der Türkei, sondern auch gegen den Beitritt Israels wetterte - der natürlich nie ernsthaft zur Debatte stand. Die FPÖ betreibe ein »hinterfotziges Spiel« mit Antisemitismus und Anti-Israelismus, der "fixer Bestandteil des FPÖ-Universums« sei, so der Standard-Redakteur Hans Rauscher: "Das war schon unter Haider so und ist unter Strache nicht anderes [sic]. « $^{537}$

Bei den älteren Autoren, die Kinder des Zweiten Weltkriegs sind, zeige sich, so Günther Scheidl, dass der Nationalsozialismus und sein Weiterleben in den Nachkriegsjahren Schlüsselerfahrungen bleiben, »auf welche gegenwärtige Erscheinungen des rechten bzw. rechtsextremen Gedankenguts rückbezogen werden ${ }^{538}$ - und meint damit etwa auch Jelineks Vergleiche Haiders mit Hitler oder der FPÖ mit der NSDAP. Scheidl bezweifelt jedoch, dass man diesen Erscheinungen dadurch gerecht werden oder sie besser begreifen könne. ${ }^{539}$

Der Stoff für ihr Lebensthema geht Jelinek nicht aus. Regelmäßig stellt sie Essays und Kommentare auf ihre Homepage, in welchen sie auf aktuelle innenpolitische Diskurse und Geschehnisse Bezug nimmt. Seit der Verleihung des Nobelpreises hat sie außerdem einen (Online-)Roman und zahlreiche Theaterstücke verfasst.

In »Rechnitz - der Würgeengel« (2008) steht die Destruktion des Opfermythos sowohl ex- als auch implizit im Vordergrund. Thematisiert wird in dem Stück ein Massaker an 200 jüdischen Zwangsarbeitern, das im Zuge eines von Margit Batthyány (geb. Thyssen-Bornemisza) veranstalteten Festes im März I 945 im burgenländischen Rechnitz stattgefunden hat. ${ }^{540}$

535 Jelinek, Von Ewigkeit zu Ewigkeit, unpaginiert.

536 "Gesinnungskameraden« und "Gesinnungsgemeinschaft« waren Lieblingswörter von Jörg Haider, worauf Jelinek in einem Essay über den als sehr rechts bekannten FPÖ-Politiker Johann Gudenus hinweist: Jelinek, Schamlos: die Zeit, unpaginiert.

537 Kommentar in: Der Standard, RAU, I9. Mai 2009

$53^{8}$ Scheidl, Ein Land auf dem rechten Weg, S. I 52.

539 Vgl. ebd.

540 Vgl. Janke, Elfriede Jelineks »Rechnitz (Der Würgeengel)«. Vgl. auch: Manoschek, Der Fall 
Gestapo-Beamte, politische Funktionäre und Leiter der Bauarbeiten am Südostwall waren unter den Gästen. 200 kranke jüdische Gefangene waren bei einem Transport auf dem Bahnhof von Rechnitz zurückgelassen worden, was dem örtlichen Gestapo-Beamten Franz Podezin während des Fests telefonisch mitgeteilt wurde. Podezin ließ eine Lehrerin und einige Volkssturmmänner ins Nebenzimmer rufen und gab ihnen Waffen und Munition. Dann brach die Gruppe auf, um den »Störfaktor« zu beseitigen. I 70 der gefangenen Juden sollen sofort, die weiteren 30 , die als Totengräber ausgesondert worden waren, am nächsten Morgen mit Genickschüssen getötet worden sein. Die Leichen wurden zum Teil nur notdürftig vergraben. Sie lagen in ein bis zwei Meter tiefen Gruben in der Nähe des Tatortes, zum Teil aber auch auf dem Hauptplatz von Rechnitz, mitten im Ort. Nach den Morden soll die Gruppe um Podezin ins Schloss zurückgekehrt und weiter gefeiert haben. ${ }^{541}$

Jelinek lässt in ihrem Stück Boten auftreten, die von diesen Geschehnissen berichten. Alle Schilderungen und Bewertungen der Gräueltaten passieren also nur mittelbar, über die Sprache und Erzählweise der jeweiligen Boten. Wiederum stellt die Autorin nicht die Geschehnisse an sich in den Mittelpunkt ihres Texts, sondern vielmehr das Sprechen darüber, denn die Sprache soll ja »sprechen gehen ${ }^{542}$.

Die lückenhafte Erinnerungskultur der Zweiten Republik gewährleistet die scheinbare Legitimität rechtspopulistischer und deutschnationaler Äußerungsformen in einer vermeintlich demokratischen Gesellschaft. Mit der konsequenten Destruktion des Opfermythos bezweckt Jelineks Literatur nicht, den Terror der nationalsozialistischen Gewaltherrschaft wiederzugeben oder Schuldige zu brandmarken. Es geht vielmehr darum, dass - mit vielen Jahrzehnten Abstand, gestützt auf umfangreiche wissenschaftliche Aufarbeitungen und begünstigt durch das Nachwachsen historisch unbelasteter Generationen - endlich eine angemessene Art und Weise gefunden werden muss, mit der über Österreichs Beteiligung an den Verbrechen des Nationalsozialismus und des Zweiten Weltkriegs im öffentlichen Raum gesprochen wird, die frei ist von Leugnung und routiniertem Bedauern.

In Elfriede Jelineks Literatur stehen immer die Sprache und die Art und Weise der Sprachverwendung im Mittelpunkt, wie der Regisseur Jossi Wieler treffend über das »Rechnitz«-Stück bemerkte:

Rechnitz. In dieser historischen Aufarbeitung enthalten ist auch ein kurzer Essay von Elfriede Jelinek (»Im Zweifelsfall«, S. I-4). Zu den Geschehnissen und der blinden Nachkriegsjustiz vgl. außerdem Butterweck, Verurteilt und begnadigt, S. 2 I0-2 I6.

54I Vgl. Butterweck, S 2 I 2 f.

542 Jelinek, Lust, S. 28. 
»Es geht nicht um die Täter, es geht nicht um die Opfer, sondern um die, die darüber berichten. ${ }^{543}$

Also um uns, die "Vielen ${ }^{544}$ von heute; und darum, wie wir mit unserem historischen Wissen hier und jetzt umgehen.

543 So der Schweizer Opern- und Theaterregisseur Jossi Wieler anlässlich der Aufführung des »Rechnitz«-Stücks bei den Wiener Festwochen 20ro. Zitat aus dem TV-Bericht "Alles anders? Wiener Festwochen 20I0« (Literaturverzeichnis).

544 Lüdtke, Macht der Emotionen, S. 54. 


\section{Methodische Reflexion}

»Inmitten der Schwierigkeit liegt die

Möglichkeit. ${ }^{1}$

I Albert Einstein, zitiert nach: http://gfa-forum.de/cms/website.php?id=/de/methodenwissen/ zitate.htm (Homepage der deutschen Gesellschaft für Arbeitsmethodik e. V.) (Zugriff am 24.6.2012). 


\subsection{Zur Intertextualität}

»Ich glaube nicht, daß mein Schreiben länger

hält, nur weil ich da ein Stück vom Fleisch

Heideggers oder Nietzsches eingegraben habe ... und die Germanisten dann Such, Hundi! spielen dürfen, was sie nicht sollen, aber trotzdem immer wieder machen. $\ll^{2}$

Es herrsche »Uneinigkeit in Analyse und Bewertung einer der wichtigsten literarischen Verfahrensweisen Jelineks, die für das gesamte Werk signifikant ist ${ }^{3}$, befand Annette Doll in den r 99oer Jahren. Einmal werde sie als »Montage-« oder »Collagetechnik«, ein anderes Mal als eine Verbindung beider Techniken beschrieben, weiters sei von "ummantelten Texten« sowie von »entlehnten Textsegmenten« die Rede. Aus dem angloamerikanischen Raum stammen die Begriffe »structural« und »contextual montage« sowie »mimikry«. ${ }^{4}$ In den I $970 e r$ Jahren sei im deutschsprachigen Raum noch vielfach von der »Kunst des literarischen Zitierens « die Rede gewesen. ${ }^{5}$ In der konkreten Textanalyse werde deutlich, dass mit keinem dieser Begriffe mehr als eine isolierte Beschreibung einzelner sprachlicher Gestaltungsformen Jelineks zu leisten sei. Die Einführung des Intertextualitätsbegriffs in die Jelinek-Forschung habe diesem Dilemma jedoch ein Ende gesetzt: Im Gegensatz zu den vorhergehenden Charakterisierungsversuchen ermögliche dieser eine Analyse der Verfahrensweisen Jelineks unter produktions- sowie rezeptionsästhetischen Gesichtspunkten. ${ }^{6}$ Eine Beschreibung der Intertextualität als Methode zur Interpretation von Jelinek-Texten bleibt Doll aber schuldig. Im Folgenden werden daher, um in die Intertextualität einzuführen, zunächst einige Begriffsdefinitionen diskutiert, in einem weiteren Schritt aber wird die Intertextualität auf ihre Praktikabilität im Umgang mit Jelinek-Texten hin untersucht.

Es war Julia Kristeva, die I 967 den Intertextualitätsbegriff prägte. Kristevas Ideen gingen ihrerseits auf Michail Bachtins »Dialogizitätsmodell« zurück, wonach es einen Dialog einzelner Stimmen innerhalb eines Textes gebe. ${ }^{7}$ Kristeva entwickelte Bachtins Konzept weiter und definierte den Begriff des »Intertexts«:

2 Jelinek, Lesen kann vernichten, S. $67 \mathrm{f}$.

3 Doll, Mythos, Natur und Geschichte bei Elfriede Jelinek, S. I9.

4 Vorgeschlagen von Allyson F. Fiddler. Vgl. ebd.

5 Zum Beispiel in Klotz, Zitat und Montage, S. 256-293. Vgl. ebd.

6 Vgl. ebd., S. I 9.

7 Vgl. ebd., S. I7 ff. 
Jeder Text sei ein »Mosaik von Zitaten«, sei »Absorption und Transformation eines anderen Textes ${ }^{8}$. Kristeva hinterfragte nicht mehr (nur) das Verhältnis verschiedener Stimmen innerhalb eines Textes, sondern auch innerhalb verschiedener Texte. Der Ausdruck »Intertextualität« war dabei ein neues Wort für einen längst diskutierten Sachverhalt, so Peter Stocker. Was den »Attraktionsoder Sensationswert« dieses neuen Begriffs ausmachte, sei allerdings der Versuch gewesen, ihn »als einen Globalbegriff zu etablieren, der manches, was davor vereinzelter Betrachtung überlassen blieb, im Zusammenhang verstehen läßt«. ${ }^{9}$

Kristevas Charakterisierung eines Texts als »Mosaik von Zitaten« birgt allerdings die Gefahr in sich, dass die Intertextualität mit dem Zitat verwechselt oder auf das Zitat reduziert wird, was tatsächlich - auch in der Jelinek-Forschung - häufig der Fall ist. Das Zitat ist aber nur eine von vielen möglichen intertextuellen Spielformen, ebenso wie die Anspielung. Auch wenn Zitat und Anspielung zum »Kernbereich der Intertextualität $~^{10}$ gehören, sind sie mit dieser aber trotzdem $»$ nicht identisch ${ }^{11}$.

Nach Zima bedeutet der Intertextualitätsbegriff die »dialogische Reaktion literarischer und nichtliterarischer Texte auf zeitgenössische oder historische Diskurse und Diskursgattungen ${ }^{12}$. Dies umfasse sowohl die bewusste als auch die unbewusste Verarbeitung von Gehörtem oder Gelesenem. ${ }^{13}$

Für den Literaturwissenschafter eröffnet das Mitdenken von Intertextualität in jedem Fall eine neue Dimension des zu untersuchenden Ausgangstextes

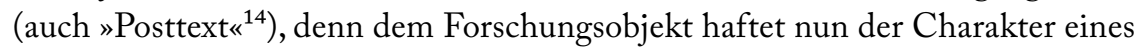
Folgetextes an, der sich auf einen, mehrere oder viele Prätexte bezieht. Dieser Bezug schafft eine Metaebene, auf der inhaltliche und formale Aspekte der Text-Text-Beziehung reflektiert werden müssen. ${ }^{15}$

Die Bezugnahme auf andere Texte wird vom Autor bewusst oder unbewusst hergestellt. Sie kann für den Rezipienten offensichtlich (»markiert«) oder verschlüsselt (»unmarkiert») sein. ${ }^{16}$ Prinzipiell ist der Bezug zu allen denkbaren Textsorten möglich, zu politischen oder philosophischen Abhandlungen ebenso wie zu (bei Jelinek sehr oft herangezogenen) trivialen Formen, zum Beispiel

8 Kristeva, Bachtin, das Wort, der Dialog und der Roman, S. 348.

9 Stocker, Theorie der intertextuellen Lektüre, S. I 8.

Io Ebd., S. 2 I.

I I Zima, Das literarische Subjekt, S. I 87.

I 2 Ebd.

I3 Vgl. ebd.

I4 Vgl. Stocker, Theorie der intertextuellen Lektüre, S. I 5.

I 5 Vgl. Becker, Literatur- und Kulturwissenschaften, S. I39.

I6 Zur Auseinandersetzung mit »markierten« und »unmarkierten« Formen vgl.: Helbig, Intertextualität und Markierung. 
Werbeslogans, Boulevardblättern oder Comics. Aus der Textsoziologie kam daher der Vorschlag, zwischen »interner« (inner-literarischer) und »externer» (nicht-literarischer) Intertextualität zu unterscheiden. Diese Unterscheidung ist allerdings nur dann aufrechtzuerhalten, wenn von der These ausgegangen wird, dass literarische und nicht-literarische Texte einen anderen Sprachgebrauch pflegen. ${ }^{17}$

Über die bereits genannten Möglichkeiten hinaus kann Intertextualität auch über Relationen zu literarischen Gattungen oder poetischen Traditionen erreicht werden. Ebenso ist die Bezugnahme über Stoffe, Themen, Motive und Figurentypen möglich. ${ }^{18}$ All die genannten Formen öffnen den Ausgangstext für einen »kulturellen Gesamttext«, so Sabine Becker, »den literarischen Diskurs, der ihm selbst vorausgeht und als dessen Teil er nun selbst betrachtet werden kann. Der einzelne Text ist damit Bestandteil der kulturellen Sinnproduktion. « ${ }^{19}$

In den poststrukturalistischen Theorien ${ }^{20}$ wird der Ausgangstext schließlich als ein nach allen Seiten hin offenes Zeichensystem betrachtet, das über sich hinaus und auf andere Zeichen, Texte und Zusammenhänge verweist. ${ }^{21}{ }$ Es gibt keine Aussage ohne eine intertextuelle Dimension « ${ }^{22}$, behauptet Tzvetan Todorov und geht damit (wohl absichtlich) über Textsorten hinweg, für die Aussagen mit intertextuellen Bezügen jedenfalls nicht typisch sind, etwa Gebrauchstexte. ${ }^{23}$ Es gibt aber wohl tatsächlich kaum einen literarischen Text ohne intertextuelle Dimension. Die Rezeption eines Texts ist, diesen Annahmen folgend, als aktiver und kreativer Akt zu verstehen. Der in diesem Zusammenhang von Roland Barthes I 968 diagnostizierte »Tod des Autors « ${ }^{24}$ bringt wiederum eine »Geburt des Lesers« mit sich: Nur diesen sieht Barthes - in Vorwegnahme einer der grundlegenden Vorstellungen der Rezeptionsästhetik - dazu in der Lage, die Bedeutungsvielfalt von Texten durch den kreativen Akt des Lesens zu entfalten. ${ }^{25}$

Kristeva überträgt die poststrukturalistische Idee vom Verweisungscharakter des Zeichens auf die Textebene und bezieht darüber hinaus den Bereich der Kultur sowie soziale Strukturen und gesellschaftliche Phänomene in ihre Überlegungen zur Textrezeption ein. Ihr Modell integriert Michel Foucaults Dis-

I 7 Vgl. Zima, Das literarische Subjekt, S. I 88.

I 8 Vgl. Becker, Literatur- und Kulturwissenschaften, S. I39 f.

i 9 Ebd., S. I 40

20 Neben Julia Kristeva ist als deren bekanntester Vertreter Jacques Derrida zu nennen.

2 I Ebd., S. I39 f.

22 Zitiert nach: Zima, Das literarische Subjekt, S. I 87.

23 Vgl. ebd.

24 Barthes, Roland: Der Tod des Autors.

25 Vgl. Becker, Literatur- und Kulturwissenschaften, S. I 43. 
kurstheorie, wonach der Autor als souverän schaffendes Subjekt seine zentrale Funktion verliere und die Bedeutung eines literarischen Texts gerade in dessen Verweisungsfunktion liege, die ihn in den allgemeinen Text der Kultur, oben nach Becker als »kultureller Gesamttext« bezeichnet, integriere. ${ }^{26}$

Die mangelnde Praktikabilität der poststrukturalistischen Theorien wurde von Seiten der Texthermeneutik immer wieder kritisiert, denn Poststrukturalisten wie Jacques Derrida gehen von der Annahme aus, dass Texte unter- und miteinander kommunizieren - eine Vorstellung, die letztlich sowohl die Souveränität des Autors in Frage stellt, als auch die von Barthes beschriebene aktive Leserinstanz ausschließt, da der Intertext für beide Instanzen nicht greifbar ist. In diesem Zusammenhang ist Kristevas besonderer Verdienst zu bemerken: Sie näherte die poststrukturalistischen Intertextualitätstheorien der Rezeptionsästhetik an, was die Interpretation eines (kommunizierenden) Textes wieder möglich machte, obwohl der Autor auch in ihrem Modell keine Rolle spielt. Die unterstellte wechselseitige Beziehung von Texten kann aber durch den Rezipienten aktiviert und somit auch durch die literaturwissenschaftliche Interpretation aufgedeckt werden. ${ }^{27}$ Die Integration von Kristevas Modell in die Praxis ermöglicht die Entwicklung konkreter Verfahrensweisen, zum Beispiel die Beschreibung des Verhältnisses von Post- und Prätexten, aber auch die Offenlegung und Analyse des sich daraus ergebenden Intertextes. ${ }^{28}$

In Hinblick auf die Rezeption von Jelinek-Texten ist die Intertexualität zugleich Segen (für die Beschreibung) wie auch Fluch (für die empirische Untersuchung). Jelineks »extrem intertextuelle $\aleph^{29}$ Schreibweise lebt davon, »in fremden Zungen [zu] reden $\aleph^{30}$. Die Frage, die sich daher stellt, ist nicht nur, ob es möglich, sondern auch ob es sinnvoll ist, die zahllosen Prätexte dekuvrieren und zuordnen zu können - denn die richtige Zuordnung muss nicht automatisch zu einer plausiblen Interpretation führen. Die Literaturwissenschafterin Konstanze Fliedl zeigte sich gar ein wenig empört über Jelineks vermeintliche Aufforderung, die Germanisten sollten »Such, Hundi! ${ }^{31}$ spielen und nach versteckten Literaturzitaten suchen. Fliedl kritisierte, dass es für den Rezipienten ohnehin klar sei, dass sich jeder Text aus »längst vorhandener und neu amalgamierter Sprache« zusammensetze, seit dem linguistic turn erübrige sich ein Quellennachweis, »der sich ja eigentlich ins Unendliche fortsetzen müsste « ${ }^{32}$.

26 Vgl. ebd., S. I44 f.

27 Vgl. ebd., S. $145 \mathrm{f}$.

28 Vgl. ebd.

29 Janz, Elfriede Jelinek, S. IX.

30 Jelinek, Ich bin im Grunde ständig tobsüchtig über die Verharmlosung, S. 90.

3 I Jelinek, Lesen kann vernichten, S. 67 f.

32 Fliedl, Im Abseits, S. 2o. Vgl. auch Steinkellner, Traditionen der Moderne, S. 7 I. 
Nun, eigentlich forderte die Autorin nicht dazu auf, ihre spezielle Zitationspraxis zu untersuchen, sondern stellte - in typischer Jelinek-Manier - süffisant fest, dass die Germanisten dies eben tun, obwohl sie es ja »nicht sollen « ${ }^{33}$. Wie aber soll nun mit Texten verfahren werden, um deren Intertextualität man weiß, wenn man diese eben nicht untersuchen soll?

Dazu sind zwei grundlegende Feststellungen zu treffen, die einmal für und einmal gegen die Intertextualität als Methode sprechen.

Auf der einen Seite sind die intertextuellen Bezüge bei Jelinek vielfach unmarkiert und können daher nur zum Teil entschlüsselt werden. Natürlich gibt es aber viele unmarkierte Bezüge, deren Verweischarakter trotzdem eindeutig ist, weil darin gängige Zitate oder Motive aufgegriffen werden. Wenn Jelinek etwa von einem Politiker schreibt, der sich "wwenn Sie so wollen, entschuldige ich mich halt‘ eben irgendwie entschuldigt « ${ }^{34}$, dann ist für (zumindest österreichische) Zeitgenossen klar, dass diese Passage eine Aussage des langjährigen FPÖ-Obmanns Jörg Haider imitiert, ohne dass dieser namentlich genannt oder das Zitat als solches kenntlich gemacht werden muss. Manchmal gibt Jelinek ihre Vorlagen aber auch dezidiert an, so sind etwa dem »Rechnitz«-Stück Danksagungen an David R. L. Litchfield, Friedrich Nietzsche und Euripides angeschlossen. ${ }^{35}$ In einer Regieanweisung ihres "Burgtheater «-Stücks verweist die Autorin mit der Bemerkung "Raimund, schau oba ${ }^{36}$ auf Ferdinand Raimunds Theatermärchen und deren allegorische Figurenwelt, auch wenn diese in weiterer Folge ironisiert und konterkariert werden. Auch in (mündlich oder schriftlich geführten) Interviews hat Jelinek wiederholt auf Querverbindungen ihrer Texte zu bestimmten anderen Texten hingewiesen. Es scheint ihr also in bestimmten Fällen wichtig gewesen zu sein, die jeweiligen Prätexte (mehr oder weniger eindeutig) auszuweisen.

Auf der anderen Seite arbeiten viele der Jelinek-Texte vorwiegend auf einer assoziativen Ebene, in der es darum geht, scheinbar natürliche Bilder zu erzeugen, um sie im nächsten Moment zu brechen (= als konstruiert zu entlarven). Auch innerhalb eines intertextuellen Rahmens gibt es diese assoziativen Ebenen auf zum Teil vielfältige Art und Weise. Gerade Jelineks Theatertexte werden von der Parallelität und mitunter auch Widersprüchlichkeit der Sprech- und Aktionsebene(n) dominiert: »Die Disparatheit von Gebärde, Bild und Sprache öffnet die Möglichkeit des freien Assoziierens « ${ }^{37}$, so die Autorin.

33 Jelinek, Lesen kann vernichten, S. 67 f.

34 Dies., Schamlos: die Zeit, S. 3.

35 Vgl. dies., Rechnitz, S. 205.

36 Dies., Burgtheater, S. I43.

37 Dies., Ich will kein Theater, S. 32. 
Die Widersprüche, die sich durch das Zusammen- und Ineinanderschneiden verschiedener intertextueller Ebenen ergeben, fordern Jelineks Rezipienten zur kritischen Reflexion heraus. Am Ende ist dies Sinn und Ziel der Destruktionsmethode: den Konstruktionscharakter gesellschaftlicher Diskurse zu offenbaren. Zu diesem Zwecke kann es hilfreich sein, Rückbezüge zu Prätexten von David R. L. Litchfield, Jörg Haider oder Martin Heidegger herstellen zu können; notwendig ist es jedoch nicht. In diesem Sinne muss Fliedl beigepflichtet werden.

Es scheint sich daher eine modifizierte Anwendung der Intertextualität als Methode anzubieten, in der evidenten oder markierten intertextuellen Bezügen zwar nachgegangen wird, weil sie das Textverständnis erhellen und erleichtern können, in der diese Bezüge aber nicht auf Biegen und Brechen hergestellt werden müssen, weil es durchaus als von der Autorin intendiert begriffen werden kann, dem assoziativen Rezeptionsverständnis zu folgen.

\subsection{Darstellung der angewandten Methodik}

»Gehalt ohne Methode führt zur Schwärmerei, Methode ohne Gehalt zum leeren Klügeln...« ${ }^{38}$

Aufbauend auf den bisher geleisteten theoretischen Vorarbeiten sollen nun im empirischen Teil drei exemplarische Textinterpretationen vorgenommen werden, welche die in der Einleitung angeführten Theorien von Faschismus und Opfermythos integrieren, um auf diese Weise einen plausiblen Lektüre- und Deutungsvorschlag anbieten zu können.

Hierfür werden in einem ersten Schritt die allgemeinen Rahmenbedingungen des jeweiligen Beispieltextes (Setting, Plot, Figuren, dramaturgische und formale Besonderheiten etc.) festgestellt. Außerdem wird auf bisherige Interpretationsansätze verwiesen, die vorwiegend aus der deutschsprachigen Literatur- und Theaterwissenschaft, aber zum Teil auch aus dem Feuilleton stammen.

In einem zweiten Schritt werden wahrscheinliche oder ausgewiesene (markierte) Intertexte herausgearbeitet und deren zeitgeschichtlicher Verweischarakter deutlich gemacht, indem darin enthaltene Überschneidungen mit aktuellen oder bereits überholten Faschismus-, Nationalsozialismus- und Opfermythostheorien bewusst gemacht werden. Daneben werden relevante Sekundärtexte, soweit vorhanden, aufgegriffen und die darin angebotenen Deutungsmöglichkeiten in die Analyse miteinbezogen.

38 Goethe, Maximen und Reflexionen, S. I 774. 
Am Ende der drei Interpretationseinheiten wird der jeweils zu untersuchende Beispieltext mit seinen Entstehungs- und Rezeptionskontexten zusammengeführt, um den ihm unterstellten gesellschaftspolitischen Anspruch (ja, sie habe sich immer darum bemüht, ihre Sprach- und Wortspiele »in den Dienst einer politischen Aussage zu stellen ${ }^{39}$ ) untermauern zu können.

Zuletzt wird ein Fazit über die Ergebnisse der drei exemplarischen Textinterpretationen gezogen. Anhand der empirischen Ergebnisse soll die Ausgangsthese des Projekts untersucht werden: Die Kritik am österreichischen Opfermythos sei von Beginn an eines der zentralen Themen Jelineks gewesen, das die Autorin über die explizite Thematisierung hinaus vor allem implizit, auf einer intertextuellen, metasprachlichen Ebene ihrer Texte realisiert.

39 Fuchs/Jelinek, »Man steigt vorne hinein...«, S. 20. Vgl. auch Kapitel r.6. I dieser Studie. 


\section{Lektüre- und Deutungsvorschläge}

»Der Rezipient erwartet eine Botschaft und wird mit einer Attacke auf den Erwartungshorizont konfrontiert. ${ }^{1}$

I Monika Szczepaniak, zitiert nach: https://jelinetz.com/2007/r2/Io/monika-szczepaniak-ichrede-und-rede-tagungsbericht/ (Zugriff am I I.09.2016). 


\title{
3.1 »Burgtheater"
}

\author{
»... wenn sie in `Heimkehr sagt, $>$ Wir kaufen \\ nichts bei Juden<, \\ hätte sie als erwachsener Mensch wissen \\ müssen, was sie da sagt. ${ }^{2}$
}

\subsubsection{Zur verwendeten Sekundärliteratur}

"Endlich weiß man wieder, warum es auch professionelle Theaterkritiker geben muß! ${ }^{3}$

$\mathrm{Zu}$ Jelineks »Burgtheater «-Stück sind vor allem feuilletonistische Reaktionen auf die Erstaufführung 1985 in Bonn vorhanden, die sich allerdings weniger mit dem Text an sich befassen, sondern vielmehr mit dem Skandalon, dass sich Jelinek ausgerechnet die Wiener Burgtheater- und Heimatfilmikonen Paula Wessely sowie Attila und Paul Hörbiger ausgeborgt hatte, um Künstler für ihre Kollaboration mit dem NS-Regime zu kritisieren. In einem viel zitierten Leitartikel sprach sich der damalige Chefredakteur des Wochenmagazins "profil«, Peter Michael Lingens, - in Verkennung der eigentlichen Textaussage - vehement gegen Jelineks Stück aus, eben weil die Autorin darin besagte Realpersonen attackiere. ${ }^{4}$ Lingens löste mit seinem Artikel eine Welle von Leserbriefen und weiteren Stellungnahmen aus, die in der Regel die Wessely/Hörbigers in Schutz nahmen und Jelinek als Autorin diskreditierten. Demgegenüber stand (übrigens in derselben profil-Ausgabe) ein weitaus differenzierterer Artikel der Literaturkritikerin Sigrid Löffler, die eine ausführliche Dokumentation der Gesamtproblematik darbrachte und den von Jelinek intendierten Bezug zum historischen Rahmen herstellte. ${ }^{5}$ Löfflers Darstellung fand jedoch ungleich weniger Widerhall als Lingens' Leitartikel. Bereits eine Woche zuvor war eine kurze Rezension von Löffler zu der Premiere des Stücks in Bonn erschienen. ${ }^{6}$ Der österreichische Publizist und Literaturkritiker Ulrich Weinzierl, damals für die Frankfurter Allgemeine Zeitung tätig, veröffentlichte im November desselben

2 Jelinek über Paula Wessely, zitiert nach: http://www.elfriedejelinek.com (Link: »Paula Wessely«) (Zugriff am 20.1 I.2007).

3 Weinzierl, Sauberes Theater, S. 224.

4 Lingens, Wieweit verdient Paula Wessely Elfriede Jelinek, S. I6.

5 Löffler, Was habe ich gewußt, S. 88-95.

6 Dies., »Erhalte Gott dir deinen Ludersinn«, S. 2 I 8-222. 
Jahres einen Artikel, in dem er auf die Zusammenhänge dieses Theaterskandals mit der österreichischen Opferthese aufmerksam machte und der daher an dieser Stelle - obwohl sich Weinzierl auch wieder nicht mit dem Text an sich, sondern nur mit dessen Rezeption befasste - besondere Erwähnung finden soll. ${ }^{7}$

Pia Janke hat in ihrer Dokumentation »Die Nestbeschmutzerin« die wichtigsten Positionen zu der Rezeptionsdebatte gesammelt und einander gegenübergestellt. ${ }^{8}$

Bemerkenswert ist, dass Jelineks »Burgtheater«-Stück, das I 985 für einen wahren "Pressekrieg " ${ }^{9}$ sorgte, von den österreichischen Kulturredaktionen jahrelang ignoriert worden war, denn das Stück war bereits I982 in den "manuskripten« erschienen - ohne nennenswertes Echo. Der Grund dafür mag darin liegen, dass sowohl die Sprache des Stücks als auch die darin zahllos enthaltenen historischen Anspielungen eine Vertrautheit mit der Wiener Kultur und Kulturszene voraussetzten, die in vielen Fällen nicht gegeben war. ${ }^{10}$ Der eigentlich vorprogrammierte Skandal war also zunächst ausgeblieben. $\mathrm{Zu}$ den wenigen Besprechungen dieser Zeit zählen ein kurzer Text des Wiener Theaterwissenschafters Peter Roessler, »Vom Bau der Schweigemauer « ${ }^{11}$, sowie eine (ebenfalls kurze) Rezension von oben bereits erwähnter Sigrid Löffler ${ }^{12}$. Abgesehen von Roessler brachte zu diesem Zeitpunkt offenbar niemand das Stück in Zusammenhang mit dem Schauspielerehepaar Wessely/Hörbiger, das I 982 noch am Wiener Burgtheater spielte. Attila Hörbigers Bruder Paul war bereits I98 I verstorben. Erst anlässlich der Uraufführung in Bonn befasste sich das österreichische Feuilleton mit dem Stück. ${ }^{13}$

Heute, ein Vierteljahrhundert später, finden sich immer noch wenige wissenschaftliche Auseinandersetzungen im bibliografischen Bestand; und wenn, dann handelt es sich in der Regel um kurze, zehn- bis I5-seitige Texte oder Buchkapitel.

So publizierte Marie-Thérèse Kerschbaumer I 989 im Rahmen ihrer Aufsatzsammlung »Für mich hat Lesen etwas mit Fließen zu tun« eine circa zehnseitige Besprechung von Jelineks »Burgtheater«-Text. ${ }^{14}$ Darin versuchte Kerschbaumer - und leistete damit Pionierarbeit - die Kunstsprache des Stücks anhand einiger exemplarischer Textbeispiele zu untersuchen. Kerschbaumers Aufsatz

7 Weinzierl, Sauberes Theater, S. 222-225.

8 Vgl. Janke, Die Nestbeschmutzerin, S. I 7 I-1 82.

9 Rathkolb, Führertreu und gottbegnadet, S. 8.

io Vgl. Janz, Elfriede Jelinek, S. 63.

I I Roessler, Vom Bau der Schweigemauer, S. 89 .

I 2 Löffler, Majestätsbeleidigung, S. 54.

I 3 Vgl. Steiner, Die verdrängten Jahre, S. I77.

I4 Kerschbaumer, Bemerkungen zu Elfriede Jelineks Burgtheater. S. I $52-16_{3}$. 
stellt bis heute eine der ganz wenigen textimmanenten Analysen zu »Burgtheater« dar. Der Autorin gebührt daher dementsprechende Anerkennung, auch wenn ihre Ausführungen nur wenige Seiten umfassen. ${ }^{15}$

Ein Symposiumsbeitrag von Hubert Lengauer wurde r 992 publiziert. ${ }^{16} \mathrm{Da}-$ rin beschreibt Lengauer »Burgtheater" als Kontrafraktur des traditionellen Wiener Volksstücks und geht vorwiegend dem Bruch von Jelineks »Posse« mit der Traditionslinie von Ferdinand Raimunds Zauberspiel »Der Alpenkönig und der Menschenfeind « nach, wobei er Raimunds Stück keineswegs als naiv beschreibt, sondern vielmehr betont, dass der Volkstheaterdichter der spielerisch-artifiziellen Programmatik Jelineks durchaus entgegenkomme. ${ }^{17}$

Auch die englische Literaturwissenschafterin Allyson Fiddler befasste sich in ihrer I 994 publizierten Dissertation «Rewriting Reality« (unter anderem) mit Jelineks »Burgtheater«-Text. Auf knappen acht Seiten gelingt es ihr, die wichtigsten Hintergründe und Besonderheiten des Texts zusammenzufassen und vor allem auch die Bedeutung der besonderen Kunstsprache des Stücks herauszuarbeiten ("Indeed language is much more than a vehicle for expression in Jelinek's play, it is something of a subject in its own right, and forms an integral part of Jelinek's >Heimat<-critique. ${ }^{18}$ )

Marlies Janz fasste I 995 in ihrem Jelinek-Band bisherige Forschungsergebnisse auf circa acht Seiten zusammen und stellte dabei immer wieder Zusammenhänge zwischen der speziellen Burgtheater-Analyse und dem allgemeinen Rahmen der Jelinek'schen Mythendestruktion her. ${ }^{19}$

Im Besonderen soll hier aber noch auf zwei Interpretationsvorschläge aus der Theaterwissenschaft hingewiesen werden, zum einen auf Beate HochholdingerReiterers Beitrag "Es ist, als liefe das Bellaria-Kino Amok ${ }^{20}$ aus dem Jahr 2004, der sich sehr textnahe und differenziert mit Jelineks Stück und dessen Rezeptionsgeschichte befasst, und zum anderen auf Evelyn Annuß’ Band »Theater des Nachlebens« aus dem Jahr 2005, in welchem sich die Autorin, eine ausgewiesene Jelinek-Expertin, in mehreren Unterkapiteln der Auseinandersetzung mit dem "Burgtheater«-Stück widmet. ${ }^{21}$

I5 Bereits in ihrem (ebenfalls in diesem Band veröffentlichten) Artikel »Porträt einer Dichterin: Elfriede Jelinek (1986)« hatte Kerschbaumer einige Absätze dem »Burgtheater«-Stück gewidmet, siehe: Kerschbaumer, Porträt einer Dichterin, S. I $50 \mathrm{f}$.

I6 Lengauer, Jenseits vom Volk, S. 2 I 7-228.

I7 Vgl. ders., S. 22 I f.

I 8 Fiddler, Rewriting Reality, S. ro7.

I 9 Janz, Elfriede Jelinek, S. 62-70.

20 Hochholdinger-Reiterer, Amok, S. 43-58.

2 I Annuß, Theater des Nachlebens, S. 59-I 35. 
Im Jelinek-Handbuch gibt es einen kurzen, lexikonartigen Beitrag zu »Burgtheater" von Evelyn Deutsch-Schreiner, der gleich zu Beginn auf den Zusammenhang des Stücks mit der österreichischen Opferthese aufmerksam macht und auf wenigen Seiten, aber sehr pointiert und nachvollziehbar, die wichtigsten Eckdaten dazu herausarbeitet. ${ }^{22}$

Auch die für diese Arbeit verwendeten biografischen Darstellungen sollen nicht unerwähnt bleiben: zum einen Maria Steiners kritische Wessely-Biografie mit dem Titel »Die verdrängten Jahre«, die 1996 publiziert wurde. Darin findet sich ein interessanter Exkurs, der dem Skandal um Jelineks »Burgtheater«-Stück gewidmet ist und bisherige Analysen - kurz, aber prägnant - zusammenfasst. Und zum anderen Georg Markus' Familienchronik »Die Hörbigers« aus dem Jahr 2006 - wobei hier anzumerken ist, dass Markus trotz wiederholter Distanzierungsversuche seine Bewunderung für die Hörbiger-Brüder, vor allem aber für Paula Wessely kaum verbergen kann. Die in dem Buch geschilderten Episoden haben dementsprechend nur sehr eingeschränkt und ergänzend zu anderen Quellen in die vorliegende Arbeit Eingang gefunden.

Es sind demnach einige Sekundärtexte vorhanden, auf die bei der Interpretation zurückgegriffen werden kann, auch wenn sie zum Teil nur wenige Seiten umfassen. Darüber hinaus ist es sinnvoll, sich mit Quellen aus Nachbardisziplinen zu behelfen, etwa mit zeithistorischen Darstellungen von Kunst und Künstlertum in der NS-Zeit ${ }^{23}$; mit deren Hilfe können plausible Zusammenhänge zwischen diversen Prä- und Jelinek'schen Posttexten hergestellt werden. Hilfreich sind in jedem Fall ein Mindestmaß an Kenntnis österreichischer Dialekte sowie deutschsprachiger Filmproduktionen der I 930er bis i 95oer Jahre, da auf diese im Text immer wieder Bezug genommen wird. ${ }^{24}$

Angesichts der literaturgeschichtlichen Bedeutung, die Jelinek als Nobelpreisträgerin bescheinigt wurde, und des großen Skandals, den die Uraufführung des Stücks in den I 980er Jahren verursacht hatte, ist es zumindest bemerkenswert, dass sich der Bestand der Sekundärtexte bis heute in überschaubaren Grenzen hält.

22 Deutsch-Schreiner, Burgtheater, S. I37-I4I.

23 Empfehlenswert ist etwa: Rathkolb, Oliver: Führertreu und gottbegnadet. Künstlereliten im Dritten Reich. Wien: Österreichischer Bundesverlag I991, zu den Wessely/Hörbigers insbesondere S. $235^{-265}$. Vgl. Steiner, Die verdrängten Jahre, S. I 83. 
3.1.2 Formales, Setting und Plot

\author{
»Das Stück thematisiert die Kontinuitäten \\ des Faschismus in der österreichischen \\ Kunstproduktion anhand des opportunistischen \\ Verhaltens einer österreichischen \\ Schauspielerfamilie im Dritten Reich.« ${ }^{25}$
}

Jelineks »Burgtheater«-Stück ist, so wie es heute vorliegt, in drei Teile gegliedert: einen ersten Teil, ein "Allegorisches Zwischenspiel« und einen zweiten Teil. In der Erstfassung des Stücks, das erstmals I 982 in den "manuskripten« abgedruckt wurde, fehlte das »Allegorische Zwischenspiel« noch, da Jelinek dieses erst nachträglich einfügte. ${ }^{26}$

Der erste Teil sowie das Zwischenspiel, das im Handlungsgeschehen direkt an den ersten Teil anschließt, sind im Wien des Jahres r 94 I situiert, drei Jahre nach der Machtübernahme der Nationalsozialisten in Österreich und zwei Jahre nach dem Ausbruch des Zweiten Weltkriegs. Der zweite Teil spielt i 945, kurz vor der Einnahme Wiens durch die Rote Armee.

Der Ort der Handlung ist in allen drei Teilen die Wohnung einer Wiener Schauspieler-Familie, die namentlich zwar nicht benannt wird, aufgrund zahlreicher, sehr eindeutiger Hinweise jedoch als Anspielung auf die Wessely/Hörbiger-Dynastie erkennbar ist:

Die Figur кӥтне verkörpert dabei die Theater- und Filmschauspielerin Paula Wessely. istvan steht für Attila Hörbiger, sснов sch für dessen älteren Bruder Paul. mitzi, mausi und Putzi sind als die drei Töchter des Schauspielerehepaars erkennbar: Elisabeth Orth, Christiane und Maresa Hörbiger.

Tatsächlich sind die Parallelen der Figuren zu den Realpersonen für den Rezipienten unvermeidlich. Alleine die Ähnlichkeit der Namen (der gutbürgerliche Name кётне steht für Paula und ähnelt dem Namen einer von Wessely verkörperten Theaterfigur, Kate, der fremdsprachige Name is Tvan steht für Attila usw. ${ }^{27}$ ), die örtliche Eingrenzung auf Wien sowie die Zusammenstellung der Familienverhältnisse (bekanntes Schauspielerehepaar mit drei Töchtern, der Bruder des Familienvaters ist ebenfalls ein erfolgreicher Schauspieler) verweisen auf die bekannte Schauspieler-Familie. Auch die zahlreichen Anspielungen auf diverse Film- und Theaterrollen von Paula Wessely und den Hörbiger-Brüdern erlauben eine (nahezu zweifelsfreie) Zuordnung. Etwaige Abweichungen von

25 Janke, Nestbeschmutzerin, S. I 7 I.

26 Vgl. Hochholdinger-Reiterer, Amok, S. 44.

27 Vgl. Annuß, Theater des Nachlebens, S. 6o. 
den realen Vorbildern sind dabei nebensächlich - so wurde etwa Maresa Hörbiger, die als Putzi bereits im ersten Teil des Stücks, der r 94 I spielt, in Erscheinung tritt, laut Regieanweisung aber auch von einer »lebensgroßen Stoffpuppe ${ }^{28}$ vertreten werden kann, erst im Jänner I 945 geboren. Auch waren Paula Wessely und Attila Hörbiger erst ab den r 95oer Jahren am Wiener Burgtheater engagiert und nicht schon in den frühen r 94oer Jahren, wie im Stück suggeriert wird. ${ }^{29}$ Das Ineinanderblenden verschiedener zeitlicher Ebenen gehört allerdings zu Jelineks bewusst gewählter dramaturgischer Methodik, was im Rahmen der Textanalyse noch genauer diskutiert werden wird.

Das Stück ist von normaler Länge, was an dieser Stelle nur deshalb festgehalten werden soll, weil einige der neueren Jelinek-Dramen aufgrund der Dichte ihrer Textflächen, auch bei starken Kürzungen, nur in Überlänge gezeigt werden können (beim »Sportstück« oder bei »Das Werk« musste das Theater-Publikum immerhin vier bis sechs Stunden ausharren.)

Jelineks »Burgtheater«-Stück kommt insgesamt mit wenig Personal und einem Minimum an Requisiten aus.

Wichtig, weil aussagekräftig, ist die Kostümierung der Protagonisten - sie entspricht jener aus den erfolgreichsten Filmen der Wessely/Hörbigers: кӓтнЕ trägt im ersten Teil »ein stark stilisiertes Trachtenkostüm mit applizierten riesigen Eichenblättern«, durch die an der Brust je ein Dolch gebohrt ist (»Die ganz großen Torheiten $\aleph^{30}$ ), im zweiten Teil ein »heruntergekommenes, aber sehr aufg'mascherltes Abendkleid im Wiener Wäschermadl Stil « ${ }^{31}$. sсновsсн ist mit einem Frack oder Smoking bekleidet und »sieht aus wie ein Ober ( OOber, zahlen! (32) $^{32}$. ISTVAN trägt ungarische Reitkleidung (»Ernte $\left.{ }^{33}\right) .{ }^{34}$ RESI, die von Jelinek in der Regieanweisung als "Anni-Rosar-Typ ${ }^{35}$ bezeichnet wird, ist in eine Altwiener Dienstmädchentracht gekleidet. MAUSI und PUTZI, die beiden kleinen Kinder, sind »unglaublich aufgemascherlt « und haben riesige Schleifen im Haar. ${ }^{36}$

Im ersten Teil, der r94I spielt, wird das Schauspieler-Ehepaar кётнЕ und ISTVAN beim gemeinsamen Essen mit istrans Bruder schorsch, der eben-

So die Autorin in der Regieanweisung zu dem Stück. Siehe Jelinek, BT, S. I 3 .

Vgl. Annuß, Theater des Nachlebens, S. 64.

Deutsche Literaturverfilmung aus dem Jahr 1937, in der Hauptrolle Paula Wessely.

BT, S. I 59 .

Österreichischer Spielfilm aus dem Jahr 1957, in den Hauptrollen Paul Hörbiger und Hans Moser.

3 Österreichischer Spielfilm aus dem Jahr 1936, in den Hauptrollen Paula Wessely und Attila Hörbiger. Gilt als Propagandaspielfilm für das austrofaschistische Regime.

Vgl. Steiner, Die verdrängten Jahre, S. I 85.

Jelinek, Burgtheater (im Folgenden abgekürzt mit BT), S. I30 (Regieanweisung).

BT, S. I 3 I. 
falls Schauspieler ist, sowie den drei Töchtern Mitzi, MAUsi und PUTZI gezeigt. Resi, die Schwester von istran und schorsch, wird wie ein Dienstmädchen behandelt. Sie serviert die Speisen und wird wiederholt mit Tritten und Zurechtweisungen für ihr Benehmen getadelt. кÄтнЕ wird von den beiden Männern immer wieder dazu ermahnt, Hochdeutsch zu sprechen. ${ }^{37}$ Eine ihr in Aussicht gestellte Filmrolle eines deutschen Mädchens in Polen ist wiederholt Gesprächsgegenstand der Tischrunde. KÄTHE, SCHORSCH und ISTVAN witzeln darüber, dass die zur Dienstbotin degradierte RES I "an wengerl zurickgeblieben« sei, betonen aber selbstgefällig sie vor dem »Eithanasieprogramm« zu beschützen ${ }^{38}$.

Auf den ersten Teil folgt ein »Allegorisches Zwischenspiel«, in das Jelinek mit einer Reminiszenz an Ferdinand Raimund (»Raimund, schau oba ${ }^{39}$ ) einführt. In einem Märchenkahn wird der in weißes Verbandszeug eingewickelte ALPENKÖNIG von der Decke auf die Bühne herabgelassen. Istvan glaubt zwar, in dem seltsamen Besucher einen Schauspielkollegen wiederzuerkennen, gerade freundlich wird dieser aber dennoch nicht begrüßt. Der ALPEnkÖNIG bittet um Spenden für den örtlichen Widerstand, woraufhin кётнE, ISTVAN und SCHORSCH ihn als »Vaterlandsverräter ${ }^{40}$ beschimpfen und zu Tode prügeln. Bevor schorsch das letzte Mal zuschlägt, steckt er dem Sterbenden aber noch schnell zehntausend Taler zu: »Werma sehn, für wos guat ist. ${ }^{41}$

Auf das blutig endende Zwischenspiel folgt der zweite Teil. Dieser spielt I 945. KÄTHE und istvan haben Angst vor den zu erwartenden Repressalien durch die russischen Besatzer. кӓтне scheint, aus Angst nicht mehr am Burgtheater spielen zu dürfen, den Verstand zu verlieren. ScHorsch ist zunächst nicht anwesend. Ein von RESI während des Kriegs versteckt gehaltener und zu ihrer Befriedigung missbrauchter BURGTHEATERZWERG, ein kleinwüchsiger, ehemaliger Theaterkollege der drei Protagonisten, wird von IsTvan entdeckt und soll von der Familie kurzerhand zum lebendigen Beweis des angeblichen Widerstands gegen das Regime umfunktioniert werden. Mit allen Mitteln soll der ZWERG, der sich alsbald lieber aus dem Staub machen möchte, zum Bleiben bewegt werden, sogar die Entjungferung der ältesten Tochter, Mi T ZI, wird ihm als Gegenleistung für die Entlastung vor den zu erwartenden Siegermächten angeboten.

Als schorsch, der mithilfe eines Tricks noch schnell für seine Inhaftierung als angeblicher Widerstandskämpfer gesorgt hat, nach drei Wochen wie ein

\footnotetext{
37 Vgl. BT, S. I40.

38 BT, S. I $42 \mathrm{f}$.

39 BT, S. I 43.

40 BT, S. I 46.

$4 \mathrm{I}$ BT, S. I 49.
} 
Held aus dem Gefängnis zurückkehrt, wird der zWERg zur politischen Rehabilitierung der Familie nicht mehr gebraucht: »... Hamma nimmer notwendich das Zwergerl. Samma söba Verfulgte. Jawull!«" ${ }^{22}$ Die zunehmend entrückte und in Panik geratende кётне unternimmt indes mehrere Bühnen-Selbstmorde und sinkt schließlich im Kreis der Familie blutend und ersterbend zusammen. Um sie herum versammeln sich alle Familienmitglieder ${ }^{43}$ und deklamieren im Chor eine Textfläche, von Jelinek als "Wortsymphonie « ${ }^{44}$ bezeichnet, die vor allem aus (sinnverzerrten) Ein- und Zweiwortsätzen besteht, in denen nationale Kulturgüter à la Mozart und Schanigarten herbeizitiert, deren Bedeutungen jedoch verfremdet und ins Lächerliche gezogen oder mit dem Nazismus in Zusammenhang gebracht werden.

Schließlich tanzen alle Anwesenden um die am Boden liegende кӓтне herum und singen eine fröhliche Passage aus Zellers »Vogelhändler«, mit der ISTVAN auch das Spiel eröffnet hatte: „Grieß enk Gott alle miteinander, alle miteinander, alle miteinander, alle miteinander... « ${ }^{45}$. In diesem verbalen und menschlichen Chaos endet das Stück.

\subsubsection{Die Figuren: »Sprachschablonen«}

„Die Figuren sprechen nicht aus sich heraus. Sie sind keine Personen, keine Menschen, sondern Sprachschablonen. Sie konstituieren sich aus dem, was sie sagen, nicht aus dem, was sie sind. ${ }^{46}$

Wie in der poetologischen Einführung bereits festgehalten, verfasst Jelinek prinzipiell keine erzählende Literatur mit sich entwickelnden, zur Identifikation einladenden Charakteren. Ihre dramatischen Texte sind vor allem durch die Austauschbarkeit der agierenden Figuren gekennzeichnet, die in erster Linie als Sprachträger Bedeutung haben und nicht als Individuen dargestellt sind. Dies ist eine dramaturgische Besonderheit, die schon in Jelineks frühen Theaterstücken (von "Nora«, I977, bis »Totenauberg", I99I) angelegt war, sich in den späteren Texten aber noch weitaus verstärkte. Seit Beginn der I 99oer Jahre stei-

42 BT, S. I80.

43 Die Regieanweisung lautet: »Alle stehen jetzt um die blutende Käthe herum.« (BT, S. г88) wobei »alle« nicht näher definiert ist: alle Figuren des Stücks oder (vermutlich) alle zur Familie gehörende Figuren. BT, S. I 88.

45 BT, S. I3 I (am Beginn; ISTVAN) und S. i 89 (am Ende, alle).

46 Jelinek, Ich will kein Theater, S. I 43. 
gerte Jelinek ihre Verfremdungsstrategien drastisch, vor allem in Hinblick auf die Austauschbarkeit ihrer Figuren. Das Moment der exemplarischen Darstellung gewann damit zunehmend an Bedeutung, die Individualität der Figuren wurde mehr und mehr eingeschränkt. ${ }^{47}$

Auch das »Burgtheater «-Stück wird, wie durch die knapp gehaltene Inhaltsangabe ersichtlich ist, nicht von einem dichten, sich aufbauenden Handlungsgeschehen, sondern vielmehr von seiner Sprache getragen, genauer: vom Sprachgebrauch seiner Figuren. Diese haben zwar durchaus benennbare Eigenschaften - es handelt sich wie auch in »Clara S. « oder »Totenauberg « sogar um real existierende Personen, die hier abgebildet werden (Mitglieder der Wessely/ Hörbiger-Dynastie ${ }^{48}$ - Jelinek möchte ihre Figuren jedoch exemplarisch verstanden wissen und nicht als Darstellung konkreter Personen, worüber noch zu diskutieren sein wird.

Von der Form her ist das Stück relativ konventionell gestaltet: Die Figuren konversieren in Dialogform, auch wenn die einzelnen Aussagen oft nicht auf zuvor Gesagtes eingehen, sondern durchaus für sich stehen könnten. Von "Sprachflächen« kann hier jedoch noch keine Rede sein. Die einzige Ausnahme stellt die bereits erwähnte »Wortsymphonie «" ${ }^{49}$ am Ende des Stücks dar, die von allen Figuren gemeinsam dargebracht wird.

Die Identifikation mit den Protagonisten wird schon alleine dadurch verhindert, dass von Beginn an in aggressivem Ton miteinander gesprochen, aber auch handfest mit Gewalt gegeneinander agiert wird. Wie in vielen anderen ihrer Texte transformiert Jelinek auch im »Burgtheater «-Stück strukturelle Gewalt in Bilder physischer Gewalt ${ }^{50}$ - diese bilden eine szenische Parallelebene zu den Dialogen, ebenso wie die wiederholte körpersprachliche Imitation diverser Theaterrollen (vor allem durch кётHE, ISTVAN und SCHORSCH).

Die "Aktionsebene ${ }^{51}$ gewann mit den Jahren insgesamt an Bedeutung in Jelineks dramatischer Arbeit, sie kristallisierte sich schließlich als zweite Handlungsebene heraus, die aber in vielen Fällen die Sprechebene nicht begleitet, sondern diese konterkariert. ${ }^{52}$ Auch in "Burgtheater" stehen Sprech- und Aktionsebene vielfach in Widerspruch zueinander. So geben die Protagonisten verschiedenste Liedanfänge und Operettentexte wieder oder deklamieren diverse Theater- und Filmrollen, schlagen dabei aber gleichzeitig aufeinander ein, miss-

47 Vgl. Scholl, Selbstinszenierungen, S. 6.

48 In »Clara S.« wird Clara Schumann, in »Totenauberg« Martin Heidegger mit Lebensgefährtin Hannah Arendt gezeigt.

49 BT, S. I 88.

50 Vgl. Scheidl, Ein Land auf dem rechten Weg, S. I45 f. Vgl. auch Kap.r.6.2. dieser Studie.

5 I Hochholdinger-Reiterer, Amok, S. 53.

52 Vgl. Scholl, Selbstinszenierungen, S. 6. 
handeln die Kinder oder REsı. Durch die Brutalität der Aktionsebene wird die scheinbare Harmlosigkeit der Sprechebene destruiert.

KÄTHE, ISTVAN und SCHORSCH definieren sich vorrangig durch ihre charakteristischen Sprechweisen, die im Wesentlichen aus einem Sammelsurium verfremdeter Prätexte bestehen und sich den "veränderten Zeitläuften ${ }^{53}$ jeweils anpassen wollen, einmal dem faschistischen, patriarchalen und hierarchisch strukturierten NS-Regime und einmal dem bevorstehenden Niedergang eben dieses Regimes bzw. der nahenden Entnazifizierung - was allerdings (in beiden Fällen) nicht konsequent gelingt. Die dabei entstehende Metaebene stellt somit den eigentlichen Inhalt der Kommunikation dar. Die Interpretation des Texts baut daher auf der Untersuchung der Sprechweisen und Wortwahl der Figuren auf, um intertextuelle Bezüge herausfiltern und Parallelen zu den in der Einführung erläuterten Faschismus- und Mythostheorien herstellen zu können.

Die Hauptfiguren des Stücks sind in allen drei Teilen кётне, ISTVAN und schorsch. Im Allegorischen Zwischenspiel nimmt der ALPENKÖNIg eine wichtige Rolle ein, im dritten Teil des Stücks der burgt heaterzwerg. Auch die Figuren Resi und Mitzi gewinnen im dritten Teil an Bedeutung.

Innerhalb der Figuren ist eine deutliche Hierarchie feststellbar, die sснов in die Rolle des Familienoberhauptes rückt und die beiden anderen Hauptfiguren, кётнE und IstVAn, unter dessen Autorität stellt. Weit abgeschlagen tauchen die ebenso in allen Teilen des Stücks anwesenden Kinder, MitzI, Mausi und PUTZI, auf, von denen die älteste, MitzI, die wichtigste Rolle einnimmt, die jüngste, PUTZI, könne auch von einer lebensgroßen Stoffpuppe dargestellt werden $;^{54}$ sie ist damit offensichtlich die »austauschbarste« aller Figuren. RESI, die wie eine Dienstbotin behandelt wird, obwohl sie eine Schwester von Ist van und schorsch ist, tritt als unterstes Glied der Rangordnung innerhalb der Familie in Erscheinung.

Die vorübergehend auftretenden Figuren ALPENKöNig und BURgtheaterZWERG erlangen vor allem durch die über sie vermittelten Rezeptionsimpulse Bedeutung. Obwohl sie keine Hauptfiguren des Stücks sind, so haben sie doch eine Schlüsselfunktion inne. Auch für sie gilt allerdings, dass sie nicht als Figuren an sich Bedeutung haben, sondern vielmehr als Sprachträger.

54 Vgl. BT, S. I30 (Regieanweisung). 


\subsubsection{SCHORSCH}

$»$... daitsch wird gredt! ${ }^{55}$

SCHORSCH tritt als ideologischer Rädelsführer auf, der die anderen Familienmitglieder im ersten Teil des Stücks, das I94 I spielt, zur Mitläuferschaft mit dem neuen Regime animiert und die nationalsozialistischen, großdeutschen Ideale als seine persönlichen ausgibt. Auffällig an der ihm in den Mund gelegten Ausdrucksweise ist, dass er sehr oft im Imperativ spricht und den anderen Figuren Anweisungen gibt, was sie zu tun und wie sie zu sprechen haben:

SCHовSCH: Stillhalten fier Daitschlond! Patzer seids! Patzer $!^{56}$

SCHORSCH : Brav sein, gscheit sein, Steigbügelhalter sein $!^{57}$

Dezidiert an KÄтHE, seltener an ISTVAN, richtet SCHORSCH die wiederholte Aufforderung, sich, um weiterhin als Schauspieler bzw. Schauspielerin arbeiten zu können, sprachlich anzupassen und nach der Schrift zu sprechen:

scHORsch : Ich hob dir vorhin scho ernsthoft gesokt, Katherl, daß des net ollweil so weitergeht mitn Semmering und die Alpen und die Liadln. Man konn jo nicht immer lochen, net wahr. Der Ernst der Stunde verlangt gebieterisch noch einem in Großdaitschlond ollgemein verständlichen Schriftdaitsch. $(\ldots)^{58}$

schorsch : Nana, Katherl ... derfst net immer so wüüd sein! Muaßt jetzt langsam gesetzter werden, mit deine drei Gschrappn! Wildfang! Bist jo ka Madl mehr... Oba vor ollem: das Weanerische muaß jetzt langsam aufheern, vastehst? (... $)^{59}$

SCHORSCH: (...) Und daitsch wird gredt! Sufurt! Urdentlich daitsch! $!^{60}$

sCHORSCHS wiederholte Zurechtweisungen, KÄTHE und ISTVAN müssten nun endlich lernen, nach der Schrift zu sprechen, damit ihr Schauspiel auch in dem geeinten Deutschen Reich akzeptabel und ihre Sprache verständlich wären, wirken äußerst komisch, da er diesen Anspruch selbst bei weitem nicht erfüllen kann. Tatsächlich gelingt ihm kein einziger »schriftdaitscher« Satz. Allein seine opportunistischen Intentionen kommen in diesen Aussagen zutage, das

\footnotetext{
55 BT, S. I 4 O.

56 BT, S. I 36.

57 BT, S. I48.

58 BT, S. $133 \mathrm{f}$.

59 BT, S. I 35 .

60 BT, S. I40.
} 
gewünschte Anpassen und der Habitus des Befehlenden, der für die Figur charakteristisch ist. Mit dieser Aufforderung nach sprachlicher Anpassung hat Jelinek ihrer Figur eine Passage in den Mund gelegt, die sie einem Rundschreiben des Produktionschefs der »Wien«-Film, Karl Hartl, entnommen haben dürfte, worauf bei Steiner hingewiesen wird ${ }^{61}$ :

Prätext (Karl Hartl)

Posttext (Jelinek)

»Von unserer vorgesetzten Behörde

werde ich darauf hingewiesen, mit beson-

derer Sorgfalt darauf zu achten, daß in unseren Filmen der Wiener Dialekt oder der Dialekt der Alpen- und Donaugaue sснов sch : »... Der Ernst der Stunde so abgestimmt wird, d.h. dem in Großdeutschland allgemein verständlichen Schrift- und Hochdeutsch angepaßt verlangt gebieterisch noch einem in Großdaitschlond ollgemein verständlichen Schriftdaitsch. ${ }^{63}$ wird, daß unsere Filme dem deutschen Publikum aller Stämme verständlich bleiben. ${ }^{62}$

Mit seinem offensiven Auftreten forciert schorsch den Abschied vom Österreichertum und der österreichischen Sprache bzw. den österreichischen Dialekten. Er beweint dies auch nicht. Natürlich müsste auch die Auswahl der Rollen den geänderten Verhältnissen, also der Weltanschauung und den propagierten Idealen des neuen Regimes, angepasst werden, drängt und befiehlt scHORscH wiederholte Male, ohne den Sinn oder die Legitimität dieser dabei zu hinterfragen:

schorsch gutmütig, brav: Was i dir neilich scho sagen wollt, Kathi, mir missen unsane Rollen jetzn, vasteht, itzo a weng... ändern. Anpassn den veränderten Zeitläuften. Dem Verlangen vom Hoamatl... staatspolitisch besonders wertvoll! ${ }^{64}$

schorsch : Oba Schluß itzo mitm monarchistischen Gschlader! Schluß mit die scheenen Uniformen! Mir missen itzo ein daitsches Filmerl mochen. (... $)^{65}$

schorsch : Ihr spüts daitsche Siedler im Polnischen. Echte polenvernichtunswillige Recken! ${ }^{66}$

6I Vgl. Steiner, Die verdrängten Jahre, S. I 82.

62 Hartl, ebd.

63 BT, S. I34.

64 BT, S. I 32.

65 BT, S. I 5 I.

66 BT, S. I 55 . 
ISTVAN : An Bauer spü i net!

SCHORsch : Mußt aber Bursch, es geht um die Wurst. ${ }^{67}$

sсновsсн drängt кётне, die am liebsten »a Grafentöchterl aus der Provinz« spielen möchte, zur Mitwirkung an einem Film über ein deutsches Mädchen in Polen. Die Thematisierung dieses möglichen Engagements von кётн E stellt eine von mehreren Anspielungen Jelineks auf Paula Wesselys Hauptrolle als MARIE THOMAS in dem NS-Propagandafilm "Heimkehr" und somit ein rekurrentes Textelement des Stücks dar. ${ }^{68}$ Auch das Jahr, in dem der erste Teil des Stücks spielt, I 94 I, kann bereits als Hinweis auf den Film interpretiert werden, der I 94I erstmals in den reichsdeutschen (also auch österreichischen) Kinos gezeigt wurde.

schorsch : A daitsches Madl in Polen wirst jetzt spün. In der Wojwodschaft Luzk. Und aus. Konnst scho onfongen, den Akzent lernen, gö $!^{69}$

Die anderen Figuren akzeptieren das autoritäre Gebaren von schorsch weitestgehend. Er scheint als Familienoberhaupt anerkannt zu sein. RES I gegenüber meint SCHORSCH lapidar, sie müsse froh sein, dass er und die beiden anderen sie vor dem "Eithanasieprogramm ${ }^{70}$ beschützen, wodurch klar gemacht wird, dass Jelineks Hauptfiguren - die stellvertretend für viele andere Österreicher stehen - im Jahr 194I bereits wissen, was hinter dem von den Nationalsozialisten als Euphemismus missbrauchten Wort »Euthanasie« steckt: Selektion und Ermordung.

Auch über die Judenvernichtungen weiß schorsch Bescheid, wie in dem Allegorischen Zwischenspiel deutlich wird. In einem Dialog mit IsTvan stellt er fest, dass die Juden plötzlich verschwunden seien (»Ich weiß es necht, wo se hingekommen seind. Doch sehe ich sie schon seit längerem nicht mehr. ${ }^{71}$ ), um im nächsten Atemzug von den »GASUngSOFEN « ${ }^{72}$, den Verbrennungsöfen in den Konzentrationslagern, zu sprechen. Neben den Judenvernichtungen werden auch die Euthanasieprogramme wiederholt thematisiert. SСHORSCH, КӓтHE und Istvan scherzen sogar über deren Opfer, etwa in dem folgenden Textbeispiel über jene Kinder, die in dem Wiener Spital »Am Spiegelgrund« (heute:

67 BT, S. I55.

68 Siehe BT, S. I64 (zweimal) sowie S. I73.

69 BT, S. I 40.

70 BT, S. I 43.

7 I BT, S. I 54 .

72 BT, S. I 58. 
"Baumgartner Höhe«) während des Zweiten Weltkriegs misshandelt und umgebracht wurden.

Schorsch : Mir treten in ainer Sondervurstellung vor die zurickgebliebenen Kinder in Glanzing auf. Damits a letzte Fraid haben! Bevurs abgespritzt wern.

Is TVAn: Oder am Spiegelgrund! Da wird man nimmermehr gesund! Jawull! Singen derfens noch a Liaderl! Jene Patschachter, die oamen gaistigen Kripperl! Jede Muatter tat rearn.

кётне klangvoll: Schweig! Stille, stille, kain Geraisch gemacht.

Istvan : Zeit der Reife.

schorsch: Losts zua! Aber vurher derfens noch mit dem Kinderarzt Doktor Engerlmacher ain scheenes Gstanzl singen, de Gstermln! Wie geschwind sie es aufgegessen haben, jenes letzte Grieskoch vor der großen Ewigkeit! (... $)^{73}$

»Doktor Engerlmacher« stellt eine unmissverständliche Anspielung auf den damaligen Stationsarzt der Klinik, Heinrich Gross, dar, der im Rahmen der so genannten »Euthanasieprogramme vermutlich an der Ermordung zahlloser behinderter Kinder beteiligt gewesen war. ${ }^{74}$

Das von istvan scheinbar unmotivierte Herbeizitieren eines Romantitels von Jean-Paul Sartre (»Zeit der Reife«) entspricht dem von der Autorin gepflegten Usus, Liedanfänge oder Filmtitel (mitunter auch Titel von Theaterstücken) in die Aussagen ihrer Figuren einzustreuen, wie Kerschbaumer vermutet als »Bekräftigungsformeln ${ }^{75}$, mit welchen Jelinek die erstarrte Hochkultur satirisch zu kritisieren trachte. ${ }^{76}$ In diesem Fall ist »Zeit der Reife« aber auch als makabres Wortspiel interpretierbar: als Variation der Redewendung »Die Zeit ist reif« (für die Tötung der Kinder).

Durch die oben zitierte Textstelle wird klar gemacht, dass die Figuren Is T VA N und schorsch, vermutlich auch кётне, Kenntnis über die Euthanasieverbrechen, die Gaskammern und Giftspritzen der Nationalsozialisten haben. Immer wieder wird im Text ausdrücklich mit dem Wissen der Nachkriegszeit operiert. Mitleid oder Solidarität mit den Opfern ist aber weder bei кётне noch bei Is TVAN oder SCHORSCH zu bemerken. Wiederholte Male ist es schorsch, der betont, dass es eben jetzt so sei und man sich danach zu richten habe. Er gibt sich damit als Rädchen einer größeren Hierarchie zu erkennen, deren Bestehen er

73 BT, S. I5 I.

74 Vgl. Kapitel I.5 dieser Studie.

75 Kerschbaumer, Bemerkungen zu Elfriede Jelineks Burgtheater, S. I 59.

76 Vgl. ebd., S. I 58 f. Vgl. auch Janz, Elfriede Jelinek, S. 63: hier als »bestätigende Abschlußformel eines Dialogparts« bezeichnet. 
nicht hinterfragt, sondern zu seinem persönlichen Vorteil auszunutzen trachtet. An der Spitze dieser übergeordneten Pyramide steht die nationalsozialistische Führungselite, an der Spitze der familieninternen Hierarchie steht schorsch. Das hier von der Autorin vorgeführte familiäre System widerspiegelt somit im Kleinen das patriarchale und hierarchische Organisationsprinzip faschistischer Parteien und Systeme, wie es der deutsche Historiker Wolfgang Wippermann Jahre später beschrieben hatte (»... hierarchisch nach dem Führerprinzip gegliedert... Betonung des jugendlichen und vor allem männlichen Charakters... pseudoreligiöse Ausrichtung...« - wobei hier die Kunst als »Pseudoreligion« missbraucht wird - usw.). ${ }^{77}$

SCHORSCH ist schließlich derjenige, der im Allegorischen Zwischenspiel so lange auf den ALPENKÖNIG, den vermeintlichen "Vaterlandsverräter « ${ }^{78}$, der als Abgesandter des örtlichen Widerstands die bestehende hierarchische Ordnung bedroht, einschlägt, bis dieser tödlich verletzt zusammenbricht. Er begeht damit ein Kapitalverbrechen, für das er kein Unrechtsbewusstsein empfindet, weil er es im Sinne des Regimes begangen hat.

Faschistische Systeme sind zeithistorischen Theorien zufolge sehr stark dadurch gekennzeichnet, dass sie Gewalt als legitimes Mittel zur Abwehr von Feinden und Fremden einsetzen (»... im Mittelpunkt sowohl der Propaganda wie der Politik « ${ }^{79}$ steht die Gewalt), was im Inneren den Zusammenhalt festigen soll. Die Verantwortung für verbrecherische Taten kann an politische $\mathrm{Ob}$ rigkeiten abgegeben werden, die exekutierenden Personen können sich auf die "Pflichterfüllung« berufen (ein im Zusammenhang mit der Waldheim-Affäre in Österreich viel diskutierter Begriff). ${ }^{80} \mathrm{Im}$ übergeordneten Kontext basierte der Opfermythos auf eben diesem Prinzip, indem die Zweite Republik als einer der drei Nachfolgestaaten des Deutschen Reichs die Verantwortung für die NS-Verbrechen »externalisierte ${ }^{81}$ und an Deutschland abgab. ${ }^{82} \mathrm{Im} »$ Burgtheater «-Stück externalisiert SCHORSCH die Verantwortung, indem er sie dem Regime überlässt, welches Kapitalverbrechen mit dem höheren Ziel der »Endlösung« zu rechtfertigen scheint.

77 Vgl. Wippermann, Hat es Faschismus überhaupt gegeben, S. 56. Vgl. auch Kapitel I.4.I dieser Studie.

78 BT, S. 146 und S. 152.

79 Wippermann, Hat es Faschismus überhaupt gegeben, S. 56. Siehe auch Kapitel I.4.I dieser Studie.

8o Vgl. Kapitel I.4.4 dieser Studie.

8I Lepsius, Das Erbe des Nationalsozialismus, S. $250 \mathrm{f}$.

82 Vgl. Kapitel I.4.4 dieser Studie. 
Sehr oft bedient sich schorsch der nationalsozialistischen Diktion, die von der Rassenlehre durchdrungen ist, indem er etwa zwischen Deutschen, »Juden ${ }^{83}$ und »Ausländern ${ }^{84}$ differenziert oder die Offenbarungen des neuen Deutschen Reichs beschwört: »unsr naiches Haus Daitschlond « ${ }^{85}$, nennt er es unter anderem, "wo man frank und frei otmen konn ${ }^{86}$ - ein glatter Widerspruch zum tatsächlichen Bespitzelungs- und Überwachungssystem des »Dritten Reichs«, der als poetisches Mittel Jelineks zur Destruktion nationalsozialistischer Vaterlandsbeschwörungen interpretiert werden kann. "So glocht homma nimma seit dem Anschluß! « und »So gschrian homma nimma seit dem Heldenplotz! « ${ }^{87}$, brüllt schORsch, während er und die beiden anderen Hauptfiguren den ALPENKÖNIg zu Tode prügeln. In dieser Szene wird wiederum die Verherrlichung von Gewalt deutlich, mehr noch, der Spaß an Gewalt, der Spaß an der Unterdrückung anderer. Auf der anderen Seite steht der Wunsch, den »veränderten Zeitläuften ${ }^{88} \mathrm{zu}$ entsprechen. Der von Fromm beschriebene »autoritäre Charakter« ist sadomasochistisch veranlagt: $\operatorname{Er}(\mathrm{sCHORSCH})$ bewundert gleichermaßen die Autorität (das NS-Regime bzw. dessen Führungselite), wie er danach strebt, sich ihr zu unterwerfen. ${ }^{89}$ Die Unterwerfung unter die Autorität bedeutet zum einen die (willkürliche) Machtausübung über andere, schwächere Ketten des Glieds, die aus der selbst definierten Gruppeneinheit ausgeschlossen werden (KÄTHE, ISTVAN und SCHORSCH als "wir«, RESI, ALPENKÖNIG und BURGTHEATERZWERG als die "anderen«), und zum anderen das Abgeben von Eigenverantwortung und Unrechtsbewusstsein: Die vom nationalsozialistischen »Rassenstaat ${ }^{90}$ künstlich hergestellten Mechanismen von »Inklusion« und »Exklusion ${ }^{91}$ werden hier in beeindruckender Weise vorgeführt. Sie rechtfertigten scheinbar die Anwendung von verbaler, aber auch physischer Gewalt gegen Gemeinschaftsfremde (»Nicht-Arier«) - ein Angebot, von dem die Hauptfiguren des Stücks reichlich Gebrauch machen.

Tatsächlich waren es viele Künstler, die mit dem Deutschen Reich kollaborierten, da sie von den Möglichkeiten, welche die Rassenpolitik des Regimes für sie bereithielt, persönlich (materiell und in Hinblick auf die berufliche Laufbahn) profitierten - ein Thema, das etwa auch Klaus Mann in seinem »Me-

83 BT, S. I 52.

84 BT, S. I45, S. 148.

85 BT, S. I 44 .

86 BT, S. I 45.

87 BT, S. I 47 .

88 BT, S. I32.

89 Vgl. Kapitel r.4.I dieser Studie.

90 Wippermann, Hat es Faschismus überhaupt gegeben, S. 58.

9I Zum Begriffspaar »Inklusion/Exklusion« vgl. Kapitel I.4.I dieser Studie. 
phisto«-Roman verarbeitet hat, der von der Karriere des Schauspielers Gustaf Gründgens in der NS-Zeit handelt. ${ }^{92}$

Insgesamt scheinen Emotionen und Eigenverantwortung für schorscH keine Rolle zu spielen - schließlich ist er ist nur eine »Schablone«. Allein die Möglichkeiten, die sich ihm und den beiden anderen schauspielenden Familienmitgliedern durch die Gegebenheiten des Regimes offenbaren und Ruhm sowie hohen Verdienst versprechen, scheinen für ihn von Interesse zu sein. Auch Neid spielt offenbar eine Rolle:

schorsch : Wann i denk, was die Röckling und der Schnuppi vadient hoben nailich bei ihnarem Auftritt im Kazett. Stacheldraht und Suchscheinwerfer gaben eine reizvolle Kulisse ab für ein menschliches wie kinstlerisches Ereignis. Knackwurst $!^{93}$

Was mit den Menschen, die in dem betreffenden »Kazett « inhaftiert sind, passiert, ist für SCHORSCH demnach nicht nur wurst, sondern sogar »knackwurst« - eine ästhetische Verunstaltung Jelineks einer umgangssprachlichen Redewendung als Mittel der Ironisierung: Hier sollen die vorgeblich künstlerischen Ambitionen ihrer Figur destruiert werden. Mit »Röckling« dürfte die Schauspielerin Marika Rökk gemeint sein, auf die auch an einer anderen Stelle des Texts angespielt wird ${ }^{94}$, mit »Schnuppi« Johannes (»Jopi«) Heesters - zwei Schauspieler, die, ebenso wie Paula Wessely und die Hörbiger-Brüder, im nationalsozialistischen Deutschen Reich erfolgreich Filme drehten und deren Karrieren auch nach I 945 nahezu nahtlos, ohne nennenswerte Konsequenzen oder Maßnahmen der Entnazifizierung, weitergingen.

Im zweiten Teil des Stücks, der 1945 situiert ist, als der Krieg bereits als verloren gilt, verabschiedet sich SCHORSCH genauso schnell vom »braunen Spuk« ${ }^{95}$, wie er ihn zunächst als Gegebenheit akzeptiert hatte. Wahre Identifikation mit der Weltanschauung der Staatsmacht war demnach zu keinem Zeitpunkt gegeben. Stattdessen wiederentdeckt er plötzlich seine Liebe fürs "Hoamatl ${ }^{96}$ Österreich und lässt sich kurz vor Kriegsende mithilfe eines Tricks als angeblicher Widerstandskämpfer inhaftieren, womit er nach seiner Freilassung prahlt:

92 Vgl. theoretische Auseinandersetzungen zu diesem Themenkomplex, etwa: Rathkolb, Führertreu und gottbegnadet, oder auch: Wulf, Theater und Film im Dritten Reich. Vgl. auch Klee, Kulturlexikon zum Dritten Reich.

93 BT, S. I 56.

94 Vgl. BT, S. I 50.

95 BT, S. I79.

96 BT, S. I32. 
schorsch : (...) I hab mi schlußendlich, fünf vor Zwölfe, no fotografieren lossen, wia i an Scheck fier die esterreichischen Patrioten unterschrieben hob. Olles fier Esterreich, domit es wieder rein und scheen werdet! Besoffen hob i gsungen, es steht a klanes Bankerl im Helenental. Des homs net wolln, die Nazibagasch! Ihr seht: Kleine Ursachen große Wirkung! A tuli Idee wor des, gö jo! ${ }^{97}$

Eine politische Wandlung gesteht Jelinek ihrer Figur schorsch nicht zu. Vielmehr verkörpert diese einen Charakter, der sich nach allen Richtungen hin absichern will, so wie er gleichzeitig auf den ALPENKÖNIG einschlägt und ihm zehntausend Taler zusteckt. $^{98}$

In "Burgtheater « steht schoRscH für einen gewissenlosen Opportunisten, der I94I ebenso begeistert nazifizierbar ist wie I 945 auch wieder entnazifizierbar. ${ }^{99}$ Er ergreift die sich ihm bietenden Möglichkeiten ungeachtet der Konsequenzen für andere, gliedert sich in patriarchale, faschistische Hierarchien ein, ist gewaltbereit und ordnungsgläubig, begeht unter dem Deckmantel der persönlichen Unverantwortlichkeit Kapitalverbrechen und animiert andere zur Mittäterschaft. Als der unpolitische Künstler, als der er gerne gesehen würde, kann er demnach beim besten Willen nicht bezeichnet werden. Mit schorsch hat Jelinek einen hohlen "Kadaver ${ }^{100}$ ohne emotionale Regung und ohne Bereitschaft und Möglichkeit zur Entwicklung auf die Bühne gebracht.

\subsubsection{ISTVAN}

»Bin nur ein Komödiant! ${ }^{101}$

Im Vergleich zu schorsch wirkt Istvan eher passiv und leicht beeinflussbar - ein Antiheld. Auch er fragt, vorgeblich seinen Leidenschaften zuliebe, nicht nach Hintergründen, sondern gibt die Verantwortung für sein Handeln und seine Entscheidungen im Zweifelsfalle lieber an den Bruder scHORSCH ab (»Der Schorschi weiß schon, was gut is, fier uns und fier die ondaren. ${ }^{102}$ ). Von sich selbst behauptet IsTVAN, nur ein »Komödiant ${ }^{103} \mathrm{zu}$ sein, wodurch er seine vermeintlich unwichtige Position unterstreicht, da Komödianten keine Entscheidungsträger, sondern nur Unterhalter sind. Auf diese Weise »ent-politi-

97 BT, S. г 80.

98 Vgl. BT, S. г67.

99 Vgl. Löffler, »Erhalte Gott dir deinen Ludersinn«, S. 220.

roo Janz, Elfriede Jelinek, S. 38.

IоI BT, S. I32.

Iо2 Ebd.

Io3 Ebd., vgl. auch S. I37 und S. I69. 
siert ${ }^{104}$ er sich selbst. Zugleich verweist der in Variationen wiederkehrende Satz (»Bin nur ein Komödiant! ${ }^{105}$, »War nur ein Komödiant. ${ }^{106}$, »Bin jo nur ain Komödiant! « ${ }^{107}$ ) auf den Titel eines österreichischen Kinofilms, der I 935 unter der Regie von Erich Engel gedreht und mit Publikumslieblingen wie Rudolf Forster, Christl Mardayn und Hans Moser besetzt war. ${ }^{108}$

So unbescholten, wie IsTVAN zunächst daherkommt, ist er aber natürlich nicht. Er wirkt zwar unscheinbar, vor allem im Vergleich zu seinem Bruder scHORsch, der eindeutig den Ton angibt, ist aber doch durchdrungen von der nationalsozialistischen Idiomatik.

Ständig zitiert er aus verschiedensten Film- und Theaterrollen und stellt diese auch mimisch dar, wie nebenbei kaut er dabei Parolen vom wiedererwachten Deutschland oder vom wackeren Führer wieder (»Die heilige Energie des Vulkes. Daitschlond erwoche! « ${ }^{109}$ oder Mein Fiehrer befiehl, mir folgen dir! « ${ }^{110}$ ). Durch das Herbeizitieren von Film- und Dramentiteln und die körpersprachliche Darstellung verschiedener Rollen, zum Teil mitten im Gespräch, wirkt er wie ein etwas weggetretener, vielleicht obsessiver, alles in allem aber harmloser Künstler. Genau dieses Bild will Jelinek jedoch durchbrechen, was ihr vor allem durch den starken Widerspruch zwischen Sprech- und Aktionsebene gelingt. ${ }^{111}$ Während кётне etwa mit sсновsсн diskutiert, der die Anpassung an das neue Regime für die weitere berufliche Karriere einfordert, gibt Is Tvan - so die Regieanweisung Jelineks - »etliche Erfolgsnummern aus seinen beliebten Filmen stumm zum Besten « ${ }^{112}$ und fordert KÄTHE auf:

Is TVAN (...): Tua schön zuhörn, Käthe, tuast halt zuhörn und machst es dann nach, gö ja. Der Schorschi weiß schon, was gut is, fier uns und fier die ondaren. Der hot seine Beziehungen zu Berlin, die was er spielen laßt, damits eahm spün lossn. Schrammeln. Eindringlich: Schrammeln $!^{113}$

Er formuliert damit die seiner Meinung nach notwendigen Strategien für eine berufliche Karriere im nationalsozialistischen Deutschen Reich: Anpassung

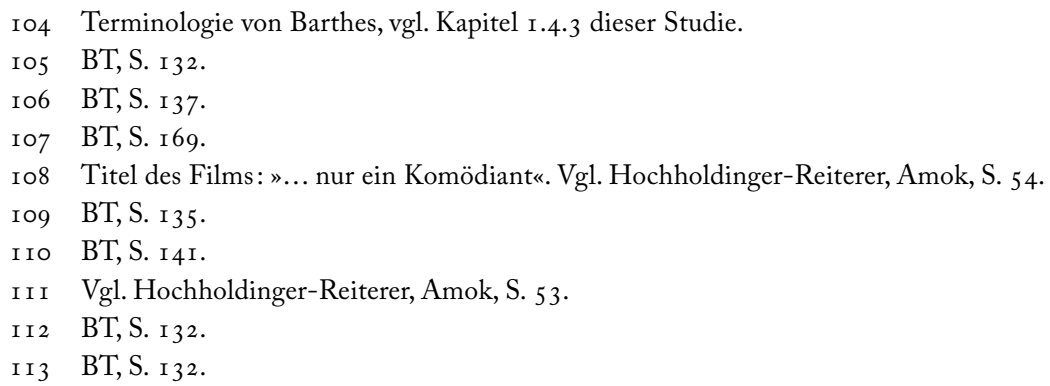


und Beziehungen. ${ }^{114}$ Auch die scheinbar unvermittelte Ausrufung »Schrammeln! « ist wohlkalkuliert, verweist sie doch auf den Titel einer I 944 gedrehten Wien-Film-Produktion mit Paul Hörbiger in der Hauptrolle, die mit den Prädikaten »künstlerisch und volkstümlich wertvoll« ausgezeichnet wurde. ${ }^{115}$ Die Anspielung auf das Mitwirken der drei Protagonisten an propagandistischen oder jedenfalls regimefreundlichen Filmen findet sich auch an anderen Stellen des Stücks wieder, etwa in einer Aussage von sсновsch (»... mir missen unsane Rollen jetzn ... a weng ändern ... staatspolitisch besonders wertvoll! « ${ }^{116}$ )

Is TVAn widerspiegelt in perfekter Manier den Typus des braven, feigen Mitläufers. Er rechtfertigt seine Enthaltsamkeit vom Kriegsdienst mit seinen angeblich unverzichtbaren schauspielerischen Verpflichtungen. So gerne wäre er dabei, bei den »topferen Burschen an der Front ${ }^{117}$, beteuert er:

IsTVAN : ... Wie gern, oh wie gern wär ich dabei! Doch bin ich hier unabkömmlich. Sowas müßtmer einmal mochen. War des a Gspaß! ... ${ }^{118}$

IS TVAN ist tatsächlich genauso opportunistisch und gewissenlos wie sein Bruder - und dazu noch feige. Es muss stets jemanden geben, der seine Verhaltensweisen deckt. So bezeichnet er es auch als »Gspaß« und »Hetz « ${ }^{119}$, gemeinsam mit KÄTHE und SCHORSCH den gewaltlosen ALPENKÖNIG zu erschlagen. In der vorausgehenden Konfrontation dieser Gewaltszene fällt Is Tvan insofern auf, als dass er immer wieder versucht, aus dem Alpenkönig herauszukitzeln, welche Art Mensch er sei: ein bekannter oder wenig bekannter Schauspielkollege, ein Jude, ein Bolschewist oder gar ein »Krowot ${ }^{120}$ ? Der Unterschied scheint für ihn von relevanter Bedeutung zu sein, was auch darin deutlich wird, dass Is TVAN den Fremden, der um Geld für Widerstandszellen bittet, mit der Bemerkung »Mir wollen hier keine Juden und Ausländer! ${ }^{121}$ wegschicken möchte und ihn als "Lumpenhund« und »Vaterlandsverräter « ${ }^{122}$ beschimpft, bevor кÄтнE und er schließlich anfangen, auf den unwillkommenen Gast einzuschlagen. So wie er seine eigene Rolle verharmlost und herunterspielt (»ent-politisiert«), verniedlicht istvan auch wiederholt die Verbrechen des Regimes, indem er sich zum

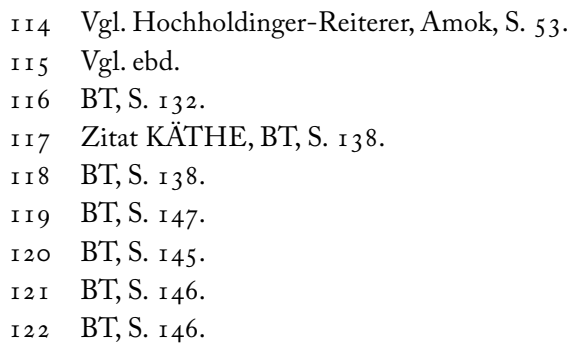


Beispiel in einer Art Babysprache über die Giftspritzen und Gaskammern lustig macht:

Istvan: Hui! Ui Jegerl! Spritzerl ins Venerl! Benzin! Gasi! Gassigassi mitm Hundi! $!^{123}$

Es drängt sich weiters die Assoziation eines anderen, ganz bestimmten Sprachgebrauchs auf, denn die ständige Verwendung von Verniedlichungen und Ausrufen wie »Ui Jegerl!«, auch an unpassendster Stelle, verweisen auf ein Genre, das heutzutage für Kinder reserviert ist: das Kasperltheater. Zur Untermauerung dieser Behauptung sei hier auf Jelineks Homepage verwiesen, auf welcher der erste und der zweite Teil des Stücks jeweils mit einem kleinen Bildkommentar abgeschlossen werden, auf dem der Kasperl und dessen Gefährte, der Teddybär "Pezi«, zu sehen sind. ${ }^{124}$ Das »Burgtheater« als der Inbegriff der österreichischen Hochkultur wird hier demontiert und in seiner künstlerischen Bedeutung mit dem Kasperltheater, einer (kaum mehr steigerbaren) Form von Subkultur, verglichen.

Möglicherweise charakterisiert sich die Figur Istvan in Jelineks »Burgtheater«-Stück selbst am besten, indem sie feststellt: »Denkt sich sein Teil und läßt den Großsulz reden! « ${ }^{125}$ In dieser kleinen Bemerkung wird eine recht gewichtige Aussage zum Ausdruck gebracht: das Stillhalten und Wegschauen in einem Willkürregime, in dem ein anderer die Entscheidungen trifft, ob es nun SCHORSCH oder ein anderer »Fiehrer« ist - Is TVAN glaubt und zieht es vor, es jedenfalls selbst nicht zu sein.

Das Bekenntnis zum Führer und die Begeisterung über den »Anschluss« wird von istvan im Laufe des Stücks wiederholte Male formuliert: »Mein Fiehrer befiehl, mir folgen dir! « ${ }^{126}$ oder »Anstrengen missen mir uns, damit mir die woamen, otmenden Laiber am Heldenplotz, die was unsarem Fiehrer ein so begeistertes Willkommen entboten hoben, auch urdentlich befriedigen kennen. " ${ }^{127}$ Jelinek greift in diesem Kontext (wie übrigens auch in anderen ihrer Texte) die von ihr offenbar als abwegig befundene »Führer-Theorie« auf, wonach die Person des »Führers« als nahezu ausschließliche Ursache für die Entstehung faschistischer Herrschaftssysteme begriffen, also etwa die Person Adolf Hitlers

I 23 BT, S. I 5 I.

I 24 Siehe Homepage Jelinek: http://www.elfriedejelinek.com sowie Hochholdinger-Reiterer, Amok, S. 49.

I 25 BT, S. I 59.

I 26 BT, S. I4I.

I 27 BT, S. I 34 . 
als allein schuldige für den Nationalsozialismus ausgemacht wird ${ }^{128}$, destruiert diese jedoch gleichzeitig, denn über Figuren wie Is T van wird deutlich gemacht, dass die jeweilige Führerperson nur erfolgreich sein kann, wenn viele Einzelne (die »Vielen ${ }^{129}$ ) ihren Vorgaben folgen oder sich jedenfalls nicht widersetzen.

Insofern ist auch Istvan in das von Fromm beschriebene Muster des »autoritären Charakters« einzureihen, wenn auch eine Stufe unter schorsch : Er (ISTVAN) bewundert gleichermaßen die Autorität (schorsch), wie er danach strebt, sich ihr zu unterwerfen. ${ }^{130}$ Die Unterwerfung unter die Autorität bedeutet gleichzeitig die (willkürliche) Machtausübung über andere, schwächere Ketten des Glieds (etwa кётнe, Resi, den Alpenkönig) wie auch das Abgeben von Verantwortung. ${ }^{131}$

Im zweiten Teil des Stücks, als der Untergang des Nationalsozialismus bereits besiegelt ist und die Rote Armee vor den Toren Wiens steht, verlässt sich IstVan wiederum auf schorsch und dessen Spürsinn, gibt also sogar in dieser Situation, in der das eigene Leben gefährdet ist, die Verantwortung ab: "Der Schorschi wird uns als der ollernaicheste Patriot bei die Russen scho aussihaun! « ${ }^{132}$, beschwört er кÄтнE, die aus Angst vor der nahenden Besatzung halbherzige Selbstmordversuche unternimmt.

So wie schorsch Verantwortung externalisiert, indem er sein Unrechtsbewusstsein mit Pflichterfüllung fürs Regime rechtfertigt, externalisiert Is TVAN seinerseits Verantwortung, indem er sie an scHORscH, das nächsthöhere Glied der familieninternen Hierarchie, abgibt - ein Verhaltensmuster, wie es in den Opfermythostheorien in größerem Maßstab beschrieben wird. Vor sich selbst rechtfertigt er seine Mitläuferschaft, die er nun, im Angesicht der militärischen Niederlage des Regimes, zwar zu erkennen, wohl aber nicht »denkend zu verarbeiten ${ }^{133}$ scheint, mit seinen schauspielerischen Erfolgen, die er während der NS-Zeit erbracht hat:

I STVAN : Nur den Mut net sinken lossen! In daitscher Herde hofgastein, aber nur, wann der Russe wirklich kimmt. Donn zeigen wir ihm, wos mir in der Zwischenzeit gemocht hoben. Nämmlich wurde ich unter Max Reinhardt der beste Jedermann! Jawull! $!^{134}$

I 28 Vgl. ebd.

I 29 Lüdtke, Macht der Emotionen, S. 54.

I 30 Vgl. Kapitel I.4.I dieser Studie.

I3 I Vgl. ebd.

I 32 BT, S. I66.

I33 Erdheim, zitiert nach: Ziegler/Kannonier-Finster, Österreichisches Gedächtnis, S. 77. Vgl. Kapitel I.4.4 dieser Studie.

I34 BT, S. I66. 
Den »Jedermann« mimte das Realvorbild für is Tvan, Attila Hörbiger, tatsächlich in den Jahren I935 bis I 937 sowie zwischen 1947 und I95 I. Max Reinhardt, der zu den Mitbegründern der Salzburger Festspiele zählt ${ }^{135}$, zu deren jährlichen Höhepunkten bekanntermaßen die Aufführung des »Jedermann« am Salzburger Domplatz gehört, sei zu Unrecht nach Amerika geflohen, befindet ISTVAn im Text wenig später. Reinhardt, der offene Affinitäten zum Katholizismus hegte, seine jüdische Konfession jedoch niemals abgelegt hatte, war I 937 in die USA geflohen, wo er I 943 auch verstarb. Wenn Reinhardt geblieben wäre, dann »hättmers eahm scho gricht ${ }^{136}$, sagt die Figur IsTvAN im Stück so stellte das Deutsche Reich mitunter Ehren-Arierschaften aus, um jüdische Künstler halten zu können. Angeblich wurde auch Reinhardt dieses Angebot gemacht. ${ }^{137}$ Hitler selbst habe Reinhardts Fähigkeiten und Verdienste nicht bestritten, vermerkte Joseph nach einem Gespräch mit Hitler im Dezember I 940 in seinem Tagebuch: »In der Reproduktion vermag der Jude manchmal etwas zu leisten ${ }^{138}$, kommentierte der »Reichsminister für Volksaufklärung und Propaganda« Joseph Goebbels den Widerspruch zwischen der Anerkennung jüdischer Kulturschaffender und der antisemitischen (Kultur-)Politik des Regimes. Durch Äußerungen wie die oben zitierte wird klar, dass Is Tvan auch im Angesicht der Eroberung Wiens durch die Rote Armee kein Unrechtsbewusstsein entwickelt hat und sich im Moment alles nur um die Frage dreht, wie er sich selbst und das eigene Tun am besten darstellen könne - nicht, was in den Jahren davor tatsächlich passiert ist.

Immer wieder kreist Jelineks »Burgtheater«-Text um die Frage, wie mit dem Nachkriegswissen umgegangen, wie aus der nachträglichen Perspektive über die Vergangenheit gesprochen, was verdrängt und was vergessen wird. Das, was die Opfermythostheorien auf theoretischer, wissenschaftlicher Basis hinterfragen, thematisiert auch Jelineks artifizielle Literatur und im »Burgtheater«-Stück auf komprimierte Art und Weise, denn darin geht es einzig und allein um die Frage, wie im Nachhinein über den Nationalsozialismus gesprochen werden kann und wie über die persönliche oder kollektive Beteiligung geurteilt werden muss. is Tvan repräsentiert dabei jenen Typus, der jedwede bewusste Konfrontation scheut und somit auch jeden Versuch von Wiedergutmachung unmöglich macht.

I 35 Gründete gemeinsam mit Hugo von Hofmannsthal, Richard Strauss, Alfred Roller und Franz Schalk im Jahr I 920 die Salzburger Festspiele.

I 36 BT, S. I72.

I 37 Vgl. Ackerl, Die bedeutendsten Österreicher, S. 94 f. Vgl. auch Steiner, Die verdrängten Jahre, S. I 87. Weiterführende Literatur zu Ferdinand Raimund: Hofinger, Die Akte Leopoldskron.

I 38 Fröhlich, Tagebücher des Joseph Goebbels, Teil I, Bd. 4, Eintrag vom 22.I 2. I 940, S. 44I. 
Der burgtheaterzWerg, den die von der Familie als minderbemittelt beschimpfte RESI versteckt gehalten hat, um ihn vor der Deportation zu bewahren, kommt istvan nur gelegen, um ihn den Russen als vermeintlichen Schutzbefohlenen präsentieren zu können und damit den »Polenfüm» (»Heimkehr«), in dem neben Paula Wessely auch Attila Hörbiger in der männlichen Hauptrolle als LUDWIG LAUNHARDT engagiert war (ein Hinweis auf außertextuelle Zusammenhänge), zu kompensieren. Is TVAN versucht RESI davon zu überzeugen, den ZWERG zu diesem Zwecke zu missbrauchen:

Is TVAn: Hörst, Resi, du werdest auf Anfrage bezaigen, daß der Zwerch von uns persenlich vor der Eithanasie vasteckt wurde. ... Dieser Zwerg muß schlußendlich unseren unieberlegten Polenfüm wettmochen. ${ }^{139}$

Resi lehnt die Instrumentalisierung des ZWERGs jedoch mit Bestimmtheit ab. Is TVAN verschwindet daraufhin für einige Zeit von der Bühne und kehrt zu bereits fortgeschrittener Stelle der Handlung mit dem Vorschlag zurück, sie alle sollten sich (als Strategie gegenüber dem Feind) als »ein einig Vulk von Gegna ${ }^{140}$ formieren, ein Einfall, den die Familie mit Begeisterung aufnimmt. Auch der nationale Konsens in Österreich lautete nach Kriegsende, dass kein Österreicher den Nationalsozialismus oder den Krieg gewollt und die Bevölkerung nur unter dem Zwang des übermächtigen Deutschen Reichs teilgenommen hätte (»... brutaler Terror und Gewalt zwangen die Menschen zu blindem Untertanentum $\left.{ }^{141}\right)$.

Die Begeisterungsstürme auf is Tvans Vorschlag hin enden schließlich damit, dass alle zusammen ein Wienerlied singen (»Erst wanns aus wird sein mit ana Musi und an Wein «... etc. ${ }^{142}$ ), was wiederum den slapstick- oder kasperlhaften Rezeptionseindruck verstärkt: Auf Is Tvans Initiative hin wird die Situation ins Lächerliche gezogen, was der in "Burgtheater" vorrangig angewandten "Methode der Ironisierung und Kontrastierung « ${ }^{143}$ entspricht. Erst kurz vor Schluss, als sich die Situation für die Familie zuspitzt, scheint Is Tvan seine Strategie des Wegschauens als fehlerhaft zu erkennen. Er lässt den BURGTHEATERZWERG, den er mit Handschellen angekettet hat, frei und stellt resignativ fest:

I39 BT, S. I72 f.

I 40 BT, S. I 83 .

I 4 I Leopold Figl, zitiert nach: Uhl, Das »erste Opfer«, S. 20. Vgl. Kapitel I.4.4 dieser Studie.

${ }^{4} 2$ BT, S. I 83 .

I 43 Hochholdinger-Reiterer, Amok, S. 49. 
IS TVAN : Is eh scho olles blunzn.... Missmer holt doch repartieren! ${ }^{144}$

Diese Feststellung beinhaltet zwar eine gewisse Einsicht in die zu erwartenden Konsequenzen durch die alliierten Siegermächte. Aufgrund der in der Inhaltsangabe bereits geschilderten »Wortsymphonie ${ }^{145}$ am Ende des Stücks, in der die Familie кётнеs Bühnentod mit den Worten begleitet: "Davon wissen mir nix! Des sengan mir gor net. Wos mir net sengan, des gibts net! « ${ }^{146}$, ist jedoch davon auszugehen, dass damit keine Einsicht der eigenen Mitschuld oder Verantwortung einhergeht, da der einmütige Vorsatz des Wegschauens und Nicht-Wissens als exemplarisch zu verstehen ist.

Jelinek hat mit istran die Figur des klassischen Mitläufers geschaffen, der das Handlungsgeschehen zwar nicht von sich aus in Gang setzt, sich aber durchaus aktiv daran beteiligt, wenn es ihm opportun erscheint. Is TVAN schätzt sich selbst als unbescholten ein, ist aber immerhin involviert genug, um den ALPENKÖNig zu erschlagen oder den вURGTHEAterzWERg als falsches Alibi missbrauchen zu wollen. Tatsächlich lädt er, der vermeintlich unpolitische Mitläufer, also auch persönliche Schuld auf sich.

\subsubsection{KÄTHE}

$» \ldots$ spielen ist ja mein Leben! ${ }^{147}$

In der familieninternen Hierarchie erst an dritter Stelle, nach schorsch und ISTVAN, folgt K ̈̈тне. Die Figur wirkt von Beginn an wankelmütig und verwirrt. Sie herzt und ohrfeigt abwechselnd die Töchter oder REsi. Sie rezitiert ständig unterschiedlichste Rollen, Gedichte und Liedtexte aus unterschiedlichen Genres und in unterschiedlichen Sprechweisen, einmal im Dialekt, einmal im schönsten Burgtheaterdeutsch. Dieses sprachliche Hin und Her ist eine signifikante und auffallende Besonderheit der Figur - sie wirkt dabei seltsam fragil. Darüber hinaus ist к ÄтнE durch ihre unausgegorene Sprache oft unfreiwillig komisch, obwohl das Sujet der Unterhaltung meist durchaus ernst ist.

К Ӓтне stellt das Lebensideal, Burgtheaterschauspielerin zu sein, über alle anderen Belange: »Spielen, spielen ist ja mein Leben! « ${ }^{148}$ ruft sie am Beginn des Stücks aus, womit Jelinek auf jenen populären Mythos verweist, der besagt, dass

I44 BT, S. I 88 .

I 45 Von der Autorin in der Regieanweisung so benannt: BT, S. I 88.

I 46 BT, S. I 88.

I 47 BT, S. I 32 .

I 48 Ebd. 
eine Trennung von Beruf und Privatleben für Schauspieler nicht möglich wäre, da die Identifikation mit den jeweiligen Rollen im Vordergrund stünde. ${ }^{149}$ Auch bei der Betrachtung der Figur Is Tvan wurde bereits auf diese Selbst-, aber auch Fremdcharakterisierung aufmerksam gemacht, die zugleich als Rechtfertigung für viele Schauspieler diente, im Deutschen Reich tendenziöse Film- und Theaterrollen anzunehmen. Die Figur кётне definiert sich geradezu über diesen Mythos.

Кётне elegisch: ...Rollen...Rollen...stets muß ich aus Aigenem gestalten! Menschen formen! In naiche Menschenkinder einischliaffen! Nie ist die Mimin sie selbst. ${ }^{150}$

кётне behauptet also von sich selbst, sich ganz und gar der Kunst verschrieben zu haben und daher (ähnlich wie ISTVAN) völlig unpolitisch zu sein, denn womit »ließen sich `Unschuld ahistorischen, überzeitlichen und >übergesellschaftlichen K Kunstbegriffs? « ${ }^{151}$. кÄтHE möchte aber nicht bloß Schauspielerin sein - nein, im Mittelpunkt ihres Begehrens steht ganz konkret das Wiener Burgtheater, als Inbegriff der österreichischen Hochkultur:

кётне:... Burgtheater! Du Stätte der Weihe am Ring! Du Ort der Verwandlung! Zauberland der Kindheit! Erstes glühendes Regen am vierten Rang! Das rotbackige Anstellen um Stehplätze! Erstes Erspüren, was Kunst sein kann, sein soll! (... $)^{152}$

Diese und ähnliche Aussagen werden jedoch als reine Lippenbekenntnisse destruiert, denn durch die sprachliche Labilität ihrer Figur disqualifiziert Jelinek in einem fort die Qualität von к ̈̈тнеs Schauspiel. Auch als sie ihr die folgenden Worte in den Mund legt, wird deutlich, dass sie к ̈̈тне als einfachen Charakter, nicht als große Künstlerin, darstellen will:

кётне : Am liabsten spü i a Grafentöchterl aus der Provinz! Des paßt am besten zu mein großflächigen Gsichterl, wos oba schwer zum belaichten is. ${ }^{153}$

Entgegen ihrer eigenen Einschätzung, eine Dienerin der Kunst und daher unpolitisch zu sein, glaubt к ÄT HE jedoch an Hierarchien und lebt sie auch: indem sie

I 49 Vgl. Hochholdinger-Reiterer, Amok, S. 53.

I5O BT, S. I4I.

I 5 I Hochholdinger-Reiterer, Amok, S. 57.

I 52 BT, S. I 42.

I53 BT, S. I 40 . 
sich einmal unterordnet (unter die Befehlsgewalt des Schwagers, zum Teil auch des Ehemannes, auch: unter die Vorgaben, Gesetze und Ideale des Regimes, die sie anfangs noch halbherzig beeinsprucht: „Niemals gebe ich einem Verlangen nicht nach. Nicht einmal wenn es von der Heimat herkommt. $\left.{ }^{154}\right)$, ein anderes Mal, indem sie sich selbst über andere stellt (über RESI, über die KINDER, über den alpenkönig sowie den burgtheaterzWerg). Die unhinterfragte Eingliederung in Hierarchien ist ein weiteres wesentliches Merkmal dieser Figur und greift wiederum Wippermanns Charakterisierung faschistischer Parteien und Organisationen voraus (»... hierarchisch nach dem Führerprinzip gegliedert... $\left.{ }^{155}\right)$.

Obwohl KÄTHE von ISTVAN und schORSCH immer wieder gemaßregelt wird, sie müsse nun »urdentlich daitsch ${ }^{156}$ sprechen, hält sie die Hochsprache wie im Übrigen auch die beiden anderen Figuren - nicht konsequent durch und verfällt immer wieder in einen ebenso wenig konsequenten, unnatürlich wirkenden Dialekt.

Jelinek legte ihrer weiblichen Hauptfigur wörtliche Zitate aus Wessely-Filmen, Kritiken und Biografien in den Mund - Zitate, die seit den I 930/4oer Jahren in verschiedenen Variationen tradiert wurden, ohne dabei jemals inhaltlich hinterfragt zu werden ${ }^{157}$, und dadurch das "unschuldige, unbestreitbare Bild « ${ }^{158}$, jenen Wessely-Mythos schufen, der die Schauspielerin jedweder politischen Verantwortung enthob, da sie als Mimin stilisiert wurde, die angeblich ohnehin niemals sie selbst sei, wie кётне in »Burgtheater« deklamiert: "Nie ist die Mimin sie selbst. « ${ }^{159}$ So stellt etwa Steiner fest, dass es bei Walter Ibach, der I 943 eine der ersten Wessely-Biografien veröffentlicht hatte, eine bemerkenswerte Charakterisierung gebe, die hier einer Passage aus »Burgtheater«, einer Selbstreflexion кÄтнEs, gegenübergestellt wird:

Prätext (Ibach)

»Sie ist im Volksmund ein Volkslied, das

bleibt und klingt, weil es echt ist: die

Wessely." ${ }^{160}$

\section{Posttext (Jelinek)}

к ̈̈тне: „Ich bin im Volksmund ein Lied, das bleibt und klingt, warum? Weil es echt ist! ${ }^{161}$

I 54 BT, S. I32.

I 55 Wippermann, Hat es Faschismus überhaupt gegeben, S. 56. Vgl. Kapitel I.4. I dieser Studie.

I 56 Vgl. BT, S. I40.

I 57 Vgl. Steiner, Die verdrängten Jahre, S. I 77.

I 5 Beschreibung des Mythos nach Barthes, vgl. Kapitel I.4.3 dieser Studie.

I 59 BT, S. I4 I.

I60 Ibach, Die Wessely, S. 78 .

I6 I BT, S. I 82 . 
Auch Walter Reisch, der I 934 gemeinsam mit Willi Forst das Drehbuch für jenen Film verfasst hatte, mit dem Paula Wesselys Schauspielkarriere in Gang gesetzt wurde, »Maskerade«, brachte in den r 97oer Jahren eine bemerkenswerte Wessely-Huldigung dar, die - sofern der Prätext bekannt ist - unverkennbar in Jelineks »Burgtheater«-Text aufgenommen und (nur leicht) verfremdet wurde, um ihre vermeintliche »Unschuld « zu durchbrechen. ${ }^{162}$

Prätext (Reisch)

»Die Paula war ja noch nie eine große Schauspielerin, die Paula war eine elementare Erscheinung, so wie ich es sehe ein Orkan, der über die Erde gerast ist. Wäre die Paula Malerin geworden, wäre sie eine große Malerin gewesen. Wäre sie eine Bildhauerin geworden, wäre sie die beste Bildhauerin geworden, die im Donaubecken je zustandekam. Die Paula hat dieses Österreichertum so unglaublich erfaßt und kann es wiedergeben in jeder Form. ${ }^{163}$

\section{Posttext (Jelinek)}

кётне:... Ich bin eine elementare Erscheinung, ein Orkan, der ieber die Erde rast. Ich bin im Donaubecken zustande gekommen. ${ }^{6}$

Und wenige Zeilen später:

кётне: ... Das daitsche Publikum aller Stämme will auch juchzen! Nur aine ainmalige künstlerische Begebenheit wie ich verhilft dazua! Österreichertum $!^{164}$

Die Verklärung der Schauspielerin Wessely wird auch an der Verwendung des bestimmten Artikels deutlich: die Wessely (Ibach) und die Paula (Reisch). Im Zusammenhang mit Personen wird diese Ausdrucksweise in der Standardsprache nur dann verwendet, wenn es sich um berühmte Persönlichkeiten handelt, deren Erwähnung keiner weiteren Erläuterung bedarf (so wie in der medialen Berichterstattung vielfach auch von der Jelinek gesprochen wird). Diese Ausdrucksweise greift die Autorin in »Burgtheater" auf, wenn кÄтнЕ von sich behauptet: "Die Käthe bin ich, einfach nur >die Käthe«. « ${ }^{165}$ Diese Sprachverwendung suggeriert Natürlichkeit, Jugendfrische, Volksnähe - in einem Wort: Unschuldigkeit.

Das Bild der unpolitischen und nicht verantwortlichen Mimin wird aber auf der Sprech- wie auch auf der Aktionsebene destruiert: кÄтнE traktiert mit Worten, aber auch mit handfester Gewalt RESI (... geht urplötzlich mit einem

I62 Vgl. Steiner, Die verdrängten Jahre, S. I77.

I63 So Walter Reisch in »Filmgeschichte(n) aus Österreich, TV-Serie, Folge 5, ORF r 97 I , zitiert nach: Steiner, Die verdrängten Jahre, S. I77.

I64 BT, S. I33.

I65 BT, S. I75. 
silbernen Kerzenleuchter auf Theres los ... ${ }^{166}$ ), die Kinder (... nimmt is TVAns Reitgerte und haut ihnen unter dem Tisch auf die Waden $\ldots{ }^{167}$ ) oder den Ehemann (... Tritt Is TVAn jäh und unerwartet zwischen die Beine ${ }^{168}$ ), nimmt nach Kräften an der Erschlagung des ALPENKÖNIGs teil (... wirft sich gegen den ALPENKÖNIG, der fällt gegen seinen Kahn, beides taumelt, wankt, kracht. ${ }^{169}$ ) und verabscheut den BURGTHEATERZWERG, den sie als »Unnatürl « ${ }^{170}$ bezeichnet, womit sie sich wiederum selbst als Verkörperung von Natürlichkeit hervortut. Für sie verkörpert der ZWERG das »unwerte Leben«, das im nationalsozialistischen Weltbild keinen Platz hat (»Ich verabscheue alles Künstliche und Gemachte wie dies zu klein geratene Wesen hier. $\left.{ }^{171}\right)$.

Auch кётне handelt demnach politisch, auch wenn sie sich stets auf das "Gemeinschaftserlebnis « ${ }^{172}$ der Kunst beruft. Zugleich spielt Jelinek in zuletzt genannter Textstelle mit dem Mythosbegriff, denn die Figur кётне steht gerade für falsche Natürlichkeit. Ihre Distanzierung von allem Künstlichen und Gemachten - ist ein Kleinwüchsiger künstlich? - ist daher als weiteres Bausteinchen der Jelinek'schen Ironisierung zu begreifen.

к ̈̈тнЕ verliert mit zunehmendem Handlungsverlauf immer mehr den Verstand, was sich in ihrem akuten Sprachverfall widerspiegelt: Ständig fällt sie in Rollen, beendet dabei viele der zitierten Textpassagen und der dazwischen gestreuten, scheinbar spontanen Sätze nicht mehr, nimmt an den Dialogen der Familie nicht mehr richtig teil und wirkt unzurechnungsfähig.

Ihre mangelnde Einschätzung der (nationalsozialistischen) Wirklichkeit kommt schon im ersten Teil des Stücks deutlich zum Ausdruck, in dem sie völlig entgeistert in einen Dialog zwischen SCHORSCH und Is Tvan einsteigt, die sich darüber unterhalten, dass die jüdischen Schauspielkollegen von der Bildfläche verschwunden seien (auch hier fällt wiederum der Wechsel zwischen Dialekt und Hochsprache auf):

кӓтне vernünftig: Woos? Weg sans? Geh weida! Wirkli? Ei freilich, ich sah sie lang nicht mehr. Lang lang ists her. Waldgrün der Heimat so duftig und traut. Itzig belästigt das daitsche Weib mit seiner abnormen Ungeschschsch - stammelt - itzlichkeit! Istvan zwickt sie in den Arsch, sie juchzt. Schleichen sie nicht mehr über die Wiesen und Auen unseres lieben Alpenvorlands? Jene spitznasigen, plattfüßigen kleinen Ge-

I 66 BT, S. I 33 .

${ }^{167}$ BT, S. I36.

I 68 BT, S. I 53.

I69 BT, S. I46.

I 70 BT, S: 169 .

I7I BT, S. I68.

I72 BT, S. I68. 
sellen? Kraxeln sie nicht mehr, ähnlich den Kasermanndln, jenen flinken Kobolden der Vollmondnächte, die sich nur guten Menschen zeigen, in den Bergen herum? Mühsam, den Faden verlierend: Absteifen sie nicht ihre Lieder im Kassenkas? Im Massenkaas? Dann isses ja guat. ${ }^{173}$

In dieser Szene erscheint к ӒтнЕ nicht nur als verwirrt oder entrückt, sondern auch eindeutig als von der nationalsozialistischen Rassenideologie beeinflusst, indem sie Juden als spitznasige, plattfüßige Kobolde imaginiert, die - wie Fabelwesen in Theaterstücken - in Bergen herumkraxeln und über Wiesen und Auen schleichen. кӓтне scheint die Realitäten der Theaterwelt mit den Realitäten der tatsächlichen, nationalsozialistisch determinierten Welt zu vermischen, so wie sie auch ständig Dialekt und Hochsprache vermischt.

Ihre fortschreitende Entrückung äußert sich nicht nur sprachlich, sondern auch darin, dass sie auf unterschiedliche Arten versucht, sich selbst das Leben zu nehmen - meist halbherzig, also mit dem Vorsatz, nicht wirklich sterben zu wollen, aber vielleicht doch Aufmerksamkeit zu erregen. кётне ist diejenige, die sich auf die veränderten Verhältnisse I 945 am schlechtesten einstellen kann. Immer wieder fällt sie in die Rolle der MARIE THOMAs aus "Heimkehr" und rezitiert Passagen aus dem Film, außerdem trägt sie - trotz ihrer Angst vor den Russen - immer noch ein Hakenkreuzkettchen um den Hals. Steiner macht darauf aufmerksam, dass auch LAUNHARDTs Ehefrau, eine der weiblichen Figuren in »Heimkehr«, ein solches Kettchen trägt und für ihre nationalsozialistische Überzeugung im Film von den Polen zu Tode gesteinigt wird. ${ }^{174}$ In Zusammenhang damit könnten кётнEs Bühnenselbstmorde gesehen werden. ${ }^{175}$ Über die Selbstmordversuche hinaus versucht кётне sogar, ihre älteste Tochter, MIтZI, zu töten: Als sie einen »bösen Kaffeefleck « ${ }^{176}$ auf dem Kleid ihrer Tochter entdeckt, übergießt sie diese mit Benzin und versucht sie anzuzünden: Der Krieg ist verloren, der braune Fleck muss weg! Im letzten Moment kann sich MITZI vor der rasenden Mutter retten. ${ }^{177}$

Ein berechtigter Einwand könnte an dieser Stelle die Frage sein, ob Jelinek die Figur к ÄTHE nicht ein wenig aus der Verantwortung nimmt, indem sie diese mehr und mehr als unzurechnungsfähig darstellt. Es ist jedoch vielmehr zu vermuten, dass die Autorin mit der überzeichneten Figur кӓтне gerade das

I73 BT, S. I 54 .

I74 Vgl. Steiner, Die verdrängten Jahre, S. I 87.

I75 Auch eine andere Deutungsvariante, die in Kapitel 3.r.6 dieser Studie angeboten wird, erscheint plausibel.

I76 BT, S. I 74 .

I77 Vgl. BT, S. I74 f. 
Nicht-Wahrnehmen von Verantwortung, die Wurzel allen Mitläufertums, darstellen wollte - schließlich verkörpert die Figur кётне eine erwachsene Frau, die in ihren Theater- und Filmrollen Vorbild für viele andere Frauen ist, außerdem ist sie Ehefrau und Mutter dreier Kinder, trifft also für sich und andere (mitunter existenzielle) Entscheidungen. Schon in ihrem »Nora«-Stück beklagte Jelinek das selbstgewählte Schicksal fremdbestimmter weiblicher Existenzen. ${ }^{178}$ In der Figur der кӥтне spitzen sich viele der Charaktereigenschaften zu, die auch bereits in der Auseinandersetzung mit scHorsch und ISTVAN bemerkt wurden - insofern ist die wankelmütige кётне als zentrale Figur des Stücks zu interpretieren.

Jelinek hat mit кӓтне eine Figur geschaffen, die all das in sich vereint, was die Autorin selbst ablehnt: Sie ist als Frau schwach, sie ist sprachlich labil, sie ordnet sich patriarchalen Familienbildern und hierarchischen Gesellschaftsordnungen unter und macht sich zu deren Komplizin, sie erniedrigt und quält andere, die ihr selbst geistig oder körperlich unterlegen sind, sie propagiert ein Kunstideal, das für sie selbst unnatürlich ist, da es nicht Teil ihres Wesens, sondern angelernt ist. Die ganze Figur ist künstlich und nur scheinbar natürlich. К ̈̈тне ist der personifizierte Mythos.

\subsubsection{ALPENKÖNIG Und BURGTHEATERZWERG}

»So wortens doch, wos in Ihnara Biographie olles drinnenstengan wird, wos man hernoch freilich sogleich wieder vergessen wird! « ${ }^{179}$

Der ALPENKöNig, die zentrale Figur des Allegorischen Zwischenspiels, definiert sich selbst in mehrfacher Weise. Einmal gibt er sich als ehemaliger Schauspielkollege von KÄTHE, ISTVAN und $\mathrm{sCHORSCH}_{\mathrm{zu}}$ erkennen, einmal als Widerstandskämpfer, der um Geld bittet, einmal konfrontiert er КӒтнE mit den Worten »Ich bin Ihnare Biographie! ${ }^{180}$, einmal ruft er aus: »Ich bin die Nachgeborenen! Ich bin Österreich! Ich bin die Zukunft! « ${ }^{181}$ Die Zukunft verkörpert der A LPEN KÖNig zumindest insofern, als dass Attila Hörbiger als R APPELKорғ und Paul Hörbiger als ALPENKöNig I 965 in Ferdinand Raimunds Stück »Alpenkönig und Menschenfeind« am Wiener Burgtheater zu sehen

I78 Vgl. Kapitel r.6.2 dieser Studie.

I79 BT, S. I 46 .

I80 Ebd.

I $8 \mathrm{I}$ BT, S. I 47. 
waren. ${ }^{182}$ Nicht ganz zufällig also hat Jelinek diese Figur - eine »Mischung aus Alpenkönig, Menschenfeind und Invalide ${ }^{183}$ - in ihr Stück eingebaut.

Durch Jelineks ALPENKöNig wird aber auch die Möglichkeit alternativer Verhaltensweisen vorgeführt, welche die Protagonisten - aus opportunistischen Erwägungen - strikt ablehnen. Der Mord an ihm wird - nach sprachlicher Wiener Art - zum »Morderl« verkleinert und damit gerechtfertigt, dass er der Intention des NS-Regimes, so genanntes »lebensunwertes Leben auszumerzen«, nachkommt. Der ALPENKÖNIG entspricht dieser Charakterisierung gleich in zweifacher Hinsicht: zum einen, weil er sich als Regimegegner und Widerständiger zu erkennen gibt, und zum anderen, weil er dem Rassenideal vom gutgebauten, allem standhaltenden »Herrenmenschen « nicht entspricht, das in den Nürnberger Gesetzen (nach Rathkolb »Pseudogesetze ${ }^{184}$ ) von I935 festgeschrieben worden war. ${ }^{185}$ Die nationalsozialistische Diktion wird dabei durch wienerische Pendants (»Schlawiner ${ }^{186}{ }^{~}$ Krispindl ${ }^{187}$ ) ersetzt. ${ }^{188}$

Sowohl mit dem ALPENKÖNIG als auch mit dem BURGTHEATERZWERG, für dessen Verkörperung sich Jelinek in der Regieanweisung »Fritz Hackl« wünscht (vermutlich eine Anspielung auf den österreichischen Künstler Karlheinz Hackl), wird ganz offen die Wiener Volkstheatertradition à la Ferdinand Raimund parodiert, denn »selbstverständlich handelt es sich bei >Burgtheater weder um ein Revival des Altwiener noch des neueren kritischen Volksstücks « ${ }^{189}$. Vielmehr geht es hier um die Destruktion des fatalen Volksbegriffs, der »trotz aller wissenschaftlichen Dementis im Begriff des Volksstücks steckt « ${ }^{190}$.

Erstmals erwähnt wird der zWERG am Beginn des zweiten Teils, als Resi die zunächst leere Bühne betritt und das »Burgtheaterzwergerl« hinter sich »herschleift«, auf der Suche nach einem Versteck für ihren Schützling, den sie offenbar bereits längere Zeit über vor den Nationalsozialisten, aber auch vor der Familie versteckt gehalten hatte:

RESI: Wo ist ein Verstecker, welches mir noch nicht gehabt haben?

I 82 Eine Aufzeichnung aus dem Burgtheater ist auf DVD erhältlich, vgl. http://www.burgtheater.at/Content.Node 2/home/service/shop/25-Der-Alpenkoenig-und-der-Menschenfeind. at.php (Zugriff am 6.1 2.2007).

I 83 BT, S. I43 (Regieanweisung).

I 84 Rathkolb, Führertreu und gottbegnadet, S. 268.

I 85 Vgl. I. 4. I. dieser Studie.

I 86 BT, S. I 47 und S. I 48.

I 87 BT, S. I 48.

I 88 Vgl. Steiner, Die verdrängten Jahre, S. I 84.

I89 Hochholdinger-Reiterer, Amok, S. 48.

I 90 Lengauer, Jenseits vom Volk, S. 2 I 9. 
ZWERG : Schnöö! Tummel dich! Ungustel!

RESI : Im Kosten worst schon, und unter mein Bett aa....

$\cdots$

RESI : Ob ich es vielleicht mit diesem Büffet versuche? Es sieht recht vertrauenerweckend aus....

ZWERG: Alles ist entschieden besser. Nur nicht die körperliche Vernichtung durch den braunen Spuk. ... ${ }^{191}$

Auch der burgtheaterzwerg verkörpert (wie der alpenkönig) einen ehemaligen Schauspielerkollegen von кӓтнE, ISTVAN und sсновSCH, der aufgrund seiner Kleinwüchsigkeit unter dem NS-Regime jedoch nicht mehr spielen konnte, sondern um sein Leben zittern musste. Durch seine Anwesenheit bringt der ZWERG aber auch RESI in Gefahr, da auch diese vor der Denunziation durch ihre Familie nicht sicher ist:

ZWERG: Nehme keine unnetigen Risiken auf dich, Theresia, liabs Kaiserwaberl! ... Deine braune Herrschaft, was einmal meine Kollegenschaft woren, teetet dich und mich ohne viel Federlesens. Singsang, klingklang. Bimbam schlägts Uhrl dem Ahndl. ${ }^{192}$

Die »braune Herrschaft«, eigentlich REsis Familie, erscheint somit als eine Bande gewissenloser Opportunisten, die im Zweifelsfalle die Zweckerfüllung im Regime dem Leben eines Familienmitglieds vorziehen würden, zumal dieses als zurückgeblieben eingestuft wird.

Der buRgtheaterzwerg wird schließlich in seinem Versteck aufgespürt. Der Familienrat beschließt jedoch, ihn nicht sogleich zu denunzieren, sondern lieber für einen anderen Zweck zu benutzen: Schließlich steht die Rote Armee bereits vor den Toren Wiens. кÄтнE und Istvan sind gefährdet, von der Fremdmacht als Mitläufer oder -täter klassifiziert und dafür bestraft zu werden (sCHORSCH ist zwischenzeitlich abgetaucht). Sie beschließen daher kurzerhand vorzutäuschen, sie hätten den Zwerg über Jahre hinweg versteckt gehalten, um ihn vor der sicher scheinenden Ermordung zu beschützen. Auf diese Weise hoffen sie, die künftigen Besatzer in ihrem Urteil milde stimmen zu können. Der burgtheaterzWerg erklärt sich zu diesem Handel bereit, wenn er im Gegenzug mit den Liebesdiensten der ältesten Tochter, M IтZı, belohnt würde. Das bevorstehende Ende des NS-Regimes hat ihm plötzlich hohen Marktwert verschafft: »I steh jetz gonz onders do, wo der Russ kimmt ${ }^{193}$, weist er REsis

I9I BT, S. I6o.

192 BT, S. г6r.

I93 BT, S. I7I. 
Annäherungsversuche brüsk von sich. Auch кётне gegenüber macht er deutlich, dass er nicht ohne die gewünschte Gegenleistung, den Beischlaf mit der jungen MITZI, für sie lügen wolle:

ZWERG : Ich verliere hier meine Zeit mit Ihnen. Seit Wochen bereits belästigen mich ehemalige Kollegen des Burgtheaters, ich sull sogen, ich bin in eahnare Kölla gehuckt. ... Nur die Allerbledesten von eahnen sind nicht in der glücklichen Loge, einen Reschimegegner ihr eigen nennen zu dirfen. De werden donn dawischt wern. ${ }^{194}$

Der Vorfall mit dem burgtheaterzwerg könnte eine Anspielung Jelineks auf Paula Wesselys biografische Legende sein, wonach diese einer Bekannten geholfen haben soll, deren Freund während des Kriegs zu verstecken. ${ }^{195}$

Diese Passage verdeutlicht einmal mehr, dass K ̈̈THE, Is TVAN und sCHORSCH als repräsentativ für jene Künstler zu sehen sind, die während der NS-Zeit mit der Staatsmacht kollaboriert hatten und nach 1945 plötzlich Widerständige oder Regimegegner gewesen sein wollen.

Der ZWERG, der auf das Liebesspiel mit Mitzi schließlich doch verzichten muss, weil sсHORsch als angeblicher Widerstandskämpfer (»der ollernaicheste Patriot $\left.{ }^{196}\right)$ bereits für die Rehabilitierung der Familie gesorgt hat, beschließt schließlich im Stück, sein Glück andernorts zu versuchen.

»Der Herrgott siecht Ihnen zu! «197

RESI, die zur Dienstbotin degradierte Schwester von ISTVAN und Schorsch, ist eine zunächst unscheinbare Figur. Sie bedient, knickst, wird getreten und beschimpft, wirkt eingeschüchtert, bleibt die ganze Zeit über untertänig. Die Familie erpresst sie mit dem Damoklesschwert der nationalsozialistischen Euthanasieprogramme:

K ̈̈THE: Sie missversteht, Theres. Sie bedenkt necht, daß sie aufgrund ihrer erblichen Schwachsinnigkeit ebenfalls aufs Äußerste gefährdet ist. Sie verdankt es unserer natierlichen Gutmietigkeit, daß sie noch hienieden weilt. ${ }^{198}$

I94 BT, S. I78.

I95 Vgl. Fiddler, Rewriting Reality, S. I04.

I 96 BT, S. I66.

I 97 BT, S. I 47 .

I 98 BT, S. I69. 
Tatsächlich ist RESIs Verhalten nicht ein einziges Mal als krankhaft zu interpretieren. Die von der Familie ins Treffen geführte »erbliche Schwachsinnigkeit« wird vielmehr dazu benutzt, RESI als Bedienerin missbrauchen zu können. Letzten Endes entpuppt sich RESI als die einzige Figur, die (wenn auch aus unlauteren Motiven) die Gesetze des Regimes bricht, indem sie den BURGTHEATERZWERG vor der Euthanasie beschützt - als Kleinwüchsiger wäre er von den Nationalsozialisten selektiert und misshandelt oder umgebracht worden. Auch wenn sie vom zwE RG Liebesdienste für die erbrachte Hilfe erwartet, die dieser uncharmant verweigert (»Glaubst, mir graust vor gor nix? ${ }^{199}$ ), so bleibt doch die Tatsache bestehen, dass sie sein Leben rettet und damit für sich selbst ein großes Risiko auf sich nimmt. Auch dem ALPEn Kön Ig begegnet sie im Gegensatz zu den anderen Familienmitgliedern - mit Menschlichkeit und bietet ihm etwas zu essen an:

RESI kommt mit Nabrung: Der orme Mo! Gonz verhungert is er schier! Kommens mit, i geb Ihne a Jausn! $!^{200}$

Seine Ermordung versucht RE I z zu verhindern, indem sie die um sich schlagende к ̈̈тне von hinten festhält und mahnt: „Gnä Frau! Gnä Frau! Jeschuschmaria! Tuan Se sich nicht versündigen! Der Herrgott siecht Ihnen zu! ${ }^{201}$ Gegen die gewalttätige Übermacht der Familie kann sie jedoch nicht viel ausrichten.

RESI, das unterste Glied der familieninternen Hierarchie, von den anderen als minderbemittelt belächelt, erniedrigt und als Dienstbotin missbraucht, ist somit die einzige Figur, die der Propaganda von Rasse und »Ariertum« nicht aufsitzt und durch ihre Parteinahme für den ALPENKöNIg und das Verstecken des burgtheaterzWergs tatsächlich Widerstand leistet. Durch resi wird klar gemacht: Es geht auch anders.

3.1.3.6 MITZI, MAUSI und PUTZI

»Oh fein! Oh wie fein! ... Mir derfen Menschenbildner sein! $\aleph^{202}$

Die zwei jüngeren Kinder, maus I und Putzı, spielen keine nennenswerte Rolle in dem Stück. PUtzi könne sogar von einer »lebensgroßen Stoffpuppe ${ }^{203}$ dar-

$\begin{array}{ll}199 & \text { BT, S. г7г. } \\ 200 & \text { BT, S. г46. } \\ 201 & \text { BT, S. I47. } \\ 202 & \text { BT, S. г36. } \\ 203 & \text { BT, S. г } 30 .\end{array}$


gestellt werden, schreibt Jelinek in der Regieanweisung - wiederum ein Hinweis auf die demonstrative Künstlichkeit. Maresa Hörbiger war zudem I 94I noch nicht geboren, sondern kam erst im Jänner I 945 zur Welt.

Die älteste Tochter, M IтZI, tritt vor allem im zweiten Teil des Stücks in Erscheinung, als ihre sexuelle Unschuld als potentieller Preis für die Falschaussage des burgtheaterzwergs vor den Russen ins Spiel gebracht wird.

MITZI sträubt sich zunächst gegen die Avancen des Zwergs, weil er ihrem Empfinden nach »unbeschreiblich häßlich und zudem sehr klein « ${ }^{204}$ sei. An einen "Krippel, der woas ausgerottet ghert ${ }^{205}$, wolle man sie verschachern, schimpft sie, wodurch deutlich wird, dass sie die rassistische NS-Idiomatik komplett internalisiert hat. Als aber der Zwerg, von dem Gehabe der Familie abgestoßen, beschließt, den Handel sausen zu lassen, will ihn miтzI schließlich doch mit allen Mitteln zum Bleiben bewegen und bedrängt ihn, vergewaltigt ihn nahezu.

Auch die Figur MiTZI verkörpert demnach einen bestechlichen und gewaltbereiten Charakter, der stets auf den eigenen Vorteil bedacht ist und sich den gegebenen politischen Verhältnissen gewissenlos anpasst.

\subsubsection{Die Sprache: ein Mythos}

»... ich kritisiere eine Sprache, die in ihrer Pervertierung die faschistische Kulturindustrie und eine nicht erfolgte Entnazifizierung in diesem Unterhaltungsindustriebereich ermöglicht hat. ${ }^{206}$

Die Figuren des Stücks konversieren in einer von der Autorin konstruierten Kunstsprache miteinander, einer Mixtur aus gesprochenem Wienerisch und hochtrabendem $\gg$ Pseudo-Burgtheaterisch ${ }^{207}$. Beides erscheint angelernt und unnatürlich, sowohl Dialekt als auch Hochsprache. Dazwischen tauchen meist unvermittelt noch andere Dialekte und phonetische Manierismen auf, die Kerschbaumer als "gesprochenen Alltag «"08 der deutsch-österreichischen Film- und Bühnenszene (zu ergänzen wäre: der I95oer Jahre) erkennt - echte und vorgetäuschte Akzente à la Heesters und Röck, echte und vorgetäuschte

204 BT, S. 176.

205 BT, S. 177.

206 Jelinek, zitiert nach: Winter, Gespräch mit Elfriede Jelinek, S. I 3.

207 Kerschbaumer, Porträt einer Dichterin, S. I 5 o.

208 Ebd. 
Regionalismen, etwa das »Behmakeln ( Freindinnen $^{209}$, Esterreichertum ${ }^{210}$ usw.), das auch Löffler in ihrer Rezension anführt ${ }^{211}$, sowie die echte und vorgetäuschte Unfähigkeit, diese Regionalismen zu simulieren (so genannter » $\mathrm{Ma}$ riandl-Dialekt«). ${ }^{212}$ Das Simulieren von Dialekten kommt zum Beispiel in folgender Aufforderung schorschs an кётнE zutage:

sсновsсн: A daitsches Madl in Polen wirst jetzt spün. In der Wojwodschaft Luzk. Und aus. Konnst scho onfongen, den Akzent lernen, gö $!^{213}$

Die in dieser sprachlichen Mixtur geführten Dialoge entbehren dabei nicht einer gewissen Komik, die jener von Hans-Moser-Filmen nicht unähnlich ist, baut diese doch auf eben jenen Brüchen zwischen Hochsprache und Dialekten auf, mit denen sich Moser in die Herzen der Kinobesucher witzelte. Hinzu kommt im »Burgtheater«-Stück allerdings die Beimischung nationalsozialistischer Diktion:

SCHORsch : Seind Sie vielleicht die rote Pest? Ui jegerl!

Is Tvan : Seind Sie vielleicht die Fratze des Bolschewismus? Ui jegerl, hob i an Spundus!

schorsch : Seind Sie vielleicht der Vertreter des Weltjudentums? Mir kaufen nix!

ALPENKÖNIG : Hier bin ich nur Österreicher, hier darf ichs sein.

кётне: Wos sokt der notiche Mensch?

sCHORsch : Er sokt, er ist oin Ausländer.

Is TVAN : A Behm? A Krowot? Schaißlich! $!^{214}$

Bereits an diesem kurzen Textausschnitt wird Jelineks Anspielungsreichtum sowie ihre komplexe Zitationsweise deutlich, in welcher sie etwa (leicht verfremdete) Verse aus deutschen Klassikern (hier: Goethes „Faust») mit Kasperl-Ausrufen (»Ui jegerl!«) und der NS-Diktion (»Fratze des Bolschewismus», »Weltjudentum« etc.) montiert und damit die Sprachgebrauchsformen der Figuren als tendenziös und scheinhaft entlarvt. Die Künstlichkeit der Sprache ist als zentrale dramaturgische Besonderheit des Stücks festzuhalten. Jelineks Anweisung für Regie und Darsteller lautet:

209 BT, S. I33.

2 I0 BT, S: I 35 .

2 I I Löffler stellt (unter anderem) »bemahkelnde Lautverschiebungen« in dem Text fest: Ludersinn, S. 220.

2 I 2 Vgl. Kerschbaumer, Porträt einer Dichterin, S. I 5 O.

2 I 3 BT, S. I 40.

2 I 4 BT, S. I 45. 
"Sehr wichtig ist die Behandlung der Sprache, sie ist als eine Art Kunstsprache zu verstehen. Nur Anklänge an den echten Wiener Dialekt! Alles wird genauso gesprochen, wie es geschrieben ist. Es ist sogar wünschenswert, wenn ein deutscher Schauspieler den Text wie einen fremdsprachigen Text lernt und spricht. ${ }^{215}$

Schon in der Regieanweisung wird damit der Bezug zu Barthes' Mythentheorien deutlich: Eine Kunstsprache, die natürlich sein will, gekünstelte Figuren, die authentisch sein wollen - all das widerspiegelt das Prinzip der Umwandlung einer bewussten Intention in eine vermeintlich unschuldige Wahrheit. Denn der Mythos verwandelt Geschichte in Natur. Er soll bestimmte Sachverhalte (hier: die Sprache) natürlich erscheinen lassen, deren Entstehung bewusst motiviert war und von Menschenhand vorgenommen wurde, um einen bestimmten Zweck zu verfolgen. Relevant für seine Bedeutung ist nicht sein Inhalt, sondern seine Form. ${ }^{216}$

Um den destruktiven Effekt auf der Sprechebene zu verstärken, hat Jelinek (in ihren mitunter recht ausführlichen Regieanweisungen) eine den Text begleitende, aber meist konterkarierende Aktionsebene eingebaut. Die Asynchronität zwischen enthemmter Action und raffiniertester Sprachlichkeit sei »meist aufreizend«, in jedem Fall aber »entlarvend ${ }^{217}$, so die Rezensentin Sigrid Löffler. Auch hat die Autorin filmische Darstellungsformen wie die Slapstick-Komik des Stummfilms (»heiterste Stummfilmhölle ${ }^{218}$ ) in ihr Stück integriert ${ }^{219}$, welche die Wirkung der Aktionsebene zusätzlich unterstreichen.

Über die demonstrativ künstliche Bühnensprache und -aktion wird nicht nur die Authentizität der Figuren, die Publikumslieblinge des Burgtheaters und des deutschsprachigen Nachkriegsfilms verkörpern, als Mythos destruiert. Jelinek greift damit auch den Mythos des Wiener Burgtheaters an, denn dieses gilt als das Synonym kultureller Identität, als repräsentativer Schauplatz herrschender Hochkultur in Österreich, das so genannte "Burgtheaterdeutsch" als sprachliches Ideal. ${ }^{220}$ Nicht nur die Figuren sind als Schablonen zu begreifen, sondern auch das Burgtheater an sich wird als schablonenhafter Ort vorgeführt, denn interessanterweise sind die Rollen, in welche die Figuren auf der Aktionsebene schlüpfen und über die sie sprechen, meist keine Theater-, sondern Filmrollen. ${ }^{221}$

2 I 5 BT, S. I30.

2 I 6 Vgl. Kapitel I.4.3 dieser Studie.

2 I 7 Löffler, Erhalte Gott dir deinen Ludersinn, S. 2 I 9.

2 I 8 Ebd., S. 2 I 8.

2 I 9 Vgl. Hochholdinger-Reiterer, Amok, S. 49.

220 Vgl. ebd., S. 47. Vgl. auch Annuß, Theater des Nachlebens, S. 6r.

22 I Vgl. Annuß, Theater des Nachlebens, S. 6r. 
Zudem sind zahllose gestalterische Elemente dem Wiener Volkstheater entlehnt, das ursprünglich in Opposition zum Burgtheaterbetrieb stand. Bereits der Untertitel des Stücks, »Posse mit Gesang «, der nur als Paradoxon zum Haupttitel »Burgtheater « gelesen werden kann, verweist auf Jelineks vorwiegend angewendete Mittel: Verfremdung, Montage und Kontrast. ${ }^{222}$ Die »Posse« als »anspruchslose, volkstümliche Komödienform, die durch vordergründige, primitiv-derbe ... Komik «23 Lachen erzeugen will, wurde zunächst nur im Vorstadttheater gezeigt, fand aber mit den Zauberpossen Ferdinand Raimunds und den Satiren Johann Nestryos Eingang ins Burgtheater:

»In der Kontrastierung von >Posse mit Gesang` und der im Haupttitel genannten Kulturinstitution wird ein Teil dieser Geschichte: nämlich die ursprüngliche Opposition von Vorstadttheater und Hoftheater und die nachfolgende Einebnung dieser Opposition im bürgerlichen Kulturbetrieb angespielt. Die Posse findet im Burgtheater statt, das Burgtheater ist eine Posse. $\aleph^{224}$

Vor allem кӒтнЕ wetteifert dem Ideal, Burgschauspielerin zu sein und Burgtheaterdeutsch zu sprechen, unentwegt nach. Ihre nahezu aggressiv zur Schau gestellte Natürlichkeit verbirgt gleichzeitig die Verantwortung für ihr Handeln. Die Natürlichkeit und die "natierliche Gutmietigkeit ${ }^{225}$ sind prononciert, angelernt und alles andere als natürlich. Allein die Regieanweisung Jelineks, die Sprache sei als Kunstsprache zu behandeln, deutsche Schauspieler mögen den Text lernen und darbringen, macht dies deutlich. Die angebliche Natürlichkeit wird hier als Mythos kenntlich gemacht. кётнЕ, die nicht müde wird, ihre Liebe zur Schauspielerei, zum Burgtheater, zur Sprache und zur Literatur hervorzukehren, wird insgesamt als mythische Figur entlarvt.

Die Sprache des Stücks »spricht «226 tatsächlich: Durch sie wird deutlich, dass hier nichts Unschuldiges vor sich geht, sondern die Protagonisten durch die Wahl ihrer Sprechweise eine bewusst motivierte Entscheidung treffen, die die Wahrheit zu verschleiern sucht: das Politikum des vorgeblich unpolitischen Künstlers im NS-Regime. ${ }^{227} \mathrm{Wiederum}$ muss an dieser Stelle darauf verwiesen werden, dass nicht der Vorwurf des Wegschauens oder des Mitläufertums in der faschistischen Diktatur im Zentrum des Texts steht, sondern der Vorwurf

222 Vgl. Hochholdinger-Reiterer, Amok, 47.

223 Wilpert, Sachwörterbuch der Literatur, S. 70r.

224 Lengauer, Jenseits vom Volk, S. 2 I 8 f.

225 BT, S. I69.

226 Jelinek, Lust, S. 28.

227 Vgl. auch Löffler, Ludersinn, S. 2 I 9. 
der Nicht-Bewältigung, der retrospektiven Negation von Eigenverantwortung und Mitschuld sowie der Selbststilisierung als Opfer nach dem Niedergang des so genannten Dritten Reichs, denn Jelineks deklariertes Ziel war es, »mit den Mitteln der Sprache zu zeigen, wie wenig sich die Propagandasprache der Blut-und-Boden-Mythologie in der Nazikunst vom Kitsch der Heimatfilmsprache in den fünfziger Jahren, einer Zeit der Restauration, unterscheidet. Dieser Sumpf aus Liebe, Patriotismus, Deutschtümelei..., der nach dem Krieg nie richtig trockengelegt worden ist, war mein Material, das ich zu einer Art Kunstsprache zusammengefügt habe ${ }^{228}$.

Dabei müssen die einzelnen Wörter nicht unbedingt etwas bedeuten. ${ }^{229}$ Hier arbeitet die Autorin wiederum vielfach auf der assoziativen Ebene. Herbeizitierte Prätexte aus Filmen und Theaterstücken sollen zwar erkannt, deren Inhalte jedoch als verlogen entlarvt werden. So sollen etwa die chorischen Anti-Österreich-Beschwörungen am Ende des Stücks laut Regieanweisung »so gesprochen werden, dass es ausgesprochen sinnvoll klingt, mit Betonungen und allem ${ }^{230}$. Die Verfremdung soll erst im zweiten Moment erkannt werden - dies intensiviert den Bruch mit dem Bekannten und Konventionellen.

»Ich arbeitete gewissermaßen linguistisch am Text, indem ich die Wörter, die schleimig und verwaschen die faschistische Ideologie transportierten, zu Wortneuschöpfungen umwandelte, Neologismen, die die ganze Brutalität des Faschismus enthüllen, ohne daß das einzelne Wort etwas bedeuten muß... ${ }^{231}$

Im Folgenden sind, um dieses Verfahren an einem Beispiel sichtbar zu machen, Auszüge aus Grillparzers »Loblied auf Österreich«, dargebracht von seiner Figur otTo von HORNECK, und die verfremdete "Anti«-Version aus Jelineks »Burgtheater«-Stück, die aus einem Dialog zwischen schorsch und IstvaN am Ende des Allegorischen Zwischenspiels extrahiert wurde, einander gegenübergestellt:

228 Jelinek, zitiert nach: http://www.rowohlt-theaterverlag.de (Zugriff am 6.6.2007).

229 Vgl. Zitat Jelinek oben, vgl. auch die Regieanweisung zur verkehrten »Österreich-Hymne« in BT.

230 BT, S. I 88.

23 I Jelinek in ihrem Essay »Ich schlage sozusagen mit der Axt drein« über ihre Arbeit an »Burgtheater«. Der BT betreffende Teil des Essays ist abgedruckt in: Janke, Nestbeschmutzerin, S. 172 . 
Prätext (Grillparzer)

HORNEK : (...)

Allein, was not tut und was Gott gefällt, Der klare Blick, der offne, richtge Sinn, Da tritt der Österreicher hin vor jeden, Denkt sich sein Teil und läßt die andern reden!

O gutes Land! O Vaterland! Inmitten

Dem Kind Italien und dem Manne

Deutschland,

Liegst du, der wangenrote Jüngling, da :

Erhalte Gott dir deinen Jugendsinn, Und mache gut, was andere verdarben! $!^{232}$
Posttext (Jelinek)

SCHORSCH U. ISTVAN (alternierend):

Allein, was nottut und was Klotz gefällt.

Der klare Blick, der offne richtge Zugewinn.

Da seicht der Österreicher hin vor Samojeden.

Denkt sich sein Teil und läßt den Großsulz reden.

O gutes Gland, o Vaterland! Verrot-

tend zwischenem Kind Italien und dem

Spengler NACKTBRAND ...

liegst du, der wangenrote KLÜNGLING da ...

Erhalte Gott dir deinen Ludersinn!

Und eingriffe gut, was andere versargen $!^{233}$

Durch die direkte Gegenüberstellung kann sichtbar gemacht werden, dass Jelinek HORNEKs Rede nahezu wörtlich exzerpiert, jedoch minimale Veränderungen an einzelnen Wörtern vorgenommen hat: Da wird »Gott« zu »Klotz« (entsprechend dem sprichwörtlichen »Klotz am Bein«), der »Sinn« zum »Zugewinn« (der Opportunist denkt nicht über Sinn oder Unsinn seines Handelns nach, sondern nur über seine persönliche Gewinnmaximierung), der »Jugendsinn« zum »Ludersinn« (Österreich als Luder, vermutlich wegen der unterstellten Anbiederung des austrofaschistischen Ständestaats ans Deutsche Reich) oder »verdarben« zu "versargen" (eine Anspielung auf die Ermordeten des NS-Regimes). Rhythmus und Phonetik der Wörter bleiben auf diese Weise weitestgehend bestehen oder verändern sich nur minimal, die Semantik jedoch wird in eine gänzlich andere Richtung gelenkt. Grillparzers Originaltext kann zwar vom Rezipienten bzw. vom Theaterpublikum wiedererkannt werden, gleichzeitig aber werden die metasprachlichen Konnotationen (mit-)rezipiert, die Jelineks »Burgtheater «-Stück wie einen roten Faden durchziehen und im krassen Gegensatz zu Grillparzers ursprünglichen Intentionen stehen: Der Vorwurf des selbstgewählten menschlichen und nationalen Niedergangs, der zum Zwecke der persönlichen Bereicherung von den Figuren hingenommen wird, destruiert Grillparzers »Loblied auf Österreich«. Warum aber der starke Konnex zu gerade diesem Grillparzer-Stück?

232 Grillparzer, König Ottokars Glück und Ende, S. 4I 4 f.

233 BT, S. I 34. 
Das Wiener Burgtheater war während des Zweiten Weltkriegs durch Bombenangriffe zerstört worden. Am I 5 . Oktober I 955 wurde es mit »König Ottokars Glück und Ende« wiedereröffnet, die Titelrolle spielte Ewald Balser, den RUDOlF mimte Attila Hörbiger und die KUnigunde Judith Holzmeister. ${ }^{234}$ Beides, sowohl die Wahl des Premierenstücks, die wohl nicht zufällig auf Grillparzers vor »Österreicharie ${ }^{235}$ strotzendes »Ottokar«-Drama fiel (das im Jelinek-Text zweimal explizit genannt wird, wenn auch orthografisch verfremdet: "Königottokarsglückundende « ${ }^{236}$ ), als auch die Besetzung des RUDOLFs mit einem bedeutenden Darsteller diverser NS-Film- und Theaterproduktionen, mögen Jelineks wiederholte Bezugnahme auf Grillparzers Stück veranlasst haben. Zudem war das "Loblied auf Österreich" Teil des Deutschunterrichts - bis in die I 97oer Jahre hinein mussten Schulkinder diesen Text auswendig lernen. ${ }^{237}$

Auch andere Grillparzer-Titel oder-Verse werden im Laufe des Texts herbeizitiert, etwa »Medea« (die große »Rassentragedie ${ }^{238}$ ) oder ${ }^{2}$ Libussa ${ }^{239}$. Dieser Intertext ist demnach rekurrent und bildet schon per se eine eigene Destruktionsebene.

Auch die Österreich-Beschwörungen am Ende des Stücks, die sich bei genauerem Hinsehen ebenso als »Anti«-Beschwörungen erweisen, destruieren ein nach dem Krieg für den Opfermythos missbrauchtes Österreich-Bild, das die sprichwörtliche »österreichische Gemütlichkeit» suggeriert und Sachertorte mit Schlag ebenso einschließt wie Lippizzaner-Hengste und Mozart-Klänge:

ALLE abwechselnd, Käthe blutet still: Davon wissen mir nix! Des sengan mir gor net! Wos mir net sengagn, des gibts net! A Schachertuatn mit Schlog. ... Das Kaffeetscherl mit Hudelzupf. Das blütige Stuterl. Der Torpido. Die Brüte. Der Ränftling. Edelschweiß! Knickschuß! Der Fahlenberg. Der Rohrschnabulierer. Krambambuli.... Die Bombenzische. Ka Kreuzer im Neck. Der gute Braune. Der Schlagoberbolzen. Das Riesenkrad. Die herzhafte Kartausche. Das Grammelschwalznot. Der Krepierer. Der Grillkarzer. Die fleißigen Henker. ... Das Umbringel. Der Himmelreiß. Die Omi. Das Wäschergasl. ... Der Kaiserschmierer. Die Hofwürg. Der Schnalzer. Salzburg! Das Krepierl! ... Das Salzkammerblut. Motzhart. Das Scheißhäusl! Schubert Brennzl. Der Abortknüttel. Papa Haydn. Die goldenen Jahre der Tellerminette. Die silbernen Jahre der Zyklonbette. Die Saubertöte. Die Senkgruabn. Ringstraßenmorderie ... Das Haus

234 Vgl. Markus, Die Hörbigers, S. 229 ff. Vgl. auch Hochholdinger-Reiterer, Amok, S. 56.

235 Löffler, Ludersinn, S. 220.

236 BT, S. I44 sowie auf S. I 89.

237 Vgl. Deutsch-Schreiner, Burgtheater, S. I39.

238 BT, S. I 44.

239 BT, S. I 44. 
Habswürg. A Gasmüch. Das Judensternderl. Mamsch und Papsch. Das Musikkazett. ... Das Wurzelmorderl. Der Finacker. Das Hunterl. Das Teatta. Das Burgteatta. Der Köpfungsfroh. Halberzehne. Der Teifel. Die guate Menschenhaut. Die Lampenstirn. (...) Der Bombenmatsch! Die Burgverrotter! Der Hundekotter! $!^{240}$

Jelinek vermischt hier das österreichische Selbstbild von Gemütlichkeit, $\mathrm{Mu}$ sikalität, Wiener Kaffeehaus-Atmosphäre und der damit verbundenen selbst zugeschriebenen Harmlosigkeit mit Waffen und Tötungsarten des Kriegs (Torpedo, Schlagbolzen, Genickschuss etc.) sowie mit Gräueltaten der Konzentrationslager (Vergasungen, Zyklon-B, auch wurden aus Menschenhaut tatsächlich Lampenschirme gefertigt etc.). Mithilfe minimaler Veränderungen an den einzelnen Wörtern wird aus Mozarts Zauberföte die »Saubertöte«, aus dem Salzkammergut das »Salzkammerblut«, aus Grillparzer »der Grilllkarzer« etc. Auch die vielen Diminutive, eine »Wiener Art ${ }^{241}$, unterstreichen Österreichs scheinbare Harmlosigkeit, so zum Beispiel das »Umbringel«, das »Wäschergasl«, das »Krepierl«, das »Judensternderl« oder das »Wurzelmorderl«, womit nach dem Krieg viel bemühte Beteuerungen ad absurdum geführt werden; bei Denunziationen, Judenermordungen und anderen Kriegsverbrechen kann man schließlich nicht »a bisserl« dabei gewesen sein.

Jelineks Destruktion der "Österreicharie ${ }^{242}$, die an dieser Stelle als eine der dominanten intertextuellen Ebenen des »Burgtheater«-Stücks festgehalten werden soll, verweist auf die ursprünglich von Karl Dietrich Bracher formulierte, viel kritisierte These vom Nationalcharakter, wonach Faschismus jeweils ein Produkt nationaler Besonderheiten wäre und sich der Nationalsozialismus in Deutschland aufgrund eines unterstellten deutschen Nationalcharakters hätte entwickeln können, womit etwa nicht erklärt werden kann, warum der Nationalsozialismus gerade in Österreich so stark gegriffen hat. ${ }^{243}$ Schon Hugo von Hofmannsthal hatte I9I7 ein $\mathrm{Schema}^{244}$ erstellt, das nationale Charaktereigenschaften der »Preußen« und »Österreicher« ersann:

240 BT, S. I $88 \mathrm{f}$.

24 I Steiner, Die verdrängten Jahre, S. I 84.

242 Löffler, Ludersinn, S. 220.

243 Vgl. Kapitel I.4.I dieser Studie.

244 Hofmannsthal, Prosa III, S. $407 \mathrm{ff}$. 
Im Ganzen:

Geschaffen, ein künstlicher Bau, von

Natur armes Land, alles im Menschen

und von Menschen,

daher: Staatsgesinnung als Zusammen-

haltendes,

mehr Tugend,

mehr Tüchtigkeit.

Soziale Struktur:

... Homogene Beamtenwelt:

Träger eines Geistes.

»Herrschende«Anschauungen und Gepflogenheiten.

Volk:

Disziplinierbarste Masse, grenzenlose Autorität ...

Der Einzelne:

... Unvergleichlich in der geordneten

Durchführung.

Handelt nach der Vorschrift. ...

Selbstgefühl.

Scheinbar männlich.

Verwandelt alles in Funktion. ...

Drängt zu Krisen.

Kampf ums Recht....

Jeder Einzelne Träger eines Teiles der

Autorität.

Streberei.

Vorwiegen des Geschäftlichen.

Harte Übertreibung.
Im Ganzen:

Gewachsen, geschichtliches Gewebe, von

Natur reiches Land,

alles von außen her: Natur und Gott,

Heimatliebe als

Zusammenhaltendes, mehr Frömmigkeit,

mehr Menschlichkeit.

Soziale Struktur:

... Polygene Beamtenwelt:

Keine geforderte Denk- und

Fühlweise.

Volk:

Selbständigste Masse, unbegrenzter Individualismus. ...

Der Einzelne:

... Rascher in der

Auffassung.

Handelt nach der Schicklichkeit. ...

Selbstironie.

Scheinbar unmündig.

Biegt alles ins Soziale um.

Weicht den Krisen aus.

Lässigkeit. ...

Jeder Einzelne Träger einer ganzen

Menschlichkeit.

Genußsucht.

Vorwiegen des Privaten.

Ironie bis zur Auflösung.

Hofmannsthals "Schema« muss als (ironische) Stilisierung eines angeblich deutschen bzw. österreichischen Nationalcharakters begriffen werden. Der dem Österreicher zugeschriebene Individualismus, die Menschlichkeit und Schicklichkeit wurden durch den »Anschluss« von I 938, der nicht nur ein äußerer, sondern 
auch einer von innen her war, sowie durch die Involvierung der Bevölkerung in das NS-System und dessen Angebote widerlegt. ${ }^{245}$ Es gilt: Nationalcharaktere sind nichts weiter als Konstrukte - nationale Mythen. Österreich konnte nach I 945 auf ein »unschuldiges Bild $\aleph^{246}$ zurückgreifen, das den urgemütlichen, kaisertreuen und gottesfrommen, Musik liebenden Individualisten beschwört, der vorwiegend dem Privaten frönt. Dieses Bild besagt weiters: Der männliche deutsche Streber, der nach Tüchtigkeit und Vorschrift handelt, hätte sich den Nationalsozialismus ausgedacht, Österreich und die Österreicher hätten beim »Umbringeln« nur ein bisschen mitgemacht - eine reduktionistische Sichtweise, die in den Opfermythostheorien als "Externalisierung ${ }^{247}$ von Schuld und Mitverantwortung bezeichnet wird.

Das wortentstellende Verfahren, das an den dargebrachten Textbeispielen aus "Burgtheater" vorgeführt wurde und als Destruktion bestehender Prätexte zu lesen ist, begleitet den gesamten Text und erinnert von seiner Form her mitunter an die Sprachexperimente der Wiener Gruppe, zum Beispiel an die Gedichte Ernst Jandls. Eine assoziative, aber auch lautliche Ähnlichkeit zu dessen Gedichten (etwa »wien: heldenplatz« oder»schtzngrbmm») findet sich bereits am Beginn des Stücks, wenn кӓтне deklamiert:

кётнЕ : Ehebaldigst böckelts im Schützengraben und die Stukas stürzen vom Himmel. Doch halt, seht! Ein Fallschirm hat sich geöffnet, der kühne Flieger konnte sich retten. Unten wartet mit brünftelndem Rock die Bäuerin.... ${ }^{248}$

Zum Vergleich dazu sei an dieser Stelle die dritte Strophe von »heldenplatz« zitiert:

pirsch!

döppelte der gottelbock von Sa-Atz zu Sa-Atz

mit hünig sprenkem stimmstummel.

balzerig würmelte es im männechensee

und den weibern war so pfingstig ums heil

zumahn: wenn ein knie-ender sie hirschelte. ${ }^{249}$

245 Vgl. Tálos/Hanisch/Neugebauer, NS-Herrschaft in Österreich.

246 Beschreibung des Mythos nach Barthes, vgl. Kapitel I.4.3 dieser Studie.

247 Begriff von Lepsius, Das Erbe des Nationalsozialismus, S. 250. Vgl. auch Kapitel I.4.4 dieser Studie.

248 BT, S. I3 I f. Vgl. Jandls Gedicht "schtzngrbmmm« in: Jandl, Laut und Luise, S. 38 f.

249 Ebd., S. 37. 
Auch hier bedeutet das einzelne Wort zumeist nichts, arbeitet der Dichter vorwiegend auf der assoziativen Ebene: So ergeben die groß geschriebenen Anfangsbuchstaben von »Sa-Atz zu Sa-Atz« (sonst konsequente Kleinschreibung) die Abkürzung für die paramilitärische Kampforganisation der NSDAP, »SA« (»Sturmabteilung«), der »knie-ender« steht für deren Uniformierung mit halblangen Stiefelhosen etc.

Offensichtlicher sind jedoch die Bezüge zu den deutschsprachigen Klassikern, neben Grillparzer wiederholt auch zu Goethe und Schiller, etwa wenn der ALPENKÖNIG (ganz faustisch) reklamiert: »Hier bin ich nur Österreicher, hier darf ichs sein. ${ }^{250}$ Oder wenig später: »Hier bin ich Mensch, hier darf ichs sein. ${ }^{251}$ Die parodistische Verfremdung deutschsprachiger Klassiker in Jelineks »Burgtheater" verweist nach Hochholdinger-Reiterer sowohl auf die im Nationalsozialismus praktizierte Instrumentalisierung humanistisch-klassischen Gedankenguts als auch auf die nach dem Krieg vielfach gepflogene retrospektive Interpretation der Klassikerpflege als Akt des inneren Widerstands. ${ }^{252}$

Zudem war es unter Baldur von Schirach, ab i94 I Gauleiter und Reichsstatthalter von Wien, kulturpolitische Linie, Volkstheater spielen zu lassen, was nach 1945 gerne als Widerstand gegen das NS-Regime umgedeutet wurde. ${ }^{253}$ Das »Volk«, das im Nationalsozialismus rassisch definiert wurde, findet sich in vielen Textbeispielen aus dem Jelinek-Stück wieder: So beschwört etwa Is T VAN im ersten Teil ( I94I) noch die »heilige Energie des Vulkes ${ }^{254}$, dieses schließt sich am Ende, I945, auf is Tvans Vorschlag hin zu einem »einig Vulk von Gegna ${ }^{255}$ zusammen - der Volksbegriff taugt also nicht viel: Vielmehr wird mit ihm Heterogenes, Widersprüchliches »zu falscher Ganzheit verschleimt ${ }^{256}$, so Lengauer. Akteur dieses Vorgangs seien in Jelineks Stück die dargestellten Volks- und Staatsschauspieler, KÄTHE, IsTVAN und schorsch, die bisweilen als willenlose Reiter auf den mit ihnen durchgehenden Zitaten und Assoziationen erscheinen. ${ }^{257}$

Im Folgenden sind Beschwörungen des deutschen Volks und der deutschen Sprache durch Paula Wessely in »Heimkehr« wiedergegeben, die Jelinek in ihrem »Burgtheater«-Stück wiederholt aufgriff. Wessely spielte in diesem Film die »Volksdeutsche« MARIE THOMAs:

250 BT, S. I 45.

$25 \mathrm{I}$ BT, S. I48.

252 Vgl. Hochholdinger-Reiterer, Amok, S. 56.

253 Vgl. Annuß, Theater des Nachlebens, S. 6r.

254 BT, S. I 35.

255 BT, S. I 83.

256 Lengauer, Jenseits vom Volk, S. 2 I 9.

257 Vgl. ebd. 
MARIE THOMAS: Leute, heimkommen werden wir bestimmt! Denkt daran, wie schön es dann sein wird, wenn alles um uns herum wieder deutsch sein wird! Wenn ihr in ein Geschäft geht, hört ihr niemals mehr Jiddisch oder Polnisch, nur noch Deutsch. Und nicht nur das Dorf, in dem wir leben, wird deutsch sein, alles, alles! Wir werden im Herzen Deutschlands leben! (...) Und ringsum schlagen Millionen deutscher Herzen. Es wird uns ganz wunderlich sein ums Herz ... Denn wir leben nicht nur ein deutsches Leben, wir sterben auch einen deutschen Tod. Und tot bleiben wir auch deutsch und sind ein Stück von Deutschland. Und ringsum singen die Vögel und alles ist deutsch." ${ }^{258}$

Wiederum finden sich in »Burgtheater« nahezu wörtliche Wiedergaben dieses filmischen Monologs (inklusive orthografischer Verfremdungen), etwa wenn ISTVAN im zweiten Teil versucht, die hysterische кётне zu beruhigen:

IS TVAN reißt sie brutal zurück: Wir werden heimkehren! Wozu jammern und fragen. Es wird doch alles gut! Käthe sabbert.

In unsarem Bette wird unser Herz pletzlich wissen: Ringsum schlagen Millionen daitsche Herzen! Daheim bist du, endlich daheim! ${ }^{259}$

Auch kurz vor Schluss, als die Protagonisten bereits dazu übergegangen sind, die »braune Brut ${ }^{260} \mathrm{zu}$ verdammen, verfällt к Films, als sie beklagt, dass der Russe ihr »Burgteatta» bezwungen habe:

кӓтне ...: Haltets eahm auf! Ringsum schlagen nämlich Millionen deutsche Herzen. $^{261}$

Zusammenfassend kann festgestellt werden, dass in Jelineks »Burgtheater « jede »Österreicharie « ${ }^{262}$ als Mythos der scheinbaren Unschuldigkeit verworfen wird und jegliche Zuschreibung eines österreichischen Nationalcharakters auf der Ebene der österreichischen Nachkriegsgesellschaft nur als Vorwand für die Opferthese interpretiert werden kann. Anhand der nicht-entnazifizierten Sprache im Unterhaltungsbereich der I 95 oer Jahre will Jelinek diesen Missbrauch offenlegen. Aufgrund der Dichte von Zitaten und Subtexten ist ein spontanes Rezep-

258 Textpassage aus dem Film »Heimkehr«, gesprochen von Paula Wessely in der Rolle der MARie thomas. Abgedruckt in: Janke, Nestbeschmutzerin, S. г7 г.

259 BT, S. I64.

260 BT, S. 178.

26 I BT, S. I 87.

262 Löffler, Ludersinn, S. 220. 
tionsverständnis nur eingeschränkt möglich. Dem deutschen Premierenpublikum in Bonn waren die österreichbezogenen Assoziationsfelder unverständlich: „Das Publikum nahm's als Exotikum, als österreichische Hetz « ${ }^{263}$ - was nicht unbedingt Sinn und Ziel der Jelinek'schen Sprachparodie ist. Die Frage, warum "Burgtheater" noch nie an einer großen österreichischen Bühne gezeigt wurde, soll im folgenden Kapitel untersucht werden.

\subsubsection{Die Rezeption: ein Skandal}

»Der >Burgtheater<-Skandal begründet in Österreich Jelineks Ruf als `Nestbeschmutzerin‘. Jelinek sperrt in der Folge das Stück für Österreich. ${ }^{264}$

Um Jelineks »Burgtheater« rankt sich in der Tat eine bemerkenswerte Rezeptionsgeschichte. I 982 wurde der Theatertext erstmals in den "manuskripten« veröffentlicht, jedoch ohne das "Allegorische Zwischenspiel«, das Jelinek erst nachträglich einfügte. Der Text erregte zunächst keine Aufmerksamkeit, das Feuilleton ignorierte das Stück weitestgehend, vermutlich weil die dargestellten Figuren zunächst nicht in Zusammenhang mit den Wessely/Hörbigers gebracht wurden. ${ }^{265}$

Die Rezeptionsgeschichte des Stücks sei eine "Nichtaufführungsgeschichte«, so Holchholdinger-Reiterer. ${ }^{266}$ Im Rahmen des »steirischen herbstes« sollte »Burgtheater« in Graz erstmals gespielt werden. Doch Jelinek selbst prophezeite:

"»Burgtheater hat überhaupt keine Chance, aufgeführt zu werden. Ich glaube auch nicht daran, dass es jetzt aufgeführt wird, wo sich einige westdeutsche Theater dafür interessieren, und wenn, dann in kleinstem Rahmen. ${ }^{267}$

Erstmals aufgeführt wurde das Stück tatsächlich am ıo. November 1985 in der Werkstattbühne Bonn, nicht im Rahmen des "steirischen herbstes« und auch sonst nicht in Österreich. In Bonn führte Horst Zankl Regie, die Protagonisten

263 Ebd., S. 22 I.

264 Janke, Nestbeschmutzerin, S. I7r. Vgl. dazu auch Fiddlers Ausführungen zu Jelinek als »desecrator«, Demythologising the Austrian »Heimat«, S. 25-44.

265 Vgl. Steiner, Die verdrängten Jahre, S. I77.

266 Vgl. Hochholdinger-Reiterer, Amok, S. 44.

267 Interview mit Jelinek, zitiert nach: Palm, Burgtheater, S. 229. 
wurden von Carmen Renate Köper (кётне), Wolfgang Krassnitzer (Istvan), Robert Tillian (sсновsch) und Luise Prasser (Resi) verkörpert. Zankls Inszenierung erhielt in der Folge Einladungen zum Berliner Theatertreffen, zu den Mülheimer Theatertagen, zu den Berner Theaterwochen des zeitgenössischen Theaters und zum Theatertreffen in Nordrhein-Westfalen. ${ }^{268}$ Innerhalb der deutschen (auch: der schweizerischen) Theaterszene reagierte man demnach mit Interesse an dem Stück. Dieses fand Anerkennung und Beifall in einem Deutschland, das seine NS-Geschichte durch kritische Reflexion, aber auch durch institutionelle und demokratiepolitische Reformen »internalisiert ${ }^{269}$ hatte, anders als Österreich, wo in den I $980 e r$ Jahren (noch vor der Waldheim-Affäre) von offizieller Seite her kein Zweifel an der Opferthese zugelassen wurde. ${ }^{270}$ Nicht aber in Deutschland, wo die Kontexte des Stücks und dessen Sprache aufgrund des starken Österreich-Bezugs nicht dementsprechend rezipiert werden konnten, sondern in Österreich löste die Aufführung von "Burgtheater" einen wahren Theater- und Medienskandal aus. Jelinek hatte mit »Burgtheater « ein heißes Eisen in die Hand genommen, denn in Österreich genossen Paula Wessely und die Hörbiger-Brüder auch in den I 98oer Jahren noch hohes Ansehen: Sie galten als Gallionsfiguren sowohl des Wiener Burgtheaters als auch des österreichischen Nachkriegsfilms.

Mit einem Schlag war Elfriede Jelinek eine persona non grata der österreichischen Literaturszene - so empfand sie es jedenfalls selbst:

»Ich würde sagen, es war der Beginn des Abstiegs von mir als Autorin in Österreich. ... Es wurde jetzt nicht diskutiert, was diese Schauspielerin getan hat oder nicht getan hat, oder ihre Familie getan hat oder nicht getan hat, das hat niemanden interessiert.... Es hat mich meinen guten Ruf als Autorin gekostet. Diese Unterstellungen haben damals begonnen, denn man sagt nicht, ich hätte die Wahrheit gesagt oder versucht über diese Wahrheit jetzt zu sprechen, sondern man sagt, ich hätte etwas gesagt, was man besser nicht hätte sagen dürfen, was man besser hätte ruhen lassen. « ${ }^{271}$

Mit dieser Einschätzung hatte Jelinek jedenfalls nicht Unrecht. Das Ehepaar Wessely/Hörbiger wurde von führenden Medien und Politikern geradezu aggressiv verteidigt und das Stück als »beispiellose Majestätsbeleidigung « ${ }^{272} \mathrm{ab}$ qualifiziert. Der Chefredakteur des Wochenmagazins profil, Peter Michael Lin-

268 Vgl. Hochholdinger-Reiterer, Amok, S. 44.

269 Lepsius, Das Erbe des Nationalsozialismus, S. 25 I. Siehe auch Kapitel I.4.4 dieser Studie.

270 Vgl. Kapitel I.4.4 dieser Studie.

27 I Jelinek, zitiert nach: »Wer hat Angst vor Elfriede J.?«, TV-Dokumentation.

272 Hochholdinger-Reiterer, Amok, S. 45. 
gens, stellte in einem Leitartikel sogar die Behauptung auf, dass Jelineks Stück bei dem fast 90-jährigen Attila Hörbiger Herzversagen hervorrufen könne. ${ }^{273}$

War Jelinek zuvor nur das Feindbild der bürgerlichen ÖVP gewesen, so gesellten sich nun die »Kronen Zeitung « und die damalige FPÖ zu dieser jelinekfeindlichen Koalition, die gegen die Autorin zu Felde zog und sie als »Nestbeschmutzerin« und »Staatsfeindin« attackierte. Zu diesen Angriffen äußerte sich Jelinek in einem ORF-Interview am I I. November I 985 in einem Beitrag, der anlässlich der Uraufführung des Stücks in Bonn gebracht wurde, folgendermaßen:

„Es wird noch immer gesagt, dieses Stück hätte vor 40 Jahren geschrieben werden sollen. Aber vor 40 Jahren war ich noch nicht geboren. Ich war eben erst jetzt imstande, es zu schreiben. Und zu sagen, man soll diese alten Leute in Ruhe lassen, das ist ganz unglaublich, wenn man bedenkt, daß der Faschismus sich nicht hätte halten können ohne diese Massenmedien-Industrie; daß jemand in einem Propaganda-Spielfilm mitmacht, eine tragende Säule des Nazi-Regimes ist. Nicht ein Mitläufer, der in irgendetwas aus Dummheit hineingeschlittert ist. ${ }^{274}$

Jelinek zeigte sich in dieser Diskussion also (zunächst) offensiv. Mit »Burgtheater« hatte sie erstmals ein Bühnenstück mit deklariertem Österreich-Bezug verfasst. Die Verweigerung der Republik, das Stück als dramatisch dargebrachte Kritik einer anerkannten Schriftstellerin zu verstehen (auch Claus Peymann lehnte die Aufführung des Stücks während seiner Zeit als Burgtheater-Intendant aus »qualitativen Gründen ${ }^{275} \mathrm{ab}$ ), quittierte sie schließlich mit einem Aufführungsverbot, das die Ausnahme vorsah, dass "Burgtheater « in Österreich überhaupt nur am Wiener Burgtheater gespielt werden dürfe (»Es muß dorthin, wo es wehtut. $\left.{ }^{276}\right)$, was bisher nicht geschehen ist.

In kleinem Rahmen wurde »Burgtheater« in Österreich ein paar wenige Male gezeigt: So gab es 1983 im Rahmen der Veranstaltungsreihe »Theater und Faschismus in Österreich I 933 - I945" eine Lesung des Stücks. I 986 wurde vom Kommunistischen Kulturbund aus Anlass der Burgtheaterfeiern eine weitere Lesung abgehalten. Am I7. September I99 I wurde auf Radio ör eine Hörspiel-Fassung unter dem Titel »Burgteatta« gesendet. ${ }^{277}$ Auf einer Theaterbühne

273 Vgl. profil, Nr. 48, I 985 , S. I 4.

274 Jelinek in einem ORF-Interview vom Ir.Ir.1985 im Rahmen eines Beitrags von Krista Fleischmann, zitiert nach: Perthold, Elfriede Jelineks dramatisches Werk, S. 25 I.

275 Hochholdinger-Reiterer, Amok, S. 45.

276 Jelinek in einem Gespräch mit Gerhard Moser von der KP-nahen Zeitschrift »Volksstimme«, Faksimile des Artikels abgedruckt in: Janke, Nestbeschmutzerin, S. I 82.

277 Hochholdinger-Reiterer, Amok, S. 46. 
erstmals gespielt wurde das Stück in Österreich endlich ein Vierteljahrhundert nach seiner Entstehung: 2005 im Grazer »Theater im Bahnhof«, obwohl der Rowohlt Theater Verlag die von ihm verlegten Stücke normalerweise keinen Off-Bühnen überlässt. Da aber kein anderes österreichisches Theater dieses Stück der inzwischen mit dem Nobelpreis gekürten Schriftstellerin zeigen wollte, bekam das kleine » Theater im Bahnhof « ausnahmsweise die Möglichkeit dazu. ${ }^{278}$

Die Erstaufführung von »Burgtheater« an einer großen österreichischen Bühne oder im Rahmen einer kulturellen Großveranstaltung steht nach wie vor aus. Der Grund dafür ist leicht zu erraten: Jelinek wählte sich zur Auseinandersetzung in diesem Stück »nichts weniger als `österreichische Institutionen aus«, so Hochholdinger-Reiterer:

»... das Burgtheater als das Synonym für Repräsentationskunst, kulturellen Wiederaufbau und kulturelle Identität, weiters Österreichs Ersatz für religiöse und monarchistische Bedürfnisse, seine legendäre Schauspielerverehrung, und die in Gestalt österreichischer Publikumslieblinge noch potenzierte `Opferthese als eines der wesentlichen Fundamente der Zweiten Republik. « ${ }^{279}$

Freilich war der Skandal vorprogrammiert. Dass er stattfand, obwohl das Stück in Österreich nicht aufgeführt wurde, ist dennoch beachtlich. "Burgtheater « ist zweifelsohne einer von Jelineks stärksten Theatertexten. Dass das Stück in Österreich bisher noch nie auf einer großen Bühne gezeigt wurde, ist der eigentliche Skandal, denn es tut sich der Verdacht auf, dass jede weitere Diskussion um das in dem Stück bearbeitete Sujet dadurch vermieden werden soll.

\subsubsection{Die Wessely/Hörbigers: eine Potenzierung des Opfermythos}

»Das, was ich kritisiere, ist immer die Sprache, so kritisiere ich im Burgtheater nur sehr am Rande die Personen, die mich im Grund überhaupt nicht interessieren. ${ }^{280}$

Jelinek betont immer wieder, auch in anderen Zusammenhängen, dass es nicht ihr Anspruch sei, mit ihren Theaterfiguren Realpersonen abzubilden oder Figuren zu erfinden, die real sein könnten. »Ich vergrößere (oder reduziere) meine

278 Ebd.

279 Ebd., S. 47.

280 Jelinek, zitiert nach: Winter, Gespräch mit Elfriede Jelinek, S. I 3. 
Figuren ins Übermenschliche, ich mache also Popanze aus ihnen«, so die Autorin. Nicht um »abgerundete Menschen mit Fehlern und Schwächen«, gehe es ihr, sondern um »Polemik, starke Kontraste, harte Farben, Schwarz-Weiß-Malerei; eine Art Holzschnitttechnik « ${ }^{281}$.

Wiederholt ließ die Autorin ausdrücklich ausrichten, dass es sich im konkreten Fall um »ein Stück über Sprache, aber nicht ein Stück über Personen « ${ }^{282}$ handle. »Burgtheater « sei zwar »an realen Personen orientiert, die in der Zeit des Faschismus berühmte Schauspieler waren..., aber nicht die Personen als solche sind mir wichtig gewesen, sondern das, wofür sie standen, was sie repräsentieren, wofür sie sich zum Werkzeug machten ${ }^{283}$. Dennoch ließ sich die Autorin - allen Beteuerungen zum Trotz, in dem Stück gehe es um den Missbrauch der Sprache, nicht um die Denunziation realer Personen - zu einigen öffentlichen Äußerungen über Paula Wessely und die Hörbiger-Brüder hinreißen, mit welchen sie auf eben jene Kritiken einging, die sie als fehlgeschlagen betrachtete, wodurch sie für die Presse umso angreifbarer wurde.

So meinte sie etwa in Paula Wessely eine Schlüsselfigur der österreichischen Theater- und Filmgeschichte zu erkennen, die sich durch ihre vorgeschobene Naivität in diesen Jahren persönlich schuldig gemacht habe, was in Österreich nicht bemerkt werden wolle. Ucickys »Heimkehr«-Film, in dem Wessely die Hauptrolle gespielt hatte, sei »der schlimmste Propagandaspielfilm der Nazis überhaupt ${ }^{284}$ gewesen. Wesselys Mitwirkung sowohl an ablenkenden Filmen als auch an diesem Propagandafilm werde bis heute unterschätzt:

»Man darf nicht vergessen, daß Paula Wessely der höchstbezahlte weibliche Star der Nazizeit war. Das Argument einer sunpolitischen Frau ... kann ich nicht akzeptieren. (...) Ich habe Paula Wessely nie für eine große Schauspielerin gehalten. Sie hat nur einen Ton gehabt, und besonders mißfallen hat mir ihr prononciertes Natürlichsein... es war eine Art Natürlichkeitsschleim, den sie über ihr Spielen breitete. ... Dieser Natürlichkeitswahn, der etwas Künstliches in Natur verwandeln will, liegt auf einer Linie mit der Naturhaftigkeit der Geburt in Blut und Boden des Vaterlandes. ... Ihre Person ist das genaue Gegenteil von dem, was ich für interessant halte am Theater. ${ }^{285}$

Die Frage, ob die Wessely/Hörbigers für die Figuren von Jelineks »Burgtheater«Stück Pate gestanden haben, muss tatsächlich positiv beantwortet werden - auch

28 I Dies., Ich schlage sozusagen mit der Axt drein, S. I4.

282 Dies., zitiert nach: Friedl, Die Tiefe der Tinte, S. 44.

283 Dies., Ich schlage sozusagen mit der Axt drein, S. I6.

284 Dies., zitiert nach: http://www.elfriedejelinek.com (Zugriff am 23.8.2005).

285 Ebd. 
wenn diese für die Autorin nur Mittel zum Zweck, ihre Kritik an einer vom Faschismus vereinnahmten Sprache, darstellten. In den meisten anlässlich des "Burgtheater«-Skandals verfassten Artikeln wurde zwischen den realen Personen und den Figuren im Stück ohnehin nicht mehr unterschieden. ${ }^{286}$ Lengauer schreibt treffend von einer »tratschmäßigen Verknüpfung « ${ }^{287}$ der Jelinek’schen Figuren mit der Biografie wirklicher österreichischer Schauspieler und verweist auf die Bedeutung des historischen Rahmens, den Jelinek andeutet. Die oben ausgeführten Assoziationsketten und die daraus resultierenden Verbindungen zu den Realpersonen müssen aber zweifelsohne als gewollt verstanden werden, auch wenn die Figuren in dem Stück zugleich als exemplarisch gelten können.

Die Attackierte, Paula Wessely selbst, reagierte auf die Uraufführung von "Burgtheater « in Bonn und die daraufhin einsetzende Medienschlacht letztlich mit folgender Stellungnahme, die sich aufgrund ihrer bemühten Sachlichkeit "wohltuend von dem Sprachunflat ihrer Boulevardpresse-Verteidiger unterschied ${ }^{288}$ :

»Ich will mich nicht mit dem Stück der Frau Jelinek auseinandersetzen, werde es aber sicher nicht verbieten lassen. Wohl aber setze ich mich mit der Rolle auseinander, die ich damals in der NS-Zeit gespielt habe: Ja, es tut mir leid, daß ich damals nicht den Mut aufgebracht habe, zurückzuweisen, daß sich dieses Regime mit mir brüstet; daß ich nicht den Mut gefunden habe, die Dreharbeiten zu >Heimkehr abzubrechen. Vielleicht habe ich aber doch einiges von dem wiedergutgemacht, indem ich konkreten Menschen, jüdischen Kollegen und Freunden, in dieser Zeit konkret geholfen habe. « ${ }^{289}$

Tatsächlich gab es Interventionen von Paula Wessely und Attila Hörbiger, mit denen diese versuchten, jüdische Freunde, etwa den Josefstadt-Regisseur Paul Kalbeck oder den Ehemann Hermine Ehrensteins, Alexander Ehrenstein, vor der Verfolgung (Berufsverbot, Enteignung, Inhaftierung) des NS-Regimes zu schützen. ${ }^{290}$

Bei offiziellen Auftritten und Äußerungen achtete das Ehepaar hingegen streng auf die politisch opportune Linie. ${ }^{291}$ Es muss zudem festgestellt werden, dass Paula Wessely eine der erfolgreichsten und bestbezahltesten Darstellerinnen des nationalsozialistischen Deutschen Reichs war. Bereits seit 1934

286 Vgl. Steiner, Die verdrängten Jahre, S. 178.

287 Lengauer, Jenseits vom Volk, S. 2 I 7.

288 Rathkolb, Führertreu und gottbegnadet, S. 26r.

289 Paula Wessely in einem Interview, zitiert nach: profil, Nr. 48, I 985, S. I6.

290 Vgl. Steiner, Die verdrängte Vergangenheit, S. 87-92.

29 I Vgl. ebd., S. 87. 
war sie Mitglied der »Reichsfachschaft Film« gewesen, hatte sich jedoch bis I 938 darum bemüht, von nationalsozialistischen Projekten nicht zu sehr vereinnahmt zu werden, da sie auch im austrofaschistischen Ständestaat Engagements wahrgenommen hatte. ${ }^{292}$ So hatte sie sich wiederholt für Veranstaltungen der Austrofaschisten zur Verfügung gestellt, die im heutigen Sinn »durchaus Werbe-Qualitäten ${ }^{293}$ aufwiesen. Im April 1937 etwa taufte sie, umweht von Krukenkreuzfahnen und beobachtet von Kameras der (von der »autoritären Halbdiktatur ${ }^{294}$ installierten) Wochenschau »Österreich in Bild und Ton ${ }^{295}$, ein von »Jungen des österreichischen Jungvolkes« gebasteltes Segelflugzeug auf den Namen »Paula«, was im Rahmen der Wochenschau den Weg in die deutschsprachigen Kinos fand und eine entsprechende Breitenwirkung hatte. ${ }^{296}$ In Jelineks »Burgtheater«-Text wird auf diese Verpflichtungen Wesselys dem austrofaschistischen Regime gegenüber immer wieder implizit, aber auch explizit hingewiesen. So deklamiert etwa к ̈̈тне, während sie eine Filmrolle imaginiert: »... in Bild und Ton! Da ist es schon! « ${ }^{297}$

Dennoch gab Wessely nach dem »Anschluss« eine Abstimmungsempfehlung zugunsten der Nationalsozialisten ab:

»Ich freue mich, am ro. April I 938 das Bekenntnis zum grossen volksdeutschen Reich mit Ja ablegen zu können und so die von mir immer betonte Kulturverbundenheit der österreichischen Heimat mit den andern deutschen Gauen zu bekräftigen! « 298

Mit dieser Formulierung schaffte sie es immerhin, sowohl Affinität zur großdeutschen Idee als auch Kulturverbundenheit mit der österreichischen Heimat zu bekunden - ein Zwiespalt, der bei кётне in Jelineks »Burgtheater«-Stück immer wieder angedeutet wird. Der im März I938 vollzogene "Anschluss« wurde mit der aufwändig beworbenen »Pseudo-Volksabstimmung «"99 am Io. April 1938 mit über 99 Prozent der Stimmen bestätigt. ${ }^{300}$ Bei der "Aufforderung zur Mithilfe am Winterhilfswerk des Deutschen Volkes« 1937 hatte Wessely zunächst noch gezögert, was Propagandaminister Goebbels nicht wei-

292 Vgl. Rathkolb, Führertreu und gottbegnadet, S. 26r.

293 Steiner, Die verdrängten Jahre, S. 87.

294 Hanisch, Der lange Schatten des Staates, S. 304.

295 Zur De-facto-Vorführpflicht der österreichischen Wochenschauen (ab 30. Mai 1933) vgl. Hofinger, Ein Volk, S. 238.

296 Vgl. ebd.

297 BT, S. I 35.

298 Wessely, zitiert nach: Steiner, Die verdrängten Jahre, S. 8o.

299 Ebd., S. 79.

300 Vgl. ebd. 
ter gestört haben dürfte. ${ }^{301}$ In Tagebucheintragungen hatte er von Wessely und ihren Filmen geschwärmt:

»Film »Maskerade`. Sehr gut gemacht. Wunderbare Paula Wessely. Wie natürlich und groß. Ein wahrer Genuß, ihr zuzuschauen. « ${ }^{302}$

"Die Wessely ist ganz herrlich. ${ }^{303}$

»Die Wessely ist ans Herz gehend und zu Tränen rührend. Man schämt sich der Rührung nicht. ${ }^{304}$

»Mit Hilpert feste Engagements von Wessely, Attila Hörbiger und Balser besprochen. Ich forciere das. Wir müssen alle großen Künstler nach Deutschland holen. « ${ }^{305}$

Auch 1943, als sich die Niederlage im Krieg für das Deutsche Reich bereits abzeichnete, führte Goebbels seine Linie fort, mit Darstellern beim Film und Künstlern im Allgemeinen »nicht allzu streng « zu sein (sofern sich diese nicht offen staats- oder kriegsfeindlich zeigten): »Künstler dürfen auf politischem Gebiet nicht ernst genommen werden ${ }^{306}$, notierte er - mehr denn je war er aufgrund der schlechten Kriegslage auf die kalmierende Wirkung angewiesen, die mit der Unterhaltungsbranche erzielt werden konnte. Wesselys durchaus registrierte altkatholische Gesinnung (»... fast jeden Sonntag in der Kirche Wien I, Annagasse ${ }^{307}$ ) wurde daher von den Nationalsozialisten toleriert, ebenso wie ihre Aktivitäten im Ständestaat vor $1938 .^{308}$

Wenn sie auch während der NS-Zeit im Privaten mit Juden verkehrte und gemeinsam mit Ehemann Attila versuchte, für jüdische Freunde und Kollegen zu intervenieren, so ließ sie sich dennoch von der NS-Elite hofieren und stellte sich für propagandistische Zwecke zur Verfügung. Schließlich übernahm sie in dem antipolnischen und antisemitischen »Heimkehr«-Film, auf den im »Burgtheater «-Text wiederholt angespielt wird, die weibliche Hauptrolle der MARIE тномаs, beschwor in dieser Rolle (vorbildhaft für das Kinopublikum) die Tu-

30 I Vgl. Rathkolb, Führertreu und gottbegnadet, S. 262.

302 Fröhlich, Tagebücher von Joseph Goebbels, Teil I, Bd. 2, Eintrag vom 22.8. 1934, S. 475.

303 Dies., Teil I, Bd. 3, Eintrag vom 28.4. I 937, S. I 26.

304 Ebd., Eintrag vom 7.I I.r 937, S. 329.

305 Ebd., Eintrag vom 8.r2.1937, S. 360.

306 Dies., Tagebücher von Joseph Goebbels, Teil II, Bd. 9, Eintrag vom 23.9.r 943, S. 584 .

307 Eintragung im Gauakt Attila Hörbiger/Paula Wessely, zitiert nach: Rathkolb, Führertreu und gottbegnadet, S. 262.

308 Vgl. ebd. 
genden des Deutschen Reichs und wirkte an der einzigen »individuell zurechenbaren ${ }^{309}$ antisemitischen Sequenz mit, in der MARIE THOMAs den jüdischen Krämer salomonsson mit den Worten zurückweist: „Nee, Salomonsson, Sie wissen ja, wir kaufen nicht bei Juden. ${ }^{310}$ Jelinek quittierte diese Filmszene mit unverhohlener Kritik an der Hauptdarstellerin: »... wenn sie in „Heimkehr« sagt, ,Wir kaufen nichts bei Juden`, hätte sie als erwachsener Mensch wissen müssen, was sie da sagt. ${ }^{311}$ Auch wenn der Wessely/Hörbiger-Biograf Markus Wert auf den Hinweis legt, dass Wessely in einem vertraulichen Gespräch mit André Heller 1976 echte Reue für ihre Mitwirkung an dem Film gezeigt habe (»Es war das Schrecklichste, das ich in meinem Leben getan habe, ich geniere mich in Grund und Boden dafür und bereue nichts mehr als das... Der Film Heimkehr war etwas Schreckliches, und es war eine uferlos opportunistische Tat, darin aufzutreten ${ }^{312}$ ), und auch wenn wohlwollend davon ausgegangen wird, dass Wessely dieses Bedauern im vertraulichen Gespräch tatsächlich äußerte, muss ihr doch angekreidet werden, dass sie in der Öffentlichkeit niemals auch nur annähernd so deutliche Worte fand.

Um die Tragweite von Wesselys Engagement in »Heimkehr« deutlich zu machen, sei hier die Handlung des Films in aller Kürze zusammengefasst: Dieser nimmt seinen Ausgang in den Monaten vor dem Ausbruch des Zweiten Weltkriegs I 939 und zeigt die Angehörigen einer »volksdeutschen Minderheit« in Polen (gemeint sind die »Wolhynien-Deutschen«), die mit jüdischer Unterstützung von »bestialischen polnischen >Untermenschen « ${ }^{313}$ misshandelt und beinahe ausgerottet wird. Wessely ist in der Rolle der "volksdeutschen« Lehrerin MARIE THOMAs zu sehen, die sich gegen die vermeintliche Willkür der Polen zur Wehr setzt, der schließlich ihr Mann zum Opfer fällt. Die Deutschen im Dorf werden verhaftet und sollen erschossen werden. Das Heranrücken der Wehrmacht verhindert dies jedoch: Hitler wird als Retter der Deutschen gepriesen, der Angriff auf Polen zur Hilfsaktion für die dort lebenden Deutschen verfälscht. Im Finale des Films wird der deutschen Minderheit schließlich in einem großen Treck die »Heimkehr « ins Reich ermöglicht. ${ }^{314}$

309 Ebd., S. 264.

3 Io Wessely als marie thomas, zitiert nach: Ebd.

3 I I Jelinek über Paula Wessely, zitiert nach: http://www.elfriedejelinek.com (Link: »Paula Wessely) (Zugriff am 20.1 I.2007).

3 2 Heller zitiert Wessely, zitiert nach: Markus, Die Hörbigers, S. 3 I 7.

3 3 Markus, Die Hörbigers, S. I 53. Das Zitat von den »bestialischen Untermenschen« dürfte aber ursprünglich von Löffler stammen, siehe Löffler, Was habe ich gewußt, S. 9r.

3 I 4 Vgl. http://www.film.at/heimkehr (Zugriff am 25.4.20I I). Vgl. außerdem Markus, Die Hörbigers, S. I 53 . 
Das Kinoprojekt war von Goebbels langfristig geplant und aufwändig beworben worden. ${ }^{315}$ Wessely äußerte I97 I, dass sie die Tragweite des Films erst habe erkennen können, als sie ihn fertig gestellt vor sich sah - ein Argument, das angesichts der Dialogstellen und der Vorankündigungen des Films nicht überzeugend ist, so Steiner. ${ }^{316}$ Alle Beteiligten haben wissen müssen, wobei sie mittaten, findet auch Löffler. ${ }^{317}$ In einer Rezension des nationalsozialistischen Propagandablatts »Völkischer Beobachter« wurde der »Heimkehr«-Film im Oktober i 94 I folgendermaßen angepriesen:

\begin{abstract}
»Vor dem Hintergrund der historischen Weltentscheidung führen die in diesem großen und ergreifenden Filmwerk gezeigten Schicksale volksdeutscher Männer und Frauen aus dem Spätsommer des Jahres I 939 zu dem Grund des uns aufgezwungenen Schicksalkampfes. Deutschland ging es nicht um imperialistische Eroberungen; die Anerkennung des Lebensrechtes deutscher Menschen in der Welt stand am Beginn, die Sicherung ihres Daseins an Leib und Seele. Was in diesen Tagen und Wochen zu uns tönt, das nahm in den Dezennien vor dem I. September 1939 in der Not der Volksdeutschen seinen Anfang: der brutale Wille der plutokratischen Demokratien, Deutschland und die Deutschen zu vernichten, zu ermorden, auszurotten. Die Schicksale des Filmwerks 〉Heimkehr« stehen für hunderttausende andere. « ${ }^{318}$
\end{abstract}

Mit dem »aufgezwungenen Schicksalkampf« ist der Zweite Weltkrieg, in Wahrheit ein Offensivkrieg des Deutschen Reichs zum Zwecke der Territorialgewinnung, gemeint. Von Anfang an wurde in der deutschen Propaganda jedoch der Mythos, das »unschuldige Bild « ${ }^{319}$, vom Defensivkrieg geschürt. Nachdem die deutsche Luftwaffe in den frühen Morgenstunden des I. September I 939, nach einem fingierten polnischen Überfall, mit 29 Sturzkampfbombern die Stadt Wieluń angegriffen hatte, übertrug der Rundfunk vormittags die aus Anlass des Kriegsbeginns gehaltene Reichstagsrede Adolf Hitlers, in welcher dieser bekanntermaßen vermeldete: „Seit 5 Uhr 45 wird jetzt zurückgeschossen. «"20

Auch im ersten Wehrmachtsbericht, der noch von Hitler selbst redigiert worden war, wurde festgehalten, dass die Wehrmacht »auf Befehl des Führers und Reichskanzlers den aktiven Schutz des Reiches übernommen« und »in Erfül-

3 I 5 Vgl. Steiner, Die verdrängten Jahre, S. I 2 I.

3 I6 Ebd., S. I 22.

3 7 Löffler, Was habe ich gewußt, S. 9 I.

3r 8 Völkischer Beobachter, 24.I0.I94I, zitiert nach: Wulf, Theater und Film im Dritten Reich, S. 394 f.

319 Barthes, Mythen des Alltags, S. 98. Vgl. auch Kap. I.4.3. dieser Studie.

320 Hitler, zitiert nach: Kershaw, Hitler 1936-1945, S. 3 I 3. 
lung ihres Auftrags, den polnischen Truppen Einhalt zu gebieten « ${ }^{321}$ Truppen des deutschen Heeres über alle deutsch-polnischen Grenzen zum Gegenangriff entsendet habe. Das Wort »Krieg« durfte von der Presse zunächst nicht verwendet werden. ${ }^{322}$

Nun war das Propagandathema von »Heimkehr« im Oktober I 94 I nicht mehr aktuell, die Kriegsfolgen lähmten den Besucherstrom zu dem bislang teuersten Filmprojekt der nationalsozialistischen Studios. Nach der Proklamation des »Totalen Kriegs« und der Verkündung des »Deutschen Volkssturms« I 944 aber lief der Streifen als wertvoller »nationaler Film« wieder in den Kinos an diesmal nicht unter den Vorzeichen der deutschen Angriffspolitik, sondern der sich bereits abzeichnenden militärischen Niederlage. ${ }^{323}$ Es galt daher, politische Durchhalteparolen, mit denen das sinnlose Sterben auf beiden Seiten unnötig in die Länge gezogen wurde, mit scheinbar moralischen Inhalten zu rechtfertigen.

Paula Wesselys und Attila Hörbigers Engagement in »Heimkehr« ist demnach als höchst problematisch zu bewerten: Der Film war mit größtem finanziellen Einsatz und massiver Bewerbung gemacht worden, um den deutschen Kriegsmythos vom Defensivangriff gegen Polen zu verbreiten. Wie nebenbei mischte er außerdem die Judenfrage unter. I 944 erfüllte er eine kriegsverlängernde Wirkung, indem er zur Aufrechterhaltung der Moral des deutschen Volkes beitragen sollte.

Es muss daher festgestellt werden, dass sich Paula Wessely den Berufsbedingungen des jeweils herrschenden politischen Systems (zunächst des austrofaschistischen Ständestaats, in Folge aber auch des NS-Regimes) zu Zwecken der Karriereförderung unterwarf - ob sie nun politisch einverstanden war oder nicht. ${ }^{324}$ Interessanterweise sollte ihr dies nach Kriegsende aber »nur kurzfristig ${ }^{325}$ Probleme bei der Entnazifizierung machen. Mit Sicherheit war es für sie hilfreich, dass sie als Frau weniger strenge Entnazifizierungsmaßnahmen auf sich nehmen musste, die von Vorurteilen über die Geschlechterrollen im Nationalsozialismus geprägt waren, wonach Frauen die aktive Teilnahme an den Angeboten des Regimes weniger zugetraut wurde als Männern. ${ }^{326}$ Bereits ab 30. August 1945, nur wenige Monate nach Kriegsende, durfte sie wieder am Landestheater in Innsbruck spielen, in der amerikanischen Zone hatte sie noch

32 I Studt, Das Dritte Reich in Daten, S. I I I.

322 Vgl. ebd., S. i i f.

323 Vgl. Rathkolb, Führertreu und gottbegnadet, S. 264.

324 Vgl. Rathkolb, Führertreu und gottbegnadet, S. $263 \mathrm{ff}$.

325 Hochholdinger-Reiterer, Amok, S. 43.

326 Zu der unterschiedlichen Behandlung von Frauen und Männern im Entnazifizierungsprozess in Deutschland und Österreich nach 1945 vgl. Krauss, Sie waren dabei. 
bis Mitte Dezember I945 Auftrittsverbot. Ab Sommer 1946 wurde schließlich auch die Erlaubnis zu Dreharbeiten wieder gegeben. Von einem »Karriereknick « ${ }^{327}$ oder von ernsthaften Bemühungen, die eigene berufliche Vergangenheit als Aushängeschild der NS-Propaganda öffentlich aufzuarbeiten, kann demnach nicht gesprochen werden. ${ }^{328}$

Attila Hörbiger, der als männlicher Hauptdarsteller in der Rolle des deutschen Wirts Ludwig LaUnhaRdT ebenfalls in dem Film mitgewirkt hatte, darüber hinaus aber auch Mitglied der NSDAP gewesen war, musste nach dem Krieg in Wien Schutt schaufeln. ${ }^{329}$ Die Frage über seine Mitgliedschaft hatte Attila Hörbiger bereits am 20. Juli 1934 in einem Fragebogen der NSDAP positiv beantwortet, was insofern besonders bemerkenswert erscheint, als dass die Partei zu diesem Zeitpunkt in Österreich noch verboten war. Allerdings hatte er keine Mitgliedsnummer angegeben. Diese erhielt er offiziell erst I94I zugewiesen. ${ }^{330}$ "Es ist sehr wahrscheinlich, daß Hörbiger mit dieser fragwürdigen Behauptung den strengen Kontingent-Bestimmungen, die >Ostmärker in Deutschland vor 1938 betrafen, vorgreifen wollte « ${ }^{331}$, meint Rathkolb dazu. Über Hörbigers politische Haltung müsse die (vielleicht sogar falsche) Angabe über seine frühe Mitgliedschaft nicht unbedingt etwas aussagen. Erst nach 1938 exponierten sich Paula Wessely und Attila Hörbiger in der Öffentlichkeit politisch im nationalsozialistischen Sinne. So nahm auch Attila Hörbiger, der als Vorbild für die Figur des Is TVAN in Jelineks »Burgtheater " angenommen werden darf, I 938 an der Künstler-Petition, in der für den »Anschluss« geworben wurde, teil:

»Wir Künstler sind froh und stolz, am neuen großdeutschen Werke mitarbeiten zu können und werden uns am ro. April I93 8 einmütig zu unserem Führer bekennen! ${ }^{332}$

Insgesamt war Hörbigers Verhalten während der NS-Zeit voll der Widersprüche. Nach außen hin deklarierte er parteipolitische Präferenzen, im Privaten versuchte er, seine »heile Welt« zu erhalten, unterhielt »sehr starke Verbindungen zu Juden ${ }^{333}$, wie der SS-Oberführer und spätere »Reichsfilmintendant«

327 Ebd.

328 Vgl. ebd. Vgl. auch Steiner, Paula Wessely, S. I 52 ff.

329 Vgl. Löffler, Was habe ich gewußt, S. $90 \mathrm{f}$.

330 Vgl. Rathkolb, Führertreu und gottbegnadet, S. 24r.

33 I Ebd.

332 Attila Hörbiger, zitiert nach: Steiner, Die verdrängten Jahre, S. 8 r.

333 So SS-Oberführer Hans Hinkel in einer vertraulichen Sitzung, zitiert nach: Rathkolb, Führertreu und gottbegnadet, S. 24I. Hinkel organisierte ab 1942 die Filmabteilung des Propagandaministeriums und war ab März I 944 Reichsfilmintendant. Vgl. Klee, Kulturlexikon zum Dritten Reich, S. 249 f. 
Hans Hinkel kritisierte, und unterstützte mit finanziellen Aufwendungen jüdische Sportvereine (etwa den Fußballklub sowie den Schwimmverein der Wiener »Hakoah«). ${ }^{334}$ Beruflich war er als Schauspieler äußerst erfolgreich, verdiente mit zwanzig Filmprojekten weitaus mehr Geld als beim Theater und wurde mitunter auch in Filmen mit politischen Inhalten beschäftigt (zum Beispiel »Wetterleuchten um Barbara«, "Heimkehr«). Er hatte beim Publikum jedoch kein starkes »Polit-Image « ${ }^{335}$. Auch Jelineks Figur Istvan behauptet wiederholte Male von sich selbst, »nur ein Komödiant ${ }^{336}$ zu sein und verweist damit auf ihre vermeintlich unpolitische Haltung. ${ }^{337}$

Die Entnazifizierung nach dem Krieg konzentrierte sich im Falle von Attila Hörbiger auf dessen Mitwirkung in Ucickys »Heimkehr«-Film. Der mit dem Fall befasste Untersuchungsausschuss stellte dazu I 947 fest, dass es Filmschaffenden zu jener Zeit nicht möglich gewesen sei, sich derartigen Aufgaben zu entziehen. ${ }^{338}$ Diese These der Pflichterfüllung treffe für die Filmbranche jedoch keineswegs zu, so Rathkolb: Wenn es auch Besetzungslisten mit unterschiedlicher Besetzungsbewertung gegeben habe, so sei doch kein Schauspieler gegen seinen Willen zu einer Rolle gezwungen worden. ${ }^{339}$

Attila Hörbigers widersprüchliches Verhalten während der Jahre der NS-Herrschaft lässt auf jeden Fall den Schluss der politischen Insensibilität zu, da er sein Filmrollenverhalten an die jeweils dominierenden politischen Strömungen anpasste, sich dabei aber letztlich mit ideologischen Fragen nicht wirklich auseinandergesetzt zu haben scheint. ${ }^{340}$

Im Sommer I945 durfte Attila Hörbiger wieder Theater spielen und übernahm die Rolle des »Jedermann" im Landestheater Innsbruck. ${ }^{341}$ Spätestens 1948, mit dem Engagement von Paula Wessely und Attila Hörbiger in dem Spielfilm »Der Engel mit der Posaune«, war den beiden Eheleuten alles "vergeben und vergessen ${ }^{342}$.

Vgl. Rathkolb, Führertreu und gottbegnadet, S. 24I f.

Ebd., S. 242.

BT, S. 132, S. 137 und S. 169.

Vgl. 3. I. 3. 2. dieser Studie.

So der Bescheid des Politischen Untersuchungsausschusses der Gewerkschaft der Angestellten der Freien Berufe, Sektion Film« vom 23. Januar 1947, zitiert nach: Rathkolb, Führertreu und gottbegnadet, S. 242.

Die Besetzungsliste reichte von Liste I (»müssen unter allen Umständen möglichst ohne jede zeitliche Vakanz im Film beschäftigt werden «) bis Liste IV (»ausdrücklich begründen, warum gerade dieser ... für diese bestimmte Rolle unabdingbar notwendig ist«). Vgl. ebd.

Vgl. ebd., S. 243.

Vgl. Hochholdinger-Reiterer, Amok, S. 43.

Löffler, Was habe ich gewußt, S. $90 \mathrm{f}$. 
Attilas älterer Bruder Paul, in Jelineks Stück unschwer in der Figur des schorsch wiederzufinden, war kein Mitglied der nsDap gewesen. Auch er hatte jedoch 1938 für die "Heimkehr Österreichs« ins Deutsche Reich geworben:

»Seit zwölf Jahren als Oesterreicher in Berlin lebend, ist für mich mit गJA zu stimmen eine klare und deutliche Angelegenheit, da ich ja nicht nur Zeuge des Verfalles in Deutschland war, sondern auch den fast unglaubhaften Wiederaufstieg miterleben durfte! ${ }^{343}$

Tatsächlich hatte Paul während der NS-Zeit beruflich mehr Erfolg als Attila. Goebbels soll von seinen Unterhaltungsqualitäten »restlos begeistert « ${ }^{344}$ gewesen sein. Zwischen 1933 und I945 wirkte Paul Hörbiger an 6r Filmen mit, davon an sechs mit politischen Inhalten. Ansonsten war er vor allem in Produktionen zu sehen, die sehr geschickt Unterhaltung mit Propaganda vermischten, zum Beispiel in dem Publikumserfolg »Wunschkonzert« von r 940. Paul Hörbiger galt daher nicht als »politischer« Darsteller im engeren Sinne. Allerdings wurde gerade in Kinostreifen wie »Wunschkonzert", die eigentlich dem Genre „Unterhaltungsfilm« zuzuordnen sind, die Frontwirklichkeit verharmlost und glorifiziert - denn »Optimismus gehört nun einmal zur Kriegsführung « ${ }^{345}$, wie Goebbels postulierte. ${ }^{346}$

Im April r 942 wurde Paul Hörbiger zum »Staatsschauspieler« ernannt. ${ }^{347}$ In der retrospektiven Eigendarstellung ${ }^{348}$ wandelte er sich danach zum Widerständigen - ein Bild, das Jelinek im »Burgtheater«-Stück anhand der Darstellung ihrer Figur schoRscH destruiert, denn dieser erschlägt gleichzeitig den ALPENкÖNIG, der als Verkörperung des Widerstands begriffen werden kann, und steckt ihm noch schnell zehntausend Taler zu - eine unmissverständliche Anspielung Jelineks auf die »Scheck-Affäre« Paul Hörbigers: Der Schauspieler wurde Ende Jänner I 945, wenige Monate vor Kriegsende, von der Gestapo verhaftet, weil er im November 1944 einen Scheck über zweitausend Reichsmark an seinen Freund Richard Patsch, Besitzer des Wiener »Café Kaisergarten« und Mitglied einer Widerstandsbewegung, übergeben hatte. Aufgrund seiner Unterschrift konnte Hörbiger mit Leichtigkeit von der Gestapo ausgeforscht werden. Der

343 Paul Hörbiger, zitiert nach: Steiner, Die verdrängten Jahre, S. 8 I.

344 Rathkolb, Führertreu und gottbegnadet, S. 244.

345 Goebbels, zitiert nach: Ebd., S. 245.

346 Ebd., S. $244 \mathrm{f}$.

347 Vgl. ebd., S. 245.

348 Paul Hörbiger verfasste in den I 97oer Jahren seine Memoiren mit dem Titel »Ich hab für euch gespielt«. 
Scheck mit der Unterschrift war für Goebbels »zu viel gewesen ${ }^{349}:$ Er strich Hörbiger von der Prominentenliste, der in Ungnade gefallene Schauspieler wurde in Folge wegen Hochverrats zum Tode verurteilt ${ }^{350}$, worauf im »Burgtheater «Stück mit folgender Bemerkung Kётнеs angespielt wird: „Unsaren Bruadan haben sie zum Tode verurteilt, die braune Brut. ${ }^{351}$ scHORSCH schließlich sei ein »beriehmter ... Widerstandskämpfer ${ }^{352}$. Der deutschsprachige Sender der BBC meldete sogar Paul Hörbigers Tod ${ }^{353}$ - dem Hörbiger-Biografen Markus zufolge eine gezielte Falschmeldung zur Demoralisierung jener Menschen, die Feindsender hörten. ${ }^{354}$ Auch auf die Falschmeldung im Radio wird im Text verwiesen, als KÄтнE ihren Schwager nach dessen Rückkehr aus der Haft erstaunt begrüßt: »Mir hom glaubt, du seist neilich erscht liquidiert wurn.« ${ }^{355}$

Tatsächlich ist der Gesinnungswandel des erfolgreichen NS-Staatsschauspielers Paul Hörbiger mehr als fragwürdig. I 944/45 war der Zusammenbruch des Regimes bereits voraussehbar. Das (nachvollziehbare) Unterschreiben eines Schecks könnte als plumper Versuch interpretiert werden, kurz vor Kriegsende noch schnell die Seiten zu wechseln, was Jelinek implizit unterstellt. Solche und ähnliche Schlussfolgerungen sind jedoch rein spekulativ. Auch im Falle von Paul Hörbiger kann und muss davon ausgegangen werden, dass er weder in die eine noch in die andere Richtung politisch orientiert war, sondern sich um der Karriere willen mit den jeweils gegebenen Verhältnissen arrangierte.

Auch ist es bezeichnend, dass Paula Wessely als erste Filmrolle nach dem Krieg die Figur der Jüdin Henriette Stein in der Verfilmung von Ernst Lothars Roman »Der Engel mit der Posaune« wählte. Der Film wurde zu einem der größten Publikumserfolge der Nachkriegszeit. Er erzählt das Schicksal der Klavierbauerfamilie Alt. Im Zentrum der Handlung steht die jüdische Ehefrau des Klavierbauern, die Selbstmord begeht, als die Gestapo sie verhaften will - ein symbolischer Akt, mit dem sich die Hauptdarstellerin, Paula Wessely "gewissermaßen selbst entnazifizierte ${ }^{356}$.

Mit diesem Hintergrund sind schließlich auch кётнеs inszenierte Bühnenselbstmorde in Jelineks »Burgtheater«-Stück erklärbar, das aus der nachträglichen Perspektive (in den frühen I 98 oer Jahren) verfasst wurde: Jelinek hat - mit unterstellter Absicht - Ereignisse sowie Film- und Theaterauftritte der Wessely/

349 Markus, Die Hörbigers, S. I79.

350 Vgl. ebd., S. $178 \mathrm{f}$.

35 I BT, S. 178.

352 BT, S. 178.

353 Vgl. Markus, Die Hörbigers, S. I 8 r.

354 Vgl. ebd.

355 BT, S. I79.

356 http://www.film.at/der_engel_mit_der_posaune (Zugriff am 5.3.20I I). 
Hörbigers aus der Nachkriegszeit in ihren Theatertext integriert. Die Absicht wird der Autorin hier insofern unterstellt, als dass davon ausgegangen werden kann, dass sie damit ihr literarisches Vorhaben unterstreichen wollte, Paula Wessely, die in dem Stück exemplarisch für viele andere Künstler des »Dritten Reichs« steht, nicht für ihre Teilnahme an dem Filmprojekt in der NS-Zeit, sondern die Verlogenheit und Scheinheiligkeit der Nachkriegszeit an den Pranger zu stellen. Die Rolle als Henriette Alt in »Der Engel mit der Posaune« hingegen kann durchaus als cineastische Reinwaschung Wesselys interpretiert werden, mit der das Thema der persönlichen Vergangenheitsbewältigung für die Schauspielerin (zumindest vordergründig) abgehakt war.

Auch der »Engel«-Film muss letzten Endes als tendenziös bezeichnet werden, da er die Schilderung der Kriegsjahre ausspart und den Nationalsozialismus - dem Opfermythos gemäß - »in einer fatalistischen Blickweise als eine Art Naturgewalt « darstellt, »die über Österreich hinweggefegt ist « ${ }^{357}$. Über den „Engel mit der Posaune « hinaus waren die Wessely/Hörbigers in den I 95 oer Jahren in vielen weiteren österreichischen Filmproduktionen, darunter zahlreichen Heimatfilmen, zu sehen, die jene heile Welt beschwörten, die nach Jelinek in Wirklichkeit die "Blut-und-Boden-Mythologie der Nazikunst ${ }^{358}$ weiterführten. Auch dies trug nicht gerade zur ehrlichen Konfrontation mit der NS-Vergangenheit im österreichischen Gedächtnis bei, ganz im Gegenteil: Das Trivialmedium Heimatfilm manifestierte in seiner scheinbaren Harmlosigkeit und Unschuldigkeit den österreichischen Opfermythos in den Köpfen der Menschen.

Ein interessantes Detail zu »Der Engel mit der Posaune« ist, wie in der Zeitschrift Spiegel (die in einer Ausgabe des Jahres I 948 von der Premiere des Films berichtete) nachgelesen werden kann, dass Paula Wessely die Verfilmung des Romans von Ernst Lothar, der nach dem »Anschluss« 1938 im amerikanischen Exil geweilt hatte, überhaupt erst angeregt haben soll:

»... Paula Wessely erhob sich und gab zu, daß sie beim Lesen des Buches auf die Idee gekommen sei, einen großartigen österreichischen Film danach zu drehen. Sie sagte das mit der natürlichen Herzlichkeit und herzlichen Natürlichkeit, die mehr als wienerisch, die ganz wesselysch ist. ${ }^{359}$

Damit ist eine "natürliche Herzlichkeit« und "herzliche Natürlichkeit» angesprochen, die Elfriede Jelinek negiert und in einer Stellungnahme zu Paula

357 Ebd.

358 Jelinek, zitiert nach: Hochholdinger-Reiterer, Amok, S. 5 I.

359 Der Spiegel, Nr. 35, I 948, I 948. Der Artikel kann online im Spiegel-Archiv abgerufen werden unter: http://www.spiegel.de/spiegel/print/d-444I 8970.html (Zugriff am 5.3.20 I I). 
Wessely offen angewidert als »Natürlichkeitsschleim « ${ }^{360}$ bezeichnete: ein in ihrem literarischen Werk rekurrenter Ausdruck, mit dem sie auf den sich unaufhaltbar (wie Schleim sich) ausbreitenden ubiquitären Faschismus aufmerksam machen will. ${ }^{361}$

»Der Engel mit der Posaune « wurde im Jahr I948 vom Publikum zum besten Film des Jahres gewählt. ${ }^{362}$ Die Uraufführung habe laut Spiegel-Bericht "ans Herz gegriffen « ${ }^{363}$, manche der eleganten Damen hätten sich die verlaufene Schminke aus dem Gesicht tupfen müssen. ${ }^{364}$ Die Darsteller - neben Paula Wessely waren auch Attila und Paul Hörbiger zu sehen, daneben andere Publikumslieblinge des deutschsprachigen Nachkriegsfilms (Helene Thimig, Maria Schell, Erni Mangold, Hedwig Bleibtreu, Hans Holt) ${ }^{365}$ - hätten sich zu einem Ensemble zusammengefunden, »wie es selten in so dichter Gemeinsamkeit gesehen worden ist ${ }^{366}$.

Jelineks »Burgtheater « ist ein Theaterstück, das offensichtlich und unverhohlen aus der Nachkriegsperspektive geschrieben wurde: Die »Images der Gegenwart ${ }^{367}$ wurden von der Autorin mit voller Absicht in die Textproduktion integriert, denn auch in diesem frühen Theatertext Jelineks geht es nicht darum, mit literarischen Mitteln historische Rekonstruktion zu betreiben, sondern vielmehr um die in sprachliche Ausweichmanöver verpackte Reflexion dieser Zeit.

Die von Jelinek in dieser Form gewählte Auseinandersetzung mit der Problematik der persönlichen Schuld Einzelner muss daher als legitim bezeichnet werden, denn bei all der Aufregung rund um die Uraufführung in Bonn ging es schließlich nie alleine um die Kritik an diesen österreichischen Publikumslieblingen, sondern vielmehr um die Frage, wie die Zweite Republik Österreich mit der Frage nach der persönlichen Involvierung von österreichischen Künstlern in das NS-Regime umging und -geht. Im konkreten Fall stellt sich vor allem die Frage nach persönlicher Verantwortlichkeit im Zusammenhang mit der Teilnahme an der nationalsozialistischen Kulturindustrie. Auf diese Frage gibt Jelineks »Burgtheater« eindeutige Antworten: »Das Stück destruiert den Mythos vom unpolitischen Künstler und denunziert seine Figuren nicht bloß als Mitläufer und Opportunisten, sondern als ideologische Vollstrecker des Holocaust. « ${ }^{368}$

360 Jelinek, zitiert nach: http://www.elfriedejelinek.com (Zugriff am 20.I I.2007).

36r Vgl. Kapitel r.6.2 dieser Studie.

362 Vgl. http://www.film.at/der_engel_mit_der_posaune (Zugriff am 5.3.20I I).

363 Der Spiegel, Nr. 35, I 948.

364 Vgl. ebd.

365 Vgl. http://www.film.at/der_engel_mit_der_posaune (Zugriff am 5.3.20 I I).

366 Der Spiegel, Nr. 35, I 948.

367 Annuß, Theater des Nachlebens, S. 64.

368 Janz, Elfriede Jelinek, S. 64. 
Schließlich ist es das Privileg der Schriftsteller, die Welt schauend und schreibend zu kommentieren und in diesem Sinne auch Gesellschaftskritik zu üben. Diese will nicht gefallen, sondern steht »im Dienste einer politischen Aussage ${ }^{369}$ und kann sich - wie im konkreten Fall - eben auch gegen Publikumslieblinge richten. Die in dem Stück angegriffenen Personen führten selbst ein öffentliches Leben und übten starke Vorbildfunktion für mindestens eine Generation von Österreichern aus. Gerade Paula Wessely - die Wessely - wird gerne als »österreichische Institution« oder »Vorzeigeösterreicherin« bezeichnet:

»Wenn Paula Wessely bei diversen Lesungen die österreichische Bundeshymne der Zweiten Republik vortrug, bedeutete dies mehr als nur eine Demonstration großer heimischer Sprechkunst. Sie selbst galt gleichermaßen als Paradeösterreicherin wie Vorzeigewienerin (ein Image, zu dem sie selbst durch ihre Rollenauswahl nicht wenig beigetragen hat).« ${ }^{370}$

Abgesehen von der Debatte um Jelineks Skandalstück ist die Involvierung der Schauspielerdynastie Wessely/Hörbiger in die NS-Propagandamaschinerie in der Zweiten Republik niemals öffentlich diskutiert worden. Trotz dieser konkreten Bezüge zu realen Persönlichkeiten können/müssen die Protagonisten des "Burgtheater «-Stücks - und dies ist kein Widerspruch - als exemplarische Figuren gelten, stehen sie doch für die Verstrickungen einer gesamten Künstlergeneration in den nationalsozialistischen Machtapparat. ${ }^{371}$ Werner Krauß, Marika Röck oder Leni Riefenstahl wären als Figuren in einem entsprechenden Jelinek-Stück ebenso wenig gut weggekommen. Jelinek wählte aber die Wessely/Hörbigers, weil es ihr vermutlich genau um jenen Österreich-Bezug ging, den sie über besagte Schauspielerfamilie herstellen konnte: die Potenzierung der Opferthese in Gestalt österreichischer Publikumslieblinge ${ }^{372}$, die aus beruflichem Opportunismus mit einem verbrecherischen Regime kooperierten, die Verknüpfung mit dem Mythos Burgtheater und die Destruktion der scheinbaren Idylle österreichischer Heimatfilme, über die der faschistische Sprachgebrauch aus dem Nationalsozialismus in die Zweite Republik transferiert und dort als Allgemeingut konserviert wurde:

»Schauspieler, österreichische Volksschauspieler ... sind wir alle, die wir uns - in größerem oder kleinerem Repertoire - dieser von Kultur und Ideologie gesättigten, kompro-

369 Fuchs/Jelinek, »Man steigt vorne hinein...«, S. 20. Vgl. auch Kapitel r.6. I dieser Studie.

370 Steiner, Die verdrängten Jahre, S. 9.

37 I Vgl. die ähnliche Einschätzung von Hochholdinger-Reiterer, Amok, S. 5 ०.

372 Vgl. ebd., S. 47. 
mittierten Sprache wie einer Suppe zur Kräftigung für die Mühen der Selbstdarstellung bedienen.... Sonst hat die Suppe immer geschmeckt; aber angesäuert, erbrochen und umgerührt wie bei Elfriede Jelinek schmeckt sie vielen nicht. « 373

\section{2 "Die Kinder der Toten«}

»Die Apokalypse, wenn es eine rgibt‘, war schon, und sie war und ist der Holocaust. ${ }^{374}$

\subsubsection{Zur verwendeten Sekundärliteratur}

»Während ihn [den Roman] Jelinek als ihr bestes und wichtigstes Werk bezeichnet, haben Kritik und Forschung das opus magnum wenig beachtet. ${ }^{375}$

Seit seinem Erscheinen im Jahr I 995 gilt der Roman »Die Kinder der Toten« als Elfriede Jelineks Opus Magnum. ${ }^{376}$ Die Autorin selbst hat ihn wiederholt als ihr bestes und wichtigstes Buch bezeichnet: „Es enthält alles, was ich sagen wollte«, so Jelinek. ${ }^{377}$ Gleichzeitig glaubt sie, dass »Die Kinder der Toten « nicht verstanden werde, weil in unserer Gesellschaft jenes spezifische Verständnis von Humor und Ironie fehle, das mit der Vernichtung und Vertreibung jüdischer Kunstschaffender im Nationalsozialismus »ausgestorben « ${ }^{378}$ sei.

Nahezu alle Sekundärautoren verweisen auf den hohen Stellenwert und die enorme Bedeutung des Romans innerhalb des Jelinek'schen Euvres. Dennoch belassen es die meisten bei diesem Hinweis.

Prinzipiell gibt es wenige Sekundärtexte, die sich dezidiert mit »Die Kinder der Toten« befassen oder sich gar an eine textnahe Interpretation heranwagen.

373 Lengauer, Jenseits vom Volk, S. $227 \mathrm{f}$.

374 Lücke, Elfriede Jelinek, S. 93.

375 Pontzen, Pietätlose Rezeption, S. 54 f.

376 Vgl. Mayer/Koberg, Ein Porträt, S. 207. Vgl. auch Pontzen, Pietätlose Rezeption, S. 54 f. Vgl. auch Just, Zeichenleichen, unpaginiert. Sehr bezeichnend in diesem Zusammenhang ist etwa der Einleitungssatz eines kurzen Aufsatzes von Ralf Schnell aus dem Jahr 20ro: Schnell schreibt, er halte Jelineks Roman »für eines der bedeutendsten Prosawerke deutscher Sprache im 20. Jahrhundert«. Schnell, Stoffwechselprozesse, S. I69.

377 profil, Nr. 42, 2004, S. I 25. Vgl. auch folgendes Interview: Venckute, Elfriede Jelinek im Zenit des Ruhms, online abrufbar unter: http://www.hagalil.com/archiv/98/I 2/jellinek.htm (Zugriff am i 7.6.201 I).

378 Jelinek, zitiert nach: Venckute, Elfriede Jelinek im Zenit des Ruhms, unpaginiert. 
Die wenigen vorliegenden Deutungsvarianten sind meist sehr kurz und allgemein gehalten. Im Feuilleton hatte der Roman sogleich den "geschäftsschädigenden Ruf der Unlesbarkeit « ${ }^{379}$ weg.

Von Seiten der germanistischen Forschung sind einige kleinere Beiträge vorhanden, die vor allem seit der Jahrtausendwende publiziert wurden. Zwar hatte Sylvia Mindlberger bereits 1996 im Rahmen ihrer in Salzburg approbierten Diplomarbeit die Konzeptuierung des »Heimat«-Begriffs in dem Roman hinterfragt, ihre Arbeit wurde jedoch nicht veröffentlicht. ${ }^{380}$

In Pia Jankes Dokumentationsband »Die Nestbeschmutzerin« aus dem Jahr 2002 findet Jelineks Opus Magnum interessanterweise gar keine Erwähnung auch nicht unter dem Kapitel »Rezeption«. Im »Werkverzeichnis ${ }^{381}$ des von Janke geleiteten Jelinek-Forschungszentrums ist immerhin eine Liste der Berichterstattung in den Printmedien vorzufinden.

Von Günther Scheidl liegt eine knapp zehnseitige Auseinandersetzung mit Jelineks Roman vor, die er im Rahmen seiner im Jahr 2003 publizierten Untersuchung über die »Entmythisierung der Zweiten Republik in der österreichischen Literatur von I 985 bis I 995 « $^{382}$ verfasst hatte. Scheidl riss dabei zwar einige interessante Fragen an, räumte aber abschließend ein, dass er insgesamt unter dem »Sprachwulst « ${ }^{383}$ des Buchs leide und sich letztlich frage, wozu der ganze Aufwand von der Autorin eigentlich betrieben werde. ${ }^{384}$ Bemerkenswert ist außerdem seine Einschätzung, dass die Wirklichkeit in Jelineks Texten »bloß als Steinbruch für das Spiel mit der Sprache ${ }^{385}$ diene und sich die Texte einer Bedeutungszuschreibung verweigern - eine Behauptung, die durch die im Folgenden angebotene Interpretation widerlegt werden kann.

In der Online-Zeitschrift TRAns veröffentlichte Klaus Kastberger 2005 einen kurzen Artikel mit dem Titel »Österreichische Endspiele: Die Toten kehren zurück « ${ }^{386}$. Kastberger wagt darin einen Vergleich zwischen Ödön von Horváths Theaterstück »Der jüngste Tag«, Hans Leberts »Wolfshaut«-Roman und Elfriede Jelineks »Die Kinder der Toten«. Die Werke der drei genannten Größen österreichischen Literaturschaffens seien deren unterschiedlicher his-

379 Mayer/Koberg, Ein Porträt, S. 207.

380 Mindlberger, Das Konzept »Heimat«. Die Arbeit beschäftigt sich mit den drei Texten »Die Liebhaberinnen«, »Oh Wildnis, oh Schutz vor ihr« und »Die Kinder der Toten«.

38I Janke, Werkverzeichnis, S. 5 I 6-520. Das Werkverzeichnis wird derzeit überarbeitet und soll in aktualisierter Auflage erscheinen.

382 Scheidl, Ein Land auf dem rechten Weg, S. I 49-I 59.

383 Ebd., S. I59.

384 Vgl. ebd.

385 Vgl. ebd., S. I 53.

386 Kastberger, Österreichische Endspiele, unpaginiert. 
torischer Positionierung zum Trotz »auf einer inhaltlichen und funktionalen Ebene vergleichbar ${ }^{387}$, resümiert Kastberger, und zwar weil in ihnen jeweils eine »Bilanz über Schuld und Unschuld « ${ }^{388}$ gezogen werde. ${ }^{389}$

Rainer Just reflektierte 2007 in einem ebenfalls sehr kurzen Aufsatz über das »Untote im Werk Elfriede Jelineks «. ${ }^{390}$ Just interpretiert das Untotenmotiv in Jelineks Werk als Ausdruck der Entfernung und Entfremdung von der Sprache (»Ein unheimliches Haus, dieses Haus der Sprache. Es spukt in seinen Zimmern. $\left.{ }^{391}\right)$. Zwar verweist er auf und zitiert immer wieder aus Jelineks Roman, bleibt bei seinen Ausführungen jedoch sehr allgemein. Ein Buch wie »Die Kinder der Toten« sei letztlich »ungenießbar«, man könne es nur »in kleinen Dosen zu sich nehmen, wie eine hochgiftige Medizin, die Heilung verspricht, aber nur um den Preis des Todes ${ }^{392}$. Konkret beruft er sich aber wiederholt auf die Nobel Lecture »Im Abseits«, in der Jelinek die Entfremdung der Autorinneninstanz von deren eigener Sprache thematisiert hatte. ${ }^{393}$ In Kombination mit anderen Sekundärtexten können aus Justs kurzem Beitrag durchaus einige Anregungen für den Umgang mit Jelineks Roman mitgenommen werden.

Verena Mayer und Roland Koberg widmeten in ihrem Autorinnenporträt Jelineks »Gespenstergeschichte ${ }^{394}$ ein etwa 20 -seitiges Kapitel, in welchem sie vor allem über Entstehungskontexte und Rezeption des Buchs berichten. Sie liefern darüber hinaus aber auch plausible Hinweise auf mögliche Prätexte des Romans, die sie nicht nur im Bereich der Literatur (Hans Leberts bereits genannter "Wolfshaut«-Roman), sondern auch in der Psychologie (Sigmund Freuds Aufsatz "Das Unheimliche«) und im Film verorten: So verweisen die beiden Biografen auf den Schwarz-Weiß-Gruselklassiker »Carnival of Souls» aus dem Jahr i 962, der die Autorin inspiriert haben soll. ${ }^{395}$

In ihrer "Einführung in das Werk ${ }^{396}$ aus dem Jahr 2008 unternahm die Jelinek-Spezialistin Bärbel Lücke den Versuch, Jelineks Roman auf knappen zehn Seiten sowohl inhaltlich wiederzugeben als auch dessen vielschichtiger Inter-

387 Ebd.

388 Ebd.

389 Die thematischen, aber auch konzeptuellen Relationen zwischen Jelineks »Die Kinder der Toten« und Leberts »Die Wolfshaut« werden im Rahmen der Textanalyse noch eingehend diskutiert werden. Just, Rainer: Zeichenleichen, unpaginiert.

39I Ebd.

392 Ebd.

393 Vgl. Kapitel r.6. I dieser Studie.

394 Mayer/Koberg, Ein Porträt, S. I 97-2 I 8.

395 Vgl. ebd., S. 200.

396 Lücke, Elfriede Jelinek, S. 9 I-ıoo. 
textualität nachzugehen; enstanden ist ein sehr dichter, komprimierter Text mit vielen Schachtelsätzen und vielen eingeschobenen direkten Zitaten; Inhaltsangabe und Interpretation wechseln einander ab. Tatsächlich sind Lückes Deutungsansätze, denen prinzipiell beizupflichten ist, nur mit viel Vorwissen gut nachvollziehbar; eine klarere Sprache und mehr Struktur wären meines Erachtens wünschenswert gewesen, um einen Lektüre- und Interpretationsvorschlag für einen so komplexen und ästhetisierten Roman wie »Die Kinder der Toten« für ein gewilltes Lesepublikum anzubieten. Zudem lässt es Lücke, und auch das muss leider kritisch angemerkt werden, an sprachlicher Sensibilität vermissen, wenn sie Jelinek unkommentiert als "Halbjüdin « ${ }^{397}$ bezeichnet, was der NS-Diktion und nicht der jüdischen Halacha entspricht. ${ }^{398}$

Sehr systematisch hingegen erscheint Alexandra Pontzens i 8-seitiger Aufsatz »Pietätlose Rezeption? «" ${ }^{399}$, der 2006 entstanden ist und Jelineks Umgang mit Literaturtraditionen in »Die Kinder der Toten« thematisiert. Pontzen konzentriert sich auf drei wesentliche Referenzsysteme des Buchs: zum einen auf die spezifischen Folien der Textorganisation (Oberflächenhandlung und Erzählinstanz), zum anderen auf Jelineks Bezüge zu Leberts »Wolfshaut«-Roman sowie auf die Frage, inwieweit und in welchen Formen Realien und Diskurse der Shoah in »Die Kinder der Toten« eine Rolle spielen. Zwar stellt Pontzen in ihrem Beitrag fest, dass die Lektüre des Romans "anstrengend ${ }^{400}$ sei und die Dekodierungsarbeit des Rezipienten, zumindest in Hinblick auf Jelineks Shoah-Referenzen, aufgrund der von Jelinek vorgenommenen Mehrfachkodierung "Zwangsläufig fehlschlagen « ${ }^{401}$ müsse; schließlich sei der »Kreis adäquater Leser ${ }^{402}$ klein oder in letzter Konsequenz gar nicht vorhanden. Dennoch schafft sie es - ohne auf inhaltliche Fragen näher einzugehen, sondern vielmehr Jelineks sprachliche Kunstgriffe zu fokussieren -, einen gelungenen ersten Einblick in die Strukturierung des Romans und einige seiner wesentlichen Intertexte $\mathrm{zu}$ bieten.

Aus dem Jahr 2008 stammt Moira Mertens' Magisterarbeit über die »Ästhetik der Untoten« in Jelineks Roman. ${ }^{403}$ Mertens weist darauf hin, dass eine

397 Ebd., S. 91.

398 Laut Halacha (dem rechtlichen Teil des Talmuds) ist derjenige Jude, der von einer jüdischen Mutter geboren wurde oder zum Judentum konvertiert ist. Zwischen »Voll-«, »Halb-« und »Vierteljuden« wird dabei nicht unterschieden.

399 Pontzen, Pietätlose Rezeption, S. 5 I-69.

400 Ebd., S. 54.

$40 \mathrm{I}$ Ebd., S. $55 \mathrm{f}$.

402 Ebd., S. 56.

403 Die an der Universität Berlin approbierte Abschlussarbeit wurde zwar bislang nicht veröffentlicht, ist aber über die Homepage des Jelinek-Forschungszentrums als pdf abrufbar. Mer- 
grundlegende, wissenschaftliche Erfassung des Buchs bislang nicht vorliege, weil die angerissenen Themen einfach zu überbordend seien, und räumt ein, auch mit ihrer Arbeit diese Leistung nicht erbringen zu können. Es muss allerdings festgestellt werden, dass Mertens eine äußerst engagierte Arbeit vorgelegt hat, die in ihren analytischen Teilen weitestgehend textimmanent orientiert ist und eine gute Basis für die Beschäftigung mit Jelineks Untotenmotiv darstellt.

Den Auftrag, Jelineks großen Roman für das Handbuch der Forschungsplattform in zehn knappen Spalten zusammenzufassen und zu analysieren, bewältigte Sabine Treude. Leider muss an dieser Stelle festgestellt werden, dass der Verweis auf den Opfermythos in ihrem Beitrag gänzlich fehlt. Zwar schreibt Treude von der »Verdrängung des Holocaust « und der »fehlenden Trauerarbeit in Österreich ${ }^{404}$, die in dem Roman thematisiert werden. Doch die nationale Selbstcharakterisierung als Opfer geht über das Phänomen der Verdrängung weit hinaus: Im Rahmen der Opferthese wird die Geschichte nicht nur verdrängt, sondern tatsächlich umgeschrieben. Wenigstens ein Hinweis auf den Opfermythos dürfte in einem Beitrag zu »Die Kinder der Toten« eigentlich nicht fehlen, dies wird im Laufe des folgenden Kapitels deutlich; bei einer Neuauflage des Lexikons sollte diese erinnerungsgeschichtliche Dimension unbedingt miteinbezogen werden.

Als Referenzliteratur, die für die folgende Textanalyse ergänzend verwendet wurde, muss auf Hans Leberts wichtigen »Wolfshaut«-Roman ${ }^{405}$ verwiesen werden, der im Rahmen dieser Studie sowohl als thematischer als auch als konzeptueller Prätext für Jelineks Roman begriffen wird, sowie auf Sigmund Freuds Aufsatz »Das Unheimliche ${ }^{406}$, auf den Mayer/Koberg (in einem Nebensatz auch Pontzen) hinweisen. In Jelineks Roman ist in der Tat eine große Übereinstimmung mit den grundlegenden Ideen, die Freud in diesem Aufsatz formuliert hatte, festzustellen.

Warum es tatsächlich nicht einfach ist, klare Handlungsstränge aus »Die Kinder der Toten « zu extrahieren, diese in intertextuelle Deutungszusammenhänge zu betten und auf diese Weise zu plausiblen Textinterpretationen zu gelangen, soll im Folgenden kurz diskutiert werden.

tens, Die Ästhetik der Untoten, online abrufbar unter: www.univie.ac.at/jelinetz (Zugriff am II.5.20I I). 


\subsubsection{Zur speziellen Rezeptionsproblematik des Romans}

»...kein Kritiker, auch der wohlgesinnteste nicht, versäumte den Hinweis, dass diese Lektüre Arbeit bedeute und der Inhalt des Buchs kaum wiederzugeben sei. ${ }^{407}$

Ebenso einhellig wie der Roman kurz nach seinem Erscheinen als Jelineks Hauptwerk anerkannt wurde, haftete ihm sogleich auch der Ruf der Unlesbarkeit an. Eine »nacherzählbare Geschichte« gebe es darin nicht, meinte etwa die Literaturkritikerin Iris Radisch in einer vernichtenden Buchbesprechung, immerhin aber einen "personalen Zusammenhang" der drei (untoten) Hauptfiguren. ${ }^{408}$ Ingesamt bedauerte sie die »mittelmäßigen Sprachspiele«, denen die Kraft und der Scharfsinn der Zerstörung fehle: "Null mal null bleibt null und das große österreichische Gesamtkunstwerk ein gigantisches Leerstück « ${ }^{409}$, so Radisch enttäuscht.

Sogar Sigrid Löffler - eine Jelinek bekanntlich wohlgesinnte Rezensentin befand, dass das Buch »sperrig und abweisend « und schließlich »verdammt schwer zu lesen« sei. Dem hartnäckigen Leser könne es allerdings auch »ungeahnte Entschlüsselungserlebnisse bescheren, so Löffler abschließend und verweist auf James Joyce' Roman »Finnegans Wake«, der ähnliche Rezeptionsprobleme bereithalte. $^{410}$

Günther Scheidl beschreibt Jelineks Roman als "gigantischen Monolog « ${ }^{411}$, in dem es keine Handlung im herkömmlichen Sinn gebe, zumindest aber gewisse Handlungsstränge ausgemacht werden können.

Auch Mertens kann mehrere Erzählstränge ausfindig machen, räumt aber gleichzeitig ein, dass diese ineinander verschlungen, abgebrochen, wiederholt und schließlich von zahlreichen Kommentaren eines multiperspektivischen $\mathrm{Au}$ torinnen-Ichs unterbrochen seien, was die Lektüre dementsprechend erschwere. ${ }^{412}$

Pontzen stellt fest, dass sich Jelineks Texte generell »nicht ausschließlich linear ${ }^{413}$ lesen lassen: Wer Büchern wie »Die Kinder der Toten« gerecht wer-

407 Mayer/Koberg, Ein Porträt, S. 207.

408 Radisch, Maxima Moralia, unpaginiert.

409 Ebd.

4IO Löffler, Am Eingang zur Unterwelt, S. I I.

4I I Scheidl, Ein Land auf dem rechten Weg, S. I 49. Zu der monologisierenden Erzählinstanz vgl. Kapitel 3.2.5 dieser Studie.

4I 2 Vgl. Mertens, Untote, S. 4.

4I 3 Pontzen, Pietätlose Rezeption, S. 53. 
den wolle, sei zum intertextuellen Lesen gezwungen, das seinerseits auch wieder durch Jelineks spezifische Verfahren erschwert werde:

»Schon dieses Diktat zum >Lesen mit Bleistift $<$ provoziert bei vielen, auch professionellen, Lesern Abwehr. Zudem reicht die Vertrautheit mit einem literarischen `Kanon nicht aus: Jelinek referiert nicht auf einen Hypotext oder mehrere, die miteinander kompatibel wären, sondern auf viele disparate Hypotexte unterschiedlicher Provenienz, Wertung und Ideologie, von Kanon bis Pop. ${ }^{414}$

Die Kritik zeige sich schließlich der einhelligen Meinung, dass der Roman keine nacherzählbare Fabel habe. ${ }^{415}$ Und das hat er - im herkömmlichen Sinne - tatsächlich nicht, auch wenn ein ungefähres Handlungsgerüst auszumachen ist. Wer die Lektüre von »Die Kinder der Toten« dennoch bewältigen will, muss daher die eigene Erwartungshaltung an den Text hinterfragen und gegebenenfalls korrigieren, denn auch der "professionelle Leser « muss sich letztlich damit zufriedengeben, dass viele der Intertexte nur assoziativ rezipiert werden können und auch das Plot nicht immer eindeutig herausgelesen werden kann.

Diese Problematik ist auch an den vorhandenen Unsicherheiten in der Sekundärliteratur erkennbar. Als Beispiel seien hier die divergierenden Todesarten einer der untoten Hauptfiguren, KARIN FRENZEL, genannt, die bei Pontzen und Lücke angeboten werden: Bei Pontzen wird Frenzel bei einem Busunglück lebensgefährlich verletzt, liegt hernach im Koma, versinkt in einem Wildbach und erliegt schließlich ihren Verletzungen. Bei Lücke kommt FrENZEL bereits bei dem Busunfall ums Leben, stürzt »aber vielleicht doch« in den Wildbach, wie die Autorin einräumt. ${ }^{416}$ So paradox es erscheinen mag: Beide Autorinnen haben irgendwie Recht. Jelineks offen-assoziative Schreibweise lässt tatsächlich beide Interpretationen $\mathrm{zu}$, wobei an dieser Stelle darauf hingewiesen werden muss, dass kein konkreter Hinweis darauf gefunden werden konnte, dass K A R IN FRENZEL nach dem Verkehrsunfall ins Koma fällt. Lücke versäumt außerdem die Erwähnung, dass es vermutlich eine Art Verdoppelungsfigur ist, die den »anderen« Tod stirbt.

Jelineks Roman lebt - noch mehr als jeder andere Jelinek-Text - von Andeutungen, Assoziationen, Kalauern und Vergleichen, wird von sprachlichen sowie inhaltlichen Sprüngen, Brüchen und Schnitten bestimmt. ${ }^{417}$ Was sich an Handlung ereignet, ereignet sich nicht im Sinne von Spannungsaufbau oder

\footnotetext{
4I 4 Ebd., S. 53 f.

4I 5 Vgl. ebd., S. 55. Vgl. dazu Kapitel 3.2.I dieser Studie.

4 I6 Vgl. Lücke, Elfriede Jelinek, S. 98.

4I 7 Vgl. Mayer/Koberg, Ein Porträt, S. 202.
} 
Figurenpsychologie, sondern jeweils als unmittelbare sprachliche Reaktion auf das zuvor Geäußerte:

»Ein Satz scheint den vorigen zu verdrängen, ein Prozess des sprachlichen Überlagerns und Überschüttens bestimmt das Buch.« ${ }^{418}$

Insofern muss Scheidl beigepflichtet werden: Der Roman ist tatsächlich ein "gigantischer Monolog ${ }^{419}$ der Autorinneninstanz, die sich von einem Satz zum nächsten tragen lässt und die eigentliche Hauptrolle spielt.

Auf diese Form von nicht linear lesbarer, auch sprachlich letztlich nicht fassbarer Literatur muss der Leser sich also einlassen, wenn er der angeblichen »Unlesbarkeit ${ }^{420}$ des Romans nicht unterliegen will. Wer sich statt mit der Hoffnung auf das "große österreichische Gesamtkunstwerk " ${ }^{421}$ mit analytischem Interesse und profundem Basiswissen über Jelineks ästhetische Verfahren dem Roman nähert, wird nicht enttäuscht werden. Zum reinen Lesevergnügen kann freilich nicht darauf zurückgegriffen werden.

An den genannten Ungenauigkeiten, die auch in Sekundärtexten profunder Jelinek-Kennerinnen bestehen, kann abgelesen werden, dass es tatsächlich schwierig ist, klare Handlungsstränge aus »Die Kinder der Toten« herauszufiltern und zu plausiblen Textinterpretationen zu gelangen. Es kann daher nur die Aufgabe jeder weiteren (und auch der hier angebotenen) Deutungsvariante sein, mehr Klarheit zu schaffen und Jelineks Roman, dem der Ruf der Unlesbarkeit anhaftet, für gewillte Leser zugänglicher zu machen.

In der folgenden Analyse soll daher versucht werden, so präzise und eindeutig wie möglich in Handlungsgerüst und Strukturen des Romans einzuführen, dabei aber die von der Autorin gesetzten Leerstellen zu respektieren, um auf diese Weise eine Interpretation zu erhalten, die textnahe und gleichzeitig nachvollziehbar ist.

Zu diesem Zweck wird zunächst der formale Rahmen abgesteckt, in welchem der Roman situiert ist. Um in Aufbau und Strukturierung einzuführen, werden in einem weiteren Schritt die wichtigsten Rückbezüge auf wahrscheinliche Prätexte geschildert. Damit ist die Komplexität des Romans jedoch noch nicht annähernd erfasst. Um in weiterer Folge zu verdeutlichen, welche Alltags- und Trivialmythen in »Die Kinder der Toten« als rekurrente Textbausteine aufgegriffen werden und mit welchen Mitteln die Autorin den Zusammenhang dieser

4I 8 Ebd.

4I 9 Scheidl, Ein Land auf dem rechten Weg, S. I 49.

420 Mayer/Koberg, Ein Porträt, S. 207.

42 I Radisch, Maxima Moralia, unpaginiert. 
Mythen untereinander, aber auch den Konnex zum österreichen Gedächtnis darstellt, soll in einem dritten Schritt eine detailliertere und mehr textimmanente Auseinandersetzung erfolgen, die Bezüge zu den im theoretischen Teil dieser Studie dargelegten Faschismus- und Mythostheorien herstellt. Dazu wurden einige der wichtigsten Mythendestruktionen aus "Die Kinder der Toten« exemplarisch zur Textanalyse ausgewählt. Diese werden in einzelnen Unterkapiteln jeweils kurz aufgegriffen und auf künstliche Weise »isoliert«: Das heißt, sie werden hier bewusst als Einzelereignisse dargestellt, um sie besser erfassen und weiters ihren Stellenwert im Text besser verstehen zu können. Bei der Lektüre stellen sich diese (hier künstlich isolierten) Einzelereignisse natürlich als ein ineinander verwobenenes, großes Ganzes dar. Für das Lektüreverständnis ist es jedoch hilfreich, sich schrittweise dem komplexen, großen Ganzen anzunähern; daher zunächst also zu den Einzelkomponenten.

\subsubsection{Formales, Setting und Plot}

»Dieser Text kommt über einen wie die Mure, und vielleicht verschüttet er seine Leser. ${ }^{422}$

Jelineks r 995 bei Rowohlt erschienener Roman umfasst 666 Seiten und einen Absatz - angeblich hatte der Verlag Probleme damit gehabt, die von der Autorin gewünschten, auf die Apokalypse verweisenden 666 Seiten typografisch umzusetzen und so blieb am Ende ein Absatz auf einer nicht paginierten Seite 667 übrig. ${ }^{423}$ Ein Prolog und ein Epilog umschließen 35 deutlich voneinander abgegrenzte, aber nicht nummerierte Kapitel, die durch neue Seiten sowie durch fettgedruckte Anfänge des jeweils ersten Satzes ausgewiesen sind. ${ }^{424}$

Dem Roman ist eine Schriftrollenskizze vorangestellt, auf der drei gefaltete Schriftbänder mit einem Satz in hebräischer Schrift zu sehen sind. In der gebundenen Originalausgabe des Buchs ist dessen Übersetzung ins Deutsche auf der Rückseite vorzufinden:

„Die Geister der Toten, die solang verschwunden waren, sollen kommen und ihre Kinder begrüßen. ${ }^{425}$

422 Lücke, Elfriede Jelinek, S. 93.

423 Vgl. Mayer/Koberg, Ein Porträt, S. 206.

424 Vgl. Lücke, Elfriede Jelinek, S. 95. Vgl. auch Janke, Werkverzeichnis, S. 59.

425 KDT, S. 6. Vgl. auch Mayer/Koberg, Ein Porträt, S. 206. Vgl. auch Lücke, Elfriede Jelinek, S. 95 . 
Treudes Recherchen zufolge stammt dieser Spruch von Jelinek selbst. Einer jüdischen Mesusa gleich, die am Türpfosten angebracht ist, um das Haus zu schützen, sollte er Jelineks Roman schützen - wovor genau, dürfte nicht bekannt sein. ${ }^{426}$ Die Schriftrolle weist aber bereits den Weg zum Titel des Romans. In der Taschenbuchausgabe wurde auf die durchaus erhellende Übersetzung ins Deutsche leider verzichtet.

Was an Plot aus »Die Kinder der Toten« extrahiert werden kann, lässt sich wie folgt zusammenfassen: Situiert ist der Roman in einem steirischen Bergdorf und dessen näherer Umgebung ${ }^{427}$, einem »Wildalpengebiet mit seinen Seen und ... [einem] Schlößchen des Erzherzogs der Habsburger « ${ }^{428}$. In einem Prolog wird von einer nicht näher definierten Erzählinstanz ${ }^{429}$ die Vorgeschichte einer Protagonistin erzählt: In der »Pension Alpenrose« werden sieben Gäste von einem Chrysler Voyager für einen Ausflug abgeholt, dessen Chauffeur »gemäß der Landessitte ${ }^{430}$ leicht angetrunken ist. Mit überhöhter Geschwindigkeit fährt der überfüllte Wagen eine schmale Serpentinen-Straße entlang und kollidiert mit einem holländischen Reisebus. Vier der Insassen sind sofort tot, auch K A R IN FRENZEL kommt bei dem Unglück ums Leben - jedenfalls dem Anschein nach, denn die pensionierte Sekretärin und »ewige Tochter « ${ }^{431}$, die ein Leben lang das "Herrschaftsobjekt ihrer tyrannischen Mutter ${ }^{432}$ gewesen ist, kann/darf noch nicht sterben: Sie soll als Untote das im Leben Versäumte nachholen. ${ }^{433}$

KARIN FRENZEL kehrt in die "Pension Alpenrose« zurück, wo sich bereits andere Untote eingefunden haben, die als "Licht- und Schattenflecken « ${ }^{434}$ durch die Räumlichkeiten huschen, darunter die Philosophiestudentin GUDRUN BICHLER, die sich wegen des universitären Leistungsdrucks in der Badewanne die Pulsadern aufgeschnitten hat und jetzt einem ebenfalls untoten Jüngling hinterherlechzt, der sich mit Gas vergiftet hat, sowie EDGAR GSTRANZ, gewesene Sportskanone und ehemaliger B-Kaderläufer im österreichischen Skiteam, der wie KARIN FRENZEL bei einem Autounfall ums Leben gekommen ist.

\footnotetext{
426 Vgl. Treude, Die Kinder der Toten, S. I I 4.

427 Explizit ausgewiesen, etwa auf S. 48:»... seien wir in der Steiermark! Dort wollen wir gefunden werden.« Oder auch auf S. 59: "In der Steiermark scheint es einen Ort zu geben, der Träger des Realen ist...«.

428 KDT, S. 8.

429 Zur Erzählinstanz vgl. 3.2. 5. dieser Studie.

430 KDT, S. 9 .

43 I KDT, S. 236.

432 Scheidl, Ein Land auf dem rechten Weg, S. I 49.

433 Vgl. ebd. Ähnlichkeiten zwischen KARIN FRENZEL und ER I к конит aus »Die Klavierspielerin« drängen sich auf, vgl. dazu Kapitel I.5 dieser Studie.

434 KDT, S. 57 .
} 
Abb. 1: Mesusa

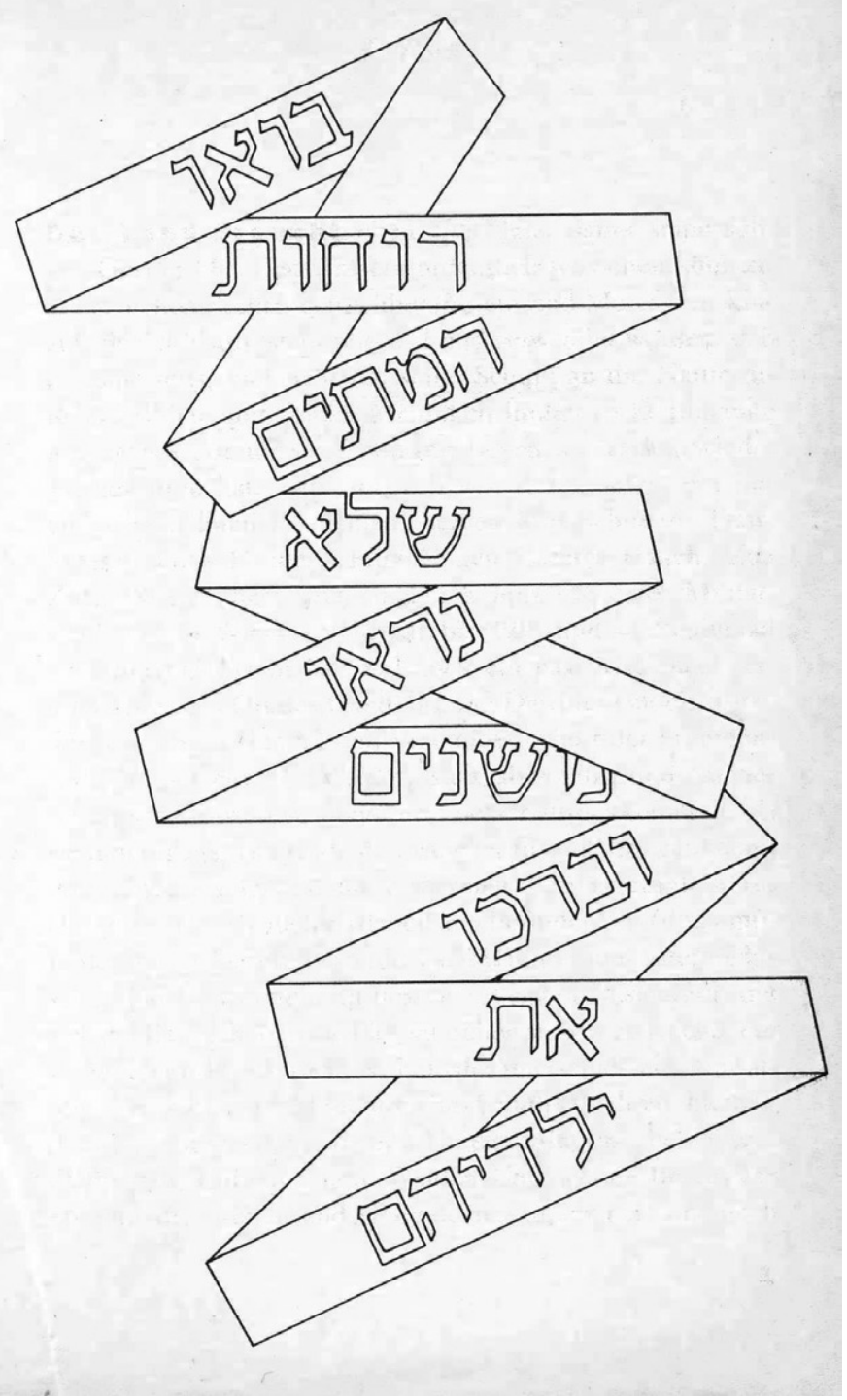


EDGAR ist dazu verdammt, sein Leben im Tod ständig zu wiederholen (»Wiederholungszwang ${ }^{435}$ ) und so rast er unaufhörlich auf Rasenrollbrettern - eine Variation der Alpinski - die Abhänge der Alpen hinab. ${ }^{436}$ In immer wiederkehrenden Nebenrollen erklimmen drei untote Wanderer die Gipfel der obersteirischen Berge und fristen zwei Förstersöhne, die sich mit dem Gewehr die Köpfe »davongeblasen ${ }^{437}$ haben, ihr untotes Dasein in der Pension bzw. deren gebirgiger Umgebung.

Die drei untoten Hauptfiguren, KARIN FRENZEL, EDGAR gSTRANZ und GUDRUN BICHLER werden von der Erzählinstanz in voyeuristischer Manier beobachtet, beobachten aber auch ihrerseits: andere Untote, aber auch Lebende sowie Verdoppelungen und Abspaltungen ihrer selbst - »die Blicke werden hier vervielfältigt ${ }^{438}$.

Sie morden und begehen kannibalische und vampirische Akte. Sie kopulieren und masturbieren und treiben angestrengt Sport (vor allem EDGAR). Gleichzeitig fungieren sie als Mittler zwischen den Daseinsformen, denn aus ihnen heraus können sich andere Tote aus der Erde erheben: So wird EDGA im Text als »Tür « ${ }^{439}$ bezeichnet, als "Zwischenlager für etwas, das da noch kommen wird, um endgültig den Tod in die Welt einzuführen « ${ }^{440}$. KARIN, die untote Pensionistin, gewinnt ihre Fruchtbarkeit zurück und gebiert im Innenraum eines BMW einen »Fleischklumpen ${ }^{441}$ aus Toten, bevor sie sich in einem geisterhaften Ritual von der alles dominierenden Mutter befreit. GUDRUN wiederum ist eine »Totensammlerin ${ }^{442}$, erlebt während einer Zeitreise, die sie um fünfzig Jahre zurückversetzt, eine sexuelle Episode mit einem jungen Mann, der auch EDGAR ist oder wenigstens so heißt (das will die Erzählinstanz »ein für allemal bestimmt ${ }^{443}$ haben), reanimiert einen im Schwimmbad ertrunkenen Jungen, wird als Lainzer Krankenschwester von einem pickelgesichtigen Lehrling erstochen und in einer weiteren Rolle als Mannequinschülerin gleich noch einmal ermordet - ein "paradox-exzessiver >Potlatsch des Todes und der Toten $^{444}$.

Parallel und überschneidend zu diesem exemplarischen Handlungsstrang der drei untoten Hauptfiguren erheben sich in immer größer werdender Zahl ano-

435 KDT, S. I 89.

436 Vgl. Scheidl, Ein Land auf dem rechten Weg, S. I49.

437 KDT, S. 26.

438 Lücke, Elfriede Jelinek, S. 97.

439 KDT, S. 200.

440 KDT, S. 205.

44I KDT, S. 336.

442 KDT, S. 24I.

443 KDT, S. I69.

444 Lücke, Elfriede Jelinek, S. 98. 
nyme Tote aus der Erde und schließen sich mit den Wassermassen anhaltender starker Regenfälle zu »einem einzigen Lebensborn-Brei « ${ }^{445}$ zusammen, der nach und nach die Landschaft flutet. Dabei wird im Lauf des Romans durch immer eindeutigere Andeutungen klar, welche Toten konkret gemeint sind, nämlich jene, die im rasenden Feuer der »Hochleistungsöfen « ${ }^{446}$ verbrannt wurden - unmissverständlich eine Anspielung auf die Millionen Ermordeten des Holocaust.

KARIN findet sich immer wieder am Rande eines rissigen Betonbeckens wieder, in dem "metallenes Wasser ${ }^{447}$ steht, das sie - Vampir-Mythen entsprechend - nicht widerspiegelt. Eine Verdoppelung ihrer selbst ist in den Wildbach gestürzt und befindet sich bereits in dem Becken (nach Lücke das »Reich der Untoten $\left.{ }^{448}\right)$.

Das unheimliche Betonbecken weist zum Ende des Romans hin immer mehr Risse und Sprünge auf und kann seinen Inhalt schließlich nicht mehr halten: Als sich erstmals alle drei Protagonisten gleichzeitig in der "Pension Alpenrose« befinden, gibt es einen »Wasserfall ${ }^{449}$ aus Leichen frei, der die Pension verschüttet. Alle Gäste und Bewohner des Hauses kommen bei dem Unglück ums Leben.

In einem Epilog schaltet sich die Erzählinstanz ein und reflektiert - scheinbar vernünfig berichtend - über das Geschehene. Sie weist darauf hin, dass bei den tagelangen Bergungsarbeiten nach der Katastrophe etwas Unerklärliches gefunden worden sei:

»Haar. Menschliches Haar. ... Nur: Es ist einfach zuviel Haar da für die geschätzte Anzahl der Verschütteten. ... das Haar von etwa zweihundert Menschen ist bereits gefunden worden, obwohl sich nur ein Bruchteil dieser Zahl hier aufgehalten haben kann...« ${ }^{450}$

Außerdem stehe in einem geheimen Protokoll, dass in dem verschütteten Haus viele Tote gefunden worden seien, die »nach dem übereinstimmenden Urteil der

445 KDT, S. 533. Der I 935 gegründete SS-»Lebensborn e. V.« war ein staatlicher geförderter, nationalsozialistischer Verein, der durch anonyme Entbindungen und Adoptionen die Geburtenrate von "arischen« Kindern aus ehelichen wie auch aus außerehelichen Verbindungen erhöhen sollte. In Fortführung des »Heiratsbefehls« von 1932 trug die Satzung des Vereins jedem Mann auf, mindestens vier Kinder zu zeugen, die in abgeschirmten Heimen geboren werden sollten und für die ggf. Adoptiveltern gesucht wurden. Lebensborn soll außerdem für die Verschleppung von Kindern aus den besetzten Gebieten verantwortlich zeichnen. Vgl. Studt, Das Dritte Reich in Daten, S. 57.

446 KDT, S. 201.

447 KDT, S. 98.

448 Vgl. Lücke, Elfriede Jelinek, S. 98.

449 KDT, S. 434.

$45^{\circ}$ KDT, S. $66_{5}$. 
Pathologen « ${ }^{451}$ bereits seit längerem tot gewesen sein müssen, zum Teil bereits sehr lange Zeit, bevor die Mure sie verschüttet habe. Aber: „Nana, man sollte nichts derart Unüberlegtes sagen! « ${ }^{452}$

Der Prozess des sprachlichen Überlagerns und Überschüttens, in dem ein Satz vom nächsten gejagt und verdrängt wird, widerspiegelt - soviel sei der Interpretation vorweggenommen - das große Thema des Romans: Verdrängung. ${ }^{453}$ Exemplarisch für ein Land, das über Jahre hinweg die präzedenzlosen NS-Menschenvernichtungsprogramme mitgetragen und sich hernach selbst zum Opfer erklärt hat, wird der Ort des Schauspiels im Finale des Buchs von der Vergangenheit eingeholt und selbst vernichtet.

\subsubsection{Referenzen und Intertexte}

» Jelinek referiert nicht auf einen Hypotext oder mehrere, die miteinander kompatibel wären, sondern auf viele disparate Hypotexte .... ${ }^{454}$

Das Opus Magnum Jelineks, einer Meisterin des intertextuellen Schreibens, weist erwartungsgemäß eine reiche Fülle an Andeutungen und Bezugnahmen auf andere Texte auf. Neben "vagen literarischen Verwandschaften « zu Friederike Mayröcker oder Ingeborg Bachmann können auch konkrete Hinweise und Bezugnahmen auf Autoren der so genannten »Antifaschistische[n] Literatur der Nachkriegszeit ${ }^{455}$ ausgemacht werden: beispielsweise auf Thomas Bernhard (»Die Billigesser nehmen eine lange Wanderung auf sich, um ihre Genußscheine vorzeigen $z u$ können... ${ }^{456}$ ), Ilse Aichinger (»Jetzt werden Sie Zeuge, wie unten, beim Kai, am Donaukanal, der Transporter mit Ilses Großmutter ... um die Kurve biegt und verschwindet... ${ }^{457}$ ) oder Gerhard Fritsch (»... unseren Opfern wird so eine Art Aussehen verliehen, dazu ein Faschingsorden, breites Lachen dröhnt durch die Täler, wenn die Gilde über Politiker Witze reißt und sich damit selbst mitsamt diesem Unkraut zusammentritt. ${ }^{458}$ ). Auch Fritsch kritisierte die verlogene Sprachverwendung, mit der Österreichs Opferthese in der Nachkriegszeit etabliert wurde:

45 I KDT, S. 666.

452 KDT, S. 666.

453 Vgl. Mayer/Koberg, Ein Porträt, S. 202.

454 Pontzen, Pietätlose Rezeption, S. $53 \mathrm{f}$.

455 Scheidl, Ein Land auf dem rechten Weg, S. I 53.

456 KDT, S. 2 I 8.

457 KDT, S. 397.

458 KDT, S. 469 . 
»Die Vergangenheit besteht aus Phrasen und Legenden. Oder wird sie gleich in Bausch und Bogen gefälscht, geleugnet, weggelogen. ${ }^{459}$

Des Weiteren finden sich in Jelineks Roman unzählige intertextuelle Anspielungen auf Werbespots, Musikverse aus dem Austropop, aus Volksliedern, der Bundeshymne, Moderationen von Radio-/TV-Sportübertragungen sowie auf Aussagen zeitgenössischer Politiker wieder.

Mayer/Koberg verweisen darüber hinaus auf den Schwarz-Weiß-Gruselklassiker "Carnival of Souls« aus dem Jahr 1962, den sie als einen von Jelineks Lieblingsfilmen bezeichnen. ${ }^{460}$ Das Plot des Films erinnert tatsächlich mitunter an einzelne Komponenten des Romans:

Drei junge Frauen lassen sich aus Übermut auf ein Autorennen ein. Ihr Fahrzeug kommt auf einer schmalen Brücke von der Straße ab und stürzt in einen Fluss. Die junge Organistin M ARY scheint als einzige überlebt zu haben: Stunden nach dem Unfall klettert sie scheinbar unversehrt aus dem Flussbecken. Das Auto liegt am Grunde des Flusses und kann vorerst nicht geborgen werden. MARY verlässt die Stadt, sie hat anderswo ein Engagement als Organistin einer Kirche bekommen. Die junge Frau verhält sich aber merkwürdig: Sie wirkt geistesabwesend und geht auf Distanz zu ihren Mitmenschen. Der Grund dafür ist, dass sie immer wieder von unheimlichen Gestalten verfolgt wird und sich in beängstigenden Entrückungszuständen wiederfindet, in denen sie versucht, auf sich aufmerksam zu machen; sie wird aber von ihrer Umgebung weder gehört noch gesehen. Im Nachhinein ist es so, als ob nichts geschehen wäre und sie sich bloß alles eingebildet hätte. Dadurch wird MARY immer verschreckter und abweisender, ihre Umgebung hält sie für hysterisch. Der jungen Frau aber wird die Welt der Lebenden zunehmend fremd. Ein verfallender Vergnügungs-Pavillon in der Nähe der Stadt hingegen strahlt magische Anziehungskraft auf sie aus: Dort scheint das Reich der lebenden Toten, der »Untoten«, zu sein, die MARY zu sich rufen. Warum diese im Pavillon weilen und ein Untoten-Dasein fristen, wird nicht aufgeklärt. Nach glücklosen Versuchen, ihrem Schicksal zu entkommen, gibt MARY dem Ruf der unheimlichen Gestalten nach und folgt ihnen in den Pavillon. Polizei und Bürger der Stadt rätseln über ihr Verschwinden. Wenig später wird das verunglückte Auto aus dem Fluss geborgen: Nicht

459 So Fritsch in seinem (Leopold Figl auf den Leib geschriebenen) Prosatext »Ein Minister meditiert« von 1963. Vgl. dazu: Zobl, Leben und Werk von Gerhard Fritsch, S. 39.

460 Vgl. Mayer/Koberg, Ein Porträt, S. 200. Die Autoren belegen ihre Behauptung nicht, vermutlich beziehen sie ihre Information entweder aus persönlichen Gesprächen mit der Porträtierten oder aus deren auf der Homepage befindlichen Essay zum Film: http://elfriedejelinek. com (Link »zum Kino«) (Zugriff am 20.6.20 I I). »Carnival of Souls« ist inzwischen coloriert und von Savoy Film auf DVD erhältlich. 
nur die beiden anderen Frauen waren bei dem Unfall ums Leben gekommen, sondern auch MARY - so die nicht ganz überraschende, aber dennoch gruselige Pointe des Films.

Wenn auch gewisse Parallelen im Handlungsgeschehen und der Motivwahl auszumachen sind (zum Beispiel der verhängnisvolle Autounfall am Beginn des Films und am Beginn des Buchs, der Pavillon im Film und das Betonbecken mit dem metallenen Wasser im Buch als Heimstätte der lebenden Toten/Untoten), so muss doch festgestellt werden, dass »Carnival of Souls« dem Gruselgenre verhaftet bleibt und, anders als »Die Kinder der Toten«, keine tiefgründige Botschaft für sich in Anspruch nehmen kann. Film und Roman haben vor allem atmosphärische Ähnlichkeiten.

Neben der möglichen Inspiration durch "Carnival of Souls« weist der Roman jedoch einige recht unverhohlene Bezüge zu Prätexten aus dem Bereich der Literatur bzw. verwandten Bereichen auf. Aus dieser Vielzahl an möglichen Bezügen sollen im folgenden Kapitel die beiden als wesentlich erachteten besprochen werden: zum einen Sigmund Freuds Aufsatz "Das Unheimliche« und zum anderen Hans Leberts Roman »Die Wolfshaut«.

Die Autorin habe mit »Die Kinder der Toten« Freuds Aufsatz literarisch umgesetzt, schreiben Mayer/Koberg. ${ }^{461}$ Tatsächlich können viele der Ausführungen Freuds in Jelineks Roman sehr direkt wiedergefunden werden. Selbst wenn dieser Bezug von der Autorin nicht intendiert gewesen sein sollte, was unwahrscheinlich erscheint, so erhellt er doch in nicht unerheblichem Maße das Textverständnis, weshalb in einem ersten Teil des folgenden Kapitels zunächst auf den Begriff des »Unheimlichen« nach Freud eingegangen wird.

Des Weiteren wurde bereits Jelineks (sehr offenkundige) Referenz auf Hans Leberts »Wolfshaut«-Roman erwähnt. Dieser wird in der Sekundärliteratur recht einvernehmlich als einer der wichtigsten Intertexte von »Die Kinder der Toten« gehandelt. Daher wird auch diese Relation in einem zweiten Teil des Kapitels in ihren thematischen und konzeptuellen Dimensionen erörtert.

46 I Mayer/Koberg, Ein Porträt, S. 204. 
3.2.3.1 Die Untoten: Freuds "Unheimliches"

"... das Unheimliche sei etwas, das im

Verborgenen hätte bleiben sollen und

hervorgetreten ist. ${ }^{462}$

Mit dem Eröffnungssatz von »Die Kinder der Toten« (»Das Land braucht oben viel Platz, damit seine seligen Geister über den Wassern ordentlich schweben können. ${ }^{463}$ ) spielt Jelinek auf das Goethe-Gedicht »Gesang der Geister über den Wassern« an:

„Des Menschen Seele

Gleicht dem Wasser:

Vom Himmel kommt es,

Zum Himmel steigt es,

Und wieder nieder

Zur Erde muß es,

Ewig wechselnd.

»Seele des Menschen,

Wie gleichst du dem Wasser!

Schicksal des Menschen,

Wie gleichst du dem Wind! ${ }^{464}$

Mit ihrer Referenz auf Goethe gibt Jelinek bereits das zentrale Motiv des Romans vor: die grenzenverwischende Darstellung von Leben und Tod. Die Autorin selbst bezeichnete ihr Buch in einem Interview als Gespensterroman in der Tradition der gothic novel ${ }^{465}$. Woher aber rührt diese Tradition?

Einer der "großen Toten ${ }^{466}$ dieses Landes, Sigmund Freud, hat im vergangenen Jahrhundert die Wurzel für das Gefühl des Unheimlichen in der Aufhebung der Trennlinie zwischen Leben und Tod erkannt und es in seinem Aufsatz »Das Unheimliche« beschrieben. ${ }^{467}$ Freud verwies dabei auf die Beziehung zwischen dem Wort »unheimlich« und dessen scheinbarem Antonym »heimlich, heimisch,

462 Freud, Das Unheimliche, S. 254.

463 KDT, S. 7 .

464 Goethe, Gedichte, S. 306 f.

465 Jelinek, zitiert nach: Grohotolsky, Provinz, S. 63.

466 Vgl. ähnliche Formulierungen in KDT, S. 7 sowie S. 4I.

467 Freud, Das Unheimliche, S. 229-268. 
vertraut ${ }^{468}$. Natürlich erscheine uns nicht alles unheimlich, was neuartig sei, so Freud, denn die terminologische Beziehung der beiden Wörter sei »nicht umkehrbar ${ }^{469}$. Etwas müsse erst hinzukommen, was das Unbekannte zum Unheimlichen mache. Den Bedeutungsvarianten des Wortes »heimlich« nachspürend, kommt Freud zu dem Schluss, dass »unheimlich irgendwie eine Art von heimlich ${ }^{470}$ sein müsse. In Wirklichkeit sei das Unheimliche als jene Art des Schreckhaften zu begreifen, welche auf das Altbekannte und Längstvertraute zurückgehe. ${ }^{471}$

Freud beruft sich in seinen Ausführungen wiederholt auf Ernst Jentsch, der I906 zuerst einen Artikel zur »Psychologie des Unheimlichen« veröffentlicht und darin gemeint hatte, dass unheimliche Gefühle geweckt würden, wenn eine intellektuelle Unsicherheit bestehe, ob etwas belebt oder leblos sei und eine gewisse Ähnlichkeit zwischen Leblosem und Lebendem bestehe. ${ }^{472}$ "Wir erinnern uns«, widerspricht Freud, »daß das Kind im frühen Alter des Spielens überhaupt nicht scharf zwischen Belebtem und Leblosem unterscheidet und $\mathrm{daß}$ es besonders gern seine Puppe wie ein lebendes Wesen behandelt ${ }^{473}$. Die Belebung der Puppe entspreche daher einem kindlichen Wunsch und sei nicht als Quelle des unheimlichen Gefühls auszumachen. ${ }^{474}$

Nach Beispielen in der Literatur suchend, verweist Freud auf E.T.A. Hoffmann, den unerreichten "Meister des Unheimlichen in der Dichtung « ${ }^{475}$ : In dessen Roman »Die Elixiere des Teufels« sei es schließlich das Doppelgängertum in all seinen Abstufungen und Ausprägungen, das unheimliche Leseerlebnisse erzeuge, darunter Ich-Verdopplung, Ich-Teilung, Ich-Vertauschung sowie die Wiederkehr des Immergleichen (Wiederholung der Gesichtszüge, der Charaktere, der Schicksale, der verbrecherischen Taten) $)^{476}$ - gestalterische Formen, wie sie in den Vervielfältigungen der untoten Hauptfiguren in »Die Kinder der Toten « wiederholt vorzufinden sind (vgl. etwa die ZWEITKARIN ${ }^{477}$, die ZWEITGU DRU N ${ }^{478}$ usw.).

Die Krankengeschichte eines Patienten mit Zwangsneurose veranlasste Freud schließlich zu der Annahme, dass das Unheimliche mit der alten Weltauffassung

468 Freud, Das Unheimliche, S. 23 I. Vg1. auch Mayer/Koberg, Ein Porträt, S. 204 f.

469 Freud, Das Unheimliche, S. 23 I.

470 Ebd., S. 237.

47 I Vgl. Freud, Das Unheimliche, S. 229-237.

472 Vgl. ebd., S. 245.

473 Ebd.

474 Vgl. ebd., S. 245 f.

475 Ebd., S. 246.

476 Vgl. ebd., S. $246 \mathrm{f}$.

477 KDT, S. 92. Auf S. 94 als »Karin Zwei«, auf S. 95 als »Kopie Karins« bezeichnet.

478 KDT, S. г 2 r. Hier auch als »Doppelgängerin« bezeichnet. 
des »Animismus« zusammenhänge: eine Auffassung, die von der Erfüllung der Welt mit Menschengeistern ausgegangen sei und sich unter anderem durch die narzistische Überschätzung der eigenen seelischen Vorgänge, die Allmacht der Gedanken und die Technik der Magie ausgezeichnet habe. ${ }^{479}$ "Es scheint, daß wir alle in unserer individuellen Entwicklung eine diesem Animismus der Primitiven entsprechende Phase durchgemacht haben « ${ }^{480}$, schreibt Freud - bloß dass wir im Laufe unseres Lebens gelernt haben, diese Gefühle ins Unterbewusste zu verdrängen. Dementsprechend sei das Unheimliche »nichts Neues oder Fremdes, sondern etwas dem Seelenleben von alters her Vertrautes, das ihm durch den Prozeß der Verdrängung entfremdet worden ist « ${ }^{481}$. Das Unheimliche sei schließlich darin zu erkennen, was »im Verborgenen hätte bleiben sollen und hervorgetreten ist ${ }^{482}$. Im allerhöchsten Maße unheimlich erscheine vielen Menschen dabei alles, was mit dem Tod, mit Leichen und mit der Wiederkehr der Toten zusammenhänge - vermutlich weil es, allen wissenschaftlichen Erkenntnissen zum Trotz, immer noch unmöglich sei, die eigene Sterblichkeit zu imaginieren. ${ }^{483}$ Die Entfremdung des Vertrauten - in seiner größtmöglichen Steigerung: das tote Ich - kann daher als das eigentliche »Unheimliche« ausgemacht werden. Die Vorsilbe »un-« an dem Wort »heimlich» stellt nach Freud dabei die "Marke der Verdrängung « ${ }^{484}$ dar. Das vergnügliche Gruseln am Unheimlichen in Literatur, TV und Film entspricht demnach einem verdrängten animistischen Urempfinden des Menschen.

Die romantische Literatur des I9. Jahrhunderts hat einige berühmte Beispiele für die unheimliche Wiederkehr der Toten hervorgebracht, deren Spannweite von Mary Shelleys »Frankenstein« bis zu Bram Stokers »Dracula» reicht, die als Evergreens des Wiedergängertums sowohl in die Literatur- als auch in die Filmgeschichte eingegangen sind, dabei einer gewissen Romantik aber nicht entbehren, weil sie auch die leidende, verletzliche Seite der unheimlichen Kreatur thematisieren. Die Kulturindustrie des 20. Jahrhunderts hat die Untoten schließlich zu einem Massenphänomen gemacht (siehe die Erfolgschichte der »Twilight«-Tetralogie von Stephenie Meyer bzw. deren Leinwandversion). ${ }^{485}$ Inzwischen sei, so Kastberger, auch eine »Trash«-Variante des Motivs bekannt:

479 Vgl. Freud, Das Unheimliche, S. 253.

480 Vgl. ebd.

48 I Ebd., S. 254 .

482 Ebd.

483 Vgl. ebd., S. 254 f.

484 Ebd., S. 259.

485 Vgl. Kastberger, Endspiele, unpaginiert. 
„Da wird das Heer der Geister, das niemand gerufen hat, mit Kettensägen traktiert und mit Küchenmixern zerstückelt [,] bis jede einzelne Körperzelle ein blutiges Ende gefunden hat. ${ }^{486}$

Gemeint sind so genannte »Splatterfilme« wie »Resident Evil«, »Dawn of the Dead« oder » 8 Days later«, aber auch Videospiele wie »Left for dead» oder „Call of Duty: World at War « - Zombie-Schocker, die möglicherweise animistische Gefühle aus unserem Unterbewussten hervorholen und damit verdrängte Bedürfnisse befriedigen.

Diese »modernen« Varianten, die sich vor allem durch die Quantität und Brutalität der auftretenden Untoten auszeichnen, erinnern dabei kaum noch an die tragischen Untoten bei Mary Shelley oder Bram Stoker. Ihre ursprüngliche Verankerung in der christlichen Vorstellungswelt ist schließlich kaum noch erahnbar - wir erinnern uns, dass der Prototyp einer untoten Hauptfigur im »Buch der Bücher«, der Bibel, zu finden ist: Jesus, der dem apostolischen Glaubensbekenntnis gemäß am dritten Tag nach seinem Tod wieder auferstanden ist. Nach Kastberger stellt die Wiederauferstehung die "zentrale Aussage des Jüngsten Gerichts « ${ }^{487}$ dar. Alle Weltreligionen bestreiten, möglicherweise in Kompensation des »Unheimlichen«, bis heute die Tatsache des individuellen Todes und versprechen (in der einen oder anderen Form) ein Leben nach dem Tod. ${ }^{488}$ Die Auferstehung Jesus' wird im Christentum jedes Jahr zu Ostern als wichtigstes Fest des Jahres begangen. Bei Jelinek sollen die "Schweigsamen« die Geschichtsleugner - beim Jüngsten Gericht selbst verschwiegen werden. ${ }^{489}$ Auch auf den Prototyp des Wiedergängers verweist Jelinek wiederholt in ihrem Text (explizit und in Großbuchstaben zum Beispiel auf den »LEI B CHR ISTI « ${ }^{490}$, der zwar leicht hingesagt, aber schwer zu beschreiben sei). Die wiederholten Nennungen und Hinweise auf die Dreifaltigkeit sowie auf christliche Ge- und Verbote können dabei als kritische Auseinandersetzung mit dem Christentum verstanden werden:

»Da ist das Christentum: halb Substanz, halb Wärme, und man sieht nicht, woher das alles kommt. Doch man weiß, daß man in die Kirche gehen muß.« ${ }^{491}$

486 Ebd.

487 Ebd.

488 Vgl. dazu auch Freud, Das Unheimliche, S. 255.

489 Vgl. KDT, S. 91.

490 KDT, S. 487 . Vgl. auch KDT, S. I75, S. I 87 f. sowie S. 482.

49I KDT, S. 344. 
Selbstständiges Denken und Handeln seien demnach im Rahmen der christlichen Religionsausübung nicht erwünscht. Nicht zuletzt muss an dieser Stelle ergänzt werden, dass die römisch-katholische Kirche tatsächlich jenen Antisemitismus über Jahrhunderte hinweg befördert hat, auf dem die rassistische Logik des deutsch-österreichischen Faschismus in den r 93oer Jahren aufbaute: So wurden die Juden als »Gottesmörder« denunziert, indem ihnen zu Unrecht die Kreuzigung Jesus' angelastet wurde, auch an der Ausbreitung der Pest im Mittelalter seien sie wegen angeblicher Brunnenvergiftung schuld gewesen. ${ }^{492}$ Sogar nach I 945 gab es von Seiten kirchlicher Würdenträger Anschuldigungen, die Juden hätten den Holocaust erfunden (»Auschwitz-Lüge $).{ }^{493}$ Diese mitunter willkürlich moralisierende und urteilende Kirche steht in "Die Kinder der Toten« im Kreuzfeuer der Kritik. Darüber hinaus schwebt über all dem die Frage, wie ein gerechter Gott das Geschehene, den Holocaust als den Superlativ des Unheimlichen und der Entmenschlichung, zulassen konnte. Der in "Die Kinder der Toten« dargelegten Kritik an der römisch-katholischen Kirche soll an dieser Stelle entgegengehalten werden, dass nicht nur mit dem Katholizismus, sondern letztlich mit jeder Religion im Laufe der Menschheitsgeschichte Missbrauch getrieben wurde, indem religiöse Ideale zweckentfremdet und Glaubensangehörige fanatisiert wurden. Da Jelinek ihre Texte immer sehr stark auf österreichische Verhältnisse fokussiert, kann die Auseinandersetzung mit der hierzulande dominierenden römisch-katholischen Kirche dennoch als folgerichtig begriffen werden.

Das den Roman begleitende Untotenmotiv (»... die Unheimlichkeit taucht ein, beginnt ihre freie, kühle Bahn ${ }^{494}$ ) stellte I 995 innerhalb des Jelinek'schen Euvres tatsächlich kein Novum dar. Mit den Vampirinnen aus dem Theaterstück »Krankheit oder Moderne Frauen« hatte die Autorin das originär Unheimliche bereits in den I 98oer Jahren zum Thema eines ihrer Texte gemacht. Das Motiv entspricht dabei ihrem in theoretischen Schriften und Interviews bereits mehrfach geäußerten Anspruch, entindividualisierte Charaktere schaffen zu wollen, deren Schablonenhaftigkeit und Austauschbarkeit vorgeführt werden sollen. ${ }^{495}$ Jelinek habe sich von Anfang an literaturästhetisch im Einklang mit Roland Barthes' dekonstruktivistischen Theorien befunden, meint dazu die Ger-

492 Vgl. etwa Schoeps/Schlör, Bilder der Judenfeindschaft.

493 Zuletzt sorgte der von Marcel Lefevbre 1988 zum Bischof geweihte Priester Richard Williamson für Aufsehen, als dieser 2009 in einem Interview mit dem schwedischen Fernsehen öffentlich die Existenz von Gaskammern in nationalsozialistischen Konzentrationslagern bestritt. Die von Johannes Paul II. wegen der unerwünschten Bischofsweihe verhängte Exkommunikation hob Papst Benedikt XVI. wieder auf, was zu Kontroversen innerhalb der römisch-katholischen Kirche führte. Vgl. Benz, Handbuch des Antisemitismus, Bd. 2, S. 888 f. KDT, S. 622. Vgl. die Kapitel I.6.r sowie 3.I.3 dieser Studie. 
manistin Moira Mertens. Mit ihrer provokanten Forderung, nur noch untote Figuren zu verwenden, stelle sich Jelinek klar gegen jede Ästhetik der Verlebendigung und damit klar gegen gängige abendländische Kulturtechniken und Lesegewohnheiten. ${ }^{496}$

Indem sie die Figuren ihres Opus Magnum zu untoten Wiedergängern und deren Vervielfältigungen werden ließ, schaffte es Jelinek in "Die Kinder der Toten«, diesen Anspruch der literarischen Darstellung von schablonenhaftem, entlebendigtem und entindividualisiertem Leben in seine größtmögliche dramaturgische Intensität zu steigern, wobei sich die Untoten des Romans sowohl in ihrer Qualität als auch in ihrer Quantität auszeichnen: Auf der einen Seite werden exemplarisch KARIN FRENZEL, GUDRUN BICHLER Und EDGAR GSTRANZ über hunderte Seiten hinweg in ihren unheimlichen Verdoppelungen begleitet und ihre Handlungen und Tode (sowie die Tode ihrer Verdoppelungen) aus verschiedenen Perspektiven besichtigt wie etwa in jener eindringlichen Szene des Romans, in der KARIN am Rande des Betonbeckens steht und ihre Kopie (»oder ist Karin die Kopie? ${ }^{497}$ ), die zuvor in den Wildbach gestürzt ist, in dem Becken mit dem metallenen Wasser wiederfindet. Auch GUDRU N BICHLER gibt es "ein zweites Mal «, die Studentin wird wiederholt "von sich selbst beobachtet « ${ }^{498}$. Während einer Zeitreise hat eine GUDRU N-»Doppelgängerin « ${ }^{499}$ Sex mit einem Unbekannten namens EDGAR (eine Verdoppelung von EDGAR GSTRANZ?):

„Gudrun-draußen-vor der Tür sieht sich jetzt im Anschnitt schräg von hinten ... Und knallrot, aus der Weiße des Fleisches wie etwas Ungehöriges ... hervorspringend, die spitzige Brustwarze, die in die Hand des Mannes springt und diese knurrend beißt.... Es schaukeln die Brustsäcke voll unzustellbarer Post an dieser zweiten Gudrun .... Ein jeder gießt für sich allein einen Schluck nach, legt noch einen Span aufs Ferkel drauf, und dann verbrauchen sie alle beide gehörig Munition. ${ }^{500}$

Auch den sexuellen Handlungen wird in solchen Szenen, in denen ein Zombie in den anderen hineinbohrt und sich durch dessen Körper »fräst « ${ }^{501}$, jede menschliche Regung genommen. Beobachtet wird ein schablonenhafter Zombie-Sex, der natürlich ohne romantische Gefühle, aber auch ohne jede Lust und Begierde ausgeführt wird.

496 Vgl. Mertens, Untote, S. 8 f.

497 KDT, S. 95.

498 KDT, S. II 9.

499 KDT, S. г г.

$500 \mathrm{KDT}, \mathrm{S}$. iा 9 f.

50I KDT, S. I2 I. 
Auf der anderen Seite braut sich - parallel zu diesem exemplarischen Handlungsstrang - ein stinkendes, braunes, stockendes Meer aus Leichen zusammen, das am Ende den Ort des Geschehens über- und unterspült:

»Es ist böses Wasser par excellence... Ein Brei, in dem obenauf Knorpel und Haarmorast treiben und in dem verwesendes Menschenfleisch schwimmt. Von den Seiten nährt sich der anschwellende Strom aus nicht weniger grausigen Armen: Tödliche Mundspülungen, (Monats)blutungen, Kammerwasser, Eiter, Kotze und Kot münden ein. ${ }^{502}$

Die (untoten) Toten sind von Anfang an überall: in der Luft, in den Gewässern, unter der Erde. Allerdings befinden sie sich zunächst im Verborgenen, ihre Anwesenheit wird von den Lebenden nur intuitiv oder als kalter Lufthauch oder als dunkle Wolke wahrgenommen. ${ }^{503}$

Die Ermordeten (»Sechsmillionen $\aleph^{504}$ ) einer verdrängten Vergangenheit müssen sich erst aus dem Verborgenen hervorarbeiten - und hier finden wir Freuds Definition des »Unheimlichen« wieder: »... etwas, das im Verborgenen hätte bleiben sollen und hervorgetreten ist ${ }^{505}$. Dieses »Etwas« in »Die Kinder der Toten« ist Österreichs (Mit-)Schuld an den Verbrechen des Nationalsozialismus - und es ist hässlich, denn die Untoten sind bei Jelinek »eher hirnlose, sprechunfähige, sexbessene Zombies« denn »vergeistigte Erscheinungen mit Sinn für das Schöne und Erhabene ${ }^{506}$, wie sie in der Literatur des I 9. Jahrhunderts vorzufinden waren.

Die Allgegenwärtigkeit der Holocaust-Ermordeten wird im Laufe des Romans immer nachdrücklicher, die Bedrohung für die Lebenden immer eindringlicher.

Und so kriechen die zu Unrecht Ermordeten schließlich als unbarmherzige, untote Rächer massenhaft aus den Wänden oder erheben sich aus schlammigen Pfützen. Manchmal sind es nur einzelne Körperteile, abgetrennte Gliedmaßen oder halbe Schädel, die in dem »bösen Wasser « ${ }^{507}$ herumschwimmen oder aus der Erde hervorlugen. Durch die starken Regenfälle verbinden sich die unzähligen Leichen bzw. Leichenteile mit diversen anderen Flüssigkeiten, bis sie schließlich als ein einziger Richtblock Wasser ${ }^{508}$ erscheinen, der eine

$502 \quad$ Kastberger, Endspiele, unpaginiert.

$503 \mathrm{Zu}$ den Andeutungen der wiederkehrenden Toten mit Natur-/Wettererscheinungen vgl. Kapitel 3.2.6 dieser Studie.

504 KDT, S. 453.

505 Freud, Das Unheimliche, S. 254.

506 Mertens, Untote, S. 5.

507 Vgl. Kastberger, Endspiele.

508 KDT, S. 253. 
bleierne Oberfläche über die steirische Landschaft legt und alles Leben unter sich erstickt.

Womöglich hat Jelinek mit »Die Kinder der Toten« tatsächlich Freuds Aufsatz über das »Unheimliche« in »Splatter«-Manier literarisch umgesetzt. ${ }^{509}$ Bei Jelinek ist dieses Motiv allerdings als (sehr zielorientiertes) Mittel zum Zweck zu begreifen - die implizite, aber deswegen nicht weniger eindringliche, weil unheimliche Kritik an einem verdrängten Kapitel österreichischer Geschichte: der Beteiligung an den Verbrechen des Nationalsozialismus und des Zweiten Weltkriegs.

\subsubsection{Die immerwährende Schuld: Leberts »Wolfshaut«}

"Die Toten haben Hunger. Man sollt' sie halt füttern. ${ }^{510}$

I960 erschien Hans Leberts Debütroman »Die Wolfshaut«. Der Autor, Neffe und Firmsohn von Alban Berg ${ }^{511}$, war damals 4I Jahre alt. Über viele Jahre hinweg hatte er an dem Roman gearbeitet. Wie Elfriede Jelinek kam auch Hans Lebert ursprünglich aus der Musik: Als junger Mann hatte er sich sein Geld als Operntenor verdient, wobei er Wagner-Opern preferierte. Es war demnach kein Zufall, dass er seinem Roman ein Zitat aus der Wagner-Oper »Walküre« vorangestellt hatte: „Doch ward ich vom Vater/ versprengt;/ seine Spur verlor ich,/ je länger ich forschte./ Eines Wolfes Fell nur/ traf ich im Forst;/ leer/ lag das vor mir:/ Den Vater/ fand ich nicht. ${ }^{512}$

Während der NS-Zeit hatte sich Lebert seiner Einberufung in die Wehrmacht widersetzt und war deshalb I94 I wegen "Zersetzung der Wehrkraft« angeklagt worden. Durch die Vortäuschung einer paranoid-schizophrenen Störung konnte er sich nach fast sechs Monaten Untersuchungshaft seiner Verurteilung entziehen und lebte bis Kriegsende zurückgezogen in den steirischen Bergen. ${ }^{513}$

509 Vgl. Mayer/Koberg, Ein Porträt, S. 204.

5 IO Lebert, Die Wolfshaut, S. 5 I.

5 I I Lebert legte Wert auf die Feststellung, dass die Schwester seiner Mutter mit Berg verheiratet war und deshalb keine direkte Blutsverwandtschaft zu dem berühmten österreichischen Komponisten bestand. Er habe den Firmonkel, der ihm statt der obligatorischen Uhr sinnigerweise eine Schreibmaschine geschenkt habe, aber schon gern gehabt. Vgl. Dobrick, „Bei dem zweiten habe ich nicht mehr gelacht«, S. Io und I4.

5 I 2 Lebert, Die Wolfshaut, S. 5.

5 I 3 Vgl. Gauß, Der Österreich-Liebhaber, unpaginiert. Vgl. dazu auch Leberts eigene Schilderungen: Dobrick, »Bei dem zweiten habe ich nicht mehr gelacht«, S. I 5 fff. 
Sein Roman, der in Österreich keinen Verleger gefunden hatte und schließlich im Hamburger Claassen Verlag mit einer bescheidenen Auflage von 3.000 Stück herausgegeben wurde schlug in die »betuliche «̈ öterreichische Nachkriegsliteratur ein »wie eine Granate ${ }^{514}$. In Rezensionen wurde das Buch als »unappetitlich« und »mehr als unschicklich ${ }^{515}$ bezeichnet. Zeitgenössische Schriftstellerkollegen (»vom konservativen Patriarchen der Literatur Heimito von Doderer bis hin zum ketzerischen Marxisten Ernst Fischer « ${ }^{516}$ ) rühmten das Buch als "grandiose Parabel von Schuld und Sühne " ${ }^{517}$. I 96 I wurde Lebert für seinen Roman mit dem Theodor-Körner-Preis und ein Jahr später mit dem Großen Österreichischen Staatspreis ausgezeichnet. Trotz alledem blieben der »Wolfshaut « die breite Rezeption und nachhaltiger Erfolg versagt. ${ }^{518}$

Der i 97 I erschienene (einzige) Nachfolgeroman »Der Feuerkreis«, ein Inzestdrama um ein Halbgeschwisterpaar, mit dem Lebert nach eigener Aussage »den faschistischen Mythos (...) von innen her aufzusprengen « ${ }^{519}$ versuchte, wurde von Kritikern und Lesern noch negativer bewertet als »Die Wolfshaut«:

»Der Feuerkreis«", ein fragwürdiges und bedenkenswertes Experiment zugleich, wurde von den auf Entmythologisierung versessenen Kathederrevolutionären jener Jahre gründlich mißverstanden und abgeurteilt. Hans Lebert verstummte. ${ }^{520}$

Aufgrund des mangelnden Erfolgs und auch wegen des frühen Todes seiner ersten Frau zog sich Lebert Anfang der r 97oer Jahre in seine Wohnung in Baden bei Wien zurück und veröffentlichte über 20 Jahre lang nichts mehr. Erst I 99 I wurde der »Wolfshaut«-Roman im Europaverlag neu herausgegeben (2008 ein zweites Mal). Zeitgenössische Autoren (Karl Markus Gauß, Gustav Ernst, Robert Menasse, Michael Guttenbrunner) bezeugten ihre Hochachtung vor der Lebertschen Prosa. ${ }^{521}$ Enthusiastisch zeigte sich Elfriede Jelinek: »Die Wolfshaut« sei eines der "größten Leseerlebnisse ${ }^{522}$ ihres Lebens gewesen, gestand sie r 99 I, als sie das Buch anlässlich der ersten Wiederauflage unter dem Titel »Das Hundefell« rezensierte:

5 I 4 Miessgang, Der Querschreiber, S. Io6 f.

5 I5 Ebd.

5 I 6 Gauß, Die Toten haben Hunger, unpaginiert.

5 I 7 Ders., Der Österreich-Liebhaber, unpaginiert.

5 8 Vgl. ders., Die Toten haben Hunger, unpaginiert.

5 I 9 Lebert, zitiert nach: Miessgang, Der Querschreiber, S. Io6.

520 Gauß, Der Österreich-Liebhaber, unpaginiert.

52 I Vgl. Müller, Ein neuer Gegenstand, S. 40.

522 Jelinek, Das Hundefell, S. Io8. 
"Dichter wie Hans Lebert verdient dieses Land der heiteren hiesigen Vergeßlichkeiten nicht. Und deshalb hat es einen wie ihn auch sehr gern und bereitwillig vergessen. Aber wo die bittere, sprachbesessene Wut eines Thomas Bernhard immer nur an der $\mathrm{Au}$ ßenmauer entlangkratzt ..., da entsteht bei Lebert der große Mythos einer für immer schuldig gewordenen Welt. ${ }^{523}$

Lebert erhielt im darauffolgenden Jahr den Grillparzer-Preis und so erfuhren seine Werke eine späte Renaissance - doch der von schwerer Krankheit bereits gezeichnete und in Zurückgezogenheit lebende Autor ertrug die späten Ehren mit »trotzigem Gleichmut ${ }^{524}$.

Mit »Die Kinder der Toten« hat Jelinek selbst einen Roman vorgelegt, der möglicherweise »eine literarische Variation, eine subjektive Fortschreibung der ,Wolfshaut « ${ }^{525}$ darstellt. Tatsächlich sind thematische Relationen zu Lebert schnell ausgemacht, denn »Die Wolfshaut« gilt als der »erste große Roman, der sich mit der österreichischen Verstrickung in Schuld « ${ }^{526}$ befasste. Weil dieser von $" \mathrm{~A}$ bis $\mathrm{Z}$ durchkonstruiert $[\mathrm{e}] \ll^{527}$ und wegen seiner ungeheuren Sprachgewalt äußerst bemerkenswerte Roman seltsamerweise immer noch wenig bekannt ist, auch in Österreich, sei hier dessen vielschichtige Handlung in aller Kürze zusammengefasst:

Im Winter 1952/53 ereignen sich in einem österreichischen Bergdorf mit dem sprechenden Namen "Schweigen« mehrere mysteriöse Todesfälle, an deren Aufklärung die Dorfgemeinschaft bemerkenswert wenig Interesse zeigt. Nur zwei Außenseiter, ein heimgekehrter Matrose namens JOHANN UnfREUnd und ein Fotograf namens maletta, der nach dem Krieg ins Dorf zugezogen ist, wollen verstehen, was in dem seltsamen Dorf vor sich geht. Die Entdeckung, dass seinen Vater ein schreckliches Geheimnis in den Selbstmord getrieben hatte, bringt den Matrosen dazu, immer wieder neue Nachforschungen anzustellen. Die Begegnung mit einem entlaufenen, aber harmlosen Sträfling, der von Gendarmerie und Dorfgemeinschaft zu Unrecht für die grausige Ermordung des gerade pensionierten Sägewerksmeisters JOHANN SCHRECKENSCHLAGER verantwortlich gemacht und auf der Flucht erschossen wird, verstärkt sein Bedürfnis, das Geheimnis, das nicht nur seinen Vater in den Freitod getrieben hatte, sondern immer noch wie ein böser Fluch über dem ganzen

523 Ebd.

524 Ebd.

525 Gauß, Ein Haufen Fleisch, S. 5 .

526 Mayer/Koberg, Ein Porträt, S. 203.

527 So Lebert selbst über die Kompositionstechniken des Romans, zitiert nach: Dobrick, »Bei dem zweiten habe ich nicht mehr gelacht«, S. $22 \mathrm{f}$. 
Dorf liegt, aufzudecken. Gespenstische Visionen und blutgetränkte Spuren im Schnee sind erste Hinweise auf das Verdrängte (»... eine Botschaft, die darauf wartet, gelesen zu werden ${ }^{528}$ ). Die unheimliche Atmosphäre wird von der Dorfgemeinschaft der vermeintlichen Gefahr zugeschrieben, die von einem streunenden Wolf ausgeht. Doch der Wolf ist vielmehr Symbol für die Schuld, das schlechte Gewissen und die Angst vor der Sühne: Das Unaussprechliche, das im Hinterhalt bereitliegt, nimmt »in den Mostschädeln Wolfsgestalt an $[\ldots]{ }^{529}$. Die unheimliche Szenerie ist von ungewöhnlichen Wettererscheinungen begleitet, Nebel, Wind und ständigen Regenfällen (»... ein dünnes, weinerliches Gewieschel, das die Wälder in graue Schleier hüllte und den Boden allmählich durchtränkte ${ }^{530}$ ). UNFREUND kommt schließlich dahinter, dass einige Dorfbewohner kurz vor Kriegsende 1945 sechs Fremdarbeiter ermordet und in einer alten Ziegelei verscharrt hatten. Sein Vater hatte beim Eingraben der Leichen geholfen und sich dadurch selbst schuldig gemacht. Um zu verhindern, dass einer der Beteiligten über die Geschehnisse berichtet, wurden die weiteren Morde begangen. Bittere Pointe des Romans: Der Hauptschuldige und Rädelsführer, ein Förster namens H A BERGEIER, ist gerade in den Landtag gewählt worden und kann sich im Schutze seiner Immunität der irdischen Gerechtigkeit entziehen. ${ }^{531}$

In ihrer Rezension zur Neuauflage von Leberts Roman schrieb Jelinek I99I von der unglaublichen »Ungerechtigkeit, daß die einen tot sind und die anderen nicht«, weil die einen »dafür gesorgt [haben], daß für die anderen alles für immer beendet worden ist «. Diese Ungerechtigkeit führe schließlich dazu, dass wir Lebenden »uns selbst ständig vernichten müssen « ${ }^{532}$.

In »Die Kinder der Toten« hat sie diese Schlussfolgerung literarisch konsequent umgesetzt, denn nicht nur die drei untoten Hauptfiguren erleben ständige Wiederholungen und Variationen ihrer Tode. Auch die Erzählins$\tan z$ vernichtet sich während des Sprechens selbst (»... schauen wir nach, was derweil draußen los ist, von wo ich mich einschalte, mir selber den Schädel einschlage und mich melde ${ }^{533}$ ), ohne dabei jedoch tatsächlich zu Tode zu kommen, denn nach vollzogenem Selbstmord wird munter weitererzählt. Leben und Tod sind nicht eindeutig voneinander abgrenzbar, denn wo die Toten untot sind, "sind auch die Lebenden nicht recht lebendig ${ }^{534}$. Ebenso wie die

528 Lebert, Wolfshaut, S. 66.

529 Ebd., S. 436.

530 Ebd., S. 45.

53 I Vgl. Miessgang, Der Querschreiber, S. ro6.

532 Jelinek, Das Hundefell, S. ıo8.

533 KDT, S. I 3 .

534 Löffler, Unterwelt, unpaginiert. 
Lebenden nur Scheinexistenzen führen, sind auch die Toten des Romans »lebende Leichname ${ }^{535}$.

In ihrem Roman griff Jelinek zentrale Motive aus Leberts Werk auf, vor allem aus "Die Wolfshaut« (zum Teil aber auch aus "Der Feuerkreis«, wie bei Kastberger erläutert wird $\left.{ }^{536}\right)$. Auch Lebert hatte im »Wolfshaut«-Roman bereits Shoah-Thematik und Grusel-Genre miteinander verknüpft, wobei Leberts Roman viel stärker plotorientiert ist als Jelineks »Die Kinder der Toten«. Doch die Verknüpfung von historischer Aufarbeitung und schauriger Kriminalgeschichte stellte bei Jelinek kein Novum und auch per se kein Skandalon dar. ${ }^{537}$

Eine augenscheinliche Parallele zwischen den beiden »Gespenstergeschichte[n] « ${ }^{538}$ ist der Rückgriff auf aggressive Natur- und Wettererscheinungen, etwa plötzlichen Nebel oder wiederkehrende Regenfälle, welche die Wiederkehr der Toten vorbereiten und begleiten. ${ }^{539}$ In Leberts Roman verwandelt anhaltender Regen die Gegend rund um das Bergdorf Schweigen in eine schlammige, "parteibraune Landschaft ${ }^{540}$, ähnlich wie in Jelineks Roman, in dem sich die Wiesen unter den "prahlerisch zu Hahnenkämmen erstarrten Erdspuren ${ }^{541}$ braun färben, während die giftige Mure, die von den Toten des Holocaust genährt wird, bedrohlich anwächst. ${ }^{542}$

Zudem beschreibt Jelinek - wie auch Lebert, der in seinen Texten nie eine konkrete Ursache für die Katastrophe des Nationalsozialismus nennt, sondern vielmehr ein "nicht näher definierbares Ur-Böses « ${ }^{543}$ beschwört - wiederholt eine transzendentale höhere Macht, die das Geschehen zu kontrollieren und zu lenken scheint.

So ist bereits zu Beginn, in Zusammenhang mit dem Busunglück, bei dem KARIN FRENZEL getötet wird, vom "Steuern eines Höheren ${ }^{544}$ die Rede. ${ }^{545}$ Weitere Hinweise auf diese zwar gottähnliche, aber nicht gütige, sondern vielmehr zornige Macht finden sich im Laufe des Texts immer wieder, mitunter auch im Plural:

535 KDT, S. I 72.

536 Vgl. Kastberger, Endspiele, unpaginiert.

537 Pontzen, Pietätlose Rezeption, S. 59.

538 In ihrer profil-Rezension hatte Jelinek Leberts "Wolfshaut«-Roman als eine »Gottesgeschichte und gleichzeitig eine Gespenstergeschichte« bezeichnet, siehe profil, Nr. 38, I99 I.

539 Zu der aggressiven Natur vgl. Kapitel 3.2.6 dieser Studie.

540 Lebert, Wolfshaut, S. I73.

$54 \mathrm{I}$ KDT, S. 570.

542 Vgl. Scheidl, Ein Land auf dem rechten Weg, S. I 54.

543 Miessgang, Der Querschreiber, S. Iо7.

544 KDT, S. I I.

545 Vgl. Scheidl, Ein Land auf dem rechten Weg, S. I 53 f. 
»Das Leben ist eine der vielen Naturkletterschulen, in der unser Schöpfer möglichst viele von uns möglichst rasch loswerden kann. Wir werden von ihm ja nicht als Obst geboren, daß man uns endlos auspressen oder als Seele in Knödel stopfen kann. « ${ }^{546}$

»Sie (wer?) sollen sie wieder auf der Erde wohnen lassen. ${ }^{547}$

»Es liegt eine fremde Hand über allem, die Hand eines Mittlers, der seine Gebühren fordern wird, denn die verschwundenen Mieter haben nicht verdient, was sie bekommen haben, und so muß einer für sie zahlen. ${ }^{548}$

Demnach sucht diese (unheimliche, zornige) Gottesinstanz Rache für die Millionen Ermordeten des Holocaust und bekommt sie letzten Endes auch: Sowohl bei Lebert als auch bei Jelinek kehren die Toten zurück, bei Jelinek in Massen, und »verschaffen der Erde ein unheimliches Strafgericht ${ }^{549}$.

Auch das Schweigen über die Toten des Nationalsozialismus, nach Jelinek Teil der österreichischen »Staatsdoktrin ${ }^{550}$, ist eine auffällige Parallele der beiden Romane: Bei Lebert ist es explizit im Namen des Dorfes formuliert, bei Jelinek fällt es als rekurrentes Textelement auf, das den Roman von Anfang bis Ende in unterschiedlichen Zusammenhängen begleitet. ${ }^{551}$

Darüber hinaus ist auch die Pointe von Jelineks Roman, die Verschüttung der »Pension Alpenrose« durch die Mure, möglicherweise eine Entlehnung aus Leberts "Wolfshaut«, worauf Pontzen in ihrem Aufsatz hinweist ${ }^{552}$ und wie aus folgender Textpassage rückgeschlossen werden könnte:

"Aus weit aufgerissenen Augen sah er [die Figur »Habicht«, ein Gendarm] zurück und erblickte hinter sich die Mure, einen Fladen, der bereits drei Meter hoch, noch immer wie ein wüster Brotteig aufging und die Knorren vergessener Bäume emporbrodeln ließ ...« ${ }^{553}$

In $»$ Die Kinder der Toten« ist die Bedrohung durch die Mure jedoch eindringlicher, da sich das Regenwasser nicht nur mit brauner Erde, sondern auch mit diversen Leichenteilen vermischt, die am Schluss des Romans die »Pension Al-

546 KDT, S. 25 .

547 KDT, S. 54 .

548 KDT, S. I64.

549 Kastberger, Endspiele. Kastberger bezieht in seinen Vergleich auch Ödön von Horváth mit ein (vor allem dessen Stück »Der jüngste Tag«).

$55^{\circ}$ Jelinek, Die Österreicher als Herren der Toten, S. 6I.

$55 \mathrm{I}$ Textbeispiele dazu in Kapitel 3.2.5 dieser Studie.

552 Vgl. Pontzen, Pietätlose Rezeption, S. 62.

553 Lebert, Wolfshaut, S. 466. 
penrose« verschütten. In beiden Romanen ist jedoch die Unausweichlichkeit der Sühne von Anfang an erspürbar, wodurch sich atmosphärische und motivische Ähnlichkeiten ergeben. Das Unheimliche, das wie ein Damoklesschwert über beiden Szenerien hängt, ist auch bei Lebert in einer seltsamen Ich-Verdoppelung wiederzufinden, die die beiden Figuren maletta und unfreund betrifft: So sucht der Fotograf maletta stets die Nähe des eigenbrötlerischen Matrosen UNFREUnd. Dieser fragt sich wiederum, ob er den seltsamen Fotografen, den er nicht abzuschütteln vermag, aus seinem früheren Leben vielleicht kennt:

"Der hat doch in meiner Erinnerung einen Geheimplatz. Dem bin ich doch schon irgendwo begegnet.« ${ }^{554}$

Etwas später erschreckt er darüber, dass sein (ihm eigentlich unsympathisches) Gegenüber dieselben Gedanken zu haben scheint wie er selbst:

»Hergott noch einmal! Wie geht denn das zu?! Das sind doch meine eigenen Gedanken! Das hätte ich ebenso selber gesagt haben können! « ${ }^{555}$

»Bist du etwa vor dir selbst geflüchtet? Und sitzt du dir jetzt glücklich selber gegenüber?« ${ }^{556}$

"Wie geht das denn zu?! Sitze ich mir wirklich selber gegenüber? Oder kann der Mensch Gedanken lesen? Stiehlt er mir meine Gedanken und macht daraus Worte? ${ }^{557}$

Das Gefühl, sich selbst in einem anderen wiederzufinden, verschafft JOHANN UNFREUND Unbehagen. Und doch kann er sich ihm nicht ganz entziehen:

„Er hatte unvermittelt das Gefühl, statt seiner könnte ihm Karl Maletta im Spiegel erscheinen, ein Gefühl, als läge dieser Vergessene, dieser Verdammte schon ein Leben lang hinter dem fleckigen Glas auf der Lauer. ${ }^{558}$

Auch malet ta spürt die Ich-Widerspiegelung in dem Matrosen, dessen Nähe er von Anfang an gesucht hatte, und erklärt sich ihm schließlich:

554 Ebd., S. 359 .

555 Ebd., S. 36r.

556 Ebd., S. 363.

557 Ebd., S. 366 .

$55^{8}$ Ebd., S. 367 . 
")... Sie sind mein Ich, mein verlorengegangenes, besseres Ich: das, was ich immer zu werden beabsichtigt habe. ${ }^{559}$

Wohingegen UNFREUND befürchtet, in MALETTA sein böses, schlechtes Ich wiederzufinden:

»Wenn ich Ihr gutes Ich bin<, flüsterte er, >dann sind Sie vielleicht mein schlechtes Ich, das Ich, das ich fürchte. Dann sind wir ja sozusagen alte Bekannte.« ${ }^{560}$

Auch hier wird - wie bei Freud - das Wiedererkennen des eigenen Ichs in seiner Entfremdung als größte Angst, als das eigentlich Unheimliche, vorgeführt. In einem Interview von 1992 ging Lebert selbst auf das Doppelgänger-Motiv in seinem Roman ein und erklärte schlicht, dass der Matrose unfreund und der Fotograf MALETTA im Grunde genommen »eine Gestalt ${ }^{561}$, zwei Hälften von ein und derselben Person, seien (was als ironische Übertreibung verstanden werden muss).

Neben den genannten motivischen Parallelen ist vor allem die Ähnlichkeit des polyphonen Erzählkonzepts in »Die Kinder der Toten « markant. ${ }^{562}$ Diese Auffälligkeit wird in dem nun folgenden Kapitel eingehender erörtert, da sie als implizites Mittel zur Darbringung der Kritik Jelineks am österreichischen Opfermythos und dessen Fortwirken in der Gegenwart begriffen wird.

\subsubsection{Die Erzählinstanz als multiperspektivische Kunst- und Kippfigur}

»Heute gibt's hier eine Erzähler-Auktion, Sie können mir dankbar sein! « ${ }^{563}$

Wie in Leberts »Wolfshaut«-Roman besteht eine der hervorstechendsten stilistischen Besonderheiten von »Die Kinder der Toten« in den stets wechselnden, sich mitunter auch überlagernden Erzählhaltungen.

Leberts Roman wird über weite Strecken hinweg in einem unkonkreten, nicht näher definierten »Wir« erzählt, das ab und zu in ein (ebenfalls nicht näher definiertes) »Ich« kippt und zugleich die Perspektive des reflektierenden, außenstehenden Erzählers wiederzugeben scheint wie auch die eines Mitglieds der Dorfgemeinschaft. ${ }^{564}$

559 Ebd., S. 524 .

560 Ebd.,

56I Dobrick, »Bei dem zweiten habe ich nicht mehr gelacht«, S. 27.

562 Vgl. Scheidl, Ein Land auf dem rechten Weg, S. I 55.

563 KDT, S. 3 I 3 .

564 Die Hinweise darauf, dass die Erzählinstanz bei Lebert eine Person aus dem Dorf sein könnte, werden gegen Ende des Romans hin eindeutiger (»... bei uns daheim in Schweigen«, S. 432). 
In Jelineks »Die Kinder der Toten« gibt es »eine Erzählerin, die sich >Frau Autor nennt und sich hin und wieder mit Sätzen wie >So, hier sind wir wieder oder >Erinnern Sie sich bitte zu Wort meldet. ${ }^{565}$ Diese Instanz ist jedoch niemals eindeutig fassbar, sie fällt ständig von einer Erzählhaltung in die andere, indem sie zwischen der ersten Person Singular ( $\gg$ Ich persönlich beschreibe lieber Autounfälle ${ }^{566}$ ) und der ersten Person Plural („Wir dienen Ihnen jetzt durch Gleichnisse ${ }^{567}$ ) hin und her wechselt und darüber hinaus offenlässt oder $a b-$ sichtlich verwischt, was unter "wir« zu verstehen ist.

Zunächst fällt auf, dass die Erzählinstanz immer wieder auf sich aufmerksam macht, indem sie den Akt des Erzählens thematisiert, den Leser gerne auch direkt anspricht (wenn auch nicht gerade freundlich):

»Achtung, ducken Sie sich, es beginnt der vorliegende Text. Er rutscht unter Ihren Händen weg, aber das macht nichts, muß mich halt ein andrer zur Vollendung tragen, ein Bergführer, nicht Sie! ${ }^{568}$

$» .$. Leser, du, melde dich nicht! ...« ${ }^{569}$

»... kommen Sie zu sich! So, jetzt sind Sie zurückgekommen und sehen, daß Sie unnütz sind. ${ }^{570}$

»Hören Sie nun der Wahrheit zu..." ${ }^{571}$

Schon im Prolog eröffnet diese mehrstimmige Erzählinstanz, bei Radisch als "anonymer Chor ${ }^{572}$ bezeichnet, die eigentliche Geschichte mit den Worten: "Wir befinden uns ... in einem österreichischen Dorf ${ }^{573}$ und berichtet in Folge von KARIN FRENZELs tödlichem Unfall. Die Erzählerinnenfigur spricht hier in der ersten Person Plural von sich - zu welchem Kollektiv sie tatsächlich zu zählen ist, wird jedoch im Verlauf des Romans immer undeutlicher: $\mathrm{Ob}$ es das "Kollektiv der österreichischen Bevölkerung « ${ }^{574}$ ist, das sich selbst für die Ver-

565 Mayer/Koberg, Ein Porträt, S. 202. Selbstbezeichnung als »Frau Autor« KDT, S. 282.

566 KDT, S. 424.

567 KDT, S. 443.

568 KDT, S. I 5 .

569 KDT, S. 49.

570 KDT, S. I 28.

$57 \mathrm{I}$ KDT S. 285.

572 Radisch, Maxima Moralia, unpaginiert.

573 KDT, S. 7 .

574 Vgl. Scheidl, Ein Land auf dem rechten Weg, S. I 55. 
brechen des Nationalsozialismus bemitleidet oder die »Kleinigkeit von ein paar Millionen Toten ${ }^{575}$ herunterspielt, oder doch das Kollektiv der Untoten (worauf durch wiederholte Andeutungen auch geschlossen werden könnte) bleibt unklar. Einmal zählt sie sich zu »uns Lebenden ${ }^{576}$, die sich (»Und wie...! ${ }^{577}$ ) auf den Tod vorbereiten wollen, und nur einige Absätze später zu »uns Toten, Maden im Speck des Lebendigen ${ }^{578}$. Möglicherweise wird damit auch angedeutet, dass diese beiden Kollektive nicht voneinander trennbar sind.

Zudem stellt sich die Erzählinstanz mitunter selbst ironisch in Frage und relativiert die Illusion der Allwissenheit (»... was wollte ich im Grunde sagen « $^{579}$ ), was zum einen generell ein Charakteristikum von Jelineks offensivem Umgang mit dem als neurotisch umschriebenen Ich darstellt und zum anderen in »Die Kinder der Toten« die Fassbarkeit der Erählinstanz vermutlich zusätzlich erschweren soll - wie auch alle anderen Figuren des Romans und sämtliche Figuren in Jelineks Theater- und Prosatexten ist auch sie eine "Vermischungs-, Verschränkungs-, Kunst- und Kippfigur « ${ }^{580}$.

Auf die Funktion der multiperspektivischen Erzählinstanz kann mit Blick auf die übergeordnete Fragestellung dieser Studie rasch rückgeschlossen werden. Der unterstellten Bedeutung wird im folgenden Unterkapitel eingehender nachgegangen.

\subsubsection{Eine »Opfer-Täter-Kippfigur»}

»... der Erzähler steigt hinunter in den Abgrund, hinab zu den Toten, ... so dass sich auch ein sprachlicher Abgrund vor den Lesern auftut. ${ }^{581}$

Die multiperspektivische Erzählinstanz in »Die Kinder der Toten« artikuliert ebenso Momente der Schuld (»Ins Gas sind viele geschickt worden... ${ }^{582}$ ) wie Verdrängung und fehlendes Unrechtsbewusstsein (»Dann werden wir damals nicht zu Hause gewesen sein. ${ }^{583}$ ).

$575 \quad$ KDT, S. 98.

576 KDT, S. 39.

577 KDT, S. 39.

578 KDT, S. 4 O.

579 KDT, S. 68.

580 Lücke, Elfriede Jelinek, S. 9.

58 I Lücke, Elfriede Jelinek, S. 97.

582 KDT, S. $70 \mathrm{f}$.

583 KDT, S. I9. 
Einmal spricht sie stellvertretend für viele Österreicher, die das Geschehene vergessen möchten, als könnten sie es dadurch ungeschehen machen:

»Waren wir nun an etwas schuld oder nicht? Es kommt auf die Interpretation dieses lieblichen Bildes an... Entweder wir waren es, dann sind wir zum Handkuß gekommen... Oder wir waren es nicht, dann vergessen wir doch bitte alles, was nie gewesen ist! « ${ }^{584}$

»... viele wollen und können es schon nicht mehr hören, ich kanns übrigens auch nicht." ${ }^{585}$

An anderer Stelle schlüpft die Erzählinstanz in die Rolle des Anklägers und findet - ohne große Verfremdungen oder Umschweife auskommend - klare Worte, die keine Ausflüchte zulassen:

"Jetzt sagen wir Ihnen wieder einmal, was sie getan haben, auch wenn Sie das wie jeden Tag von uns nicht hören wollen. ${ }^{586}$

»Die Wahrheit ist nichts Vergangenes. Wir wollen, daß sie wiedererweckt wird. Die brandigen Toten sollen bitte als neue Welle anrollen, nur hereinspaziert... « ${ }^{587}$

Zu beachten ist dabei der Entstehungskontext des Romans, die frühen r 99oer Jahre: Zum einen entschuldigte sich erstmals ein österreichischer Bundeskanzler, Franz Vranitzky, öffentlich für die Taten österreichischer Bürger während der NS-Zeit und relativierte damit den jahrzehntelang gepflogenen Opfermythos der Zweiten Republik. Zum anderen eilte Jörg Haider, damals noch FPÖ-Parteivorsitzender und Landeshauptmann von Kärnten, trotz Aussprüchen wie jenem von der »ordentlichen Beschäftigungspolitik ${ }^{588}$ im Dritten Reich von Wahlerfolg zu Wahlerfolg. In Österreich begann sich in Folge eine doppelgleisige Erinnerungskultur herauszubilden, mit der einerseits "gebetsmühlenhaft ${ }^{589}$ der Opfer des Nationalsozialismus gedacht wurde und sich daneben die politische Rechte trauen konnte, NS-Gräueltaten öffentlich in Frage zu stellen oder $\mathrm{zu}$ verniedlichen. ${ }^{590}$

584 KDT, S. 450.

585 KDT, S. 452 .

$586 \mathrm{KDT}, 469$.

587 KDT, S. 5 I 2.

588 Zum Entstehungskontext vgl. Kapitel 3.2 dieser Studie. Zur Widerlegung dieses Mythos vgl. auch das Kapitel »Beschäftigungspolitik (ordentliche)« in Horaczek/Wiese, Handbuch gegen Vorurteile, S. $20 \mathrm{fff}$.

589 Jelinek, zitiert nach: Janke/Kovacs/Schenkermayr, „Die endlose Unschuldigkeit«, S. I 9.

590 Vgl. die theoretischen Auseinandersetzungen um den Opfermythos, Kapitel I.4.4 dieser Studie. 
Hinzu kommt eine poetologische Weiterentwicklung in Jelineks Schaffen, in welchem die Autorin die Erzählinstanzen in all ihren Texten, epischen wie auch dramatischen, immer mehr in den Vordergrund rückte. In ihrem bislang letzten Roman, »Neid«, der 2007 in Fortsetzungen online auf Jelineks Homepage veröffentlicht wurde, ließ die Autorin die vordergründige Handlung rund um die Geigenlehrerin BRIGITTE K. schließlich vollends von einer reflexiv inszenierten Autorschaft dominieren. ${ }^{591}$

In »Die Kinder der Toten« tritt die Erzählinstanz vor allem als Sprachrohr eines sich widersprechenden Kollektivs in Erscheinung. Dieser Widerspruch bezieht sich auf die Art und Weise des Umgangs mit der nationalsozialistischen Vergangenheit Österreichs, in der Opfer-Mythologeme vordergründige Schuldeingeständnisse überlagern. Vor dem Hintergrund des Entstehungskontexts und der angesprochenen poetologischen Überlegungen kann die Erzählinstanz damit als Kippfigur zwischen Opfer- und Täterschaft ausgemacht werden.

Anhand dieses sprachlichen Kunstgriffs, mit dem Jelinek eine »Opfer-TäterKippfigur « geschaffen hat, kritisiert sie genau jenen erinnerungsgeschichtlichen Kompromiss, der sich seit den I99oer Jahren als offizielle Haltung Österreichs $\mathrm{zu}$ der Beteiligung an den Verbrechen des NS-Regimes durchgesetzt zu haben scheint und den Botz - auch in Hinblick auf jüngste Entwicklungen - als »Opfer-Täter-Gedächtnis « ${ }^{592}$ bezeichnet. Dieses beinhaltet sowohl das Eingeständnis der Mitverantwortung als auch das Beharren auf dem Opfermythos. ${ }^{593}$

Die Opfer-Täter-Kippfigur bleibt bis zum Ende des Romans eine unfassbare Größe: Als Leser weiß man nie so recht, woran man gerade ist. Eine Identifikation ist in jedem Falle ausgeschlossen. Damit, dass gewisse Unklarheiten vorhanden sind, die auch zum Ende hin nicht aufgelöst werden, muss sich der Leser letztlich abfinden, denn gerade sie machen eines der wesentlichen Charakteristika von "Die Kinder der Toten" aus: die Ungewissheit von hier und jetzt, die auf eine Vergangenheit zurückzuführen ist, in der sich das angesprochene Kollektiv, die österreichische Bevölkerung, schuldig gemacht hat.

Das wahre Versäumnis, das hier angeprangert wird, besteht - wie auch in anderen Texten Jelineks - darin, aus der rückschauenden Perspektive kein hinreichendes Unrechtsbewusstsein entwickelt zu haben, was an der unzulänglichen Sprachverwendung über den Holocaust (ein Schwanken zwischen Leugnung und routiniertem Bedauern) abgelesen werden kann. Jelineks literarische Abrechnung mit diesem unverzeihbaren Versäumnis macht alle Österreicher zu

59I Vg1. Pontzen, Pietätlose Rezeption, S. 57 (Fußnote 23).

592 Botz, Nachhall und Modifikationen, S. 6or.

593 Vgl. Kapitel I.4.4 dieser Studie. 
Untoten, die sich aufgrund ihrer historischen Schuld »selbst ständig vernichten müssen ${ }^{594}$ :

»Wir implodieren in unsere Schuld hinein und können nicht mehr getötet werden, weil

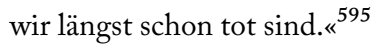

In »Die Kinder der Toten«, wo die Entlebendigung der Jelinek'schen Figuren ihren vorläufigen Höhepunkt erreicht hat, ist auch das Leben ein Mythos - eine Form ohne Inhalt. Insofern kann die Bedeutung der polyphonen Erzählinstanz für die Textaussage gar nicht überschätzt werden: Ein "gigantischer Mono$\log { }^{596}$ sei der Roman, schreibt Scheidl und irrt nicht. Plot und Figuren in »Die Kinder der Toten« sind sekundär, auch die Erzählinstanz ist nur als Schablone zu verstehen. Wichtig ist wieder die Sprache: Nicht die Frage, was erzählt wird, sondern wie erzählt wird, steht dabei im Mittelpunkt. Das polyphone Erzählkonzept kann daher als eine der wesentlichen Äußerungsformen von Jelineks Kritik am Fortwirken des österreichischen Opfermythos begriffen werden.

\subsubsection{Selbstthematisierungen}

»Eine Trennung der Person Jelinek oder ihres Handelns von ihren Texten ist unmöglich.«" ${ }^{597}$

Im Sinne des mehrstimmigen Erzählens finden sich auch indirekte sowie direkte Selbstthematisierungen Jelineks (»Selbstinszenierungen ${ }^{598}$ ) im Roman wieder, etwa wenn sich die Erzählerin über ihre »eigene Berufung zur Dramatikerin ${ }^{599}$ freut oder wenn sie beklagt, dass sie zu denjenigen gehöre, die »nicht

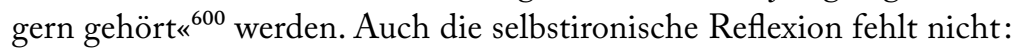

»... weil wir alle miteinander so viel dazwischen schwätzen! Gilt besonders für mich! ${ }^{601}$

594 Jelinek, Das Hundefell, S. ro8.

595 KDT, S. 456.

596 Scheidl, Ein Land auf dem rechten Weg, S. I 49.

597 Scholl, Selbstinszenierungen, S. 96.

598 Begriff von Scholl. Dieser bezieht sich in erster Linie auf die Selbstthematisierungen Jelineks in ihren Theaterstücken, verweist aber immer wieder auch auf Prosawerke.

599 KDT, S. 78.

600 KDT, S. 2 I 9.

60I KDT, S. 49. 
"Ich kann das nicht so gut erzählen... Ich versuchs trotzdem...«" ${ }^{602}$

Im Besonderen sind es die Beschreibungen der »Mutter-Tochter-Hölle ${ }^{603}$ zwischen KARIN FRENZEL und deren dominanter Mutter, die frappante Ähnlichkeiten zu Jelineks eigener biografischer Legende aufweist. Vor allem ist man immer wieder an die Figur der ER I к конUт erinnert, der Titelheldin jenes Romans, den Jelinek in Interviews wiederholt als ihre eingeschränkte Biografie bezeichnet hat: "Die Klavierspielerin«. ${ }^{604}$ "Natürlich erinnert das Psychogramm der Figur an Erika Kohut ${ }^{605}$, vermerkt Pontzen, doch sei dieses Motiv nur ein Biographem der Figur unter anderen (womit sie - wahrscheinlich unwillentlich - die Autorinnenbiografie mit jener der Romanfigur ER I K A конит gleichsetzt).

So wird die untote Hauptfigur KARIN in »Die Kinder der Toten« als »ewige Tochter ${ }^{606}$ bezeichnet, deren Mutter üblicherweise im »befehlerischen Ton ${ }^{607}$ zu ihr spricht und sich »wie eine gehäkelte Klopapierhülle« über sie stülpt, »für den Fall, daß einer sie einwickeln möchte ${ }^{608}$. In ihrer Ehe war die verwitwete KARIN eine Gefangene gewesen, auch im Bereich der Sexualität - schließlich wird die Figur als ein Mensch beschrieben, der sich »nicht früh genug auf die Hinterbeine gestellt « hat, "damit man sein Geschlecht einmal sehen kann ${ }^{609}$. Nach dem Unfall muss sie das Versäumte im Tod nachholen, was sich vor allem in sexuellen Handlungen mit anderen Untoten manifestiert. ${ }^{610}$ Ihren einzigen Satz spricht die Figur, als es im Roman schließlich zu einem geisterhaften »Befreiungsakt ${ }^{611}$ von der Mutter kommt:

"Irgendetwas ist da an der Decke und breitet seine Arme nach seiner Mutter aus, ich sehe es zur Zeit noch nicht ganz deutlich, aber auf jeden Fall ist es nicht Jesus, der seiner Mutter einen Befehl zu geben wünscht, wer seine Kleider bekommen und an wen das Packerl Unsterblichkeit geschickt werden soll, denn es ist ihm davon ein bißchen was übriggeblieben (...) Wie das Licht möchte nun auch das Leben Karin verlassen, es zanken sich längst schon welche um ihr Kleid. (...) Als hauchte man schräg über den

\footnotetext{
602 KDT, S. 480.

603 Radisch, Maxima Moralia, unpaginiert.

604 Vgl. Kapitel I.5 dieser Studie.

605 Pontzen, Pietätlose Rezeption, S. 57 (Fußnote 23).

606 KDT, S. 236.

607 KDT, S. 482 .

608 KDT, S. 78.

609 KDT, S. 79.

6 Io Vgl. Scheidl, Ein Land auf dem rechten Weg, S. I 49.

6 I I Mayer/Koberg, Ein Porträt, S. I 29.
} 
Spalt einer Orgelpfeife, so ein leiser Ton: Mutter, Mutter erkennst du mich nicht? Ich bin zwar kein Sohn, aber tot bin ich schon. ${ }^{612}$

Den Klang von Orgelpfeifen kennt die Verfasserin dieser Zeilen als diplomierte Organistin nur zu gut. (Die untote Protagonistin in »Carnival of Souls«, MARY, ist - welch Zufall - ebenfalls Organistin.) Aber auch die Figur GUdRun soll zu Lebzeiten ihre Kräfte fürs Klavierspiel aufgebracht haben (»Wie ein letzter Vorwurf ist die Klinge zwischen den Sehnen, die Gudrun früher fürs Klavierspielen benötigt hat, ins Weiche gesprungen, als bestiege sie ein Pferd. « $^{613}$ ) - eine Ergänzung, die wiederum als verspielter Hinweis auf die Autorinnenbiografie interpretiert werden kann.

Auch die Kleidung der karin frenzel, an der die Mutter im Roman wiederholt herumkritisiert, ist immer wieder Thema, wenn es um Jelineks eigene Darstellung in der Öffentlichkeit geht: Wiederholt wurde die Autorin in Interviews gefragt, wie sie ihren Faible für Mode und Accessoires mit ihren schriftstellerischen Ansprüchen unter einen Hut bringen könne. »Es ist eigenartig, daß mir das so oft vorgeworfen wird, daß ich mich für Kleider interessiere ${ }^{614}$, so Jelinek in einem Interview, sie sehe nicht ein, warum sie sich diese Spielerei versagen solle, nur weil die Leute meinen, Feministinnen müssten sich in Sack und Asche kleiden. ${ }^{615}$ Auch in einem Interview nach dem Bekanntwerden der Nobelpreis-Entscheidung sagte Jelinek, dass sie gedenke, das Preisgeld, immerhin knapp I, I Million Euro, für ein japanisches Designerkleid auszugeben (und meinte es freilich nicht ernst). ${ }^{616}$ Die Figur eriкA конUт in $» D i e$ Klavierspielerin« muss sich vor der Mutter dafür rechtfertigen, wenn sie mit dem selbst verdienten Geld ein neues Kleid kauft (»Es schreit die Mutter: Du hast dir damit späteren Lohn verscherzt! ... da du nicht warten konntest, hast du jetzt nur einen Fetzen, der bald unmodern sein wird. ${ }^{617}$ ).

Neben diesen mehr oder weniger direkten Anspielungen auf die Beziehung zur Mutter ist es vor allem das Schicksal der jüdischen Vater-Familie, das Jelinek unverhohlen in den Text miteingebracht hat, etwa als sie zur Mitte des Buches (S. 333) mit den Bedeutungsvarianten des Wortes »mögen« spielt: Der Name

6 I 2 KDT, S. 487 .

6г 3 KDT, S. 52 .

6I 4 Jelinek, zitiert nach: Winter, Gespräch mit Elfriede Jelinek, S. I 5 f.

6 I 5 Vgl. Winter, Gespräch mit Elfriede Jelinek, S. I6.

6r6 Vgl. profil, Nr. 49, 2004, S. г 30. Diese Aussage ist allerdings als Koketterie zu verstehen. Wenige Wochen zuvor hatte Jelinek angekündigt, für sich nur einen Teil des Preisgeldes behalten zu wollen und den Rest zu spenden, vielleicht an engagierte Frauenprojekte. Vgl. profil, Nr. 42, 2004., S. I 24.

6 I 7 Jelinek, Die Klavierspielerin, S. 8. 
Jelinek »möge für viele Millionen [Ermordete] stehen, er mag aber nicht.« ${ }^{618}$ Auch etwas später wird explizit auf die Ermordeten der Familie Friedrich Jelineks verwiesen:

„Im Haus meines Vaters sind viele Wohnungen. Aber allein aus dem Haus von meinem Vati sind mindestens 49 Österreicher verschwunden, die brauchen jetzt keine Wohnung mehr. ${ }^{619}$

Von einer Cousine hatte Jelinek erfahren, dass 49 Familienmitglieder in der NSZeit ums Leben gekommen seien. Auf diese Information beruft sie sich offensichtlich in der zitierten Textpassage - ob es tatsächlich genau 49 Verwandte waren, die im Zuge der nationalsozialistischen Vernichtungspolitik zu Tode kamen, ist dabei als sekundär zu betrachten, da hier alleine die von der Autorin bewusst hergestellte Parallele zu der eigenen Familienbiografie von Interesse ist. ${ }^{620}$

In »Die Kinder der Toten« erwähnt Jelinek überdies auch den »Muffelofen der Firma J. A. Topf \& Söhne ${ }^{621}$ und benennt damit konkret einen Erfurter Industriebetrieb, der bereits in den r92oer Jahren Feuerungsanlagen in internationalem Maßstab gefertigt hatte und in den I93oer Jahren zum »zuverlässigen Geschäftspartner ${ }^{622}$ der SS-Bauleitungen avancierte: Topf \& Söhne installierten in Auschwitz, Buchenwald und anderen Konzentrationslagern Feuerungsanlagen für die industrielle Vernichtung von menschlichen Körpern. ${ }^{623}$ Der Antrag, den die Firma im Jahr r 942 für ihr Produkt beim Deutschen Patentamt einreichte, wurde mit folgenden Worten eingeleitet:

"In den durch Krieg und seine Folgen bedingten Sammellagern der besetzten Ostgebiete mit ihrer unvermeidbar hohen Sterblichkeit ist die Erdbestattung der großen Menge verstorbener Lagerinsassen nicht durchführbar. ${ }^{624}$

Die Ingenieure von Topf \& Söhne wussten demnach, was in den Konzentrationslagern der Nationalsozialisten vor sich ging. Der zuständige Chefingenieur

\footnotetext{
6I 8 KDT, S. 333 .

6 I9 KDT, S. 459.

620 Vgl. Kapitel I.5 dieser Studie.

62 I KDT, S. I 27 f. Zum Patentantrag selbst vgl. auch Horaczek/Wiese, Handbuch gegen Vorurteile, S. I 5, darin auch der Hinweis, dass das Deutsche Patentamt diesem Antrag »in makabrer Gedankenlosigkeit« mehrere Jahre nach Kriegsende stattgegeben hat, vgl. dies., S. I9 (End-

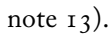

622 Assmann/Hiddemann/Schwarzenberger, Firma Topf \& Söhne, S. 7.

623 Vgl. ebd.

624 Schwarzenberger, Topf \& Söhne, S. I I.
} 
hatte sich den Lagerbetrieb in Auschwitz vorführen lassen und war dabei auf "MMängek bei der Durchführung der Vernichtung « ${ }^{625}$ gestoßen. Sein Kollege, der Leiter der Abteilung Ventilation, behob diese Mängel angeblich »schnell und professionell « ${ }^{626}$. Es ist diese teilnahmslose Kälte, diese Bürokratensprache, diese nüchterne Sachlichkeit der Handlung, die einen erschaudern lässt “ ${ }^{627}$, resümiert der Kulturwissenschafter Eckhard Schwarzenberger, der sich eingehend mit der Involvierung des Betriebs in die nationalsozialistische Vernichtungsmaschinerie beschäftigt hat. Bemerkenswert ist an dieser Stelle wiederum die Art und Weise, wie Elfriede Jelinek den Hinweis auf die Firma Topf \& Söhne in ihren Text einflicht - sie weiß über deren unheilvolle Geschäftsbeziehungen offenbar genauestens Bescheid, meint aber, den Leser darüber nicht belehren zu müssen, sondern erwähnt nur wie nebenbei den Namen der Firma, was sie auch 2002 bei der Verleihung des Heine-Preises in Düsseldorf gemacht hat: Dem Krematorium sei ihre Tante Lotte gerade noch entkommen, stellte Jelinek bei dieser Gelegenheit fest, doch die Tante sei immer noch in Auschwitz, denn »sie muß schauen und zurückschauen ... und was sieht sie? Sie sieht auf den Verbrennungsofen ihren Namen geschrieben. Auf dem Ofen, für den sie bestimmt ist, in den sie aber zum Glück nicht hineingekommen ist, steht ihr eigener Familienname geschrieben: Topf. Firma Topf. Und Söhne. Soll man also überhaupt schauen? « $^{628}$ Allein die wiederholte Nennung schafft Neugierde, was sich hinter diesem harmlos scheinenden Namen verbirgt. Die Beantwortung mithilfe historischer Aufarbeitung ist ernüchternd.

Und schließlich wird im Buch auf Jelineks Urgroßvater, den »Kriegsheimkehrer Isidor Kupido Jelinek«, verwiesen: »ein fescher Toter « ${ }^{629}$. An späterer Stelle wird von der Erzählinstanz noch der Jüdische Friedhof am Wiener Zentralfriedhof aufgesucht, in welchem beide Urgroßeltern begraben sind. Deren Gräber sind im Buch geschändet (»... und wer hat an Uropa Isidors und Uroma Bettys Grabstein gerüttelt, bis er umgefallen ist? ${ }^{630}$ ) - ein Verweis auf das geschändete Andenken der jüdischen Familienmitglieder.

Elfriede Jelinek ist für die Selbstinszenierungen ihrer Person in der Öffentlichkeit wie auch in ihren Texten bekannt. ${ }^{631}$ Anhand der Figur KARIN FRENZEL hat sie sich in "Die Kinder der Toten« an der neurotischen Hass-Liebe zur Mutter abgearbeitet - dies aber, wie es scheint, nur vordergründig. Vor allen

625 Assmann/Hiddemann/Schwarzenberger, Firma Topf \& Söhne, S. 7.

626 Ebd.

627 Schwarzenberger, Topf \& Söhne, S. I 2.

628 Österreich. Ein deutsches Märchen, unpaginiert.

629 KDT, S. 176.

630 KDT, S. 490.

63 I Vgl. Kapitel I.5 dieser Studie. 
anderen Selbstreferenzen ist es in erster Linie das Trauma der Vater-Familie, das zu Jelineks eigenem Trauma wurde, die Verfolgung und Vernichtung der europäischen Juden im Zweiten Weltkrieg, das in ihrem Opus Magnum die Feder führte, wie im weiteren Verlauf der Interpretation deutlich werden wird.

\subsubsection{Der Opfermythos als perfides Geflecht nationaler Mythen}

»Seit Jahrzehnten schreibt Elfriede Jelinek mit großem Erfolg an einem einzigen Buch.

>Die Kinder der Toten ist die Summe all ihrer Themen, ihrer Verachtung und ihrer Obsessionen.

Es ist das in seiner thematischen Gigantomanie und seiner sprachlichen Zerstörungswut radikalste Werk der Autorin. ${ }^{632}$

Wie Radisch treffend anmerkte, stellte Jelineks Roman 1995 kein Novum, sondern vielmehr die Summe aller bis dato aufgegriffenen Motive und Themen der Autorin dar. Auch in früheren Texten beschäftigte sich Jelinek bereits mit der sarkastischen Entlarvung und Destruktion verschiedener Alltags- und Trivialmythen (Sport, Medien, Heimat, Natur, Familie, Sexualität usw.). Auch in früheren Texten beschrieb sie ent-individualisierte und ent-lebendigte Charaktere, um ihre Mythendestruktion über deren Sprachverwendung darzubringen.

Das übergeordnete Ziel all dieser Mythendestruktionen, im Einzelnen aber auch in Summe betrachtet, ist es, Bewusstsein zu schaffen für die Beeinflussbarkeit und Manipulierbarkeit durch bestimmte Sprachgebrauchsformen in politischen und medialen Diskursen.

Mit Blick auf österreichische Spezifika stellen sich der Opfermythos und sein Fortwirken in der Gegenwart als perfides Geflecht nationaler Mythen dar, welche die unterschwellige, aber ständige Präsenz und auch gesellschaftliche Akzeptanz faschistischer oder zumindest rechtsideologischer Strukturen in Österreich widerspiegeln und damit die unzureichende kollektive, aber auch individuelle Auseinandersetzung mit Österreichs Zeitgeschichte befördern.

Im Folgenden werden daher einzelne, rekurrente Mythendestruktionen aus »Die Kinder der Toten« exemplarisch herausgegriffen und ihr Zusammenhang zu dem zentralen Thema des Romans hergestellt: der Verdrängung österreichischer Schuld für die Verbrechen des Nationalsozialismus und der Shoah.

632 Radisch, Maxima Moralia, unpaginiert. 


\subsubsection{Der Mythos vom Siegen: Sport ist Krieg}

»... Sport ist doch Krieg; oft wird mit anderen

Mitteln gekämpft, manchmal auch mit den

gleichen. ${ }^{633}$

Nach eigener Aussage empfindet Elfriede Jelinek einen allgemeinen »Haß auf Sportler ${ }^{634}$. Dieser ziehe sich als Thema durch all ihre Texte. In »Die Kinder der Toten« wird die scheinbare Harmlosigkeit des Sports auf Jelinek'sche Manier als Mythos destruiert. So wird etwa die Ausdrucksweise der Sportberichterstattung in »Die Kinder der Toten" hinterfragt, indem Jelinek die Reportersprache kopiert und sprachliche Parallelen zum Krieg herstellt: Sport sei ein »Kampf gegen die Uhr ${ }^{635}$, heißt es da, an anderer Stelle wird auf den »Krieg des Sports ${ }^{636}$ verwiesen. Diese Parallele rührt nicht von ungefähr: Der Zusammenhang zwischen Krieg und Sport und insbesondere zwischen Nationalsozialismus und Sport wurde bereits von zahlreichen wissenschaftlichen Publikationen beschrieben. ${ }^{637}$

Wie auch in Hinblick auf andere totalitäre Systeme festzustellen ist, verdankte der Nationalsozialismus seine breite Akzeptanz der Bevölkerung in seinen Anfangsjahren seiner geschickten propagandistischen Inszenierung, die sämtliche Bereiche des Alltags- und Freizeitlebens erreichte. Es sei an dieser Stelle nur an die Umorganisation des Vereinslebens verwiesen, die sich etwa im Bereich des Sports signifikant auswirkte. Den Ergebnissen sporthistorischer Forschung zufolge stellte gerade der Sport für die Umsetzung politischer Ziele und Interessen des nationalsozialistischen Regimes eine Reihe von funktionalisierbaren Elementen zur Verfügung, wobei als Hauptziele die »Rassenideologie« und der anvisierte "Angriffskrieg« zu erkennen sind. ${ }^{638}$ "Menschen üben Macht über andere Menschen aus. Diese Macht ist immer auch eine Macht über deren Körper « ${ }^{639}$, so der Sportwissenschafter und Historiker Rudolf Müllner. Die nationalsozialistische Sportpolitik habe sich an der Formierung eines imaginären sportlichen »Volkskörpers« orientiert. Die angestrebte Massenertüchtigung sei dabei unter die Leitziele »Volksgemeinschaft, Wehrhaftigkeit, Rassenbewusstsein und Führertum« gestellt worden. Diese Parameter seien allen Organisationsformen

633 Jelinek, zitiert nach: Venckute, Elfriede Jelinek im Zenit des Ruhms, unpaginiert.

634 Dies, zitiert nach: Ebd.

635 KDT, S. 25.

636 KDT, S. 32.

637 Auch in Kapitel I.4.I dieser Studie.wurde bereits darauf verwiesen.

638 Vgl. Müllner, Die Mobilisierung der Körper, S. 7.

639 Ebd., S. I I. 
des Sports übergeordnet gewesen. ${ }^{640}$ Auch in den Jugendorganisationen HJ und $\mathrm{BdM}$, den Betriebssportgemeinschaften und der neu geschaffenen Organisation »Kraft durch Freude « $(\mathrm{KdF})$ wurden Sport und körperliche Ertüchtigung gefördert und damit Siegeswille, Disziplin und Unterordnung einer breiten Masse als anzustrebende Ideale vermittelt. ${ }^{641}$ Ein wesentlicher Teil der ideologischen Arbeit des Nationalsozialismus lag in der Schaffung einer "Volksgemeinschaft«, eines »Wir-Gefühls« (»Die Reihen fest geschlossen«), wofür unter anderem der Sport ideale Voraussetzungen bot. In nahezu allen gesellschaftlichen Bereichen ist sowohl die ideelle, als auch finanzielle und politische Aufwertung von Sport und Leibesübungen im nationalsozialistischen Deutschen Reich festzustellen. ${ }^{642}$ Parallel zu dieser Aufwertung wurde ein »Neuarrangement der Werte am Körper « ${ }^{643}$ vollzogen, wobei der »erwünschte männliche arische, starke Soldatenkörper« in Wertungshierarchien ganz nach oben gestellt wurde. Und er hatte einen »Antikörper«: den »Judenkörper ${ }^{644}$.

Die Olympischen Spiele I 936 in Garmisch und Berlin stellten den Höhepunkt nationalsozialistischer Sportpolitik dar. Mit großem propagandistischem Aufwand wurden die Spiele vorbereitet und begleitet. ${ }^{645}$ Die deutsche Schauspielerin und Filmemacherin Leni Riefenstahl drehte im Auftrag des Propagandaministeriums die bekannten Olympia-Filme (»Fest der Völker« und »Fest der Schönheit«), für die sie national, aber auch international vielfach ausgezeichnet wurde. ${ }^{646}$ Die Sensibilität von Seiten der internationalen Staatengemeinschaft in Hinblick auf die nationalsozialistische Rassenpolitik war offenkundig zu diesem Zeitpunkt nicht in dem bereits erforderlichen Ausmaß gegeben - die Sportpropaganda des NS-Regimes hatte ihre Wirkung allem Anschein nach nicht verfehlt.

Problematisch ist Sport vor allem deshalb, weil sich seine Strukturen und Organisationsformen (etwa die zahlreichen Sportvereine) zur politischen Funktionalisierbarkeit geradezu anbieten. So wurde er im nationalsozialistischen Deutschen Reich massiv propagandistisch genutzt, um die Rassenpolitik des

\footnotetext{
640 Vgl. ebd., S. Io f.

64I Vgl.http://www.schlossbergmuseum.de/templates/archiv/sportstadt/c5-IIIreich.htm (Zugriff am 30.3.2012)

642 Beispielsweise rückte die Note für Leibesübungen in Schulzeugnissen an erste Stelle, wobei durch die differenzierte Aufschlüsselung der schulsportlichen Einzelleistungen der größte Teil des Zeugnisformulars ausgefüllt wurde. Vgl. Müllner, Mobilisierung der Körper, S. г 2.

643 Ebd.

644 Ebd., S. I 2.

645 Vgl. http://www.schlossbergmuseum.de/templates/archiv/sportstadt/c5-IIIreich.htm (Zugriff am 30.3.2012)

646 Vgl. Hovdar, Mein Schweigen half mir nicht zu vergessen, S. 42 ff.
} 
Regimes in breiten Teilen der Bevölkerung ideologisch zu verankern und den anvisierten Angriffskrieg vorzubereiten. ${ }^{647}$ Während des Kriegs erfüllte er eine kalmierende Wirkung, weil er zur Aufrechterhaltung scheinbarer Normalität beitrug und den Zusammmenhalt des (inzwischen schon angeschlagenen) »Volkskörpers" propagierte. Nach dem Krieg beförderte er das Vergessen und Verdrängen: Die Kriegshelden wurden von Helden eines scheinbar unpolitischen Sportgeschehens abgelöst.

Mit willfährigen Sportlern, die sich gerne in der Öffentlichkeit produzieren, rechnet Jelinek in ihrem Roman ebenso ab (die Autorin nennt als Beispiele etwa Niki Lauda oder Thomas Muster, die sich "rücksichtslos zu feiern « ${ }^{648}$ gedenken) wie mit der österreichischen Nation, die diese bloß aus Eigennutz anfertige, um von den Toten, die dieses Land hervorgebracht hat, abzulenken:

»Sportler: Österreich ist ja wie ein Bauplatz für diese halbfertigen Leute, die sich ohne sich mäßigen zu müssen, auf ihren Brettln in den Abgrund stürzen, wahrscheinlich weil ihnen die Räumlichkeiten oben schon zu voll sind. « ${ }^{649}$

Gerade in Österreich ist die Verquickung von Sport und Politik im Nationalsozialismus ein noch weitgehend unaufgearbeitetes Feld. ${ }^{650}$ Auch die Kontinuitäten in diesem Bereich nach dem Zusammenbruch des Regimes r 945 wurden von wissenschaftlicher Seite her bisher kaum untersucht. So stellt sich etwa die Frage, warum eine der Autobiografien von Toni Sailer, Nationalheld und Dreifachsieger von Cortina, dem auch in "Die Kinder der Toten « gedacht wird ${ }^{651}$, ausgerechnet von dem Autor und Lehrer Karl Springenschmid ${ }^{652}$ verfasst

647 Vgl. Müllner, Mobilisierung der Körper, S. I 2.

648 KDT, S. 444.

649 KDT, S. 28.

650 So muss sogar ein massives österreichisches Forschungsdesiderat eingeräumt werden: Wie Marschik 2008 feststellte, ist die NS-Zeit in Deutschland inzwischen die bestuntersuchte Phase der Sportgeschichte, in Österreich klafft hier (abgesehen von Detailstudien) immer noch ein großer weißer Forschungsfleck. Vgl. Marschik, Sportdiktatur, S. 8 f.

65 I Vgl. KDT, S. 37.

652 Springenschmid war bereits 1932 in die (damals in Österreich noch illegale) NSDAP eingetreten und hatte sich im NS-Lehrerbund engagiert. Nach dem "Anschluss« 1938 hatte er verschiedene, hochrangige Ämter inne: So war er etwa als Leiter des NS-Schulwesens in Salzburg sowie als Leiter der Abteilung für Erziehung und Kulturpflege im Reichsgau Salzburg, ab 1943 auch als SS-Hauptsturmführer tätig. Ein Enkel Springenschmids veröffentlichte in den r $980 e r$ Jahren eine sehr beschönigende Biografie des Großvaters (Laserer, Karl Springenschmid). Zu der eindeutigen und vielschichtigen Involvierung Springenschmids in das NS-Regime und seinen ideologisierenden Büchern vgl. Klee, Kulturlexikon zum Dritten Reich, S. 581, sowie Reiter, Der Waldgänger, S. 307-31 9. 
wurde $^{653}$ - einem Nationalsozialisten der ersten Stunde, der als Leiter des Nationalsozialistischen Lehrerbundes (NSLB) auf dem Salzburger Residenplatz die einzige Bücherverbrennung in Österreich veranstaltete. ${ }^{654}$

Eine nicht-wissenschaftliche, sondern poetische Auseinandersetzung mit dieser Problematik findet sich in »Die Kinder der Toten«, wobei auch hier festzustellen ist, dass Jelinek mit dem scharfen Blick als Autorin genau jene Mechanismen beschreibt, die auch in der kritischen Sporthistoriografie untersucht werden: die Ent-individualisierung im Sport, das Aufgehen in der Gemeinschaft eines sportlichen Sinnkollektivs zur Stärkung völkischen Zusammenhalts sowie die Schaffung von (Sport-)Mythen und deren personifizierter Aushängeschilder.

Als scheinbar "schuldlos « ${ }^{65}$ werden Österreichs Idole, namentlich Anita Wachter, Roman Ortner und Patrick Ortlieb, die Skistars der I 99oer Jahre, in Jelineks Roman entlarvt. Auch damals populäre Tennisstars wie Boris Becker, Steffi Graf (»Boris! Steffi! « ${ }^{656}$ ) und Thomas Muster (der »Spieler Muster ${ }^{657}$ ) oder die Formel I-Fahrer Gerhard Berger (»Sieg für Gerhard Berger! « ${ }^{658}$ ) und Karl Wendlinger (»... ein Fingerzeig ... des Gottes Wendlinger ${ }^{659}$ ) werden erwähnt - jedoch nur als Statisten einer unheimlichen Szenerie. Dominant sind die wiederholten Seitenhiebe auf den alpinen Skisport, die zum Teil auch recht detailliert und ausgeschmückt sind.

So wird etwa auch Ulli Maiers tödlicher Unfall r 994 bei der Kandahar-Abfahrt in Garmisch-Partenkirchen zweimal genannt. ${ }^{600}$ Die Besonderheit dieses Unfalls lag vor allem darin, dass er live im Fernsehen übertragen wurde. »... oh, das tut mir jetzt leid für die Ulli ${ }^{661}$, kommentiert die Fernseh-Sprecherin in »Die Kinder der Toten« das Geschehen, das tödliche Ausmaß des Sturzes verkennend. Solche Unglücke rauben dem Mythos Sport die scheinbare Unschuld - zumindest vorübergehend. Denn tragische Todesfälle, die auch noch via TV von einem Millionenpublikum verfolgt werden, sind selbstverständlich nicht vorgesehen und stehen in krassem Gegensatz zu den propagierten Glücksmomenten der Tourismuswerbung. Das Rennen in Garmisch, bei dem Ulli Maier verunglückte, wurde nach einer kurzen Unterbrechung fortgesetzt: The show must go on.

\footnotetext{
653 Sailer, Mein Weg zum dreifachen Olympiasieg.

654 Vgl. Reiter, Der Waldgänger, S. 309. Vgl. auch Marschik, Sportdiktatur, S. 8. Zu der Bigorafie Toni Sailers vgl. Müllner, Anton Sailer, S. $242-258$.

655 KDT, S. 25.

656 KDT, S. 25.

657 KDT, S. 345 .

658 KDT, S. 343.

659 KDT, S. I 89.

660 Vgl. KDT, S. 24 f. sowie S. 29.

66I KDT, S. 25.
} 
In »Die Kinder der Toten« wird klargemacht, dass die Opfer des Sports ebenso wie die Opfer des Kriegs - keine Bedeutung haben:

»... jeder Spaziergang wird hierzulande so eingerichtet, daß die Essenszeit nicht versäumt werde. Mit Essen richten wir uns ein, da kommt es schon vor, daß man versehentlich ein paar Menschen mitißt, das zählt hier noch zum Sport. « ${ }^{662}$

Wenn es weiters in »Die Kinder der Toten« heißt, dass wir beim Sport oft aufgeben, weil uns klar ist, dass wir "nicht zu den Siegern ${ }^{663}$ gehören, dann ist mit großer Sicherheit nicht der Krieg des Sports damit gemeint, denn österreichische Athleten sind - abgesehen von den eher glücklosen Fußball-Nationalspielern - auch auf internationaler Ebene erfolgreich. Dass Jelinek die Diktion des Sports immer wieder mit Parolen des Kriegs verknüpft, ist vielmehr als Hinweis darauf zu werten, dass der tatsächliche Krieg gemeint ist, in den wir unsere Söhne geschickt haben und der eine »fünfundzwanzig Meter lange Blutspur im Schnee ${ }^{664}$ hinterlassen hat, denn Österreich gehört, gemeinsam mit Deutschland, zu den klaren Verlierern des Zweiten Weltkriegs.

Im Roman ist der Sport schon alleine deshalb als rekurrentes Textelement auffällig, weil eine der untoten Hauptfiguren, EDGAR GSTRANZ einen gewesenen Nationalsportler darstellt - und wohl nicht zufällig einen Skifahrer: Der alpine Skisport ist in Österreich besonders populär, dementsprechend viel Geld wird auch in diesen Bereich investiert. Dessen wirtschaftliche Umwegrentabilität macht sich vor allem für die Tourismusindustrie bezahlt, die den alpinen Wintersport zu Vermarktungszwecken hinlänglich zu nutzen weiß. Auf Plakaten und in TV-Einschaltungen der Tourismuswerbung werden glitzernde schneeweiße Berge und glückliche, lachende Menschen gezeigt, die verschlafene Tiefschneehänge herunterwedeln. Die Mythosbildung findet hier vor allem im Bildbereich statt. Wie aus dem Kapitel über Roland Barthes' Mythentheorien bekannt, kann jedes Medium zum Träger einer mythischen Aussage werden, sowohl der geschriebene Diskurs als auch die Fotografie, der Film, die Reportage, das Schauspiel oder Werbeplakate. ${ }^{665}$

Solche Bilder zieht Jelinek heran, entfremdet und verzerrt sie aber, um sie als Mythen kenntlich zu machen, und schreibt ihnen das Unheimliche ein, etwa wenn sie die unaufhörlichen Skiabfahrten des mit dem Auto tödlich verunglückten EDGAR GSTRANZ begleitet, der möglicherweise eine Anspielung auf

662 KDT, S. $42 \mathrm{I}$.

663 KDT, S. I 27.

664 KDT, S. 32.

665 Vgl. Barthes, Mythen des Alltags, S. 87. 
den I99 I verunglückten Rudi Nierlich darstellt - auch dieser war mit seinem Auto gegen eine Hausmauer geprallt wie Jelineks Figur EDGAR :

»Dieser junge Mann hat ja so lange Zeit ohne Liebe, aber für Österreichs Alpinkader, gelebt, als man ihn in einem schnellen Fahrzeug die Hausmauer hochjagte, bis, ja bis zum Fenster im Erdgeschoß... «66

EDGAR rast in einem »Wiederholungszwang « ${ }^{667}$ unentwegt die Abhänge der Alpen hinab. Von Idylle kann hier aber keine Rede sein: Unheimliche Gestalten erscheinen wie aus dem Nichts und greifen nach EDGAR, glotzen ihn an, untote Wanderer öffnen ihre Rucksäcke - um ihn darin verschwinden zu lassen? (»Sind sie zurückgekommen, um ihn zu holen? « ${ }^{668}$ ) Die Untoten, die EDGA R vielleicht als »Landemarke« für ihre »Totengleichenfeste ${ }^{669}$ gebrauchen möchten, werden immer mehr, sind plötzlich überall, wollen EDGA R zu sich holen. Zahllose Hinweise, machen deutlich, welche Toten gemeint sind:

"In der Luft formieren sich immer mehr Leute, Edgar streift sie fast beim Dahinrasen. Aus den Fenstern im Boden schauen scheue Wesen zu ihm herauf, die schon vor Jahren ihren (in der Öffentlichkeit wenig bemerkten) Abgang genommen haben.... Doch da sind Gesichter, die unter Edgars Fußbreite aufwachen, immer mehr Gesichter, die aus dem Gras hervorwachsen wie modrige Pilze, die sich aufgeblasen haben, schon fährt Edgar über ihre Engelssamen. ... Ein Ast der Vergangenheit, die auch anders hätte laufen können, peitscht hervor ... Endlos ist die Masse der Menschen, die den Boden verlassen wollen. Und alle sehen sie äußerst gequält aus. ${ }^{670}$

Aufgrund der Ausdrucksweise in diesen und ähnlichen Passagen wird unmissverständlich klargemacht, dass die gequälten Gestalten die Shoah-Toten sind, die als "Ast der Vergangenheit« hervorpeitschen und nach dem unglücklichen Alpinsportler greifen.

Der alpine Skisport ist typisch für Österreich. Hierzulande lernen Kinder fast ebenso selbstverständlich Ski fahren wie Lesen oder Schreiben. Die Helden des Skisports sind die beliebtesten Werbeträger, weil sie im internationalen Vergleich überproportional erfolgreich sind. EDGAR ist demnach nicht zufällig gewesener Alpinskisportler. Der Missbrauch des Sports für ideologische Zwecke

666 KDT, S. г9o.

667 KDT, S. I 89.

668 KDT, S. I89.

669 KDT, S. 192.

$670 \mathrm{KDT}, \mathrm{S}$. $197 \mathrm{f}$. 
ist Jelinek ein Dorn im Auge. Anhand ihrer Figur EDG A R macht sie wiederholt die Verquickung mit dem Opfermythos deutlich, etwa wenn sie schreibt, dass ihre Figur einem »Meer von Landsleuten« ähnlich ist:

»[Diese] stimmen immer mit großen Mehrheiten ab und sind dann verwundert, wenn sie die Geschichte auf einmal hinter sich haben, die sie, tragende Säulen, grade eben noch machtvoll über sich gespannt hatten und mit rechten Geraden in sich hineinstoßen fühlten. So viel von etwas haben sie nun auch wieder nicht gewollt... « ${ }^{671}$

Die hier genannte "große Mehrheit« verweist vermutlich auf die Volksabstimmung zum so genannten »Anschluss« Österreichs an das Deutsche Reich, der am Io. April I 938 mit über 99 Prozent der Stimmen bestätigt worden war. ${ }^{672}$ Die »rechte Gerade« bezeichnet den rechten Arm, der ausgestreckt zum Hitler-Gruß erhoben wurde - nach dem »Anschluss« von vielen Tausenden, die sich in einem Menschenmeer am Wiener Heldenplatz und auch an vielen anderen österreichischen Plätzen eingefunden hatten, um den Machtwechsel zu bejubeln. Dass »so viel von etwas« nicht gewollt gewesen wäre, verweist auf die österreichische Selbstcharakterisierung, die zur Verniedlichung und Diminuierung tendiert (»ein bisserl« hätten wir nur gerne mitgemacht...).

In »Die Kinder der Toten« wird der Sport als Mythos destruiert: ein Vehikel der Massenmobilisierung, dessen sich die Nationalsozialisten in den I 93oer/4oer Jahren erfolgreich bedienten und das nach dem Zusammenbruch des Regimes bis heute zur Verwässerung des nationalen Selbstbildes beiträgt, indem es einfache Bilder zur Verfügung stellt, die Idylle (glitzernde Tiefschneehänge), die Stärkung völkischen Zusammenhalts und sportliche Höchstleistungen einzelner Athleten zu Zwecken der unhinterfragten kollektiven Identifikation mit dem Vaterland in den Vordergrund stellen. Die Abgründe der Vergangenheit gehen dabei im Scheinwerferlicht des allgemeinen Erfolgstrubels unter.

67I KDT, S. 283.

672 Vgl. Haas, Der Anschluss. Vgl. auch Steiner, Die verdrängten Jahre, S. 79. 


\subsubsection{Klingendes Österreich: Von Volksmusik bis Austropop}

»Einige Takte Volksmusik, Ötztaler Bläser schlagen ihre Lippen und Zähne in Menschen, die dauernd glauben, daß sie derweil etwas Besseres gerade versäumen, vielleicht Zillertaler Schürzenjäger ...« ${ }^{673}$

Auch österreichisches Liedgut, das Volkslieder und das Jodeln ebenso einschließt wie die Bundeshymne und Austropop à la Rainhard Fendrich ${ }^{674}$, wird in »Die Kinder der Toten« wiederholt als dankbares Mittel zur Zerstreuung aller Selbstzweifel beschrieben:

»Die Forderungen der Feriengäste gehen jetzt ... in eine ganz andere Richtung, stärker ins Volkstümliche, damit sie die Niederlage ihres Lebens durch einen großen Sieg, den Sieg im zweiten Weltkrieg, krönen können, den dieses Volk im Singen und Jodeln gewonnen hat... ${ }^{675}$

Die bösen Seitenhiebe auf (vorwiegend) triviale Musikgenres rühren nicht von ungefähr - nichts wird von Elfriede Jelinek, die selbst seit frühester Kindheit in klassischer Musik an verschiedenen Instrumenten ausgebildet wurde, dem Zufall überlassen. In »I am from Austria« besingt Fendrich seine fast schon romantische Liebe zur Heimat (»Do bin i her, da g'hör i hin « $\left.{ }^{676}\right)$. Selbstkritische Töne sind in trivialen Musikgenres wie volkstümlicher Schlagermusik oder Austropop nicht üblich, denn diese bedienen das Bedürfnis nach Harmonie und Wunscherfüllung. In diesem Sinne zielt diese Art von Unterhaltungsmusik auch darauf ab, den Nationalstolz zu befriedigen und zu befördern.

Prinzipiell schaffen Schlagermusik und ähnliche Musikrichtungen einfache, harmonische und scheinbar eindeutige Bilder, die - je nach Intention - mit unterschiedlichen Bedeutungen aufgefüllt werden können. Auf diese Weise kann auch die von Jelinek kritisierte seichte Unterhaltungsmusik zu einer Aussage werden (nach Barthes können »die Objekte selbst ... [zu] Aussagen werden, wenn sie etwas bedeuten«). ${ }^{677}$

673 KDT, S. 304.

674 Vgl. KDT, S. I9.

675 KDT, S. 22.

676 Steht zum Beispiel als Musikvideo auf YouTube zur Verfügung: http://www.youtube.com.

677 Ebd., S. 87 . 
Zudem scheint die Autorin, selbst diplomierte Organistin, die Qualität der dargebotenen Musikstücke für unerträglich zu halten, da sich die Erzählinstanz in „Die Kinder der Toten« sehr deutlich mit einer Botschaft über den regelmäßig am Samstag Abend ausgestrahlten "Musikantenstadl« an das öffentlich-rechtliche Fernsehen wendet:

»... ich denke mich noch nicht als ein Neuerer, bloß weil ich immer etwas hinzuerfinde, was aber schon oft gedacht wurde, allerdings muß ich dem ORF und dem ZDF sagen: Diese Musik ist grauenvoll. ${ }^{678}$

Ein weiteres Charakteristikum trivialer Musikgenres ist, dass sie zu einer nahezu uneingeschränkten Form der Identifikation (zum »Mitschunkeln«) einladen, in der kritische Reflexion keinen Platz hat. Jelinek geht in ihrer Kritik sogar noch weiter, denn auch an der echten Volksmusik (die sich in ihrer musikalischen Komplexität doch erheblich von Schlagermusik oder der so genannten »volkstümlichen Musik« unterscheidet) lässt sie kein gutes Haar. Ein sehr expliziter Verweis auf die scheinbare Idylle, die im »Musikland« Österreich mit Singen und Jodeln aufrechterhalten werden will, findet sich zum Beispiel in folgender Passage:

»... siehe da, die Menschen werden gestimmt, sie werden fröhlich gestimmt, und die Architektur versucht, uns eine ländliche Harmonie vorzuspielen, die man >das Jodeln` nennt. ${ }^{679}$

Dass die Menschen "gestimmt« werden, kann dahingehend interpretiert werden, dass sie auf politischer Linie gleichgeschaltet werden, dass sie "fröhlich gestimmt « werden, dass sie weiters von kritischer Reflexion ferngehalten werden und das, was ihnen an Identifikationsmöglichkeiten angeboten wird, unhinterfragt annehmen. Das genannte Jodeln ist dabei nur eines der möglichen Beispiele, wie Einfluss auf die Masse genommen werden kann.

Neben dem Singen und Jodeln begleiten auch verschiedenste andere $\mathrm{Me}$ lodien aus verwandten Musikgenres den nicht versiegenden Sprachfluss in "Die Kinder der Toten «, etwa der "Austria-Blues ${ }^{680}$ eines weiteren »Austrobarden ${ }^{681}$, Ostbahn-Kurti: KARIN FRENZEL hofft, das quälende Schweigen mit Musik aus dem Kofferradio unterbrechen zu können. Doch auch der »Herr

678 KDT, S. 439.

679 KDT, S. 42.

680 Vgl. KDT, S. 86.

68 I KDT, S. 20. 
Kurt Ostbahn« - in Österreich eigentlich als sozialkritischer Musiker bekannt wirft nur »seine triefenden Brocken ins Wilde hinaus, der Sänger der Arbeiter und Angestellten, damit diese die Fleischfetzen, als fertige Scheibengerichte, zwischen den Zähnen aus dem Nichts ihrer Wünsche wieder zurück apportieren... « ${ }^{682}$. Versuche einer kritischen Auseinandersetzung verhallen unverstanden. Und auch an dieser Stelle muss wieder auf die Jelinek'sche Methodik verwiesen werden, die nichts dem Zufall überlässt, denn Kurt Ostbahn tönt (wie übrigens auch Rainhard Fendrich ${ }^{683}$ ) ausgerechnet aus dem Kofferradio, was zeitlich weder zum Entstehungskontext des Buchs noch zu dem bekannten Musiker passt. Das Kofferradio gilt als technische Errungenschaft und typisches Accessoire der I 95 oer und I 96oer Jahre, bevor die Hörkultur vom Fernsehen abgelöst wurde. ${ }^{684}$

Diese ersten Dekaden nach dem Zusammenbruch des nationalsozialistischen Regimes standen unter dem Eindruck der »Stunde Null«, in der es galt, nach vorne zu schauen und das Gewesene zu vergessen: den Krieg mit seinen großen Verlusten auf allen Seiten und die bestialische Rassenpolitik des Regimes. Auf diese Weise schafft Jelinek in »Die Kinder der Toten« eine Kulisse, in der nebenbei erwähnte Kleinigkeiten große Bedeutung bekommen, denn sie staffiert ihre unheimliche Szenerie geschickt mit »sprechenden Requisiten« aus (die Objekte selbst werden zu Aussagen, wenn sie etwas bedeuten...).

Doch es gibt auch direktere Hinweise auf das große Thema des Romans, so wird etwa die Popmusik als »übergroße Helle ${ }^{685}$ bezeichnet, die uns immer wieder ins Dunkel stößt und die "alte Leier ${ }^{686}$ ablöst, was als Hinweis auf Aussagen öffentlicher Personen, etwa Politiker, interpretiert werden kann, doch endlich dieses Kapitel der österreichischen Geschichte auf sich beruhen zu lassen (»... sprechen wir nicht mehr davon ${ }^{687}$ ). Insgesamt werden die »österreichischen Lieder im Radio ${ }^{688}$ als seichte Unterhaltung für unmusikalische Pensionisten und als Geschäftemacherei abgewertet (»... damit der Sänger auch ordentlich kassiert $\left.{ }^{689}\right)$. Die Volksmusik, der Austropop und verwandte $\mathrm{Mu}-$ sikgenres sind damit nach Jelinek zu jenen Trivialmythen zu zählen, die zur Ent-historisierung und Ent-politisierung gesellschaftlicher Diskurse beitragen.

682 KDT, S. 86.

683 Vgl. KDT, S. I 9.

684 Zur Radiohörkultur der I 95oer und i 96oer Jahre vgl. Weber, Das Versprechen mobiler Freiheit, S. 85-I 42.

685 KDT, S. I I3.

686 KDT, S. I67.

687 KDT, S. 3 I9.

688 KDT, S. 2 I.

689 KDT, S. 2 I. 


\subsubsection{Der schöne Schein in TV und Werbung}

»... wie sagt der Dichter? Du schaust nicht ins Fernsehen, das Fernsehen schaut auf dich! ${ }^{690}$

Als Vermittler des »unverwechselbaren Tons der Unschuld « ${ }^{691}$, der nicht nur die triviale Unterhaltungsmusik, sondern auch die nationale Erinnerungskultur bestimmt, sind die österreichischen Massenmedien, allen voran der mächtige ORF, aber auch große Tageszeitungen, namentlich »Kronen Zeitung« und »Kurier«, in "Die Kinder der Toten« schnell ausgemacht:

»Und das Heilige erwacht in uns und wird uns vom ORF sowie tausenden Kilometern Glasfaserkabeln vermittelt. ${ }^{692}$

Die Massenmedien verbreiten ideologisch aufgeladene Trivialmythen und nutzen ihre Breitenwirkung darüber hinaus für die gewinnbringende Vermarktung von Werbezeiten aus. Der Werbung in TV und Radio, die uns Verbrauchern suggeriert, was uns gesund, schön, reich und glücklich macht, wird in »Die Kinder der Toten « auf vielfältige Weise Rechnung getragen: So taucht in unvermuteten Nebensätzen immer wieder ein Schokoriegel namens "lila Pause " ${ }^{693}$ auf oder wird das (domestizierte) Tier in KARIN mit »Chappi und Pappi ${ }^{694}$ gefüttert. Ähnliche Seitenhiebe finden sich auch auf die »Kinder-Milchschnitte« oder den Schokoriegel mit dem Namen eines Gottes, »Mars«, der kurzerhand $\mathrm{zu}$ »Gott Mars« umfunktioniert wird - ein kleiner aber deutlicher Hinweis auf die Götter, die wir fälschlicherweise anbeten. ${ }^{695}$

Und wenn die Gastwirtin der Pension Alpenrose nach dem Himmel sieht, den sie »am liebsten bei sechzig Grad vorwaschen würde, damit er sauber, nicht nur rein wäre ${ }^{696}$, dann ist dies nicht nur als Anspielung auf den Werbespot einer bekannten Waschmittel-Marke zu verstehen, sondern zugleich auch als weiterer Verweis auf die unliebsame Vergangenheit, die man in Österreich am liebsten »wegwaschen« würde, denn in »Die Kinder der Toten« ist der Himmel voll von Geistern der Holocaust-Toten. Mithilfe der Vorgaukelung einer heilen Welt (zum Beispiel in Werbespots) wird die kritische Auseinandersetzung mit nationalen Mythen jedoch unterbunden.

690 KDT, S. 4II.

69I KDT, S. 23.

692 KDT, S. 22. Zu »Kurier« und »Kronen Zeitung«vgl. KDT, S. 4I, S. 428.

693 KDT, S. I 25 oder S. I90.

694 KDT, S. 77.

695 Vgl. KDT, S. I9r.

696 KDT, S. 54. 
Versatzstücke aus der Waschmittelwerbung hatte Jelinek bereits in eines ihrer ersten Bücher, »wir sind lockvögel baby!«, eingebaut (WHite GiAnT). ${ }^{697}$ Die Kritik an den Medien zieht sich wie ein roter Faden durch ihr literarisches Werk, so hatte sie auch schon in dem frühen Essay »Die endlose Unschuldigkeit« die modernen Massenmedien als »kontrollinstanzen« der Gesellschaft, das Fernsehen als das "massenkommunikatorische über ich« bezeichnet. ${ }^{698}$ Die Destruktion des Mythos Medien gehört demnach zum Jelinek'schen Grundrepertoire. Wie auch in Hinblick auf andere in diesem Kapitel angeführte Mythendestruktionen ist auch hier wieder festzustellen, dass die Beispiele in »Die Kinder der Toten« aufgrund der Kompimiertheit, aber auch der im Jelinek'schen Euvre einmaligen Länge des Texts einfach zahlreicher, zum Teil auch expliziter als in anderen Jelinek-Texten sind, wie etwa in folgenden Textpassagen deutlich wird:

»... keine Rätsel mehr. Denn das Fernsehen hat sie uns schon tausendmal erklärt.« ${ }^{699}$

»... Ein Wirbelsturm aus Faserschmeichlermasse, wie sie uns, beim Werben um uns, schon öfter vorgeführt worden ist, am Beispiel einer Angorajacke (`Ist die neu? Nein, mit Fewa Wolle gewaschen!`). Die Durchsichtigkeit der Gefühle ist restlos entfernt worden, sonst würde ja das Fernsehen uns anschaun und nicht wir das Fernsehen ... ${ }^{700}$

»... Sie! Dagmar Keller oder wie Sie heißen, was verrenken Sie sich knackend den Hals, damit Sie noch einen winzigen Moment Anwesenheit herausmelken aus dem Objektiv dieses zur Objektivität verpflichteten Mediums, das mich, blau schimmernd, jeden Tag um mein Leben betrügt? ${ }^{701}$

»... halt!, über die Showtreppe tanzen jetzt unsere Marika R. und unsere Paula W., hopperla, wie die ihre Gebeine um sich herumstreuen ... Machen Sie keine blöden Witze über Ernst und Juppi, die eigens hier ins Fernsehgerät gereist sind! Die singen doch so schön .... ${ }^{702}$

Die forcierte Auseinandersetzung mit den (vor allem österreichischen) Medien in Jelineks Text hängt eng mit der Beurteilung der Geschichte zusammen. In einem 1998 geführten Interview meinte Jelinek, die österreichische Presse sei

697 Vgl. Kapitel r.6.2 dieser Studie.

698 Vgl. Kapitel r.6. I sowie r.6.2 dieser Studie.

699 KDT, S. 2 I 6.

700 KDT, S. 270.

701 KDT, S. 465 .

702 KDT, S. 566. 
eine Boulevardpresse, hierzulande gebe es keine Zeitung wie die Frankfurter Allgemeine in Deutschland, die sich um die Aufarbeitung der NS-Geschichte kümmerte. ${ }^{703}$

Und in der Tat scheint die Selbstreflexion im Sinne eines kollektiven Unrechtsbewusstseins und der Mitverantwortung an den Verbrechen der NS-Zeit ohne eine gesellschaftspolitisch versierte und historisch-kritische Presse auch heute noch, gut 20 Jahre nach Erscheinen des Romans und mit inzwischen über 70 Jahren Abstand zum nationalsozialistischen Regime, im österreichischen Gedächtnis nur unzulänglich stattzufinden. ${ }^{704}$ In »Die Kinder der Toten« bietet Jelinek schließlich die in diesem Sinne einzig logische Konsequenz an: »Eigentlich dürfte man überhaupt keinen einzigen Fernsehapparat besitzen. « ${ }^{705}$

\subsubsection{Mythos der Unschuld von Bergen und Seen}

»Dieses Land hat immer stillgehalten ... Seine Landschaft ist so schwierig, daß man nicht einfach gradeaus gehen kann. ${ }^{706}$

Mit der scheinbaren Unschuld österreichischer Natur befasst sich Jelinek bereits seit langem. "Kennen Sie dieses sснӧNE land mit seinen tälern und hügeln?«, fragte die Autorin einleitend in ihrem »Liebhaberinnen«-Roman (I 975), »es wird in der ferne von schönen bergen begrenzt. es hat einen horizont, was nicht viele länder haben. kennen Sie die wiesen, äcker und felder dieses landes? kennen Sie seine friedlichen häuser und die friedlichen menschen darinnen? ${ }^{707}$ Die Destruktion des Mythos Natur ist eines der vordringlichsten und dabei ein immer wiederkehrendes Thema in ihrem Werk. ${ }^{708}$

In »Die Kinder der Toten« gelingt es der Autorin unter anderem über die wiederholten Bezugnahmen auf die Mechanismen des Sports und dessen Ausbeutung menschlicher Ressourcen auch die dafür in Kauf genommene Ausbeutung der Natur vorzuführen (so rast zum Beispiel EDGAR über rasierte Berge dahin).

Hinter der vordergründigen Destruktion des Mythos Natur steckt eine historisch-politische Botschaft, denn die Naturkatastrophe in Gestalt der stetig

703 Jelinek, zitiert nach: Venckute, Elfriede Jelinek im Zenit des Ruhms, unpaginiert.

704 Vgl. Kapitel r.4.3 dieser Studie.

705 KDT, S. 436.

706 KDT, S. I6.

707 Jelinek, Liebhaberinnen, S. 5.

708 Vgl. etwa den Roman »Oh Wildnis, oh Schutz vor ihr». 
anwachsenden, alles rächenden Mure wird in dem Roman schließlich »eins mit einer Geschichtsapokalypse ${ }^{709}$.

Die Natur genießt hierzulande einen hohen Stellenwert, denn Österreichs Berge und Seen haben einen hohen konkreten (nämlich finanziellen) Wert für Sommer- und Wintertourismus, die einen wichtigen Faktor für die heimische Wirtschaft darstellen (»Was hat diese vom Tourismus schon ein wenig angekleckerte Landschaft sich jetzt wieder für sie einfallen lassen? Ist es das, was die hier unter Erlebnisurlaub verstehen? « $^{710}$ ) Zum anderen wird die österreichische Natur nach Jelinek dazu missbraucht, um eben jenen Teil der Geschichte, den die österreichische Bevölkerung dem Opfermythos entsprechend seit I 945 zu vergessen sucht, im Barthes'schen Sinne zu »ent-historisieren ${ }^{711}$, denn bei Jelinek ist auch die Natur nur scheinbar natürlich:

»Der Mensch hat ein moralisches Interesse an diesem hellen Schein, der die Schönheit der Natur ausmacht, er vergißt, daß ers war, der der Natur diesen Schein gegeben hat, indem er sich zu ihr bemühte. ${ }^{712}$

Die von der Tourismusindustrie viel strapazierten Bilder von schneebeckten A1pen, glitzernden Badeseen und verschlafenen Wanderpfaden werden in »Die Kinder der Toten« als Mythos entlarvt, indem immer wieder ihre Unheimlichkeit dargestellt wird: Im Boden der idyllisch scheinenden Natur, die erholungshungrige Touristen im Roman durchwandern, liegen Millionen Ermordete (wie »Dünger ${ }^{713}$ ), sogar in der Luft befinden sich diese (»Das Land braucht oben viel Platz ...« $\left.{ }^{714}\right)$, weil das Land gar nicht genug Gräber zur Verfügung stellen könnte.

Auf den »unheimlichen«, morbiden Charakter der österreichischen Natur und die Allgegenwärtigkeit der Toten weisen im Text zahlreiche Wortspiele hin: Zum Beispiel zählen »ein paar Millionen Zerquetschte ${ }^{715} \mathrm{zu}$ den großen Toten des Landes, wie gleich zu Beginn des Romans klargestellt wird, wobei die Formulierung »Zerquetschte« im Normalfall suggeriert, dass es sich nur um ein paar wenige handelt - hier sind die "Zerquetschten« allerdings wörtlich zu verstehen.

Die Natur wird bei Jelinek ihrer Unschuld beraubt, indem sie als etwas bisweilen sehr Grausames und Unberechenbares dargestellt ist. Plötzliche Wetter-

709 Mayer/Koberg, Ein Porträt, S. 205.

7 Iо KDT, S. 43 I.

7I I Vgl. Kapitel I.4.3 dieser Studie.

71 2 KDT, S. 27

713 KDT, S. 47 .

$7 \mathrm{I} 4$ KDT, S. 7.

7I 5 KDT, S. 7 . 
umschwünge, Unwetter, Regen, Nebeleinbrüche und heftiger Wind begleiten ähnlich wie in Leberts »Wolfshaut«-Roman - das Handlungsgeschehen in »Die Kinder der Toten«. Da wird zum Beispiel der »rasende Rauch des Nebels « ${ }^{716}$ angekündigt oder plötzlich aufkommender Wind beschrieben:

"Der Wind wird immer stärker, ein heftiges Atmen, ein weißes Hauchen weht über die Flanken des Gebirges, die Schatten zucken in den Klüften, den Hautfalten, die mit Menschenwachs geölt sind, damit sie vom vielen Dreck nicht wund werden. ${ }^{717}$

»... es droht ja zu dieser Jahreszeit jeden Moment das sogenannte schlechte Wetter. Regen haben wir heuer im Sommer genug gehabt, und die schweren Güsse der letzten Wochen, die immer wieder, wie Vogelschwärme, über das Land hergefallen sind und seine Wege und Straßen zerbissen haben, und zwar in enormer Ausdehnung des überregneten Gebiets, sind noch in frischer Erinnerung. Das Wasser hat die Leute von der Haut der Landschaft heruntergeklescht, als hätte sich ein Oberer, nein, nicht ein Ober, höher!, dann hat der Schlag mehr Wucht, von ihnen wie von einem Ungeziefer belästigt gefühlt. ${ }^{718}$

»Der Himmel ist eben noch strahlend blau gewesen ... aber dort drüben, wo das Wetter herkommt, dort braut es sich jetzt wirklich zusammen, es wird fast unmerklich dunkler, es wird scho glei dumper, nein, das Christkind kommt noch nicht. Es ist anders als sonst, wenn ein Gewitter kommt. ${ }^{719}$

»Immer öfter brüllt jetzt stoßweise dieser Wind auf, in dicken wattigen Böen kehrt er den Himmel, fährt über alles hinweg, ein Maler, dem die Lebewesen, die er malt, dafür das Leben weggenommen haben. ${ }^{720}$

Mitunter wird die Natur oder werden Naturerscheinungen (wie etwa oben genannte Wetterumschwünge) auch anthropomorphisiert dargestellt - möglicherweise auch eine motivische Übernahme von Lebert ${ }^{721}$, die das Ausdrücken des »Unheimlichen« verstärkt. So ist bei Lebert der Wind ein Kutscher, der »saß dort oben und knallte mit seiner Peitsche, hetzte die Wolken über das Land und pfiff ein altes Fuhrmannslied ${ }^{722}$. Auch bei Jelinek kommen Nebelfetzen

7 I 6 KDT, S. 27.

717 KDT, S. Iо2 f.

7 I 8 KDT, S. 5 I4.

719 KDT, S. 520.

720 KDT, S. 625.

72 I Vgl. Scheidl, Ein Land auf dem rechten Weg, S. $153 \mathrm{f}$.

722 Lebert, Wolfshaut, S. 68. 


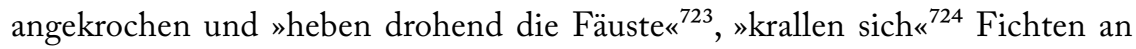
Erdreste, atmet die Talsohle »laut und schwer ${ }^{725}$ oder schüttelt sich die Erde »vor dem, was sich ihr in die Brust drängt«:

»... soviele Menschen, daß es geradezu das Gestein wegsprengt. Ja. Es wird ihr eng um die Brust. Wir haben ihr die Luft abgeschnürt, obwohl wir ihr soviele Menschen entnommen haben. Sie wurde uns nicht leichter dadurch. ${ }^{726}$

An anderer Stelle wirkt die Natur weniger menschlich als vielmehr wie ein Tier. Ist etwa der Regenschleier bei Lebert ein »blaugraue[s] Einhorn«, das mit »unbeschlagenen Nebelhufen ${ }^{727}$ durch breite Pfützen trottet, so tritt die Natur bei Jelinek mitunter als hund- oder wolfsähnliches Tier in Erscheinung:

»Da kommt ein Wesen gekrochen, der Wald atmet plötzlich laut, er hechelt, als wäre er zum Waldi geworden, woher nimmt er noch die Kraft dazu? Man kann ja schon durch sein Laub hindurchsehen! ${ }^{728}$

»... launisch legt die Natur auf dies und jenes ihre Pranken, läßt wieder los, ohne zu beachten, daß der Spielkamerad von ihr vollkommen zerquetscht, zerfetzt worden ist. Sie schnüffelt an den Stücken, heult ihr Lied ins Helle hinein, bis die Nacht kommt, und dann heult sie ein anderes Lied, tief aus der Kehle heraus. $" ~ " 29$

»... Moment, war da nicht ein Donnern? Ja, da hat ihm einer glatt das Fell des zahmen Waldes, der plötzlich zu einem wilden Untier geworden ist, über Nacken und Schultern geworfen.... ${ }^{730}$

In »Die Kinder der Toten« entpuppt sich Österreichs Natur als etwas Unheimliches, denn der Mensch hat ihr längst seinen morbiden Stempel aufgedrückt, zum einen durch die wirtschaftsorientierte Vergewaltigung ihrer Ressourcen, zum anderen aber durch den »freigiebigen Umgang « ${ }^{731}$ dieses Landes mit seinen Menschen: die willkürliche Ermordung tausender Menschen im Rahmen des

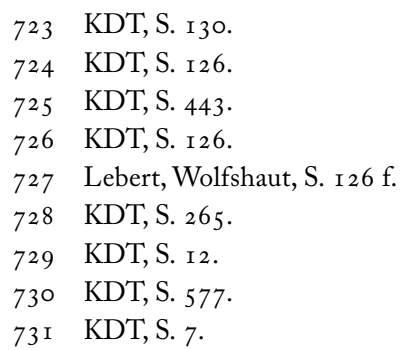


Nationalsozialismus und des Zweiten Weltkriegs auf dem scheinbar idyllischen Grund und Boden österreichischer Naherholungsgebiete.

\subsubsection{Auschwitz: Wir waren's nicht}

»Einer muß das Gemüt ja tragen, und die Deutschen, tragen es am liebsten, die geben es nicht an den Nachbarn ab, wenn sie müde werden. ${ }^{732}$

Im Text befinden sich etliche Hinweise auf jene zahllosen »lebende[n] Leichname ${ }^{733}$, die sich allmählich aus ihren Verstecken hervorarbeiten und sich mit den Regenfluten zu jenem braunen, giftigen Untoten-Brei vermischen, der letzten Endes als Mure über die Pension kommt. Dieses Motiv wird im Lauf des Romans sowohl in seiner Eindringlichkeit als auch Eindeutigkeit immer mehr gesteigert, denn mit immer expliziteren Hinweisen wird ausgedrückt, welche Leichname konkret gemeint sind: Da wird zum Beispiel auf das Gas verwiesen, in das die Opfer der nationalsozialistischen Vernichtungspolitik seit Anfang I 942 geschickt wurden: $:^{734}$

„Es muß sehr giftiges Gas gewesen sein, woher sonst die zinnoberrote Haut? Da ist etwas böse aus den Düsen gezischt... ${ }^{735}$

»Es gibt ja inzwischen Citygas light, viele wären ärgerlich gewesen, hätte es das zu ihrer Zeit schon gegeben. Sie hätten sich etwas anderes zum Sterben aussuchen müssen oder ... atmen können, und es wäre ihnen gar nichts passiert. ${ }^{736}$

»Ins Gas sind viele geschickt worden...« ${ }^{737}$

»Die neuen Toten haben nicht mehr die Qualität der älteren, die von uns noch gründlichst abgeduscht worden sind. ${ }^{738}$

732 KDT, S. 497.

733 KDT, S. I72.

734 Bei der Wannseekonferenz im Januar 1942 wurde die so genannte "Endlösung der Judenfrage« beschlossen. Vgl. Studt, Das Dritte Reich in Daten, S. 77 f.

735 KDT, S. 67.

736 KDT, S. 69.

737 KDT, S. $70 \mathrm{f}$.

738 KDT, S. 435 . 
Aber auch der Rauch und das Feuer der Schornsteine, in welchen die Zyklon-B-Vergifteten verbrannt wurden, als die Aufnahmefähigkeit der Massengräber in den Konzentrationslagern erschöpft war, werden wiederholt thematisiert:

»... schon wieder ist eine Bekanntschaft Schall und Rauch...« ${ }^{739}$

»Wenn wir nur Geduld hätten, am Rad des Schicksals rechtzeitig zu drehen, dann könnten wir noch die Kurve kratzen. Aber was wir dann auch essen müßten, das wäre ziemlich angebrannt. ${ }^{740}$

»... keuchend ziehen sich Leiber an einer unsichtbaren Reißleine bergauf, sie sind lang im Rauch gelegen und ganz schwarz geworden, ihre Konditionen sind nicht die besten. ${ }^{741}$

»Es singen die Jünglinge im Muffelofen der Firma J. A. Topf \& Söhne. « ${ }^{742}$

"Asche. Große Ursache, kleiner Rest. ${ }^{743}$

$\mathrm{Zu}$ den nationalsozialistischen Vernichtungslagern zählten unter anderem die Konzentrationslager Majdanek, Sobibor, Treblinka und Belzec. Aber ein Name vor allen anderen ist es, der zum Synonym für die Judenvernichtung unter nationalsozialistischer Herrschaft wurde: Mit »DER ORT IN POLEN « ${ }^{744}$ verweist Jelinek im Roman unmissverständlich auf Auschwitz-Birkenau ${ }^{745}$. Der Name des Lagers wird jedoch nicht genannt - die Leerstelle ist bereits deutlich genug.

In Auschwitz und in vielen anderen Lagern brannte jenes Feuer, »das in insgesamt ${ }_{4} 6$ Brennkammern im Dauerbetrieb über 24 Stunden mehr als 4700 Leute verbrennen ${ }^{746}$ konnte.

Auch spart Jelinek nicht an Hinweisen auf die materiellen Werte, die den NS-Opfern im Rahmen der Arisierungen oder in den Konzentrationslagern ty-

\section{KDT, S. 20.}

KDT, S. 43.

KDT, S. 127.

KDT, S. I 27 f. Zu der hier genannten Firma »Topf \& Söhne« siehe Kapitel 3.2.4.2 dieser Studie.

KDT, S. 589 .

KDT, S. 632. Im Roman (die Bedeutung und Wirkung unterstreichend) mit Großbuchstaben geschrieben.

Auch als »Auschwitz II « bezeichnet.

KDT, S. 4I9. 
pischerweise geraubt wurden, etwa das Haar, auf das in folgendem Wortspiel hingewiesen wird:

»Was scheren wir die Toten, Nachwuchs gibt es genug, und der kann sich dann die Haare wachsen oder auch ganz kurz stehen lassen, weil das auf dem Foto so fesch ausschaut. ${ }^{747}$

Mit dieser Formulierung wird nicht nur (im übertragenen Sinne) ausgedrückt, dass uns Österreicher die Toten nicht scheren, wir ihrer also nicht in dem gebotenen Ausmaß und unter Einbeziehung der eigenen Schuld gedenken, sondern zugleich auch, dass sie (im wörtlichen Sinne) tatsächlich geschoren wurden, denn in den KZs wurde den Gefangenen meist das Haar abrasiert, bevor sie zur Strafarbeit oder ins Gas geschickt wurden - es hatte schließlich materiellen Wert, ebenso wie andere persönliche Gegenstände, zum Beispiel Schmuck, Schuhe, Brillen oder Goldzähne, die gesammelt wurden und welche die untoten Holocaust-Opfer am Ende des Buchs mit im Gepäck haben, als sie zu Hauf die »Pension Alpenrose« heimsuchen.

Das geschorene Haar der Shoah-Toten quillt im Roman immer wieder und immer öfter unvermutet aus der Erde, aus Bergritzen oder Möbelstücken hervor oder legt sich in anderen schaurigen Bildern über die Landschaft.

Die rekurrente Verwendung der Haar-Metapher erinnert an Paul Celans berühmtes Gedicht »Todesfuge«:

\section{»(...) Schwarze Milch der Frühe wir trinken dich nachts}

wir trinken dich morgens und mittags wir trinken dich abends wir trinken und trinken

Ein Mann wohnt im Haus und spielt mit den Schlangen der schreibt

der schreibt wenn es dunkelt nach Deutschland dein goldenes Haar Margarethe

Dein aschenes Haar Sulamith wir schaufeln ein Grab in den

Lüften da liegt man nicht eng (...)

Schwarze Milch der Frühe wir trinken dich nachts wir trinken dich mittags der Tod ist ein Meister aus Deutschland wir trinken dich abends und morgens wir trinken und trinken der Tod ist ein Meister aus Deutschland sein Auge ist blau 
er trifft dich mit bleierner Kugel er trifft dich genau ein Mann wohnt im Haus dein goldenes Haar Margarete er hetzt seine Rüden auf uns er schenkt uns ein Grab in der Luft

er spielt mit den Schlangen und träumet der Tod ist ein

Meister aus Deutschland

dein goldenes Haar Margarete

dein aschenes Haar Sulamith ${ }^{748}$

Das »aschene Haar« Sulamiths ist darin als Bild für die jüdischen Opfer der Shoah zu begreifen. Celans Gedicht taucht auch an anderer Stelle ein weiteres Mal auf, als auf die "schwarze Milch der Frühe ${ }^{749}$ Bezug genommen wird: Die Untoten bereiten sich gerade auf ihren finalen Racheakt vor und »behäbige Gesichter« heben sich zur Nacht hinauf, aus der wir »die schwarze Milch von einem Dichter [Celan] ansaugen und dann in unsere Glasln spucken ${ }^{750}$. In Jelineks Roman ist an der Haarmetapher vor allem das wichtig, worauf diese verweist: nämlich auf das, was nicht mehr da ist - die Männer, Frauen und Kinder, denen die Haare abrasiert wurden. Die Haare können als unübersehbare "Zeichen einer abwesenden Anwesenheit ${ }^{751}$ gedeutet werden.

»Ist das nicht Haar? Dort kommen Blut und Haar aus der Zimmerdecke herabgeschossen, Tentakel einer grundlegend anderen Existenz. ${ }^{752}$

"... jetzt ist es soweit: Das ganze Volk Abrahams wirft sein Haardach herab, ein rotes Meer, das sich ein zweites Mal nicht wieder teilen wird, da soviele versucht haben, es aus beinernen Humpen zu saufen, eine alte Sitte hierzulande... ${ }^{753}$

Auch die "Lampenschirme aus Menschenhaut ${ }^{754}$, die Jelinek bereits in ihr "Burgtheater «-Stück eingebaut hatte, werden in »Die Kinder der Toten« wieder genannt. Sie versinnbildlichen geradezu Freuds »Unheimliches«, denn in ihnen steckt das Bekannte und Altvertraute, das in seiner Entfremdung - den ent-humanisierten Opfern der Konzentrationslager - zu grausigem Entsetzen führt.

748 Celan, Mohn und Gedächtnis, S. 37 ff.

749 Ebd.

$75^{\circ}$ KDT, S. $55^{8}$.

75 I Just, Zeichenleichen.

752 KDT, S. 404.

753 KDT, S. $405 \mathrm{f}$.

754 KDT, S. 279. 
Auch in den folgenden Textbeispielen wird die immer eindringlichere Präsenz der nach Rache trachtenden Untoten deutlich:

»Sind die Löcher im Boden überhaupt tief genug? Die Toten sind doch, um ihrer selbst willen, zerkleinert worden. Werden sie ihre Körper wiederfinden aus der Asche ? « ${ }^{755}$

»Fremdeste Kulturen erscheinen in einem Kastel und werden, körperlos wie Licht, herumgetragen, müssen sich vorzeigen, wie eine neue Darreichungsform der hl. Eucharistie, und werden trotzdem nicht erkannt, wenn sie unter uns erscheinen. Diese Körper schweigen, wenn auf sie getreten wird, und nichts mehr bringt sie zum Unaussprechlichen des Lebens zurück... « ${ }^{756}$

»Nur keine überflüssigen Flüssigkeiten! Also überall klebt und ist vollkommen angetrocknet diese Menschenscheiße, dieses Produkt des Todes, ähnlich dem Geld oder dem Wort, die auch zur Gesamtschule des Todes integrativ dazugehören. « ${ }^{757}$

»... unter der Erde hat sich etwas empört... $\ll^{758}$

»Die wesentlichen Wesenheiten können heute nicht vollständig sich uns anschließen, sie sind im Gegenwärtigen gefangen und können nicht das Gewesene werden, aber auch nicht Gegenwart. Dafür wollen sie uns die Heimat unheimisch machen. Sie wollen, beim Nachspiel, ein Ergebnis ertrotzen in diesem zur Zeit noch unentschiedenen Spiel, bei dem wir mit ihren Knochen und Schädeln müßig herumgekickt haben, um uns keck ihre Teppiche und Halsketterln, ihre Goldzähne, Bilder und Briefmarkensammlungen zu grapschen. ${ }^{759}$

Wo der Supergau der Unmenschlichkeit stattgefunden hat, daran lässt Jelinek in ihrem Roman keinen Zweifel: nicht nur, weil sie in den betreffenden Textpassagen die grammatikalische Entscheidung für Nominativ Plural getroffen hat (vgl. etwa das Textbeispiel oben: "wir« haben mit den Knochen und Schädeln der Opfer herumgekickt und haben "uns« ihre Teppiche und Goldzähne gegrapscht usw.). ${ }^{760}$ Immer wieder werden Österreich und Deutschland ausdrücklich als Kriegstreiber sowie als Hauptschuldige für den Holocaust genannt:

755 KDT, S. I 8.

756 KDT, S. 23.

757 KDT, S. 68.

758 KDT, S. 60.

759 KDT, S. 93.

760 Die Verwendung des Nom. Pl. ist aufgrund der häufigen Perspektivenwechsel der Erzählinstanz nicht durchgängig, in aussagekräftigen Textpassagen, aber häufig und auffällig. 
»Aus dem Fleischhaufen ... der österreichischen Städte, die es mit ihren Völkern immer schon toll getrieben haben, sind drei Personen herausgefischt worden... « ${ }^{761}$

»... das Unheimliche beginnt die Erde zu umkreisen, nachdem es zuvor in Deutschland und Österreich heftig herumgeschnuppert hat, bis in die letzten Winkel und Ritzen hinein. Seit diese Länder ihre Totenfabriken geschlossen haben, haben sie sich mehr aufs Empfinden verlegt, das ist die Medienmedizin, die sie uns jeden Abend in die Augenschluchten eintropfen. ${ }^{762}$

In zuletzt zitiertem Textausschnitt ist in einem Satz sowohl thematisch als auch sprachlich sehr vieles enthalten, das im Laufe des Romans in immer variierten Formen wiederkehrt: das »Unheimliche«, das im Zusammenhang mit dem möglichen Bezug zu Freud angesprochen wurde und hier anthropomorphisiert dargestellt ist - es erinnert damit an die unheimliche, transzendentale Macht, die stets über all dem Geschehen wacht und uns "am Genick " ${ }^{763}$ fasst, wenn wir nicht damit rechnen. Darüber hinaus sind Österreich und Deutschland, die Hauptaggressoren des Zweiten Weltkriegs, in dieser Passage explizit erwähnt. Die »Totenfabriken« verweisen auf die Gaskammern und Schornsteine jener Konzentrationslager, die als "Vernichtungslager» traurige Berühmtheit erlangten.

Dieser Hinweis kann als eindeutig erachtet werden, auch wenn hier auf das assoziative Textverständnis abgezielt wird: Die Schornsteine von Fabriken erinnern an die Schornsteine der Konzentrationslager, in welchen die Gastoten massenweise verbrannt wurden, was Betroffenen-Berichten zufolge einen charakteristischen süßlichen Geruch verbreitet haben soll. Vermehrte Hinweise auf einen süßlichen Gestank finden sich im Roman vor allem ab Seite 437, die Mure ist zu diesem Zeitpunkt bereits kräftig angewachsen und macht sich bereit, die steirische Landschaft zu überfluten:

„Ein gewisser, ihnen aus älteren Hirnschichten bekannter Geruch lastet über dem Ort, wo kommt er nur her? Als hätte ein Abdecker etwas aus seinem Lkw gekippt. Es ist niemand zu sehen, aber der Gestank ist geblieben, er wird sogar stärker, ist da eine $\mathrm{Zu}$ ckerlfabrik? Die Leute lachen in ihrer Vereinsmeierei, sie warens nicht ... «" ${ }^{764}$

\footnotetext{
76I KDT, S. 28.

762 KDT, S. 54 .

763 KDT, S. I 3 .

764 KDT, S. 437.
} 
"Ist es übernatürliches Fleisch, das hier, da sies eben noch knusprig angebraten hat, dann doch verdirbt? ... Der Gestank legt sich wie eine Zierdecke über Haus, Garten, Wald. ${ }^{765}$

"Auf der anderen Seite verbreiten die großen Scheiterhaufen einen solchen Gestank, daß die Gegend im Umkreis von vielen Kilometern verpestet ist. " ${ }^{766}$

Und schließlich bringt Jelinek in oben zitierter Textpassage die »kontrollinstanzen der gesellschaft ${ }^{767}$ zur Sprache (die »Medienmedizin«, die uns jeden Abend in die »Augenschluchten getropft wird»): Sie füttern uns mit Trivialmythen und machen uns blind für die Schuld, die wir für die Millionen Toten tragen. Kompakter als in diesem kleinen Absatz hätte die Autorin die großen Themen ihres Romans kaum zusammenfassen können.

Auch erfolgen in »Die Kinder der Toten« immer wieder Gegenüberstellungen der beiden für den Zweiten Weltkrieg und den Holocaust hauptverantwortlichen Länder, Österreich und Deutschland, die in puncto Entfnazifizierung und Wiedergutmachungsmaßnahmen von Seiten der alliierten Siegermächte nach 1945 äußerst unterschiedlich behandelt wurden und dementsprechend auch nach innen hin mit der Konfrontation von Schuld und Mitverantworung jeweils sehr verschieden umgegangen sind (»... DIE SIEGER, die waschen uns bald rein, damit wir ein paar Jahre später unbesorgt ihr Gewand anziehen und selber Sieger werden können. $\left.{ }^{768}\right)$. In diesem Punkt stimmt Jelinek weitestgehend mit den Charakterisierungen des deutschen Soziologen Mario Rainer Lepsius überein, der die Terminologie der »Externalisierung « und »Internalisierung« von Schuld geprägt hat. ${ }^{769}$

»Einer muß das Gemüt ja tragen, und die Deutschen tragen es am liebsten (Internalisierung, Deutschland), die geben es nicht an den Nachbarn ab (Externalisierung, Österreich), wenn sie müde werden. « ${ }^{770}$

Auch bezeichnen sich die Österreicher gerne als weniger obrigkeitshörig als die Deutschen - eine immer wieder zitierte, gefällige Selbstcharakterisierung, die bei Jelinek ironisch zu verstehen ist.

765 KDT, S. 438.

766 KDT, S. $487 \mathrm{f}$.

767 Jelinek, Die endlose Unschuldigkeit, S. 53. Vgl. auch Kapitel r.6.2 dieser Studie.

768 KDT, S. 497.

$769 \mathrm{Zu}$ den Begriffen »Externalisierung «, »Internalisierung « und »Universalisierung « von Schuld siehe Lepsius, Das Erbe des Nationalsozialismus, S. 250-264. Vgl. auch Kapitel I.4.4 dieser Studie. KDT, S. 497. 
"Eine Stimme aus Halle fordert in fremdartigem Deutsch die Einhaltung dieses Gebots Geschwindigkeitsbeschränkung, uralte Gehorsamkeiten zucken in den Pfoten dieser Frau, aber hierzulande beachtet man die Gebote der Behörden grundsätzlich nicht so genau ... Hier ist die Obrigkeit noch etwas, das grundsätzlich bekämpft gehört. «771

Auch mit Formulierungen wie dem »unverwechselbaren Ton der Unschuld « ${ }^{772}$, in dem sich in der Pension eine österreichische Dame mit einer deutschen unterhält, wird auf die österreichische Selbstdefinition als Opfer aufmerksam gemacht.

Wie bereits im »Burgtheater«-Stück stellt sich Jelinek auch in »Die Kinder der Toten « gegen jedwede Konstruktion eines vermeintlichen Nationalcharakters, indem sie diese als vorgeschobene Rechtfertigung Österreichs für den Opfermythos entlarvt. Dieser ist in den folgenden Textpassagen sehr explizit formuliert:

"Auf einmal, völlig zwecklos, ist die Vergangenheit wieder da, unmöglich sie zu lieben. Wieso jetzt? Wir haben sie doch gerade erst zum Einkaufen geschickt, in einen Supermarkt, dort gibt's Ersatz-Menschenteile, und jetzt ist sie schon wieder da. Wir haben noch kein Kleingeld zum Herausgeben. Außerdem müssen erst die alten Vorräte aus dem Kühlschrank unseres Gedächtnisses geräumt werden, wo sie aufgehoben und aufgeschoben waren. ${ }^{773}$

»Wir waren vorhin beim Gestein: man vermag es, wie das Gestern, nicht romantisch zu betrachten, wenn man es fünf Zentimeter vorm Gesicht hat und keine Hand frei, sich aus ihm vorzubringen: wir warens nicht! Menschen verschwanden! Ja, hier, aus der Natur, diesem bänglichen Anfänglichen. ${ }^{774}$

Mit diesen deutlichen Worten wird klargestellt: Wir waren es! Wir sind schuldig! Der Mythos des nationalen Opfers konnte nur funktionieren und über Jahrzehnte hinweg aufrechterhalten werden, indem sich ein Großteil der österreichischen Bevölkerung (die »Vielen « ${ }^{775}$ ?) aufs Schweigen verabredet hatte.

77 I KDT, S. го.

772 KDT, S. 23.

773 KDT, S. I $5 \mathrm{f}$.

774 KDT, S. I6.

775 Lüdtke, Macht der Emotionen, S. 54. Bei Alf Lüdtke bezeichnen die »Vielen« jene, die sich während der NS-Zeit weder aktiv in der NSDAP oder einer ihrer Organisationen noch im Widerstand betätigt haben. Vgl. Kapitel I.4.2 dieser Studie. Hier wird hingegen vielmehr die Frage aufgeworfen, wie sich die "Vielen« nach I 945 verhalten haben mögen: Haben sie auch nach dem Zusammenbruch des NS-Regimes stillgehalten und über das Geschehene geschwiegen? 
Auch am Schauplatz des Romans wird über die Toten des Nationalsozialismus eisern geschwiegen.

Das »Schweigen« ist bei Lebert explizit im Namen des Dorfes formuliert, bei Jelinek fallen das Stillhalten und Schweigen als rekurrente Textelemente auf, die einmal ex- und einmal implizit formuliert sind. Man solle über die »Toten, die unser Land schließlich ausmachen, nicht sprechen ${ }^{776}$, heißt das Schweigegebot, das bereits zu Anfang formuliert ist. Viele weitere Beispiele folgen:

»Ruhe, hier schweigen Existenzen!«777

"Länder, die zum Schweigen gebracht worden sind. $" 778$

»Diese Körper schweigen... ${ }^{779}$

»Das Schweigen beginnt für sie erst. ${ }^{780}$

»... jeder Tritt wird sofort mit einer Fußangel aus Schweigen umschlossen. ${ }^{781}$

"Manche, die man vorher hier noch nie gesehen hat, schweigen, ihre Worte suchen noch nach den Unterkünften, erst danach werden sie beruhigt wieder ausschwirren können. ${ }^{782}$

$» .$. die Sichtbaren wollen sich an nichts erinnern können. ${ }^{783}$

In »Die Kinder der Toten« wird das konsequente Schweigen durch den Dauergenuss alkoholischer Getränke befördert, eine "Landessitte ${ }^{784}$, so Jelinek. Die Lebenden in "Die Kinder der Toten « sind »immer alle etwas bezecht ${ }^{785}$. Schon der Busfahrer, der am Beginn des Buchs durch seinen riskanten Fahrstil den folgenreichen Unfall mit dem Chrysler Voyager verursacht, ist alkoholisiert und dürfte sich natürlich nicht ans Steuer setzen, denn für Berufsfahrer gilt

\begin{tabular}{ll}
\hline 776 & KDT, S. 4 I. \\
777 & KDT, S. г 8. \\
778 & KDT, S. 22. \\
779 & KDT, S. 23. \\
780 & KDT, S. 50. \\
78 I & KDT, S. 86. \\
782 & KDT, S. 434. \\
783 & KDT, S. 59 . \\
784 & KDT, S. 9. \\
785 & KDT, S. 9.
\end{tabular}


die Null-Promille-Regel. Der Alkoholeinfluss, der in Österreich zum guten Ton gehöre, helfe dabei, bestimmte Geheimnisse zu bewahren:

»In unserem fleischigen Schweigen sind Geheimnisse verborgen, und zwar in Weingläsern. Unser Wasser muß nur noch verwandelt werden. ${ }^{786}$

"Der Schnaps ... kreist in der Mitte dieser Menschen und hält sie zusammen. ${ }^{787}$

Auch die Waldarbeiter in "Die Kinder der Toten« haben sich mit Alkohol "gedüngt ${ }^{788}$, um die Grausamkeiten der Natur ertragen zu können, und das Blut der Einheimischen enthalte schließlich »viele Prozente Verwirrung “ ${ }^{789}$. In folgender Passage ist zudem eine (hochprozentige) Andeutung versteckt, in welcher der »Wein« mit dem »Weinen« in Verbindung gebracht wird:

»Wir öffnen uns unter dem Ansturm des Sturms, dieses trüben Weinens, das schon gekeltert ist; das ist auch schon das Unmittelbarste, was uns berührt. « ${ }^{790}$

An anderer Stelle wird der Wein als "Blutsaft der Massen ${ }^{791}$ bezeichnet - eine Formulierung, die wiederum sehr vampirisch anmutet und das Untotenmotiv des Romans unterstreicht. Und schließlich finden sich auch sehr direkte Bezugnahmen auf die Verbrechen des Holocaust wie etwa in folgendem Wortspiel, das eindringlicher kaum sein könnte:

»Ein Cousin der Wirtin brennt selber! Ein paar Millionen brennen mit! « ${ }^{792}$

»Selber brennen« meint natürlich die Eigenherstellung von Schnaps, die »paar Millionen«, die "mitbrennen«, bezeichnen hingegen die in den Hochöfen der KZs verbrannten Opfer nationalsozialistischer Verfolgung - eine Parallele, die landläufig wohl eher nicht hergestellt würde; Jelinek hingegen macht sich die Mehrfachbedeutung des Wortes »brennen« zunutze - eine von ihr vielfach angewendete Methodik - um traditionelle Ausdrucksweisen in Frage zu stellen und gleichzeitig auf das eigentliche Thema ihres Texts aufmerksam zu machen. 
Es bleibt anzuzweifeln, dass Alkoholmissbrauch in Österreich ein nationales Spezifikum darstellt, ebenso wenig wie Österreicher harmloser, gemütlicher oder weniger obrigkeitshörig sind als Angehörige anderer Nationalitäten. Elfriede Jelinek ist eine Autorin, die ihre Analysen immer sehr zielgerichtet auf österreichische Verhältnisse fokussiert. Dass das Trinken hierzulande eine "Landessitte» darstellt, wie die Autorin in "Die Kinder der Toten» mit zahlreichen Seitenhieben andeutet, hat jedenfalls nicht zu bedeuten, dass anderswo nicht getrunken würde.

\subsubsection{Mythos der Einmaligkeit: Kontexte und Kontinuitäten}

»In der Umgebung, in den verschiedenen Ausflugsorten, wollen ... Menschen schon wieder zackig den Arm heben. ${ }^{793}$

»Die Kinder der Toten« entstand in der ersten Hälfte der I 99oer Jahre. Eine »kleine Gespenstergeschichte ${ }^{794}$ hatte daraus werden sollen - am Ende wurde es das Opus Magnum der späteren Nobelpreisträgerin, das Buch, das sie »immer schreiben wollte, ja musste ${ }^{795}$. Die innenpolitischen und gesellschaftlichen Rahmenbedingungen dieser Jahre hatten die Schreibwut der Autorin zweifelsohne beflügelt:

Seit dem Innsbrucker Parteitag 1986, als der junge rechtspopulistische FPÖPolitiker Jörg Haider den eher liberalen Parteichef Norbert Steger vom Obmannsessel gestoßen hatte, befand sich die rechts außen stehende, offen fremdenfeindliche Freiheitliche Partei auf einem scheinbar nicht zu bremsenden Höhenflug. Mitte der I99oer Jahre dachte Haider bereits laut über eine Kanzlerkandidatur nach.

Auf der anderen Seite war Österreich kurz vor der Veröffentlichung von »Die Kinder der Toten « im August 1995 der Europäischen Union beigetreten. Und: W ir wollen das Match auf Europaebene gewinnen! " ${ }^{796}$ Die unliebsame Vergangenheit als Teil des faschistischen Deutschen Reichs passte so gar nicht ins Programm der runderneuerten außenpolitischen Selbstdarstellung Österreichs. ${ }^{797}$ Dementsprechend wurde Jelineks Roman bei Österreichs Auftritt als Schwerpunktland auf der Frankfurter Buchmesse nicht unbedingt in den Vordergrund der medialen Aufmerksamkeit gerückt, was durch die schlechte Kritik im Feuilleton gerechtfertigt

793 KDT, S. 446.

794 Jelinek, zitiert nach: Mayer/Koberg, Ein Porträt, S. 200 f.

795 Dies., zitiert nach: Ebd., S. 206.

796 KDT, S. 467.

797 Vgl. Mayer/Koberg, Ein Porträt, S. 206, 
schien. Nach eigener Aussage hatte Jelinek ohnehin nicht zur Buchmesse mitfahren wollen, denn »wo man sich, flankiert von Jazz-Musik, Burgschauspielern und Veranstaltungen wie `Oh, du mein Österreich selbst zu feiern gedachte ${ }^{798}$, wollte sie nicht sein. Zudem war die Autorin nach Mayer/Koberg vermutlich noch damit beschäftigt, den Skandal um ihr am Wiener Akademietheater im Herbst I 994 uraufgeführtes Stück »Raststätte oder Sie machens alle« emotional abzuarbeiten. Die Premiere des Stücks unter der Intendanz von Claus Peymann wurde weltberühmt für ein Bild, das zwei Burgschauspielerinnen mit heruntergelassenen Höschen auf einer Damentoilette zeigt. Es diente im Herbst I994 als Beweisfoto für den angeblichen Kulturverfall in Österreich, die Kritiken des Stücks waren vernichtend. Wolf Martin, »Hausdichter « ${ }^{799}$ der »Kronen Zeitung «, begann eine Reihe bizarrer Hohn- und Spottgedichte über Jelinek zu verfassen und die Wiener FPÖ nutzte die Stimmung, um sich im Rahmen ihres Wahlkampfs an den parteikritischen Künstlern Jelinek und Peymann zu rächen. ${ }^{800}$

Nach außen hin gab sich das Land unter SPÖ-Bundeskanzler Franz Vranitzky und ÖVP-Außenminister Alois Mock weltoffen, multikulturell und zukunftsorientiert. In Wahrheit aber hatte Österreich mit dem Erstarken des »Dritten Lagers« zu kämpfen, denn das politische Klima der I 99oer Jahre wurde von niemandem so sehr bestimmt wie von Jörg Haider und seiner prosperierenden Freiheitlichen Partei. ${ }^{801}$

In »Die Kinder der Toten« bleckt ein »junge[r] Führer« mit Hitlers Bauart das Gebiss in dem »etwas schief geratene[n] Gesichtsfabrikat ${ }^{802}$ und schnell ist klar, wem die Autorin die Rolle dieses Doppelgängers zugewiesen hat, denn als Haider-Kritikerin war Jelinek omnipräsent im öffentlichen Bewusstsein. ${ }^{803}$ Freilich verkörperte Haider all das, was Jelinek auf persönlicher wie auch auf politischer Ebene ablehnte, ja zutiefst verabscheute, wie Mayer/Koberg bemerken:

„Er war ein Narziss wie aus einem ihrer Bücher, ein Sportlertyp wie Erika Kohuts Klavierschüler Walter Klemmer, allerdings in der Landei-Ausgabe. Jörg Haider stand für Provinzialität, Antiintellektualismus und neues Geld, dem alte Schuld anhaftete ...« ${ }^{804}$

798 Ebd.

799 Mayer/Koberg, Ein Porträt, S. I 97.

800 So ließ die Wiener FPÖ unter dem Motto »Freiheit der Kunst statt sozialistischer Staatskünstler« Plakate aufhängen, auf welchen sich die Namen der Autorin Jelinek und des Burgtheaterdirektors Peymann mit den Namen von drei SPÖ-Politikern wiederfanden, was Jelinek nach eigener Aussage zutiefst verletzte. Vgl. ebd., S. 197 f. Vgl. auch Kapitel I.5 dieser Studie.

801 Vgl. Mayer/Koberg, Ein Porträt, S. I 98.

802 KDT, S. 46.

803 Vgl. Kapitel 3.3 dieser Studie.

804 Mayer/Koberg, Ein Porträt, S. I98. 
Allerdings - und auf diesen wichtigen Punkt weisen die Biografen nicht hin spricht Jelinek Haider die Einmaligkeit ab: In »Die Kinder der Toten« negiert sie die von Seiten der deutschsprachigen Geschichtsforschung längst verworfene Führertheorie, wonach die Führungskompetenz oder das Charisma von Einzelpersonen als nahezu ausschließliche Ursache für die Entstehung und Etablierung faschistischer Parteien oder Regime gesehen wird; im öffentlichen Diskurs und der Publizistik wird diese vereinfachende, monokausale Theorie immer wieder unreflektiert bemüht; auch Formuliererungen wie »Hitler-Deutschland», »Hitler-Regime« oder »Hitler-Krieg« spielen dieser Theorie in die Hände.

Überdies stellt sich Jelinek gegen Ernst Noltes Begriff vom »Epochencharakter des Faschismus. ${ }^{805}$ „Der Führer. Man würde ihn mit einer Lampe suchen gehen, verschwände so einer in Österr. einmal von der Bild-Fläche«, kommentiert die Erzählinstanz in »Die Kinder der Toten«:

„So einen Mann hat dieses Land bereits einmal erbaut (die Pläne hat es sicherheitshalber aufgehoben), und da der große Aufruhr, den dieses Bauen hervorgebracht hat, gestillt war, reichte man sie wieder ein, die Pläne, für eine heftige Volksbewegung, für eine dritte Republik, aus der Tiefe geholt, aber doch etwas von oben herab.« ${ }^{806}$

Nicht eine Einzelperson habe demnach im Nationalsozialismus die österreichische Gesellschaft verführt, sondern die Bevölkerung bringe im Umkehrschluss Verführer dieser Bauart immer wieder hervor, weil sie - vor allem in Zeiten der "großen Aufruhr« - aus sich heraus danach verlange. Damit wird deutlich, dass die Autorin eine Konstruktion des Nationalsozialismus als »Mobilisierungs- und Manipulationsprojekt ${ }^{807}$ der politischen Eliten für nicht haltbar erachtet, sondern das NS-Regime - Ergebnissen der neuesten zeithistorischen Forschung entsprechend - vielmehr als soziale Praxis begreift und darzustellen sucht, welche die deutsch-österreichische Bevölkerung mitkonstruiert habe und an welcher sie "in vielfältiger Weise beteiligt « ${ }^{808}$ gewesen sei.

Auch der "Führer« wird als Schablone begriffen, nach deren Muster ohne weiteres eine Verdoppelungsfigur angefertigt werden könne - und wenn gewisse gesellschaftliche Rahmenbedingungen erfüllt seien, werde diese Aufgabe auch prompt umgesetzt. Dementsprechend wird der Politiker Haider in »Die Kinder der Toten« als eine von vielen möglichen Doppelgänger-Figuren des »Führers« vorgeführt (was dem damaligen FPÖ-Parteiobmann nichts von seiner »Unheim-

805 Vgl. Kapitel I.4.I dieser Studie.

806 KDT, S. 47.

807 Kritisch dazu Bauer, Mobilisierung, S. 288.

808 Bajohr, Zustimmungsdiktatur, S. I 2 I. 
lichkeit« raubte). Dabei musste die Autorin in ihrem Roman »Haider« nicht beim Namen nennen, um unmissverständlich auf ihn zu verweisen. Jelinek benutzt beim Schreiben »Umwege«, denn ihr »Erfolg liegt im Umkreisen ${ }^{809}$. Allein die Ausdrücke »Volksbewegung« und »Dritte Republik« in oben zitierter Textpassage sind deutliche Hinweise auf die Haider-FPÖ der I 99oer Jahre, die sich als »Bewegung “ deklarierte und aus der "Zweiten« eine »Dritte Republik« zu formen wünschte. ${ }^{810}$

In »Die Kinder der Toten« setzen sich die Seitenhiebe auf den »junge[n] Herr[n] Parteivorsitzende[n] ${ }^{811}$ und dessen Partei fort, wenn etwa auf die Vorliebe der "Burschen ${ }^{812}$ für blaue Accessoires verwiesen wird (»Stahlblaue Schals wehen wie Schwerter vom Muskelgestrick...«"13) oder auf die Ankündigung des FPÖ-Vorsitzenden, I998 Bundeskanzler werden zu wollen:

»So, jetzt jagen sie wieder vereint, sie kommen zu sich selbst, in ihrem Willen zur Macht, aber sie gelangen erst I 997, nein 1998 über sich hinaus, wie sie verkünden, da werden wir dann persönlich den Zeit und die Raum für sie aufschließen, damit sie wieder einen guten Platz in der Geschichte bekommen können. ${ }^{814}$

Im anschließenden Satz wird sogleich auf Österreichs Selbststilisierung als Opfer des Nationalsozialismus verwiesen, mit dem der "gute Platz in der Geschichte gesichert werden konnte und die im Opfermythos ihren Ausdruck gefunden hat: Schließlich habe der Pistolenlauf im Zweiten Weltkrieg "alles von ganz alleine getan «, und mit wenigen Worten könne man wieder harmlos werden (»... lieber der Schein selber sein, damit man nicht wahr gewesen ist! ${ }^{815}$ ).

Auch auf Haiders berühmt-berüchtigte Ausflüchte für provokante Aussagen, mit denen er die Verbrechen des Zweiten Weltkriegs herunterspielte oder die NS-Zeit glorifizierte ${ }^{816}$, wird in »Die Kinder der Toten« wiederholt angespielt (»Wir können nicht einmal uns selbst fassen, wenn unsere Taten einmal vorbei sind. Dann werden wir damals nicht zu Hause gewesen sein. $\left.{ }^{817}\right)$. Natürlich fehlt auch ein Hinweis auf Haiders umstrittenen Ausspruch von der »ordentlichen Beschäftigungspolitik im Dritten Reich ${ }^{818}$ in »Die Kinder der Toten«

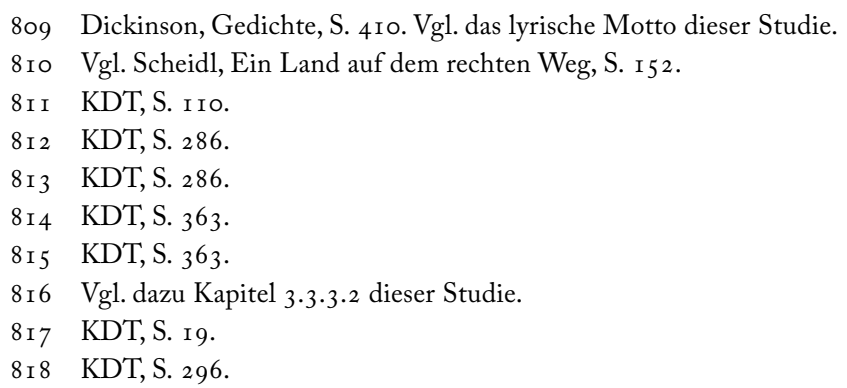


nicht, der ihn r99 I das Amt des Kärntner Landeshauptmanns kostete (das er I 999 wieder zurückeroberte). ${ }^{819}$

Wiederholt wird mit Wortspielen wie mit dem hölzernen Herrgott, der sich »im rechtesten Winkerl, das Sie hier finden werden ${ }^{820}$, befindet, auf das Erstarken der rechtspopulistischen FPÖ Bezug genommen, denn mit der - hier auffälligen - Verwendung des Superlativs wird klargemacht, dass mit »rechts« keine Richtung, sondern eine politische Haltung gemeint ist.

In Hinblick auf die Entstehungskontexte des Buchs erscheint die Einbeziehung der Haider-FPÖ in Jelineks Text als folgerichtig, denn Jörg Haider war das lebende Beispiel für die Kontinuität eines bestimmten »ewiggestrigen « Denkens. ${ }^{821}$ Zwar gestand Bundeskanzler Franz Vranitzky auf wachsenden internationalen Druck hin in einer Rede vor dem Nationalrat, die als »berühmte, gelenkige Rede des Vaters Franz « ${ }^{822}$ Eingang in Jelineks Roman gefunden hat, I99I die Mitverantwortung österreichischer Bürger für die Verbrechen der NS-Zeit ein und entschuldigte sich ausdrücklich im Namen der österreichischen Bundesregierung. ${ }^{823}$ Doch die Wahlerfolge der Haider-FPÖ in den r 99oer Jahren, die mit der Regierungsbeteiligung der Partei im Jahr 2000 ihren Höhepunkt fanden, widerspiegeln die mangelnde Verankerung dieses Eingeständnisses im kollektiv-nationalen Bewusstsein. Heutzutage führt die FPÖ unter Heinz Christian Strache das Ideal der »deutschen Volksgemeinschaft ${ }^{824}$ wieder im Parteiprogramm. "Das war der Hit von circa I 900 bis I 945 . Jetzt haben wir es wieder im Angebot ${ }^{825}$, empört sich der »Standard «-Redakteur Hans Rauscher darüber.

Auch der anhaltende Erfolg der traditionell fremdenfeindlichen und antisemitischen »Kronen Zeitung" spricht nicht unbedingt für eine Trendwende in der österreichischen Erinnerungskultur. So konnte der Kolumnist Richard Nimmerrichter alias »Staberl« in den r 99oer Jahren den Genozid an den Juden ungestraft als »Märtyrer-Saga« bezeichnen und ihn mit dem seiner Meinung

8I 9 Nach seiner Äußerung im Kärntner Landtag wurde Haider Ende Juni I 99 I nach einem Misstrauensantrag von SPÖ und ÖVP als Kärntner Landeshauptmann abgewählt. Zu dem umstrittenen Zitat siehe Kapitel 3.3.3.2 dieser Studie.

820 KDT, S. 2 I.

82 I Vgl. Mayer/Koberg, Ein Porträt, S. 200.

822 KDT, S. 178.

823 Zu Vranitzkys Rede vgl. auch Kapitel r.4.3 dieser Studie.

824 Unter Punkt 2 des FPÖ-Parteiprogramms, »Heimat, Identität und Umwelt«, ist zu lesen: »Sprache, Geschichte und Kultur Österreichs sind deutsch. Die überwiegende Mehrheit der Österreicher ist Teil der deutschen Volks-, Sprach- und Kulturgemeinschaft.«Zitiert aus dem Parteiprogramm der Freiheitlichen Partei Österreichs, Österreich zuerst, S. 5. Online abrufbar unter: https://www.fpoe.at/themen/parteiprogramm/ (Zugriff am o6.09.2016).

825 Der Standard, RAU, I6./I 7.7.201 I. 
nach »noch barbarischeren Kreuzigungstod Jesu Christi« vergleichen. ${ }^{826}$ Für diese Äußerungen erlangte die »Kronen Zeitung« über die Landesgrenzen hinaus "schaurige Berühmtheit ${ }^{827}$.

Den Verkaufszahlen schadeten sie jedoch nicht: Die »Krone« ist bis heute die meistgelesene Tageszeitung Österreichs.

Vor diesem gesellschaftlich-politischen Hintergrund verfasste Elfriede Jelinek in den I99oer Jahren ihren Roman. Und das Unheimlichste in ihm war tatsächlich der Verweis auf die Wirklichkeit.

\subsection{6 »Die Kinder der Toten«: Die große Anklage}

"Alles ist fort, denn niemand kann sich vornehmen, das, was geschehen ist, nicht getan zu haben. ${ }^{828}$

Jelineks Opus Magnum vereint alle großen Themen der Nobelpreisträgerin: So destruiert die Autorin darin Mythen von Familie, Sexualität, Medien, Natur und Sport, ebenso wie sie sich in dem Text immer wieder selbst inszeniert; sie betrauert die Toten des Nationalsozialismus aus der Vaterfamilie und arbeitet sich offenkundig anhand der Figur KARIN FRENZEL an der eigenen, neurotischen Beziehung zur Mutter ab. Zudem stellt sie immer wieder sich selbst, als Person und als Autorinneninstanz ironisch in Frage ( $» .$. ich selbst weiß ja alles nur vom Hörensagen ${ }^{829}$ ), was dem Text mitunter eine gewisse Leichtigkeit, ja sogar Komik verleiht. Auch »Die Kinder der Toten« ist schließlich als Satire zu lesen - wie sämtliche Jelinek-Texte. Nach Meinung der Autorin fehle den Österreichern aber jenes spezifische Verständnis von Humor, das mit den Juden »ausgestorben " ${ }^{830}$ sei (weil ein Großteil der österreichischen Juden im Zuge des Holocaust vertrieben oder ermordet wurden), was möglicherweise ein Grund für die geringe Akzeptanz ihres Opus Magnum von Seiten der Leserschaft und des Feuilletons sein könnte.

Und es ist wahr, diese Satire ist anders - mit Nestroy oder Horváth nur schwer vergleichbar. Figuren und Plot sind in einer Art Zwischenwelt situiert, in der es keine eindeutigen Grenzen zwischen Leben und Tod gibt. Stilistisch umgesetzt ist diese Grenzen verwischende Präsentation von Leben und Tod, indem

826 Vgl. Mayer/Koberg, Ein Porträt, S. 200. (Beide »Staberl«-Zitate in: „Kronen Zeitung«, I0.5. I992.)

827 Ebd.

828 KDT, S. 208.

829 KDT, S. 470.

830 Jelinek, zitiert nach: Venckute, Elfriede Jelinek im Zenit des Ruhms, unpaginiert. 
zum einen die Perspektive der Erzählinstanz ständig wechselt (Singular/Plural?, lebendig/tot?, Opfer/Täter?) und zum anderen die Hauptfiguren als untote Wesen erscheinen, die als Geister und Vervielfältigungen ihrer selbst auftreten, als Medium für Tote fungieren, in andere lebende wie auch tote Figuren eintauchen oder sich in deren Geschlechtsteile fräsen. Zwar tragen sie Namen wie KARIN, EDGAR oder GUDRUN und haben eine Geschichte, die meist anhand von rückblickenden Sequenzen im Text dargelegt sind, dennoch bleiben sie für den Leser als Figuren im traditionell dramatischen Sinne unfassbare Größen. Eine Identifikation ist in jedem Fall unmöglich, denn Jelineks untote Protagonisten sind »eher hirnlose, sprechunfähige, sexbessene Zombies« denn »vergeistigte Erscheinungen mit Sinn für das Schöne und Erhabene « ${ }^{831}$. Die Figuren sind als ent-individualisierte, ent-lebendigte Schablonen zu begreifen, auf welche die Autorin zum Teil seitenlange Sprachflächen projiziert (sie finde »mal wieder kein Ende ${ }^{832}$, gesteht die Erzählinstanz an einer Stelle des Texts selbstironisch ein). Diese Sprachflächen referieren in der Regel nicht auf einen Hypotext, sondern »auf viele disparate Hypotexte unterschiedlicher Provenienz, Wertung und Ideologie. ${ }^{833}$ Die in der Interpretation ausfindig gemachten Erzählstränge sind ineinander verschlungen, werden ständig und scheinbar willkürlich abgebrochen, ohne Überleitung in andere Settings übertragen und von dem nicht fassbaren, multiperspektivischen Autorinnen-Ich kommentiert. ${ }^{834}$

Dennoch muss an dieser Stelle festgehalten werden: Trotz aller bestehenden Unklarheiten, Überlagerungen, Sprünge und Grenzverwischungen ist die Aussage des Texts unmissverständlich. Auf nahezu jeder Seite des gut 666 Seiten umfassenden Romans wird deutlich: „Die Kinder der Toten« ist Jelineks große Anklage an Österreich und die Anklagepunkte lauten: Bis heute wurde keine adäquate Sprache gefunden, mit der die Ermordung von sechs Millionen europäischen Juden und die weiteren zahllosen Verbrechen des NS-Regimes (»... deckenhohe Stellagen mit Hirnen von kleinen Kindern! « ${ }^{835}$ ) Ausdruck finden. Politiker mit »stahlblaue[n] Schals ${ }^{836}$, Zeitungskolumnisten und katholische Geistliche dürfen die »Kleinigkeit von ein paar Millionen Toten ${ }^{837}$ ungestraft öffentlich herunterspielen.

Auch Jahrzehnte nach der großen Katastrophe besteht bei vielen politischen und sozialen Repräsentanten der Republik, aber auch in Teilen der Bevölkerung

83 I Mertens, Untote, S. 5 .

832 KDT, S. 506.

833 Pontzen, Pietätlose Rezeption, S. 53 f.

834 Vgl. Mertens, Untote, S. 4.

835 KDT, S. 45 o.

836 KDT, S. 286.

837 KDT, S. 98. 
immer noch kein hinreichendes Unrechtsbewusstsein, was an der unzulänglichen Sprachverwendung über den Holocaust abgelesen werden kann. Aber auch "wenn einer die Schuld nicht mehr aushält«, denn das sei ja »normal « ${ }^{838}$ : Es ist geschehen, es muss zur Kenntnis genommen und es muss in dieser Deutlichkeit ausgesprochen werden. Die »Bilanz über Schuld und Unschuld ${ }^{839}$, die in $» D i e$ Kinder der Toten « gezogen wird, ist eindeutig.

Kann Jelineks Opus Magnum also tatsächlich als "gigantisches Leerstück « ${ }^{840}$ bezeichnet werden, wie die Rezensentin Iris Radisch behauptet? Nein, mit Sicherheit nicht. Aber der Text setzt »ein Wissen voraus, dessen Verdrängung er behauptet ${ }^{841}$. Das Wissen um zeithistorische Zusammenhänge und die Kompetenz, dieses auch in den Lektürevorgang miteinzubeziehen, sind Grundvoraussetzungen für ein positives Leseerlebnis (»Tell all the Truth $-/$ but tell it slant/ Success in Circuit lies... « ${ }^{842}$ ). Der Ruf der Unlesbarkeit tut dem Roman also unrecht, auch wenn er in der Tat »verdammt schwer ${ }^{843}$ zu bewältigen ist. Was am Ende bleibt, ist das Unheimliche - das Damoklesschwert der Schuld und der in Aussicht gestellten Sühne.

\section{3 "Das Lebewohl«}

»Ein Meisterstück literarischer Rhetorik ...» ${ }^{844}$

\subsubsection{Zur verwendeten Sekundärliteratur}

»Der Theatermonolog >Das Lebewohk zeigt deutlich, warum Elfriede Jelinek den Freiheitlichen ein Dorn im Auge ist. ${ }^{845}$

Jelineks kleines Drama »Das Lebewohl« ist bis dato ein weitgehend unbeackertes Feld literaturwissenschaftlicher Auseinandersetzung. Dabei ist der Text, wie Wendelin Schmidt-Dengler bemerkte, ein »Meisterstück literarischer Rheto-

838 KDT, S. 457 .

839 Kastberger, Endspiele, unpaginiert.

840 Radisch, Maxima Moralia, unpaginiert.

84I Pontzen, Pietätlose Rezeption, S. 64.

842 Dickinson, Gedichte, S. 410. Vgl. das lyrische Motto dieser Studie.

843 Löffler, Am Eingang zur Unterwelt, unpaginiert.

844 Wendelin Schmidt-Dengler über »Das Lebewohl«; zitiert nach: profil, Nr. 42, 2004, S. I 28.

845 Zauner, Das Lebewohl, unpaginiert. 
rik « ${ }^{846}$ und über den eng abgesteckten Zeitraum der Regierungsbeteiligung der Haider-FPÖ in den beginnenden $2000 e r$ Jahren hinaus immer noch von großer (innen-)politischer Brisanz.

Von Seiten der deutschsprachigen Literaturwissenschaft hat sich bislang einzig Bärbel Lücke ${ }^{847}$ an eine detailliertere Interpretation herangewagt. In dieser versucht Lücke, einen möglichen Zusammenhang des Texts zu den Machttheorien Nietzsches, Foucaults und Baudrillards herzustellen, wobei ihr deutlicher Fokus auf dem Foucault'schen Begriff des »Dispositivs« liegt. Interessanterweise räumt Lücke selbst etwas unsicher ein, dass es tatsächlich »fraglich « ${ }^{848}$ sei, ob dieser mit Fug und Recht auf den Text angewendet werden könne. ${ }^{849}$ Folgt man Lückes Argumentation, ist der - ansonsten sehr weit gefasste - Dispositivbegriff hier als Machttheorie zu verstehen, welche die Summe von Diskursen und Praktiken zusammenfasst, die die sozialen Beziehungen innerhalb der Gesellschaft koordinieren. Zu Foucaults thematischem Schwerpunkt gehörte dabei die Geschichte der Sexualität, die um die Fragen einer "Macht von unten« kreiste. Die Sexualität - selbst kein vorfindliches Objekt, sondern Produkt von Diskursen und Praktiken - stellte für Foucault den Schlüsselbegriff zur Erklärung der Geschichte des I9. und 20. Jahrhunderts dar. ${ }^{850}$ Bei Lücke steht die Macht der Verführung im Mittelpunkt des analytischen Interesses, was durchaus auf Jelineks Text (den Monolog eines politischen Verführers) angewendet werden kann. Kritisch angemerkt werden soll an dieser Stelle die unreflektierte Ausdrucksweise, mit der Lücke von »Hitlers wahnhafter Massenvernichtung der Juden « ${ }^{851}$ schreibt, mit der die (in der Zeithistorie längst verworfene) "Führertheorie « ${ }^{852}$ bedient würde, was sicher nicht im Sinne der Autorin ist.

Darüber hinaus liegt ein erhellender Aufsatz in englischer Sprache von Allyson Fiddler vor, der vor allem durch seine analytische Strukturiertheit und seine klare Sprache besticht. Fiddler bettet darin den Primärtext in seine zeithistorischen Kontexte, benennt die wichtigsten intertextuellen Bezüge und zieht Parallelen zu Jelineks (Kurt Waldheim auf den Leib geschriebenem) Dramolett "Präsident Abendwind « aus dem Jahr 1986. ${ }^{853}$ Kritisch angemerkt werden muss dennoch, dass Jelineks Vater in Fiddlers Text als »half-Jew ${ }^{854}$

846 Schmidt-Dengler, zitiert nach: profil, Nr. 42, 2004, S. I 28.

847 Lücke, Gespenster, S. 75-I 29.

848 Ebd., S. I05.

849 Vgl. Lücke, Gespenster, S. го5.

850 Vgl. Daniel, Kulturgeschichte, S. $174 \mathrm{ff}$.

85 I Lücke, Gespenster, S. Io4.

852 Vgl. Kapitel I.4.I dieser Studie.

853 Vgl. Fiddler, Staging Jörg Haider, S. 357 f.

854 Fiddler, Staging Jörg Haider, S. 353. 
bezeichnet wird, was nationalsozialistischer Diktion entspricht. (Ähnliches wurde bereits bei Lücke festgestellt, die in ihrem Einführungsband Jelinek als »Halbjüdin ${ }^{855}$ betitelt.) Auch von der unkommentierten Verwendung des Ausdrucks »Third Reich ${ }^{856}$ (»Drittes Reich«) sollte in Sekundärtexten Abstand genommen werden, da dieser als Propagandabegriff der Nationalsozialisten missbraucht worden war (bevor er durch den Begriff »Tausendjähriges Reich» ersetzt wurde). Die gegenwärtige Verwendung des Begriffs ist unter Historikern umstritten. ${ }^{857}$

Neben den Sekundärtexten von Lücke und Fiddler liegen einzelne Rezensionen zur Publikation des Stücks ${ }^{858}$ sowie eine kleine Materialsammlung zur Erstaufführung bzw. Erstlesung in Pia Jankes wichtigem Jelinek-Band »Die Nestbeschmutzerin « ${ }^{859}$ vor; außerdem ein dreispaltiger Beitrag im »Jelinek-Handbuch« von Evelyn Deutsch-Schreiner, der das Plot skizziert und die wichtigsten Intertexte benennt. ${ }^{860}$

Für die in der vorliegenden Arbeit gewagte Interpretation wurde des Weiteren Literatur zu Jörg Haider, der Haider-FPÖ und der so genannten »Wende» im Jahr 2000 herangezogen. Hierbei ist in erster Linie Christa Zöchlings Haider-Biografie ${ }^{861}$ aus dem Jahr I 999 zu nennen: eine sehr gewissenhaft recherchierte und unbedingt lesenswerte (wenn auch leider schlecht lektorierte) Lebensdarstellung zu Jörg Haider, die mit vielen Hintergrundinformationen aufwarten kann und biografische Zusammenhänge zu politischen Entscheidungen bewusst macht. Bedauerlicherweise gibt es keine aktualisierte Neuauflage, in welche die Ereignisse rund um die »Wende« 2000 eingearbeitet wären.

Darüber hinaus muss auch auf das bereits 1992 erschienene, damals für viel Aufsehen sorgende Buch "Haiders Kampf ${ }^{862}$ von Hans-Henning Scharsach verwiesen werden, das ebenso für die Textanalyse bemüht wurde, sowie auf die sehr aufschlussreichen, weitgehend unkommentierten Zitate-Sammlungen von Hubertus Czernin ${ }^{863}$.

855 Lücke, Elfriede Jelinek, S. 9r. Vgl. dazu auch Kapitel 3.2.I dieser Studie.

856 Fiddler, Staging Jörg Haider, S. 359 sowie S. 362.

857 Vgl. Eitz/Stötzel, Wörterbuch der Vergangenheitsbewältigung, S. I35-I42. Diese Publikation weiß für derlei »Problemfälle« terminologische Alternativen anzubieten, die neuesten zeithistorischen Forschungsergebnissen gerecht werden.

858 Zum Beispiel: Treude, Keiner wußte davon, unpaginiert. Außerdem: Zauner, Elfriede Jelinek: Das Lebewohl, unpaginiert.

859 Janke, Die Nestbeschmutzerin, S. I 47-I 52.

860 Deutsch-Schreiner, Das Lebewohl, S. I44 ff.

86 I Zöchling, Haider.

862 Scharsach, Haiders Kampf.

863 Czernin, Wofür ich mich meinetwegen entschuldige. Ders.,Der Westentaschen-Haider. 
Als Literatur zur »Wende« soll hier auf Michael Fleischhackers Essay »Wien, 4. Februar 2000 oder Die Wende zur Hysterie « ${ }^{864}$ verwiesen werden, außerdem auf Gerfried Sperls Publikation »Der Machtwechsel ${ }^{865}$ : eine detaillierte und kommentierte Zusammenfassung der Ereignisse rund um den Regierungswechsel r 999/2000.

Des Weiteren wurde vor allem Haiders News-Artikel „Glücksgefühl nach bangen Stunden ${ }^{866}$ für die vorliegende Interpretation herangezogen. Für »Das Lebewohl« hat Jelinek daraus viele Textpassagen paraphrasiert oder sogar wörtlich übernommen, wie in der Textanalyse gezeigt werden wird.

Auch auf Aischylos' »Orestie ${ }^{867}$ muss an dieser Stelle verwiesen werden: Aus der antiken Dramentrilogie hat Jelinek vor allem das Pathos der Rede sowie (in abgewandelter Weise) den Orest'schen Muttermord entlehnt (den Orest beging, um den Vater zu rächen, wovon hier noch die Rede sein wird).

Beide Texte wurden von der Autorin explizit als Referenzliteratur angegeben.

\subsubsection{Formales, Setting und Plot}

»Ich muss jetzt in mein Bundesland zurückfahren. Doch erzählt, daß ihr mich

saht. ${ }^{868}$

„Das Lebewohl (Les Adieux)« ist ein 26 Seiten umfassender, absatzloser Theatertext, ein Monolog der Hauptfigur mit dem unspektakulären Namen der SPRECHER. In Rezensionen wird dieser Theatermonolog aufgrund seiner Kürze gerne auch als »Dramolett« bezeichnet. Das Besondere an ihm ist, dass er unverhohlen einer real existierenden Person in den Mund gelegt ist: Jörg Haider. Bereits in der Regieanweisung ist festgehalten, in welcher Weise der Sprecher des »Haidermonologs ${ }^{869}$ von ihn umringenden Knaben betrachtet werden soll.

Jelinek verfasste »Das Lebewohl« im Jahr 2000 als Reaktion auf den Rücktritt Jörg Haiders als FPÖ-Parteiobmann und seinen vorübergehenden Rückzug aus der Bundes- in die Landespolitik Kärntens. Der Text sei keine politische Stellungnahme, betonte die Autorin in einem Interview mit der Tageszeitung

864 Fleischhacker, Die Wende zur Hysterie.

865 Sperl, Der Machtwechsel.

866 Haider, Glücksgefühl nach bangen Stunden, S. 30 f.

867 Aischylos, Die Orestie. In dieser Übersetzung von Walter Jens sind die drei Teile des Dramas folgendermaßen bezeichnet: »Agamemnon«, »Die Choephoren« und »Die Eumeniden«.

868 Jelinek, Das Lebewohl (im Folgenden abgekürzt mit LW), S. I I.

869 LW, S. 9. 
"Der Standard«, sondern eine "Zustandsschilderung ${ }^{870}$ : Sie bemühe sich, für bestimmte Inhalte auch spezifische ästhetische Methoden zu finden, die von der Sprache selbst ausgehen. ${ }^{871}$ In dieser Hinsicht entspricht »Das Lebewohl« Jelineks ästhetischem Programm. Doch im Gegensatz zu den meisten ihrer anderen Theatertexte gibt es in »Das Lebewohl« mit dem SPRECHER eine wirkliche, greifbare Figur, die man »notgedrungen ${ }^{872}$ als Jörg Haider definieren könne, so die Autorin.

»Das Lebewohl« ist zusammen mit zwei weiteren kleinen Dramen (»Das Schweigen« und »Der Tod und das Mädchen« II) im Jahr 2000 im Berlin Verlag erschienen und wurde 2004 wiederaufgelegt.

Der Inhalt des Texts lässt sich wie folgt in nur wenigen Sätzen zusammenfassen: Der sprecher kündigt seinen Rückzug aus der Bundes- in die Landespolitik nach Kärnten an und verabschiedet sich mit pathetischen Floskeln von seiner Anhängerschar: schönen, stummen Knaben, die ihm Blumen streuen und seiner Rede andächtig lauschen. Der Abschied beinhaltet jedoch gleichzeitig die Ankündigung der beabsichtigten Wiederkehr: »Wir werden kommen. Und bleiben. « ${ }^{873}$ Der Rückzug wird damit als strategischer Schachzug angedeutet, der eine fulminante Rückkehr in Aussicht stellt.

Im Zentrum des Texts steht wiederum nicht dessen Inhalt, sondern vielmehr die Auswahl der Formulierungen, die verwendeten Bilder, Zitate und Intertexte.

Der französische Untertitel des Dramas ("Les Adieux«) bezieht sich vermutlich auf Ludwig van Beethovens Klaviersonate Nr. 26 - eine Sonate, in der das immer gleiche Thema in Variationen wiederaufgegriffen wird. Beethovens Sonate kann als musikalisches Pendant zu der Abschiedsrede der Hauptfigur begriffen werden, die in selbstmitleidiger Manier des SPRECH ERs um das immer gleiche Thema (»Ich muß jetzt in mein Bundesland zurückfahren ${ }^{874}$ ) kreist.

Rückbezüge zu möglichen Prätexten sind im Falle von »Das Lebewohl« schnell ausgemacht, denn die Autorin hat ihrem Stück dezidierte Hinweise auf ihre Referenzliteratur vorangestellt. Zum einen dankt sie der Zeitschrift »News«: Diese hatte im März 2000 einen Originaltext Jörg Haiders mit dem Titel »Glücksgefühl nach bangen Stunden « ${ }^{875}$ abgedruckt, in welchem Haider seinen Rückzug aus der Bundespolitik kommentiert hatte. Und zum anderen

870 Jelinek in einem Interview mit der Tageszeitung »Der Standard«, zitiert nach: Janke, Nestbeschmutzerin, S. 148.

87 I Dies., zitiert nach: Ebd.

872 Dies., zitiert nach: Ebd.

873 LW, S. 23.

874 LW, zum Beispiel S. I I, I 5, 25, 27.

875 News Nr. Io, S. $30 \mathrm{f}$. 
dankt sie dem antiken Dichter Aischylos für seine »Orestie ${ }^{876}$. Mit der Kombination dieser beiden sehr unterschiedlichen Referenztexte habe sie eine Art "dialektische Wechselwirkung erzeugen wollen «" ${ }^{877}$, so die Autorin: Ihr Text, in dem sie »erbärmliche " Haider-Zitate mit »historisch und pathetisch aufgeladenen« Passagen aus der »Orestie« verknüpft, verfolge letztlich das Ziel, Haider "lächerlich zu machen ${ }^{878}$. Es sei ihr unvorstellbar erschienen, dass gerade in Österreich, einem der Täterländer des Nationalsozialismus, die extreme Rechte wieder an die Macht komme. Aber gerade, indem man dieses Ereignis, die so genannte »Wende« vom Februar 2000, mit der Zeitenwende, die Aischylos' Atridendrama markiert, zusammenbringe, entfalte es seine ganze Lächerlichkeit und Banalität: Es sei »Tragödie und Farce in einem ${ }^{879}$.

\subsubsection{Der SPRECHER: Destruktion eines vermenschlichten Mythos}

»Die ... größte Stärke des Jörg Haider war seine

Begabung und Fähigkeit, auf die Leute zugehen zu können. ... Jörg Haider hörte zu, was man

ihm sagen wollte. ${ }^{880}$

Auch wenn in der Regieanweisung zu »Das Lebewohl« nicht explizit festgehalten wäre, dass es sich um einen »Haidermonolog “ ${ }^{881}$ handelt, so könnte das reale Vorbild für den SPRECHER schnell erraten werden. Zahlreiche Originalzitate Jörg Haiders sind im »Lebewohl« paraphrasiert, manche fast direkt aus erwähntem News-Text oder früheren bekannten Reden und umstrittenen Stellungnahmen des FPÖ-Parteiobmanns übernommen.

Außerdem hat Jelinek ihre Hauptfigur mit weiteren, eindeutigen Charakteristika ausgestattet, die hohen Wiedererkennungswert haben: So fehlt etwa ein Verweis auf die stets sonnen- oder solariumgebräunte Haut des Parteiobmanns ebensowenig ("Jeder Sonne ihr eigenes Studio zum Scheinen... Ich will das echte Licht, das reine, doch find ich es nicht, hilft mir das künstliche auch. ${ }^{882}$ )

876 In der Übersetzung von Walter Jens.

877 Jelinek, zitiert nach: Janke, Nestbeschmutzerin, S. I48.

878 Dies., zitiert nach: Ebd., S. I 49.

879 Dies., zitiert nach: Ebd., S. I 48.

880 Die Herausgeber Georg Lux, Arno Wiedergut und Uwe Sommersguter in der Einleitung zu ihrem Sammelband über Jörg Haider: Mensch, Mythos, Medienstar, S. 9.

88 I Auf dem Flugblatt zur Uraufführung mit Martin Wuttke auf dem Ballhausplatz stand im Untertitel: »Ein Haidermonolog« - auf diese Weise war der Zusammenhang mit der Donnerstags-Demo bereits deutlich gemacht.

882 LW, S. I7. 
wie auf Haiders medienwirksame Teilnahme am New York City Marathon I 999 (»... quälen will ich mich nicht, höchstens beim Laufen wohin. ${ }^{883}$ ), die sein Image als jung gebliebener, sportlicher Parteiführer hervorheben sollten.

Jörg Haider war bereits vor seinem Unfalltod im Oktober 2008 der vermenschlichte Mythos eines volksnahen und geradlinigen Politikers, der die Dinge ohne Umschweife beim Namen nennt, mit Proporz und Privilegien aufräumt und für die Rechte der »kleinen Leute« kämpft. Diesen Mythos trägt Jelinek in »Das Lebewohl« Stück für Stück ab.

In ihrem Dramatext wird Haider als homophiler Narziss dargestellt, der ideologisch dem nationalsozialistischen Erbe seiner Familie verhaftet ist, sich aber ganz Populist - für seinen politischen Erfolg wie ein Fähnchen im Wind dreht. Scheinbare und halbherzige Eingeständnisse der historischen Schuld werden als strategisches Kalkül entlarvt. Dabei steht die Hauptfigur exemplarisch für viele Österreicher - Zeitzeugen, aber auch Nachgeborene -, die aufgrund des äußerlichen Drucks zwar die Verbrechen des Nationalsozialismus verurteilen, gleichzeitig aber an dessen Mythen festhalten (Arbeitsbeschaffung, Reichautobahnbau, Jugend- und Sozialwohlfahrt, Bedrohung des Reichs durch so genannte »Bolschewisten«, Zweiter Weltkrieg als Defensivkrieg gegen Aggressoren von außen, Mythos der »sauberen« Wehrmacht usw.).

»Das Dunkel will uns stürzen und unseren Boden sehen«, beklagt Jelineks SPRECHER, "doch den zeigen wir nicht, den dunklen Boden, in dem wir das Schweigen versenkten. ${ }^{884}$ Das Motiv ist bereits aus »Die Kinder der Toten« bekannt, das hier angesprochene Schweigen meint die Verdrängung der dunklen Vergangenheit, der Verbrechen des Nationalsozialismus - und auch wenn man das Schweigen bricht, bleibt das Dunkel bestehen, denn: "Jetzt sprechen wir so und denken anders. $"{ }^{85}$ Das Schuldeingeständniss ist unaufrichtig und bedient bloß den schönen Schein.

Nach seinem plötzlichen Tod zollten Haider bemerkenswerterweise auch viele vormalige Kritiker Lob und Beifall für seine Bemühungen um Österreich. Alfred Gusenbauer hielt bei der Trauerfeier in Klagenfurt eine bewegte Rede, in der er dazu mahnte, den Verstorbenen über politische Meinungsverschiedenheiten hinweg in seinem Bestreben für die Heimat anzuerkennen:

»Ja, am heutigen Tag sollten wir über alle politischen Lager und Unterschiedlichkeiten hinweg sagen: Respekt und Anerkennung. Jörg Haider, du hast vieles gewollt. Du hast nicht alles, aber sehr viel erreicht. Zahlreiche Menschen danken dir dafür, und viele

883 LW, S. I6.

884 LW, S. I7.

885 LW, S. I7. Vgl. dazu Lücke, Gespenster, S. I 13. 
werden vielleicht die Größe aufbringen, deinen Tod zum Anlass zu nehmen, sich mit dir als Mensch zu versöhnen. ${ }^{886}$

Im Angesicht seines plötzlichen Todes schienen Haiders Nähe zum Rechtsextremismus, seine zweifelhaften Darstellungen zur österreichischen Zeitgeschichte sowie seine unzähligen öffentlichen Beleidigungen (»WestentaschenNapoleon ${ }^{887}$ ) nahezu vergessen, die Wandlung vom innenpolitischen Enfant terrible zum weltmännischen Politiker schien akzeptiert.

Die Hintergründe rund um Parteienfinanzierung, Hypo-Alpe-Adria-Verkauf oder den umstrittenen Klagenfurter Stadionbau werden allmählich offengelegt; auch von millionenschweren Schwarzgeldkonten Haiders in Liechtenstein wird in österreichischen Medien berichtet. ${ }^{888}$ Diese und ähnliche Enthüllungen rütteln erstmals nachhaltig an dem Mythos Haider.

Elfriede Jelinek hatte dem schönen Schein noch nie getraut. Mit allen ihr zur Verfügung stehenden Mitteln hatte sie seit dem Innsbrucker FPÖ-Parteitag 1986, als Jörg Haider den eher liberalen, aber führungsschwachen FPÖ-Parteichef Norbert Steger vom Obmannsessel gestoßen hatte, das rechtsideologische, ausländerfeindliche Wertesystem der im Aufschwung begriffenen Partei bekämpft, Gastkommentare verfasst, gegen das so genannte »Ausländervolksbegehren" protestiert, Interviews gegeben, war bei Demonstrationen gegen Fremdenhass mitmarschiert, hatte am Lichtermeer teilgenommen und diverse Artikel in in- und ausländischen Zeitungen publiziert. ${ }^{889}$

Mit ihren sprachkritischen Verfahren hatte sie schon in ihrem Opus Magnum »Die Kinder der Toten«, aber auch in zahlreichen Essays der I 99oer Jahre versucht, Haider als demokratieunfähigen, fremdenfeindlichen und antisemitischen Populisten und seine »Burschen ${ }^{890}$ als obrigkeitshörige Jünger zu demaskieren, was die FPÖ mit Plakatierungen gegen »linke Künstler« (Jelinek, Peymann) quittiert hatte. ${ }^{891}$

886 Der damalige SPÖ-Parteichef und Bundeskanzler Alfred Gusenbauer, zitiert nach: Lux, Jörg Haider, S. 222.

887 Haider über Jacques Chirac, zitiert nach: Czernin, Wofür ich mich meinetwegen entschuldige, S. 7 I.

888 Vgl.profilvom3r.Juli 20 Iosowievom7.August 201о,onlineabrufbarunter:http://www.profil.at/ articles/ro3o/560/274862_si/exklusiv-haider-45-millionen-euro-liechtenstein sowie http:// www.profil.at/articles/I03 I/560/274862/joerg-haiders-geldgeschaefte-diktator-saddamhussein (Zugriff am 6.10.2012).

889 Vgl. Mayer/Koberg, Ein Porträt, S. I 98 f.

890 KDT, S. 286.

89I Vgl. Kapitel I.5 dieser Studie. 
»Das Lebewohl« aus dem Jahr 2000 stellte schließlich den Höhepunkt der langjährigen Auseinandersetzung zwischen Haider und Jelinek dar. In gewohntem Understatement stellte Jelinek ein knappes Jahr nach der ersten öffentlichen Lesung von »Das Lebewohl« über Jörg Haider fest:

»Er wird Leuten wie mir immer überlegen sein. Der Brutalität seiner Rede hat Kunst nichts entgegenzusetzen. ${ }^{892}$

Was im Folgenden mit den Mitteln der Wissenschaft widerlegt werden kann.

\subsubsection{Ein homophiler Narziss}

»... meine Leidenschschaft gilt ... euch Burschen, ihr Herrlichen, Guten. Wie gute Tropfen kommt ihr über meine Lippen ...« ${ }^{893}$

Bereits in der detaillierten Regieanweisung zu "Das Lebewohl« wird das so genannte »Dritte Lager «, die politische Rechte in Österreich, als homoerotischer Männerverein vorgeführt, in dem der SPRECHER als gottähnliche Führergestalt die Fäden zieht:

»Einige schöne Knaben, die Gesichter zu einem ewigen Lächeln geschminkt, in kindlichen, pludernden Spielhöschen, umringen einen Mann, der ebenfalls den Mund zu einem zeitlos-ewigen Lächeln gemalt hat und zu den Knaben spricht. Den Mund nicht grotesk-clownhaft, sondern wirklich schön, aber etwas unheimlich, lächelnd, sie streuen dem Mann aus Körben Blütenblätter, die Knaben. Wenn es zu teuer ist, Knaben zu bekommen, kann man die Blütenblätter auch vom Schürboden herunterwerfen lassen. Nein, Mädchen kann man dafür nicht nehmen.» ${ }^{894}$

Dass sowohl die Knaben als auch der SPRECher geschminkt sind, hebt die Künstlichkeit der Szenerie hervor. Das routinierte Lächeln der Figuren wird als Schauspielerei entlarvt. Der geschminkte Mund des sprechers ist außerdem von Bedeutung, weil er zur Wiedererkennung beiträgt: Der markante Mund mit den großen (zunächst leicht schiefen) Schneidezähnen war Jörg Haiders äußerliches Markenzeichen. Dieses Mannes Zähne »flammen beim Sprechen « ${ }^{895}$, so

892 Jelinek, zitiert nach: Janke, Nestbeschmutzerin, S. I 52.

893 LW, S. I7.

894 LW, S. 9.

895 LW, S. 33. 
die Beschreibung des sprechers in »Das Lebewohl«. Eine ähnliche Anspielung hatte Jelinek bereits in »Die Kinder der Toten« eingebaut: Auch dort bleckt ein junger Führer das Gebiss, dessen Zähne »Flammen« sind, die »das etwas schief geratene Gesichtsfabrikat ${ }^{896}$ verbergen sollen.

Die Regieanweisung, dass man für »Das Lebewohl« keine Mädchen nehmen könne, unterstreicht die Absicht einer rein männlichen Szenerie, in der jede Weiblichkeit, auch im Sexuellen, entbehrlich ist. Die Entbehrlichkeit geht dabei bis zur totalen Eliminierung alles Weiblichen, wie vor allem an folgender Textpassage erkennbar wird, in der - an der Textoberfläche - auf Haiders Lamento im News-Artikel über die Abwesenheit seines langjährigen (politischen und persönlichen) Weggefährten und damaligen FPÖ-Generalsekretärs Peter Westenthaler während seiner Abschieds-Pressekonferenz hingewiesen wird:

»Der Obmann leider das Knie zum zweiten Mal gebrochen, der Allerbeste, der Erste der Knaben. Ich nehme ihn an meine Brust, das ist nicht Milch, da bin nur ich Starker, komm, Knabe, zerbeiß die Brust, bis rote Klumpen bleiben... « 897

Die Texttiefenstrukturen jedoch brechen mit dem Urbild von Weiblichkeit, dem Nähren des Säuglings an der Brust, was hier der »Führer« übernimmt, nicht ohne zugleich auf Bilder des Kriegs (Blut, Schmerz, Machtkampf) zu verweisen, denn der Genährte zerbeißt die Brust, die keine Milch gibt, bis Blut kommt: möglicherweise ein aus der »Orestie« entlehntes (Alp-)Traumbild Klytaimestras von einem Drachen, den sie zur Welt bringt und der beim Trinken der Muttermilch Blut aus der Brust saugt - eine Schreckensvision ihres bevorstehenden Untergangs. ${ }^{898}$ An der zitierten Passage aus dem »Lebewohl« können bereits wesentliche Aussagen des Monologs abgelesen werden, die auf die im theoretischen Teil dieser Studie genannten Charakteristika faschistischer Parteien und Regime verweisen, denn die Eliminierung des Weiblichen ist im Motivfeld der patriarchalen, faschistischen Abwertung der Frau zu finden. ${ }^{899}$

In Hinblick auf den Nationalsozialismus hat sich vor allem Hitlers Kampfruf, das »Schlachtfeld der Frau" sei der Kreißsaal ${ }^{900}$, eingeprägt, was den tatsächlichen Lebensrealitäten von Frauen im Nationalsozialismus natürlich nicht entsprechen konnte. Diese waren weitaus vielschichtiger und ebenso wie alle anderen Lebensbereiche zwischen I 933/38 und I 945 nach rassistischen Denk-

896 KDT, S. 46.

897 KDT, S. I 9.

898 Vgl. Aischylos, Orestie, S. 95.

899 Vgl. Lücke, Gespenster, S. 99.

900 Vgl. Mosse, Der nationalsozialistische Alltag, S. 66. 
mustern organisiert, die arische Frauen in der Hierarchie über nicht-arische Männer stellte: Die Kategorie »Rasse « prioritierte die Kategorie »Geschlecht «. ${ }^{901}$ Allerdings sind anachronistische Idealvorstellungen wie jene Hitlers, die Frauen auf ihre Rolle als »arisch reine, ungeschminkte Hausfrau und Mutter vieler Kinder « ${ }^{902}$ reduzieren, in verschiedenen Männerbünden, etwa gewissen Burschenschaften, nach wie vor von Belang. Doch wo diese Reduktion tatsächlich vorgenommen wird, entsteht ein sexuelles Vakuum, das mit anderen Attraktionen aufgefüllt werden muss.

Schon Theweleit hatte Ende der r97oer Jahre in seiner zweibändigen Abhandlung "Männerphantasien« darauf hingewiesen, dass Männerbünde zur Ausbildung latenter oder offener Homosexualität neigen. ${ }^{903}$ Nach Theweleit ist es vor allem die Übertretung einer Vorschrift oder Sitte, die Machtgefühle weckt und dadurch Lust abwirft: Der Gebrauch dieser Macht sei es, welche die Bereiche des Homosexuellen für den faschistischen Mann möglicherweise besonders attraktiv mache. ${ }^{904}$

Jelinek hatte Haider schon seit Anfang der r 99oer Jahre beschuldigt, im Geheimen homosexuell zu sein oder mit einer homosexuellen Orientierung jedenfalls zu kokettieren. In »Die Kinder der Toten« ist der junge Führer, eindeutig als Haider erkennbar, für »den Genuß junger Männer wie gemacht ${ }^{905}$. In einem Interview mit der Berliner Morgenpost vom Februar 2000 sagte die Autorin, Haider arbeite bewusst mit »homophilen Codes, natürlich ohne sich wirklich als homosexuell zu bekennen«, weil das seine politische Macht stärke. Man könne sich das heute zwar nicht mehr vorstellen, aber auch Heidegger habe von Hitlers schönen Händen und blauen Augen geschwärmt. ${ }^{906}$

Auch in oben zitierter Regieanweisung zu »Das Lebewohl« ist Jelineks Unterstellung klar herauszulesen. Zu einer homosexuellen Orientierung, und das soll hier eindeutig festgehalten werden, hatte sich Haider bis zu seinem Tod nie bekannt. Er konnte diese Gerüchte aber auch niemals gänzlich zerstreuen - und wollte es möglicherweise auch nicht, denn nachdrücklich dementiert hat er sie nie.

Nach seinem Unfalltod 2008 wurden die Gerüchte vielmehr noch dadurch genährt, dass einer seiner engsten Mitarbeiter in Kärnten, Stefan Petzner,

90 I Vgl. Hovdar, Mein Schweigen half mir nicht zu vergessen, S. 24.

902 Zipfel, Die Welt ist so schön, S. I72.

903 Vgl. Theweleit, Männerphantasien, vor allem das Kapitel »Homosexualität und weißer Terror « in Bd. 2.

904 Vgl. Theweleit, Männerphantasien 2, S. 3 I 9.

905 KDT, S. 46.

906 Das Interview ist als »Haider-Outing « auf der Homepage der Wiener HOSI online abrufbar unter: http://www.hosiwien.at/haiderouting/medien/ironie-unter-der-strasenwalze (Zugriff am 4.IO.2012). 
Pressesprecher und Sekretär, öffentlich emotionale Zusammenbrüche zeigte, die auf mehr als nur eine berufliche Zusammenarbeit schließen lassen konnten. So habe er den »Mann seines Lebens« verloren, klagte Petzner unter anderem. ${ }^{907}$

Haiders tatsächlicher sexueller Orientierung soll im Rahmen dieser Analyse nicht weiter nachgegangen werden, sie ist nicht von Belang. Von Interesse ist hier aber, dass Jelinek die wiederholten Anspielungen auf eine mögliche Homosexualität Haiders in das Setting für ihr Stück übernommen hat. Damit trägt sie dem ambivalenten Umstand Rechnung, dass die Haider-FPÖ zum einen mit homophilen Codes operierte, zum anderen aber Homosexualität vor dem Gesetz nicht als gleichwertige Lebensform akzeptierte und in Wahlkämpfen sogar Stimmung gegen Lesben und Schwule machte. Im Nationalsozialismus wurden Homosexuelle als »Untermenschen« verfolgt und in Lagern oder Gefängnissen interniert (und dies, obwohl auch namhafte NS-Größen als homosexuell galten bzw. sich zum Teil auch in NS-Kreisen offen dazu bekannten, beispielsweise SA-Stabschef Ernst Röhm ${ }^{908}$, den Hitler allerdings I934 liquidieren ließ). ${ }^{909}$ Eine Anerkennung von Homosexuellen als Verfolgte des Nationalsozialismus im Opferfürsorgegesetz ist jedoch in Österreich bis heute nicht erfolgt, nicht zuletzt deshalb, weil sich Teile der FPÖ sowie der ÖVP gegen eine Novellierung des Gesetzes sperren.

"Angst und Vorurteile sind die schärfsten Waffen der Wahlkämpfe « ${ }^{910}$, erkennt der Journalist und Haider-Kritiker Hans-Henning Scharsach. Und so hatte auch die FPÖ in den r 99oer Jahren mit Vorurteilen gegen Homosexuelle um Stimmen gebuhlt: So bezeichnete etwa der freiheitliche Generalsekretär Walter Meischberger das von Heide Schmidt gegründete Liberale Forum, das sich für den Ausbau der Rechte von Schwulen und Lesben stark machte, als »Schwuchtelpartie«. Haider selbst soll r 996 in seiner Funktion als Klubobmann die Abgeordneten seiner Partei dazu verdonnert haben, gegen die Angleichung des Schutzalters an heterosexuelle Partnerschaften zu stimmen, obwohl sich zuvor einige der freiheitlichen Abgeordneten für die Liberalisierung eingesetzt hatten. ${ }^{911}$

Die Abwesenheit eines weiblichen Parts, wie sie Jelinek in ihrem Theatermonolog vorführt, legitimiert die Überhöhung der (männlichen) Führerfigur sowie die Organisation in männlich-patriarchalen Hierarchien.

907 Vgl. etwa Jan Feddersons taz-Artikel "Jörg Haiders Witwer - Die Tränen von Stefan Petzner«, online abrufbar unter: http://www.taz.de/!24855 (Zugriff am 4.IO.20I2).

$908 \mathrm{Vgl}$. Theweleit, Männerphantasien 2, S. 33 I.

909 Vgl. Kapitel I.4.I dieser Studie.

910 Scharsach, Haiders Kampf, S. I5.

9 I I Vgl. den einschlägigen Artikel des profil-Redakteurs Herbert Lackner, bei profil-online abrufbar unter: http://www.profil.at/articles/o843/560/223477/joerg-haiders-leben-der-umgang-sexualitaet (Zugriff am 6.10.2012). 
Ob homo- oder heterosexuell: Haiders Führungsposition innerhalb der Partei war nahezu unumstritten. Die Wahlerfolge der FPÖ gaben seinem politischen Stil, der auf Rechtspopulismus und dem Eindruck einer Ein-Mann-Partei gründete, scheinbar Recht. Als gottesähnliche Figur tritt er in Jelineks Theatertext auf, als »)Gott (Apoll?) Haider ${ }^{912}$. Und so schilderte Haider in bereits erwähntem News-Artikel, den er anlässlich seines Rücktritts als Parteiobmann im Jahr 2000 veröffentlichen ließ, eine gebrochene Partei, die nur unter größtem Protest und mit starker Wehmut ihren langjährigen Frontmann ziehen lässt: Bei Bekanntgabe seiner Entscheidung hätten viele seiner Mitstreiter geweint. ${ }^{913}$ Von diversen Schocks ob der Rücktritts-Entscheidung wird (im Originaltext, aber auch in Jelineks Monolog) berichtet: Neben dem verzweifelten FPÖ-Generalsekretär Peter Westenthaler habe auch Klubobmann Herbert Scheibner versucht, mit Mimik und Körpersprache Protest zu artikulieren ${ }^{914}$ (»Scheibner, Knabe, du auch, mein Herbert, zeigst es mir an, daß du Protest erhebst gegen meinen Entschluß? ${ }^{915}$ ).

Jelineks Haider-Figur legt eine eitle Selbstverliebtheit an den Tag, die ihresgleichen sucht (»Es ist nichts. Nur ich bin. ${ }^{916}$ ). Haider-Biografin Zöchling zeigt sich davon überzeugt, dass auch das reale Vorbild für Jelineks S PRECHER vor »Selbstliebe ${ }^{917}$ nur so gestrotzt habe. ${ }^{918}$

Das »Ich« ist von Beginn an ein starkes Element, steigert sich jedoch zum Schluss hin, indem die Autorin auffällige syntaktische Verschiebungen vornimmt, die das »Ich« noch mehr hervorheben, indem sie es an das betonte Ende der Sätze stellt, worauf jeweils ein die Aufmerksamkeit sammelnder Doppelpunkt hinweist ${ }^{919}$ - einem literarischen ${ }^{2}$ Crescendo« gleich:

9I 2 Lücke, Gespenster, S. 97.

9I 3 Anmerkung: In Haiders Originaltext ist zu lesen: „Viel entschlossener als eigentlich gedacht sagte ich meinen Freunden und Funktionären ..., dass ich zurücktrete und der Entschluss unwiderruflich ist. Das war gut so. Denn hätte ich dabei in die Runde geblickt und die Tränen in den Augen vieler meiner langjährigen Mitstreiter gesehen, wer weiß, ob ich nicht schwach geworden wäre. So aber suchte ich weder Blickkontakt zu meinen Freunden, noch ließ ich Raum für eine Diskussion...« - Wie es ihm möglich war, die Tränen in den Augen seiner Kollegen zu sehen, obwohl er nicht in die Runde geblickt und auch keinen Blickkontakt gesucht hat, klärt Haider nicht auf. Vgl. News, Nr. Io, 2000, S. 30.

9I 4 Vgl. News, Nr. Io, 2000, S. 30.

9I 5 LW, S. 2 I.

9 I 6 LW, S. 20.

91 7 Zöchling, Haider, S. I 7.

91 8 Vgl. Zöchling, Haider, S. I7.

919 Vgl. Lücke, Gespenster, S. i I 8. 
»Auch wenn die Hauptlast tragen muss: ich, und die haßerfüllte Linke weltweit zum Dämon gemacht hat: mich.... In den Spiegel schauen können will: ich auch mich. Zögern will nicht auch: ich. Mein Vater sein will auch: ich. « ${ }^{920}$

Im Finale des Texts, einem »Fortissimo « des Egozentrismus, spitzt sich schließlich alles nur noch auf das »Ich« der Hauptfigur zu, dessen Wahn-Wutgesang zwischen Schuld und Schuldverleugnung, Vater-Komplex und Mutter-Bindung, Machtbegierde und -verlust oder Machtstillstand, Mordwahn und Untergangsvisionen pendelt ${ }^{921}$ :

»Das Tuch vor Augen, um die Gemordeten zu sehen, brauche nicht: ich. Alle niedermachen will auch: ich. Alle sein will auch: ich. Kein Stein auf dem andern sein will auch: ich. Die Freiheit sein will auch: ich. Vaters Kind sein will auch: ich. Sags Mutter, sags Vater, sags Mutter, sags Vater. Sag ich. Sag doch: ich! Die ganze: Zeit! « ${ }^{922}$

Jelineks Haider-Figur, der SPR ECHER, erscheint insgesamt als eitler Narziss, der im Monolog seine durch den politischen Rückzug zugefügten Wunden leckt, mit scheinbarer Vernunft jedoch seinen Entschluss begründet.

In außerordentlichen Situationen sei "Klugheit nicht verboten ${ }^{923}$, lobte sich der Original-Haider selbst für seine Entscheidung zum Rücktritt. Auch diese bemerkenswerte Aussage hat (wortwörtlich) Eingang in Jelineks Theatertext gefunden. ${ }^{924}$

Das von der FPÖ unter der Obmannschaft Jörg Haiders deklarierte Selbstbild, das eine Gesinnungsgemeinschaft zeigt, die patriarchal-faschistische Tugenden wie Stärke, Virilität, Volksgemeinschaft, Kameradschaft, Jagd und Militarismus hochhält, wird durch die Szenerie in »Das Lebewohl«, die einen schön geschminkten, in seiner narzisstischen Eitelkeit verletzten, vielleicht pädophil-homosexuellen Anführer zeigt, dem schöne aber mundtote Knaben Blumen streuen, konterkariert. Alleine durch diese (sehr einfach gehaltene) Aktionsebene trägt der Text zur Destruktion des vermenschlichten Mythos Haider bei: Jelinek hält dem propagierten Bild des starken, männlichen, geradlinigen Führers ein Gegenbild vor, das es lächerlich erscheinen lässt und seine Künstlichkeit entlarvt.

920 LW, S. 34.

92 I Vgl. Lücke, Gespenster, S. I I 8.

922 LW, S. 35 .

923 News, Nr. Iо, 2000, S. 30.

924 Vgl. LW, S. I 7 . 
Und so wird Haider in der Figur des SPRECHERs zur »Popanze ${ }^{925}$ gemacht, wie die Autorin selbst den Anspruch auf ihre Thaterfiguren formuliert hat.

\title{
3.3.3.2 Von der Verharmlosung zur Verherrlichung
}

\author{
»Im Kabarettland Österreich war Haider ein \\ rechter Kabarettist, der durch assoziative Logik \\ zu seinen gruseligen Pointen kam.» ${ }^{926}$
}

Haider war ein geschickter Rhetoriker. Obwohl aus einfachen Verhältnissen stammend, hatte er ein Gymnasium besucht und nach einem einjährigen Militärdienst innerhalb weniger Jahre ein rechtswissenschaftliches Studium absolviert. ${ }^{927}$ An verschiedene Gesprächspartner und -situationen konnte er sich schnell anpassen. Der verbale Tabubruch gehörte dabei zu seinem festen rhetorischen Repertoire. Provokante Aussagen wie jene von der »ordentlichen Beschäftigungspolitik « ${ }^{928}$ im Dritten Reich brachten ihm große mediale Aufmerksamkeit ein und sorgten neben empörten Kritiken auch für launiges Bravo aus dem rechten Lager. Man könnte daher vermuten, dass diese Provokation wie auch zahllose ähnliche Aussagen eher taktischer Natur waren, die eine gewisse Wählerklientel bedienen sollten.

Zudem verstand sich Haider bestens auf die Kunst der ambivalenten Ausflüchte und Entschuldigungen für umstrittene Aussagen, mit denen er gleichzeitig deutlich machte, dass es ihm in Wirklichkeit nicht leid tue. Jelineks Haider-Figur äußert sich zu der Frage nach der historischen Schuld Österreichs folgendermaßen:

»Wir haben den Fall von Anfang an erörtert: wir warens nicht, und unsre Väter warens auch nicht. Sie könnens nicht gewesen sein. Ach! Unsere Väter warens vielleicht doch, aber es hat nichts gemacht. Es hat ihnen nicht geschadet. Wenn Sie so wollen, dann waren sies halt. ${ }^{929}$

925 Jelinek, Ich schlage sozusagen mit der Axt drein, S. I 4.

926 Mayer/Koberg, Ein Porträt, S. 200.

927 Vgl. Zöchling, Haider, S. 23-50 sowie S. 73-94.

928 Haider hatte im Juni I 99 I an die SPÖ gerichtet vor dem Kärntner Landtag gesagt: »Na, das hat's im Dritten Reich nicht gegeben, weil im Dritten Reich haben sie ordentliche Beschäftigungspolitik gemacht, was nicht einmal Ihre Regierung in Wien zusammenbringt. Das muss man auch einmal sagen.« Zitiert nach: Czernin, Der Westentaschen-Haider, S. 35 ff. 
Die Figur vollzieht in dieser Passage eine für Haider typische verbale Kehrtwendung, mit der das Beharren auf dem eigenen Standpunkt deutlich gemacht, gleichzeitig aber das vom vermuteten Gegenüber eingeforderte Schuldeingeständnis dargebracht wird. Die offensive Formulierung »Wenn Sie so wollen« impliziert dabei, dass das Eingeständnis seiner eigenen Meinung nicht entspricht und er dies auch öffentlich gesagt haben will, ohne sich damit aber juristisch angreifbar zu machen. ${ }^{930}$ Diese wie auch ähnliche Floskeln wurden von Haider gebraucht, wenn er sich in die Ecke gedrängt fühlte. Als er im Februar I 985 in einem profil-Interview gefragt wurde, ob er Schwierigkeiten damit habe, von Vergasungen und Massenmord im Nationalsozialismus zu sprechen, antwortete er ausweichend:

»Wenn Sie so wollen, dann war es halt Massenmord." ${ }^{931}$

Dieses verbale Spiel, ein ständiges Mäandern zwischen Schuldeingeständnis und Verurteilung auf der einen Seite sowie Leugnung und trotziger Selbstüberhöhung auf der anderen Seite, legt Jelinek ihrer Haider-Figur in den Mund, führt es fort und variiert es:

„Es waren abscheuliche, einmalige Verbrechen. Sowas wird's nie wieder geben. Es war einmal, es ist nicht mehr. Nie wieder, sagen wir! Nie wieder! Und schon bekommen wirs frisch herein, wir warens zwar, gut, wenn Sie so wollen unbedingt, und wenn wir jemand gekränkt haben, wir bedauern, aber haben wir nicht Recht? ${ }^{932}$

»Früher waren wir der Tod, wir entschuldigen uns und sind hiemit entschuldet. Wenn Sie so wollen, dann waren wirs halt. ${ }^{933}$

»Diese Verbrechen waren so entsetzlich verbrecherisch, das kann ich ohne Nachsicht sagen. Jetzt sprechen wir so und denken anders und wo anders, herrlich, herrlich! Aber entsetzlich natürlich schon auch.« ${ }^{934}$

Diese Aussagen des sprechers stellen eindeutige Anspielungen auf umstrittene Haider-Zitate dar, mit denen dieser als einflussreicher Politiker zur Ver-

930 Im Staatsvertrag hat sich Österreich dazu verpflichtet, »alle Spuren des Nationalsozialismus« zu tilgen. Das Verbotsgesetz bedroht jeden mit Strafe, der »irgendwie« für nationalsozialistische Ziele wirbt. Auch die »Verharmlosung« ist strafbar. Vgl. Scharsach, Haiders Kampf, S. 7.

93 I Haider, zitiert nach: Czernin, Wofür ich mich meinetwegen entschuldige, S. I6.

932 LW, S. I3 f.

933 LW, S. I4.

934 LW, S. I7. 
harmlosung, aber auch zur Verherrlichung des Nationalsozialismus im öffentlichen Bewusstsein beitrug. So lehnte Haider jedwede »Kollektivschuld « ${ }^{935} \mathrm{ab}$ und sprach stattdessen von "Pflichterfüllung " ${ }^{936}$. Die Konzentrationslager bezeichnete er wiederholt als "Straflager ${ }^{937}$ - ein Ausdruck, der impliziert, dass die inhaftierten Frauen, Männer und Kinder aufgrund eines Vergehens dort gewesen wären, obwohl völlig Unbescholtene in KZs deportiert, dort gequält und ermordet wurden. Soldaten, die zu Partisanen geflüchtet waren, nannte er »Verräter « ${ }^{938}$. Die Treffen von SS-Veteranen am Ulrichsberg hingegen bezeichnete er als »Friedenstreffen ${ }^{939}$, den Zweiten Weltkrieg als »Kampf für die Freiheit Europas ${ }^{940}$ - um nur einige wenige »Highlights« $\mathrm{zu}$ nennen. Den verurteilten Kriegsverbrecher Walter Reder machte Haider zu einer ehrenwerten Persönlichkeit, denn dieser habe schlichtweg »seine Pflicht erfüllt, wie es der Eid des Soldaten gebietet « ${ }^{941}$. Dass der aus Österreich stammende SS-Obersturmführer Reder I95 I in Italien als Hauptverantwortlicher für das Massaker von Marzabotto mit mehr als I.ooo Toten zu lebenslanger Haft verurteilt worden war, beeindruckte den damaligen FPÖ-Chef offenbar wenig. Schließlich hätte das Schicksal Reders "jeden unserer Väter ereilen können ${ }^{942}$. (Dass es ebenso gut unsere Väter hätten sein können, die erschossen oder ins Gas geschickt wurden, vergaß Haider zu erwähnen - seine Empathie war einseitig.)

Dieses Beharren auf der eigenen Position findet in "Das Lebewohl "Ausdruck, etwa wenn der sPRECHER über die Toten- und Jammerklagen der Opfer berichtet, nicht ohne hernach hinzuzufügen:

»... auch beim Jüngsten Gericht: entschuldigen tun wir uns nicht! ${ }^{943}$

Dass die Figur die zuvor angesprochenen Verbrechen als »entsetzlich " ${ }^{944}$ erkannt hat, wird dadurch als Alibi-Handlung entlarvt. Das knappe Vorbeischiffen an

935 Siehe z.B. Czernin, Der Westentaschen-Haider, S. I 7 u. 2 I ; auch: Czernin, Wofür ich mich meinetwegen entschuldige, S. I 8.

936 Vgl. Czernin, Wofür ich mich meinetwegen entschuldige, S. I 8.

937 Haider, zitiert nach: Czernin, Der Westentaschen-Haider, S. 4I und 63.

938 Ders., zitiert nach: Czernin, Wofür ich mich meinetwegen entschuldige, S. I 9.

939 Ders., zitiert nach: Ebd., S. I 8.

940 Scharsach, Haiders Kampf, S. 7 f.

94I Haider, zitiert nach: Czernin, Wofür ich mich meinetwegen entschuldige, S. I 5.

942 Als Reder 1985 nach Österreich zurückkehrte, begrüßte ihn FPÖ-Verteidigungsminister Frischenschlager mit Handschlag, was Haider mit der Bemerkung goutierte: »Für mich war das die Übernahme des letzten österreichischen Kriegsgefangenen.« Zitiert nach: Czernin, Wofür ich mich meinetwegen entschuldige, S. I 5. Vgl. dazu auch Scharsach, Haiders Kampf, S. 7 f. LW, S. 28.

944 LW, S. I7. 
Wahrheiten, aber auch deren inversive Umkehrung charakterisierten Haiders Umgang mit heiklen Themen, inbesondere dem Nationalsozialismus. Wenn ihm der mediale und politische Gegenwind zu stark wurde, passierte es mitunter, dass er bestimmte Äußerungen nachträglich dementierte oder sich »meinetwegen ${ }^{945}$ dafür entschuldigte und tat mit dieser Formulierung zugleich seinen Unwillen kund. Die Haider-Biografin Christa Zöchling nennt diese Taktik die »Strategie der kontrollierten Skandalisierung«:

"Zum Beispiel: Man stellt eine unerhörte Behauptung auf und dementiert sie nachträglich. Damit hat man durch zweierlei die Aufmerksamkeit der Medien erregt: erstens durch die unerhörte Behauptung und zweitens durch das Dementi. Geschickt ist es auch, wenn man den Überbringer der unerhörten Behauptung zum Schuldigen erklärt." ${ }^{946}$

So waren es immer wieder »linke Journalisten ${ }^{947}$ oder gerne auch das öffentlich-rechtliche Fernsehen, die ihn falsch zitiert hätten, um ihm und seiner Partei zu schaden, beschwerte sich Haider bei unzähligen Gelegenheiten. ${ }^{948}$ Wenn eine Entschuldigung unausweichlich war, fiel sie in der Regel halberzig aus. Auch die Haider-Figur in Jelineks Text, der sPRECHER, entschuldigt sich wiederholt, jedoch nur scheinbar:

"Meinetwegen entschuldige ich mich halt. ${ }^{949}$

»Ich entschuldige mich, wenn Sie so wollen, für das Wetter, das schlimme, und für das beigesellte Unheil entschuldige ich mich auch.« ${ }^{950}$

Die Entschuldigung verliert bei solchen Formulierungen ihren Wert. Sie ist unaufrichtig und verkommt zur Floskel. Diese und ähnliche Textpassagen aus dem »Lebewohl« zeigen eindrucksvoll, wie Jelinek mit einfachen Mitteln ihre Kritik an dem heutigen »Umgang mit dem Nationalsozialismus« in eine für den SPRECHER konstruierte Sprache verpackt hat - eine paradoxe Sprache, die das paradoxe österreichische Gedächtnis widerspiegelt: Dieses schwanke, so die Autorin,

945 Vgl. Czernin, Wofür ich mich meinetwegen entschuldige, S.70.

946 Zöchling, Haider, S. 2 го.

947 Zum Beispiel: Haider, zitiert nach: News, Nr. ro, 2000, S. 3 I.

948 Vgl. Zöchling, Haider, S. 2 Io f. Von dieser Taktik machen im Übrigen auch andere Politiker Gebrauch, zum Beispiel Heinz Christian Strache oder (in sehr beeindruckender Manier) der Industrielle und Neo-Politiker Frank Stronach.

949 LW, S. 24.

950 LW, S. 25. 
zwischen hohlen, ritualisierten Schuldbekenntnissen und totaler Verleugnung. ${ }^{951}$ Auch das konsequente Leugnen von Schuld, das jedwede selbstkritische Reflexion auf kindlich-trotzige Manier ausschließt, ist im Text wiederzufinden:

»Wir schwören, wir warns nicht, und schon waren wirs wirklich nicht." ${ }^{952}$

»Seht ihr, wir sind doch ganz harmlos, wenn wir herrschen. Hauptsache herrschen. Wir machen ja nichts. Und wir haben nichts gemacht. « ${ }^{953}$

»Wir haben keine Mitschuld an der Tat. Wir haben auch keine Morde befohlen.«" ${ }^{954}$

Auch in Bezug auf diesen kleinen Dramentext bleibt daher festzuhalten, dass die Autorin wiederum nicht den Holocaust per se, sondern vielmehr die unzulängliche Sprachverwendung thematisiert, mit der Mitverantwortung und Schuld an den Verbrechen des Nationalsozialismus im öffentlichen Diskurs zwar eingestanden werden, jedoch ohne die gebotene Eindeutigkeit und ohne ehrliches Unrechtsbewusstsein: Die Sprache selbst wird damit als Mythos entlarvt - als Form ohne Inhalt. Der "Brutalität « ${ }^{955}$ von Jörg Haiders Rede kann Elfriede Jelinek entgegen eigener Einschätzung mit ihrem sprachkritischen Verfahren tatsächlich einiges entgegensetzen.

\subsubsection{Vermeintliche Feinde und falsche Opfer}

»Und wieder schlagen sie uns, die selbsternannten Fürsten, die Dichterfürsten, noch einmal, noch einmal. ${ }^{956}$

Jelineks Bühnenmonolog zeigt eine Figur, die sich selbst auffällig oft und in verschiedenen Zusammenhängen in die Position eines Opfers rückt: Von den Linken werde er verfolgt, lamentiert der SPRECHER, weltweit hätten sie ihn "Zum Dämon gemacht ${ }^{957}$ (ein Originalzitat aus Haiders News-Artikel ${ }^{958}$ ). Er aber habe ihnen mit seinem Rückzug nach Kärnten ein Schnippchen geschlagen

95 I Jelinek (sinngemäß), vgl. Kapitel 3.3.3.2 dieser Studie.

952 LW, S. I I.

953 LW, S. I 2.

954 LW, S. I3.

955 Jelinek, zitiert nach: Janke, Nestbeschmutzerin, S. I 52. Vgl. auch Kapitel 3.3.3 dieser Studie.

956 LW, S. I 2.

957 LW, S. 34.

$95^{8}$ Haider, zitiert nach: News, Nr. Io, 2000, S. 3 I. 
(»Die Strategie der Linken ist durchkreuzt ${ }^{959}$ - ebenfalls ein Originalzitat ${ }^{960}$ ). Auch dreiste Dichter, die ihn und seine Mitstreiter mit Worten attackieren, zählen zu den vermeintlichen Verfolgern: ${ }^{961}$

»Das Gift der Schreiberlinge nutzlos tropft zu Boden. Sie verbreiten Lügen, die Frucht und Feld verseuchen." ${ }^{962}$

In dieser Passage spielt die Autorin auf Angriffe Jörg Haiders und der FPÖ gegen sie selbst an, denn als Haider-Kritikerin war Jelinek in den I 99oer Jahren im öffentlichen Bewusstsein so präsent wie keine zweite. Aber auch die angebliche Hatz österreichischer Journalisten beklagt Jelineks Haider-Figur:

»Fort mit Schaden! Fort mit allem mit diesen drei alles Negative gebärenden Journalisten des ORF! ${ }^{963}$

»Haßtriefende Zeit im Bild! ${ }^{964}$

In Haiders News-Text las sich das Lamento des scheidenden Parteiobmanns ähnlich :

»Während wir uns in Susannes [Susanne Riess-Passers] Wohnung niederließen, lief die ZIB 3. Drei linke österreichische Journalisten ließen sich so über mich aus, dass der Hass nur triefend aus dem TV-Gerät herausquoll. « ${ }^{965}$

Die drei »linken österreichischen Journalisten«, die in der Zeit im Bild 3 über Haiders Rücktritt als Parteiobmann diskutierten, waren Christa Zöchling von der Zeitschrift "profil ${ }^{966}$, Hubert Wachter von "News» (jener Zeitschrift, die Haiders selbstbeweihräuchernden Abschieds-Text abdruckte) und Hans Rauscher, Kolumnist bei »Format« und »Der Standard«. 
Die Medien waren für Haider immer ein wichtiges Instrument zur Inszenierung seiner Person und zur Vorantreibung seiner politischen Ziele gewesen. In zahlreichen Interviews und Reportagen wurde ihm auch stets viel Raum gegeben, um sich medial darstellen zu können - vermutlich, weil Haider immer für einen Aufreger gut war und die Einschalt- bzw. Leserquoten dementsprechend hoch waren. Auf der anderen Seite verstand es Haider jedoch geschickt, angebliche Medienhetzen gegen ihn für zwischenzeitliche Rückschläge verantwortlich zu machen. So meldete etwa die "Neue Freie Zeitung« im Januar 1993, dass Haider eine neue Variante für die Abkürzung »ORF« erfunden habe: »Österreichs rücksichtslosester Falschmelder ${ }^{967}$. Der Staatsrundfunk, so Haider, sei ein Instrument der Altparteien (gemeint sind die Parteien der damals regierenden Großen Koalition, SPÖ und ÖVP), das »Angst, Verunsicherungs- und Verleumdungspropaganda verbreite, um ihm und seiner Partei zu schaden und Loyalitätsverluste unter den eigenen Anhängern zu begrenzen. ${ }^{968}$

Jelineks Haider-Figur bringt eine weitere Opfer-Täter-Inversion ins Spiel, die vor allem in Hinblick auf das paradoxe österreichische Gedächtnis bemerkenswert ist und in deren Perfektionierung sich der Original-Haider jahrzehntelang übte: Täter und Mitläufer des Nationalsozialismus als Angeklagte und Verfolgte darzustellen, da ihre Schuld Jahrzehnte nach der Tat doch »endlich einmal« verjährt und vergeben und vergessen sein müsste.

Unter Haiders Schutzherrschaft habe das kollektive schlechte Gewissen zu den Akten gelegt werden dürfen, befindet Haider-Biografin Zöchling und erklärt damit den großen Zuspruch, den Haider in den Jahren nach der Waldheim-Affäre (möglicherweise eine Inspiration für ihn) von Seiten der österreichischen Wählerschaft erfahren durfte. ${ }^{969}$ In Jelineks Theatermonolog fordert die Hauptfigur jene "Befreiung« ein, die Haider seit den späten I $980 e r$ Jahren versprochen hatte:

»Tod will Tod. Alter Mord. Neuer Mord. Gar kein Mord. Egal. Das Schandrecht des Mörders jetzt Ehre! « ${ }^{970}$

»Am liebsten würden wirs fortjagen, das ganze Land, wo immer nur Angeklagte wir sein werden, vor welchem Gericht?, doch wo herrschten wir dann, und wo wären die Schaulustigen, die uns bewundern? ${ }^{971}$

967 Haider, zitiert nach: Czernin, Westentaschen-Haider, S. I63.

968 Ders., zitiert nach: Ebd., S. 169.

969 Vgl. Zöchling, Haider, S. r6.

970 LW, S. I I.

97 I LW, S. I3. 
»Wir haben uns entschuldigt, mehr als entschuldigt, und viel mehr können wir nicht tun. Jetzt in die Zukunft schauen. ${ }^{972}$

»... Schuld - ebenfalls: genug! «"973

In diesem Zusammenhang werden auch persönliche Angriffe (etwa gegen Haiders Familie) in »Das Lebewohl« aufgegriffen - doch das Gegenteil von Mitleid wird hier bekundet, denn die Art und Weise der Formulierung (Übertreibung, Schwarz-Weiß-Malerei, Ausdrücken von Selbstmitleid) impliziert Distanzierung:

»Ich mußte miterleben, wie meine Familie, die Schönen, die Guten, Gescheiten, die vor Blondheit Strotzenden, von brutal Gewalttätigen in Mitleidenschaft gezogen wurde. ${ }^{974}$

So wird etwa mit der Formulierung »die vor Blondheit Strotzenden« die Nähe der Haider-Familie zum Nationalsozialismus, der den groß gewachsenen, blonden "Arier« als "Herrenmenschen« idealisierte, angedeutet. Insbesondere Haiders Eltern sollen überzeugte Nationalsozialisten gewesen sein.

Die Mutter, Dorothea Rupp, eine Primarstochter aus großbürgerlichem, nationalem Haus, war während der NS-Zeit Bannmädchenführerin beim BDM gewesen. Der Vater, Robert Haider, ein Schuhmachergeselle aus ärmlichen Verhältnissen (welch Mesalliance!, befand die mütterliche Verwandtschaft ${ }^{975}$ ), war bereits als I 8-Jähriger der SA beigetreten - zu einem Zeitpunkt, als die NsDAP in Österreich noch illegal gewesen war. Als Mitglied der SA hatte er sich I 934 an dem gescheiterten Juli-Putsch beteiligt. In Österreich stand er deshalb auf einer Fahndungsliste, weswegen er über die Grenze nach Bayern flüchten musste. Dort leistete er zweijährigen Militärdienst, trat formell der NSDA P bei und arbeitete anschließend in München bei der Firma »Agfa«. Nach dem »Anschluss« Österreichs an das Deutsche Reich I 938 tauchte Robert Haider wieder in Österreich auf und wurde »Gaujugendwalter« der »DAF» (»Deutsche Arbeitsfront«) in Linz. Zwei Jahre später wurde er zur Wehrmacht eingezogen. Ein Onkel der Mutter Dorothea erwarb indes im November I 94 I das arisierte Kärnter Bärental, das der Großneffe Jörg in dem Jahr seiner Wahl zum Bundesobmann der FPÖ schließlich erben sollte:

972 LW, S. I 4.

973 LW, S. 34.

974 LW, S. I6 f.

975 Vgl. Zöchling, Haider, S. г 8. 
»... wie zur Strafe - daß ja niemand glaubt, er könne seinem Familienroman entkommen - erbte Haider im Jahr I 986 von seinem reichen, deutschnationalen Großonkel das Kärntner Bärental, einen ehemals jüdischen Besitz, der mit dem Geld des Onkels sentjudet` wurde. Die Bedingung der Nationalsozialisten damals war, >das Deutschtum in diesem slowenischsprachigen Teil Kärntens hochzuhalten.«" ${ }^{976}$

Nun war es an Jörg Haider als Erbe, das »Deutschtum« in diesem Teil Kärntens hochzuhalten - und so »wie er sich um ein ethnisch homogenes Österreich sorgt $[\mathrm{e}]{ }^{977}$, scheint er auch dieser Bedingung weitestgehend nachgekommen zu sein. ${ }^{978}$

Der Vater, Robert Haider, war im Krieg an der West- und Ostfront mehrfach verwundet worden, konnte aber I 945 als Leutnant in die Heimat zurückkehren. ${ }^{979}$

In den ersten Nachkriegsjahren war Robert Haider als ehemals »Illegaler« von den Entnazifizierungsmaßnahmen der Alliierten besonders betroffen. So musste er Massengräber für die Ermordeten im Konzentrationslager Ebensee ausheben und wurde im Internierungslager Glasenbach bei Salzburg (das die Mutter als »KZ « bezeichnete ${ }^{980}$ ) inhaftiert.

Mutter Dorothea musste in einem ehemaligen Kinderheim der Volkswohlfahrt Putzarbeiten verrichten, wobei sie sich sehr erniedrigt fühlte, und litt unter dem jahrelangen Berufsverbot als Lehrerin. Außerdem verloren Haiders Eltern ihre Wohnung in Linz und mussten in ihren Heimatort Bad Goisern zurück. Dort lebten sie in einem Häuschen, einer »Keusche«, die sie anfangs mit einer anderen Familie teilen mussten. Jahrelang wohnte die Familie in zwei Zimmern. Im Zuge des Verbotsgesetzes wurden schließlich beide Eltern als »minderbelastet « eingestuft. ${ }^{981}$ Politisch blieben Haiders Eltern nach dem Krieg dem nationalistischen Lager verbunden. So war etwa Hermann Foppa, der letzte Obmann der Großdeutschen Partei und Reichstagsabgeordneter der nsDap, Taufpate für Sohn Jörg, Jahrgang I $950 .{ }^{982}$

In diesem Rahmen nationalistischer, großdeutscher Gesinnung und unter dem Eindruck der Schmach durch die Bestrafung der Eltern als ehemalige $\mathrm{Na-}$ tionalsozialisten wurde Jörg Haider sozialisiert. Natürlich war die Elterngenera-

976 Ebd., S. I 9.

977 Ebd.

978 Vgl. ebd.

979 Vgl. ebd., S. 32 ff.

980 Dorothea Haider, zitiert nach: Ebd., S. 36.

98 I Vgl. ebd., S. 36.

982 Vgl. die Kurzbiografie Jörg Haiders unter: http://de.wikipedia.org/wiki/Jörg_Haider (Zugriff am 10.10.2012). 
tion durch das im Nationalsozialismus und im Krieg Erlebte auf gewisse Weise traumatisiert. So musste jeder für sich einen Weg finden, mit der mehr oder minder belasteten Vergangenheit weiterleben zu können. Die Strafmaßnahmen gegen die Eltern, vor allem den Vater, mögen Jörg Haider also geprägt und ihn die Rolle des »ewigen Opfers" gelehrt haben.

Schon in seiner Kindheit war er in eine Welt von Sein und Schein eingeführt worden, in der die Eltern versucht hatten, die Welt draußen nichts von der Armut und den Demütigungen wissen zu lassen, denen sie sich ausgesetzt fühlten. ${ }^{983}$ Jörg Haider als Nesthäkchen der Familie und Musterschüler im Gymnasium, der stets darauf bedacht war, seine Mitschüler bei Leistungskontrollen auszustechen, hatte schon früh erfahren, dass man sich von der nationalsozialistischen Vergangenheit distanzieren muss, um als vollwertiges Mitglied der Gesellschaft anerkannt zu werden - auch wenn in seinem Milieu ganz anders geredet wurde. „Gefesselt in ihrer Schuld und in ihrer Trauer über die verlorenen Jahre« habe Haiders Elterngeneration nie wirklich eine Sprache für das Geschehene gefunden, glaubt Zöchling, und als »der Politiker Haider darüber Rede und Antwort stehen musste, konnte er es auch nicht ${ }^{984}$.

Immer wieder sprach Jörg Haider, zum Beispiel bei den umstrittenen SS-Veteranentreffen am Ulrichsberg, von der fehlenden Anerkennung, die Österreich den ehemaligen Wehrmachts- und SS-Veteranen zu Unrecht verweigere:

"Ich habe mir gedacht, es ist vielleicht ganz gut, auch ein öffentliches Zeichen zu setzen, ... dass klargemacht wird, dass es keine Schande ist, sich mit den Teilnehmern am Ulrichsberg als österreichischer Politiker zu treffen... Wir leben halt wirklich in einer Zeit, in der political correctness ... verbreitet wird und man versucht, jene Treffen und Begegnungen von der älteren Generation, die eigentlich nur in einer Gemeinsamkeit daran denken will, was sie alles durchgemacht hat, wofür sie gestanden ist und wofür sie heute noch steht, zu diskriminieren. ... Ich möchte einmal wissen, ob jemand von denen, die zu feige sind dort hinzugehen, oder die ständig den Stab über das Ulrichsbergtreffen brechen, ob sie einmal ein vernünftiges Argument sagen können. Es gibt nämlich keines, außer dass man sich ärgert, dass es in dieser Welt einfach noch anständige Menschen gibt, die einen Charakter haben und die auch bei größtem Gegenwind zu ihrer Überzeugung stehen und ihrer Überzeugung bis heute treu geblieben sind.« ${ }^{985}$

Welche Überzeugung das im Konkreten ist, führte Haider in seiner Rede nicht aus - die Anwesenden fühlten sich ohnehin bestätigt, und für die Kritiker war

983 Vgl. Zöchling, Haider, S. I 8.

984 Ebd., S. I 8.

985 Czernin, Westentaschen-Haider, S. 53 ff. 
das, was Haider sagte, juristisch nicht verfolgbar: Anständige Menschen zu loben, die zu ihren Überzeugungen stehen, ist nach dem Wiederbetätigungsgesetz nicht strafbar. Menschen, die zu ihrer nationalsozialistischen Überzeugung stehen, öffentlich zu bestärken und anzuerkennen, hingegen schon:

»Das Verbotsgesetz bedroht jeden mit Strafe, der sirgendwie < für nationalsozialistische Ziele wirbt. Schon die $>$ Verharmlosung $\ll$ ist strafbar. ${ }^{986}$

Auch Haiders Eltern waren in der Regel bei den Ulrichsbergtreffen anwesend. Dass sie trotz Entnazifizierung ihrer Gesinnung nicht abgeschworen hatten, darf also vermutet werden. Jelineks Haider-Figur ruft in »Das Lebewohl« immer wieder den Vater an und beklagt dessen schweres Schicksal (»Mein Vater noch ganz im Joch des Leidens eingeschirrt... « ${ }^{987}$ ). Außerdem verspricht er, den Vater, dem Unrecht angetan wurde, zu rächen. In diesem Zusammenhang findet sich das Motiv des Orest'schen Muttermordes wieder - eine Demonstration patriarchaler Machtausübung:

»Rache für den Vater! Tötet das Land, tötet die Mutter, tötet sie..." ${ }^{988}$

»Vater! Zweifach, dreifach, vielfach werden wir jetzt Erhöhten die Schuld dir bezahlen, nicht wahr, Knaben? ${ }^{989}$

Bei Jelinek wird der archaische Muttermord des Orest zum Mord am Land selbst, das die Stelle der Mutter einnimmt:

»Mutter! Wir sind Zeugen gewesen, wie die Frauenlist des Landes meinen Vater verriet, das Land: eine Frau." ${ }^{990}$

Zum Ende hin wird das antike Rache-Phantasma immer dichter und drängender, Erlösung heißt nun immer mehr »Rache nehmen für den Vater«, womit Jelinek die eigene traumatische Biografie Haiders in den Vordergrund stellt. ${ }^{991}$

Die in »Das Lebewohl« dargestellte Systematik, in der die Aggression von außen heraufbeschworen oder gar eine (bewusste) Verschiebung von Opfer-Tä-

986 Scharsach, Haiders Kampf, S. 7.

987 LW, S. 33.

988 LW, S. 26.

989 LW, S. 33.

990 LW, S. 27. Vgl. dazu Lücke, Gespenster, S. I I 7.

99 I Vgl. Lücke, Gespenster, S. I I 7. 
ter-Position vorgenommen wird, ist ein typisches Charakteristikum faschistischer Systeme. Im Nationalsozialismus wurden vor allem Juden und »Bolschewisten« als angebliche Feinde der inneren Sicherheit und des ökonomischen Gleichgewichts verfolgt und bekämpft. Die zeithistorische Forschung spricht in diesem Zusammenhang von der »Exklusion ${ }^{992}$ Gemeinschaftsfremder. Der italienische Fascismo unter Benito Mussolini hatte sich die Ausschaltung der sozialistischen, kommunistischen, liberalen und demokratischen Kräfte zum Ziel gesetzt. Die im Faschismus sowohl verbal als auch mit Waffengewalt ausgetragene Bekämpfung vermeintlicher Feinde diente einerseits der Abschreckung nach außen sowie andererseits der Festigung des Zusammenhalts nach innen. ${ }^{993}$

In ihrem Text deckt Jelinek »Krebsgeschwüre eines wuchernden faschistischen Einheits- und Gemeinschaftswillens« auf, so Bärbel Lücke, der »das vereinnahmt, was dazugehören soll und das vernichtet, was nicht dazu gehört « ${ }^{994}$. Als sehr klarer und eindeutiger Hinweis auf diesen tumorartigen Gemeinschaftsgeist kann etwa folgende Textstelle herangezogen werden:

»Wir sind alle, und wer noch fehlt, den verrechnen wir nachher miteinander. Mit dem rechnen wir ab. ... Wir sind angefordert von jedem, der da ist : anständig, tüchtig, fleißig. Die vielen zählen nicht mehr, denn wir sind jetzt da. Wir sind alle.« ${ }^{995}$

Die im Text als rekurrent auffällige Formulierung "Wir sind alle« drückt die Konfrontation aus zu den »vielen«, die »nicht mehr zählen«, also als Feinde betrachtet werden und übergangen oder sogar ausgeschaltet werden sollen. Denn der unbedingte Wille zur Gemeinschaft bringt die Notwendigkeit mit sich, jeden, der diese zu Fall bringen könnte, zu eliminieren. Dieses Phänomen konnte in Realität im Kriegswinter I 942/43 beobachtet werden, als Propagandaminister Goebbels die kriegsmüde Bevölkerung des Deutschen Reichs (dieses nunmehr an zwei Fronten verstrickt, von Luftangriffen der Engländer gezeichnet und unter dem Schock der Katastrophe von Stalingrad) auf den »Totalen Krieg« einschwor, was eine fanatisierte Menge im Sportpalast mit frenetischem Beifall und »Sieg Heil«-Rufen bejubelte. ${ }^{996}$ Erschreckenderweise scheint der Zusammenhalt einer Gemeinschaft letzten Endes immer umso stärker zu sein, je stärker die Abgrenzung gegen die (wie auch immer definierten) »anderen« - in Jelineks Text »die vielen« - ausgelebt wird.

992 Vgl. Kapitel I.4.I dieser Studie.

993 Vgl. Wippermann, Hat es Faschismus überhaupt gegeben, S. 56.

994 Lücke, Gespenster, S. I I I.

995 LW, S. I 5.

996 Vgl. Studt, Das Dritte Reich in Daten, S. 206 f. 
Auch Haider gründete seine politische Karriere nicht zuletzt auf der Konstruktion und Aufrechterhaltung von Feindbildern, gegen die er mit seiner Partei und auch persönlich vorzugehen trachtete: etwa gegen die "Großkopferten « ${ }^{97}$ in Wien und Brüssel, gegen »Linke» (im weitesten Sinne), "Ausländer« und Juden oder in Kärnten auch gegen die autochthone Volksgruppe der Kärntner Slowenen (erinnert sei hier nur an den nicht enden wollenden »Ortstafelstreit«). Dabei schuf er das Image des »Privilegienritters«, der die Nöte des »kleinen Mannes« kenne und unerschrocken für dessen soziale Besserstellung kämpfe. Auch der sprecher erkennt:

„Denn der kleine Mensch, der braucht sein kleines Haus. «"998

Die in Jelineks Text geschilderte Haider-FPÖ der r 99oer Jahre kommt in einigen Punkten der im theoretischen Teil dieser Studie wiedergegebenen Charakterisierung Wolfgang Wippermanns einer (idealtypischen) faschistischen Partei auffallend nahe: Sie ist streng hierarchisch nach dem Führerprinzip gegliedert, zelebriert ihren politischen Stil auf ritualisierten Massenkundgebungen und betont dabei ihren jugendlichen und vor allem männlichen Charakter. Im Mittelpunkt ihrer politischen Agitation steht die Ablehnung und (verbale) Bekämpfung von Außenstehenden. ${ }^{999}$

Dass das Versprechen der Besserstellung oftmals mit der Zurücksetzung anderer (den Feinbild-Gruppen angehörenden bzw. gemeinschaftsfremden Personen) eingelöst werden wollte, vermochte immerhin knapp ein Drittel der Wähler bei den Nationalratswahlen im Herbst I 999 nicht abzuschrecken: Nach einem aggressiven »Anti-Ausländer«-Wahlkampf erreichte die Freiheitliche Partei Österreichs unter Bundesobmann Jörg Haider knapp 27 Prozent der Wählerstimmen - ein demokratiepolitisch zweifelhafter Erfolg, welcher mit der in Jelineks Text angebotenen Deutung des sprechers - eine Verschränkungsfigur von (homoerotischer) Sexualität, Macht und Verführung ${ }^{1000}$ - jedenfalls zum Teil erklärt werden kann.

\footnotetext{
997 LW, S. 2 I.

998 LW, S. 32.

999 Vgl. Wippermann, Hat es Faschismus überhaupt gegeben, S. 56. Vgl. dazu auch Kapitel I.4.I dieser Studie.

I ooo Vgl. Lücke, Gespenster, S. 93.
} 


\begin{tabular}{llrcc}
\hline Partei & Kurzbezeichnung & Stimmen & in \% & Mandate \\
\hline Sozialistische Partei Österreichs & SPÖ & I,532.448 & 33,2 & 65 \\
Österreichische Volkspartei & ÖVP & I,243.672 & 26,9 & 52 \\
Freiheitliche Partei Österreichs & FPÖ & I,244.087 & 26,9 & 52 \\
Liberales Forum - Heide Schmidt & LIF & I68.6 I 2 & 3,7 & - \\
Die Grünen - Die Grüne Alternative & GRÜNE & 342.260 & 7,4 & I4 \\
Kommunistische Partei Österreichs & KPÖ & 22.0 I6 & o,5 & - \\
Die Unabhängigen - Liste Lugner & DU & 46.943 & I & - \\
Nein zu NATO und EU Bürgerinitiative & NEIN & r 9.286 & 0,4 & - \\
Christliche Wählergemeinschaft & CWG & 3.030 & $0, \mathrm{I}$ & - \\
\hline
\end{tabular}

Abb. 2: Ergebnisse der Nationalratswahlen vom 3. Oktober 1999

Jörg Haider hatte es geschafft: Die Regierungsbeteiligung der FPÖ und die Position als Vizekanzler waren in greifbare Nähe gerückt. Warum Haiders bundespolitische Karriere im Jahr 2000 trotzdem (zumindest vorerst) ein abruptes Ende fand, wird im folgenden, abschließenden Kapitel erläutert.

\subsubsection{Entstehungskontext und Rezeption}

»Ein solches Stück Literatur bezieht seine Wirkung nicht von dem, der sie veranlasst, es meint mehr als den Kärntner Landeshauptmann.« ${ }^{1001}$

»Mehr als ein Jahrzehnt anpatzen und diffamieren, wie man es mit mir gemacht hat, das ist vorbei«, deklamiert Jelineks Haider-Figur, der SPRECHER, "für die Wende arbeitete ich.... ${ }^{1002}$ Die so genannte »Wende«, auf die im Text Bezug genommen wird, sollte nach der langjährigen Koalition von SPÖ und ÖVP I 999/200o einen politischen Neuanfang bringen, frischen Wind und neue Ideen, mit denen Österreich regiert werden sollte - so der Tenor der frisch gebackenen Koalitionspartner ÖVP und FPÖ. Aufgrund der offen fremdenfeindlichen, rassistischen und antisemitischen Positionen des kleinen Koalitionspartners sowie

I O० I Wendelin Schmidt-Dengler über »Das Lebewohl«; zitiert nach: profil, Nr. 42, 2004, S. I 28.

го०2 LW, S. г6. Jörg Haiders Originalzitat aus News dazu im Vergleich: »Mehr als ein Jahrzehnt habe ich für diese Wende gearbeitet, habe mich anpatzen und diffamieren lassen (Feindbilder!) und musste auch miterleben, wie meine Familie von gewalttätigen Demonstranten in Mitleidenschaft gezogen wird.«Haider, zitiert nach: News, Nr. Io, 200o, S. 30. 
dessen problematischem Verhältnis zur Geschichte schlug der »schwarz-blauen« Regierung allerdings großer Protest entgegen: Zehntausende Österreicher gingen auf die Straße, um an Demonstrationen gegen das Schüssel-Haider-Kabinett teilzunehmen, auch Elfriede Jelinek. ${ }^{1003}$ Bundespräsident Thomas Klestil nahm die Angelobung der neuen, schwarz-blauen Regierung nur mit demonstrativem Unwillen vor. Die (damals) I 4 anderen EU-Staaten sowie die Tschechische Republik belegten Österreich gar mit diplomatischen Sanktionen, welche die bilateralen Beziehungen des Landes vorübergehend einschränken sollten. ${ }^{1004}$

In Folge der massiven Proteste, die vor allem dem - zum Teil auch im Ausland - umstrittenen FPÖ-Obmann Haider galten, entschied sich dieser überraschend zum Rückzug aus der Bundespolitik und übergab mit tränenerstickter Stimme die Obmannschaft Anfang Februar 2000 an Parteikollegin Susanne Riess-Passer. Etwa einen Monat später erschien Haiders persönliche Stellungnahme zu seinem Rücktritt in News: „Glücksgefühl nach bangen Stunden«. Diesen Text nahm Jelinek, wie am Beginn dieses Kapitels bereits dargelegt, zum Ausgangpunkt für ihren Haider-Monolog »Das Lebewohl«. Mit Haiders Aufzeichnungen habe sich ihr die Sprache förmlich in die Hand gegeben, so Jelinek: "... ein Geschenk des Himmels, so etwas bekommt man nicht oft. « ${ }^{1005}$

Am 22. Juni 2000 wurde "Das Lebewohl« als Auftakt einer regierungskritischen »Wiener Donnerstagsdemo ${ }^{1006}$ am Ballhausplatz im Beisein der Autorin von dem Schauspieler Martin Wuttke verlesen. Etwa I.200 Zuschauer verfolgten Wuttkes Darbietung, die mit Kärntner Liedern eingeleitet wurde. ${ }^{1007}$ Die Uraufführung am Theater fand noch im Dezember desselben Jahres statt: „Das Lebewohl« wurde am Berliner Ensemble in der Inszenierung von Ulrike Ottinger gezeigt (für österreichische Bühnen hatte Jelinek ein Aufführungsverbot ihrer Stücke verhängt, das bis 2002 aufrecht blieb). Auch in der Berliner Inszenierung schlüpfte Martin Wuttke in die Rolle des rechtspopulistischen österreichischen Politikers. ${ }^{1008}$

Dieser hatte offen auf eine Regierungsbeteiligung der FPÖ hingearbeitet und bereits Mitte der I990er Jahre seinen Anspruch auf die Kanzlerschaft angemeldet.

I003 Vgl. Janke, Nestbeschmutzerin, S. I 47-1 50.

roo4 Zur »Wende« vgl. den sehr interessanten, mit Begriffen aus der Psychoanalyse operierenden Essay von Michael Fleischhacker, Die Wende zur Hysterie, oder auch das Buch zum Thema von Gerfried Sperl, Der Machtwechsel.

Io05 Jelinek, zitiert nach: Janke, Nestbeschmutzerin, S. I 48.

Ioo6 Die Wiener "Donnerstagsdemos« wurden aus Protest gegen die Bildung der Regierungskoalition von ÖVP und FPÖ über zwei Jahre hinweg wöchentlich abgehalten.

I007 Vgl. Janke, Nestbeschmutzerin, S. I 47.

roo8 Vgl. ebd., S. I49. 
»Ich geh' gern in eine Regierung, wenn ich Kanzler bin, alles andere reizt mich nicht sehr. Ich bin ein schlechter Zweiter. ${ }^{1009}$

»Wir sind eine politische Großmacht geworden. Unser Ziel ist es, den Kanzler und den Landeshauptmann zu stellen! ${ }^{1010}$

Nach den Nationalratswahlen im Herbst I 999 konnte die (zwar krisengeschüttelte, aber immer noch stimmenstärkste) sozialistische Partei unter Viktor Klima keine handlungsfähige Regierung bilden. Die von Bundespräsident Klestil verordneten »Sondierungsgespräche « ${ }^{1011}$ scheiterten. Wolfang Schüssel, Obmann der ÖVP, die erstmals hinter der FPÖ auf Platz 3 in der Wählergunst gelandet war (auch wenn die Differenz marginal war), packte die Gelegenheit beim Schopfe, als Drittplatzierter Bundeskanzler zu werden, was nur mit Unterstützung der FPÖ möglich war. Innerhalb weniger Tage und ohne offiziellen Auftrag des Bundespräsidenten fanden sich ÖVP und FPÖ im Jänner $2000 \mathrm{zu}$ einer neuen Regierungskoalition zusammen. Frühere Äußerungen Schüssels, in denen er angekündigt hatte, als Drittplatzierter in Opposition zu gehen, und in denen er eine Zusammenarbeit mit der FPÖ strikt abgelehnt hatte, entpuppten sich als Lippenbekenntnisse:

»Eine FPÖ, die die EU ablehnt, die Integration torpediert, den Euro mit Schauergeschichten bekämpft und in der Ausländerfrage mit den Gefühlen der Menschen spielt, lehne ich ab.« ${ }^{1012}$

"Haider hat seinen abstrusen Ideen nie abgeschworen. Bei seinen zentralen Botschaften hat er immer wieder ein Schäuferl nachgelegt. Also kommt er für uns nie in Frage. ${ }^{1013}$

Michael Fleischhacker führt in seinem Essay zur »Wende« 2000 Schüssels inkonsequenten Umgang mit früheren Feststellungen auf einen Zusammenhang zum psychischen Krankheitsbild der »Hysterie» (im Freud'schen Sinne) zurück: Da werden der "gleiche Sachverhalt, dieselbe Frage... zwei oder drei Tage später ganz anders geschildert und beurteilt, ohne dass zumindest das Bedürfnis nach einer Rechtfertigung für diese Diskrepanz auftaucht « ${ }^{1014}$.

roog Haider, zitiert nach: Czernin, Westentaschen-Haider, S. 2 I 2.

го го Ders., zitiert nach: Ebd., S. 2 I 3.

Io I Fleischhacker, Die Wende zur Hysterie, S. I7.

Iо 2 Schüssel, zitiert nach: Czernin, Westentaschen-Haider, S. 8.

Ior3 Ders., zitiert nach: Ebd.

Ior4 Fleischhacker, Die Wende zur Hysterie, S. 23. 
Das schwarz-blaue Projekt kam jedoch bald ins Straucheln. Bereits 2002 mussten Neuwahlen vorgezogen werden, die mit Einbußen für die FPÖ endeten. 2005 schließlich spaltete sich die Partei nach massiven internen Auseinandersetzungen in FPÖ (unter Heinz Christian Strache) und BZÖ (unter Jörg Haider) auf. 2008 kehrte Haider als BZÖ-Parteivorsitzender und dessen Spitzenkandidat im Wahlkampf in die Bundespolitik zurück und verdoppelte den Stimmenanteil seiner Partei bei den Nationalratswahlen im September auf beinahe I I Prozent. Haider war wieder im Rennen. Seine zuvor belächelte neue Partei, das BZÖ, hatte mit ı,,7 Prozent immerhin die Grünen (ı, 4 Prozent) knapp überholt. ${ }^{1015}$

Wenige Wochen später verunglückte der BZÖ-Parteichef und Kärntner Landeshauptmann bei einem Autounfall tödlich, und sein großes Comeback fand ein jähes Ende. Mit dem Essay »Von Ewigkeit zu Ewigkeit« verabschiedete sich Elfriede Jelinek in der ihr eigenen Weise von Jörg Haider, der im katholischen Österreich zu Unrecht als »Erlöser « ${ }^{1016}$ ersehnt worden sei.

\begin{abstract}
»Wir hatten nur einen wie ihn. So einer kommt nicht wieder. So einen kriegen wir nie wieder. Er kommt vielleicht wieder, aber man wird ihn nicht erkennen können: die Tragik des Erlösers, er kommt immer wieder, auch als ein andrer, doch er muß immer er bleiben, und man erkennt ihn bald nicht mehr. Man erkennt ihn womöglich in einem anderen. Entsetzlich! ${ }^{1017}$
\end{abstract}

2009 spaltete sich das haidertreue Lager im BZÖ als FPK ab. Seit 20 Io kooperierten FPÖ und FPK, im Juni 2013 kehrte die FPK wieder in den Schoß der Bundes-FPÖ zurück. Das BZÖ ist derzeit nur noch im Kärntner Landtag mit zwei Mandaten vertreten - das Ablaufdatum der Partei scheint vorprogrammiert. ${ }^{1018}$

In Bezug auf Jelineks Theatermonolog muss an dieser Stelle festgehalten werden, dass die Rezeption, wenn sie auf die expliziten Anspielungen auf Jörg Haider und die Haider-FPÖ der I 99oer Jahre sowie die angesprochenen Ereignisse rund um die »Wende« von $1999 / 2000$ fokussiert ist, nur für Österreicher oder profunde Österreich-Kenner und über einen eingeschränkten Zeitraum hinweg möglich ist. Tatsächlich ist es so, dass sich Jelinek beim Schreiben immer auf ein

ror $5 \mathrm{Zu}$ den genauen Wahlergebnissen vgl. Kapitel 3.3.3.3 dieser Studie.

Ior6 Jelinek, zitiert nach: Janke, Nestbeschmutzerin, S. I 52.

Ior7 Dies., Von Ewigkeit zu Ewigkeit, unpaginiert.

Ior 8 Das BZÖ unter Parteiobmann und Spitzenkandidat Josef Bucher erreichte bei den Nationalratswahlen im September 2013 nur noch 3,5 Prozentpunkte und konnte somit die für den Nationalrat vorgegebene Vier-Prozent-Hürde nicht überspringen. 
bestimmtes Hier und Jetzt festlegt, denn sie versteht sich selbst als politische Autorin und nimmt in ihren Texten direkt Bezug auf aktuelle politische Verhältnisse, Vorgänge und agierende Personen. »Natürlich versteht man diesen Text in Österreich besser « ${ }^{1019}$, räumte sie in einem Interview 200 I ein, gab aber zu bedenken, dass es ja leider auch außerhalb Österreichs allgemeine Tendenzen der Rechten gebe, die etwa in Ulrike Ottingers Inszenierung in Berlin aufgegriffen worden seien. Insofern kann und muss Jelineks Haider-Figur als exemplarisch verstanden und das Stück als Vorlage für Dramaturgen und Regisseure begriffen werden, ihre Inszenierungen an jeweils aktuelle Vorgänge und Zustände anzupassen. "Man kann es ... natürlich auch ganz anders machen ${ }^{1020}$, ist bereits in der Regieanweisung zu »Das Lebewohl« festgehalten. Der Insenzierung bleibt wie immer bei Jelineks Theaterstücken - großer Spielraum. Die Erhabenheit des Stücks über Raum und Zeit bringt Bärbel Lücke folgendermaßen auf den Punkt:

»Es ist... ein echter Bühnenmonolog, bei dem die Probleme von Politik, Macht und Herrschaft auf der Folie der Theorien des zwanzigsten Jahrhunderts sverhandelt und durch sie transparenter werden, so dass das >kl. Drama aus der Kategorie des `Zeitstücks` ... herausgehoben wird und auch dann noch dramatische Brisanz und künstlerische Aktualität haben wird, wenn vielleicht niemand mehr weiß, wer Jörg Haider war. ${ }^{1021}$

Österreich und den Österreichern wird Jörg Haider zweifelsohne noch eine Weile in Erinnerung bleiben; sein aggressiver Rechtspopulismus, seine zweifelhaften Darstellungen zur österreichischen Geschichte, aber auch seine Beleidigungen internationaler Repräsentanten haben es über die Landesgrenzen hinaus zu zweifelhafter Berühmtheit gebracht. In »Das Lebewohl« hat Jelinek viele von ihnen versammelt, neu arrangiert und als Halbwahrheiten, Doppeldeutigkeiten oder Lügen entlarvt. Der Mythos Haider wird in »Das Lebewohl« mit einfachen Mitteln entzaubert.

Nachkommende Generationen werden die Aufregungen um Jörg Haider und seine »Burschenpartei« vielleicht kaum noch nachvollziehen können. Inzwischen sorgen aber bereits andere Rechtspopulisten für "gruselige Pointen « ${ }^{1022}$, die Elfriede Jelinek vermutlich weiterhin an den Schreibtisch treiben und die Dramaturgen der deutschsprachigen Bühnen mit stets neuen Aufgaben versorgen werden.

Ior 9 Jelinek, zitiert nach: Janke, Nestbeschmutzerin, S. I 5 I.

I020 LW, S. 9.

IO2 I Lücke, Gespenster, S. 80.

I022 Ebd. 


\section{Resümee}

"Das Denken für sich allein bewegt nichts, sondern nur das auf ein Ziel gerichtete und praktische Denken. ${ }^{1}$

I Aristoteles, zitiert nach: http://www.zitate.de/autor/Aristoteles (Zugriff am I 8.1 2.20I 2). 


\subsection{Zusammenfassung der Ergebnisse}

»Das Fragen aber findet kein Ende.

Darum bleibt die Wissenschaft nicht stehen ...

Das letzte Wort ist niemals gesprochen. ${ }^{2}$

Ziel der vorliegenden Arbeit war es, eine neue, interdisziplinäre Herangehensweise zu finden, mit der die hoch artifiziellen, semantisch heterogenen Texte von Elfriede Jelinek zugänglicher gemacht werden können. Zwei wesentlichen Komponenten galt es dabei Rechnung zu tragen: zum einen der unübersehbaren inhaltlichen Aufladung der Texte mit historisch-politischen Themen; zum anderen deren ästhetischer Realisierung, die über die explizite Thematisierung hinaus vor allem auf einer intertextuellen, metasprachlichen Ebene stattfindet.

Im Rahmen der Einführung wurde festgestellt, dass innerhalb des umfangreichen Sekundärwerks zu Elfriede Jelinek interessanterweise immer noch kaum schlüssige Interdependenzen zwischen dem sprachkritischen Verfahren der Autorin und einem ihrer wichtigsten Themen hergestellt werden: ihrer über die Jahre hinweg kontinuierlich gepflogenen Kritik am österreichischen Opfermythos. Vor allem an plausiblen Interpretationsvorschlägen herrscht in dieser Hinsicht (dem Nobelpreis und der dadurch entstandenen Aufmerksamkeit zum Trotz) immer noch großer Mangel. Weiters wurde festgestellt, dass mitunter sogar zwischen der Person und der Schriftstellerin Jelinek unterschieden wird - eine Differenzierung, die die Autorin selbst ablehnt: Das politische Engagement sei Teil ihrer Literatur, so Jelinek. ${ }^{3}$

Als grundlegendes ästhetisches Verfahren Elfriede Jelineks wurde die »Destruktion« vorgefundenen Sprachmaterials aus verschiedenen Zusammenhängen erkannt: Die orthografische, syntaktische, semantische und/oder phonetische Verfremdung bestehender Sprachgebrauchsformen soll deren konventionelle Bedeutung in Frage stellen, um auf diese Weise die Künstlichkeit und Verlogenheit gesellschaftlicher, politischer oder medialer Diskurse im satirischen Sinne zu entlarven.

Um dieses Verfahren in Zusammenhang mit dem Thema der vorliegenden Arbeit anschaulich machen zu können, war es zunächst notwendig, die grundlegenden Begriffe zu diskutieren, mit denen im empirischen Teil gearbeitet werden sollte. Weiters sollte mit der vorliegenden Begriffsdiskussion eine Sensibilisierung für bestimmte Ausdrücke erreicht werden, die von der Jelinek-Forschung gerne und häufig - offenbar jedoch ohne einschlägige Vorkenntnisse - aus der Zeithistorie entlehnt werden.

2 Sellin, Geschichtswissenschaft, S. 8I.
3 Vgl. Jelinek, zitiert nach: profil, Nr. 42, 2004, S. I 24. 
Dazu gehört in erster Linie der sensible Faschismusbegriff, der anhand der wichtigsten Definitionen und Theorien der letzten Dekaden erläutert wurde, wobei die grundsätzliche Feststellung getroffen wurde, dass ältere Theorien vor allem monokausal orientiert waren bzw. einen Merkmalskatalog zu entwickeln versuchten, welcher der Dynamik der realhistorischen Faschismen nicht gerecht werden konnte. Definitionen der letzten beiden Dekaden versuchen, die verschiedenen, zum Teil ambivalenten Wege des Faschismus zu vergleichen und lenken dabei den Blick verstärkt auf dessen soziale und kulturelle Praktiken. Tatsächlich ist der Faschismusbegriff damit (vor allem dank der regen angloamerikanischen Forschung) ein ganzes Stück flexibler geworden - er ist prozessual ausgerichtet und will das Entwicklungspotential und die Wandelbarkeit des faschistischen Phänomens erfassen. In Übereinstimmung mit dem Gros der herangezogenen Autoren wurde der Nationalsozialismus als spezifische Form (als »nationale Variante«) des Faschismus bezeichnet und ein kurzer Exkurs in die aktuelle Nationalsozialismusforschung unternommen, die sich vor allem durch einen grundlegenden Perspektivenwechsel auszeichnet: Demnach gelten heute nicht mehr der Eroberungskrieg oder die Zerschlagung von Demokratie und Sozialismus als Hauptmerkmale des NS-Regimes, sondern der »Zivilisationsbruch Auschwitz «", dem im gesellschaftlichen und wissenschaftlichen Diskurs seit den i98oer Jahren wachsende Beachtung geschenkt wird. Heute gilt der Holocaust, der Genozid an den europäischen Juden, als präzedenzloses und zentrales Kernereignis des Nationalsozialismus. Die Frage nach den Ursachen dieser großen menschlichen Katastrophe befördert auch das zeithistorische Interesse für die »Einzelnen« und ihre Erfahrungen, Handlungen und Handlungsspielräume. ${ }^{5}$ Hatten frühere Modelle das NS-Regime vor allem als "Mobilisierungs- und Manipulationsprojekt ${ }^{6}$ der politischen Eliten zu beschreiben versucht, fokussieren neuere Ansätze verstärkt auf anthropologische Themen und versuchen (etwa anhand mikro- oder alltagsgeschichtlicher Studien) konkrete »Lebenswelten $\aleph^{7} \mathrm{zu}$ rekonstruieren, was die Wandelbarkeit und Dynamik des deutsch-österreichischen Faschismus nachvollziehbar macht und damit zur Differenzierung und Weiterentwicklung früherer Modelle beiträgt.

In einem weiteren Schritt wurde der für Jelineks poetisches Verfahren in seiner Bedeutung kaum zu überschätzende »Mythos«-Begriff erläutert: Nach Roland Barthes ist der Mythos eine Aussage, die unbewusste, kollektive Bedeu-

\footnotetext{
4 Diner, Zivilisationsbruch. Vgl. auch: Ders., Den Zivilisationsbruch erinnern.

5 Vgl. Burghartz, Historische Anthropologie, S. 206.

6 Kritisch dazu Bauer, Mobilisierung, S. 288.

7 Zu dem historischen Begriff der »Lebenswelt(en)« vgl. Kapitel I.4.2 dieser Studie.
} 
tungen in sich trägt. Diese Bedeutungen werden von der Sprachgemeinschaft als scheinbar natürlich wahrgenommen und daher nicht hinterfragt. Es wurde festgehalten, dass die Mythendestruktion heute innerhalb des Sekundärwerks sehr einhellig als Jelineks bevorzugtes Verfahren begriffen werde, wenn auch die Begriffe »Dekonstruktion « und »Destruktion« in inkohärenter Verwendung vorzufinden seien. ${ }^{8}$

Zuletzt wurde die finale Verknüpfung all dieser Ausdrücke in dem aus der Zeithistorie entlehnten Begriff des österreichischen "Opfermythos « analysiert: Dieser bezeichnet ein wirkungsmächtiges Geschichtsbild der Zweiten Republik, das Österreich als das erste Opfer nationalsozialistischer Aggressionspolitik beschreibt. Verantwortung und Schuld für die Verbrechen des Nationalsozialismus und des Zweiten Weltkriegs fallen im Rahmen dieser Geschichtsdarstellung einer »Externalisierung " ${ }^{9}$ zum Opfer, welche die Alleinschuld an den größten Nachfolgestaat des Deutschen Reichs, die Bundesrepublik Deutschland, verweist. Es wurde gezeigt, dass sich in den Jahrzehnten nach I 949/50 tatsächlich verschiedene, zum Teil widersprüchliche Narrationsstränge entwickeln konnten, die neben dem Opfermythos etwa zu einer Heldenverehrung der gefallenen österreichischen Wehrmachtssoldaten, im Laufe der i 99oer Jahre aber auch zur so genannten "Mitverantwortungsthese ${ }^{10}$ führten. In jüngster Vergangenheit bildete sich weiters ein erinnerungsgeschichtlicher Kompromiss heraus, der nach Gerhard Botz als "Opfer-Täter-Gedächtnis « ${ }^{11}$ bezeichnet wird: Dieser beinhaltet sowohl das Eingeständnis der Mitverantwortung als auch das Beharren auf dem Opferstatus. Gerade in dem Nebeneinander widersprüchlicher Narrationen ist aber möglicherweise das eigentliche Charakteristikum österreichischer Geschichtspolitik auszumachen. ${ }^{12}$

Neben der mitunter sehr deutlichen Kritik am österreichischen Opfermythos spiegelt sich in Jelineks Texten genau dieses paradoxe österreichische Gedächtnis wider, das bis heute die Ausbildung einer adäquaten Sprache verhindert hat, mit der Mitverantwortung und Schuld unmissverständlich und ohne selbstmitleidigen Unterton im öffentlichen Diskurs ausgedrückt werden. Zudem herrscht immer noch - und wie gezeigt wurde, selbst im geisteswissenschaftlichen Diskurs - mangelnde Sensibilität im Umgang mit historisch belasteten Begriffen. Bei der extremen Rechten schließlich findet auch heute noch - und zum Teil

8 Vgl. Kapitel I.I dieser Studie.

9 Lepsius, Das Erbe des Nationalsozialismus, S. 250.

Io Uhl, Das »erste Opfer«, S. 27.

I I Botz, Nachhall und Modifikationen, S. 6or.

I 2 Vgl. Uhl, Das »erste Opfer«, S. 20 sowie S. 23-26. 
recht unverhohlen - »totale Verleugnung «" ${ }^{13}$ statt. Die Kritik an dem allgemeinen sprachlichen Unvermögen findet sich in einem Großteil von Jelineks Texten wieder: manchmal ex-, manchmal implizit, sehr oft in Mischformen.

Um die Besonderheit Jelineks literarischer Ästhetik, die sich durch das ständige Experimentieren mit neuen Formen auszeichnet, herausarbeiten zu können, wurde in einem nächsten Schritt eine Annäherung an die Autorinnenbiografie geleistet, welche die theoretische Auseinandersetzung nicht nur mit lebensgeschichtlichen Details zu Elfriede Jelinek bereichern, sondern auch literarische Traditionen bewusst machen sollte, an welche die Autorin mit ihren Methoden von Collage, Montage und Destruktion anknüpft. In erster Linie sind es die sprachkritischen und avantgardistischen Literaturtraditionen des i 9. und 20. Jahrhunderts, die Jelinek in jungen Jahren geprägt haben. Die Nähe zum Wiener Aktionismus und zu der Experimentierfreudigkeit der Wiener Gruppe ist auch heute noch erkennbar. Für Jelinek selbst ist dabei die Feststellung wichtig, dass sie sich »leidenschaftlich und patriotisch und geradezu fanatisch" als österreichische und nicht als deutsche Autorin fühle, denn das Österreichische sei »eine ganz andere Sprache ${ }^{14}$, die sich unter dem Einfluss jüdisch-österreichischer Literaturtraditionen in der Habsburger Monarchie entwickelt habe: Durch den Einfluss des Jüdischen sei vor allem das satirische Schreiben in die österreichische Literatur getragen worden, das der nationalsozialistische Faschismus mit seiner eindimensionalen Auffassung von Kunst und der Ausrottung bzw. Vertreibung jüdischer Kunstschaffender vernichtet hat.

In einem weiteren Schritt wurde darauf aufmerksam gemacht, welchen Stellenwert die Auseinandersetzung mit dem Opfermythos in Elfriede Jelineks literarischem CEuvre einnimmt: Hierfür wurde ein roter Faden gesponnen, der von frühen Texten in den r 96oer und 7oer Jahren bis hin zu jüngsten Veröffentlichungen reicht, welche die Kritik an Opfermythos und Faschismus in ihren Mittelpunkt stellen. Dabei wurde die wichtige Erkenntis herausgestrichen, dass Jelineks spezifischer, marxistisch geprägter Faschismusbegriff über das singuläre historische Ereignis des deutsch-österreichischen Nationalsozialismus hinausgeht und allgemein die ungleichen Gewalt- und Besitzverhältnisse innerhalb der Gesellschaft beschreibt. In geistiger Nähe zu Theodor Adorno ist Faschismus bei Jelinek als Phänomen der Masse zu lesen, die durch eine ideologisch vereinnahmte Sprache manipuliert, verdummt und ent-politisiert wird. ${ }^{15}$

Ihr Destruktionsverfahren ermöglicht es Jelinek, Sprachgebrauchsformen widerzuspiegeln, anhand deren parodistischer Verfremdung Mythen erkannt und

I 3 Jelinek, zitiert nach: Janke/Kovacs/Schenkermayr, »Die endlose Unschuldigkeit«, S. I 9.

I4 Dies., zitiert nach: Sander, Textherstellungsverfahren, S. i $9 \mathrm{f}$.

I 5 Vgl. Kapitel I.6.2 dieser Studie. 
reflektiert werden können. In diesem Sinne wurde das »Wiedergängertum des Faschismus « ${ }^{16}$ als Konstante und zentraler Gegenstand ihres Werks erkannt; nicht nur als Thema, sondern auch als Fixpunkt ihrer Methodik.

Um nun die chiffrierten, metasprachlichen Ebenen der hoch ästhetisierten Texte Jelineks aufspüren zu können, wurde in dem folgenden Kapitel eine Auseinandersetzung mit verschiedenen Definitionen des wichtigen »Intertextualitäts«-Begriffs unternommen und dessen Praktikabilität in Hinblick auf die Interpretation von Jelinek-Texten untersucht. Die »Intertextualität« wurde allgemein als Bezugnahme von Texten auf andere Texte definiert, wobei verschiedenste Spielformen dieser Bezugnahme auszumachen sind. In diesem Zusammenhang wurde davor gewarnt, die Intertextualität mit den rhetorischen Figuren Zitat und Anspielung zu verwechseln, was sogar innerhalb der Jelinek-Forschung mitunter der Fall ist. Als Fazit der Diskussion über die Intertextualität als Analysemethode konnte herausgearbeitet werden, dass zwei grundlegende Komponenten gegeneinander abgewogen werden müssen: zum einen das in manchen Fällen offensichtlich von der Autorin gewollte Herstellen von Bezügen zu Prätexten, die sie in satirischen, sprachkritischen Verfahren zu destruieren sucht, zum anderen das in anderen Fällen herausgeforderte assoziative Rezeptionsverständnis, welches das Decouvrieren zahlloser Prätexte ad absurdum führen würde. Im Rahmen dieses abschließenden theoretischen Kapitels wurde daher eine modifizierte Anwendung der Intertextualität als Methode vorgeschlagen, mit der offenkundigen und/oder markierten Bezügen zu bestimmten Prätexten zwar nachgegangen wird, weil sie das Textverständnis erhellen können, auf der anderen Seite aber dem assoziativen Erleben Raum gegeben wird.

Zur exemplarischen Analyse im empirischen Teil dieser Studie ausgewählt wurden die beiden Theatertexte "Burgtheater" und "Das Lebewohl« sowie Jelineks großer Roman »Die Kinder der Toten«. Es zeigte sich, dass die Texttiefenstrukturen der untersuchten Beispieltexte in vielen Aspekten den im ersten Teil dieser Studie auseinandergesetzten Theorien von Faschismus und Opfermythos entsprechen bzw. diese in literarisch ästhetisierter Form aufgreifen und weiterführen, manchmal aber auch verwerfen.

In Bezug auf Jelineks frühes Theaterstück »Burgtheater« (I982/84) wurden zwei Deutungsvorschläge aus der Theaterwissenschaft, die den Primärtext in seine wichtigsten Kontexte betten, im Besonderen erwähnt. ${ }^{17}$ Darüber hinaus wurde für die Analyse auch auf feuilletonistische Beiträge zurückgegriffen, die als Reaktion auf die Erstaufführung des Stücks in Bonn r 985 entstanden waren und in erster Linie das Skandalon thematisierten, dass die Autorin mit den Fi-

I6 Lücke, Elfriede Jelinek, S. 7.

I 7 Hochholdinger-Reiterer, Amok, sowie Annuß, Theater des Nachlebens. 
guren ihres Stücks Ikonen des österreichischen Burgtheaters angegriffen hatte: Paula Wessely und das Brüderpaar Attila und Paul Hörbiger.

Im Rahmen der empirischen Analyse wurde ermittelt, dass Jelineks Hauptfiguren in »Burgtheater« als »Sprachschablonen« zu begreifen sind, die in erster Linie nicht als Individuen Bedeutung haben, sondern exemplarisch zu verstehen sind, was vom Feuilleton weitestgehend missverstanden worden war. Die Sprache des Stücks wurde als »Kunstsprache« bezeichnet, deren literarische Wirkung vor allem darin besteht, ihre Künstlichkeit und ihren tendenziösen Gehalt zu offenbaren. Demnach wurde die Sprache selbst als Mythos erkannt, den Jelinek durch ihre destruktiven Mittel zu entlarven sucht. Allein durch die Brutalität der Aktionsebene wird die scheinbare Harmlosigkeit der Sprechebene immerfort durchbrochen. Im Mittelpunkt stehen aber stets die bemerkenswerten Sprachgebrauchsformen der Figuren, mit der Jelinek eine Sprache zu kritisieren sucht, die win ihrer Pervertierung die faschistische Kulturindustrie ermöglicht und eine nicht erfolgte Entnazifizierung in diesem Unterhaltungsindustriebereich ermöglicht hat ${ }^{18}$. Der Mythos vorgeblich unpolitischen Künstlertums wird auf diese Weise destruiert. Weiters wurde festgestellt, dass in »Burgtheater « jede "Österreicharie «" ${ }^{19}$, auf die nach 1945 zurückgegriffen wurde, um sich vom angeblich »deutschen« Faschismus zu distanzieren, als Mythos der scheinbaren Harmlosigkeit und Unschuldigkeit verworfen wird und jede Zuschreibung eines österreichischen Nationalcharakters (in Anlehnung an Karl Dietrich Brachers längst überholte These vom deutschen Nationalcharakter, die im Zuge der Goldhagen-Debatte Ende der I99oer Jahre wieder aufgewärmt wurde) nur als Vorwand für die Opferthese interpretiert werden kann. Die Frage nach der indivuellen Schuld der in dem Stück angegriffenen Realpersonen wurde als legitim erachtet und musste positiv beantwortet werden, denn neben dem Engagement in einschlägigen NS-Propagandafilmen ist den Wessely/Hörbigers vor allem vorzuwerfen, dass sie nach I945 Stars einer Unterhaltungsindustrie waren, die in Gestalt deutschsprachiger Heimatfilm-Produktionen das Vergessen von Verantwortung und Mitschuld bekräftigte und in Österreich das Bild eines vom »deutschen« Nationalsozialismus überrollten, geknebelten Volkes stützte. ${ }^{20}$ Das öffentliche Eingeständnis von Mitverantwortung oder persönlicher Involvierung - die »Internalisierung « ${ }^{21}$ von Mitschuld und Eigenverantwortung - blieben die drei Publikumslieblinge bis zu ihrem Ableben schuldig.

I 8 Jelinek, zitiert nach: Winter, Gespräch mit Elfriede Jelinek, S. I3.

I 9 Löffler, Ludersinn, S. 220.

20 Vgl. Kapitel 3.r.6 dieser Studie.

2 I Lepsius, Das Erbe des Nationalsozialismus, S. 250. 
Im zweiten Teil der empirischen Analyse wurde Jelineks großer Roman »Die Kinder der Toten« besprochen. Es musste festgehalten werden, dass Jelineks Opus Magnum der Ruf der Unlesbarkeit anhaftet und, von einzelnen engagierten Abschlussarbeiten abgesehen, bisher keine umfangreicheren Interpretationen vorliegen. Ein I 8-seitiger Tagungsbeitrag von Alexandra Pontzen, in dem vor allem die Referenzsysteme des Romans verhandelt werden, wurde als systematisch und aufschlussreich hervorgehoben.

Die inhaltliche Zusammenfassung vorausschickend wurde die Problematik dargelegt, dass der Roman nicht »ausschließlich linear lesbar « ${ }^{22}$ sei, weil es tatsächlich schwierig ist, klare Handlungsstränge aus ihm $\mathrm{zu}$ extrahieren: Ein »Prozess des sprachlichen Überlagerns und Überschüttens bestimmt das Buch « ${ }^{23}$. Dem assoziativen Lesen muss in diesem Fall viel Raum gegeben werden, sonst ist der gut 666 Seiten starke Roman, auch für geübte Leser, kaum bewältigbar.

Trotz der vorhandenen Unklarheiten wurde versucht, den Inhalt des Buchs so klar und eindeutig wie möglich zusammenzufassen. Dabei wurde festgestellt, dass es einen exemplarischen Handlungsstrang gibt, der anhand der drei untoten Hauptfiguren KARIN, EDGAR und GUDRUN verfolgt wird, sowie einen übergeordneten allgemeinen Handlungsstrang, der vor allem in schaurigen Bildern ausgedrückt wird, zum Beispiel mit sich aufbauenden Wetter- und Naturerscheinungen, aber auch mit Hinweisen auf unheimliche, gespenstische Anwesenheiten im Boden, in der Luft und den Gewässern des Landes, die sich nach und nach mit den Wassermassen anhaltender starker Regenfälle vermischen und zu einer übermächtigen, alles vernichtenden Schlamm- und Leichenlawine zusammenballen. Zahlreiche Andeutungen, die im Verlauf des Buchs immer eindringlicher werden, lassen keinen Zweifel daran, dass mit den allgegenwärtigen Toten die Opfer nationalsozialistischer Vernichtung gemeint sind. Beide Handlungsstränge werden in dem Buch parallel und überschneidend verfolgt, bis sie in einem grausigen Finale schließlich zusammengeführt werden, in dem der Schauplatz der Geschichte (die »Pension Alpenrose«) von der gewaltigen Mure aus Schlamm und Leichen verschüttet wird.

Es wurde festgehalten, dass der Prozess des sprachlichen Überlagerns und Überschüttens das große Thema des Romans widerspiegelt: Verdrängung. Exemplarisch für ein Land, das über Jahre hinweg in die willkürliche, rassistisch begründete Menschenvernichtung des NS-Regimes involviert war, wird der Ort des Schauspiels im Finale des Buchs von der Vergangenheit eingeholt und selbst vernichtet.

22 Pontzen, Pietätlose Rezeption, S. 53.

23 Mayer/Koberg, Ein Porträt, S. 202. 
Um in Aufbau und Strukturierung des Texts näher einzuführen, wurden in einem weiteren Schritt die wichtigsten Rückbezüge auf wahrscheinliche Prätexte geschildert. Die Grenzen verwischende Darstellung von Leben und Tod, das zentrale Motiv in »Die Kinder der Toten«, wurde mit Freuds Ausführungen über »Das Unheimliche« verglichen. In Referenz auf E.T.A. Hoffmann ${ }^{24}$ hatte Freud in seinem Aufsatz aus dem Jahr I9 I 7 herausgearbeitet, dass es vor allem das Doppelgängertum in all seinen Abstufungen und Ausprägungen sei, das in der Literatur für das Unheimliche stehe, darunter Ich-Verdoppelung, Ich-Teilung, Ich-Vertauschung sowie die Wiederkehr des Immergleichen (Wiederholung der Gesichtszüge, Charaktere, Schicksale, der verbrecherischen Taten ${ }^{25}$ gestalterische Formen, wie sie in den gezeigten Vervielfältigungen der untoten Hauptfiguren in »Die Kinder der Toten« wiederholt vorzufinden sind. Im allerhöchsten Maße unheimlich erscheine vielen Menschen alles, was mit dem Tod, mit Leichen und mit der Wiederkehr der Toten zusammenhänge - vermutlich weil es, allen wissenschaftlichen Erkenntnissen zum Trotz, immer noch unmöglich sei, die eigene Sterblichkeit zu imaginieren. ${ }^{26}$ Die Entfremdung des Vertrauten - in seiner größtmöglichen Steigerung: Das tote Ich - konnte daher als das eigentliche »Unheimliche« ausgemacht werden.

Die Parallelen zu Leberts »Wolfshaut«-Roman bestehen neben thematischen und motivischen Relationen vor allem in der Übernahme eines polyphonen Erzählkonzepts, was als hervorstechendste stilistische Besonderheit des Romans bezeichnet wurde. Das multiperspektivische Erzählerinnen-Ich in »Die Kinder der Toten« wurde als »Opfer-Täter-Kippfigur» bezeichnet, die in ihrer Darstellungsform als Spiegelbild der österreichischen Erinnerungskultur begriffen werden kann; diese entwickelte sich seit den I 99oer Jahren hin zu einem »Opfer-Täter-Gedächtnis«, wie - auf den theoretischen Teil dieser Studie verweisend - festgehalten wurde. Darüber hinaus wurde in diesem Kontext auch auf Selbstthematisierungen der Autorin aufmerksam gemacht, die auf das familiäre Trauma von Verfolgung und Vernichtung jüdischer Familienmitglieder im $\mathrm{Na}-$ tionalsozialismus verweisen sowie auf die von der Autorin selbst als neurotisch beschriebene Beziehung zu ihrer Mutter.

In einem weiteren Schritt wurden einige der wichtigsten Mythendestruktionen aus »Die Kinder der Toten« exemplarisch zur Analyse ausgewählt. Mit diesem textimmanenten Kapitel sollte gezeigt werden, dass der Opfermythos und sein Fortwirken in der Gegenwart bei Jelinek als ein perfides Geflecht nationaler Mythen dargestellt sind, welche die unterschwellige, aber ständige Präsenz und

24 Vor allem dessen Roman »Die Elixiere des Teufels«.

25 Vgl. Freud, Das Unheimliche, S. $246 \mathrm{f}$.

26 Vgl. ebd., S. 254 f. 
auch gesellschaftliche Akzeptanz rechten Gedankenguts in Österreich widerspiegeln und damit die unzureichende kollektive, aber auch individuelle Auseinandersetzung mit der belasteten Zeitgeschichte befördern. Die Unterschiedlichkeit der Themen (Sport, Musik, Medien, Natur, Geschichtsdarstellung und nationales Selbstbild) sollte dabei Jelineks spezielle Methodik veranschaulichen, die (in Rückbezug auf Roland Barthes) stets verschiedenste "Mythen des Alltags « zueinander in Beziehung setzt, um die Manipulierbarkeit der Masse anhand bestimmter Sprachgebrauchsformen bewusst zu machen. Die dargestellten Figuren in diesem Roman wie auch bereits in früheren Texten der Autorin sind dabei als ent-individualisierte (hier auch: ent-lebendigte) Charaktere, nicht als sich entwickelnde, psychologisierende Figuren im klassisch dramatischen Sinne zu begreifen. Insofern stellte der große »Gespensterroman« der späteren Nobelpreisträgerin I 995 kein Novum im Jelinek'schen CEuvre dar, aber es ist bis heute »das in seiner thematischen Gigantomanie und seiner sprachlichen Zerstörungswut radikalste Werk der Autorin «"

Die analysierten Mythendestruktionen zusammenführend, konnte in diesem Kapitel abschließend festgehalten werden, dass trotz aller bestehenden Unklarheiten, Überlagerungen, Sprünge und Grenzverwischungen die Aussage des Texts unmissverständlich ist: „Die Kinder der Toten« ist Jelineks große Anklageschrift gegen Österreich. Auch Jahrzehnte nach der Katastrophe bestehe demnach bei den politischen und wirtschaftlichen Eliten, bei sozialen Repräsentanten (etwa der katholischen Kirche), aber auch in Teilen der Bevölkerung immer noch kein hinreichendes Unrechtsbewusstsein für die Ermordung von sechs Millionen europäischen Juden und die zahllosen weiteren Verbrechen des nationalsozialistischen Regimes, was an dem sprachlichen Unvermögen abgelesen werden könne, mit dem im öffentlichen Diskurs Eingeständnisse von Schuld und Mitverantwortung entweder gebetsmühlenartig wiedergekäut oder umschifft werden. Die »Bilanz über Schuld und Unschuld ${ }^{28}$, die in »Die Kinder der Toten« gezogen wird, ist eindeutig.

Im dritten und letzten Teil des empirischen Kapitels wurde Jelineks kleiner, aber wortgewaltiger Theatermonolog »Das Lebewohl« aus dem österreichischen »Wendejahr« 2000 analysiert. Die einzige deutschsprachige Interpretation, die zu diesem »Dramolett« ausfindig gemacht werden konnte, stammt von Bärbel Lücke und konzentriert sich auf einen möglichen Zusammenhang des Texts zu dem Foucault'schen Begriff des »Dispositivs« (hier als Machttheorie interpretiert). Daneben existiert ein elfseitiger Aufsatz von Allyson Fiddler in englischer Sprache, der in pointierter und sprachlich klarer Form die zeitgeschichtlichen Zusammen-

27 Radisch, Maxima Moralia.

28 Kastberger, Endspiele. 
hänge des Primärtexts herausarbeitet und dessen wichtigste Intertexte benennt, aufgrund der Kürze jedoch wenig textimmanente Interpretation anbieten kann. ${ }^{29}$

Die in der vorliegenden Arbeit angebotene Deutungsvariante fokussiert auf Jelineks spezielle Darstellungsweise von Faschismus und Opfermythos, die hier im Gewand eines neuen, gefährlichen Rechtspopulismus präsentiert werden. Der Protagonist des Stücks, unverhohlen eine Anspielung an den inzwischen tödlich verunglückten FPÖ-/BZÖ-Politiker Jörg Haider, kündigt seinen Rückzug aus der Bundes- in die Landespolitik nach Kärnten an und verabschiedet sich in einem 26 Seiten langen Monolog von seiner Anhängerschar: schönen, stummen Knaben. Der Abschied beinhaltet jedoch die Ankündigung einer fulminanten Wiederkehr und wird damit als strategischer Schachzug eines politischen Taktierers entlarvt.

Die Analyse einleitend wurde auf die von der Autorin explizit benannten Referenztexte des Monologs hingewiesen: Aischylos' antikes Atriden-Drama »Die Orestie« sowie Jörg Haiders persönliche Stellungnahme zu seinem Rücktritt als FPÖ-Parteiobmann mit dem Titel »Glücksgefühl nach bangen Stunden«. Es wurde außerdem festgehalten, dass die auffälligste formale Besonderheit des Texts darin besteht, dass Jelinek mit ihrer Hauptfigur, dem sPRECHER, eine konkrete Person abbildet, was ihrem ästethischen Programm, wonach sie ent-personalisierte, mitunter sogar ent-lebendigte Charaktere schafft, zuwiderläuft - eine Ausnahme.

Im Rahmen der Interpretation konnte gezeigt werden, dass Jelinek den vermenschlichten Mythos Haider Stück für Stück abträgt. Zunächst ist die Szenerie bemerkenswert, die das so genannte »Dritte Lager» als homoerotischen Männerbund zeigt, in dem alles Weibliche entbehrlich scheint, auch im Sexuellen. Jelineks Haider-Figur wird als homophiler Narziss dargestellt, der im Monolog seine durch den politischen Rückzug entstandenen Wunden leckt. Die Strategie der homophilen Selbstpräsentation dient dabei der gottähnlichen Überhöhung der Führergestalt in einem Männerbund - und als solcher wird Haiders Burschenpartei ${ }^{30}$ begriffen, die stets auf vermeintliche Tugenden wie Virilität, Volksgemeinschaft, Kameradschaft und Militarismus pochte. Durch die Szenerie in »Das Lebewohl« wird dieses Bild konterkariert und die Figur des SPRECHERs lächerlich gemacht.

Des Weiteren ist es vor allem die manipulative Sprachverwendung des rechtspopulistischen Politikers, die Jelinek in ihrem Monolog aufdeckt: Mit eindeutigen Anspielungen auf allgemein bekannte und umstrittene Haider-Zitate, die sie - ihrem Destruktionsverfahren gemäß - in unvermutete Zusammenhänge bettet oder an aussagekräftiger Stelle verfremdet, macht die Autorin deutlich,

29 Vgl. Kapitel 3.3.I dieser Studie.

30 Darunter wird die FPÖ der I 99oer und beginnenden 200oer Jahre verstanden. 
inwiefern Jörg Haider als einflussreicher Politiker zur Verharmlosung, aber auch zur Verherrlichung patriarchal-faschistischer Ideale im öffentlichen Bewusstsein beitrug. Haiders Umgang mit heiklen Themen, insbesondere der österreichischen NS-Vergangenheit, wird in dem Text als geschicktes rhetorisches Spiel entlarvt: ein ständiges Mäandern zwischen Schuldeingeständnis und Verurteilung auf der einen sowie Leugnung und trotziger Selbstüberhöhung auf der anderen Seite. Die paradoxe Sprache der Haider-Figur widerspiegelt in raffiniert unscheinbarer Weise das paradoxe österreichische Gedächtnis. ${ }^{31}$

Eine weitere Besonderheit, die Jelineks Haider-Figur auszeichnet, ist die als »Opfer-Täter-Inversion« bezeichnete Systematik, wonach sich der SPRECHER auffällig oft und in verschiedenen Zusammenhängen in die Position eines $\mathrm{Op}$ fers rückt: So sei er etwa ein Verfolgter der Linken, österreichischer Journalisten und Autoren. Wie nebenbei beschreibt Jelinek damit eines der wichtigsten Charakteristika faschistischer Regime, die in ihrem blinden Einheits- und Gemeinschaftswillen stets das auszugrenzen oder gar zu vernichten trachten, was ihrer Definition nach nicht dazugehört - ein Phänomen, das aktuelle Faschismustheorien als »Inklusion« und »Exklusion« bezeichnen. In »Das Lebewohl« ist diese Systematik sprachlich in der rekurrenten Gegenüberstellung von »wir alle« und "die vielen« (bzw. Variationen dieser Formulierungen) realisiert. Immer wieder streut die Autorin Seitenhiebe auf Haiders nationalsozialistisch belastete Familiengeschichte in ihren Text ein, weswegen in diesem Zusammenhang auch einige biografische Informationen zu Jörg Haider und dessen Familie gegeben wurden. Jelineks sprecher beklagt wiederholt die Peinigung des Vaters und verspricht schließlich Rache, was mit Haiders Eintreten für die Vätergeneration in Zusammenhang gebracht wurde, das von der Forderung nach Anerkennung für die Pflichterfüllung ehemaliger Wehrmachtssoldaten bis hin zur provokativen Teilnahme an den jährlichen Ulrichsbergtreffen reichte.

Zuletzt wurde der Entstehungskontext, die Ereignisse rund um den Regierungswechsel im Februar 2000, kurz erläutert und die exemplarische Funktion der Hauptfigur hervorgehoben. Freilich sei demnach der konkrete Bezug zu Jörg Haider und der Haider-FPÖ vorhanden und von Jelinek, einer deklariert politischen Autorin, gewollt. Dementsprechend sei die erfolgreiche Rezeption des Stücks zeitlich und örtlich eingeschränkt. Doch Jelineks Bühnenmonolog weist über den damaligen Kärntner Landeshauptmann weit hinaus: Es ist der Mono$\log$ eines politischen Verführers, der sich den Willen der Bevölkerung zu Einheit und Gemeinschaft zunutze macht. Darüber hinaus steht die Figur exemplarisch für die ambivalente Erinnerungskultur eines Landes, das es bis zum heutigen Tag nicht geschafft hat, seine historische Schuld zu internalisieren. Insofern wird

Vgl. Kapitel 3.3.3.2 dieser Studie. 
Jelineks Dramolett auch dann noch »dramatische Brisanz und künstlerische Aktualität haben (...), wenn vielleicht niemand mehr weiß, wer Jörg Haider war « ${ }^{32}$.

Mit »Burgtheater«, »Die Kinder der Toten« und »Das Lebewohl« wurden in der vorliegenden Studie drei Texte analysiert, die formal sehr unterschiedlich sind und aus unterschiedlichen Schaffensphasen der Autorin datieren. Auf diese Weise sollte ein möglichst repräsentativer Querschnitt durch das Werk Elfriede Jelineks geleistet werden.

Bemerkenswert ist, wie in der empirischen Analyse herausgearbeitet wurde, dass alle drei Beispieltexte die Kritik am österreichischen Opfermythos in ihren Mittelpunkt stellen, und zwar über die explizite Thematisierung hinaus vor allem implizit, auf einer intertextuellen, metasprachlichen Ebene. Die eingangs formulierte Hypothese, die Destruktion des Opfermythos stelle eines der zentralen Themen in Jelineks Werk dar, wird somit als bestätigt erachtet.

\subsection{Interdisziplinäre Zusammenschau: Zum »Mehrwert« von Literatur}

$$
\begin{array}{r}
\text { »Vielleicht sagt ein poetischer Satz das, } \\
\text { was ich nicht weiß.» }{ }^{33}
\end{array}
$$

In der vorliegenden Studie wurde die Entwicklung einer neuen, interdisziplinären Methodik zur Interpretation der literarischen Texte Elfriede Jelineks angeregt, die zeitgeschichtliche Parameter einschließt und dabei der intertextuellen Schreibweise der Autorin gerecht wird. Dabei wurde zur Erläuterung evidenter Textisotopien ebenso selbstverständlich auf Theorien der Geschichtswissenschaft (in erster Linie zeithistorische Faschismus-, Nationalsozialismus- und Opfermythostheorien) zurückgegriffen, wie umgekehrt versucht wurde, jene herangezogenen Theorien, die das 20. Jahrhundert erklären wollen, durch die Interpretation dreier Beispieltexte anschaulich zu machen.

Dass eine literaturwissenschaftliche Interpretation historisches Wissen braucht, ist eine obsolete Feststellung, denn Texte bedeuten nichts ohne ihre Kontexte. Ein erfolgreicher Lesevorgang muss nicht zwangsläufig von Verstehen begleitet sein:

»Ein Text ... kann ohne seine Kontexte nicht verstanden werden, selbst wenn er richtig‘ gelesen wird. ${ }^{34}$

32 Lücke, Gespenster, S. 8o.

33 Waterhouse, Lobreden auf den poetischen Satz, S. I 9.

34 Rossbacher, Lesen, S. I6. 
In diesem Zusammenhang ist allerdings die nicht immer selbstverständliche Feststellung zu treffen, dass mit dem hier angesprochenen Kontextwissen nicht allein das so genannte "Tatsachenwissen« im Sinne einer "histoire totale» gemeint ist, sondern auch diskursanalytisches Wissen: Wenn Texte im Zuge einer literaturwissenschaftlichen Interpretation in Zusammenhang mit ihren historischen Kontexten gebracht werden, so wird automatisch auch auf deren Diskursebene Bezug genommen, in der sich die konzeptuelle Vielfalt und Wandelbarkeit historischer Methoden und Bewertungen widerspiegelt. Es gilt dabei, sich dieser Ebene bewusst zu sein, um sie auf konstruktive und sinnvolle Art und Weise in die angestrebte Interpretation integrieren zu können.

In Hinblick auf den geschichtswissenschaftlichen Diskurs muss etwa darauf verwiesen werden, dass sich seit den I $980 e r$ Jahren durch die zunehmende Kritik an den strukturgeschichtlich dominierten Zugängen in mehreren Entwicklungsschüben (»Turns«) eine Revolutionierung der historischen Disziplinen vollzogen hat ${ }^{35}$, was im Rahmen der vorliegenden Untersuchung vor allem anhand der Paradigmenwechsel in der Faschismus- und Nationalsozialismusforschung herausgearbeitet wurde. ${ }^{36}$ Die Kritik an der strukturgeschichtlichen Dominanz hatte innerhalb der Geschichtswissenschaften dazu geführt, dass neue Perspektiven ausgelotet, neue Themen und Methoden vorgeschlagen, scheinbar altbekannte Begriffe neu diskutiert und nationalhistorisch eingeschränkte Blickwinkel von wissenschaftlichen Globalisierungstendenzen abgelöst wurden. ${ }^{37}$ Darüber hinaus hatte sie letzten Endes zu einer verstärkten Beschäftigung mit dem Einzelnen und seinen jeweiligen »Lebenswelten « ${ }^{38}$ geführt, aber auch das Interesse an symbolischen Formen und Ritualen und deren Bedeutungen und Eigen-Logiken befördert. ${ }^{39}$ Die Vorstellung einer Geschichte im Kollektivsingular - gedacht als »einheitlicher, zusammenhängender, zukunftsoffener Entwicklungsprozess « ${ }^{40}$ - wurde von dem Verständnis historischer Realitäten als diskursiver Konstruktionen abgelöst: Geschichte ist nicht das, was passiert ist, sondern das, was wir erinnern, wie wir es erinnern und wie wir über das Erinnerte sprechen, im individuellen wie auch im kollektiven Gedächtnis. ${ }^{41}$

35 Vgl. Eibach/Lottes, Kompass, S. 7.

36 Vgl. Kapitel I.4.I und Kapitel I.4.2 dieser Studie.

37 Vgl. Eibach/Lottes, Kompass, S. 7.

$38 \mathrm{Zu}$ dem historischen Begriff der »Lebenswelt(en)« vgl. Kapitel I.4.2 dieser Studie.

39 Vgl. Burghartz, Historische Anthropologie, S. 206.

40 Welskopp, Historische Erkenntnis, S. I 28.

4I Vgl. Burghartz, Historische Anthropologie, S. 208. Vgl. auch Uhl, Zivilisationsbruch und Gedächtniskultur, S. I I. 
An diese Idee knüpfte der amerikanische Literaturwissenschafter Stephen Greenblatt mit seinem Modell des New Historicism an. ${ }^{42}$ Dieses gründet auf der Auffassung, dass Geschichte von einer Vielzahl von Diskursen bestimmt werde, die in der zeitgenössischen Literatur (sofern sie denn Kunst ist) zusammenlaufen und aufeinandertreffen. ${ }^{43}$ Die Besonderheit eines literarischen Textes bestehe demnach nicht mehr in seiner ästhetischen Einheitlichkeit, sondern vor allem in seiner Fähigkeit, kulturelle Diskurse in ihrer Vielfältigkeit und bisweilen auch Widersprüchlichkeit aufzunehmen und darzustellen. ${ }^{44}$

Greenblatts These entwickle die Möglichkeit, Texte »in Zusammenhang oder gar als Teil von Erinnerungskulturen zu denken ${ }^{45}$, befindet die Literatur- und Kulturwissenschafterin Sabina Becker. Die in diesem Sinne unterstellte historische Dimension von literarischen Texten kann mit den Erkenntnissen aus der empirischen Analyse der vorliegenden Untersuchung argumentiert werden. Gerade die starke Intertextualität von Jelinek-Texten, die bereits im theoretischen Teil erläutert wurde, verweist auf deren großes Potential zur Widerspiegelung und Brechung diskursiver Konstruktionen von Geschichte.

Der österreichische Opfermythos wird in der Literatur Elfriede Jelineks in all seinen Grundfesten und Manövern zur Schau gestellt und destruiert. Aber auch eindimensionale, monokausale Faschismus- und Nationalsozialismustheorien, die im öffentlichen Diskurs, in populärwissenschaftlichen Büchern und Filmen oder der Publizistik mitunter immer noch zur Erklärung des faschistischen Phänomens herangezogen werden, obwohl sich die Geschichtswissenschaft längst von ihnen distanziert hat (These vom Nationalcharakter, Führertheorie, Nationalsozialismus als "Mobilisierungs- und Manipulationsprojekt ${ }^{46}$ der politischen Eliten etc.), werden durch die ästhetische Kraft der Jelinek'schen Literatur verworfen.

Ja, nur in den Geschichten »sind Menschen zu erkennen« - doch die Geschichte ist den Geschichten nicht "feindlich ${ }^{47}$, wie der Schriftsteller Peter Bichsel 1982 noch behauptet hatte, denn auch die Geschichtswissenschaft schreibt heute viele Geschichten. Mit der Hinwendung zum Einzelnen kommt

42 Greenblatt entwickelte sein Modell im Rahmen einer detaillierten Shakespeare-Studie in den frühen r 98oer Jahren und präzisierte es in den Folgejahren. Vgl. Greenblatt, Renaissance Self-Fashioning, sowie ders., Shakespearean Negotiations, sowie ders., Schmutzige Riten, sowie ders., Kultur (New Historicism).

43 Vgl. Becker, New Historicism, S. I75.

44 Vgl. ebd., S. I 78.

45 Ebd.

46 Kritisch dazu Bauer, Mobilisierung, S. 288.

47 Das ursprüngliche Zitat lautet: „Die Geschichte ist den Geschichten feindlich, und nur in den Geschichten sind Menschen zu erkennen. Bichsel, Der Leser, S. 20. 
sie Jacques Le Goffs bereits Ende der I 97oer Jahre formulierten Anspruch nach, eine Auseinandersetzung mit Geschichte zu leisten, wie sie Menschen gelebt und erlebt hatten. ${ }^{48}$ Die »Historische Anthropologie«, die sich seitdem rund um dieses Forschungsfeld im deutschsprachigen Raum formierte, versammelt eine Vielzahl methodischer Ansätze. Gemeinsam ist ihnen ihr Interesse am Menschen und dessen Wahrnehmungs- und Deutungsschemata im Wandel der Zeit. ${ }^{49}$

Genau diesen spürt auch die Literatur Elfriede Jelineks nach, denn darin geht es, wie im empirischen Teil der vorliegenden Analyse gezeigt wurde, in erster Linie nicht um die Rekonstruktion von Geschichte, sondern vor allem um deren retrospektive Betrachtung und Bewertung, die anhand spezifischer Sprachverwendungsformen reflektiert werden. In diesem Sinne befördert das Jelinek'sche Euvre nicht nur ein empathisches Verständnis für historische Vorgänge und Ereignisse, sondern rückt darüber hinaus Vielschichtigkeiten und Ambivalenzen in den gesellschaftlichen, politischen, aber auch wissenschaftlichen Diskursen ins Bewusstsein. Und darin besteht der besondere "Mehrwert ${ }^{50}$ von Literatur für die geschichtswissenschaftliche Forschung: nicht die Rekonstruktion von Geschichte betreiben zu wollen, sondern das Sprechen über Geschichte in seinen mannigfaltigen Diskursformationen ausleuchten zu können. Es braucht aber methodisch reflektierte Verfahren, um ästhetisierte Texte für das wissenschaftliche Arbeiten »bändigen« zu können, denn die Literatur muss sich bekanntlich nicht an festgelegte Spielregeln halten, wie sie für das wissenschaftliche Arbeiten unumgänglich sind. Gerade Elfriede Jelinek ist eine Autorin, die ihre Texte bewusst stark ästhetisiert, die mit Assoziationen, Bildern und Metaphern arbeitet - eben um im Moment der sprachlichen Verfremdung Klarheit und Sensibilisierung zu erreichen (»Success in Circuit lies ${ }^{51}$ ).

In methodischer Hinsicht sind daher zwei Feststellungen zu treffen, die ein Forschungsdesiderat bezeichnen, das sich sowohl an die germanistische als auch an die historische Forschung richtet.

Zum einen gilt: Es ist und bleibt eine Notwendigkeit, sprach- und literaturwissenschaftliche Verfahren zur Textinterpretation heranzuziehen; es hat sich aber im Rahmen der vorliegenden Studie als fruchtbar erwiesen, das Instrumentarium der neueren Geschichtswissenschaft in diese zu integrieren, um kontextuelle Dimensionen von literarischen Texten und damit auch deren Bedeutungsvielfalt besser erfassen und beschreiben zu können.

48 Vgl. Le Goff, Neue Geschichtswissenschaft, Vgl. dazu auch Burghartz, Historische Anthropologie, S. 206.

49 Vgl. Burghartz, Historische Anthropologie, S. 206.

50 Hanisch, Ein Historiker als Leser von Dichtung,S. I66.

5 I Dickinson, Gedichte, S. 4 Io. Vgl. das lyrische Motto dieser Studie. 
Zum anderen erweist es sich als äußerst lohnend, die im Modell des New Historicism beschriebene "Textualität von Geschichte ${ }^{52}$ verstärkt in die geschichtswissenschaftliche Forschungspraxis einzubeziehen, denn nicht nur Texte sind geschichtlich, sondern auch Geschichte ist textuell, da sie vor allem über Texte darstellbar ist - nicht zuletzt über literarische Texte. ${ }^{53}$

Die Debatte um den so genannten "Linguistic Turn« sei am Ende doch nicht sinnlos gewesen, meint der österreichische Zeithistoriker Ernst Hanisch, denn sie habe die Historiker darauf aufmerksam gemacht, dass die Grenze zwischen Fiktion und Ereignis kein "Eiserner Vorhang «" ${ }^{54}$ sei: Schließlich seien es zuerst die Schriftsteller gewesen, die den allmächtigen, einseitigen Opfermythos in Frage gestellt haben. ${ }^{55}$ Neben Schriftstellern wie Hans Lebert, Helmut Qualtinger oder Thomas Bernhard konnten auch die wortgewaltigen Texte von Elfriede Jelinek einen wichtigen Beitrag zur Erosion dieses wirkungsmächtigen Geschichtsbildes der Zweiten Republik leisten.

Als Fazit der in dieser Studie angebotenen, interdisziplinär angelegten Deutung dreier exemplarischer Jelinek-Texte soll daher an dieser Stelle ein klares Plädoyer für eine intensivierte methodische Verschränkung der historischen und philologischen Disziplinen ausgesprochen werden, denn diese wäre in jedem Fall ein Gewinn - sowohl für die Geschichtswissenschaft, die mithilfe eines gezielteren Instrumentariums den "Mehrwert« von Literatur noch mehr ausschöpfen könnte, als auch für die Germanistik, die bei der literaturwissenschaftlichen Analyse mitunter noch gewisse Unsicherheiten in puncto Kontextuierung aufweist. Das größte Manko stellt dabei die mangelnde Kenntnis aktueller historischer Diskurse dar.

Die Ergebnisse der vorliegenden Arbeit mögen daher auch als Anregung für die internationale Jelinek-Forschung dienen, jene Termini operandi, die aus der Zeithistorie entlehnt sind, etwa den viel zitierten »Faschismus«-Begriff, in Zukunft genauer zu definieren und achtsamer zu nutzen. Gleiches sei für den Gebrauch historisch sensibler Begriffe geraten: So sollten Ausdrücke wie »Anschluss«, "Drittes Reich«, »Halbjude/-jüdin« oder »Hitler-Deutschland« usw. nicht oder jedenfalls nicht unkommentiert verwendet werden. ${ }^{56}$

52 Montrose, Poetik und Politik der Kultur, S. 67.

53 Vgl. Becker, New Historicism, S. 179.

54 Hanisch, Ein Historiker als Leser von Dichtung, S. I65.

55 Vgl. ebd., S. 168.

56 Es sei an dieser Stelle noch einmal auf das zweibändige "Wörterbuch der Vergangenheitsbewältigung« von Thorsten Eitz und Georg Stötzel verwiesen, das auch Nicht-Historikern einen raschen und fundierten Überblick über besonders problematische Ausdrücke vermittelt, siehe Literaturverzeichnis. 


\section{Epilog - Wir waren's nicht?}

»Man kann sich nicht im Konjunktiv entschuldigen. ${ }^{57}$

Was aus heutiger Perspektive, mit dem Abstand von sieben Jahrzehnten zu Gewaltherrschaft und Krieg, geleistet werden kann, ist, die ent-historisierte Geschichte $\mathrm{zu}$ re-historisieren: historisches Bewusstsein endlich in adäquate sprachliche Formen zu gießen.

Solange sich die Involvierung der „Vielen« nicht in angemessener Form im öffentlichen Diskurs widerspiegelt, werden die Gespenster der Vergangenheit nicht ruhen. Sie werden sich immer wieder aus ihren Gräbern erheben und durch unsere Schlüssellöcher schauen, denn die kollektive Sprachlosigkeit angesichts der übermächtigen Schuld gibt ihnen keinen Frieden (»Die Seelen der Toten sind unzufrieden mit uns. ${ }^{58}$ ).

Der Holocaust war das Ergebnis des Zusammenwirkens tausender ganz »normaler« Menschen, die andere ganz »normale« Menschen, Frauen, Männer und Kinder, geschlagen, erniedrigt, gepeinigt, ihnen das Haar abrasiert, sie zur Arbeit gezwungen, vergewaltigt, erschossen, erschlagen, vergast, in Gruben geworfen oder in Hochleistungsöfen geschoben, medizinische Experimente mit ihnen durchgeführt und aus ihren menschlichen Überresten Lampenschirme und Seife gefertigt haben.

Nicht einzelne, sondern tausende ganz »normale« Bürger haben die unfassbarsten Grausamkeiten begangen, Deutsche wie auch Österreicher. Und die "Vielen ${ }^{59}$, die nicht unmittelbar in Verbrechen involviert waren, profitierten doch von ihnen: von Berufsverboten, Enteignungen, Vertreibung und Vernichtung.

Schließlich muss eingestanden werden, dass der Wahnsinn im Mai I 945 nicht aus Einsicht beendet wurde, nein: Der Nationalsozialismus wurde von den alliierten Mächten militärisch in die Knie gezwungen. Bis zur letzten Minute fuhren vollbesetzte Züge nach Auschwitz. ${ }^{60}$

Sie ist tatsächlich schwer auszuhalten, diese historische Bürde. Und wer sich über einen längeren Zeitraum hinweg mit dieser Thematik befasst, stößt unwei-

57 Redakteur Müller zu Haider in einem Interview mit dem Berliner Tagesspiegel, zitiert nach: Czernin, Westentaschen-Haider, S. 73.

58 Lebert, Wolfshaut, S. I66.

59 Lüdtke, Macht der Emotionen, S. 54.

6o Vgl. Peukert, Volksgenossen und Gemeinschaftsfremde, S. 79 . 
gerlich an seine emotionalen Grenzen. Die schlimmste und verstörendste Erkenntnis, die aus dieser Auseinandersetzung mitgenommen werden muss, ist die »vergessene Normalität « ${ }^{61}$, die in all diesen ungeheuerlichen Verbrechen steckt und in Götz Alys provokanter, aber erhellender Publikation »Hitlers Volksstaat» treffend beschrieben wurde:

„Die Aly-Deutschen kennen wir nämlich: Sie gleichen uns fast aufs Haar. Sie suchen Wohlstand, materielle Sicherheit für die Kinder und fürs Alter, sie wollen das Haus im Grünen, das eigene Auto, den Urlaub. Die Kosten für Nachbarn und Nachfahren kümmern sie wenig. ${ }^{62}$

Rechtfertigen die NS-Verbrechen, obwohl präzedenzlos, nicht die Annahme, dass die Bedingungen dafür hätten ungewöhnlich sein müssen ${ }^{63}$

So kommt am Ende alles auf die große, emotional aufgeladene Frage nach dem Warum zurück, deren Beantwortung man sich auf rationaler Basis nur mit differenziertem historischen Wissen annähern kann. Auf emotionaler Basis wird die ersehnte Antwort immer von einer großen Ohnmacht unterdrückt bleiben einer Mixtur aus Wut und Verzweiflung über die eigenen historischen Wurzeln, die Elfriede Jelinek in dicken Lettern in die Welt hinausschreit.

Die "Aly-Deutschen« gleichen den in der Textanalyse präsentierten Jelinek-Figuren fast aufs Haar. So wollen beide, der Wissenschafter, der mit seinen historischen Analysen stets für Unruhe und Aufsehen in seiner Zunft sorgt, wie auch die nicht minder umstrittene Autorin, der Gesellschaft einen Spiegel vorhalten - mit unkonventionellen, oft unbequemen, vielleicht nicht immer angemessenen Mitteln. Doch was kann man tun, damit die Botschaft gelesen wird?

Nur die Kenntnis historischer Zusammenhänge und die damit verbundene Entwicklung eines kollektiv-österreichischen Unrechtsbewusstseins für die »kilometerlange ... Schuldenliste ${ }^{64}$, auf der die Zweite Republik gründet, können verhindern, dass sich derartige Gräuel - wenigstens auf österreichischem Grund und Boden - wiederholen. Das abverlangt uns keine Selbstgeißelung, aber klare Worte: ein klares »Nein«, wenn österreichische Rechtspopulisten öffentlich den Holocaust verharmlosen, Migration als »Umvolkung « ${ }^{65}$ bezeich-

6 I Aly, Hitlers Volksstaat, S. 365.

62 So der deutsche Geisteswissenschafter und Publizist Gustav Seibt, zitiert nach: Aly, Hitlers Volksstaat, S. 366 .

63 Vgl. Aly, Hitlers Volksstaat, S. 365.

64 Vgl. KDT, S. 3 I 9.

65 Johann Gudenus (FPÖ), zitiert nach: Der Standard, I5.I0.2015, S. I 3 (Zitat stammt aus dem Jahr 2004). 
nen, Asylwerber pauschal als Verbrecher vorverurteilen oder die Europäische Union scheinbar humorig als "Negerkonglomerat ${ }^{66}$ betiteln. Es kann und darf nicht im Sinne einer Gesellschaft sein, die sich die demokratische Legitimation an die Fahne heftet, dass mit solch diffamierenden, haltlosen und von historischer Unkenntnis gezeichneten Aussagen politisches Kleingeld gemacht wird. Es bedarf daher eines grundlegenden politischen Umdenkens. Das sind wir, auch die Nachgeborenen, den Opfern des deutsch-österreichischen Faschismus schuldig, darin bestünde eine Chance, dem millionenfachen sinnlosen Leiden und qualvollen Sterben wenigstens nachträglich Sinn zu geben - damit der Jelinek'sche Ruf nach dem »Nie wieder! ${ }^{67}$ auch tatsächlich eintreffen möge.

66 Andreas Mölzer (FPÖ), zitiert nach: http://derstandard.at/I $395363004736 /$ Deutsch-Moelzer-soll-Kandidatur-zurueckziehen (Zugriff am 4.5.20I4).

67 Jelinek zitiert nach: Nüchtern, »Ich bin ein Racheengerl«, Falter I 4/o3. 


\section{Anhang}

$» \ldots$ wer sucht, findet... ${ }^{1}$

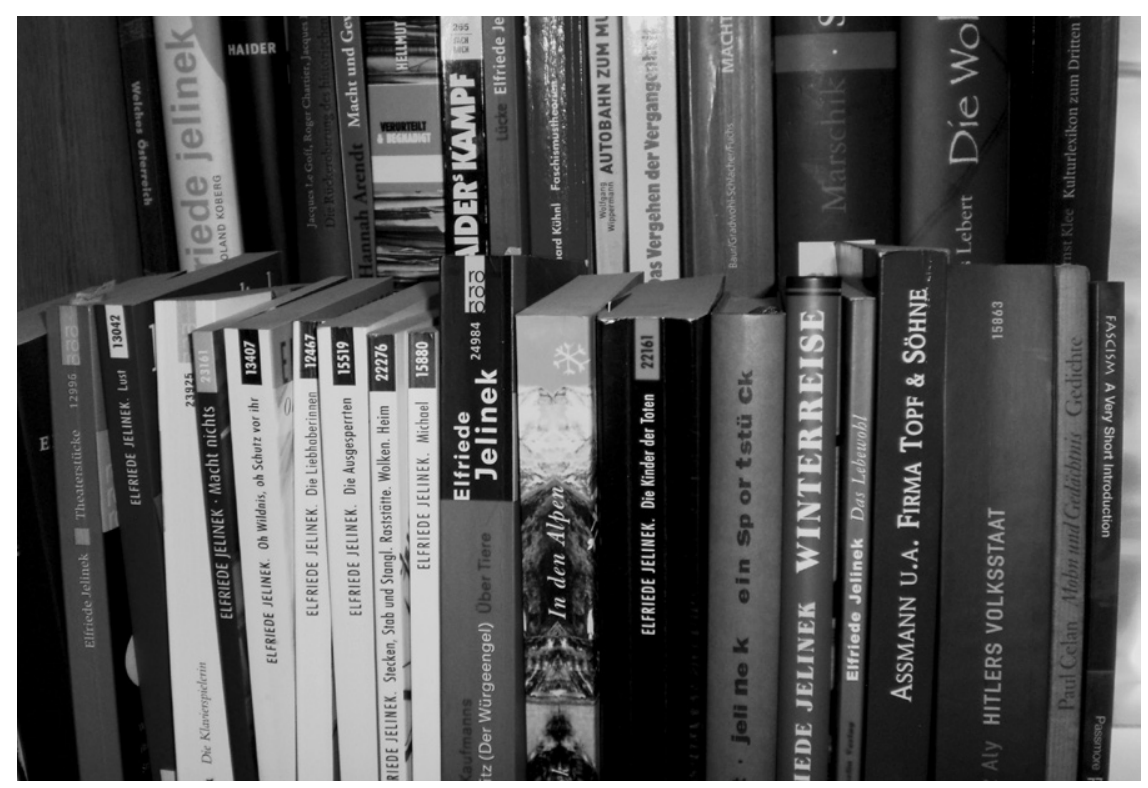

Abb. 3: BücherBücher

I Matthäus-Evangelium 7.3, zitiert nach: Schwegler/Herzog/Perk, Die heilige Schrift des Alten und Neuen Testaments, S. I $430 \mathrm{f}$. 


\subsection{Literaturverzeichnis}

\subsubsection{Primärliteratur}

Jelinek, Elfriede: Theaterstücke. Was geschah, nachdem Nora ihren Mann verlassen hatte oder Stützen der Gesellschaften. Clara S. - musikalische Tragödie. Burgtheater. Krankheit oder Moderne Frauen. Mit einem Nachwort von Ute Nyssen. Reinbek bei Hamburg: Rowohlt: ${ }^{7} 2004$.

Dies.: Die Kinder der Toten. Reinbek bei Hamburg: Rowohlt ${ }^{2} 2000$.

Dies.: Das Lebewohl. 3 kl. Dramen. Berlin: Berlin Verlag ${ }^{2} 2004$.

Dies.: wir sind lockvögel baby! Reinbek bei Hamburg: Rowohlt ${ }^{6} 2004$.

Dies.: Michael. Ein Jugendbuch für die Infantilgesellschaft. Reinbek bei Hamburg: Rowohlt ${ }^{7} 2004$.

Dies.: Die endlose Unschuldigkeit. München: Schwiftinger Galerie r 980 ( 970 verfasst).

Dies.: Die Liebhaberinnen. Reinbek bei Hamburg: Rowohlt ${ }^{25} 2004$.

Dies.: Stecken, Stab und Stangl. Raststätte oder sie machens alle. Wolken. Heim. Neue Theaterstücke. Mit einem »Text zum Theater« von Elfriede Jelinek. Reinbek bei Hamburg: Rowohlt ${ }^{2} 2002$.

Dies.: Die Klavierspielerin. Reinbek bei Hamburg: Rowohlt 2004 (Sonderausgabe).

Dies.: Oh Wildnis, oh Schutz vor ihr. Reinbek bei Hamburg: Rowohlt ${ }^{3}{ }_{2004}$.

Dies.: In den Waldheimen und auf den Haidern. Rede zur Verleihung des Heinrich-Böll-Preises der Stadt Köln I 986. In: Alms, Blauer Streusand, S. 42 ff.

Dies.: Ich schlage sozusagen mit der Axt drein. In: TheaterZeitSchrift Nr. 7/1 984, S. I $4-$ I6.

Dies.: »Ich will kein Theater. Ich will ein anderes Theater.«In: Theater heute Nr. 30, Heft 8/i 989 .

Dies.: Die Komponistin. Wortmaterial in den Kompositionen Patricia Jüngers. In: Henze, Die Chiffren.

Dies.: Ich möchte seicht sein. In: Gürtler, Gegen den schönen Schein, S. I 57-I6r.

Dies.: Das Hundefell. In: profil, Nr. 38, г99 I, S. го8.

Dies.: Ich glaube nicht an Gott und schreibe dauernd über ihn. In: Welt am Sonntag, 29. September 2002.

Dies.: Die Österreicher als Herren der Toten. In: Janke, Die Nestbeschmutzerin, S. 6 I ff. Dies.: Lesen kann vernichten. In: Literaturen Nr. Io, 2005, S. 67 f.

Dies.: Von Ewigkeit zu Ewigkeit. Essay, 2008. Online: http://www.elfriedejelinek.com (Link: »zu Politik und Gesellschaft«).

Dies.: Schamlos: die Zeit. Essay, 2008. Online: http://www.elfriedejelinek.com (Link: "zu Österreich«).

Dies.: Drei Theaterstücke. Die Kontrakte des Kaufmanns, Rechnitz (Der Würgeengel), Über Tiere. Reinbek bei Hamburg: Rowohlt 2009. 
Dies.: Österreich. Ein deutsches Märchen. Rede zur Verleihung des Heinrich-HeinePreises, 2002. Zitiert nach: http://www.elfriedejelinek.com (Link: "zu Österreich«).

Dies.: oh mein Papa. Essay, 200I. Zitiert nach: http://www.elfriedejelinek.com (Link: »zu Politik und Gesellschaft«).

Dies.: r6.3.200 r. Rotz. Rede auf einer Antirassismus-Kundgebung der Demokratischen Offensive in Wien, 200I. Zitiert nach: http://www.elfriedejelinek.com (Link: »200I«).

Dies.: Moment! Aufnahme! Essay, r 999. Zitiert nach: http://www.elfriedejelinek.com (Link: »zu Österreich«).

Dies.: Was zu fürchten vorgegeben wird. Rede auf einer Demonstration gegen Rassismus und Fremdenfeindlichkeit in Österreich, r 999. Zitiert nach: http://www.elfriedejelinek.com (Link: » 1999«).

Dies.: Dem Faß die Krone aufsetzen. Essay, 2002. Zitiert nach: http://www.elfriedejelinek.com (Link: »zu Österreich«).

\subsubsection{Sekundär- und Referenzliteratur}

Ackerl, Isabella: Die bedeutendsten Österreicher des I 9. und 20. Jahrhunderts. Wiesbaden: marixverlag 20 I .

Adorno, Theodor W./Frenkel-Brunswik, Else/Levinson, Daniel J./Sanford, R. Nevitt: The Authoritarian Personality. New York: I950. (In deutscher Übersetzung posthum erschienen unter dem Titel: Adorno, Theodor W.: Studien zum autoritären Charakter. Frankfurt am Main: Suhrkamp ${ }^{7}$ I 989.)

Ders.: Negative Dialektik. Frankfurt am Main: Suhrkamp ${ }^{3}$ I 982.

Ders./Horkheimer, Max: Dialektik der Aufklärung. Philosophische Fragmente. Frankfurt am Main: Suhrkamp ${ }^{2}$ I984.

Aischylos: Die Orestie. Eine freie Übertr. von Walter Jens. München: dtv I 98 I .

Albrecht, Karl-Otto: Wie sozial waren die Nationalsozialisten? Der vermeintliche nationalsozialistische Wohlfahrtsstaat. Frankfurt am Main: R. G. Fischer Verlag I 997.

Alms, Barbara: Triviale Muster - »hohe« Literatur. Elfriede Jelineks frühe Schriften. In: Umbruch 6 Nr. I/I 987 , S. 3 I -35 .

Dies.: Blauer Streusand. Frankfurt am Main: Suhrkamp I 987.

Aly, Götz: Hitlers Volksstaat. Raub, Rassenkrieg und nationaler Sozialismus. Frankfurt am Main: Fischer ${ }^{2} 2006$ (= Die Zeit des Nationalsozialismus, Fischer I 5863).

Ammon, Ulrich: Die deutsche Sprache in Deutschland, Österreich und der Schweiz: Das Problem der nationalen Varietäten. Berlin/New York: de Gruyter I 995.

Annuß, Evelyn: Elfriede Jelinek - Theater des Nachlebens. München: Wilhelm Fink 2005 .

Dies.: Wa/h/re Intertextualität. Zur Schreibweise Jelineks. Berlin: Magisterarbeit I 994. Arendt, Hannah: Elemente und Ursprünge totaler Herrschaft. München: Piper ${ }^{\mathrm{Io}} 2003$. 
(Zuerst r955 auf Deutsch erschienen: Arendt, Hannah: Elemente und Ursprünge totaler Herrschaft. Frankfurt am Main: Europäische Verlagsanstalt i 955.)

Dies.: Macht und Gewalt. München: Piper ${ }^{\text {I2 }}$ I 996.

Assmann, Aleida/Hiddemann, Frank/Schwarzenberger, Eckhard (Hg.): Firma Topf \&

Söhne - Hersteller der Öfen für Auschwitz. Ein Fabrikgelände als Erinnerungsort?

Frankfurt am Main: Campus 2002.

Bachtin, Michail: Die Ästhetik des Wortes. Frankfurt am Main: Suhrkamp ${ }^{2}$ I 979.

Bartens, Daniela/Pechmann, Paul (Hg.): Elfriede Jelinek. Die internationale Rezeption.

Dossier. Graz,/Wien: Droschl r 997 (= Die Buchreihe über österreichische Autoren, Extra).

Barth, Hans: Masse und Mythos: die ideologische Krise an der Wende zum 20. Jahrhundert und die Theorie der Gewalt. Reinbek bei Hamburg: Rowohlt i 959 (Rowohlts deutsche Enzyklopädie Bd. 88).

Barthes, Roland: Mythen des Alltags. Deutsch von Helmut Scheffel. Frankfurt am Main: Suhrkamp i 964 .

Barthes, Roland: Der Tod des Autors. In: Wirth, Performanz, S. го4-г 20.

Bartsch, Kurt/Höfler, Günther A.: Elfriede Jelinek. Dossier 2. Graz/Wien: Droschl I 99I (= Die Buchreihe über österreichische Autoren, Bd. 2).

Baßler, Moritz (Hg.): New Historicism. Literaturgeschichte als Poetik der Kultur. Tübingen: Francke 200 I (= UTB für Wissenschaft, Bd. 2265).

Bauer, Ingrid: Das 68er-Gedächtnis in Österreich, männergeschichtliche Deutungen und Models als `Expertinnen der Emanzipation. In: L'homme, Nr. 2, 2009, S. I $29-$ I 36.

Bauer, Ingrid: Mobilisierung, soziale Versprechen, Kontrolle, Verfolgung. Mechanismen der NS-Herrschaft in der Phase ihrer Stabilisierung, I 938/39, und die Partizipation der Bevölkerung. In: Kramml/Hanisch, Hoffnungen und Verzweiflung, S. 282-325.

Baur, Uwe/Gradwohl-Schlacher, Karin/Fuchs, Sabine (Hg.): Macht Literatur Krieg. Österreichische Literatur im Nationalsozialismus. Wien/Köln/Weimar: Böhlau I 998 (= Fazit; Ergebnisse aus germanistischer und komparatistischer Literaturwissenschaft, Bd. 2).

Becker, Sabina: Literatur- und Kulturwissenschaften. Ihre Methoden und Theorien. Reinbek bei Hamburg: Rowohlt 2007.

Benz, Wolfgang (Hg.): Handbuch des Antisemitismus. Judenfeindschaft in Geschichte und Gegenwart. Berlin: de Gruyter Saur 2009.

Bergmann, Werner/Erb, Rainer/Lichtblau, Albert (Hg.): Schwieriges Erbe. Der Umgang mit Nationalsozialismus und Antisemitismus in Österreich, der DDR und der Bundesrepublik Deutschland. Frankfurt am Main/New York: Campus I 995.

Beutner, Eduard/Tanzer, Ulrike (Hg.): Lesen. Heute. Perspektiven. Innsbruck/Wien/ Bozen: Studien Verlag 20 io (= ide-extra, Bd. I 5).

Biron, Georg: »Wahrscheinlich wäre ich ein Lustmörder.« Gespräche mit Elfriede Jelinek. In: Die Zeit, 28.9.1 984. 
Blänsdorf, Agnes: Die Einordnung der NS-Zeit in das Bild der eigenen Geschichte. Österreich, die DDR und die Bundesrepublik Deutschland im Vergleich. In: Bergmann/Erb/Lichtblau, Schwieriges Erbe, S. I 8-45.

Botz, Gerhard: Eine deutsche Geschichte r 938 bis 1945 ? Österreichische Geschichte zwischen Exil, Widerstand und Verstrickung. In: Zeitgeschichte I4 (Heft I): I986, S. $19-38$.

Ders.: Geschichte und kollektives Gedächtnis in der Zweiten Republik. In: Kos, Wolfgang (Hg.): Inventur 45/55. Österreich im ersten Jahrzehnt der Zweiten Republik. Wien: Sonderzahl I 996, S. 5 I-85.

Ders.: Der Kanzler als Schulmeister der Nation? In: Der Standard. I 2.3.2005, S. I 2.

Ders./Sprengnagel, Gerald (Hg.): Kontroversen um Österreichs Zeitgeschichte. Verdrängte Vergangenheit, Österreich-Identität, Waldheim und die Historiker. Frankfurt am Main/New York: Campus ${ }^{2} 2008$ (= Studien zur Historischen Sozialwissenschaft I $_{3}$ ).

Ders: Nachhall und Modifikationen ( $1994-2007$ ): Rückblick auf die Waldheim-Kontroversen und deren Folgen. In: ders./Sprengnagel, Kontroversen um Österreichs Zeitgeschichte, S. 574-635.

Bracher, Karl Dietrich: Die deutsche Diktatur. Entstehung, Struktur, Folgen des Nationalsozialismus. Frankfurt am Main: Ullstein ${ }^{6}$ I 979.

Braun, Sabine Edith: Sprache und Ironie bei Elfriede Jelinek am Beispiel des Romans »Die Kinder der Toten«. Wien: Diplomarbeit 2002.

Brockhaus Enzyklopädie in vierundzwanzig Bänden. Bd. I5. Mannheim: Brockhaus ${ }^{19}$ I 99 I, S. 355

Broich, Ulrich (Hg.): Intertextualität. Formen, Funktionen, anglistische Fallstudien. Tübingen: de Gruyter 1985 .

Budde, Gunilla/Freist, Dagmar/Günther-Arndt, Hilke (Hg.): Geschichte. Studium Wissenschaft - Beruf. Berlin: Akademie Verlag 2008 (= Akademie Studienbücher Geschichte).

Burger, Rudolf: Der böse Blick der Elfriede Jelinek. In: Gürtler, Gegen den schönen Schein, S. I 7-29.

Burghartz, Susanna: Historische Anthropologie. In: Eibach/Lottes, Kompass der Geschichtswissenschaft, S. 206-26o.

Carp, Stefanie: Ich bin im Grunde ständig tobsüchtig über die Verharmlosung. Ein Gespräch mit Elfriede Jelinek. In: Theater der Zeit, Nr. 3, Mai/Juni I 996. (Das Interview ist auch auf Jelineks Homepage unter dem Link »zum Theater« abrufbar.)

Celan, Paul: Mohn und Gedächtnis. Gedichte. Stuttgart: Deutsche Verlags-Anstalt ${ }^{\mathrm{I}} \mathrm{I} 98 \mathrm{I}$.

Claßen, Ludger: Satirisches Erzählen im 20. Jahrhundert: Heinrich Mann; Bertolt Brecht; Martin Walser. München: Fink I985 (= Literatur in der Gesellschaft; N. F., Iо). 
Czernin, Hubertus (Hg.): Wofür ich mich meinetwegen entschuldige. Haider, beim Wort genommen. Wien: Czernin ${ }^{2} 2000$.

Czernin, Hubertus (Hg.): Der Westentaschen-Haider. Wien: Czernin 2000.

Daniel, Ute: Kompendium Kulturgeschichte. Theorien, Praxis, Schlüsselwörter. Frankfurt am Main: Suhrkamp ${ }^{5} 2006$.

Degner, Uta: Mythendekonstruktion. In: Janke, Jelinek-Handbuch, S. 41-46.

De Saussure, Ferdinand: Cours de linguistique générale. Paris: Payot 1972 (posthum I 9 I 6 erstmals erschienen).

Deutsch-Schreiner, Evelyn: Burgtheater. Posse mit Gesang. In: Janke, Jelinek-Handbuch, S. I37-I4I.

Dies.: Das Lebewohl. In: Janke, Jelinek-Handbuch, S. I 44 ff.

Dickinson, Emily: Gedichte; englisch und deutsch. Herausgegeben, übersetzt und mit einem Nachwort von Gunhild Kübler. München/Wien: Carl Hanser 2006.

Diner, Dan: Den Zivilisationsbruch erinnern. Über Entstehung und Geltung eines Begriffs. In: Uhl, Zivilisationsbruch und Gedächtniskultur, S. I 7-34.

Ders. (Hg.): Ist der Nationalsozialismus Geschichte? Zu Historisierung und Historikerstreit. Frankfurt am Main: Fischer i 99 I.

Ders. (Hg.): Zivilisationsbruch. Denken nach Auschwitz. Frankfurt am Main: Fischer I 988.

Dobrick, Barbara: »Bei dem zweiten habe ich nicht mehr gelacht.« Gespräch mit Hans Lebert. In: Fuchs /Höfler, Hans Lebert, S. 9-33.

Doll, Annette: Mythos, Natur und Geschichte bei Elfriede Jelinek. Eine Untersuchung ihrer literarischen Intentionen. Stuttgart: M \& P r 994 (Zugleich Köln: Diss. I 992).

Duden. Herkunftswörterbuch. Etymologie der deutschen Sprache. Bd. 7. Mannheim/ Leipzig/Wien/Zürich : Dudenverlag ${ }^{3} 200$ I.

Dülmen, Richard van (Hg.): Das Fischer Lexikon. Geschichte. Frankfurt am Main: Fischer Taschenbuch Verlag i 990.

Ehlers, Heike: Die Faschismuskritik der Elfriede Jelinek. Exemplarisch dargestellt an den Theaterstücken »Stecken, Stab und Stangl« und »In den Alpen«. Wien: Diplomarbeit 2004 .

Eibach, Joachim/Lottes, Günther (Hg.): Kompass der Geschichtswissenschaft. Ein Handbuch. Göttingen: Vandenhoeck \& Ruprecht 2002 (= UTB für Wissenschaft, Bd. 2271).

Eitz, Thorsten/Stötzel, Georg: Wörterbuch der Vergangenheitsbewältigung. Hildesheim : Olms 2007 (Bd. I) und 2009 (Bd. 2).

Fleischhacker, Michael: Wien, 4. Februar 2000 oder Die Wende zur Hysterie. Wien: Czernin 2001 .

Eatwell, Roger: Fascism. A history. London: Chatto \& Windus I 995.

Ebner, Paulus/Vocelka, Karl: Die zahme Revolution. '68 und was davon blieb. Wien: Ueberreuter 1998. 
Eder, Thomas/Vogel, Juliane (Hg.): Lob der Oberfläche. Zum Werk von Elfriede Jelinek. München: Fink 20 Iо.

Eibach, Joachim/Lottes, Günther (Hg.): Kompass der Geschichtswissenschaft. Ein Handbuch. Göttingen: Vandenhoeck \& Ruprecht 2002 (= UTB für Wissenschaft, Bd. 2271).

Embacher, Helga (Hg.): Umkämpfte Erinnerung: Die Wehrmachtsausstellung in Salzburg. Salzburg/Wien: Residenz I 999.

Fiddler, Allyson: Reckoning with Rechnitz: on Elfriede Jelinek, tranlation and cultural reproduction. In: Austrian Studies, vol. 22, I 8. I 2.20 I 4, S. I 99-2 I 4.

Dies.: Staging Jörg Haider: protest and resignation in Elfriede Jelinek's Das Lebewobl and other recent texts for the theatre. In: Modern Language Review, vol. 97/no. 2, or.04.2002, S. 353-364.

Dies.: Rewriting Reality: an introduction to Elfriede Jelinek. Oxford: Berg I 994.

Dies.: Demythologising the Austrian »Heimat«: Elfriede Jelinek as »Nestbeschmutzer». In: McGowan/Schmidt, From High Priests to Desecrators, S. 25-44.

Fliedl, Konstanze: Im Abseits. Elfriede Jelineks Nobelpreisrede. In: Rétif/Sonnleitner, Elfriede Jelinek, S. I 9 - 3 I.

Freud, Sigmund: Das Unheimliche. In: Gesammelte Werke. Chronologisch geordnet. Zwölfter Band: Werke aus den Jahren r 917-1920. Frankfurt am Main: S. Fischer ${ }^{3}$ I 966, S. 229-268.

Friedl, Harald (Hg.): Die Tiefe der Tinte. Salzburg I990.

Friedrich, Carl Joachim: Totalitäre Diktatur. Stuttgart 1958.

Fröhlich, Elke (Hg.): Die Tagebücher von Joseph Goebbels. Sämtliche Fragmente. Teil I, Aufzeichnungen I 924 bis I 94 I (in vier Bänden). München/New York/London, Paris: K. G. Saur I 987 .

Dies.: Die Tagebücher von Joseph Goebbels. Teil II, Diktate r94I bis I945 (in neun Bänden). München/New Providence/London/Paris: K. G. Saur I 993.

Fröhlich-Steffen, Susanne: Die österreichische Identität im Wandel. Wien: Braumüller 2003 (= Studien zur politischen Wirklichkeit, Bd. I 5).

Fromm, Erich: Die Furcht vor der Freiheit. Frankfurt am Main: Europäische Bildungsgemeinschaft ${ }^{2}$ I 966 .

Fuchs, Gerhard/Jelinek, Elfriede: »Man steigt vorne hinein und hinten kommt man faschiert und in eine Wursthaut gefüllt wieder raus.« Ein E-Mail-Austausch, I 998. In: Bartens/Pechmann, Elfriede Jelinek, S. 9-27. ${ }^{2}$

Fuchs, Gerhard/Höfler, Günther A. (Hg.): Hans Lebert. Dossier. Graz: Droschl I 997 (= Die Buchreihe über österreichische Autoren, Bd. I 2).

2 Das Interview soll laut Fuchs Anfang 1998 stattgefunden haben. Der Band wurde allerdings bereits 1997 herausgegeben - möglicherweise hat Fuchs sich im Jahr geirrt. 
Gabriel, Manfred: Lebenswelt und Handeln. Zur Verständigung über den »state of the art«. In: Haas, Städtische Lebenswelten seit I 945, S. 37-56.

Gauß, Karl-Markus: Die Toten haben Hunger. In: Die Zeit, Nr. 44, I99 I, unpaginiert, online abrufbar im Archiv von Zeit Online: http://www.zeit.de/r 99 I/44/die-totenhaben-hunger.

Ders.: Der Österreich-Liebhaber. In: Die Zeit, Nr. 35, I 993, unpaginiert, online abrufbar im Archiv von Zeit Online: http://www.zeit.de/ı993/35/der-oesterreich-liebhaber.

Ders.: Ein Haufen Fleisch. In: Die Presse, 9./ro.9.1 995 , S. 5.

Gehler, Michael/Sickinger, Hubert (Hg.): Politische Affären und Skandale in Österreich. Von Mayerling bis Waldheim. Thaur/Wien: Kulturverlag I 995.

Geiger, Theodor: Die soziale Schichtung des deutschen Volkes: soziographischer Versuch auf statistischer Grundlage. Stuttgart: Enke I 967 (unveränderter Nachdruck der Original-Ausgabe von I932).

Geiss, Imanuel: Die Habermas-Kontroverse - ein deutscher Streit. Berlin: Siedler 1988.

Geml, Gabriele: Zum Begriff des Faschismus bei Adorno. Wien: Diplomarbeit 2002.

Gentile, Emilio: Der Faschismus. Eine Definition zur Orientierung. In: Mittelweg 36, Nr. I, 2007, S. 8 I-99.

Ders.: Fascismo. Storia e interpretazione. Rom/Bari: Laterza 2002.

Ders.: Le religioni della politica. Fra democrazie e totalitarismi. Rom/Bari: Laterza $200 \mathrm{I}$. (Liegt auch in englischer Übersetzung vor: Ders.: Politics as Religion. Berkeley: University Presses of CA 2006.)

Ders.: Le Origini dell'Ideologia Fascista (r9 1 8-r 92 5). Bologna: Il Mulino r 996.

Goethe, Johann Wolfgang von: Gedichte. In: Beutler, Ernst (Hg.): Goethes Werke in zehn Bänden. Erster Band. Zürich: Artemis I 96 I.

Ders.: Maximen und Reflexionen. In: Stapf, Paul (Hg.): Goethe. Werke. Fünfter Band. Berlin/Darmstadt/Wien: Deutsche Buchgemeinschaft I 967 .

Goldhagen, Daniel Jonah: Hitlers willige Vollstrecker. Ganz gewöhnliche Deutsche und der Holocaust. Berlin: Siedler 1 996. (Zuerst auf Englisch erschienen: Ders.: Hitler's willing executors. Ordinary Germans and the Holocaust. New York: Random House I 996.

Göllner, Siegfried: Die politischen Diskurse zu »Entnazifizierung«, »Causa Waldheim» und »EU-Sanktionen«. Opfernarrative und Geschichtsbilder in Nationalratsdebatten. Hamburg: Verlag Dr. Kovač 2009 (= Studien zur Zeitgeschichte, Bd. 72).

Görlich, Ernst Joseph/Romanik, Felix (Hg.): Geschichte Österreichs. Innsbruck: Tyrolia Verlag I 970.

Greenblatt, Stephen: Kultur. In: Baßler, New Historicism, S. 48-6o.

Ders.: Schmutzige Riten. Betrachtungen zwischen den Weltbildern. Frankfurt am Main: Wagenbach 1990.

Ders.: Shakespearean Negotiations. The Circulation of Social Energy in Renaissance England. Los Angeles: University of California Press 1988. 
Ders.: Renaissance Self-Fashioning. From More to Shakespeare. Chicago: University of Chicago Press i 980 .

Griffin, Roger: The Nature of Fascism. London: Pinter Publishers r 99 I.

Grillparzer, Franz: König Ottokars Glück und Ende. Trauerspiel in fünf Aufzügen. In: Stapf, Grillparzer, S. 355-458.

Grohotolsky, Ernst (Hg.): Provinz, sozusagen. Österreichische Literaturgeschichten. Graz/Wien: Droschl i995.

Gürtler, Christa (Hg.): Gegen den schönen Schein. Texte zu Elfriede Jelinek. Frankfurt am Main: Neue Kritik ${ }^{2} 2005$.

Dies.: Forschung. In: Janke, Jelinek-Handbuch, S. 356-366.

Haas, Hanns: Der Anschluss. In: Tálos/Hanisch/Neugebauer/Sieder: NS-Herrschaft in Österreich, S. 26-54.

Ders./Hoffmann, Robert/Kriechbaumer, Robert (Hg.): Salzburg. Städtische Lebenswel$\mathrm{t}(\mathrm{en})$ seit I 945. Wien, Köln, Weimar: Böhlau 2000 (= Schriftenreihe des Forschungsinstitutes für politisch-historische Studien der Dr.-Wilfried-Haslauer-Bibliothek Salzburg, Bd. I I).

Haider, Jörg: Glücksgefühl nach bangen Stunden. In: News, Nr. Io, 9.3.2000, S. 30 f.

Haller, Max/Nowotny, H. J./Zapf, W. (Hg.): Kultur und Gesellschaft. Verhandlungen des 24. Deutschen Soziologentages, des I r. Österreichischen Soziologentages und des 8. Kongresses der Schweizerischen Gesellschaft für Soziologie, Zürich I 988. Frankfurt am Main/New York: 1989.

Hamburger Institut für Sozialforschung: Verbrechen der Wehrmacht: Dimensionen des Vernichtungskrieges I94I-I 944. Ausstellungskatalog. Hamburg: Hamburger Ed. 2002.

Hanisch, Ernst: Ein Historiker als Leser von Dichtung. In: Beutner/Tanzer, Lesen, S. I63-i 70 .

Ders.: Der lange Schatten des Staates. Österreichische Gesellschaftsgeschichte im 20. Jahrhundert. Wien: Ueberreuter I 994.

Hartmann, Christian (Hg.): Verbrechen der Wehrmacht: Bilanz einer Debatte. München: Beck 2005.

Hassel, Ursula/Herzmann, Herbert (Hg.): Das zeitgenössische deutschsprachige Volksstück. Akten des internationalen Symposiums: University College Dublin, 28. Februar-2. März r 991. Tübingen: Stauffenburg 1 992, (= Stauffenburg Colloquium, Bd. 23).

Häupl, Waltraud: Die ermordeten Kinder vom Spiegelgrund. Gedenkdokumentation für die Opfer der NS-Kindereuthanasie in Wien. Böhlau: Wien 2006.

Heindl, Bernhard: Wir Österreicher sind ein anständiges Volk!« Kurt Waldheim. Linz: agis/sandkorn I 99 I.

Helbig, Jörg: Intertextualität und Markierung. Untersuchungen zur Systematik und Funktion der Signalisierung von Intertextualität. Heidelberg: C. Winter 1996 (= Beiträge zur neueren Literaturgeschichte, Bd. I4I). 
Henze, Hans Werner (Hg.): Die Chiffren. Musik und Sprache. Neue Aspekte der musikalischen Ästhetik IV, I 990.

Herbert, Ulrich: Der Historikerstreit. Politische, wissenschaftliche, biographische Aspekte. In: Sabrow /Jessen/Kracht, Zeitgeschichte als Streitgeschichte, S. 92 - 108.

Heyer, Petra: Von Verklärern und Spielverderbern. Eine vergleichende Untersuchung neuerer Theaterstücke Peter Handkes und Elfriede Jelineks. Frankfurt am Main: Peter Lang 200I (= Bochumer Schriften zur deutschen Literatur, Bd. 59).

Hiebl, Ewald: Sit-In, Teach-In, Go-In. Studentischer Protest um » 968 « in Österreich. In: Historische Sozialkunde, $3 / 2010$, S. 10-1 8.

Ders.: Zahme Viertelstunde oder heiße Revolution? Die Lebenswelt(en) der 68er in Salzburg. In: Haas,/Hoffmann/Kriechbaumer, Städtische Lebenswelt(en) seit I945, S. 299-328.

Hochholdinger-Reiterer, Beate/Peter, Birgit (Hg.): Maske und Kothurn. Internationale Beiträge zur Theaterwissenschaft. 50. Jg., Heft 2 : Burgtheater. Mythos - Eros - Imago. Wien/Köln/Weimar: Böhlau 2004.

Hochholdinger-Reiterer, Beate: "Es ist, als liefe das Bellaria-Kino Amok.» - Elfriede Jelineks Burgtheater. Posse mit Gesang. In: Hochholdinger-Reiterer/Peter, Maske und Kothurn, S. 43-58.

Hofinger, Johannes: »Ein Volk - Ein Reich - Ein Führer«. Audiovisuelle Dokumente zum Jahr I 938 in Salzburg. In: Kramml/Hanisch, Hoffnungen und Verzweiflung, S. $238-28 \mathrm{I}$.

Ders.: Die Akte Leopoldskron. Max Reinhardt - Das Schloss - Arisierung und Restitution. Salzburg: Anton Pustet 2005.

Hoffmeister, Donna: Access Routes into Postmodernism. Interviews with Innerhofer, Jelinek, Rosei and Wolfgruber. In: Modern Austrian Literature, Vol. 20/I987, Nr. 2, S. $97-$ I 30 .

Hofmannsthal, Hugo von: Prosa III. Frankfurt am Main: Fischer I 964.

Horaczek, Nina/Wiese, Sebastian: Handbuch gegen Vorurteile. Von Auschwitzlüge bis Zuwanderungstsunami. Wien: Czernin 20 I I.

Hörbiger, Paul: Ich hab für euch gespielt. Erinnerungen. Frankfurt am Main/Wien: U11stein, ${ }^{2}$ I 989 .

Hovdar, Sylvia: »Mein Schweigen half mir nicht, zu vergessen.« Das Erinnern und Verdrängen der NS-Vergangenheit in den autobiographischen Texten von Leni Riefenstahl, Traudl Junge und Ilse Schmidt. Saarbrücken: Verlag Dr. Müller 2007.

Ibach, Alfred: Die Wessely. Skizze ihres Werdens. Wien: Wilhelm Fink Verlag I 943.

Ihwe, Jens (Hg.): Literaturwissenschaft und Linguistik: Ergebnisse und Perspektiven. Bd. 3: Zur linguistischen Basis der Literaturwissenschaft. Frankfurt am Main: Athenäum Verlag 1972.

Jandl, Ernst: I 925-2000: Laut und Luise. Mit einem Nachwort von Helmut Heissenbüttel. Stuttgart: Reclam i 976. 
Janke, Pia (Hg.): Jelinek-Handbuch. Stuttgart/Weimar: Carl Ernst Poeschel/Metzler 2013.

Dies.: Einleitung. In: Janke, Jelinek-Handbuch, S. VII-IX.

Dies./Kovacs, Teresa/Schenkermayr, Christian (Hg.) : "Die endlose Unschuldigkeit«. E1friede Jelineks Rechnitz (Der Würgeengel). Wien: Edition Praesens 20 го.

Dies. (Hg.): Literaturnobelpreis Elfriede Jelinek. Wien: Edition Praesens 2005.

Dies. (Hg.): Werkverzeichnis Elfriede Jelinek. Wien: Edition Praesens 2004.

Janke, Pia (Hg.): Die Nestbeschmutzerin. Jelinek \& Österreich. Salzburg und Wien: Jung und Jung 2002.

Janz, Marlies: Elfriede Jelinek. Stuttgart und Weimar: Metzler i 995.

Dies.: Die Geschichte hat sich nach 45 entschlossen, noch einmal ganz von vorne $\mathrm{zu}$ beginnen ...«. In: Bartens/Pechmann, Elfriede Jelinek, S. $225^{-2} 3^{8}$.

Dies.: Falsche Spiegel. Über die Umkehrung als Verfahren bei Elfriede Jelinek. In: Gürtler, Gegen den schönen Schein, S. 8 I-97.

Just, Rainer: Zeichenleichen - Reflexionen über das Untote im Werk von Elfriede Jelinek. Wien: 2007. Online: www.univie.ac.at/jelinetz (Zugriff am I 0.5.20 I I)

Kafka, Franz: Brief an Oskar Polack vom 27. Januar 1904. In: Max Brod (Hg.): Franz Kafka. Gesammelte Werke. Briefe r 902-r 924. New York: 1958.

Kastberger, Klaus: Österreichische Endspiele: Die Toten kehren zurück. In: Trans, Internet-Zeitschrift für Kulturwissenschaften, Nr. I 5 , 2005. Online abrufbar unter: http:// www.inst.at/trans/ I $5 \mathrm{Nr} / 0_{5}$ I 6/kastberger I 5 .htm (Zugriff am 8.5.20 I I).

Keller, Fritz: Wien, Mai 68 - Eine heiße Viertelstunde. Wien: Junius ${ }^{2}$ I 988.

Kerschbaumer, Marie-Thérèse: Für mich hat Lesen etwas mit Fließen zu tun. Wien: Wiener Frauenverlag I 989.

Dies.: Porträt einer jungen österreichischen Autorin (1 971). In: Dies., Für mich hat Lesen etwas mit Fließen zu tun, S. I44-I47.

Dies.: Porträt einer Dichterin. Elfriede Jelinek (1986). In: Dies., Für mich hat Lesen etwas mit Fließen zu tun, S. I 47-1 52 .

Dies.: Bemerkungen zu Elfriede Jelineks Burgtheater. In: Dies., Für mich hat Lesen etwas mit Fließen zu tun, S. I 5 2-I63.

Kershaw, Ian: Hitler 1936-1945. Stuttgart: Deutsche Verlags-Anstalt 2000.

Kindlers Neues Literatur Lexikon. Studienausgabe. Bd. 8 Ho-Jz. München: Kindler I 996.

Klee, Ernst: Das Kulturlexikon zum Dritten Reich. Wer wer was vor und nach 1945 . Frankfurt am Main: Fischer Taschenbuch 2009.

Klotz, Volker: Zitat und Montage in neuerer Literatur und Kunst. In: Sprache im technischen Zeitalter, Nr. 60, 1976, S. $256-293$.

Kramml, Peter F./Hanisch, Ernst (Hg.): Hoffnungen und Verzweiflung in der Stadt Salzburg 1938/39. Vorgeschichte - Fakten - Folgen. Salzburg: Stadtgemeinde Salzburg 20 Iо (= Schriftenreihe des Archivs der Stadt Salzburg 28, Bd. I). 
Kraus, Karl: Aphorismen, Sprüche und Widersprüche. Pro domo et mundo. Nachts. Frankfurt am Main: Suhrkamp 1986.

Krauss, Marita (Hg.): Sie waren dabei. Mitläuferinnen, Nutznießerinnen, Täterinnen im Nationalsozialismus. Göttingen: Wallstein 2008 (= Dachauer Symposien zur Zeitgeschichte, Bd. 8).

Kristeva, Julia: Bakhtine, le mot, le dialogue et le roman. In: Critique, H. 239, i967, S. $43^{8}-465$; in deutscher Übersetzung: Bachtin, das Wort, der Dialog und der Roman. In: Ihwe, Literaturwissenschaft und Linguistik, S. 345-375.

Kühnl, Reinhard: Faschismustheorien. Ein Leitfaden. Aktualisierte Neuauflage. Heilbronn: Distel Verlag I 990.

Ders. (Hg.): Vergangenheit, die nicht vergeht. Die »Historiker-Debatte«. Dokumentation, Darstellung und Kritik. Köln: Pahl-Rugenstein I 987.

Landes, Brigitte (Hg.): Stets das Ihre. Elfriede Jelinek. Arbeitsbuch 2006. Berlin: Theater der Zeit 2006.

Le Goff, Jacques/Chartier, Roger/Revel, Jacques (Hg.): Die Rückeroberung des historischen Denkens. Grundlagen der Neuen Geschichtswissenschaft. Frankfurt am Main: S. Fischer I 990 (zuerst I 978 unter dem frz. Originaltitel »La nouvelle histoire« bei Retz-C.E.P.L. Paris erschienen).

Le Goff: Neue Geschichtswissenschaft. In: Ders./Chartier/Revel, Die Rückeroberung des historischen Denkens, S. I I-6 I .

Lebert, Hans: Die Wolfshaut. Leipzig: Neuer Europa Verlag 2008.

Leiprecht, Helga: Die elektronische Schriftstellerin. In: du. Die Zeitschrift der Kultur. Nr. 700/Oktober I 999.

Lengauer, Hubert: Jenseits vom Volk: Elfriede Jelineks »Posse mit Gesang« Burgtheater. In: Hasse1/Herzmann, Das zeitgenössische deutschsprachige Volksstück, S. 2 I 7-228.

Lepsius, Mario Rainer: Das Erbe des Nationalsozialismus und die politische Kultur der Nachfolgestaaten des »Großdeutschen Reiches«. In: Haller/Nowotny/Zapf, Kultur und Gesellschaft, S. 247-264.

Leser, Norbert/Wagner, Manfred (Hg.): Österreichs politische Symbole: historisch, ästhetisch und ideologiekritisch beleuchtet. Wien, Köln, Weimar: Böhlau r 994 (= Schriftenreihe des Ludwig-Boltzmann-Instituts für Neuere Österreichische Geistesgeschichte; Bd. 6).

Linke, Angelika/Nussbaumer, Markus/Portmann, Paul R.: Studienbuch Linguistik. Tübingen: Max Niemeyer I 99 I (= Reihe Germanistische Linguistik, Bd. I 2 I).

Lipset, Seymour Martin: Soziologie der Demokratie. Neuwied am Rhein u.a.: Luchterhand 1962 .

Löffler, Sigrid: Majestätsbeleidigung: Käthe, Istvan, Schorsch. Elfriede Jelineks in Wien leider unaufführbare Posse Burgtheater ist jetzt wenigstens im Druck erschienen. In: profil, Nr. 29, I 9.7.1 982 , S. 54.

Dies.: »Was habe ich gewußt - nichts«. In: profil, Nr. 48, 25. I I. I 985 , S. 88-95. 
Dies.: Am Eingang zur Unterwelt. Zum neuen Roman von Elfriede Jelinek: >Die Kinder der Toten«. In: Süddeutsche Zeitung, I r.8.1995, S. I I.

Dies.: »Erhalte Gott dir deinen Ludersinn«. In: Bartsch/Höfler, Dossier 2. S. 2 1 8-222 (zuerst erschienen in profil, Nr. 47, I8.1 I.1985).

Loh, Werner/Wippermann, Wolfgang (Hg.): »Faschismus« kontrovers. Stuttgart: Lucius \& Lucius 2002 (= Erwägungskultur in Forschung, Lehre und Praxis, Bd. 3).

Lücke, Bärbel: Jelineks Gespenster. Grenzgänge zwischen Politik, Philosophie und Poesie. Wien: Passagen 2007.

Dies.: Elfriede Jelinek. Eine Einführung in das Werk. Paderborn: Wilhelm Fink 2008.

Lux, Georg; Wiedergut, Arno; Sommersguter, Uwe (Hg.): Jörg Haider: Mensch, Mythos, Medienstar. Wien/Graz/Klagenfurt: Carinthia 2008.

Mann, Michael: Fascists. Cambridge: Cambridge University Press 2004.

Ders.: Der Faschismus und die Faschisten. In: Mittelweg 36, Nr. I, 2007, S. $26-54$.

Manoschek, Walter (Hg.): Der Fall Rechnitz. Das Massaker an Juden im März I 945. Mit einem Text von Elfriede Jelinek. Wien: Braumüller 2009.

Ders. (Hg.): Die Wehrmacht im Rassenkrieg. Der Vernichtungskrieg hinter der Front. Wien: Picus 1996.

Marboe, Ernst: Das Österreich-Buch. Wien: Verlag der österreichischen Staatsdruckerei I 948.

Markus, Georg: Die Hörbigers. Biografie einer Familie. Wien: Amalthea Signum 2006.

Marschik, Matthias: Sportdiktatur. Bewegungskulturen im nationalsozialistischen Österreich. Wien: Turia + Kant 2008.

Ders./Spitaler, Georg (Hg.): Helden und Idole. Sportstars in Österreich. Innsbruck: Studienverlag 2008.

Mattl, Siegfried: Geschlecht und Volkscharakter. Austria engendered. In: ÖZG, Nr. 7 , I 996/4, S. 499-5 I 5 .

Mayer, Verena/Koberg, Roland: Elfriede Jelinek. Ein Porträt. Reinbek bei Hamburg: Rowohlt 2006.

McGowan, Moray/Schmidt, Ricarda (Hg.): From High Priests to Desecrators: Contemporary Austrian Literature. Sheffield: Academic Press I 993.

Meister, Monika: Bezüge zur Theatertradition. In: Janke, Jelinek-Handbuch, S. 68 - 73.

Meyer, Adolf Ernst u. a (Hg.): Sturm und Zwang. Schreiben als Geschlechterkampf. Hamburg: Klein I 995 .

Miessgang, Thomas: Der Querschreiber. In: profil, Nr. 38, г 99 I, S. 106 f.

Mindlberger, Sylvia: Das Konzept "Heimat« in Elfriede Jelineks Texten Die Liebhaberinnen, Ob Wildnis, ob Schutz vor ibr und Die Kinder der Toten. Salzburg: Diplomarbeit 1996.

Montrose, Louis: Die Renaissance behaupten. Poetik und Politik der Kultur. In: Baßler, New Historicism, S. 6o-93.

Mosse, George L.: The Fascist Revolution. Towards a General Theory of Fascism. New York: Howard Fertig, I 999. 
Ders.: Der nationalsozialistische Alltag. Frankfurt am Main: Hain Meisenheim ${ }^{3}$ I 993.

Ders.: International Fascism. New Thoughts and New Approaches. London: SAGE 979 (= SAGE Readers in $20^{\text {th }}$ Century History, Vol. 3 ).

Muhr, Rudolf/Schrodt, Richard/Wiesinger, Peter (Hg.): Österreichisches Deutsch Linguistische, sozialpsychologische und sprachpolitische Aspekte einer nationalen Variante des Deutschen. Wien: Hölder-Pichler-Tempsky I995 (= Beiträge der internationalen Sprachwissenschafter-Tagung »Österreichisches Deutsch« an der KarlFranzens-Universität Graz vom 22. bis 24. Mai r 995).

Müller, André: Elfriede Jelinek. In: Österreicher(innen). Wien/Linz/Weitra/München: Bibliothek der Provinz i 994, S. I9 I-206.

Ders./Jelinek, Elfriede: Ich bin die Liebesmüllabfuhr. In: Landes, Brigitte (Hg.): Stets das Ihre. Elfriede Jelinek. Arbeitsbuch 2006. Berlin: Theater der Zeit 2006, S. 2 I28 (erstmals erschienen in profil, Nr. 49, 29.1 I.2004, S. I30-I37, außerdem in der Schweizer Weltwoche, 2.I 2.2004). ${ }^{3}$

Müller, Sabine/Theodorsen, Cathrine (Hg.): Elfriede Jelinek: Tradition, Politik und Zitat. Ergebnisse der internationalen Elfriede Jelinek-Tagung I.-3. Juni 2006 in Tromsø. Wien: Praesens 2008 (= Diskurse.Kontexte.Impulse. Publikationen des Elfriede Jelinek-Forschungszentrums, Bd. 2).

Müller, Karl: „Ein neuer Gegenstand, ganz erneuert durch die Sicht.« Zur Prosa Hans Leberts. In: Fuchs, Gerhard/Höfler, Günther A. (Hg.): Hans Lebert. Dossier. Graz: Droschl 1997 (= Die Buchreihe über österreichische Autoren, Bd. I 2), S. 37-63.

Müllner, Rudolf: Anton Sailer. Österreichs Sportler des Jahrhunderts. In: Marschik/Spitaler, Helden und Idole, S. 242-258.

Ders: Die Mobilisierung der Körper. Der Schul- und Hochschulsport im nationalsozialistischen Österreich. Wien: WUV-Universitätsverlag I 993.

Nederling, R. (Hg.): Die Reichsparteitage der Nsdap. 1923-1939. Leoni am Starnbergersee: Druffel i 98 I.

Nolte, Ernst: Der Faschismus in seiner Epoche. München: R. Piper \& Co. I 963.

Ders.: Das Vergehen der Vergangenheit. Antwort an meine Kritiker im sogenannten Historikerstreit. Berlin: Ullstein 1987.

Nüchtern, Klaus: »Ich bin ein Racheengerl«. Elfriede Jelinek im Interview. In: Falter I 4 /o3.

Palm, Kurt (Hg.): »Burgtheater - Zwölfeläuten - Blut - Besuchszeit: Vier österreichische Stücke.«Wien: I 987.

Passmore, Kevin: Fascism. A Very Short Introduction. Oxford: University Press 2002. Patlagean, Évelyne: Die Geschichte des Imaginären. In: Le Goff/Chartier/Revel, Die Rückeroberung des historischen Denkens, S. $244-276$.

3 In Landes, Stets das Ihre, wird darauf verwiesen, dass das Interview erstmals in der Schweizer Weltwoche erschienen wäre, tatsächlich aber zuerst: profil, $\mathrm{Nr} .49$, 2004, S. I30-I 37 . 
Paxton, Robert O.: Die fünf Stadien des Faschismus. In: Mittelweg 36, Nr. I, 2007 , S. $55-80$.

Payne Stanley: Geschichte des Faschismus. Aufstieg und Fall einer europäischen Bewegung. München/Berlin: Ullstein 200 I.

Perthold, Sabine: Elfriede Jelineks dramatisches Werk: Theater jenseits konventioneller Gattungsbegriffe. Dissertation, Wien I991.

Peukert, Detlev: Volksgenossen und Gemeinschaftsfremde. Anpassung, Ausmerze und Aufbegehren unter dem Nationalsozialismus. Köln: Bund-Verlag I 982.

Pfeiffer, Lorenz: Sport im Nationalsozialismus. Zum aktuellen Stand der sporthistorischen Forschung. Eine kommentierte Bibliografie. Göttingen: Die Werkstatt 2004.

Pontzen, Alexandra: Pietätlose Rezeption? Elfriede Jelineks Umgang mit der Tradition in Die Kinder der Toten. In: Müller/Theodorsen, Tradition, Politik und Zitat, S. 5 I-69.

Radisch, Iris: Maxima Moralia. Elfriede Jelinek und ihr österreichisches Gesamtkunstwerk »Die Kinder der Toten«. In: Die Zeit, Nr. 38, I 5.9.1995. Online abrufbar im Archiv von Die Zeit unter: http://www.zeit.de/ı 995/38/Maxima_Moralia.

Rathkolb, Oliver: Führertreu und gottbegnadet. Künstlereliten im Dritten Reich. Wien: Österreichischer Bundesverlag I99I.

Reichardt, Sven: Neue Wege der vergleichenden Faschismusforschung. In: Mittelweg 36, Nr. I, 2007, S. 9-25.

Reiter, Andrea: Karl Springenschmid: Der Waldgänger. Rechtfertigungsprosa im Biedermeierstil? In: Baur/Gradwohl-Schlacher/Fuchs, Macht Literatur Krieg, S. 307-3 I 9.

Rétif, Francoise/Sonnleitner, Johann (Hg.): Elfriede Jelinek. Sprache, Geschlecht und Herrschaft. Würzburg: Königshausen \& Neumann 2008.

Roessler, Peter: Vom Bau der Schweigemauer: Überlegungen zu den »Reaktionen« auf Elfriede Jelineks Stück Burgtheater. In: TheaterZeitSchrift, Heft 2, I 982, S. 89.

Rossbacher, Karlheinz: Lesen. Was sonst? Eine Abschiedsvorlesung als Eröffnungsvortrag. In: Beutner /Tanzer, Lesen, S. I 5-28.

Rot-Weiß-Rot-Buch: Gerechtigkeit für Österreich! Darstellungen, Dokumente und Nachweise zur Vorgeschichte und Geschichte der Okkupation Österreichs (nach amtlichen Quellen). Wien: Verlag der Österreichischen Staatsdruckerei 1946.

Sabrow, Martin/Jessen, Ralph/Kracht; Klaus Grosse (Hg.): Zeitgeschichte als Streitgeschichte. Große Kontroversen seit I 945. München: Beck 2003.

Sailer, Toni: Mein Weg zum dreifachen Olympiasieg. Salzburg: Bergland-Buch I 956.

Sander, Margarete: Textherstellungsverfahren bei Elfriede Jelinek: das Beispiel »Totenauberg«. Würzburg: Königshausen \& Neumann 1996 (= Würzburger Wissenschaftliche Schriften: Reihe Literaturwissenschaft, Bd. I79).

Scharsach, Hans-Henning: Haiders Kampf. München: Heyne 1992.

Scheidl, Günther: Ein Land auf dem rechten Weg? Die Entmythisierung der Zweiten Republik in der österreichischen Literatur von I 985 bis I 995 . Wien: Braumüller 2003. Schieder, Wolfgang: Der italienische Faschismus: r 9 19-1945. München: Beck 20 ı。. 
Ders.: Faschistische Diktaturen. Studien zu Italien und Deutschland. Göttingen: Wallstein 2008.

Ders.: Faschismus. In: Dülmen, Fischer Lexikon Geschichte, S. I 77-195.

Schmidt, Rainer F.: Der Zweite Weltkrieg. Die Zerstörung Europas. Berlin-Brandenburg: be.bra 2008.

Schnell, Ralf: Stoffwechselprozesse. Oberfläche und Tiefenstruktur in Elfriede Jelineks Roman Die Kinder der Toten. In: Eder/Vogel, Lob der Oberfläche, S. I69-I79.

Schoeps, Julius H./Schlör, Joachim (Hg.): Bilder der Judenfeindschaft. Antisemitismus Vorurteile und Mythen. Augsburg: Weltbild ${ }^{2}$ I 999.

Scholl, Guido: Selbstinszenierungen einer Autorin: Elfriede Jelinek als literarische Figur und öffentliche Person. Magisterarbeit. München: Grin 2004.

Schüssel, Wolfgang: Österreich erstes NS-Opfer. In: Der Standard, I o. I I.200o, S. го.

Schwarzenberger, Eckhard: J. A. Topf \& Söhne - Ort und Gegenstand der Auseinandersetzung mit der "ganz normalen« Mittäterschaft. In: Assmann/Hiddemann/Schwarzenberger, Firma Topf \& Söhne, S. I I-32.

Schwegler, Theodor/Herzog, Franz Alfred/Perk, P. Johann (Hg.): Grosse Familien-Bibel.

Die heilige Schrift des Alten und Neuen Testamentes. Zürich/Frankfurt am Main/ Innsbruck u.a.: Stauffacher ${ }^{4}$ I 974 .

Seiler, Christian: Zombieball. In: profil, Nr. 33, I4.8.1995, S. 65 f.

Sellin, Volker: Einführung in die Geschichtswissenschaft. Göttingen: Vandenhoeck \& Ruprecht I 995 .

Spanlang, Elisabeth: »Ein Strindberg-Stück ist eine Operette dagegen«/Anmerkungen zu einer ungewöhnlichen Biographie. In: Bartsch, Kurt/Höfler, Günther A.: Dossier 2, Elfriede Jelinek. Graz/Wien: Droschl i 99 I, S. 247-259.

Spann, Gustav: Zur Geschichte von Flagge und Wappen der Republik Österreich. In: Leser/Wagner, Österreichs politische Symbole, S. 37 - 64 .

Sperl, Gerfried: Der Machtwechsel. Österreichs politische Krise zu Beginn des 3. Jahrtausends. Wien: Molden 2000.

Stapf, Paul (Hg.): Grillparzer. Werke. Erster Band. Dramen. Berlin/Darmstadt/Wien: Deutsche Buchgemeinschaft 1965 .

Steiner, Maria: Paula Wessely: Die verdrängten Jahre. Wien: Verlag für Gesellschaftskritik I 996.

Stocker, Peter: Theorie der intertextuellen Lektüre. Modelle und Fallstudien. Paderborn/ Wien (u.a.): Schöningh r 998.

Szczepaniak, Monika: Dekonstruktion des Mythos in ausgewählten Prosawerken von Elfriede Jelinek. Frankfurt am Main/Wien (u.a.): Lang I 998.

Tálos, Emmerich/Hanisch, Ernst/Neugebauer, Wolfgang (Hg.): NS-Herrschaft in Österreich I 938-r945. Wien: öbv \& hpt ${ }^{2} 2000$.

Theweleit, Klaus: Männerphantasien 2. Männerkörper - zur Psychoanalyse des weißen Terrors. Reinbek bei Hamburg: Rowohlt ${ }^{2}$ I 987 . 
Treude, Sabine: »Keiner wußte davon, bleiben wir bei dieser offiziellen Version.»In: female sequences, Nr. 2, 200I, S. $22-25$.

Uhl, Heidemarie (Hg.): Zivilisationsbruch und Gedächtniskultur. Das 20. Jahrhundert in der Erinnerung des beginnenden 2 I. Jahrhunderts. Innsbruck/Wien/München/ Bozen: Studien Verlag 2003.

Dies.: Das »erste Opfer«. Der österreichische Opfermythos und seine Transformationen in der Zweiten Republik. In: Österreichische Zeitschrift für Politikwissenschaft ÖZP 2001/ , S. I9-34.

Urbach, Tilman: Die Sprache unter dem Skalpell. In: du. Die Zeitschrift der Kultur. Nr. 70o/Oktober i 999, S. I 4 f.

Venckute, Jolita: Lust: Elfriede Jelinek im Zenit des Ruhms? Interview für die litauische Tageszeitung »Lietuvos rytas« (haGalil onLine, 7.I 2.I998). Abrufbar unter: http:// www.hagalil.com/archiv/98/. 2/jellinek.htm (I7.6.20 I ).

Wahrig, Gerhard: Fremdwörterlexikon. München: Bertelsmann/Mosaik 1985 .

Wassermann, Heinz P.: Naziland Österreich? Studien zu Antisemitismus, Nation und Nationalsozialismus im öffentlichen Meinungsbild. Innsbruck: Studien Verlag 2002 (= Schriften des Centrums für Jüdische Studien; Bd. 2).

Weber, Heike: Das Versprechen mobiler Freiheit: zur Kultur- und Technikgeschichte von Kofferradio, Walkman und Handy. Bielefeld: Transcript 2008.

Weidinger, Bernhard: Der Konsens, der niemals war. In: Der Standard, 8.6.2009, S. 28.

Weinzierl, Ulrich: Sauberes Theater. In: Bartsch/Höfler, Dossier 2, S. $222-225$ (zuerst erschienen in der Frankfurter Allgemeinen Zeitung, 27.I I.1 985 ).

Welskopp, Thomas: Historische Erkenntnis. In: Budde/Freist/Günther-Arndt, Geschichte, Kapitel 7, S. I 22-I 37 .

Welz, Frank: Kritik der Lebenswelt. Eine soziologische Auseinandersetzung mit Edmund Husserl und Alfred Schütz. Opladen: Westdeutscher Verlag I 996.

Wilpert, Gero von: Sachwörterbuch der Literatur. Stuttgart: Alfred Kröner ${ }^{7}$ I 989.

Winkler, Heinrich August: Mittelstand, Demokratie und Nationalsozialismus. Die politische Entwicklung von Handwerk und Kleinhandel in der Weimarer Republik. Köln: Kiepenheuer \&Witsch, 1972.

Winter, Riki: Gespräch mit Elfriede Jelinek. In: Bartsch, Kurt/Höfler, Günther A.: Dossier 2, Elfriede Jelinek. Graz, Wien: Droschl I 99 I, S. 9-ı 9.

Wippermann, Wolfgang: Faschismustheorien. Die Entwicklung der Diskussion von den Anfängen bis heute. Darmstadt: Wissenschaftliche Buchgesellschaft ${ }^{7}$ I 997 (= Erträge der Forschung, Bd. I7).

Ders.: Hat es Faschismus überhaupt gegeben? Der generische Faschismusbegriff zwischen Kritik und Antikritik. In: Loh /Wippermann, „Faschismus« kontrovers, S. 5 I 70.

Ders.: Umstrittene Vergangenheit. Fakten und Kontroversen zum Nationalsozialismus. Berlin: Espresso I 998. 
Wirth, Uwe (Hg.): Performanz: zwischen Sprachphilosophie und Kulturwissenschaften. Frankfurt am Main: Suhrkamp 2002.

Wittgenstein, Ludwig: Philosophische Untersuchungen. Frankfurt am Main: Suhrkamp I 977 (Suhrkamp Taschenbuch Wissenschaft, Bd. 203).

Wulf, Joseph (Hg.): Theater und Film im Dritten Reich. Eine Dokumentation. Frankfurt am Main u.a.: Ullstein I983.

Zauner, Anne M.: Elfriede Jelinek: Das Lebewohl. Auf der Homepage des Literaturhaus Wien abrufbar unter: http://www.literaturhaus.at/index.php?id=2620 (Zugriff am 22.9.2012).

Ziegler, Meinrad/Kannonier-Finster, Waltraud: Österreichisches Gedächtnis. Über Erinnern und Vergessen der NS-Vergangenheit. Wien: Böhlau ${ }^{2}$ I997.

Zima, Peter V.: Das literarische Subjekt. Zwischen Spätmoderne und Postmoderne. Tübingen/Basel: Francke 200I.

Zipfel, Gaby: Die Welt ist so schön und wir zerstören sie. In: Schmidt, Ilse: Die Mitläuferin. Erinnerungen einer Wehrmachtsangehörigen. Berlin: Aufbau 2002, S. I67-1 89.

Zobl, Susanne: »... weil du aus der Zerstörung des Krieges nicht heimfinden kannst«. Zu Leben und Werk von Gerhard Fritsch. In: Der literarische Zaunkönig, Nr. I/2004, S. $38 \mathrm{ff}$.

Zöchling, Christa: Haider. Licht und Schatten einer Karriere.Wien: Molden ${ }^{3} 2000$.

\subsubsection{Zeitungen und Zeitschriften}

Austrian Studies, vol. 22, I 8.12.2014.

Critique, H. 239, I967.

Der literarische Zaunkönig, Nr. I/2004.

Die Zeit, Nr. 27, 1978.

Die Zeit, Nr. 44, I 99 I.

Die Zeit, Nr. 35, 1993.

Die Zeit, Nr. 38, r 995.

Die Zeit, Nr. 3, 2006.

female sequences, Nr. 2, $200 \mathrm{I}$.

Kurier, I 2.I 2.1 986.

Kurier, 23.I 2.r 986.

Literaturen Nr. Iо, 2005.

Maske und Kothurn, Nr. 2, 2004.

Mittelweg 36, Nr. I, 2007.

Modern Austrian Literature, Vol. 20/ 987

Modern Language Review, Vol. 97/no. 2, or.04.2002.

News, Nr. I0, 9.3.2000.

ÖZG, Nr. 7, I 996/4. 
profil, Nr. 29, 1982.

profil, Nr. 48, 1985 .

profil, Nr. 38, I 99 I.

profil Nr. 07, I 995 .

profil Nr. 34, I 995.

profil, Nr. 34, 1998.

profil, Nr. 42, 2004.

profil, Nr. 49, 2004.

Falter Nr. I 4, 2003.

Literaturen Nr. IO, 2005.

Der Spiegel, Nr. 35, I 948.

Der Standard, RAU, I 9.5.2009.

Der Standard, RAU, I6./I 7.7.20 I I.

Der Standard, I 5. I0. 2015 , S. I 3.

Süddeutsche Zeitung, I I.08. I995.

TheaterZeitSchrift, Nr. 2, I 982.

Trans, Internet-Zeitschrift für Kulturwissenschaften, Nr. I 5, 2005.

Umbruch 6 Nr. I/I987.

Wiener Zeitung, 22.12.2005.

\subsubsection{Filme und TV-Beiträge}

„Carnival of Souls«. DVD, coloriert, Savoy Film GmbH.

"Alles anders? Wiener Festwochen 20 Io«. TV-Bericht anlässlich der Eröffnung der Wiener Festwochen 2010, ausgestrahlt am I4-5.2010 auf 3sat.

»Wer hat Angst vor Elfriede J.? Ein Porträt der Nobelpreisträgerin Elfriede Jelinek.«

TV-Dokumentation, ausgestrahlt am I I.I 2.2004 auf ORF 2.

»thema«. Reportagesendung des ORF, ausgestrahlt am 7·7.2008 auf ORF 2.

\subsubsection{Internet-Seiten}

Der letzte Zugriff für alle aufgelisteten Weblinks erfolgte am I9.09.20 I6. http://www.elfriedejelinek.com

http://www.elfriede-jelinek-forschungszentrum.com/publikationen

https://fpjelinek.univie.ac.at/

http://www.aphorismen.de

http://gfa-forum.de/cms/website.php?id=/de/methodenwissen/zitate.htm

http://www.film.at/heimkehr

http://de.wikipedia.org/wiki/Hans_Hinkel

http://www.film.at/der_engel_mit_der_posaune 


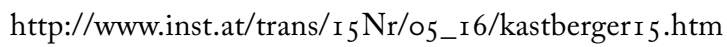

http://www.zeit.de/ı 995/38/Maxima_Moralia.

http://de.wikipedia.org/wiki/Lebensborn

https:/www.fpoe.at/themen/parteiprogramm/

http://www.schlossbergmuseum.de/templates/archiv/sportstadt/c5-IIIreich.htm

http://gfa-forum.de/cms/website.php?id=/de/methodenwissen/zitate.htm

http://www.ris.bka.gv.at/Dokumente/BgblPdf/I945_I_o/I945_I_o.pdf

http://wahlo8.bmi.gv.at

http://www.burgtheater.at/Content.Node2/home/service/shop/25-Der-Alpenkoenig-

und-der-Menschenfeind.at.php

http://de.wikipedia.org/wiki/Menschenmaterial

http://www.zeit.de/r 99I/44/die-toten-haben-hunger

http://www.zeit.de/r 993/35/der-oesterreich-liebhaber

http://www.youtube.com

http://www.bmi.gv.at/cms/BMI_wahlen/nationalrat/NRW_i 999.aspx

http://www.zitate.de/autor/Aristoteles

http://www.rowohlt-theaterverlag.de

http://www.univie.ac.at/jelinetz

http://derstandard.at/2000034653467/Khol-sieht-Oesterreich-als-Opfer-des-

Nationalsozialismus

https://jelinetz.com/2007/I 2/Io/monika-szczepaniak-ich-rede-und-rede-

tagungsbericht/

\subsection{Abbildungsverzeichnis}

Abb. г : Mesusa. Abbildung kopiert aus: Jelinek, KDT, S. 5 .

Abb. 2 : Ergebnisse der Nationalratswahlen vom 3. Oktober i 999. Tabelle kopiert aus: http://www.bmi.gv.at/cms/BMI_wahlen/nationalrat/NRW_i 999.aspx (Zugriffam 30. Io. 2012).

Abb. 3: BücherBücher. Foto: (C) Sylvia Paulischin-Hovdar 


\section{Register}

\subsection{Personenregister}

Adorno, Theodor 25, 34, 67, 70, 72, 80, 283

Aichinger, Ilse 186

Aischylos 250, 252, 256, 289,

Aly, Götz 39, 297

Arendt, Hannah 26, 35, 88, I I 6

Artmann, H.C. 68,69

Bachmann, Ingeborg 185

Bajohr, Frank 38-4I, 242

Barthes, Roland 4I-43, 67, 70, 8I, 85, I02, I03, I 26, I 34, I 45, I 5 2, I64, I 93, 2 I 8,22 I, 227, 281, 288

Batthyány, Margit I 8,96

Baudrillard, Jean 248

Bauer, Ingrid 7, 36-40, 68, 242, 28 I

Bernhard, Thomas 5 1, 1 86, 198, 295

Botz, Gerhard 46, 50-54, 207, 282,

Bracher, Karl-Dietrich 25, 29, I50, 285

Brecht, Bert 72, 84

Canetti, Elias 70

Celan, Paul 232

Derrida, Jacques I 9

Dickinson, Emily 9, 23, 84, 243, 247, 294

Diner, Dan 26, 37, 50, $28 \mathrm{I}$

Doderer, Heimito von 197

Eatwell, Roger 26, 30, 32

Engel, Erich I 26

Ernst, Gustav 197

Euripides I04

Felice, Renzo di 25

Fiddler, Allyson I 4, I 7, 56, 72, I00, I IO, I4I, I $55,248,249,288$

Figl, Leopold 46, I3 I, I 87

Fischer, Ernst 197

Foppa, Hermann 269

Forster, Rudolf I 26
Foucault, Michel 248

Freud, Sigmund I75, I77, I 88- I 92, I 95, I 96, 203, 233, 234, 276, 287

Fritsch, Gerhard 186, I 87

Fromm, Erich 34, I23, I 29

Gauß, Karl Markus 196- г98

Gentile, Emilio 24, 27, 3 I , 32, 35

Goebbels, Joseph 83, I30, I6 I, I62, I64, I68, I69, 272

Goethe, Johann Wolfgang von 22, 57, I05, I 44, I 53, I 89

Goldhagen, Daniel 29, 30, 285

Görlich, Ernst Joseph 48

Greenblatt, Stephen 293

Griffin, Roger 26, 30-33

Grillparzer, Franz I 47 - I 50, I 53, I 98

Gross, Heinrich 60, I 2 I

Gürtler, Christa I 4, I 7, I 9, 67, 74, 89

Guttenbrunner, Michael 197

Habermas, Jürgen 26, 36

Haider, Jörg I I , I 5 , 44, 52, 62-64, 88, 89, 9 I, 93-96, 104, I05, 206, 240-244, 248-278, 289-29I, 296

Haneke, Michael 55

Hanisch, Ernst I 52, I6 I, 294, 295

Hartl, Karl I I 9

Haslinger, Josef $5 \mathrm{I}$

Häupl, Michael I3, 94

Hausberger, Franz 93

Heesters, Johannes I 24, I 43

Heidegger, Martin 93, I00, I05, I I 6, 257

Hitler, Adolf 29, 30, 39, 40, 45, 46, 48, 5 I, 94, 96, I 28, I $30, I_{63}$, I 64, 220, 24I, 242, 248 , 256-258, 295, 297

Hofer, Norbert Gerwald 52

Hoffmann, E. T. A. I 90

Hofmannsthal, Hugo von I 30 , I 5 O, I 5 I

Hörbiger, Attila 88, г08, I09, I I 2, I I 3, I 30 , 
I 3 I, I3 8 , I 49, I 57, I60, I62, I65-I68, I 7 I, 285

Hörbiger, Christiane I I 2

Hörbiger, Maresa I I 2, I I 3, I 43

Hörbiger, Paul 88, I08, I09, I I 2, I 27, I 38 , I 68, I 69, I 7 I, 285

Horváth, Ödön von 7I, I 74, 20I, 245

Hüngsberg, Gottfried 55, 6o, 61, 76

Jandl, Ernst 68, 69, I 52

Janke, Pia I 4, I 8, 29, 47, 53, 62, 63, 66, 74, 79, 89, 90, 94-96, го9, I I 2, I 47, I 54, I 55, I 57 , I 74, I 8 I, 206, 249, 25 I, 252, 25 5, 265, 275, $277,278,283$

Janz, Marlies I 2, I 4, I6, I 7, 22, 23, 4I , 42, 6 I, $63,69,70,72,73,80,86-88,92$, I03, I09, I IO, I 2 I, I 25

Kaiser, Leander 60

Khol, Andreas I 3, 53

Kraus, Karl 70, 7 I

Kreisky, Bruno 92, 93

Kristeva, Julia roo- I03

Lebert, Hans I 74-I77, I88, I96- I98, 200-203, 228, 229, 238, 287, 295, 296

Le Goff, Jacques 294

Lingens, Peter Michael Io8

Litchfield, David R. L. I04, I05

Löffler, Sigrid I08, I09, I 25, I 44- I 46, I 49, I 5 O, I 54, I63, I64, I66, I67, I 78, I 99, 247, 285

Lücke, Bärbel I 2, I 9, 67, 72, 75, 79, 80, 84, 97, I 75, I 84, I $85,205,2$ I $7,248,249,253,256$, $259,260,27 \mathrm{I}-273,278,284,288,29 \mathrm{I}$

Mann, Michael 25, 30, 3 I, 33, 4I

Mardayn, Christl I 26

Martin, Wolf 24I

Mattl, Siegfried 48

Mayröcker, Friederike 68, I 86

Meischberger, Walter 258

Menasse, Robert 197

Mertens, Moira I76- I 78, I 94, I 95, 246

Meyer, Stephenie I9I

Mock, Alois 24I

Mosse, George 26, 28, 30, 256
Moser, Hans I I 3, I 26

Müller, Karl 7, I97

Mussolini, Benito 24, 29, 272

Nestroy, Johann 7 I, 89, 245

Nietzsche, Friedrich 93, I00, I 04, 248

Nimmerrichter, Richard (»Staberl«) 91, 244, 245

Nolte, Ernst 25-28, 79, 242

Novotny, Franz 6I, 85

Orth, Elisabeth I I 2

Passmore, Kevin 23, 30, 32, 33

Paxton, Robert Owen 23, 25, 30, 33

Payne, Stanley 24-26, 28

Petzner, Stefan 257,258

Peymann, Claus 63, 94, 24 I, 254

Podezin, Franz 97

Pontzen, Alexandra I73, I76-I79, I86, 200, 201, 207, 209, 246, 247, 286

Radisch, Iris I 78, I 80, 204, 209, 2 I 3, 247, 288

Raimund, Ferdinand 7 I, I O4, I IO, I I 4, I30, I38, I39, I46

Rathkolb, Oliver I o9, I I I, I 24, I39, I6o- I62, I65- I 68

Rauscher, Hans 96, 244, 266

Reder, Walter 263

Reich, Wilhelm 34, 86

Reichardt, Sven 23, 24, 26, 28-35

Riefenstahl, Leni I 72, 2 I 5

Riess (Ries-Passer), Susanne 266, 275

Röhm, Ernst 258

Rökk, Marika I 24, I 43, I 72

Romanik, Felix 48

Roth, Gerhard 5 I, 69, 94

Roth, Joseph 70

Sartre, Jean Paul 86, 87, I 2 I

Scheibner, Herbert 259

Schieder, Wolfgang 28, 29, 33

Schildt, Axel 39, 40

Schirach, Baldur von I 53

Schleef, Einar 63

Schlingensief, Christoph 64

Schmidt, Heide 258, 274

Scholl, Geschwister 40 
Schüssel, Wolfgang 52, 53, 275, 276

"Staberl" (siehe Nimmerrichter, Richard)

Stangl, Franz 9I

Steger, Norbert 88, 240, 254

Stemann, Nicolas 64

Stoker, Bram I91, I 92

Strache, Heinz-Christian 5 2, 96, 244, 264, 277

Szczepaniak, Monika I4, I7, I8, 4I, I07

Thurlow, Richard 26, 30

Treude, Sabine I 9, I 77, I 82, 249

Turrini, Peter 94

Ucicky, Gustav I 59, I67

Uhl, Heidemarie 36, 44-46, 49-54, I 3 I, 282 , 292

\subsection{Sachregister}

Angriffskrieg 37, 214, 216

"Anschluss« 44, 49, 5 I, I 23, I 28 , I 5 I, I6 I I I 66, I 70, 216, 220, 268, 295

Antisemitismus 30, 49, 96, I 93

Aufführungsverbot 63, 64, I57, 275

Austropop I87, 221, 223

Autoritärer Charakter 72, I 23

Auschwitz/Auschwitz-Birkenau 36, 37, 50, 85, 87, I 93, 2 I I I 2I 2, 230, 23 I, 28 I, 296

Baumgartner Höhe 6o, I 2 I

Borodajkewycz-Affäre 50

Bündnistheorie 33

Bündnis Zukunft Österreich (BZÖ) 277, 289

Carnival of Souls I75, I87, I 88, 2 IO

Collage 73, 100, 283

Dekonstruktion I 5, I7, 4I, 43, 282

Destruktion 7, I4-I 7, 20, 21, 43, 77-80, 82, 87,96 , I05, I Iо, I 23, I 39, I 49, I 5 O, I 52 2, I 72 , I 8I, 2I $3,225,226,252,26$ I , 280, 282

Dialekt 69, 73, 74, 8 I, 92, I I I , I I 9, I 32, I 34, I 36, I 37, I 43 - I 45

Diktatur 25, 29, 36, 38-40, I46, I6 I, 2 I6, 217,242
Vranitzky, Franz 5I , 52, 206, 24I, 244

Waldheim, Kurt 44, 46, 50, 5 1, 62, 88, 89, I 22 , I $56,248,267$

Wessely, Paula 88, I08, I09, II I-I I3, I I6, I 20, I 24, I3 I, I34, I35, I4I, I 53 - I 56, I $58-\mathrm{I} 67, \mathrm{I} 69-\mathrm{I} 72,285$

Westenthaler, Peter 256, 259

Wieler, Jossi 63, 97, 98

Wippermann, Wolfgang 23, 25-28, 40, I 22 , I 23, I34, 272, 273

Wuttke, Martin 252, 275

Zankl, Horst 155, I 56

Zöchling, Christa 88, 249, 259, 261, 264, $266-268,270$

Emanzipation 35, 4I, 43, 83, 84

Entnazifizierung 50, 60, 87, II 7 , I 24, I43, I65, I 67, 269, 271, 285

Entschädigung 50, 54

Epochencharakter 25, 79, 242

Exklusion 35, 38, 123, 272, 290

Externalisierung 48, I 52, 236, 282

Fascismo (ital.) 24, 25, 27, 3I, 33

Faschismus I 2, I4, I6, I7, 20, 22-36, 39, 4I, $47,70,72,79-8 \mathrm{I}, 83,86,87,89-9 \mathrm{I}, 95$, IO5, II 2, I I 7 , I 22, I 23, I I 4 , I 47 , I 5 O, I 57 , I 59, I60, I 7 I I I 8 I, I 93, 242, 272, 273, 28 I, $283-285,289-293,295,298$

Feminismus 80, 84, 85

Frankfurter Schule 21, 67

Freiheitliche Partei (FPÖ) 52, 53, 63, 64, 88, 9I-96, 104, I 57, 206, 240-244, 247-250, $252,254,256,258-260,263,264,266,268$, $273-277,289,290,297,298$

Führertheorie 29, 242, 248, 293

Gas/Vergasung 87, I 20, I 2 I I I 28 , I 49, I 5 O, I 82, I 93, 205, 230, 232, 235, 262, 263, 296

Gedenkjahr (I988) 5 I

Gefälligkeitsdiktatur 39

Gleichschaltung/Selbstgleichschaltung 39 


\section{Grazer Gruppe 68}

Heimat 81, 83, 89, I Io, I 34, I36, I 55, I6 I, I 74, 2 I 3,22 I , 234, 244, 253, 269

Heldenplatz 43, 5 I, I 52,220

Hierarchie 83 , II 7, I 2 I, I 22, I 25, I 29 , I 32 - I 34, I 42,2 I $5,257,258$

Holocaust I 9, 25, 26, 29, 30, 36, 37, 46, 52, 58, 79, 87, I7 I , I73, I77, I85, I93, I95, 200, 20I, $207,224,232,235,236,239,245,247,265$, 28I, 296, 297

Ideologie $26,30-32,35,72,73,80,81,84,85$, $88,89,93, \mathrm{I} 37, \mathrm{I} 47, \mathrm{I} 72, \mathrm{I} 79,2 \mathrm{I} 4,246$

Inklusion $35,38, \mathrm{I} 23,290$

Internalisierung 236,285

Intertextualität 2I, 72, 8I, I00-I05, 284, 293

Ironie $57,60,66,67,73,74, \mathrm{I} 5 \mathrm{I}, \mathrm{I} 73,257$

Kollektivschuld 263

Kommunistische Partei (KPÖ) I 3, 274

Konzentrationslager (KZ) 45, 58, 85-87, 91, I 20, I 5O, I 93, 2 I I , 23I-233, 235, 239, 263, 269

Kronen Zeitung 64, 90, 91, 96, 157, 224, 24I, 244,245

Lebensborn 185

Lebenswelten 37, 39, 68, 28 I, 292

Manipulation 23, 36, 43, 79, 80, 87, 242, 28I, 293

Marxismus 14, 25, 67

Massenmedien 69, 80, 83, 90, I 57, 224, 225

Mikrohistorie 36,38

Mitläufer I I 8, I 27, I 29, I32, I 38, I 40, I46, I 57, I7 I, 267

Mitverantwortungsthese 52, 282

Montage 56, 73, 100, I46, 283

Moskauer Deklaration 45

Mülheimer Dramatikerpreis 63-65

Mythos (nach Roland Barthes) I6, I7, 23, $4 \mathrm{I}-43,48-5 \mathrm{O}, 56,57,69,70,72,78,8 \mathrm{I}, 85$, 93, I00, I I 7, I $32-\mathrm{I} 34, \mathrm{I} 36, \mathrm{I} 38, \mathrm{I} 43$, I 45 , I 46 , I 5 2, I 54, I64, I 72, I 8 I, I 97, I 98,206 , $208,2 \mathrm{I} 4,2 \mathrm{I} 7,2 \mathrm{I} 8,220,225-227,237,240$, $252-254,260,265,278,28 \mathrm{I}, 285,289$
Nationalsozialismus I4, I 7, 20, 22, 24-26, $28,29,35-40,44-49,53,54,62,68,79$, $80,85-87,89,96,97$, I05, I 22, I 29-I 3 I, I 5 O, I 52 , I 53, I 56, I 65 , I 70, I 72, I 73 , I 95 , I 96, 200, 20I, 205, 206, 2 I 3, 2 I 4, 2 I 6,230 , $236,238,242,243,245,252,253,256,258$, $262-265,267,268,270,272,28 \mathrm{I}-283,285$, $287,29 \mathrm{I}-293,296$

Nestbeschmutzerin I 3, I5 , 62, 63, 89, 90, 94, 95, I09, I I 2, I 47, I 54, I 55, I 57 , I 74, 249, $25 \mathrm{I}, 252,255,265,275,277,278$

New Historicism 293, 295

Nobelpreis (für Literatur) I 2, I 3, I 8, 22, 55, $64,65,67,74,77,78,96$, I I I , I 58, 2 1 о, 240, $245,280,288$

Opfermythos/-these 7, I 2, I4, I6, I9-2I, $23,43-45,49-54,62,79,80,83,85,93$, 96, 97, I05, I06, I09, I I I , I 22, I 29, I 30 , I 49, I 52 , I 54 , I 56, I 58 , I 70 , I 72 , I 77 , I 86, 203, 206-208, 21 3, 220, 227, 237, 243, 280, 282-285, 287, 289, 29I, 293, 295

Opfer-Täter-Gedächtnis 53, 207, 282, 287

Pflichterfüllung 44, 49, I22, I 29, I67, 263, 290 Phänomenologische Methode 26

Politische Religion 3 I

Propaganda 27, 49, 83, II 3 , I 20, I 22, I 30, I 42 , I 47, I 57, I 59, I6I, I64-I66, I68, I72, 2 I 5 , $249,267,272,285$

»Rasse« (NS-Diktion) 22, 25-27, 49, 79, I 23 , I 37, I 39, I 42, I 49, 2 I 4, 2 I 5, 22 3, 257

Restitution 5 I, 53

Sarkasmus 57,66

Satire I 5, 70, 72, 78, I 46, 245

Shoah 37, I76, 200, 21 3, 21 9, 232, 233

Staatsdoktrin $43,89,20 \mathrm{I}$

Textflächen 75, 9I, I I 3 , I I 5

These vom (deutschen) Nationalcharakter 29, I $50-$ I 52, I 54, 237, 285, 293

Topf \& Söhne 2 I I , 2 I 2, 23 I

Totalitarismus 26, 27, 31, 85

Unabhängigkeitserklärung 45,46

Universalisierung 47,236 
Verfremdung 69, 74, 8I, I I 6, I 46, I 47, I 53 , I 54, 206, 280, 283, 294

Waldheim-Debatte/-Affäre 46, 50, 5 I , 62, 89, I 22, I 56, 267

Wehrmacht (Deutsche) 44, 49, I63, I64, I96, $253,268,270,282,290$

Weltanschauung 24, 3 I, I I 9, I 24

Widerstand 36, 40, 44, 45, 48, 62, 63, I I 4, I 22 , I 24, I 27, I 38 , I 39, I 4 I, I 42, I 53 , I 68, I 69, 237
Wiener Gruppe I 4, 2 I, 68-7I, 74, 8I, 85, I 52, 283

Zivilisationsbruch 36, 37, 50, 28 I, 292

Zustimmungsdiktatur 39, 40, 242

Zweiter Weltkrieg 36, 44, 45, 48, 49, 68, 93, 96, 97, I I 2, I 2 I, I 49, I63, I64, I 96, 2 I 3, 2 I 8 , $22 \mathrm{I}, 23 \mathrm{O}, 235,236,243,253,263,282$ 


\section{LITERATUR UND LEBEN}

NEUE FOLGE

EINE AUSWAHL

BD. 78 | RÜDIGER GÖRNER

DIE PLURALEKTIK DER ROMANTIK

STUDIEN ZU EINER EPOCHALEN

DENK- UND DARSTELLUNGSFORM

2010. 302 S. BR. | ISBN 978-3-205-78528-6

BD. 79 | DIETMAR SCHARMITZER

ANASTASIUS GRÜN (1806-1876)

LEBEN UND WERK

2010. 604 S. 13 S/W-ABB. BR.

ISBN 978-3-205-78575-O

BD. 80 | CARSTEN SCHOLZ

DER JUNGE HEBBEL

EINE MENTALITÄTSGESCHICHTE

2011. 675 S. 29 S/W-ABB. AUF TAF. GB.

ISBN 978-3-412-20820-2

BD. 81 | JOHANN GEORG LUGHOFER (HG.)

\section{THOMAS BERNHARD}

GESELLSCHAFTLICHE UND POLITISCHE BEDEUTUNG DER LITERATUR

2012. 453 S. GB. | ISBN 978-3-205-78811-9

BD. 82 | ALEXANDER LÖCK,

DIRK OSCHMANN (HG.)

LITERATUR \& LEBENSWELT

2012. 242 S. 8 S/W-ABB. GB.

ISBN 978-3-412-20950-6

BD. 83 | CHRISTOPHER DIETZ

ALEXANDER LERNET-HOLENIA UND MARIA CHARLOTTE SWECENY

BRIEFE 1938-1945

2013. 462 S. 19 S/W-ABB. FRANZ. BR.

ISBN 978-3-205-78887-4

BD. 84 | PATRICIA KÄPPELI

\section{POLITISCHE SYSTEME BEI FRIEDRICH} DÜRRENMATT

EINE ANALYSE DES ESSAYISTISCHEN UND DRAMATISCHEN WERKS 2013. 302 S. 11 FAKSIMILES. GB. ISBN 978-3-412-21030-4

BD. 85 | JULIA MÜLLER SPRACHTAKT

HERTA MÜLLERS LITERARISCHER DARSTELLUNGSSTIL

2014. 324 S. 9 S/W-ABB. GB. ISBN 978-3-412-22151-5

BD. 86 | ANTONIA BARBORIC

DER HOLOCAUST IN DER

LITERARISCHEN ERINNERUNG

AUTOBIOGRAFISCHE AUFZEICHNUNGEN VON UDO DIETMAR UND ELIE WIESEL

2014. 332 S. FRANZ. BR.

ISBN 978-3-205-79524-7

BD. 87 | RUTH STEINBERG

DIE SCHRIFTSTELLERIN EMMI LEWALD (1866-1946)

WEIBLICHE AUTORSCHAFT, ZEITGEIST UND LITERATURMARKT

2015. 507 S. 2 S/W-ABB. GB.

ISBN 978-3-412-22400-4

BD. 88 | SYLVIA PAULISCHIN-HOVDAR DER OPFERMYTHOS BEI ELFRIEDE JELINEK

EINE HISTORIOGRAFISCHE UNTERSUCHUNG

2017. 323 S. 3 S/W-ABB. GB ISBN 978-3-205-20325-4

BÖHLAU VERLAG, URSULAPLATZ I, D-50668 KÖLN, T:+49 22I 9I3 90-O INFO@BOEHLAU-VERLAG.COM, WwW.BOEHLAU-VERLAG.COM | WIEN KÖLN WEIMAR 
Auch Jahre nach dem Nobelpreis mangelt es immer noch an schlüssigen Lektüre- und Interpretationsansätzen zu Elfriede Jelineks literarischem Werk. Sylvia PaulischinHovdar bietet in dieser Studie eine neue Analysemethode an, die zeithistorische Theorien zu Faschismus, Nationalsozialismus und Opfermythos integriert. Die anhand von drei exemplarischen Textinterpretationen erzielten Ergebnisse sprechen für die Effizienz der vorgeschlagenen interdisziplinären Methode.

Sylvia Paulischin-Hovdar, geboren 1979, kultur- und gesellschaftswissenschaftliches Studium an der Paris Lodron-Universität Salzburg; Promotion mit interdisziplinärer Dissertation an den Fachbereichen Germanistik und Geschichte; war bis 2011 in der Literaturvermittlung tätig und arbeitet heute in der akademischen Internationalisierung. 